\title{
RECOGNISING THE LANGUAGE OF CALYPSO AS "SYMBOLIC ACTION" IN RESOLVING CONFLICT IN THE REPUBLIC OF TRINIDAD AND TOBAGO
}

By

\author{
Everard Mark Phillips, B.Sc., M.A.
}

This thesis is presented to the Department of Law of the The London School of Economics and Political Science, the University of London

In fulfilment of the requirements for the degree of:

DOCTOR OF PHILOSOPHY

\section{I ( $F$ the London School of Economics and Political Science}


UMI Number: U213600

All rights reserved

\section{INFORMATION TO ALL USERS}

The quality of this reproduction is dependent upon the quality of the copy submitted.

In the unlikely event that the author did not send a complete manuscript and there are missing pages, these will be noted. Also, if material had to be removed, a note will indicate the deletion.

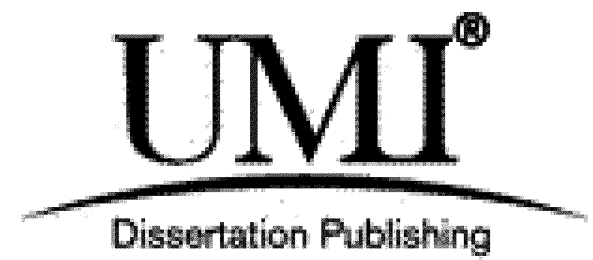

UMI U213600

Published by ProQuest LLC 2014. Copyright in the Dissertation held by the Author.

Microform Edition (c) ProQuest LLC.

All rights reserved. This work is protected against unauthorized copying under Title 17, United States Code.

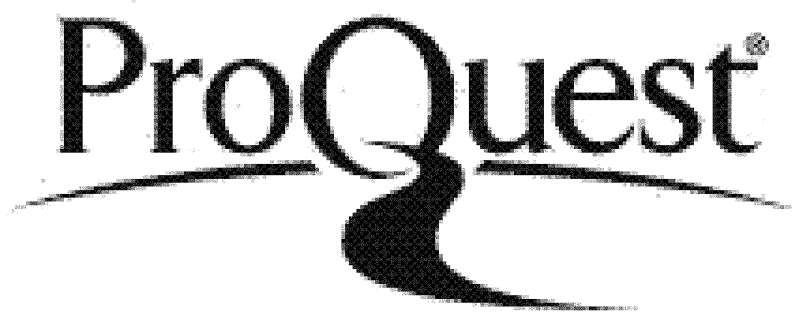

ProQuest LLC

789 East Eisenhower Parkway

P.O. Box 1346

Ann Arbor, MI 48106-1346 
F

9449

1273987 


\section{ABSTRACT}

\section{Recognising the Language of Calypso as "Symbolic Action" in Resolving Conflict in the Republic of Trinidad and Tobago}

The Calypso, which forms an integral part of the carnival celebrations of the Republic of Trinidad and Tobago, is a syncretic popular art-form, having its origin in Africa. This art-form, having been influenced and adapted by the experiences of enslaved Africans in the Diaspora, has been fused in the vortex of plantation society. Today, the music of Carnival has evolved considerably, so that the Calypso has become one of the cornerstones of the Carnival celebration, being significantly influenced by this Carnivalesque tradition.

This work looks at those Calypsos that offer commentary on the socio-political and economic issues in the Republic of Trinidad and Tobago (Trinbago), recognising them as bedded in a popular practice of ritual resistance. It shows how, through the medium of the Calypso, the skilful Calypsonian, using verbal creativity, freely comments on aspects of Trinbago's everyday life, exposing scandals of politicians and the rich while recounting gossip, as they redress the powerful. This thesis argues that Calypsonians, using this localised language that is steeped in colloquialisms, to sing on the prevailing socio-political and economic ills within Trinbago, function as liminal-servants in an Indigenous, Non-Formal, Community Conflict Management Mechanism.

This monograph, draws on Kenneth Burke notion of "Language as Symbolic Action", to show how, through a dialectic process, these Calypsos attempt to raise the audience's consciousness, enabling them to consciously make decisions regarding the actions they may take, to resolve the perceived contradictions and/or oppositions within their society.

Everard Phillips

Department of Law

April 2005 


\section{CONTENTS}

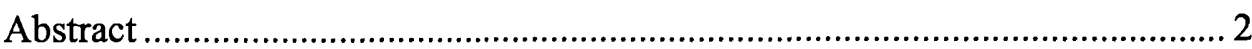

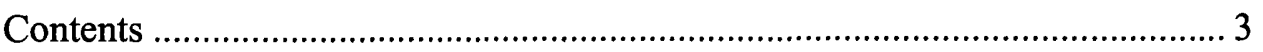

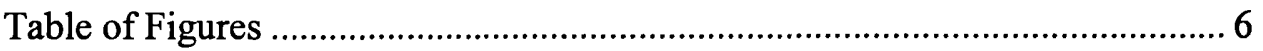

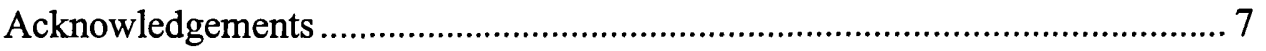

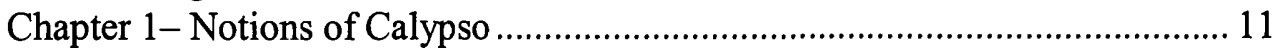

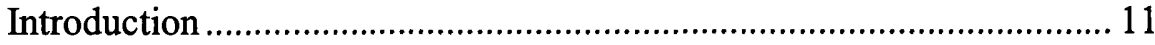

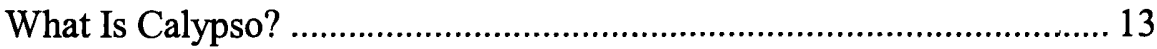

Defining The Purpose Of This Work ………....................................... 19

Statement Of The Problem.................................................................... 22

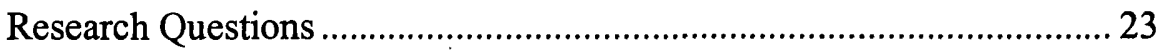

Trinidad - A Potted History .......................................................... 24

Trinidad after emancipation ...................................................... 30

Aspiring to independence....................................................... 32

Ideological Conditions of Anthropology and Implications for Discourse 36

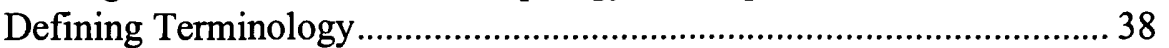

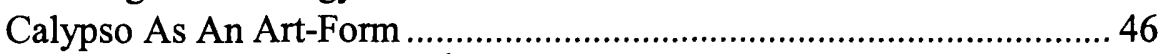

Moulding Of The Calypso - Carnival Syncretism ................................ 48

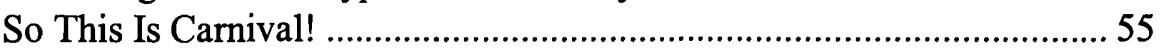

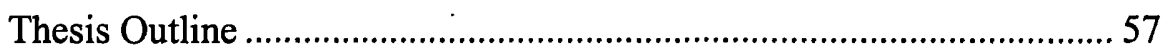

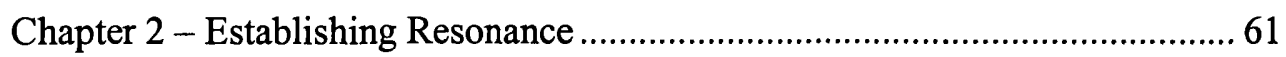

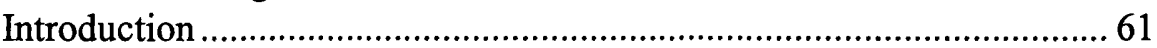

Researching the Lived Phenomenon of Calypso Language ..................... 61

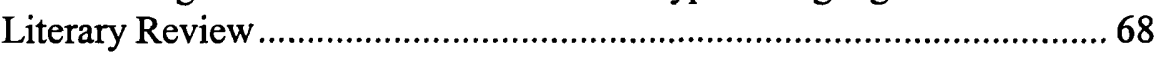

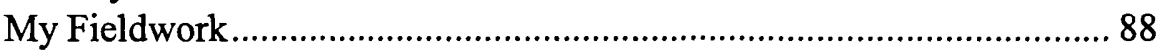

Inclusion of Compact Discs :............................................................... 96

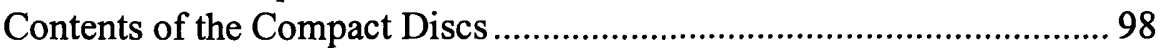

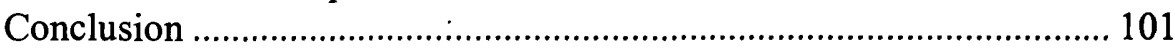

Chapter 3-Calypsonians and Their Lives: Fieldwork in Action ...................... 102

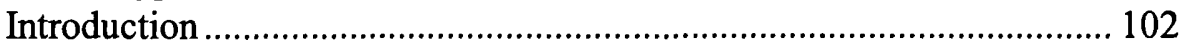

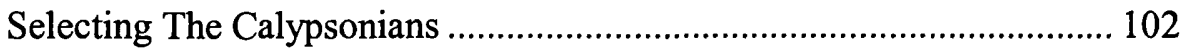

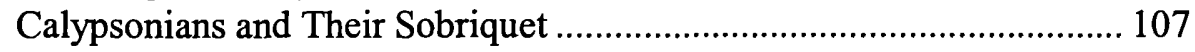

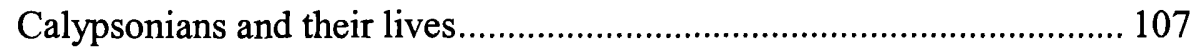

Morel Peters - Sobriquet: Luta .................................................. 109

Michael Anthony Osuana - Sobriquet: Sugar Aloes................... 111

Winston Peters - Sobriquet: Gypsy ........................................ 117

Weston Rawlins - Sobriquet: Cro Cro....................................... 122

Anthony Francis - Sobriquet: Almanac ................................... 128

Eric Taylor - Sobriquet: Pink Panther ................................... 137

Denyse Plummer - Sobriquet: Denyse Plummer ........................ 144

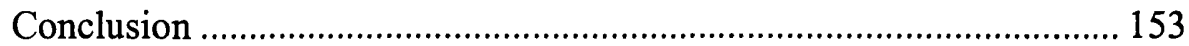

Chapter 4 - Conflict in Trinidad: The Wider Perspective ................................. 155

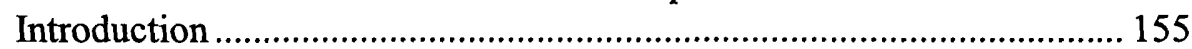

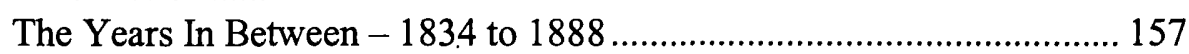

Social Stratification in Pre-emancipation Trinidad............................... 159

1. Stickfighting, Steelband and Conflict ............................................. 161

2. Camboulay and Carnival: The Years of Revolt ................................ 171

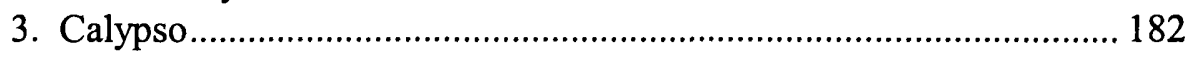

The Seditious Act and Publications Ordinance, 1920................ 182 
The Theatres and Dance Halls Ordinance 1934 ......................... 184

4. Contemporary Expressions of Conflict .............................................. 189

Conflict Through the Conduit of Carnival ................................ 189

Calypsonians: Conflicts for Acceptance .................................... 196

Contemporary Conflict in Calypso........................................... 199

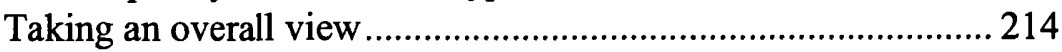

Positive Aspects of Conflict.................................................... 216

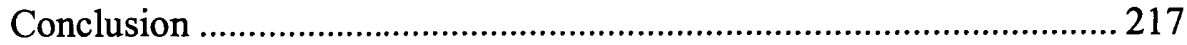

Chapter 5: Language as Symbolic Action ...................................................... 218

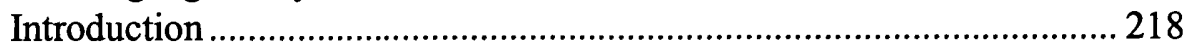

The Purposes of Symbolic Action..................................................... 220

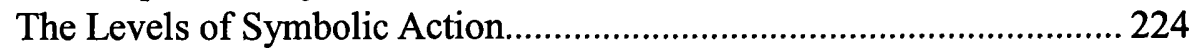

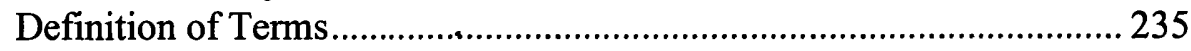

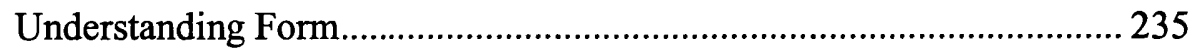

Syllogistic Progression............................................................. 236

Qualitative Progression ........................................................... 237

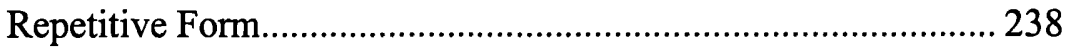

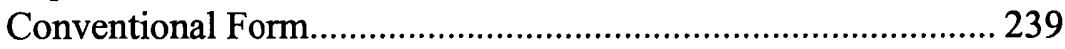

Minor or Incidental Form ..................................................... 240

The Appeal of Form ........................................................................ 240

Evaluating The Intrinsic And Extrinsic Applications Of Form .............. 243

Chapter 6 - Linguistic Form in Calypso: Reframing in Resolving Conflict 245

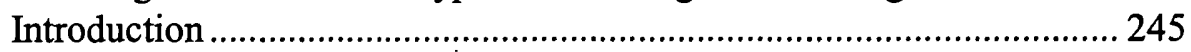

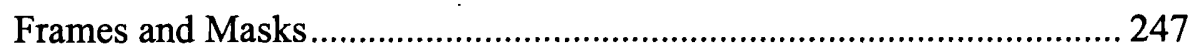

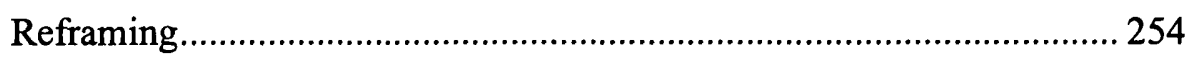

The Use of Metaphor, Metonymy and Polysemy................................. 257

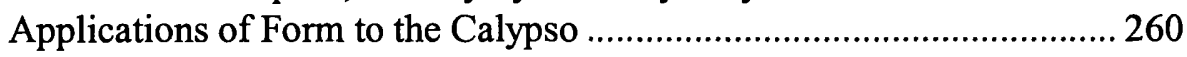

The Vicissitudes of the Banana Industry............................................. 260

Background to the banana war.................................................. 260

The Caribbean situation ........................................................... 263

The Use of Form In: The Sinking Ship ............................................... 268

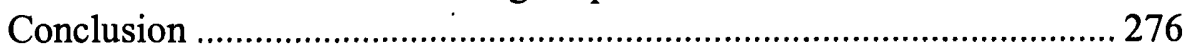

Chapter 7 - The Media Used In Calypso Presentations..................................... 277

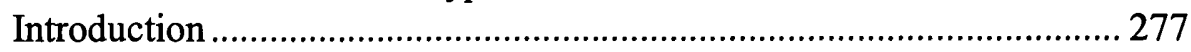

Cross-Fertilization Among Festival Genre ......................................... 278

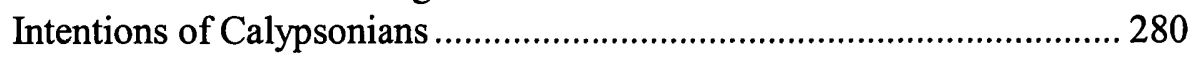

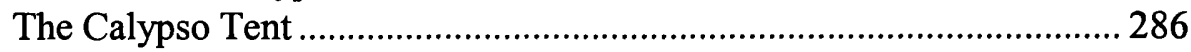

Ritual and Theatre of a Calypso Performance..................................... 289

Discussing the Ritual of the Calypso Tent ............................................ 295

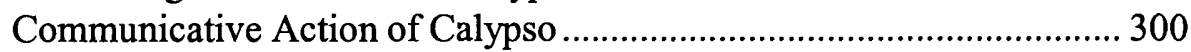

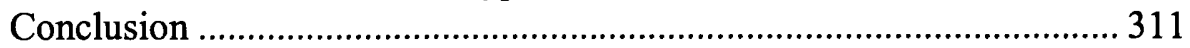

Chapter 8-Conscientização: Calypso As An Agent Of Social Cognition......... 312

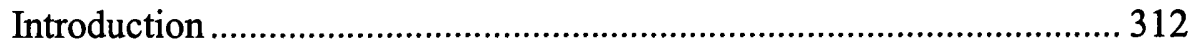

Calypsos, Image Schema and Restructured Cognition............................ 314

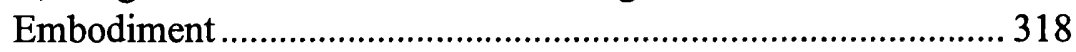

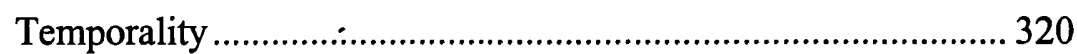

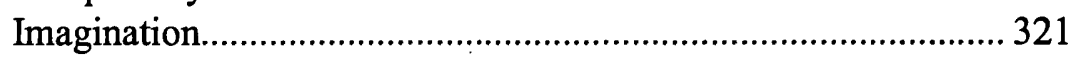

Social Interaction.............................................................. 323

Morality: Heteroglossia and Nascent Counter-Hegemony........... 325

Calypso: An Agent of Negotiation ..................................................... 328 
The Role of Calypso In the Community ................................................. 329

Calypsos, Carnival and Cultural Politics .............................................. 335

Towards A Pragmatic View Of The Calypso.......................................... 337

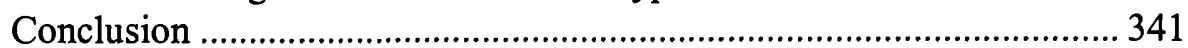

Chapter 9 - The Audience As Co-Mediator ..................................................... 343

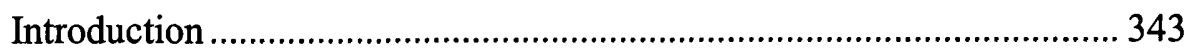

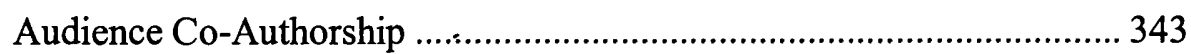

The Concept of Call and Response ...................................................... 348

Philosophic Implications of African Retention..................................... 349

Developing the Paradigm of Call and Response .................................... 352

The Caller-Calypsonian........................................................... 354

Mechanisms of the Call.......................................................... 356

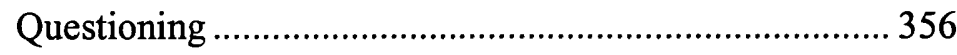

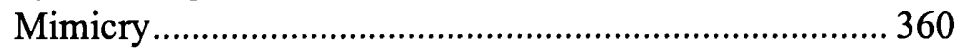

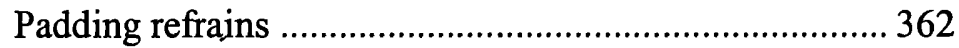

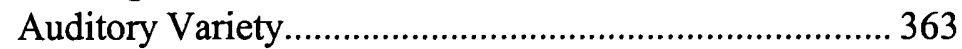

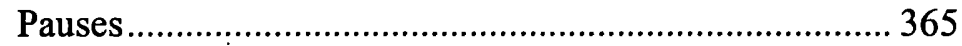

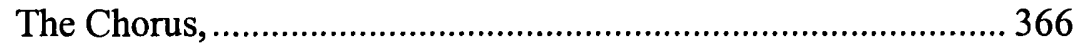

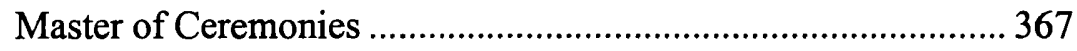

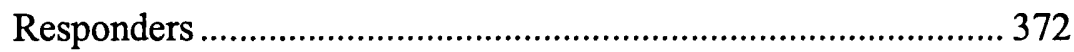

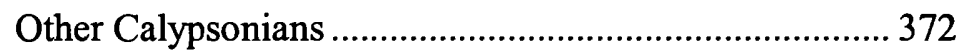

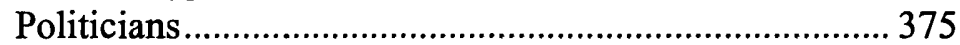

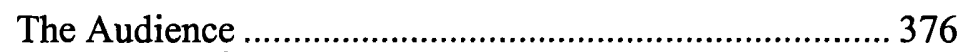

The Symbolic Use of Toilet Paper as a Response........... 378

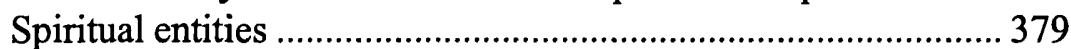

The Word - The Message as Expressed in the Calypso.............. 382

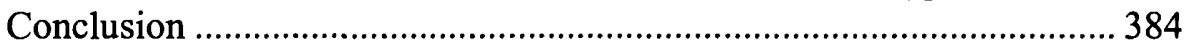

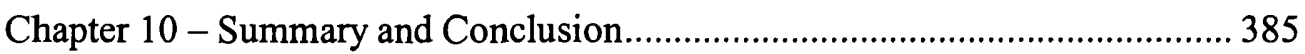

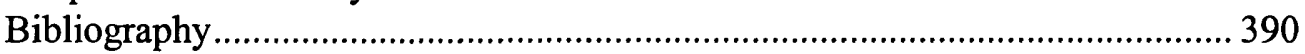

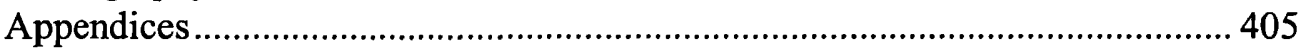

Appendix 1 - Lyrics Of The Calypsos Used In The Text ........................ 407

Appendix 2 - A Chronology of Key Events in Trinidad and Tobago... 459

Appendix 3 - Sobriquets and Real Names of Calypsonians ................... 463

Appendix 4 - Calypsonians Researched but not Interviewed ................. 472

Dr. Slinger Fransisco - Sobriquet: The Mighty Sparrow............ 473

Real Name: David Rudder - Sobriquet: David Rudder .............. 477

Appendix 5 - Theatres and Dance Hall Ordinance 1934 ........................ 480

Appendix 6 - Gestalt Philosophy......................................................... 484

Appendix 7 - Calypso Tents and their Performers ............................... 485

Appendix 8-Words, Phrases \& Expressions used in Trinidad \& Tobago491

Appendix 9-Glossary of Terms Used in the Calypsos.......................... 498 


\section{TABLE OF FIGURES}

1.1 - A Conceptual framework of African American music genres 18

1.2 - The Caribbean Archipelago $\quad 25$

1.3 - The Republic of Trinidad and Tobago 26

1.4 - Figures of the 1806 Population Census 29

1.5 - Constituents of Carnival $\quad 50$

2.1 - Newspaper advert for the Calypso Revue Tent 91

2.2 - Newspaper advert for the closure of public services over carnival 92

2.3 - Newspaper adverts contrasting two public service approaches to carnival 93

2.4 - Newspaper adverts showing carnival schedule 94

2.5 - Prize money for the Calypso monarch 95

2.6 - Contents of Compact Discs 100

$\begin{array}{ll}3.1 \text { - Photo of Luta } & 109\end{array}$

3.2 - Photo of Sugar Aloes $\quad 111$

3.3 - Photo of Aloes and Phillips $\quad 112$

$\begin{array}{ll}3.4-\text { Photo of Gypsy } & 117\end{array}$

3.5 - Photo of Gypsy with his son and father 118

3.6 - Photo of Cro Cro 122

3.7 - Photo of Pink Pantha 137

3.8 - Photo of Denyse Plummer 144

4.1 - Stickfighting among slaves $\quad 162$

4.2 - Modern Stickfighting 163

4.3 - Pan Am North Stars Steel Orchestra 169

4.4 - Modern day Desperadoes Steel Orchestra 170

4.5 - The 1846 Notice prohibiting masking $\quad 172$

4.6 - Advice for the 1882 Carnival · 177

4.7 - Melton Prior depicting carnival on Fredrick Street POS in $1888 \quad 181$

4.8 - The half-human half-machine figure of Mancrab 191

4.9 - King Callaloo trampling across the river with water splashing 193

4.10 - Children of the Moon 194

4.11 - The Adoration of Hiroshima 196

4.12 - Trinidad Guardian article on Sugar Aloes 205/6

4.13 - Newspaper article discussing Cálypsonians' freedoms 208

4.14 - Newspaper discussion by Prof. Lewis $\quad 210$

4.15 - Newspaper discussion by UNC treasurer $\quad 211$

4.16 - Newspaper articles expressing views on Calypsos and Calypsonians 213

4.17 - Finding of UWI research $\quad 215$

4.18 - Positive aspects of conflict $\quad 216$

7.1 - Photo of Kaiso House Calypso Tent 287

7.2 - Calypsonians advertised as appearing at Kaiso House Calypso Tent 288

7.3 - Comparison of attributes of ritual and theatre 293

7.4 - The inter-relationship between social drama and stage drama 294

7.5 - Calypsonian engaged in both theatre and ritual 306

9.1 - A paradigm of call and response - audience co-authorship 353

9.2 - Photo of caller \& responder interaction 377

Appendix 2 - Photo of Dr. Eric Williams 460

Appendix 2 - Photo of Mr. A.N.R. Robinson 461

Appendix 2 - Photo of Mr George Chambers 461

Appendix 2 - Photo of Mr Patrick Manning 462

Appendix 2 - Photo of Mr Basdeo Panday 462

Appendix 4 - Photo of Young Sparrow 473

Appendix 4 - Photo of singing Sandra and Singing Sandra 475

Appendix 4 - Photo of David Rudder . 477 


\section{ACKNOWLEDGEMENTS}

Although officially I started this thesis in 1998, its concept is the child of my experiences having been born in Trinidad, growing up there until the age of 20 , when I migrated to the UK. This work, although an extension of the dissertation I necessarily completed as part of my MA at Goldsmith's College, to me, is more than an academic piece of work. In many ways, it recaptures my experiences as a child growing up in Trinidad, and as a young man, understanding the dynamics of the country, learning to negotiate my transition into adulthood in the country of my birth.

Were I to say that the process of completing this work has been a phenomenal learning experience for me, I would be making a gross understatement. To my mind, words fail abysmally, to adequately describe the experience of engaging in this work. As a personal experience, even from one like me, who has had many and varied experiences in this world, this work and the process of getting here, stands out, 'out-there', on its own and un-eclipsed!

To me, the process of completing this project has been more than just an academic exercise. It has been an experience of rebirth and reintegration with my homeland, the land that I never truly left. It has been a deeply profound and moving experience!

Apart from being an academic exercise, this work has also been an extremely engaging journey. Every Calypso that I have ever listened to, has made a significant contribution to each aspect of this work. However, to cite them all would be an insurmountable task. As such, I need to record that those Calypsos mentioned herein are but samples from a cohort of those abundantly available.

It would be exceedingly negligent of me not to recognise and acknowledge the accumulation of the many other life experiences that have so contributed to the breadth, depth and bountifulness of my life, guiding me to the place from which I could undertake this enterprise. In this regard, I look upon my time in the Forces with deference. Without acknowledging and valuing the contribution made to this work, by the learning gained from that part of my life when I worked as a lecturer, I would be very remiss. Similarly, my later training and work as a psychotherapist as well as that as a consultant and trainer have greatly helped me fine tune and hone in the art of both inner and outer communication which has been an integral part of this endeavour. Finally, both my work as a mediator, as well as the good fortune of being a Winston Churchill Fellow, completing a transatlantic evaluation of modes of Alternative Dispute Resolution (ADR), have been invaluable in my process of gaining an insight to this indigenous approach to community conflict management and resolution.

In mentioning internal communication, I cannot omit acknowledging my gratitude to Het Heru for the overwhelming and bountiful gifts that have nourished and sustained me throughout the course of this work, providing for me, abundantly. In expressing my gratitude, my abundant and heartfelt thanks to Het Heru and Auset, for paving the way for me to get to this point in this research project, I acknowledge the tender love, care, guidance and inspiration, that has graciously and benevolently been provided. Engaging congregative thinking, 'those who have eyes to see' will recognise the abundant display of Het Heru's gifts, as they are profusely displayed through the creative and imaginative use of metaphor, myth, metaphoreins, and stories to further explain the heart of the 
approach to this work. Needless to say, I also thankfully acknowledge those who introduced me to this System. I feel truly blessed and highly favoured to find myself in the position to be able to offer this work in thanks for all the guidance and help I have been given.

Thanks also to my earthly helpers, without whose input I probably would not have completed this work. I specifically thank my supervisor Prof. Simon Roberts, for his constructive and very helpful interventions and challenges which, through a process of stepwise refinement, helped me enormously in fine tuning my thinking. I found his constructive suggestions and guidance to be of enormous benefit. Without his help, I may not have been able to refine this monograph, to its current quality. I also thank all those who have in some way accompanied me along either the whole or part of my journey. I specifically thank Andy Jack of the LSE inter-library loan staff, for painstakingly acquiring the most obscure references, when all else seemed to have failed. My gratitude is also extended to Karon James of the law IT cluster, for patiently allowing me to be a nuisance, similarly with Steve of LSE Media Department, who went beyond the call of duty.

Thanks to all my friends who, recognising my need, allowed me to have tunnel vision, during the period when regrettably, I felt forced to ignore them, while being engaged and very focused in the pursuit of my goal of completing this work, with the tenacity of a long distance runner. Last, but most certainly not least, thanks also to my parents, who gave me what it takes.

Finally, a note to readers: in this manuscript, I have elected to use the word 'Calypso' to represent the singular and Calypsos to represent the plural form. For ease of reference, in referring to The Republic of Trinidad and Tobago I will frequently use either the words Trinidad or Trinbago to embrace the duality of the two-island state. Similarly, readers will also recognise the use of the word Trinbagonians as one of the ways that I will refer to the combination of people who populate the islands. Except where otherwise indicated, throughout this text, I have elected to use italics to indicate quotations.

The text of this thesis contains the words of various Calypsos that were heard during my fieldwork. On some occasions, when either the Calypsos predated my fieldwork or quality of my sound recording was poor, I purchased commercially available CDs with the appropriate Calypsos. All of the selected tracks were subsequently transferred to the CD that accompanies this Thesis. This CD is of MP3 format. The tracks can be heard by inserting the $C D$ into the drive of any computer on which Windows Media Player $(\mathrm{WMP})^{1}$ is available. The disc should then self-load and run automatically.

To those who, unfamiliar with the Calypso beat, on hearing the music in the accompanying $\mathrm{CD}$, comment as some have, that the beat can sound repetitive, I say: "it's the words that carry the messages and the message is in the meaning."

\footnotetext{
${ }^{1}$ WMP is a standard application, available on most PCs that are less than 4 years old
} 


\section{Peoples' Parliament}

Sung by: The Mighty Chalkdust

Real Name: Dr Hollis Liverpool

Anywhere ah walk in town

Ah hearing the same old song

How come you eh go Chalkie?

For elections like Gypsy

You could be ah minister

You could take charge of culture

You could ah be like Sudaman

Driving million dollar car

Yuh well qualified because you have a big Ph.D.

Why not use your education like Eric and Rowley

Do like the great Attila de Hun in history

Who won his seat elections 1950

Ah tell dem flat, Chalkie not in dat

I'm no doormat, for them Red House rats

I'm not siding, with Panday nor Manning

I'm not for NJAC

To hell with PNM and UNC

I'm PPP, the Poor People's Party

Is them I represent, and the Kaiso Tent is meh Parliament

I does tell all meh critics

Red House politicians sick

Deceitful to each other

And all of them congosa

But the Kaiso Tent my friend

Engages time honoured men

Like the illustrious Kitchener,

Stalin, de super star

Some like the Mighty Shadow does deal in poverty

Pink Panther and Aloes are the true macos of society

Some like the Lion and Cro Cro, sing out fearlessly

Others like Delamo stand for truth and honesty

Car house and look I don't give a hoot

I prefer truth and men of repute

I don't favour: fish, foul or iguana

I'm for fairness and justice

Going up for elections can't give me this

I'm for people: black, white, yellow, purple

Race I doh compliment

And the kaiso Tent is my Parliament

With kaiso the nation becomes my constituency

Ah know Dan Rhaj Singh can't come here and wine on me 
So the PPP already chose me

Honourably to serve this country

In my chamber Tommy Joseph is the speaker

And the opposition is all them harbingers of corruption

So don't confuse me with Gypsy or Jimmy

Jack eh pay me a cent

And the Kaiso Tent is meh parliament

Kaiso and the Kaiso Tent

Goes back to the days of enslavement

Where under a spreading tamarind tree

Blacks sung against whites fearlessly

Through kaiso they made their laws

Through Kaiso they fought their wars

Kaiso and its sweet minor cords

Was the poor blackman's House of Lords

So Kaiso is our big, big insurance policy

Against dictators and the parasitic oligarchy

Kaiso is the atomic bomb in our possession

For all who want to degrade our Constitution

So real kaisonians are important men

They bigger than Red House Rats my friend

They sing sociology

And spew out Philosophy

So to join the Red House set

Is to climb down from a king to a Jamette

So North Stand and Grand Stand

You are an important institution

You more important that government

So all-yuh welcome to Parliament

These are the words of "The People's Parliament" as sung by The Mighty Chalkdust, which I offer as a pretext for this manuscript. In this Calypso, Chalkdust sets out a view of the kingly role of the Calypsonian which he exalts above the vermin of Members of Parliament that he calls "Red House rats". In so doing he recognises the potential of the Calypso, its capacity in resolving conflict, to make laws and fight wars.

And so, welcome to this thesis 


\section{CHAPTER 1- NOTIONS OF CALYPSO}

People are interested to know where Calypso originated: Some say it came from Cuba, some say British Guyana Some contend seriously it was sung by Moses crossing the Red Sea But I told them no, no, oh no, Trinidad is the Land of Calypso.

It was a serious contention that was causing some real confusion Some said its Japanese or the folksong of ancient Chinese A fellow said yes certainly, I used to sing Calypso to Samson One said he heard when Nero was burning Rome he sang Calypso One said that in India they sang Calypso when charming cobra Another said that Elijah sang a Calypso in the chariot of the fire They argued with one another, trying to find out the owner They mentioned every country, all but the land of la Trinity!

"Trinidad, Land of Calypso" by the Roaring Lion

\section{INTRODUCTION}

$\mathrm{L}$ istening to the media, when I first came to live in the UK in 1968, I was introduced to a notion of the Calypso to which I was unaccustomed. This (to me) new notion was born out of a Western concept of the Caribbean songs that were popularised in the UK by singers such as Harry Belafonte and the Andrews Singers. As I listened to these versions of some recognisable words of "The Banana Boat Song" and "Jamaican Farewell", now being sung to a different rhythm and percussion style, by singers like Belafonte, and 'Rum and Coca Cola', as sung by the Andrews Sisters, my attention was arrested by the stark differences. "Are these Calypsos?" I queried to myself. The largely UK born, European colleagues with whom I had been listening to these songs heard them as nothing more than some light entertainment. To me however, the spirit of the message, its energy, the essence and vibrancy, the vitality of the 'real Calypso,2 was missing from these remnant versions, of this adapted form of Caribbean

\footnotetext{
2 The terminology 'real Calypso' was used by the American ethnomusicologist: Samuel Charters. To me, it is synonymous with "the real Calypsonian" as used by Dr Hollis Liverpool (whose Calypsonian sobriquet is: "The Mighty Chalkdust") in a lecture delivered at the University of East London in 1996. $\mathrm{He}$ also used this term in the last verse of the lyrics of his Calypso "The People's Parliament". The lyrics of this, as with all other significant Calypsos used in this text, are available at Appendix 1
} 
Chapter 1- Notions of Calypso

culture, which seemed to have been washed up on the derelict, desolate shore of entertainment.

Although the words that the Andrews Sisters were singing were the same as those of the originator Lord Invader, I surmised that the intention of each was different. For his part, Invader was commenting on the degradation of the social structure within the island that resulted from the World War II presence of US forces in Trinidad. However, for the Andrews Sisters, the context appeared to be one of pure entertainment.

These Western versions were not seen to subscribe to the 'Trinidadian Calypso Tradition' (of which I will be writing abundantly in this manuscript) and in Trinidad are generally referred to as 'Calypso-Song'. There is yet a third terminology, that of 'Kaiso'. This latter term is usually reserved for exclamations of acknowledgement, by members of the audience, and used when the Calypsonian has succeeded in pleasing them by the manner of performance and presentation.

Further to the issue of these differences, it must be emphasised that Belafonte himself acknowledged that he was not singing Calypso. In an article by McNamara (1975:9) Belafonte is quoted as saying:

As a matter of fact .... My two big records right now aren't Calypso at all, even though everybody seems to have hung that tag on them. One, Jamaica Farewell, is a West Indian folk Ballad. The other, Day-O, is a West Indian folk song.

McNamara (1957:9)

The above is part of the considerable controversy that exists around the origin and nature of Calypso music. 
Chapter 1- Notions of Calypso

Henceforth, in this manuscript, I will use the word 'Calypso' to represent 'real

Calypso'. Also, recognising the other spellings of the plural form of the word Calypso, I elect to use the spelling 'Calypsos' when referring to its plural. For ease of reference, I will use either the words: Trinidad or Trinbago to embrace the duality of the two island state of the Republic of Trinidad and Tobago. Similarly, readers will also recognise the use of the word Trinbagonians as one of the ways that I will refer to the combination of people who populate the islands. Except where indicated otherwise, the use of italics indicate a quotation.

\section{WHAT IS CALYPSO?}

Some authors (Espinet and Pitts (1944), Warner (1982), Liverpool (1996), Hill (1997)), claim that Calypso rhythms can be traced back to the first African slaves who were brought to work the sugar plantations of Trinidad. Forbidden to talk to each other in their indigenous tongue, and robbed of all links to family and home, these African slaves began to sing songs that voiced their 'discontentment' and their longing for their homeland and families. In addition, these authors assert that African slaves also used this early type of Calypso as a means of communication among themselves, and, as a way of mocking their slave masters. This Thesis not only adopts this viewpoint, but extends it, showing how, locked in a social structure where these slaves found themselves bereft of any meaningful power, these early Calypsos were a mechanism of nascent counter-hegemony, that was designed to resolve the social imbalance. Today, within a somewhat different social structure, they continue to serve this function.

Liverpool (1996) himself a Calypsonian (The Mighty Chalkdust) and educator, argues that although the Carnival celebrations, which currently take place at various locations 
Chapter 1- Notions of Calypso

around the world, vary considerably from each other, all Carnivals have their roots in ancient Africa. He further contends that the Calypso also has its roots in Africa and that the art form was brought to the Caribbean by enslaved Africans. During the period of enslavement in the Caribbean, these songs became the oral literature of an oppressed people, who sung of their circumstances, their trials and tribulations, in a code that they believed they alone understood.

Jean Michel Gibert, head of the Trinidadian Label Rituals asserts that:

Calypso came from the griots. When Africans came as slaves they brought their traditional songs, and the only way for them to survive culturally was to come together and listen to the griot, who told stories of the community and mocked the slave master. A lot of slave masters back then were French, which is why you can find some patois in the original Calypso.

Carib Planet Virtual Citing, (n.d.),

On the other hand, in his book: "Calypso From France To Trinidad - 800 Years Of

History" (1987), veteran Calypsonian Roaring Lion controversially challenges the view that Calypso, in the strictest sense, is of African origin; he contends that it derives from French 'ballade', which was given the pseudonym 'Calypso' in the 1900's. In his account, Lion writes:

There is no evidence, to support the claim that it is either a variant of African folk songs or that it was invented by African slaves in Trinidad. This belief is purely speculative.

(Roaring Lion, 1987:1)

Lion also states that it was only since the Black Power revolt in Trinidad in the early 1970s that there has been a desire to stress Calypso's African roots, (Roaring Lion, 1987:80). 
In 1947, Francis Herskovits published "Trinidad Village" which was based on his recordings and research while he lived in a small Trinidadian village. In his work, Herskovits was seeking to establish the connection between Africa and the new world, through showing retention of African culture in the Diaspora. He sought to do this through showing the survival of many of the Yoruba traditions.

Nehusi (2000:78), contends that while the etymology of the word "carnival" originates in Italy, both the concept and the substance of the festival, its rites and practices, are much older. He argues that since the cradle of civilization originated in Egypt, (i.e. Kemet) in Africa, that the festival initially started in the Nile Valley as one of the festivals of ancient Kemet.

On the other hand, Cowley (1998), claims that the word Calypso was first used in 1882, to describe a dance.

The same is probably true for the 'abominable dance called Calypso' .... . 'According to the old negroes', the dance was 'the cause of perversion of young men and girls'.

(Cowley 1998:98)

Whatever the circumstances of its origin, it seems certain that the music itself derived from Trinidad's multi-colonial past. The island itself had frequently changed hands over the centuries, having been owned by Spain, then Britain, and along the way receiving French immigrants subsequently having a large influx of enslaved Africans. Cowley tells us that the word Calypso first appeared in 1900 and at that time was spelled 'calipso'. Cowley (1998:138). He also suggests that it was the French who originally brought the idea of Carnival to Trinidad, and that it was from this that a twinned component, the Calypso, derived. 
Chapter 1- Notions of Calypso

Indeed, the first evidence for the term 'calipso' appears in Port of Spain Gazette during the 1890 Carnival season. During the period leading up to the 1890 Carnival, the Gazette reported on Carnival songs which they labelled 'calendas'. These songs appear to be synonymous 'lavways' that were sung in French Creole by nègre jardin stickmen and their followers.

Whatever the truth about the story of its creation, the reality of the origin of Calypso is now lost in a mist of conjecture. However, there is a consensus among all the aforementioned authors that contemporary Calypso originated in Trinidad.

There is also general agreement that the songs, which originally featured improvised observations and social commentary served as a medium that dispensed information to poorer people, and probably had some relationship in its derivation from the West African praise singer, the Griot, who was the traditional recorder of tribal history, commentator, celebrator and satirist. Many historical and contemporary Calypsos attest to this role. However, I would particularly like to cite two Calypsos that for me, stand out as fulfilling this function, these are the Mighty Chalkdust's: “The People's Parliament" and Sugar Aloes': "Why Ah Stay". In Chapter 7, I offer a fuller discussion of these Calypsos, with the complete lyrics of each Calypso being provided in Appendix 1.

The terms "Calypso" and "Kaiso", which are used in Trinidad interchangeably, probably come from a West African Hausa term, which, depending on context, can mean regret, triumph, and contempt. Today in Trinidad, the word "Kaiso!" is often used by patrons of the Calypso Tent ${ }^{3}$, who wish to show their approval. Other possible derivations of

\footnotetext{
${ }^{3}$ Calypso Tents are venues for the performance of Calypsos. Chapter 7 further illuminates this concept.
} 
Chapter 1- Notions of Calypso

the word 'Calypso' include West African 'kaiso', French patois 'carrousseaux', Spanish 'caliso' and the Virgin Islands topical song 'careso'.

Based on her research into the American traditions of black music, Maultsby (1991) argues that the established musical traditions of the slaves derived from their African heritage and that over the years, and certainly after Emancipation, these customs evolved in response to the local demands and the circumstances of the environment, where each generation of slaves and freeborn blacks created new musical genres and performance styles, (Maultsby 1991:185). Although Maultsby's conceptual framework for the musical genres and performance styles of African American music does not expressly mention Calypso music, there is no doubt that the experiences of the enslaved African Americans was similar to those enslaved in the Caribbean. It therefore seems reasonable to surmise that were this framework to be rewritten to include all the musical genres within the Diaspora, depending on the slant of any given Calypso, each would be regarded as falling under general heading of "African American Secular Traditions," and be grouped under either "Work Songs, Field Calls And Protest Songs" or the "Game Songs and Social Songs" that sprouted during the 1600s. See Fig 1:1 below

In her discussion on the role of African American musical forms, and the aspects of these that have been retained in formal and informal settings, Maultsby (1991:187) recognises the fundamental concept underlying music performance in African and African-derived cultures. She contends that music-making is a participatory group activity that serves to unite black people into a cohesive group for a common purpose, (Maultsby 1991:187). 


\section{A Map of the Music}

\section{The Evolution of African American Music}

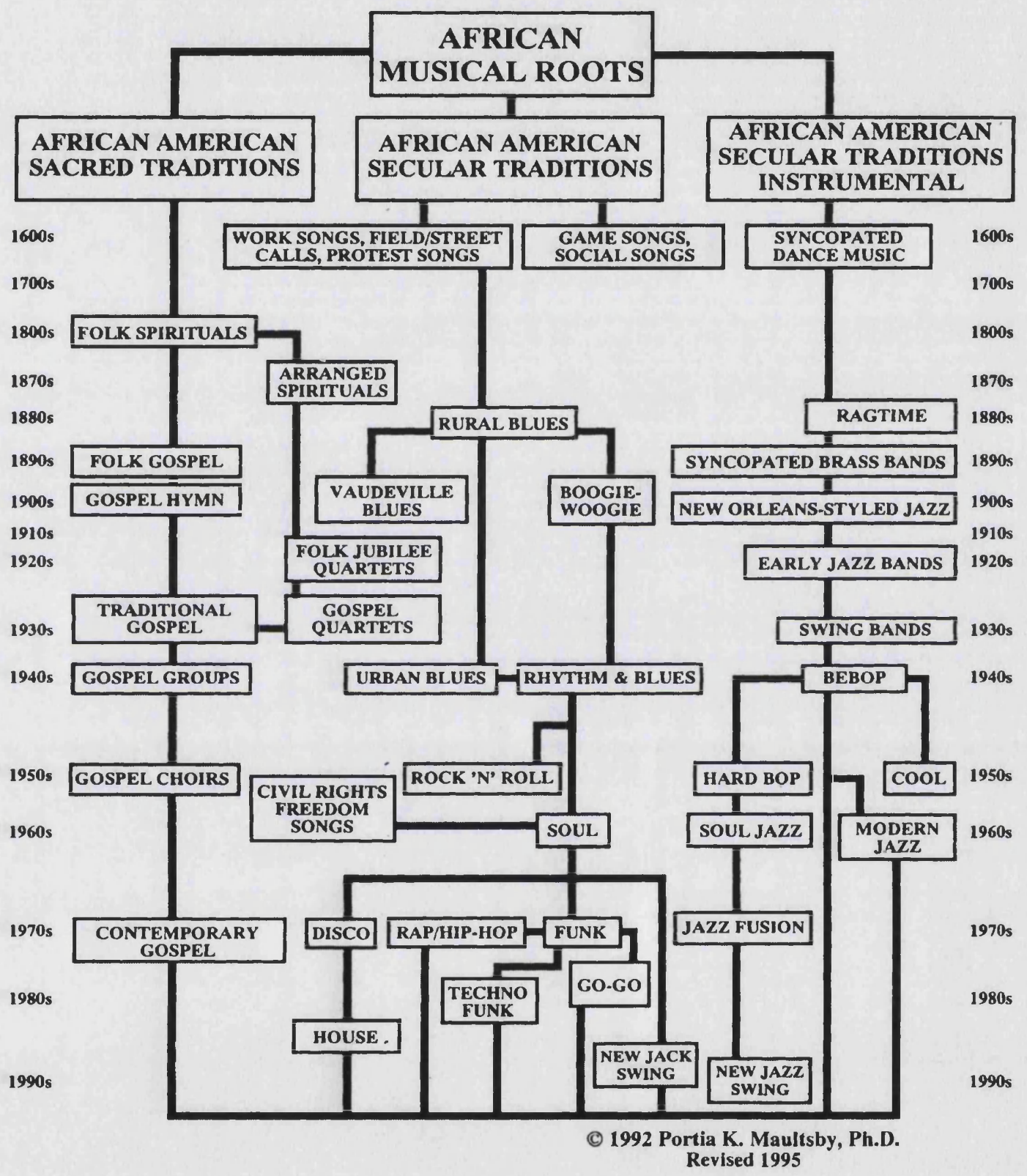

Figure 1.1 - A Conceptual Framework of African American Music Genres and Performance Styles 
In the light of the experience of my fieldwork, I can attest to the fact that Calypso music subscribes to this function. In contemporary Trinidad, the Calypsonian occupies a central place in the cultural fabric of the country. However, of the range of Calypso performers within this carnival art-form, the "serious" Calypsonian is also seen by many to have a profound impact in the social, economic and political domains. As such, this literary art-form has itself both initiated change, as well as experienced change during the centuries.

The Calypsonian has traditionally recognised a body of questions that provide a conceptual link between individual citizens, national consciousness and current events. It is inevitable that the Calypso, being as entwined as it is, in the social, cultural and political dimensions of the lived experiences of Trinbagonians, is compelled to bear testimony to our history over the centuries, and convey the nation's current epistemology.

\section{Defining The PuRpose Of ThIS WORK}

This study is premised on my belief that Calypsos offering commentary on the social, political or economic issues in Trinidad, are driven by a partly conscious element, but mainly unconscious need, to resolve the inter and intra-strata conflict that occurs within the structure Trinidad society. In this work I contend that the carnival season gives authority for a degree of "misrule". By using the term "misrule", the suggestion is that the constituent art-forms comprising the Carnival festival, but more specifically, Calypso, serve a function that is greater than being merely a release-valve, deflecting attention from a people's social reality. More specifically, I contend that, not only do Calypsos support and perpetuate certain community values, but that those offering 
Chapter 1- Notions of Calypso

commentary on the country's social and political issues, in criticizing the political order, serve as a mirror for the people, drawing their attention to the febroils within the country. Through this process of awareness raising, they enable the people to recognise that they have the capacity to "act" to change their circumstances. In arguing that this function, of portraying social discontent is circumscribed by conflict, I contend that more importantly, the process is inevitably underwritten by a commitment to resolve the identified conflict.

In identifying this approach to the resolution of conflict, this research identifies the language of Calypso as engaging in a process that helps individuals acquire a level of knowledge from which they can interpret their lived experiences, in a way that may subsequently enable them to affect their socio-political and/or economic behaviour. As a consequence, this research holds the work of Kenneth Burke as its backdrop, as it recognises[ing] the language of [certain] Calypso[s] as "Symbolic Action" in resolving conflict in Trinidad.

In so doing, this work builds on work previously conducted in this area of the Trinidad carnival art-forms, showing how, locked in a social structure where pre and post emancipation slaves and their descendants, finding themselves bereft of any meaningful power, used Calypsos as a medium of nascent counter-hegemony, in their attempt to resolve the social imbalance in their society.

Today, within a somewhat different social structure in the island, I intend taking a current view of the role and function of these Calypsos as they create seek to create the opportunity for all the citizens 'to be' and 'be respected'. Hence, this Thesis goes beyond a mere examination of the function of the Calypso. Through the interviews 
Chapter 1- Notions of Calypso

conducted during my fieldwork, I try to examine the intentions of the Calypsonians themselves.

Although Calypso is but one of the attributes of the total expression of the Trinidad Carnival, and it can be argued that Carnival itself is an approach to resolving conflict in an inverted world, it is nevertheless beyond the scope of this work to engage in research regarding the other attributes of Carnival. However, later in this Chapter I will show the contextual relationship between Carnival and Calypso.

This work looks at the Trinidad Calypso which is one of the constituents of the Trinidad Carnival. It is framed in recognition of the centrifugal force exerted by the Calypso, driving for change in that society and the centripetal impulse exerted by the "system" seeking to maintain the status quo. These two prime forces are seen to be employed in a conflict within the confines of Trinidad society. The culture of Calypso, enshrined as it is in the negotiation of a 'better,' happier future, is driven by the cultural-linguistic dualism, as manifested in the differing experiences of enslaved Africans and free white Europeans. It has, locked into its archetypal expression, the dream of the emancipated ex-slave, of utopian abundance, equilibrium and a freedom 'to be' and 'be respected.'

In the context of resolving inter-strata societal conflict, I intend to show that the Calypso gives support to what Carlo Ginzburg has succinctly characterised as a circular, reciprocal relationship between the cultures of the subordinate and ruling classes (Ginzburg, 1980). 
Chapter 1- Notions of Calypso

This work focuses on the cultural-linguistic literary genre of the Calypso, the images created thereby, and how at any period in time, these musically created images, intrinsically reflect the people's hopes and their striving to turn their backs on a dying era of an old power-divide, while greeting a new and 'better' lived experience.

In this work I will be showing that in Calypso, as with mediation, language is the key tool that Calypsonian have at their disposal to engage with and raise the awareness of individuals. I argue that Calypsonians enable their audiences to view a situation from multiple perspectives, bringing aboút the development of inter-subjective understanding, while engaging methods of learning such as situated cognition, reflection in action and constructivism. That is to say that through the medium of their Calypsos, Calypsonians, acting as agents of consciousness, are able to create little vortices of learning, within which individuals are 'permitted' to gain understanding, derive meaning, and construct knowledge from the events within their contemporary worlds. My identified task is to show how Calypsonians, through the skilled use of the Calypso art-form, arrive at a point where they are able to create an alternative perspective to a given set of events. They do so by restoring, re-mythologizing, reconnecting the consciousness of their audiences, allowing their audiences to have a living dialogue with the mental images of their desired utopia.

\section{Statement Of The Problem}

Calypso music serves many different functions in Trinidad society. This thesis examines whether the language of the Calypsos that offer commentary on the social, political and economic issues in Trinidad (among their various other functions in the society that generated its birth, and which still sustains a significant position in the 
Chapter 1- Notions of Calypso

community), also function as a medium that helps individuals to acquire a level of knowledge, from which they can interpret their lived experiences, in a way that subsequently enables them to affect their socio-economic and/or political behaviour, and by so doing, actively engages the process of resolving conflict within Trinidad society.

The process of achieving this outcome requires describing and analysing the characteristics of the Calypso, while examining whether the lyrics of Calypsos, create the possibility for the resolution of conflict within the society of Trinidad.

\section{RESEARCH QUESTIONS}

In view of the identified problem stated above, the research will focus on getting answers to the following major research questions:

- Do Calypsos that focus on social and political commentary facilitate the resolution of conflict within the society of Trinidad and Tobago?

- If Calypsos on social and/or political commentary do facilitate the resolution of conflict, how is this outcome achieved?

- Does the Calypsonian recognise him/herself as facilitating the resolution of conflict?

- What tools and skills from the domain of conflict resolution can be mapped onto Calypsos that are sung on topics of social and/or political commentary?

- What paradigm of conflict resolution do Calypsos that are sung on social or political commentary support?

Answering these questions requires an understanding of the use and place of ritual, myth, folklore, and the stories in the lives of the indigenous population. Through this understanding I will be able to convey a measure of the worlds, conditions and the experiences of the participants, as I engage in what Geertz calls the double tasks of 
Chapter 1- Notions of Calypso

uncovering the conceptual structures that inform our subjects ' acts (Geertz 1973:27) in my process of constructing a system of analysis in whose terms what is generic to those structures may be identified (Geertz 1973:27). In the process, I will determine whether, and if so, to what extent, this ritualistic demonstration of Calypso, depicts the sufferings of a generation, while giving the population an opportunity to leap into freedom.

This work focuses principally on the Calypso as one attribute of the combination of carnival art-forms. In raising questions about the primary role of Calypsos that comment on the social and/or political issues in Trinidad, I question their impact on the awareness of Trinidadians, as Calypsonians attempt to generate opposition to the established order. In doing so, I examine how these Calypsos become a vehicle of resolving conflict. This work is therefore intended to examine the role of this type of Calypso, as this role relates to the process of resistance and opposition, while the Calypsonian seeks to orchestrate alternative perspectives to the presented situations.

In setting about this task, I propose looking at the trajectory of the development, and application of the Calypso art-form from its early days, with the view of determining how the Calypso achieves the defined outcome.

\section{TRINIDAD - A POTTED HISTORY}

My research into the history of Trinidad and Tobago showed the islands, but more particularly Trinidad, to be a mosaic of movement of the various peoples who have populated it. The islands were originally inhabited by the Caribs and the Arawaks, with Europeans first establishing contact with the island in the $15^{\text {th }}$ Century when Christopher Columbus, a Portuguese navigator, sailed under the Spanish flag for King 
Chapter 1- Notions of Calypso

Ferdinand and Queen Isabel. One of Columbus' original intentions was to prove that the world was round and not flat as was the prevalent view at that time. He sought to achieve this by showing that he would not fall off the edges of the surface of the earth, but would arrive in the east if he continued to sail westward, (Parry and Sherlock 1956; Augier et al 1960; Williams 1964; Williams 1970).

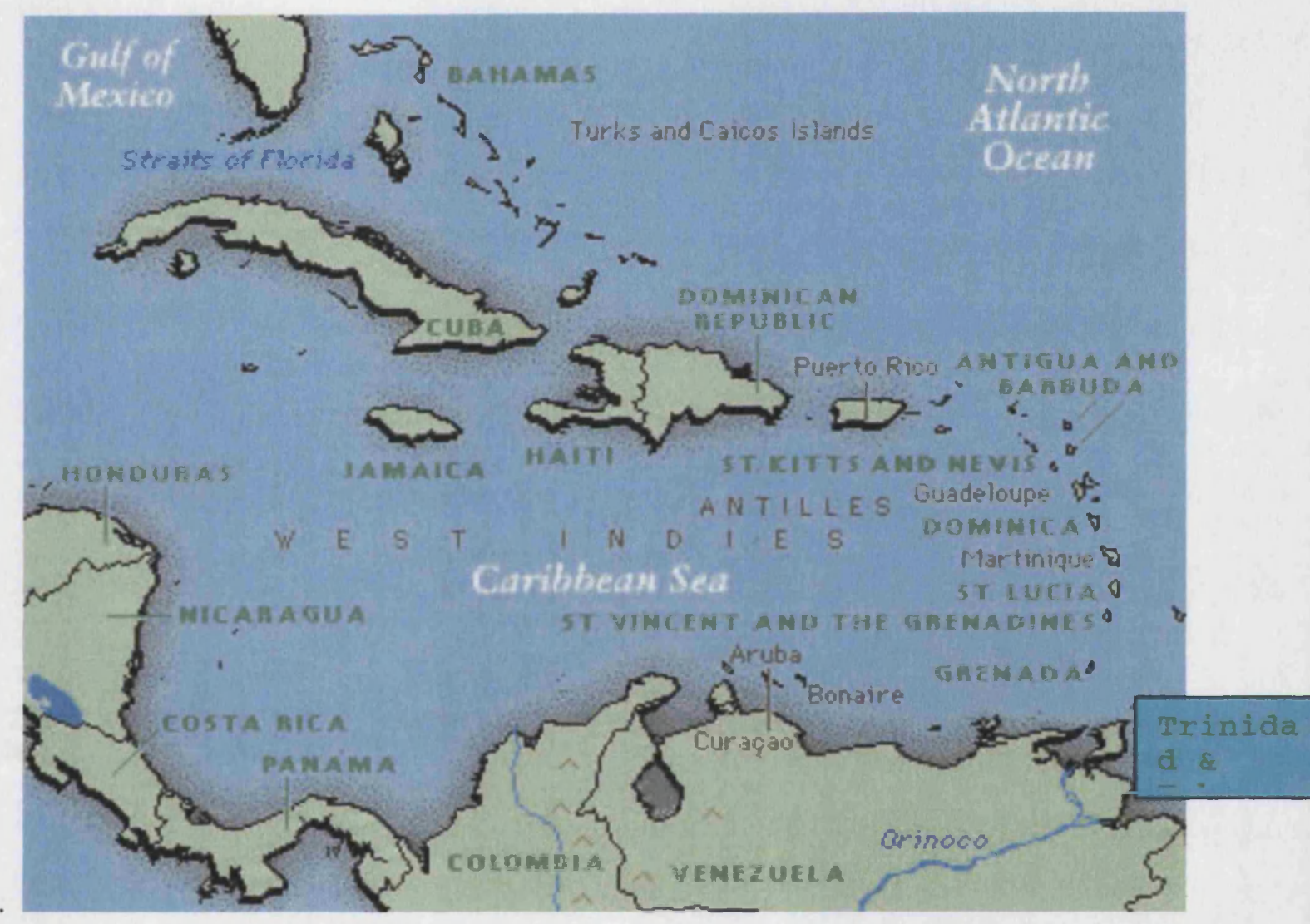

Figure 1.2 - The Caribbean Archipelago

During the first voyage with his three ships and a crew of 'expendable' convict seamen,

Columbus came upon what much later came to be known as the Watling Island. In claiming this on behalf of the Spanish Crown, Columbus named it San Salvador. In subsequent journeys he established contact with the Caribbean archipelago, which was 
later called the West Indies. At the time these islands were inhabited by the Caribs and Arawaks (Parry and Sherlock 1956; Augier et al 1960; Williams 1964; Williams 1970).

In 1498 , during one of his subsequent journeys, Columbus encountered Trinidad, the most southerly island of the archipelago. Also claiming this on behalf of the Spanish Crown, Columbus named it in honour of the "Blessed Trinity". This name was chosen as an act of thanksgiving to God, in recognition of Columbus' earlier belief that he and his men were lost at sea.

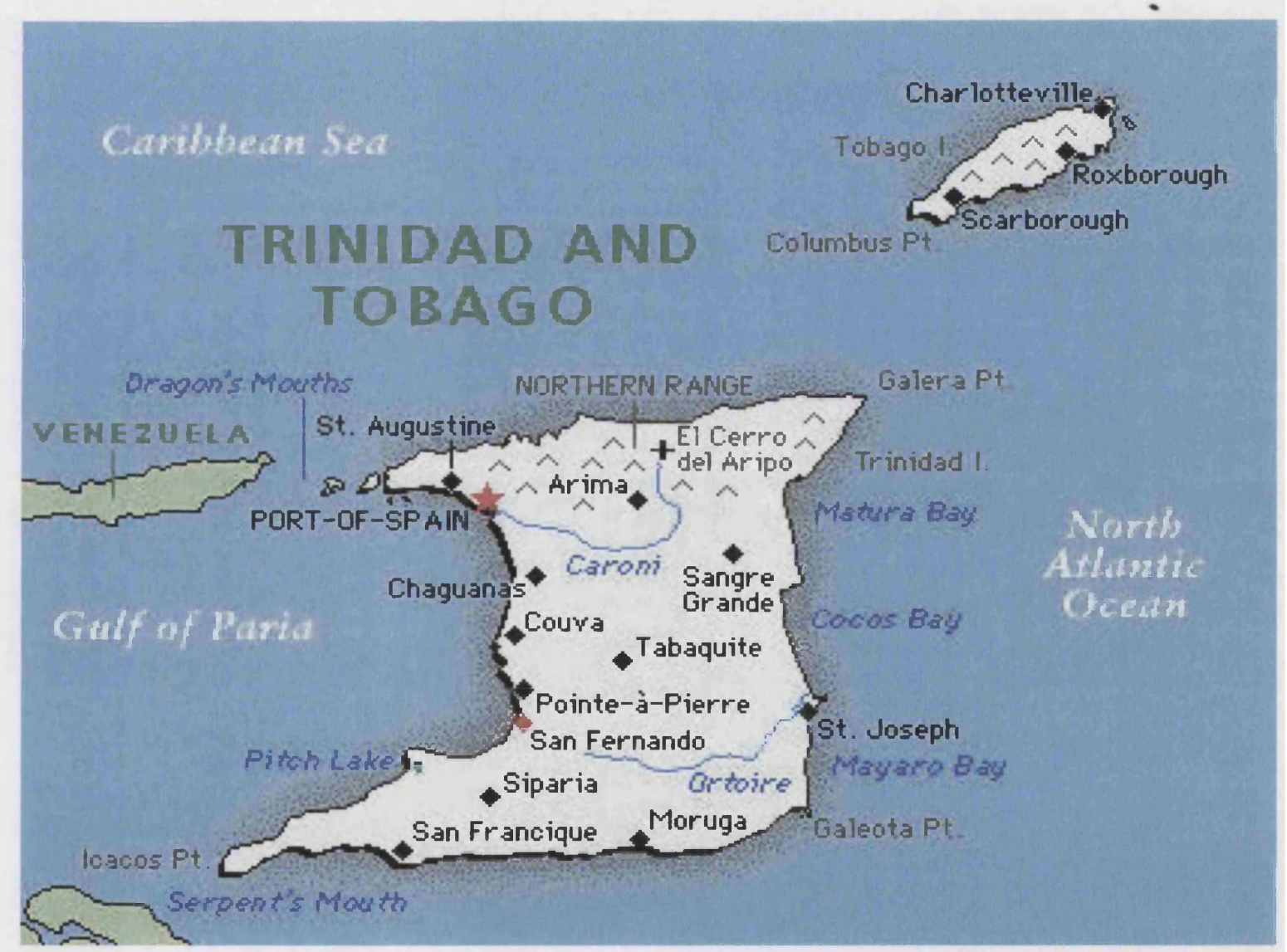

Figure 1.3 - The Republic of Trinidad \& Tobago

For almost 300 years this island was ruled by Spain, with little attention being paid to it, remaining relatively unimportant to the Spanish Crown, being one of her most 


\section{Morel Peters - Sobriquet: Luta}

Morel was born in Point Fortin, Trinidad in 1951 and grew up in the remote country village of Tortola with his aunt, who has a small shop in which he worked, when he came back from school.

His Aunt regarded Calypso as taboo and therefore forbade him

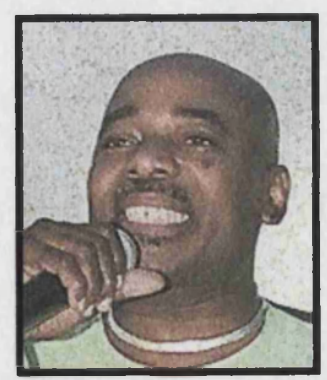

Figure 3.1 - Luta from listening to them or being involved in them in any way. Out of respect for his Aunt, his contact with the Calypso world was clandestine. He first started writing Calypsos at the age of 18 , doing so for friends, young people and other Calypsonians around his village. However he waited till he had legally attained manhood at 21 to sing his first Calypso, which was entitled "Granny Say". At that time he sang under his original sobriquet of "Sugar Stick". He left his Aunt's home at 22 and come to live and work in Port of Spain. Although he had trained as a draftsman, he had little practical knowledge about the building trade and set about gaining some experience while he lived in the city. Initially life in the city was tough, but he worked hard and learnt quickly and developed the essential survival skills, necessary to make it in the capital.

Lord Kitchener and the Mighty Sparrow were the early icons after whom he modelled himself. During my interview with him he recalled how he marvelled at their versatility and their ability to produce numerous records, on the wide variety of topics that they did over the number of successive years.

In responding to the question: who were his inspirations? He recounted as follows:

For diction, I admired Superior, whose name is very seldom called. He was a master of Calypso. I loved his diction also Christo. The Mighty Sparrow was

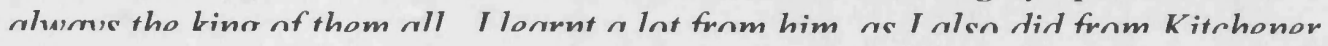


Chapter 1- Notions of Calypso

'underdeveloped' American possessions (Cowley 1998:9). It was not until the 1770's when the 'Bourbon reforms' were brought in by Charles III, that any significant attention was paid to the island of Trinidad. Charles issued two significant Cédula (i.e. decrees). The first of these, issued in 1776, was in response to the neglect of the island. It encouraged the migration to Trinidad from other islands, of French West Indian planters with their slaves. Incentives of land grants were offered, to encourage them to migrate.

In 1783 the Spanish, who were predominantly Roman Catholic, extended this earlier Cédula with a further Cédula de Población (Decree of Population), this time extending a further invitation to settle on the island. The conditions attached to this further Cédula were that any settlers would take an oath of loyalty to the Spanish Crown, and secondly, that the settlers would be followers of the Catholic faith. Many French settlers were enticed to take up residence on the island not only because it meant that they evaded the marauding of the Napoleonic wars, but also because they were offered land grants and various tax concessions. Andrew Carr writes:

The French were never in possession of the island by virtue of discovery or conquest, but they migrated to the island in such numbers that they exercised a cultural dominance in the society. For example, in 1783, the Spaniards in the population numbered 126 Whites and 245 free Coloured, and when the British captured the Island in 1797, their total was still merely 150 whites and 200 Free Coloured. At this time the French on the other hand, numbered 2250 Whites and 4700 coloured.

(Carr, 1975:363)

These two decrees had the effect of swelling the French population on the island with experienced white planters and their slaves, as well as with free-coloureds. This influx of inhabitants came mainly from Haiti and other French speaking Caribbean islands. The effect of this was that by the time of the British conquest in 1797 , there was a 
significant French-speaking landed aristocracy. This tier of Trinidadian society created flourishing tobacco, sugar, cotton, and coffee plantations through the use of enslaved Africans. This economically prosperous and numerically growing French plantocracy demanded increasing numbers of slaves in order to maintain its market position. The figures of the 1806 census below retrieved from the National Archives in Trinidad and Tobago, shows the distribution of the population along race, gender and nationality This growing, mainly French society, was socially stratified along lines of both race and class. One of the effects of this a stratification of the society was that the whites remained socially separate from the group of free coloureds (this group including the free blacks). In this stratification the white upper class group enjoyed the greatest privilege and civil rights.

There were further political divisions among the population wherein the whites identified more with the Royalists and were later to favour the takeover of Trinidad by the British. On the other hand the colourds adopted a Republican or pro-revolutionary stance. However, this takeover by the British in 1797 did not have much impact on the implementation of a legal system, as finding the Spanish law to be considerably more repressive than theirs, Brereton tells us that the British permitted the continuation of Spanish law, (Brereton 1981).

The capture of Trinidad by the British had three significant outcomes:

1. It launched a different epoch, starting a large influx of migrants from other British West Indian islands, as well as from France, Spain, Africa and North America. This latter was principally the result of wars on the South American Mainland. The overall effect was an increase in the complexity of the variegated social fabric of the island. (See the figures obtained from the 1806 Census below). 
2. There was resentment of the British by the now well established French upperclass. In-turn this had the effect of developing a political alliances between the French upper-class and the middle and lower classes.

3. The British now started restricting the civil rights and freedoms that had hitherto been enjoyed by the free coloureds during the Spanish Rule.

Prior to the emancipation of slaves in 1834 , as Trinidad prospered, the number of slaves present on the island also progressively increased. This was more because of the switch from the cultivation of cocoa to the more lucrative, but more labour intensive sugar crop. One of the results of this was that although the British Slave trade officially ended in 1807 , between 1813 and 1820 more that 4,000 slaves were brought to the island to work the sugar plantations (Brereton 1981:56).

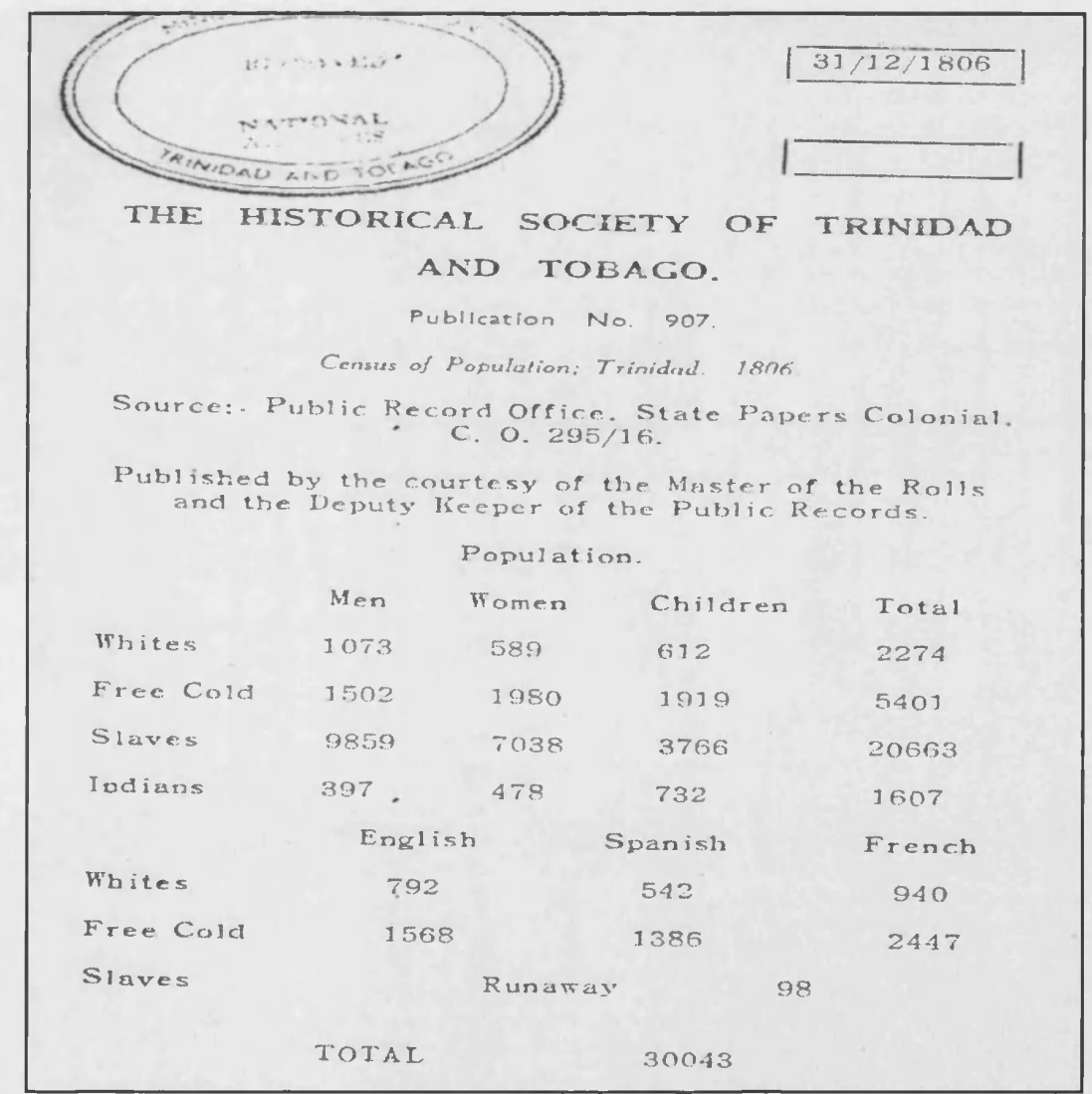

Figure 1.4 - Figures of the 1806 Population Census 
Chapter 1- Notions of Calypso

In the period between the abolition of the slave trade and the emancipation of enslavement, the majority of the enslaved population were being born on the island. The impact of this was that the newly arriving Africans as well as those who were more established on the island experienced a culture which was predominantly a mixture of African-French-Caribbean. This gave rise to a Caribbean-French Creole 'patois'. In relation to this population structure, Cowley writes:

From the arrival of French planters, the history of Carnival can be divided into four phases. These cover slavery, the period immediately following Emancipation, the last quarter of the nineteenth century, and the period from 1897 to the aftermath of the First World War. This complex development illuminates the interrelated evolution of black music in the island.

(Cowley 1998:10)

These phases created a complexity in the structure of the society, inevitably generating a variegated pattern in the social make-up of the island. It will now be helpful to look at the period just following the emancipation of slaves.

\section{Trinidad after emancipation}

In 1833 the British Government declared that enslavement in all British Colonies was to be abolished on $1^{\text {st }}$ August 1834 . In recognition of the consequential stark change to the available labour force, the British Government decided upon a transition period, during which the ex-enslaved Africans would remain on the plantations in Apprenticeships. During this period of Apprenticeship they would receive training to prepare them for their lives as free people. For ex-slaves in Trinidad, this transitional period of Apprenticeship eventually ended on $1^{\text {st }}$ August 1838 . The ex-enslaved considered the Apprenticeship scheme to be another form of enforced labour and frequently refused to take part. As a result it was seen to be a failure. 


\section{Chapter 1- Notions of Calypso}

Faced with a shortage of labour to man the sugarcane crop, the government instituted an indentureship scheme, where workers from a range of countries were brought in on contract to work the plantation estates. These workers included black Americans and some free Africans coming from Sierra Leone. Those seeking indentureships also included some Europeans of Portuguese, French and German origin, as well as a number of Chinese. The European and Chinese combination frequently left the agricultural labouring work in favour of commercial ventures. Despite this there was still a significant shortage of labour to run the plantations. This shortage of labour was addressed by mass recruitment of Indians from the Asian sub-continent.

From 1845 to the end of the Second World War in 1917 approximately 145,000 Indians had migrated to Trinidad to work the sugarcane fields as indentured labourers. This same period also saw people from Syria and Lebanon also migrating to Trinidad and setting themselves up as small businessmen. However, the two largest groups populating the island were those of African and those of East Indian origin.

Hence we can see that in just over four centuries, Trinidad was engulfed in phenomenal transitions in its social, cultural, political, and economic structure. The island ended up as a repository for a cultural mix that included such a diverse range of people as:

German, Portuguese, Chinese, British, French, Spanish, Africans, Indians, American and Middle Eastern peoples. This is the setting which drives the international recognition today of Trinidad as a highly cosmopolitan country. This multi-cultural and multi-racial melting-pot formed the foundation for much of what Trinidad is today. 
Chapter 1- Notions of Calypso

\section{Aspiring to independence}

The advent of the discovery of crude oil in Trinidad in the early 1920's brought significant changes to the Island. As a result of this discovery and subsequent production of petroleum products, the economy of the island began shifting from an agrarian to an industrial focus. Similarly there followed a schism in the pursuits of the two main groups populating the country, the Africans and the East Indians. While the lower-class African population rejected the agricultural work they had hitherto been forced into, moving to the oil fields; the Indians tended to stay in either rural agricultural plantations or small private holdings.

The now largely black industrial workers, so inspired by the international workers movement, now began organising themselves into their own trade union movement. This group of workers began becoming increasingly militant during the 1930's and with the heritage of enslavement still very present in the minds of African Trinidadians, the concept of industrial bargaining became a hotbed of protest and revolution. One author recalls the impact of this time thus:

......the focus on industry and the growth of the proletariat has been the emergence of forceful, militant, often clearly Marxist labor unions and with this the development of finely articulated political ideologies. Militant trade unionism exploded in the oilfields of South and the central Trinidad during the 1930's. At a time when other British territories were more quiescent than rebellious, Trinidad shook with violent turmoil as strikes and states of emergency set the colony into a paroxysm of political crisis. Trinidadian radicalism spread to the other islands and, even in recent years, since independence, political leaders throughout the Caribbean have viewed Trinidad as a hotbed of radicalism, promising to politically contaminate what they often, and usually erroneously, suppose to be their rather more stable states

(Lieber 1988:7)

In parallel with these political and economic developments, but yet quite separate from them, there also began surfacing a black cultural renaissance in which black performing 
Chapter 1- Notions of Calypso

artists began valuing and propagating their own cultural heritage. This was the combination of internal and external circumstances that gave rise to the drive to seek independence from England.

It is clear from the forgoing that a complex tapestry of politics, race and class shaped the development and growth of the country. However the situation was further complicated by the presence of American forces on the island during and after the Second World War. It was seen by many that the Americans contaminated the fabric of the country, disrupting its economy and significantly throwing its social life off-centre as mothers and daughters were relegated to the realms of prostitution. The Calypso "Rum and Coca Cola" epitomises this created asymmetry in the words:

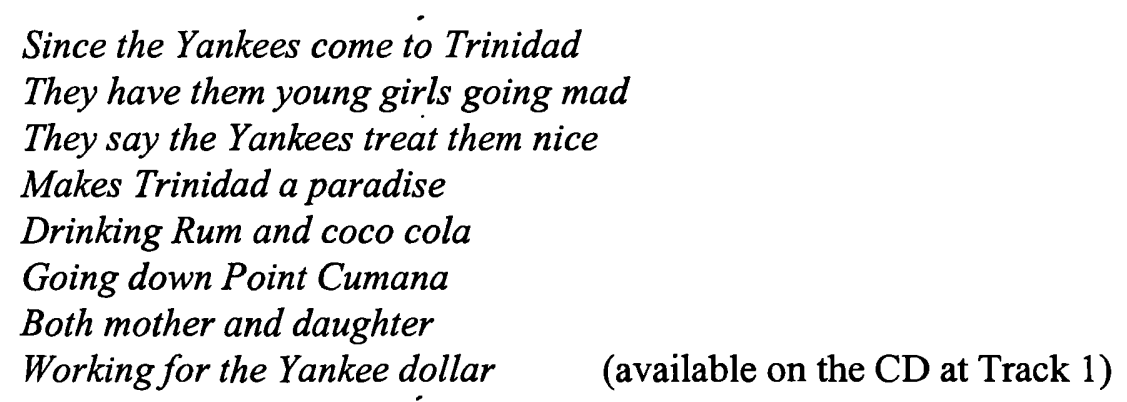

The literary review in Chapter 2 of this work identifies Elder's analysis of the impact of the Americans on the country, as their presence impacted on the Calypsos of the era. It was not until the ascent to power in 1956 of the Peoples National Movement (PNM), led by Dr Eric Williams, that the presence of the Americans on the island was to be seriously challenged. The PNM changed the political landscape of the country. Essentially this was the first time in the history of the colony that it had, what was seen ostensibly as a black government, in leadership. It was through the agency of the PNM that in 1962 the country acquired Independent, with the American base simultaneously closing. In 1976 Trinidad became a Republic. 
The departure of the American milifary did not diminish the cultural and economic influence that the Americans had had in Trinidad, and the legacy of America is still obvious in the country today. Not the least of these is what, oftentimes is referred to as the "Caribbean Diaspora"4.

One of the effects of this Diasporic movement was the inspiration that the black militants in Trinidad received from the Black Power movement in the USA. Fired by the belief that the PNM was squandering the national revenues gained during the oil boom, as well as by the inequalities within the system and an awareness that within Trinidad, privilege was granted largely on the basis of the lightness of the complexion of one's skin, the Black Power Movement in Trinidad was born. Vying for change in the socially and ethnically segregated Trinidad society, 1970 saw violent protests by "Black Power" supporters demanding a solation to unemployment, and an end to foreign influence over the economy. The conditions brought together an:

Unlikely amalgam of ... university radicals and academic Marxists, leftist labour unions, dissident factions within the armed forces, black nationalist groups, and a rather amorphous lumped-proletarian and street-based conglomeration of neighbourhood, youth and ethnic groups

(Lieber 1988:11)

During this revolt hundreds of army soldiers mutiny in support of their claim for equality. However, within days of its start, the rebellion collapsed.

\footnotetext{
${ }^{4}$ This term refers to the large scale migration of Caribbean people to the UK and the North American mainland. In the UK, many of the Caribbean migrants settled in London, Liverpool, Sheffield, Birmingham and Manchester. Many of these migrants sought to maintain contact with their families by constant movement back and forth to their homeland, hence, bringing a kind of exchange of social, political and cultural currencies, so that in many of these large metropolitan cities, there now exists a Carnival that has been inspired by that of Trinidad, with accompanying Calypso Tents. London's Notting Hill Carnival was originally started by a small group of such Trinidadians. It has an associated Calypso Tent which is housed at the Yaa Asantewaa Centre, Chippenham Mews.
} 
Chapter 1- Notions of Calypso

Dr. Eric Williams died in 1981 and George Chambers succeeded him as Prime Minister. The PNM ended its 30 year rule in 1986, when they were replaced by the National Alliance for Reconstruction (N.A.R.) led by Mr. A. N. R. Robinson, (who in Calypsos is often referred to as "Robbie").

In order to pull the nation out of its economic downturn Robinson adopted, what was seen by many to be a tough fiscal strategy, this included:

1. Taking a loan from the International Monetary Fund (IMF)

2. The introduction of Value Added Tax (VAT) and

3. The abolition of Cost of Living Allowance (COLA) for all public servants.

The latter two of these measures had a direct impact on individuals' spending power and made Robinson and his government exceedingly unpopular, so that on $27^{\text {th }}$ July 1990 , Abu Baka led a number of Muslimeen to stage a coup. After some negotiation Robinson and his government were returned to power, (I re-examine this in Chapter 7).

In 1991 the PNM were returned to power but were voted out in 1995 in favour of the UNC under the leadership of Mr Basdeo Panday, who remained in power until they were replaced by the PNM in 2002, this time under the leadership of Mr Patrick Manning. Today Trinidad and Tobago, which has a population of approximately 1.3 million people, is seen as one of the most industrious, prosperous and economically stable islands of the Caribbean. 


\section{IDEOLOGICAL CONDITIONS Of ANTHROPOLOGY AND THE IMPLICATIONS FOR DISCOURSE}

Grounded as this anthropological work on the Calypso Art-Form is, on the implications of ritual communication, it is helpful to briefly review the relevant ideas around this area of the ideological conditions and their implications for discourse, in as much as this relates to the Trinidad situation. Although various authors have made significant contributions to the area of anthropological discourse, inevitably these studies have not been about what the individual knows and thinks and feels about his world. It is his theory of what his fellows know, believe and mean, his theory of the code being followed, the game being played, in the society into which he is born (Keesing, 1974:89). This monograph sets a different course. As an indigenous ethnographer having been born and having lived in Trinidad for a substantial and significant period up to my adult life, I bring to this work a wealth of knowledge and lived experience, gained on both sides of the Atlantic, which allows me to bridge the etic/emic divide. My unique position as an indigenous ethnographer permits me the opportunity to be able to interpret applications of the Calypso art-form using my inter-subjective understanding, gained from life and experiences 'iniside'.

It is for this reason that this work differs from contributions like Maurice Bloch's theoretical work of the late 70 's, in which he considered the social determination of ideas, (Bloch 1977). In his article, Bloch focuses on the question of a society's capacity for change when all ideas and apprehensions of that society are socially determined. $\mathrm{He}$ observes that attempts to resolve this question encounter one of two difficulties, (Bloch 1977:280-1). In recognising a distinction between normative and ritual communication, Bloch sees that for normative societal systems, the choices that are allowed to 


\section{Chapter 1- Notions of Calypso}

individuals in their daily course of action, are still hemmed in by a bedrock of concepts that define and determine a body of existing rules and codes of conduct, (Leach 1970;

Firth 1964). Within this milieu, the choices available to individuals do not include any that incorporate the reality of change.

Some Marxist anthropologists have on the other hand, put their case forward for a self sustaining infra-structure, having its own 'rationality' and which appears to drive change quite independent of any of man's apprehension (Godelier 1972). In the final analysis, we find that social change is left bereft of the social agency of human action.

In response to this divide Bloch posits an alternative concept of individuals being neither encompassed by layers of common concepts and rules, nor moulded by the self sustaining forces that are beyond our apprehension.

In this connection, Bloch identifies two types of communication that are prevalent in the processes of social life:

On the one hand there is a system used in normal communication based on universal notions of time and cognition ... a system which is used for the organization of practical activities, especially productive activities, and on the other hand there is another totally different system referred to by RadcliffeBrown as social structure, based on stranger and much more culturally specific system of classification.

The presence of the past in the present is.... one of the components of that other system of cognition which is characteristic of ritual communication, another world which unlike that manifested in the cognition system of everyday communication does not directly link up with empirical experiences

(Bloch 1977:287)

With regard to ritual communication, of the type to which I consider the events of the Calypso Tent subscribe, Bloch suggests that in having the principal role of legitimating 
Chapter 1- Notions of Calypso

social inquiry, it has a propensity to-flourish in types of societies that support elaborate political forms. However, through the mechanisms of their practical activity, people have access to an array of concepts that are universally shared. Far from being dependent exclusively on efforts to legitimate the powerful, this array of concepts can be employed either to describe life as it is, or to criticise, as in this case, where Calypsos are sung on social, political or economic issues. Bloch argues that it is through this latter process that change is instigated.

Bloch (1974) contends that ritual communication and the symbolic interpretation of reality that this necessarily involves, occurs at set times and places in the course of daily life. For my part, I identify a direct correspondence between his theoretical position and the practical occurrences within the Calypso Tent. The examples of ritual communication that he offers all suggest particular times during which people are drawn away for a minute, an hour or a number of days from their practical activity. These resonate with the culture of the Calypso and the associated Carnival season.

Bloch's position can be summarised by stating that symbolic interpretation is structurally determined and occurs during ritual, while normal communication is not structurally determined, and operates in all other areas of social life. I shall subsequently be revisiting the application of these concepts when I turn to determine Non-formal conflict resolution as is applicable to the Trinidad situation.

\section{DEFINING TERMINOLOGY}

In this section I examine the development of conflict resolution systems in Trinidad. In doing so, I am acknowledging that traditionally, in the field of Legal Anthropology, the 
Chapter 1- Notions of Calypso

resolution of conflict has been divided into Formal and Informal approaches, However, in extending on this duality, I will show that with respect to the Trinidad situation, there is a third strand which I have labelled: "Non-Formal".

As with many other colonised countries, in Trinidad, the very practice of colonialism propagated the imperial power's metropolitan legal system throughout the territory, imposing this as the formal dispute resolution process to be used when resolving conflict. However, there were significant differences occurring between the available structures for resolving conflict in the territories of the New World and those available in the African continent or the Indian sub-continent.

These differences resulted from the fact that imperialism in the African continent, like the Indian sub-continent, was imposed on a people who were already well established in their own homeland, having their own operational socio-cultural systems which included well recognized methods for resolving their conflict. The emergent dispute resolution systems in these societies, was a form of legal pluralism where, a hegemonic colonial power shaped the formation of a formal dispute resolution processes, while the parallel, local, informal system continued to coexist. For the reasons embedded in the complexity of the social, political and economic matrix that drove developments in Trinidad, (as delineated in the earlier section dealing with Trinidad history), this structure was not mirrored in Trinidad.

Hitherto being supplanted in Trinidad, this composite group of Africans from different tribes, now arriving as slaves, had been used to a variety of socio-cultural system that ranged from chiefdoms to acephalous societies. In their new Caribbean homeland, the 
Africans collectively became an amalgamation of disorientated, disempowered, bemused people, from a range of different tribal systems, having neither a sense of community, nor continuity nor a common language with which to communicate.

Newly arrived in Trinidad, these totally disorientated people found themselves in submissive bondage, with their primary drive being survival. Within these complex dynamics of subordination and struggle, the Africans, although numerically superior, were not of the mindset that allowed them to entertain either the idea of implementing a unified dispute resolution system, or the resurrection of one to which any of them had previously been accustomed. On the other hand, for their part, the migrant Europeans now residing in Trinidad, already had their own imported formalised dispute resolution system which became the de facto system for the application of justice.

The 1797 change in imperial governance from Spanish to English, supplanting Hispanic law with British law engendered accompanying tensions within the Trinidad community, (Wood 1968). This further impeded the capacity of the African slaves to form an integral, informal structure for the resolution of conflict among either themselves or between themselves and their slave masters. The absence in Trinidad of the type of formal/informal legal pluralism that existed in Africa and the Indian subcontinent was sustained for some considerable time. Writing in 1947 in relation to the microcosm of the Trinidad Village of Toco, Herskovits and Herskovits, comment that most of the villagers, being born elsewhere, had no long, common local tradition to be upheld, or that required the support of the people in their old ways. As a consequence their research identified that the procedure for the resolution of disputes was through a Court system that was entirely of European origin, (Herskovits and 
Herskovits, 1947). For my part, my research into pre $20^{\text {th }}$ century Trinidad has not revealed any informal system of dispute resolution existing in the island that corresponds to that available in either Continental African or the Indian subcontinent.

Quite apart from this, the 60's and 70's temporarily gave rise to an informal system of resolution wherein respected members of the community (Priests, Head-Teachers, the Post Master/Mistress, and the Village Police Officer) assumed an informal role of peacemaker in local disputes. Within the last 10 years, Trinidadians have grown in their awareness of the potential of Alternative Dispute Resolution (A.D.R.), with a corresponding increase in commitment to the mediation process. Currently, various State and private bodies, following a North American model of mediation, offer certain types of disputing parties the opportunity to informally resolve their conflicts.

In turning now to the wider area of legal anthropology we see the release of Bronislaw Malinowski's study at the end of the first quarter of the $20^{\text {th }}$ Century (Crime and Custom in Savage Society), heralding in a significant epoch in modern legal anthropological studies. However, this approach so skewed the understanding of the entire spectrum of the conflict resolution processes that were engaged in at this local level, that it further distorted aspects of the theoretical development that would otherwise have been available. This occurrence was a consequence of the fact that these early studies produced a static analysis that took no account of the interactions between the formal and informal systems, neither did they consider the implications of the asymmetric power imbalance between the processes, particularly with regard to the importance and impact of the imperial models. 
Chapter 1- Notions of Calypso

The 70's saw the field of dispute resolution continuing to evolve and grow in a significant way (Gulliver (1978), Comaroff \& Roberts, (1981) Moore, (1985). During this period Nader and Todd (1978) produced a pioneering florescence of studies of village law, using a choice-making model of action, a focus on local places and a processual mode of analysis of disputes, hence, producing a framework of typology for dispute processing. Correspondingly, this inspired other legal ethnographic research work, into socio-cultural frameworks in various locations around the world, providing rich descriptions of the local significance of these contexts.

The literature of the 70's and 80's shows an awareness of the need to regard not just the localised, informal, rational, choice-making models of behaviour, but the formal as well. Some researchers (Snyder 1981) (Chanock, 1985), criticised the micro-level approach to the study of disputing, with Starr \& Collier (1989) generating an expanded framework of dispute analysis incorporating historical, temporal and the world system.

In recognition of the link between methods of dispute resolution and culture, Clifford Geertz expressed the view that law is a type of social abstraction that is driven by culture and imagination and is designed to regulate social life (Geertz 1983). Geertz argued that there is a direct relationship and correspondence between law on the one hand and myth, ritual, ideology, art or classification systems focused on structures of meaning, especially on the symbols and systems of symbols through whose agency such structures are formed, communicated and imposed (Geertz 1983:182). 
Chapter 1- Notions of Calypso

The field of dispute processing has evolved considerably over the last 40 years or so, with legal anthropologists defining and redefining this evolving domain to embrace socio-cultural systems, (Comaroff \& Roberts (1981), Starr \& Collier (1989)).

The processual model of law, of which dispute processing forms part, developing from the 1950s, (Turner (1957) Gluckman (1955), Bohannan (1957)) built upon Malinowski's action oriented functionalism, and was supported by comprehensive case analysis. The establishment of this model of dispute processing launched a significant challenge to the existing rule-centred approach. However, the 1970's saw legal scholars attempting to produce a synthesised model that bridged both the rule centred and the processual models. The 1980's saw legal anthropologists developing a concern for meaning and power, hence drawing from the theoretical orientations of different disciplines, producing enriched and expanded theoretical frameworks that provided a bridge between aspects of the social sciences and law (Comaroff \& Roberts (1981); Starr \& Collier (1989); (Abu-Lughod (1990); Comaroff (1985); Comaroff \& Comaroff (1991); Scott (1985)). These newer innovations sought to combine the areas of dispute processes in a social context, with notions of how legal institutions and actors create and transform meaning within the context of their particular cultural framework.

This work from the colonial and post-colonial worlds was taken up from the late 1970's, and drawn upon in the process of the renovation of metropolitan legal systems. The ensuing shift in orientation from formal to informal processes for resolving disputes has been accompanied both in metropolitan centres and in the post-colonial world with new understandings of theories of dominance and resistance, (Abu-Lughod (1990). 
The objective of this manuscript, recording as it does the experience of the ethnographic research that I essentially completed as part of my study, is to illuminate key processes that underlie a different, yet complementary approach to the resolution of conflict, as applicable to Trinidad's local, temporal context. In doing so I am adding a set of intellectual tools that enable us to recognise the Language of Calypso as "Symbolic Action" In Resolving Conflict in Trinidad. My approach, set as it is against the backdrop of the discussions around ideological conditions of anthropology and the implications of these conditions for discourse, enables a vision primarily of Calypsonians, and secondarily their audiences, as social actors, both engaging and demonstrating their potential for human action or agency within a Matrix of Domination $^{5}$ (Collins 1990). It invites an understanding of how Calypsonians, through the medium of the Calypso, influence the social creation, maintenance and alteration of structure, in their process of articulating the inequality problematic ${ }^{6}$ in the localised situation of Trinidad.

This being the case, using an interpretive framework, I define a Non-Formal approach to the resolution of structural conflict within Trinidad, thus taking us somewhere new. In doing so, I extend the duality of resolution processes earlier identified, taking a quite different line from previous researchers of the Calypso Art-Form. Hence, this work unveils a third strand, adding intellectual tools that offer an understanding of aspects of

\footnotetext{
${ }^{5}$ Matrix of Domination refers to the dynamic interaction of the combination: race, class and colour. It addresses the disempowered effect of the interactive and reinforcing process that exists between these attributes, not as individual attributes in themselves, but only in relation to the interaction between the various attributes as these affect and influence inequality.

${ }^{6}$ Inequality problematic: In using this term I am referring to the Calypsonians' attempt to articulate the pertinent issues that arise from the Matrix of Domination, (as it applies to the Trinidad situation), as they operationalise an approach that necessarily addresses the issues within this Matrix.
} 
Chapter 1- Notions of Calypso

the Calypso art-form, which show it as a Non-Formal approach to resolving conflict.

In this view, the Calypsonian functions as a liminal servant, using in part, a Trinidadian language, the vocabulary of which reveals the various ideas encoded in the restricted terminology, which is used to represent the daily challenges that some Trinidadians face.

I need here to highlight that the ideologies discussed in this work reflect the Trinidad situation wherein there exists radical class inequalities, which in turn, generate clear forms of socio-political and economic conflict which, correspondingly, is accompanied by the government's attempts to exercise control through censorship.

In using the term Non-Formal, I am therefore referring to a process wherein the Calypso functions as a facilitator in a dialectic that is attempting to resolve contradictions or oppositions, as perceived by the Calypsonians, in either the sociopolitical or economic domains of Trinidad. Functioning as a liminal-servant, the Calypsonian has a sense of immediacy of purpose, offering the audience verbal symbols as part of an artistic rite, which is a response to pathologically prevailing issues. In Chapter 9, I show how the audience become co-celebrants in a learning process that is characterised by their committed participation and involvement in "the act", thereby creating a truly deep, meaningful and edifying learning experience for them.

This monograph is based on a recognition of how, in relation to the events occurring within a Calypso Tent, the rules for this particular approach to dispute processes are negotiated, and simultaneously, social life within the Calypso Tent is governed by normative repertoires that involve the manipulation by the Calypsonians, of the rules of 
Chapter 1- Notions of Calypso

performance, in order to bring about increased consciousness. My approach builds on other authors (Benda-Beckmann et al (1988); Roberts, (1979)) who, lending their weight to an informal approach, argue that rules governing localised conflict behaviour are not internally consistent codes of action analogous to Western written law, but can instead be negotiable, internally contradictory repertoires that are applied with discretion.

Hence, my approach to the anthropology of dispute resolution, offers a cultural analysis that identifies how the local institution of the Calypso Tent and its actors create meaning. I identify the impact of this meaning on the surrounding social relationships, and the effect of the cultural framework of the Calypso Tent on the nature of the processes of resolution itself.

I recognise a parallel between my work and that of Comaroff \& Roberts (1981:18-19) who, in their work on dispute processes within Tswana society, examined the cultural logic of the localised dispute procesises. Other authors, (Schapera $\left.{ }_{2} 1955\right)$, (Dikobe 2003) contend that there are striking similarities between Calypso and Tswana songs of derision in which grievances are articulated.

\section{Calypso As An ART-Form}

Quintessentially, the Calypsonian serves many functions that may be paralleled to that of a mediator. S/he enables the individual to be a moral agent, enhancing the individual's awareness of their capability to choose in relation to their work, national politics and domestic life. Calypsos support various modes of development. In 
Chapter 1- Notions of Calypso

particular, because Calypsos are frequently sung on topical and controversial issues, the subsequent discussion generates levels of social interaction that contribute to the development of social cognition, (see Chapter 7 for the development of this point).

It is through the Calypsonians' skilled application of a wide range of "linguistic form" (I develop this in Chapters 5 and 6), in his/her artistic expression, that communication within and among communities is sustained. History shows that it was as a consequence of the successful use of these linguistic structure that, even after the stringent 1868 sedition laws that Calypsonians were still able to severely criticise those in authority.

In a lecture delivered at the University of East London, (1996) Liverpool divided contemporary Calypsonians into two brackets. The first group consisted of those who are skilled in the art of using what he called "double entendre" (and to which, in this work, I will be referring to as Polysemy).

Liverpool argues that the Calypsonians who fall into this first group use the Calypso as an art form in an attempt to educate the community, usually for little or no monetary gain. Into the second group, Liverpool places the crop of commercial Calypsonians who he considered to be less skilled in the art of this most fundamental attribute of the true Calypsonian, double entendre. They, he argues, in singing it as it is, usually draw attention to their issues in a more direct, mundane and crass manner (Liverpool 1996). My research revolves around the first group, i.e. the group that Chalkdust (sometimes referred to as Chalkie) labelled real Calypsonian. 
This ability he regarded as the hallmark of the real Calypsonian. Liverpool illustrated the Calypsonian's skill at using innuendo, pun and hyperbole to make two quite different statements within the lyrics of the same Calypso thus:

The Governor tall, tall, tall,

The Governor peeping over the Wall

Liverpool claimed that here the Calypsonian is referring to the over 6 feet tall figure of Governor Hubert Rance and his attempts to be "nosy", (what colloquially is referred to as "macoing") gaining ubiquitous knowledge of community activities. He then went on to draw attention to the words of the Calypso "Watch Out My Children" as follows:

\author{
Watch out my children \\ Watch out my children \\ It have a fella called Lucifer \\ With a bag of white powder \\ And he don't want to powder your face \\ But to bring shame and disgrace \\ To the human race (Available on $\mathrm{CD}$ at track 2)
}

This excerpt from the Calypso shows the artful use of words that is very characteristic of Calypsonians, although, nowhere in the Calypso does he directly mention either the substance or the names of any 'drug lord' there is no mistake in the minds of the members of the audience about the advice that is being given, as the Calypsonian Ras Shorty I, adopting the parental position, offers worldly advice and guidance to the 'children' of his audience in relation to the dangers of using Cocaine.

\title{
Moulding Of The Calypso - CaRnival SynCREtism
}

In my attempt to effectively focus on the Calypso and its role in resolving conflict, it is necessary for me first to contextualise the place that the Calypso occupies in the whole Carnival experience of Trinidad and Tobago. My objective in so doing is to identify the 
relationship of Calypso to the other Carnival art-forms and in-turn, the direct contribution that Calypsos make to Carnival itself. This approach will help to better illustrate the functional use of Calypsos in resolving conflict.

Calypso is such an integral part of the multifaceted annual Trinidad Carnival celebrations that it can be regarded as the wind beneath the wings of Carnival. So intrinsic is this link between Calypso and Carnival that Juneja states: there can be no carnival without the Calypso and no Calypso without the carnival, Juneja (1988:89).

The very substance of this Thesis reveals the primary and interstitial link between Carnival, on the one hand, and the nation at large, on the other. In general, Carnivals, but more specifically the Trinidad Carnival, can be regarded as a constellation of rituals that are expressed as games, symbols and carnal excesses. These rituals describe an alternative "social space" within which individuals are able to explore and express an increased level of freedom. It is within this created space that individuals are able to abundantly express in equality, the utopian promise of abundance and redemption. To be pragmatic, cultural expressions of Carnival show up as a number of different attributes, viz.: drama, the parade, dancing, clowning and the songs and music of the various forms of the Calypso art-form. This kaleidoscope of carnivalesque rituals is seen to challenge the system seeking to release mankind from what Marx called the dull compulsion of economic necessity. For the Trinidad Carnival however, the music manifests in a number of different ways, one of these being through the Calypso. 
Chapter 1- Notions of Calypso

The diagram below shows the various attributes that combine to make up the totality of the festival that is carnival. This work is focused on but one aspect of the whole circle. Going counter-clockwise from the top, it focuses only on one part of the contents of the first smaller circle that is met.

In their article entitled "Land of the Calypso: The Origin and Development of Trinidad Folksongs", Espinet and Pitts (1944) asserts that there is a mistaken link between Carnival and Calypso. In arguing that any relationship between Calypso and Carnival is one of convenience, they express the view that while the Calypso has its roots in African folk songs, Carnival has its origins in the Latin culture brought with the Spanish and French settlers (Espinet and Pitts 1944: 51).

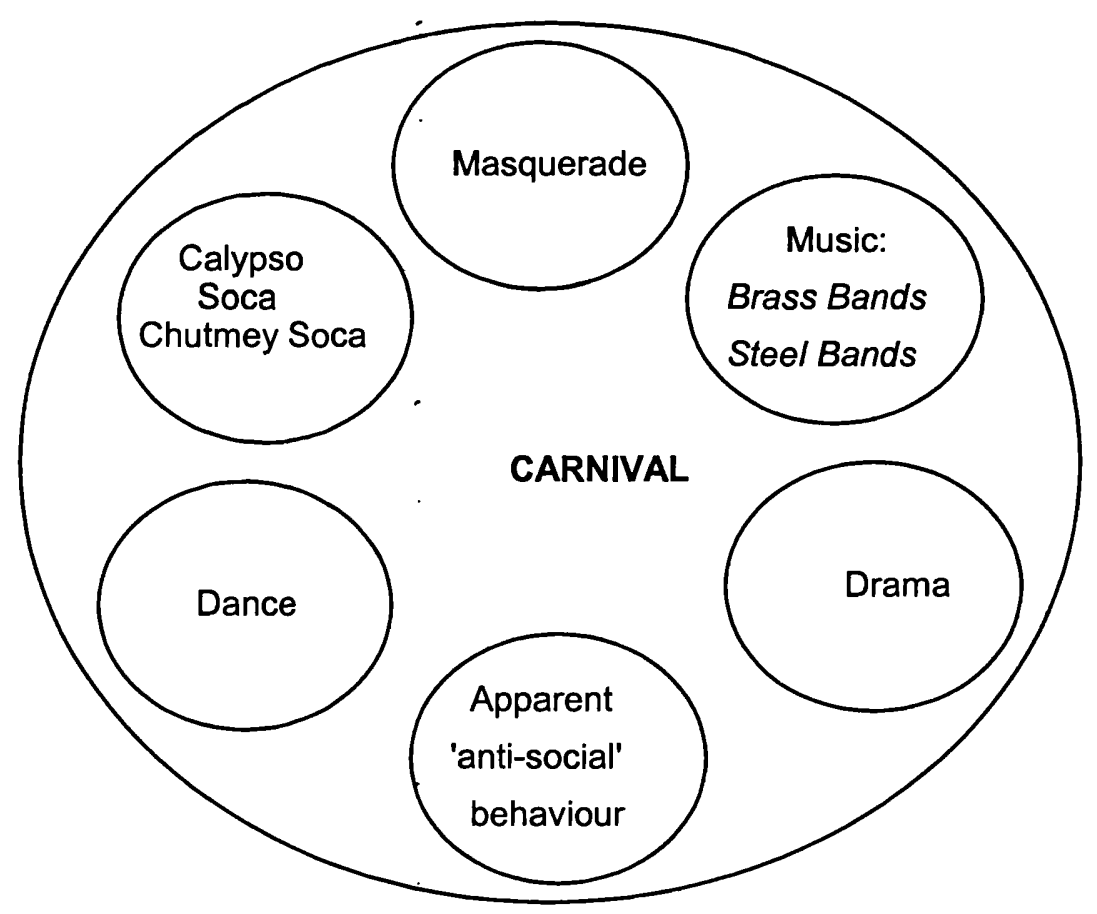

Figure 1.5 - Constituents of Carnival 
Chapter 1- Notions of Calypso

They contended that although Carnival has had no direct influence on the songs, the [carnival] festival has become a sort of Salzburg Festival for the Calypso (Espinet and Pitts 1944: 52). They state that the composers as well as singers of Calypsos use the Carnival period to air their views and the more popular and catchy hits of the year, known as the "Le' go's," become the theme songs of the year's Carnival (Espinet and Pitts 1944: 52). On the other hand, Liverpool states that the Calypso has its roots in a style that was:

African in music, content and character and that the Calypsonian had to deal with the relationships that existed between the landed gentry and the landless.............commenting on the various conflicts that arose in the society Liverpool 1986: 9)

In addressing the relationship between the Calypso and Carnival, Warner (1982: 9-11) attempts to trace the development of the Calypso and forges the link between it and Carnival by examining the status of Calypso in both pre- and post-emancipation periods. Prior to Emancipation, Carnival was celebrated by the white Creole upper class with masked balls, house to house visiting, street promenading .(Pearce 1956: 175-193;

Brereton 1975: 46-57; Hill 1972: 60-61). However, post-emancipation Carnival changed significantly with freed Africans celebrating it with songs, street dancing and stick-fighting.......... and scanting criticisms levelled at the powerful by the powerless (Rohlehr 1972: 3). The latter seems to have perpetuated through to today.

In her historical account of the period, Brereton states:

Around the 1860's Carnival came to have a distinctive character: the 'Jamet' Carnival of the diamètre class. ${ }^{7}$. The festival was almost entirely taken over by the Jamets, who had created in the backyards of Port of Spain their own subculture. Here the urban lower class lived in long barrack ranges situated behind the city blocks, centring on a yard which formed a common living space.

\footnotetext{
7"Jamet" (also and more frequently "Jamette") is derived from the French "diamètre," meaning

"diameter." It means an under class or underworld type, that is to say one beneath the "diameter" of social respectability.
} 
At about this time, yard 'hands' were formed: groups of men and women, boys and girls who went around together for singing, fighting and dancing. Such bands existed all the year round, but were especially active in the weeks before Carnival, when they rehearsed their songs, dances and stick-fighting. The yard 'chantwelle,' or singer, insulted rival yards and yard stickmen sought out rivals for single

(Brereton 1975: 47)

These 'chantwelle', argues Rohlehr (1972: 3-4), were the earliest Calypsonians.

Cowley (1998:100) recalls that in 1884 the conditions of "Torch Ordnance" were subsumed into the "Peace Preservation Ordinance". As a result of these changes, the Governor was given the powers to prohibit carnival celebratory activities of the Canboulay, i.e. the forerunner of Carnival. This early form of carnival consisted of stick-fight, bands of drummers, and the Chantwells. The Chantwells were singers who would urge the participants on. The Chantwells were the first real Calypsonians, entertaining at Carnival time. They had grand sobriquet like Hannibal and Boadecia (a tradition which currently still continues with many Calypsonians).

Warner also argues that present-day Calypsonians have:

lost some of the spontaneity of the chantwell leading the bands and [have] wellprepared and well-rehearsed numbers to be presented to the public during the "Calypso season". $\quad$ Warner (1982:10-11)

Some changes have been made while moving towards the twentieth and twenty-first century, for although groups of people still form themselves into a Carnival band, with few exceptions, these bands no longer have a direct association with any Calypsonian. Exceptions to this norm are David Rudder, Machel Montano and Ronnie McIntosh who are lead singers, turned Calypsonians for their respective music bands. The situation has now changed such that Calypsonians now group together to form commercial 'Calypso 
Tents'. It is only the more popular Calypsonians who have year long recognition. Most Calypsonians come to the forefront only during the Calypso season.

Currently the Calypso season sets the start date for the 'overt' Carnival Season. Before the 1960s, the Calypso Season and therefore the 'overt' Carnival season stretched from immediately after the twelfth day after Christmas to Carnival Monday night (i.e. the night of the day before Shrove Tuesday). At present, the Calypso season starts six weeks before the start of carnival with the official opening of the Calypso Tents. However in the past the season has been known to encroach on the Christmas celebrations, commencing as early as the day after Boxing Day. The Carnival/Calypso season unabatedly builds to a climax on Carnival Tuesday, with the Tents closing on the (Carnival) Saturday night before the Carnival Monday's start of the street parade.

In the latter half of the twentieth century, the link between Carnival and Calypsos has been strengthened further by the fact that almost without exception, only the Calypsos released during any given Carnival season are played on the radio or television stations or either sung or played in other public venues, including the 'Calypso Tents'.

As observed during my fieldwork, two other significant events bridge the Carnival and Calypso seasons and support the umbilical link between them. The first of these is the events on the Sunday night preceding the "Carnival Monday" start of the parade of the Carnival bands. On this occasion there is the major "Demanche Gras" competition which takes place on the stage of the Queens Park Savannah (the venue that is colloquially known as the "Big Yard"). In this grand display of a variety of Carnival art- 
Chapter 1- Notions of Calypso

forms, Calypsonians compete to be crowned 'Calypso Monarch' as do kings and queens of the bands for the coveted title of 'King' or 'Queen' of the Bands, as appropriate.

The title of this competition changed from Calypso King to Calypso Monarch in 1978. This change to the title was driven by the need to accommodate the possibility of a female Calypsonian appearing on the show. This was the first time in the history of the competition that a woman, in the person of Calypso Rose, had been entered for the finals.

Secondly, on the two Carnival days, (i.e. Carnival Monday and Carnival Tuesday), the tune from that year's crop of Calypsos that is most frequently played by the population of DJs, Steel-bands and brass-bands, wins for that Calypsonian the coveted "Road March" prize.

The experiences of my fieldwork have brought me to a recognition that currently Calypso is well recognised as an integral cultural art-form which is frequently used as an expression of the social, political and economic concerns of the people of Trinidad. It is in this respect that the Calypso merits the extensive attention given to it in this work as a mechanism that achieves two fundamental, nevertheless closely and reciprocally interlinked outcomes. The Calypso is uniquely placed to work within the domain of conflicting values, beliefs and actions by first, raising awareness of the issues within the community, by a process that surfaces the pertinent social, political and economic challenges faced by the population at large. Second, it serves the purpose of being a vehicle of expression of the concerns of the population, thereby enabling the other 
Chapter 1- Notions of Calypso

parties, (both inside and outside the conflict) to hear the issues. In so doing Calypsos raise the people's awareness of the prevailing issues as seen from another party's point of view, i.e. this is equivalent to enabling the population to take "reverse perspective" on the issues.

Within a community that is fuelled by a whole constellation of socio-political, economic, and cultural factors, the first of these functions can be seen as a process of education, both requiring and inducing levels of cognitive thinking about the issues, the second is fundamentally that of awareness raising. These two roles are dealt with more fully in Chapter 8.

\section{So THIS IS CARNIVAL!}

Annually, on the Monday and Tuesday which precede Ash Wednesday (i.e. the day which starts the Christian period of austerity, commonly known as Lent), the twin islands of the Republic of Trinidad and Tobago host what is considered to be the largest Carnival celebrations of all of the islands which comprise the Caribbean archipelago. Although to varying degrees, these festivities take place in locations throughout the islands, the main focus of the celebrations occurs in the capital Port of Spain, which is situated in the north-western corner of the island of Trinidad.

Over the years this style of Carnival festivity has been subjected to a multiplicity of interpretations. Depending on the observers and their orientation, these interpretations have varied along a spectrum from devil-worship to a kaleidoscope of drunken revelling and debauchery. This latter perception partly arises from the various tinsel decorated artefacts, the paint, the feathers, and the immediately obvious attitudes of the revellers. 
Chapter 1- Notions of Calypso

Not unlike Levi-Strauss's myths, carnival can be interpreted as a shifting "liminal zone" that calls into question the boundary between nature and culture, a division "official" Western society has desperately striven to maintain for the last two or three hundred years, (Gardiner 1993).

In seeking to establish the contextual relationship between Calypso and the Carnival ritual, against a background of an approach to resolving conflict, I recognise the need to go beyond the myopia of the superficial frivolity and expose the subtext and its structure. Looking behind these activities, one is able to tease out the broader value of the experience of Carnival, or in this case more specifically Calypso, in the context of its use as an agent of the process of resolving inter and intra strata conflict in Trinidad and Tobago.

Although Liverpool $(1990,2001)$ and Hill (1972) have addressed conflict in Carnival, their work has mainly been with regard to recognising the existence of that conflict and charting its development. In this work I will be taking an alternative perspective in relation to the role that Calypso plays in a society that faces the particular types of challenges which Trinidad and Tobago does.

My interest in the subject arises in part from the observations of Johnson (1984) who states that Carnival has only become important in those countries which had a combination of Roman Catholicism and a significant enslaved African population. Thus, she states that while Brazil has a Carnival, Argentina does not, similarly Haiti does but the Dominican Republic does not and Vera Cruz does but not Mexico City. 
Chapter 1- Notions of Calypso

This statement of Johnson's is the fulcrum for this work and has been very central in generating the fundamental research questions.

Calypso and its cultural twin Carnival are both spawned in recognition of the relationship that exists between people who, historically experienced themselves as disempowered and underprivileged, and the inevitable conflict which results from such experiences, as these people use the language of Calypso to liberate themselves from their feelings of 'oppression'.

\section{THESIS OUTLINE}

This manuscript is the result of an ethnographic study of the language of Calypsos originating in the Republic of Trinidad and Tobago. It specifically looks at those Calypsos that comment on the prevailing socio-political and/or economic issues within the country. Its aim is to show how the language used in such Calypsos is 'Symbolic Action', supporting an indigenous community conflict management mechanism.

(Indigenous conflict management mechanisms n.d.)

My ethnographic approach is underpinned by Kenneth Burke's paradigm, wherein he defines Language as Symbolic Action. In the context of my particular approach, I show how Calypsos that comment on the social and political issues occurring in Trinidad, raise consciousness, in a process that supports the resolution of the conflict occurring within the country. 
Chapter 1- Notions of Calypso

This thesis is divided into nine chapters with the title of each Chapter being designed to serve as an icon, encapsulating the contents of that Chapter's substance. In two specific cases I considered that while a specific Chapter gave an insight into the specific process, i.e. 'the what', a second Chapter shared the experiences of 'the how' i.e. how the theory in the previous Chapter was applied with the achieved outcome. Under such circumstances where there was an umbilical link between two Chapters, they were judiciously juxtaposed. Such an occurrence was Chapters 2 (Establishing Resonance) and 3 (Calypsonians and Their lives: Fieldwork in Action). While Chapter 2 alludes to an interpretive epistemology relating to the process of the fieldwork, Chapter 3 relates the details of the actual interviews/conversations with the seven informant Calypsonians during which they shared information about their purpose, their personal history, their experiences and their life work.

The history of Calypso and its cultural twin Carnival, are steeped in conflict. It would be inappropriate, incomplete and therefore wrong to ignore the wider field of conflict that has subtended the development of the art form. Being mindful of this, Chapter 4 defines the trajectory of the wider sphere of conflict occurring within the Republic of Trinidad and Tobago, giving its wider contextual background, as it integrates Stick-fighting, Carnival, Steelband and Calypso.

Chapters 5 (Language as Symbolic Action) and 6 ("Linguistic Form" in Calypso: Employing Reframing as a Multidimensional Tool in Resolving Conflict) both of which are inextricably linked, were also appropriately juxtaposed. In as much as this work is underpinned by Kenneth Burke's philosophy of "Language as Symbolic Action" it becomes appropriate to divulge the orientation to the Burkean paradigm. Chapter 5 attends to this. Chapter 6 shows the application of the Burkean paradigm, looking as it 
Chapter 1- Notions of Calypso

does at the practicalities, processes and application of the reframing language when used by Calypsonians as a multidimensional tool. This Chapter therefore embraces a pragmatic consideration leading to an understanding of how Calypsonians effect their craft, while influencing and persuading their audiences.

Chapter 7 (The Media Used in Calypso Presentations) takes a functional view of the Calypso, being mindful of the concepts of performance theory. This Chapter therefore examines the relationship between performance, theatre, spectacle and ritual communication, as these relate to the public performances of Calypsos. It therefore shows the links between the 'social drama' and the 'stage drama'. This Chapter addresses the appropriateness of the application of the theories of anthropologists like Victor Turner and Max Gluckman, as well as of those of Roger Abrahams. It identifies how these relate to the structure of the ritual communication processes, when applied to the identified function of the Calypsos that are sung (or performed) before audiences in the Trinidad situation.

Chapter 8 (Conscientização: Calypso as an Agent of Social Cognition) pays attention to the Calypsonians' use of image schema to restructure cognition identifying how Embodiment, Temporality, Imagination, Social Interaction and Morality all play a part in this restructuring process. This Chapter concludes by contrasting the socio-cognitive developmental models of Freire, Vygotsky and Bakhtin while relating these to the Calypso Art-Form. 
Chapter 1- Notions of Calypso

Dealing as it does with an aspect of a retained African tradition, it would be incomplete to conclude this Thesis without some consideration of traditional West African concepts of social organisation, rhythm, music and the cosmology that go with such a retained tradition. Chapter 9, (The Audience as Co-Mediator) therefore looks at the role of the audiences as they engage in the process of co-authorship through "Call and Response", yielding a combined effort to bring about resolution. 


\section{CHAPTER 2 - ESTABLISHING RESONANCE}

Ethnography is actively situated between powerful systems of meaning. It poses its questions at the boundaries of civilization, culture, classes, races, and genders. Ethnography decodes and recodes, telling the grounds of collective order and diversity, inclusion and exclusion. It describes processes of innovation and structuration and is itself part of these processes.

(Clifford 1986:2)

\section{INTRODUCTION}

$I_{R}^{n}$

$\mathrm{n}$ reality, Calypsos have a diverse range of functions within the society of The

Republic of Trinidad and Tobago. In recognising this fact, I must state from the outset that, this work is neither intended as a comprehensive approach, nor does it coherently or authentically represent the whole of Calypso culture. In situating this ethnographic work, I am locating it within the historical context of the development of the socio-political Calypsos that are used as a means of protest, addressing the prevalent ills within the society. That being the case, in the vein of the post-modern ethnography as espoused by James Clifford $(1986,1988)$, I intend using an interpretative paradigm in this work to, where possible intertwine and where necessary juxtapose, the structure of this indigenous community conflict management mechanism with that of the Calypso art-form. I further propose to establish the relationship between these two domains of conflict resolution and artistic form, bridging them through the pragmatism of my fieldwork.

\section{Researching the Lived Phenomenon of Calypso LANGUAGE}

In this work, I am contending that for any given year, the crop of Calypsos released that comment on the social and political issues of that year are expressions of existing local conflict. Furthermore, the very expressions of these Calypsos are tantamount to an 
attempt to resolve community conflict in as much as they raise awareness of the prevailing issues, as the Calypsonian, who rises from among the people, and thus identifies with the plight of the poorer person, champions their cause by drawing attention to those prevailing issues. This work is my attempt to show the Calypsonians' understanding of themselves and their function. Consequently, my chosen methodology needs to provide a handle to the Calypsonians' reality.

One of the first decisions I needed to make in relation to this research project was to select an appropriate research method that adequately sheds light on the role of the Calypso as an agent in the process of resolving indigenous community conflict. In making that decision, I recognise that a research method is only a way of investigating questions, and in this respect, what is important is not the method itself, but rather the questions and the way I orientate myself to, and understand the questions. Having said so, I must hasten to add that, certain research methods have a predisposition to certain types of research domains. In the instance of this work, having the intimate knowledge of the society and culture of the Republic Trinidad and Tobago that I do, and my skill and experience, gained as a practitioner while operating in the trenches as a conflict resolution practitioner, it is my view that an interpretive paradigm is most appropriate for this research.

I therefore commenced my work being aware that this research is my attempt to understanding and translating a cultural phenomenon of the Republic of Trinidad and Tobago. In using the word 'culture' in this way, I am mindful of the definition offered by Harris (1968:16), who wrote: the culture concept comes down to behavior patterns associated with particular groups of people, that is to 'custom, ' or to a people's 'way of life'. Although in general terms this definition can suffice, unfortunately it does not recognise the different view of culture that the outsider (etic) may have, as compared to that of the insider (emic). This is particularly significant since behaviour patterns, 
customs, and people's way of life can always be defined, interpreted, and described from a number of different perspectives, each dependent on the 'spectacles' through which the observer looks. For my part, my goal in this ethnographic study is expressed succinctly by Malinowski, thus: to grasp the native's point of view (Malinowski 1922:25). In view of this objective, I found it more helpful to redefine the concept of culture in a way that was more appropriate to my expressed goal. Hence, my research is based on identifying the language of Calypso as a process that helps individuals to acquire a level of knowledge from which they can interpret their lived experiences, in a way that may subsequently enables them to affect their social and/or political behaviour.

In this research, I use ethnographic thick description (Clifford 1988:38; Geertz 1973), to reveal a localised model of cultural linguistics, thereby creating the basis for understanding the language of socio-political Calypsos as an approach to resolving conflict in the Republic of Trinidad and Tobago. This work contends that through the lyrics of this type of Calypso, 'Trinbagonians' are able to gain new insight and as a result, we are then able to embrace a new vision of hope for our future. This is so because the lyrics enable us to grow and develop new, enhanced consciousness as we face our own variety of social, political and economic challenges.

Engaging in this process of conscious raising requires of Calypsonians, not only that they have creative minds, but also consciences that are sensitive to the disadvantage, the misery, the suffering of their oppressed fellow 'Trinbagonians'. The very process of the development of this critical awareness, in itself becomes self-perpetuating. That is to say, it regenerates itself in the audience as they listen to the Calypsos that had previously been composed and are now being sung to them by the Calypsonian.

In relation to my research, the practical implications of all of the above is that the research revolves around determining the boundaries of, as well as the relationships 
between the lyrical content of the Calypsos, the method of their presentation, and the story, i.e. the context or historical events that led to the Calypsos being written. In real terms, the dynamics of this triad can be considered to be the relationship between the lyric, the drama and the epic. While the lyric creates the space for individuals to vent the issue(s) (this idea is further developed in Chapter 6) - be that through expressions of emotion of the performer or the individual members of the public - the stage drama enables the portrayal to the audience, of the identified conflict, (this idea is further developed in Chapter on 7). The third strand of this triad, (i.e. the epic), allows the collective expression of Trinbagonians at large (see Chapter 9).

My approach to this research cautiously considers each strand of this triad with a view to understanding its impact in relation to my identified objectives. In relation to my research, I came to think about the lyric as relating to the individual Calypsonian or the "I". I regarded the Dramatic as the 'they/them' of the audience present at the performance in the Calypso Tent and the epic as the 'we/us' that is representative of the public at large and integral to any approach of resolving conflict.

In its most basic way, the Calypsos that are sung are sung about people. They are sung about a people's experiences, their feelings, their joys and their passions. Therefore researching Calypso as an agent of conflict resolution is to research the pleasures and pains, tensions and solutions, passions and companions of the people involved. It is my belief that these can best be understood through ethnographic research, using a hermeneutic approach to the phenomenon of Calypso. For while phenomenology showed me how to orient to the lived experience, hermeneutics enabled my interpretation of these Calypso texts in the contexts of the semiotics. My approach therefore required that my written text depicts both my understanding and interpretation 
of the phenomena of Calypso, as I participate in and experience it with fellow Trinbagonians.

A major question with which I needed to grapple in deciding upon the selection of the most appropriate research method was linking both input and output. That is to say, since Calypsos manifest as an expression of what Dilthey (1987) calls Geist (i.e. feelings, mind, thoughts, consciousness, values, emotions, actions and purpose) how then do I determine both the generator of the lyrics and the impact of the Calypsos. To my mind, the answer to that quagmire revolves around the application of the Burkean concept of "Language as Symbolic Action" as applied to the Calypso (see Chapter 5).

Indeed, Dilthey contended that all of these attributes of Geist, manifest in humans, and therefore in human science in four different ways, i.e. as language, beliefs, art and institution. When interpreted in the domain of the verbal art of Calypso, I recognise the following correlations:

a) language i.e. the lyrics of the Calypsos themselves,

b) beliefs i.e. those of the Calypsonian, the audience,

c) art i.e. the skill with which the Calypsonian is able to use linguistic form (discussed in Chapter 7) in order to effectively convey the message, and

d) institutions, i.e. the function of, as well as the organisation and administration of the Calypso Tents on and of their own, and through the institution of the Trinbago Unified Calypsonians Organisation (TUCO).

I recognised that in order for me as a researcher of Geist, to successfully recognise, realise and embrace the four constituents mentioned above, I would need to develop a level of resonance that is synonymoús with an intimate level of emic understanding while simultaneously operating with an etic objectivity. Hence, the use of phenomenology and hermeneutics required of me a level of inseparability, of inter- 
permeation of myself and Calypso in accordance with the principle of "intentionality". This I achieved by my total involvement in the Calypso art-form.

I responded to the demands of this bipolar emic/etic relationship by recognising the benefits of the natural growth that automatically accompanied the personal transitions occurring in my life. That is, in the context of my personal history, recognising the fact that I was born in Trinidad, having had my formative years there, and having lived there continuously for the first 20 years of my life, I considered that I was ably positioned to be at an 'emic one' with the culture and society of the people of the Republic of Trinidad and Tobago. This experience was also augmented by sustained regular harmonising visits to my homeland since migrating to the UK. This process of initial fieldwork and subsequent annual revisits facilitated my reflecting on my initial experiences. The impact of these subsequent visits could only be likened to bending my consciousness back on itself, thereby enabling me to have newer understanding and interpretation both of my initial and ongoing experiences. It was as though new light was being shone in the old corners, enabling a clearer understanding and interpretation of previous interaction. Taking this level of exposure as a whole permitted me to identify myself with the concept of the indigenous ethnographer Clifford (1986:9)

On the other hand, having also lived in the UK for over 30 years, allows me to place myself in a position where I can be sufficiently removed from Trinidad life, society and culture, to bring an etic objectivity to this research. This unique combination placed me in a position where I could be open to, and aware of, the vehicle of Calypso, while simultaneously regarding the intersection of the various levels of experience of the people of Trinidad, that have influenced and moulded the Social and/or Political Commentary Calypso (SPCC), making it into what it currently is for the people of Trinidad. 
As part of my evaluation of methodologies with the view of selecting an appropriate process I came to recognised that positivistic research methods would be less appropriate in investigative work of this sort because:

- of the level of frivolity that is usually resident in the social world of the Calypso Tents.

- the aspect of conflict resolution, as I conceptualise it occurring, is more nebulous.

- of my extrapolated expectations of the individuals. This is based on my knowledge of the level of 'awareness' that can at times be found among audiences.

Consequent upon this was a recognition of the need for me to perform the delicate balancing act of, at one level, 'bracketing' (holding at bay) my preconceived notions of the impact of Calypso, while at another level, allowing the volume of my knowledge about Trinidad Calypso, derived from first hand experience, to positively inform this work. In the process of the interpretative phenomenological epistemology chosen, both during and after my conversation with the informants, I reflected on the various aspects of our interactions. This process allowed me to gain a better understanding of my fieldwork situations, ultimately yielding a level of inter-subjective understanding of the process by which Calypsos inadvertently subscribe to the resolution of conflict.

In researching the linguistic phenomena of Calypso, as applied in the non-formal resolution of conflict, I used my somatic sensitivity, as a tool to augment my lived experience, enabling these experiences to be the totality of my ethnographic and phenomenological research. I therefore engaged in an interpretative ethnography as the research methods for this investigation in such a way that enabled my written work to animate my lived experiences through textual expressions of this cultural art-form, by providing thick descriptions of my experience that are: relational, experiential, contentoriented, and qualitative. 


\section{LITERARY REVIEW}

In Chapter 1, I showed the synchronous link between Calypso and Carnival. In relation to Carnival, Babcock (1978) in her book: "The Reversible World", has shown how the process of masking and costuming facilitates an opportunity for inversion. I see a parallel between this Carnival process and that of the Sobriquet that some Calypsonians assume. It is my view that the use of a Sobriquet is also an act of masking. Using a sobriquet enables the Calypsonian to make a statement that he or she is taking on a different, a separate identity from their daily one. The sobriquet becomes a mask or a costume, allowing, or permitting even, a separate identity that allows for freedom of expression. This too allows for an inversion within their worlds. This parallel process further illustrates the links between Carnival and Calypso mentioned in Chapter 1. This close connection between these two cultural twins creates an intersection in the available literature, and although this work ostensibly is about Calypso, any attempt to show regard for Calypso while disregarding the broader contextual picture of carnival would be artificial. So, although carnival is a cultural twin with Calypso, in the context of my aims in this work, Carnival becomes an adjunct that simply provides a larger frame. However, the very nature of the inter-relationship between Calypso and Carnival requires that to some limited extent, the Literary Review embraces aspects of Carnival as well.

Perusing the literary field related to the Trinidad Carnival Art-Form, and more specifically Calypso, I have become aware that a considerable volume of work has already been done by researchers on various aspects of both these areas. However, I am not aware of any research having been devoted to the performance of the Calypso per se, specifically in relation to the relationship between performance, spectacle, theatre and 
ritual, wherein the Calypso is regarded as a mechanism for resolving conflict. This is surprising, particularly because the Calypso art-form plays such a central role in the society of the Republic of Trinidad and Tobago. This work attends to this deficiency.

From the 1930's there began emerging in the Caribbean, a distinctive core of literature that focused on the Calypso and Carnival. More generally, in more recent times, significant Caribbean authors like: V. S. Naipaul; C. R. L. James; Earl Lovelace, and Samuel Selvon, to mention just a few, have included remarks relating to Carnival and Calypso in their various texts on Trinidadian life. The impact of all this is that, while on the one hand, this review shows how other researchers in this field of study have approached their studies of the various aspects of Calypso and its twin, Carnival, on the other, this review also serves as a touchstone for my theoretical perspective.

This monograph, fusing as it does the very diverse fields of ritual communication and conflict resolution, with Trinbago history and Calypso, requires that for practical reasons, this work cannot be steeped in the ideological paradigm of a single academic discipline. The very nature of this work requires that it encompasses the dynamic interplay between popular art, music, language, Calypso and an understanding of the approaches and methods of conflict resolution, establishing a symmetrical balance between each of these elements.

Hence, to achieve success in the desired outcomes as identified in the Research Questions in Chapter 1, suggests a strict adherence to some order in the flow of these diverse areas, as well as an awareness of the prominent works in these fields. However, it would be false to create the belief that within this work, these fields all, and always 
remain discrete. Indeed, in many of the works quoted, there are significant areas of overlap between, at times, two or more of these areas. That said, after a brief mention of the works on the history of Trinbago, this review focuses specifically on Calypso and carnival as these are central to this work. Where appropriate, reviews of the work on communication and conflict resolution are left to Chapters 5 and 7 respectively.

In taking this course, I recognise the need to chart the work that has already been done on the field of the Calypso and to draw parallels between such existing work and the task at hand. However, an equally important objective of this Literary Review is the opportunity to situate this work in the field of existing scholarship, in-as-much-as that scholarship brings light to bear on my work and thus underpins it.

Historians have given various accounts of many aspects of the development of Trinidad's social, historical, economic and political life. These accounts can be found abundantly in the anthologies of Herskovits and Herskovits (1947), Parry and Sherlock (1960), Lewis (1968), Williams (1970), Beckford (1972), Lowenthal (1972) and Breareton (1981) and I have appropriately drawn on their works in Chapters 1 and 4.

In the field of Calypso, Elder's dissertation, (Elder 1966), remains as one of the most highly significant works on the Trinidad Calypso. His categorisation of types of Calypso, provides a statistical analysis of various elements in structure, style and content across the various types of Calypsos. He places them within the total Calypsos-song tradition, relating them to a standard process for the making of songs. In one of his subsequent works, Elder(1968) also presented a unique view of the Calypso as a thermometer of gender issues in Trinidad and Tobago. He analysed a population sample of 107 Trinidadian and Tobagonian songs that were released over a period of 50 years, 
which included some Calypsos performed by "major singers". Unfortunately, there are some unanswered questions about origins of the population sample and the reader is left with some uncertainty regarding how representative the sample is of the available Calypsos?

In this work, after doing a psychoanalytic analysis of both the topics and singers of the Calypsos, he concludes that the male singer is directing his aggression predominantly at the female; he has anxiety over separation from this love-object, and is preoccupied with his love-object (Elder 1968: 36).

Elder expressed the view that Calypsos which supported notions of a gender war were a consequence of males who, having been brought-up in female-dominated, single-parent households, felt the need to struggle against maternal repression and frustration. He adds that repressed anti-female hostility underlies the aggressive derisive songs the Calypsonians sing about women, partly because she supplants his role in society, provokes his anger and threatens him (Elder 1968: 37).

Elder concludes that since in the society The male, it may be, is evening up with females in status, prestige and authority (Elder 1968: 38) that the rate of aggressiveness to females, as expressed in Calypsos over the period 1940 and 1968, had decreased. This he attributed to his belief that males were experiencing less aggression evoking stress from frustration caused by women. On the other hand, Austin (1976) questions Elder's conclusions by providing evidence that Trinidad and Tobago did not have a matrifocal family system during the relevant period and that the status of the man had been higher than that of the woman during the period in question.

Both Liverpool (1986) and Rohlehr (1990) also appear to disagree with Elder. They suggest that the instances of sex as a topic in the Calypso increased over the period of the Second World War. This they argue coincided with the presence of the American 
military. Rohlehr in particular attempts to account for how male-female relationships are dealt with in Calypsos by identifying the chequered history of the islands that in the past had frequently changed governance between competing European powers. $\mathrm{He}$ suggests that the religious and other cultural influences of these nationalities may have so affected male-female relationships that it resulted in guilt and ambiguity surrounding moral and religious ideals versus actual behaviour (Rohlehr 1990).

Aho, in continuing with the theme of the Calypso as a medium for the expression of male-female conflict, studied Calypsos released during the 11-years from 1969 to 1979. He concluded that there is no change in the amount of male-female conflict expressed in Trinidad's Calypso lyrics (Aho 1984: 141-148).

In Kaiso and Society, Liverpool (1986) examines the role that the Calypso has had over the years as a chronicle of, not only local, but also global events. He argues that the Calypso has both reflected as well as powerfully influenced the views of the population. In his later work entitled Education And Culture, Liverpool (1990), in examining the implications of Carnival in Trinidad and Tobago and its impact on Education in secondary schools, concludes that the Calypso is a powerful medium and that teachers should utilise. the Calypso especially as motivating factors in the learning process (Liverpool 1990: 83).

Liverpool's further work traces the trajectory of the development of Carnival as a Ritual of Power and Rebellion, (Liverpool 2001). In this work Liverpool has brought together aspects of some of his previous texts and some of his academic dissertations. This book builds a contextual bridge between, the social, political, economic and cultural forces that drove the Carnival celebration making it what it is today. Through this work 
Liverpool traces the people's struggle against oppression, a struggle that was driven by a desire to maintain their own particular culture and identity in the New World.

Liverpool shows that as a cultural celebration, Carnival sprang from the intermingling of races and the melting pot of cultures that characterised the society at the close of the eighteenth century. He traces its development as well as that of the steelband and Calypso, and describes attempts to suppress the celebration through legal restrictions, virulent attacks by the press and censorship. He identifies the responses to these as masqueraders, Calypsonians and panmen retaliated with "active" and "passive" resistance. Revellers rioted and fought with police, songs of satire and protest emerged, gang warfare increased with the rise of the steelbands and "badjohns" resisted against a society that refused to see any good or anything creative in the black masses or in their villages. He also identifies how this parody of high society is lived out every "J'Ouvert" morning.

This work shows how resistance and protest are an integral part of the masks, the costumes, the dances and music of the people of Trinidad and Tobago. In as much as the period under consideration spans 1763 to 1962 the work inevitably covers the class struggles, economic deprivation and political strife occurring in more recent times, as these have been entwined with the Carnival celebration. Although Liverpool's work recognises the conflict occurring throughout the history of Carnival, steeped as it is in protest, unfortunately, he does not extend his work to embrace the pragmatic use of Calypso in the processes resolving conflict within the society of The Republic of Trinidad and Tobago. This work attends to that deficiency. 
In essence, "From The Horse's Mouth" (Liverpool 2003) is a publication that is an update of an undergraduate thesis written in 1973. In this volume, Liverpool shares his interviews with 10 Calypsonians. The outstanding benefit of this work is its historical contribution, given that some of the Calypsonians interviewed are no longer with us. The book is appropriately titled as it sheds light on the important aspects of the history, roots, development and motives of the singers as they speak at first-hand of the events that had a significant impact on the growth and development of the Calypso art-form. These Calypsonians share their lives, their love for the art-form, and the obstacles that they faced in their struggle to make a living, while simultaneously securing for the Calypso, its rightful place in the society.

Warner (1982) in his study of the Calypso as oral literature examines the impact of the Calypso from 1956 to 1980 . He argues that 1956 was significant from two points; it was the year of the birth of a new political awareness with the election of the People's National Movement (PNM) with its leader Dr. Williams, and it is the year that one of the leading Calypsonians, the Mighty Sparrow revolutionised the art-form. In this extensive work on the Calypso, Warner looks at the evolution of the Calypso with a view to determining how it has arrived at its present position. He engages in an analysis of the Calypso and shows how the language of the Calypso reflects not only social and political commentary, but also male/female interplay, as well as humour and fantasy. Finally, he places the Calypso at the centre of Trinidad and Tobago literature and concludes that it is central to the fabric of the society.

In his later work, Warner (1994) examines the use of double entendre in the Calypso in the projection of aspects of sexual imagery. He concludes that while the Calypsonian 
frequently writes material that is equally as suggestive as some of the lyrics of songs emanating from America and the UK, Calypsos are usually more imaginative (Warner 1994:181).

Lost in the rush of what ostensibly appears to be a male dominated activity (i.e. the singing of Calypsos) are two significant pieces of literature. They are significant if only because they are produced either by or on women in Calypso. It is clear that in terms of quantity, Calypsos have been dominated by male performers. However, Ottley (1992) draws attention to the fact that in terms of quality, female Calypsonians are to be reckoned with. Ottley, in focusing exclusively on female Calypsonians, analyses their contribution to the art-form and discusses the impact of various female Calypsonians saying of one of the better known ones:

Francine is definitely a Calypso treasure, a woman who dared to challenge the system and who used the medium of Calypso to highlight, inspire and address issues which affect or focus on women in our society.

(Ottley 1992: 30)

I interpret this statement as a clear expression of Ottley's recognition of the place of the female in the delivery of effective community representation. Ottley recognises that female Calypsonians have an increasing role to play in the society. Claudia de Four (1993) on the other hand composed a discography of the works of the Mighty Sparrow. In this work she commented that even from her position as a Librarian at the St Augustine Campus of the University of the West Indies, she found the availability of primary material to support research for one who had been so honoured by the University was limited (Claudia de Four 1993: xiii).

Ottley (1995 and 1998) has produced landmark literature chronicling the lives of Calypsonians. Both volumes of Ottley's "Calypsonians From Then to Now" are packed with rich material and are extremely helpful in enabling readers to embrace a different perspective of the life and times of the selected Calypsonians, their toil and strife. 
In his book: "Carnival, Canboulay and Calypso: Traditions in the Making," Cowley (1998) traces the developmental changes that Carnival and secular black music have gone through, commencing with the period of slavery to the first decades of the twentieth century. Identifying links between Trinidad and the other territories within the Caribbean, he sets out the trajectory of the development of Calypso, Cowley shows how, from the end of the nineteenth century, Calypso emerged as one of the leading Carnival musical forms identifying its historical link with Carnival.

In the latter part of the book, Cowley looks at the history of Calypso recordings identifying the first commercial recordings of the Trinidad 'calipsos', stringbands and 'kalendas'. Cowley accesses a range of source from folklore material and newspaper articles to colonial documents, thereby adding credence to his historical account of Trinidad culture.

Two major events of the University of the West Indies have also been significant in the scholarly developments of the study of Carnival and Calypso. The first of these was the series of seminar papers entitled: The Social and Economic Impact of Carnival (1983), published by The Institute Of Social and Economic Research. This series of papers provides an extensive overview of the whole spectrum of Carnival related activities. The second of these supporting events was the 1986 seminar on Calypso again providing a wide-ranging coverage of topics related to Carnival and Calypso. One of the papers that originated from this seminar was Hill's (1989) retrospective look at Calypsos that deal with war, whether international, regional or domestic, and its consequences in Trinidad and Tobago. His paper considers the attitudes and points of view of the singers and estimates how far they do in fact represent the majority view. He concludes by summarising the development of the Calypso war tradition in Trinidad and Tobago. 
Although this type of Calypso war is hardly ever sung in today's Tent, it does survive in a different form, e.g. the Calypso feud or vendetta that is carried outside the Tent by singers who are rivals for public acclaim, or by the open challenge issued through their songs to the world at large, and more particularly to competing bands of supposed detractors.

Another significant academic contributor to the field of Carnival and its cultural twin the Calypso was the papers originating from the series of World Carnival Conferences that were sponsored in part by Trinity College Hartford, CT, USA and The National Carnival Commission of Trinidad and Tobago. Furthermore, a special issues of the Caribbean Quarterly (1956), updated and reprinted in 1985, also presents a cornerstone for understanding the development and culture of Carnival and Calypso.

Meredityh, (1998), Asserts that Calypso is the engine driving carnival, providing the Road March for the street parade as well as one of the key events on the night of the prestigious Calypso Monarch Competition. He investigates the number of Calypsos produced and sung each year in the form of satire, humour and upbeat tempo music. He describes the Calypso Tent, its origins, how Calypsonians achieve their status, as well as the unwritten rules of how a Calypso is structured.

Jacob (1998), analyses the CDs and'music trend of Calypsos that were released during the 1998 Carnival season, he noted the various music styles used, i.e. Soca, Calypso, Rapso. He also pays specific attention to the increasing experimentation with crossover music that combines different music styles. He examines the CDs and albums of established entertainers and brass bands, as well as the music of some rising stars. $\mathrm{He}$ 
discusses the different compilation CDs containing the works of various artists under a particular music label or popular music from the Carnival of 1998.

For his part, Regis, (1999a), examines the impact of the politics of Dr. Eric Williams on the development of the Calypso and, to a much lesser extent the Steelband. While Regis recognises that each Calypso is a subjective expression, he explains that clusters of Calypsos on the same event and/or theme can establish a sense of objective reality which can be assessed against non-Calypso statements, especially those made by administrators of the Arts.

As stated earlier in this Chapter, in view of the fact that Carnival has long had an umbilical link with Calypso, no thematic review of the subject of Calypso would be complete without also looking at the literary works of the carnival.

The world of Carnival is vast and indeed very diverse. Accordingly, it has received attention from a very wide sphere of researchers seeking to address aspects of Carnival as are appropriate to their area of interest. One such person who has made a significant sociologist's contribution to the study of Carnival is Johnson. She, in arguing that the Trinidad Carnival has meant different things to different social classes, traces these meanings through their historical developments.

For the middle classes carnival was a form of social excitement which gave psychological release from their "rectitude" and simultaneously affirmed their cultural cohesiveness as a class; the black working class, on the other hand, experienced carnival as a celebration of freedom and a catharsis of the severe oppression they felt,

(Johnson 1984: 188-189)

Johnson contends that: 
the modern carnival contains the different elements united to form a differentiated whole, with each of its constituent elements in symbiosis or conflict with the other

(Johnson 1984: 189).

In recognising how much of carnival is situated centrally in conflict, Johnson goes on to state that:

.... the modern carnival contains the different elements united to form a differentiated whole, with each of its constituents elements in symbiosis or conflict with the other

(Johnson 1984: 189).

Amidst her view that Carnival needs to be taken in the context of an expression of opposition to the established order, Johnson makes the observation that, in relation to the "New World", Carnival has become important in those places which, in addition to Roman Catholicism being the predominant religion, they also had a significant enslaved African population. Thus, she states that while Brazil has a Carnival, Argentina does not, similarly Haiti does but the Dominican Republic does not and Vera Cruz does but not Mexico City (Johnson 1984). An exploration of this combination is crucial to this work, as it will help an understanding of why it is that this particular combination spawns the product of Carnival as a mechanism of protest. The explanation of this phenomenon probably rests on an understanding of the teaching and doctrine of Roman Catholicism, while seeing the parallels between this doctrine and the African experience of enslavement.

In Chapter 9, I draw on aspects of African Spirituality. It will be seen that some of the core themes of this Cosmology are in direct contradiction to Roman Catholicism. When I distil the various African approaches to cosmology, the common theme that emerges is that humans are made as extensions of the creator, thus also intrinsically having a creative potential. My intimate connection with Roman Catholicism (RC), gained while growing up as a child in a predominantly Christian household, has brought me to a different understanding. These RC teachings espouse that God created humans 
.......as less than Who I Am so that you could have the chance to become as who I Am, working against all odds - and, I might add against every natural tendency I am supposed to have given you.

Among these so-called natural tendency to sin. You are taught that you were born in sin, that you will die in sin and that to sin is your nature.

One of your religions even teaches you that you can do nothing about this. Your own actions are irrelevant and meaningless. It is arrogant to think that by some action of yours you can "get to heaven." There is only one way to heaven (salvation) and that is through no undertaking of your own, but through the grace granted you by God through acceptance of His Son as your intermediary.

Once this is done you are "saved." Until it is done, nothing that you donot the life you live, not the choices you make, not anything you undertake of your own will in an effort to improve yourself or render you worthy-has any effect, bears any influence. You were created that way.

(Walsh 1996:136)

While I recognise the spiritual implications of these words, on the mundane level of day- to-day existence, they also coincidentally and inadvertently describe the conditions and plight of the enslaved Africans. In the final analysis, the combination of the fundamental nature of the taught version of Catholicism as being born into sin, as well as the nature of the existence of the enslaved Africans, being born into enslavement, both resonate. This combination produced a double dose of oppression that both marginalized and dehumanised the enslaved Africans, reducing them to a position of having no hope.

Is it therefore not understandable that as Johnson observes, Carnivals in the New World, spawned from these two very repressive conditions, is pregnant with conflict? These drivers of Carnivals in the New World are not entirely dissimilar from the experiences that drove each of the events in the European Carnivals that both Ladurie and Bakhtin describe.

In his book "Carnival in Romans", Ladurie records the events that took place in Romans on the 15th February 1580. Ladurie recognises that religious festivals frequently 
provided the occasion for the urban "lower class" to overtly express their negative and sometimes hostile views of the wealthy town folk through symbolic representation. In his book, Ladurie alludes to a view of the events during that Carnival in Romans as being more than the isolated incidence of violence that lay behind the precise formal gardens of the 16th Century France.

Interestingly, there are striking resemblances between these events in the small French town of Romans (in the Dauphiné) and the Camboulay Riots that took place in Trinidad during the carnivals of 1881 and 1884 . It is also noteworthy to review these quite separate incidents recalling the common thread of the French influence in both locations.

In his study of the events of the "Carnival In Romans", Ladurie (1979) contends that the Carnival event ceased to be a purely agrarian phenomenon. He argues that as the trajectory of Carnival tended towards defining groups, it inevitably implied social conflict. He goes on to state that Carnival developed its own far from innocent terms for dealing with conflict, Ladurie(1979).

In his text, Ladurie reports how the events around the 1580 Carnival In Romans were seen to be highly significant in the context of the social and political events occurring in France at that time. He reports that this year's festival erupted in considerable violence with the notables killing or imprisoning the leaders of the craftsman's party. These events were seen to be one strand of a background of conflict that predominated in France at that time.

In the case of Romans the city's shopkeepers, artisans, guildsmen, poor women and men all took to the streets. Their carnival celebration coincided with a demonstration of their 
opposition to an increase in government taxation. They were also venting their displeasure at the evident corruption of the town oligarchs. For the working classes then carnival was for them their "folk dance". This 1580 carnival was therefore a folk dance with the theme: rich men: give the town back your dishonest gains! (Ladurie 1979:162163). This revolt was both anti-noble as well as a protest against the burden of government taxation. Ladurie labelled this a revolutionary situation (Ladurie 1979:33). Being weary of an uprising of revolutionary proportions, the local government leaders lured Jean-Serve Paumier a leader of the popular people's party, and a master craftsman, from his house. He was then assassinated while his supporters were also beaten and some of them murdered. Sibeuf, although wounded, managed to escape over the town wall running to the village of St Paul there raising the alarm that "the powerful of Romans were killing the people". Ladurie reports that:

Large groups of the peasantry had taken up arms. They combated the outlaw soldiers of noble birth who had been terrorising the countryside. They fought against certain aspects of domination by the landlords, and most of all against the tax-exempt status of the nobles. The urban bourgeoisie was to varying degrees in conflict with the two privileged ranks. The craftsmen and common folk were locked in a struggle with the bourgeois patricians.

(Ladurie, 1979:33)

It is this conjecture of fiscal opposition with class-based revolt that allows Le Roy Ladurie to call Carnival a revolutionary situation (Ladurie 1979:33).

For Ladurie, Carnival is a microcosm of the world we have lost. This view has much in harmony with the concepts expressed in Minshall's trilogy depicting the struggle for technological advancement, as discussed in Chapter 4. However, in his work, Ladurie 
sees the historical events from the perspective of those who endured it, as opposed to those who made it. From this perspective he concludes that:

Carnival is reminiscent of the Grand Canyon: "It shows, preserved in crosssection, the social and intellectual strata and structures which make up a 'très ancien régime'. In the twilight of the Renaissance it articulates a complete geology, with all its colours and contortions. (Ladurie 1979: 370)

In "Rabelais and His World," (Bakhtin 1965), he focuses on the cultural dynamics of a particular historical movement. He examines the collapse of medievalism and the emergence of a more secularised humanistic society particularly as reflected in the work of Francois Rabelais, a figure who epitomizes the spirit of the Renaissance. Bakhtin's work examines both the popular humour as well as the folk culture of the middle ages as well as the period of the Renaissance but more particularly the Carnivalisque. Bakhtin argues that the spirit of laughter and irreverence prevailing at carnival time is the dominant quality of Rabelais's art. In his work Bakhtin emphasises the significance of folk culture as it plays a major role in the proper understanding of Rabelis's narratives. Hence Carnival is a window through which we are able to gain a view of the "other" pattern of life. This view is grounded in an understanding of death and degradation as these are prominently displayed in an offensive way that opens up to a powerful metaphor for the level of conflict that inevitably accompanies any process of social change that requires questioning and justification of relative positions. For his particular cultural area of study into carnival, Bakhtin argues that this process happens in carnival through the laughter of the Carnivalesque spirit and that makes it a paradoxical vehicle of new utopian ambivalence to social order challenging the political status quo and religious repression. 
In Bakhtin's view, Carnival is the time when all social groups join together in a wild saturnalian celebration. This celebration involves the fusion of each group's dialogical strata into a parodic, ironic festival of language, (Bakhtin 1965).

Bakhtin argues that each level of hetroglossia ${ }^{8}$ is linked to the next by a common folkloric laughter, the roots of which go back deep into pre-class folklore. He further contends that at Carnival time, these roots serve to destroy traditional connections and abolish idealised strata, thus bringing out the crude, unmediated links between words and concepts that are normally kept very separate.

Ladurie(1979), like Bakhtin (1965), invites us to see the symbol of Carnival as intending to shock individuals within society, so that they develop a sense of solidarity, while promoting a primordial social ocean, wherein marginalised people who find themselves ostracised from the mainstream of the flow of life, as manifest in their absence from the echelons of power, may join together in new expressions of social opinion.

In as much as the spirit of 'Carnival' is usually an expression of spontaneous explosion of vernacular culture seeking to defy the dominant culture and with that the 'powers of authority' it is not unusual to find that the event of Carnival is surrounded by some degree of violence which results in opposition to some requirement for rapid change. The protests at Greenham Common in the UK in the 70's originally started with a sort of Carnival spirit, generating much laughter and frivolity, before this turned into bitterness and resentment. The same is true of the antiwar protesters in the USA during the late

\footnotetext{
${ }^{8}$ Bakhtin's term for unmerged dialogue. He also uses the words multivoiced, polygot and polyphony all interchangeably.
} 
1960 's. A general overview of the occurrences of Carnival celebrations shows that there can be a predisposition to violence, and certainly this has also been the case in Trinidad and Tobago, (see Chapter 4).

In their work on Carnival, Cohen (1993) and John (1986: 7-19) examine the Notting Hill Carnival during the difficult conflict years of the mid 1970s. John quickly progresses to parallel this to the difficult early years of the Trinidad Carnival. He takes a nostalgic overview of the historic development of Carnival in Trinidad, bringing readers up to date with his observations on revisiting Trinidad at Carnival time. $\mathrm{He}$ does so while intertwining the experiences of the Carnivals in which he had participated over the years.

On the other hand, Lockledge (1991) describes Caribbean street festivals as celebrations that reflect the historic, climate, and movement patterns of the region. In her paper Lockledge looks at celebrations such as Carnival, as well as Hosay and Jonkonnu. She proposes that Carnival as well as other festivals can be linked to the five thematic generalisations often utilised by geographers. These themes are location, place, relationships, movement, and region. She concludes that placing holiday celebrations into the framework of the themes of geographic education will lead learners to look beyond the celebration to the culture and the environment that created it. In her work Lockledge suggests a perspective of street festivals such as Carnival as a medium for learning activities. This can be interpreted as the learning that occurs through conflict.

In another work on the subject, Lockledge (1992: 17-20) describes holiday celebrations in the Caribbean as important contemporary social events with historical, geographical, 
and cultural significance. In discussing the origins, development, and customs of the major Caribbean street festivals, Lockledge suggests that in the learning environment, the holidays can combine all social science disciplines and both focus on and emphasise the geographic themes of location, place, relationships and movement of the region.

In citing criticisms of current Carnival celebrations, Juneja acknowledges the observation that the current ephemeral art of Carnival has become too much spectacle and "showbiz". She recognises the argument that the increased size of the bands, the opportunity to purchase ready-made costumes and therefore the consequent lack of the personal involvement of the individuals, in what at one time occupied the status of a folk festival, all contribute to the sense that Carnival has lost the cathartic and celebratory ritual it once was, (Juneja 1988: 87-99).

In discussing the changes that Carnival has undergone, Juneja draws attention to the fact that as society changes, so also is there a need for Carnival to change and keep pace. For Carnival not to metamorphosise at a rate commensurate with that of the world it expresses, would be a statement of bankruptcy, of retrograde movement. Juneja states:

to lament the changing of spirit of the carnival is to ignore the syncretic character, its organic relationship with the community, its responsiveness to new influences. If carnival has changed so has the nature of the community in Trinidad. The lessening of violence in the carnival may reflect society's relative ability to satisfy proletarian needs. Nor have resistance and aggression disappeared altogether; only the nature of weaponry has changed. Dimanche Gras and Panorama have institutionalized competition not obliterated it. Calypsos retain the tradition of caustic social commentary, including commentary on the state of the carnival; protest takes on new forms,

( Juneja (1988: 96)

On the other hand, Deosaran takes a functional view of Carnival, arguing that the Trinidad Carnival, stands out as a cultural event of tremendous psychological and 
social significance, (Deosaran, 1978: 35-40) from other Carnivals that occur around the world. He contends that this social event dictates the lifestyles and thinking of its thousands of participants for months ahead of the ultimate appearance and that its effects are similar to those of a tranquilliser yielding a type of national therapy.

Deosaran (1978: 41-45) examines how Carnival art, through reverse psychology and shrouded as it is in symbolism permits psychic mobility, while being used both to mock society and as an expression of a wounded heritage. In this work, Deosaran suggests that Carnival fulfils the place of a "quickie palliative" against the reality of social injustice.

Deosaran goes on to acknowledge questions regarding the extent to which Carnival contributes to the sanity and stability of Trinidad and Tobago society. He recognises the view that the Carnival displays, be they learning, release or wish-fulfilling can carry over into the larger society and beyónd the Carnival event in a kind of Carnival Mentality, which may be in opposition to the work ethic, (Deosaran 1978: 46-50). He identifies the need to mobilise and direct Carnival energy and motivation into daily, mundane operations such as working for a living. In responding to these criticisms of Carnival, and the view that Carnival celebrates too much of the flesh at the expense of the spirit he incorporates the notion of functionalism and contends that the benefits of Carnival, being emotional are less easily perceived. In debating the issue of the role of Carnival, Deosaran contends that: if the ideal of the democratic state is to establish a voluntary society, then Trinidad carnival is an indigenous social institution worthy of further study in this respect, (Deosaran 1978: 46-50) 


\section{MY FIELDWORK}

Although this study is based on fieldwork that was formally conducted between January 1999 and August 2001, I need to register two other significant facts. First, this period of formal fieldwork has been further enhanced by a collage of subsequent visits to my homeland of Trinidad over the carnival seasons of the years 2002 to 2004 inclusive. Second, as an 'indigenous ethnographer', my experience of Trinidad is an intrinsic part of me, as a result of having been born and lived there to my early 20 's. This latter means that I shared experiences, friendships and acquaintances with numerous carnival artists, as we all grew up together, on the island. For example: David Rudder was a school mate and Vonric Maynard the one time drummer for Charlies Roots was a class mate. The musician and arranger Clive Bradley taught me English Literature, while the neighbour and friend Inskip Morris was the nephew of superior metal-worker, Ken Morris.

This emic combination permitted me as an adult, to reflect on both my intrinsically incidental learning about Calypso and Carnival, as well as my experiences, as I grew up in Trinidad. From my position as an adult reflecting and contemplating my childhood experiences, new awareness of the events of my childhood in Trinidad fostered a better understanding of the festivity. I was then able to reflect on these areas of growth, verifying them as source, on each of my subsequent visit to the country of my birth.

During the initial period of my fieldwork, I spent substantial periods interviewing seven Calypsonians, talking to them on numerous occasions about their lives and work. In Chapter 3, I share the results of my personal interactions with Calypsonians. However, 
during the whole period of my fieldwork, I also spent a considerable amount of my time interviewing informants, such as patrons of the various Calypso Tents, members of the general-public, as well as members of the media.

In the period in which I conducted this research, not only did I have the opportunity to interact with both Calypsonians and audiences, but I had also spent significant proportions of time engaging in participant observation. This provided a rich source of demonstrable evidence on which to base this work.

While in the field, I also took the opportunity of supporting my work with the photographic evidence that is displayed in the various parts of the body of this work. This meant that I took the opportunity to photograph various aspects of the events of which I was a part and this evidence presents support to the quality of the interactions that I experienced during my research effort.

I found both the current newspapers, as well as previous editions that were available through the reference libraries to be a rich source of information relating to events associated with the Carnival as a whole. Accordingly, I spent considerable periods of time, not only reviewing the daily newspapers, but also visiting the local libraries, accessing originals of documents kept in the National Archives, the National Library and the Special West Indian collection, housed in the Library of the University of the West Indies.

Newspapers are produced daily and there are three main newspapers and a number of smaller ones. The main newspapers are The Trinidad Guardian, The Express and 
Newsday. The Guardian, the Express and Newsday are released daily, on weekdays and on Saturdays. On Sundays they are known as the Sunday Guardian and The Sunday Express respectively.

In 1999 a Daily Express newspapers costs $\$ 1.50$ while during the same time the (Daily) Guardian cost $\$ 1.00$ as did Newsday. On the other hand, the Sunday Express cost $\$ 3.00$ and as did the Sunday Guardian also cost $\$ 3.00$. By way of a rough comparison, depending on the fluctuations of currency, a $£ 1$ can be exchanged for anything between $\$ 8.50$ to $\$ 11.00$. Even allowing for differences in cost of living this still makes the daily newspapers very affordable to locals spending the Trinidad dollar.

From my observations gained during my fieldwork, newspapers are regarded locally as a community billboard and are checked daily by Trinbagonians who want to find out what events are scheduled to occur on a daily basis.

The insertion on the following page is a typical example of the type of advertisement that appears daily, giving notice to the public of the intended performance of a Calypso Tent. It is worth noting that the advertisement does not show a date. This is because it is a standard advert that appears on a rolling basis in the newspapers.

More importantly though, the newspapers also serve as a medium for the presentation of community discussions. From the launch of the carnival season, articles and views appear which reflect the thoughts and feelings of the citizens about the proceedings for that Calypso and Carnival season. One of the main media for presentation is through the Calypso Tent, (Chapter 7 explains the concept of the Calypso Tents). The Calypso 
season extends over the six weeks preceding the Carnival event. During this period, many people frequent the Calypso Tents to hear the new Calypsos. Such visits usually serve as the launching pad for the sometimes spirited, sometimes passive discussions that occur afterwards. These discussions are usually linked to the issues raised in the Calypsos just heard.

At various intervals during the season, the Tents have what are billed as "clashes". During these clashes, clusters of about three Calypsonians from one Tent sing alternately with a similar number from another Tent. Such "clashes" can at times also occur across gender. The advert featured below, shows that this clash is between Calypso Revue and Spektakula (pronounced Spectacula).

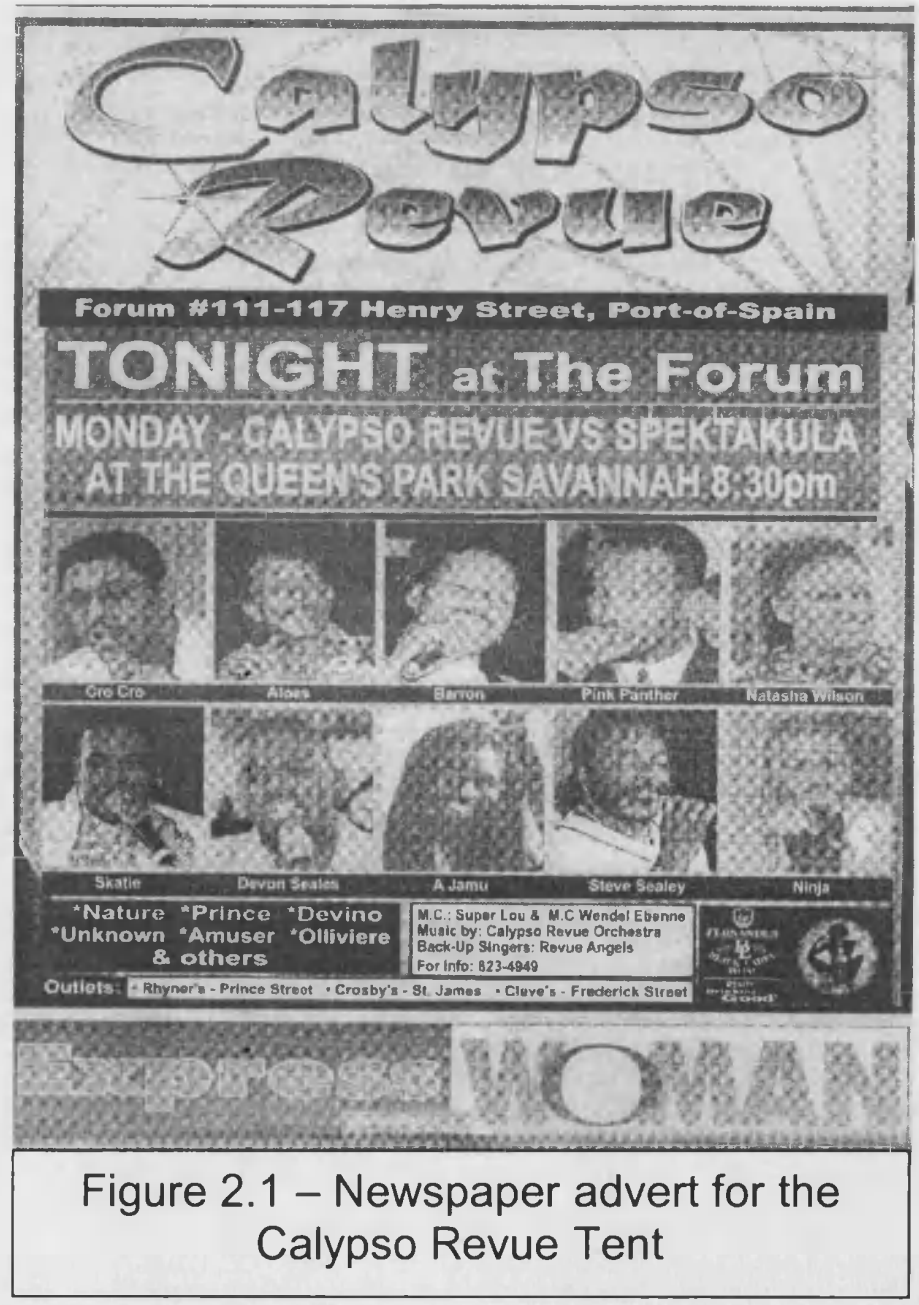


Although with few exceptions most Tents have a base from which they usually perform nightly, such "clashes" usually take place on neutral territory. Accordingly, this clash took place in the Queens' Park Savannah. Such clashes can have in excess of 20 Calypsonians billed to appear on the night. With most of these Calypsonians singing two Calypsos, it is not unusual for the night's performance by all the Calypsonians to end at some time after 1.00 a.m. the following morning. Given the practicalities of having all Calypsonians identified on such a relatively small advertisement, only the faces of the more established Calypsonians are usually shown or mentioned as appearing.

In Chapter 4, I traced the trajectory of the development of carnival. The fact remains that Carnival has always been and today still remains an unofficial celebration.

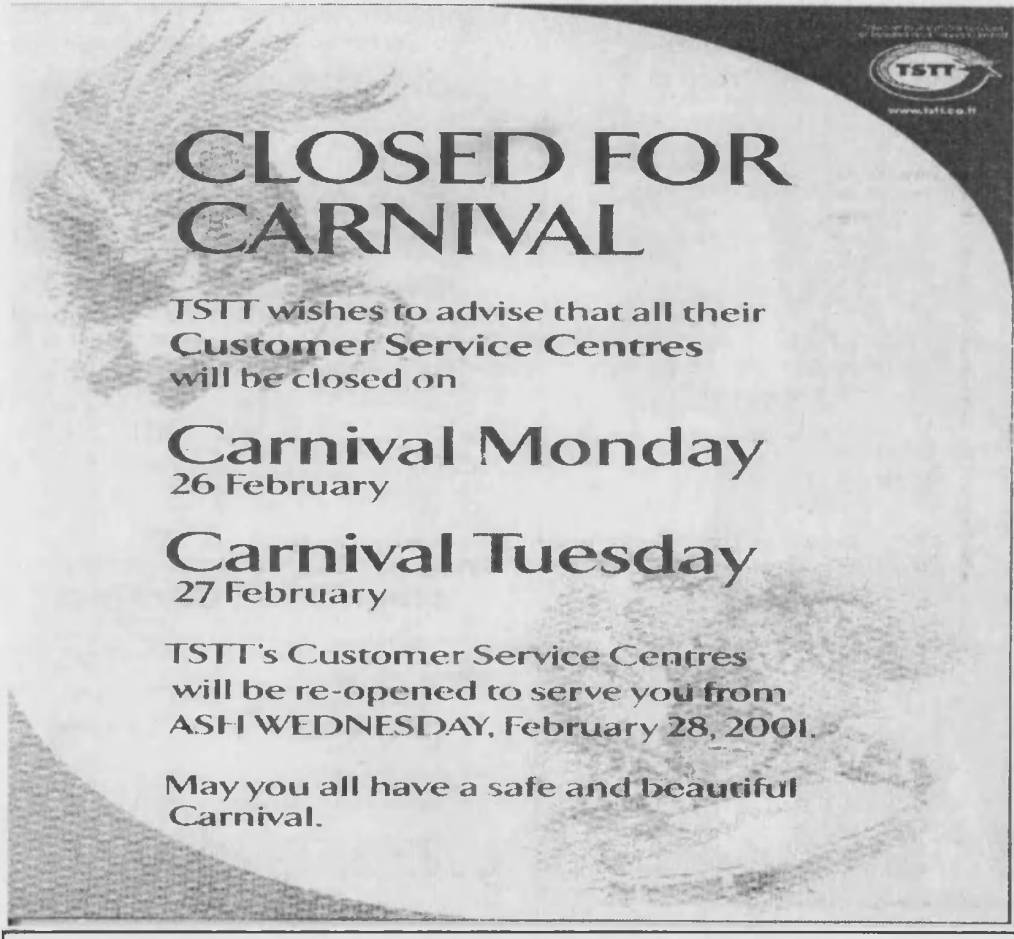

despite this it is expected that staff of Public Services over carnival 
(citizens) will not be at work on these two days. Furthermore, employees do not claim the two days off as a part of their holiday entitlement. Consequently staff are remunerated for those days as if they were at work.

In the absence of staff, most businesses remain closed on the two carnival days, reopening again on the Wednesday following the two carnival days. The advertisement above evidences one example of this impact of Carnival. It substantiates the fact that the only (nationalised) telephone company is closed during the two Carnival days.

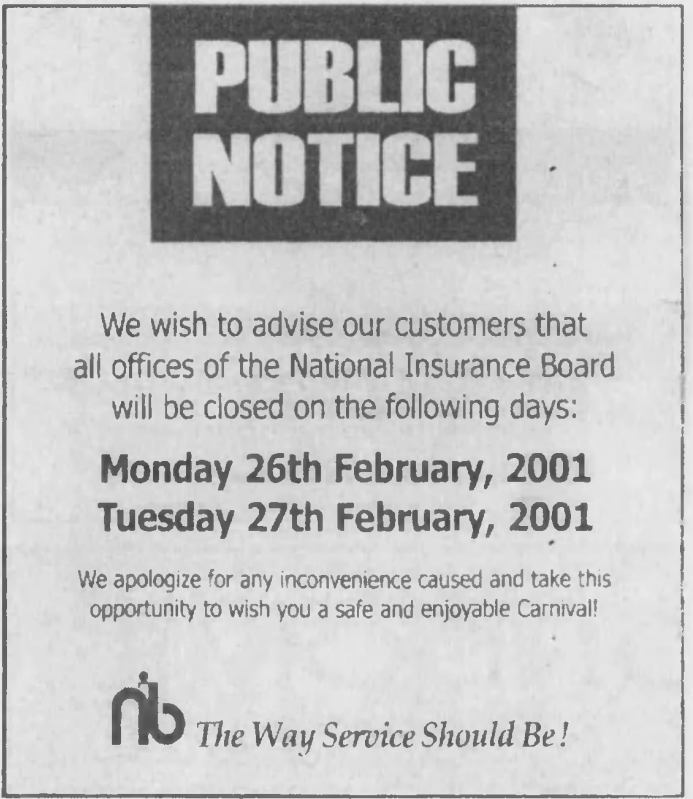

Carnival enjoys the same status that Christmas does in most Christian countries. It forms a datum by which life in the country is measured, so much so that everything else revolves around Carnival

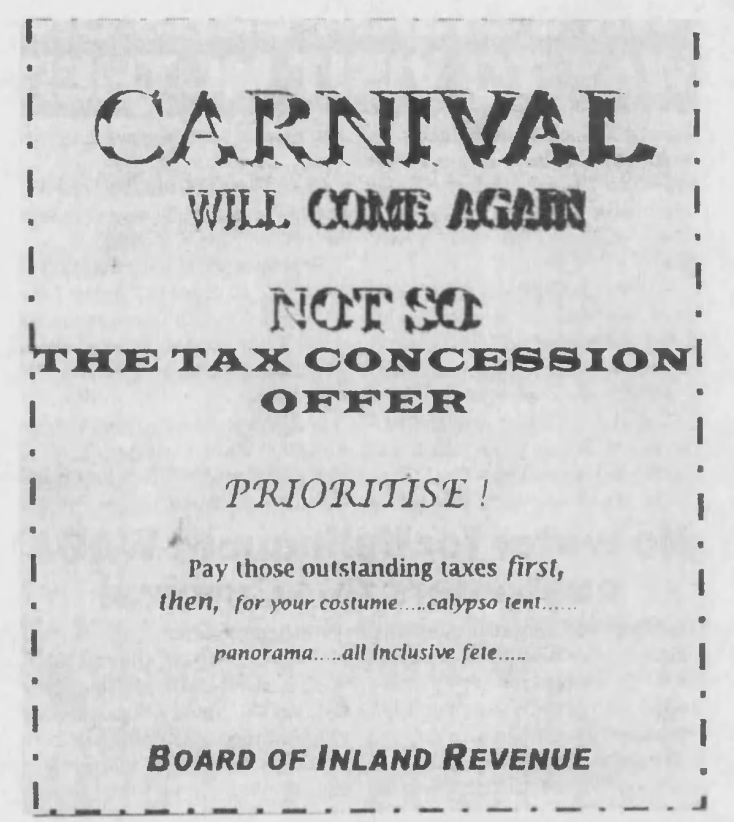

The advertisement above exhorts that tax payers should attend to their sense of priorities by first settling their Tax Debt then engaging in carnival expenditure

Figure 2.3 - Newspaper adverts from public bodies contrasting two approaches to carnival 
This attitude to carnival and the

effect that carnival has is also

noteworthy. The two adverts above

appeared in the local newspapers

and bear testimony to the reality of

this impact of Carnival. Of these

two advertisements, the one on the

left shows that the National

Insurance Board remains closed

during the Carnival, while the one

on the right exhorts, what in the field

of personal development, is called:

"delayed gratification". The

approach here is to suggest that

individuals should examine their

priorities when it comes to paying

for their Carnival costumes as

opposed to settling their Tax debts.

There are few exceptions to the

unwritten rule of not working on the

carnival days. The exceptions are all

members of the security services as

Figure 2.4 - newspaper advert showing carnival schedule

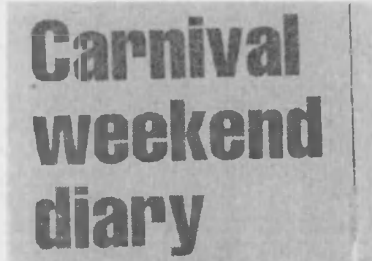

\section{8 am \\ Junior Parade of Bands. \\ Frederick StreetSavannah. \\ $1 \mathrm{pm}$}

Junior King and Queen of the Bands, Individuals and Couples, Shaw Park. To bago.

Kendra Phagwa Festival Pichakaaree elimination contest, Divali Nagar Auditorium.

$4 \mathrm{pm}$

AIDS Awareness Concert, featuring Suriname's South South West, Carnival Village. Princess Building Grounds.

\section{$8 \mathrm{pm}$}

Miss Republic Carnival Oueen Pageant, Crowne Plaza, Wrightson Road.

National Conventional Panorama Final, Queen's Park Savannah.

9 pm

Camival hump-Up. Music by Iraffik, Atlantik, krosfyah, Crosby Sounds, pan round neck and tassaz. Hitton Poolside.

Skinner Park Fete. Music by Traffik, Blue Ventures, Sur face, Horyzon and more.

We Coming True Back in Time Carnival Fete. Music by Ed Watson's Brass Circle, D'Original Wax, Ken Gray and Marsicans. Sylvester's II. St Joseph Street, Arima.

\section{$11 \mathrm{pm}$}

Island People's Annual In somnia, the Ultimate Breakfast Party. Mobs2, Chaguaramas.

\section{SUNDAY}

1 am

Junior Parade of Sands. Skinner Park, San Fernando.

Noon

Downtown Junior Parade of the Bands. South Quay.

1 pm

Kiddies Carnival. Market Square, Roxborough, Tobago.

Nostalgia: Old Time Camival. Victoria Square, Port-ofSpain.

Queen's Park Cricket Club's Soca on the Ball allinclusive fete. Music by Bhe Ventures with Ronnie Mclntosth. Oueen's Park Oval, Have lock Street.

Junior Camival. Outside Lit. tle Hardware, Sangre Grande.

$2 \mathrm{pm}$

Dancing In the Sanctuary.

Music by St James Tripolians,

D.Js Richard Simply Smooth,

Syndicate, Point Fortin Engine Room and St James Tassa Drummers. 39 Windsor Road, Valsayn

Camival Jump-Up. Music by Traffik, Atlantik, krosfyah, Crosby Sounds, pan round neck and tassa. Hilton Pook side.

TASA presents The Sunday Fete. Music by David Rudder \& Charlie's Roots. Soutti Soutth West, Trinidad Nostalgic, Indigo and Mega Force, Queen's Hall Carpark, St Ann's.

$7 \mathrm{pm}$

National Calypso Monarch Final. Dimanche Gras, King and Queen of Carnival Finals. Queen's Park Savannah.

$8 \mathrm{pm}$

Free Jam and Ole Mas Competition, Bands, Individuals, Couples. Roxbor. ough, Tobago.

$9 \mathrm{pm}$

We Coming True Back in Time Carnival Fete. Music

by Ed Watson's Brass Circle, D'Original Wax, Ken Gray and Marsicans, Sylvester's II. St Joseph Street, Arima.

$10 \mathrm{pm}$

J'Ouvert Party. Trinidad Country Club, Champs Elysees, Maraval. 
My fieldwork established how pervasively intrinsic carnival is to Trinidad and its society. I recognised that the phenomenon of Carnival is as central to life in Trinidad as it is to its structure. This commitment to Carnival builds up, and reaches its crescendo on Carnival Monday and Tuesday. The events on these two days are but a flavour of the overall activities for the whole period. The diary of events for the Carnival weekend above is as extract from page 13 of the "Trinidad Guardian," dated 2 February 2001. It shows a list of some of the more prominent events that occur over the Carnival weekend. I need to stress that this is only an officially published list and that in reality, there are numerous other activities and events that are not published nationally.

During my fieldwork, I sought to determine what value the community placed on the Calypsonians. I thought that the easiest way of determining this was to try to link it with some sort of monetary gain for the Calypsonian.

\begin{tabular}{|cl|}
$\begin{array}{c}\text { Year of } \\
\text { Competition } \\
1970\end{array}$ & $\begin{array}{c}\text { Value of prize in TT\$ for winning the } \\
\text { Calypso Monarch }\end{array}$ \\
1984 & 23,200 \\
1997 & 20,000 plus a new car valued at 120,000 \\
2000 & 100,000 plus a car valued at 150,000 \\
2004 & 250,000 \\
\hline Table 2.5 - Prize Money For the Calypso \\
Monarch
\end{tabular}


I then recognised that the best judge of the growth in value of the Calypsonian and therefore the value placed on the art form by the society was best determined by whether there was any change in the value of the winning Calypsonian's prize over a given period. In this respect, the table above sets out the growth in the value of the prize between 1970 and 2004. This change in prize money over this period represents a growth in excess of $200 \%$.

In relation to this competition, it also needs to be recognised that the judges have specific criteria for scoring the Calypsonians. The scoring is based on the following categories:

- Lyrics: $\quad 30 \%$

- Melody: 30\%,

- Rendition: 20\%,

- Presentation: $10 \%$,

- Originality: $\quad 10 \%$

\section{INCLUSION OF COMPACT DisCS}

As explained earlier, my research engages an examination of the linguistic phenomena of the Calypso art-form. As such, there are few ways in which I could make my lived experiences and the totality of my ethnographic and phenomenological research, available to readers.

Despite my very best endeavours, I recognise the inadequacy of the words of this text alone, in conveying the bountiful ethnographic richness of the actual experience of being in a Calypso Tent. Faced with such a limitation, my challenge was to consider how to bring the wealth of that bountiful experience to life for the reader of this work, 
short of taking readers to a Calypso Tent in Trinidad during the Calypso season? The practicalities of that process inevitably preclude it from the realistic range of possibilities. However, in concert with the proverb regarding Mohammed getting to the mountain, I chose to access the nexf best option i.e. that of bringing the Tent to the reader with the expectation of creating a highly significant level of inter-subjective understanding for the reader. This I have achieved through the inclusion of a CD, part of which was recorded in Calypso Tents, on various nights, during the course of my fieldwork.

As faithful as these recordings are, in my view, having lived through the experience of spending numerous evenings in Calypso Tents, they still only partially convey the abundance of the ambiance, the spirit, the energy that is so alive during the evening's performances. This is so, simply because a $\mathrm{CD}$ only operates with the audio function of our senses. That is to say, the enclosed CD still does not honour the other four senses that are so vital in conveying a faithful representation of a typical night in a Calypso Tent. To be more specific, the CD has no way of bring alive:

* the visual - to offset this limitation, I have included various photographs in the appropriate parts of this text.

* the kinaesthetic - although the combination of the CD and photos can go some way to create the energy of an event they are only limited in their ability to do so as they cannot recreate for the reader the energy of the volume of people present. Their interaction with each other and with the performer and his/her supporters. 
* the gustatory - Trinidad has its own unique cuisine which is abundantly evident at the Tent and outside the venue. The nuts man. The doubles sellers, the Stag beer and Carib beer sellers, all of whom periodically walk through the aisles selling their produce. 'Usually there is an abundance of 'Corn Soup' vendors who are mainly outside but at times can also be found inside the Tent as well. I have on occasion also known the uniquely Trinidadian version of the Roti to be available to patrons as well.

* the olfactory - needless to say, the combination of the aroma of an array of extremely tasty foods, mingled with such a variety of people, tastefully adorned and scented with the most exquisite fragrances, as are present at the Tent, create for the Tent its own unique bouquet.

Despite my very best endeavours, unfortunately, these aspects of my nightly ethnographic experiences in the Calypso Tents, cannot be brought to life by the enclosed CD.

This recorded form can only illustrate the events that I describe in the text. However, what is more significant is that the $\mathrm{CD}$ enables me to animate my written work with aspects of my lived experiences, in support of the textual expressions that are central to this cultural art-form. In the final analysis, through using this technology, I am able to augment for the reader, the thick descriptions of my experience in a way that is relational, experiential, content-oriented, and qualitative.

\section{Contents of the Compact Discs}

The text of this thesis contains the words of various Calypsos that were heard during my fieldwork. On some occasions, when either the Calypsos predated my fieldwork or 
quality of my sound recording was poor, I purchased commercially available CDs with the appropriate Calypsos. All of the selected tracks were subsequently transferred to the CD that accompanies this Thesis. This CD is of MP3 format. The tracks can be hear by inserting the $\mathrm{CD}$ into the drive of any computer on which Windows Media Player $(\mathrm{WMP})^{9}$ is available. The disc should then self-load and run automatically. Of the tracks on the $\mathrm{CD}$, the 'live recordings' were made in a Calypso Tent and are intended to convey:

- The context of the occasion, recreating the ambiance in as much as is possible

- The lyrics, as they are presented to the audiences.

- The process of co-authorship/co-mediation between singers and audiences (as discussed in Chapter 9).

- An indictment of the process of 'call and response' that is central to this indigenous non-formal community conflict management process.

Although the complete lyrics of the key Calypsos mentioned in this text are available at Appendix 1, with one exception the-table below lists the names of each Calypso in the order in which it occurs in the text, the Calypsonian and the Chapter in which it is primarily mentioned:

\footnotetext{
${ }^{9}$ WMP is a standard application that is automatically available on most PCs which are less than 4 years old
} 


\begin{tabular}{|c|c|c|c|}
\hline $\begin{array}{c}\text { Track } \\
\#\end{array}$ & Name of Calypso & Calypsonian & $\begin{array}{c}\text { Used } \\
\text { primarily } \\
\text { in } \\
\text { Chapter \# }\end{array}$ \\
\hline 1. & Rum and Coca Cola & $\begin{array}{l}\text { Trinidad Rio } \\
\text { Original by Lord } \\
\text { Invader }\end{array}$ & $1 \& 4$ \\
\hline 2. & Watch Out My Children & Ras Shorty I & $1 \& 6$ \\
\hline 3. & This Stage is Mine & Sugar Aloes & $4,6,7 \& 9$ \\
\hline 4. & Voices from the Ghetto & Singing Sandra & 5 \\
\hline 5. & Rip Off & The Mighty Sparrow & 5 \\
\hline 6. & People Will Talk & $\begin{array}{l}\text { Mystic Prowler } \\
\text { Original by King Fisher }\end{array}$ & 5 \\
\hline 7. & The Judge & Sugar Aloes & 6 \\
\hline 8. & We Like it so & The Mighty Sparrow & $6 \& 8$ \\
\hline 9. & Still the Best & Cro Cro & 6 \\
\hline 10. & The Banana Death Song & David Rudder & 6 \\
\hline 11. & Sinking Ship & Gypsy & 6 \\
\hline 12. & Chauffeur Wanted & The Mighty Chalkdust & 6 \\
\hline 13. & Why Ah Stay & Sugar Aloes & 7 \\
\hline 14. & The People's Parliament & The Mighty Chalkdust & 7 \\
\hline 15. & Respect the Calypsonian & Gypsy & $7 \& 8$ \\
\hline 16. & $\begin{array}{l}\text { Sprangalangs Soliloquy on "a } \\
\text { man's personal loss" }\end{array}$ & Sprangalang & 7 \\
\hline 17. & The Immigrants & David Rudder & 8 \\
\hline 18. & Prophet of Doom & The Mighty Sparrow & 8 \\
\hline 19. & Capitalism Gone Mad & The Mighty Sparrow & 8 \\
\hline 20. & Education is Essential & The Mighty Sparrow & 8 \\
\hline 21. & Burn Dem & Black Stalin & 9 \\
\hline 22. & Fire & Cro Cro & 9 \\
\hline 23. & The People's Advice, & Stinger & 9 \\
\hline 24. & De Facts & Sugar Aloes & 9 \\
\hline
\end{tabular}

Fig 2.6 Contents of Compact Discs 


\section{CONCLUSION}

In this Chapter, I have unveiled my interpretative style for developing the approach that allowed me to go beyond the lyrics of the Calypsos, to look past their outer trappings and semblances, to that which counts more: seeing them as "Symbolic Action". There is thus a natural symbiosis between this Chapter and Chapter 5 where I elucidate the theoretical concepts of my approach.

I have shown in this Chapter how, I fostered empathy and compassion in my process of Establishing Resonance, and in the process, developed sympathetic feeling and synchronous thought.

I am grounding my interpretations in the concepts that the informants' use in their own daily lives, e.g. their forms of discourse. I therefore developed an approach to this work that was driven by a thought-feeling approach. Using this approach, in my work, I was able to engage with the world of the Calypsonians, and the audiences, grasping the conveyed meanings that do not reside singly in either, the individual words of the Calypsos, the "facts" of the occurrences of the events that drove the composition of the Calypso, nor the lyrics of the complete Calypso. I therefore came to see the words (i.e. the lyrics of the Calypsos) as ways of producing effects rather than as entities that have or convey intrinsic meaning (Rorty 1989:15).

Through the medium of the following Chapter, from my position as an "Indigenous Ethnographer", I look at "the Calypsonians and their lives". Chapter 3, therefore focus on the pragmatics of the fieldwork that was done in the completion of this manuscript. 


\section{CHAPTER 3 - CALYPSONIANS AND THEIR LIVES: FIELDWORK IN ACTION}

Modern ethnographic histories are perhaps condemned to oscillate between two metanarratives: one of homenization, the other of emergence, one of loss, the other of invention. In most specific conjunctures both narratives are relevant, each undermining the other's claim to tell "the whole story," each denying the other a privileged Hegelian vision."

(Clifford 1988:17)

\section{INTRODUCTION}

$\mathrm{T}$ This Chapter gives a synopsis of my interactions with the seven Calypsonians whom I interviewed during my extended fieldwork in Trinidad. This is but an extremely thin slither of the entire volume of work that was done in the field, most of which, due to limitations, cannot now be documented herein. This work does not therefore recount the numerous interactions I also had with informants from the media, citizens in the country and patrons of the Tents. I have however used the knowledge gained from interviews with these informants in the text in ways that compliment the body of this manuscript.

\section{Selecting The Calypsonians}

I identified earlier in Chapter 1, that the domain of Calypso singing is divided into two fundamental strands, these being Soca and Calypso. Indeed, Soca was introduced by "Lord Shorty", (who later renamed himself "Ras Shorty I"). The word "Soca" is an amalgamation of the first two letters of the words, "Soul" and "Calypso". Bringing these two syllables together in this way, symbolise the fusion of the two different types of music. The evolved Soca beat is faster and more jumpy than that of the traditional Calypso. As such, my initial understanding was that Trinidadians experience Soca more in the vein of party music rather than as a means of delivering a meaningful message, as 
Chapter 3 - Calypsonians and Their Lives: Fieldwork in Action

is well recognised to be the case with Calypso. Accordingly, I approached my research with the view that the lyrics of a Soca tune are considerably less sensitive to the political and economic conditions existing in the country than are those of the Calypso, which requires a more attentive ear from the audience. As a starting point I held the global view that the lyrics of a Soca tune can be quite repetitive and do not contain a significant message.

This initial view was supported by Calypsonians like Shorty, who in one of his Calypsos, refers to the singers of Soca saying that "dey singing tata". In the local parlance, "tata" is the word for excretion.

For his part the Calypsonian "Sugar.Aloes" less subtly expresses his criticism of these Soca singers and this type of music in his Calypso: "Why ah Stay". In that Calypso, he asserts that despite all the maltreatment that he has been the victim of, he has continued as a Calypsonian residing in Trinidad and not emigrated. His expressed view is that he has demonstrated this commitment because he recognises that were he to leave the shores of Trinidad, there would be fewer Calypsonians available to represent the public in the vital work of resolving the conflicts occurring in the society. Part of this statement of his position is:

Calypso is a thing must be edifying Not the shit them young boys singing Lord Pretender told me no matter what it be, Always try to tell a story So ah want all them young singers know Commentary is the roots of true Calypso Me ent really have nothing against jam and wine But try your best and give the public a story line 
Chapter 3 - Calypsonians and Their Lives: Fieldwork in Action

Using the phrase "Jam and wine," Aloes is referring to a type of close dancing that at times simulates human intimacy. In my conversations with informants during my fieldwork, this terminology was frequently utilised from a number of different perspectives so much so that, in recognition of the fact that both the words 'jam' and 'wine' refer to human consumables, during conversation, humorous transitions frequently took place through the use of pun thus: I have heard of jam and bread, jam and bake, but never jam and wine.

My work was driven by that category of performer that Liverpool (1989) calls "the real Calypsonian" i.e. the Calypsonian who, offers observations and seeks to raise the consciousness of the people of the country.

Given this level of support from other Calypsonians who were very well respected in the Calypso fraternity, I felt comfortable, cocooned in 'serious/party' dichotomy. Clearly, my choice to look at Calypso as opposed to Soca music permitted me paying attention to substance, custom, institution, ritual, and authenticity; attributes that I was sure were not as readilly available in Soca music. Just as I became accustomed to and comfortable with this way of thinking, my view of the dichotomy was shattered by a challenge from an informant who asserted that the 'serious/party' division was false. She held the view that the division is rooted in a rhetoric that is based on a power relation that customarily exists between the traditional and the new, i.e. between 'the selves' and 'the other'. In this relationship, 'the self' seeks to maintain the old status quo steeped in tradition and the authenticity of the message being conveyed, while 'the other', tries to usher in a new dimension, and in this case, by promoting soca commercially as party music, this in itself, is a very serious message. This brought to mind the words of Clifford that: 


\begin{abstract}
...... twentieth century academic ethnography does not appear as a practice of interpreting distinct, whole ways of life but instead as a series of specific dialogues, impositions, and inventions. 'Cultural' difference is no longer a stable, exotic otherness; self-other relations are matters of power and rhetoric rather than of essence. A whole structure of expectation about authenticity in culture and in art is thrown in doubt.

(Clifford 1988:14)
\end{abstract}

Through our discussion, I came to recognise that it is possible for any given Calypso to contain attributes that ascribe both to serious as well as party dimensions. She further argued that the increased commercial value of soca tunes like Gary Cordner's “Ah Feel to (Hold On \& Wine)" convey an important message about bringing love in the party, and that this is a significant message about traditional, authentic values. On the other hand, the converse also applies to serious Calypsos like "Sinking Ship", in that they do not deny the opportunity to dance, and enjoy oneself.

I needed to be mindful of this in deciding upon my selection of Calypsonian informants, particularly in view of my plan for the structure of my interviews. Also, I recognised that for the purpose of my ethnographic research, each Calypsonian informant needed to have some personal history in the art-form, which would allow for balancing the metanarratives, hence allowing for the whole story to be told. Clifford puts it thus:

Modern ethnographic histories are perhaps condemned to oscillate between two metanarratives: one of homenization, the other of emergence, one of loss, the other of invention. In most specific conjunctures both narratives are relevant, each undermining the other's claim to tell "the whole story," each denying the other a privileged Hegelian vision."

(Clifford 1988:17)

Consequently, in order for me to not contaminate the product of the interviews, I

committed myself to remaining symmetrically balanced between these two extremes of Soca and Calypso. In the final analysis, I came to see that the international performances of the artists from each of these camps, have helped to put the music on 
Chapter 3 - Calypsonians and Their Lives: Fieldwork in Action

the international stage. One of the by-products of this international exposure showed up as the constant flux that the music experienced which in turn was resulting from its constant interactions within the international music industry. This in turn had a reciprocal knock-on effect on local musical interactions, and the accompanying local rhetoric.

In choosing the seven Calypsonians, I arrived at what I saw as a compromise. I strove to simultaneously straddle the spectrum of types of Calypsonians, embracing differences in gender, popularity, status and standing within the community, e.g. Gypsy is an MP. Almanac who is not so well known is blind. Denyse Plummer is a female Calypsonian of European decent.

I have selected these Calypsonians as harbingers of the wider domain of the field of Calypso. I offer them as icons that serve to illustrate the substance of my argument, rather than being the points themselves. This means that I neither necessarily nor specifically use the work of each of them in this text.

I was limited in my selection by the availability of the artist. For example Chalkdust who now lectures at the University of the Virgin Islands, was not available except by emails and brief telephone conversations. David Rudder, who now lives in Canada, was not available at all, Watchman now lives in North America. The Mighty Sparrow seemed deliberately elusive and, from the brief encounters I had with him, probably would have wanted to be remunerated for any participation in this research effort. 
Chapter 3 - Calypsonians and Their Lives: Fieldwork in Action

I therefore chose Calypsonians who I considered would be consistently available over the period of my research, had established themselves in the Calypso arena and shared some sort of interest in this area of research.

\section{Calypsonians AND Their SObriquet}

Most Calypsonians use a sobriquet, such stage names usually give some sort of insight to an aspect of their personality. This assumed name is the medium through which the Calypsonian transforms his/her social identity, adopting attributes of the character of their sobriquet. Hence the Mighty Sparrow sings sweetly, while the Mighty Chalkdust became a Calypsonian while employed as a teacher. For his part, Sugar Aloes is a contradiction, for while sugar is sweet, aloes is bitter. Indeed Aloes says of himself: sweet voice, bitter lyrics. A list of sobriquets and real names of Calypsonians operating in Trinbago is available at Appendix 3.

In my conversations with the Calypsonian informants, they attested to the fact that while on stage, they assume the character that their sobriquet gives vent to. The sobriquet then becomes a personal mask. Such sobriquets enable Calypsonians to transcend their everyday, commonplace roles, and çonventions in a variety of ways. Through such sobriquets, they can take flights of imagination from the mundane level of reality, sometimes becoming the medium for men to enter into relations with the supernatural world (Levi-Strauss 1961:19) in a ritual rebellion.

\section{CALYPSONIANS AND THEIR LIVES}

My fieldwork was conducted from January 1999 to August 2001. During this time I held a number of interviews with each of the seven Calypsonian informants. It would 
Chapter 3 - Calypsonians and Their Lives: Fieldwork in Action

be impossible to relate in this text, the content of the entire interview I had with each of the Calypsonian informants. This work is therefore a distillation of the essential elements of the series of interviews with each Calypsonian. 


\section{Morel Peters - Sobriquet: Luta}

Morel was born in Point Fortin, Trinidad in 1951 and grew up in the remote country village of Tortola with his aunt, who has a small shop in which he worked, when he came back from school.

His Aunt regarded Calypso as taboo and therefore forbade him

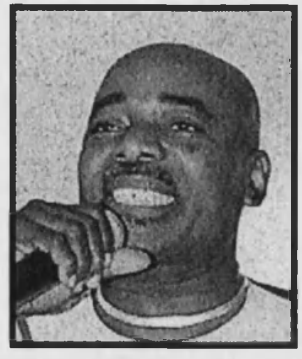

Figure 3.1 - Luta from listening to them or being involved in them in any way. Out of respect for his Aunt, his contact with the Calypso world was clandestine. He first started writing Calypsos at the age of 18, doing so for friends, young people and other Calypsonians around his village. However he waited till he had legally attained manhood at 21 to sing his first Calypso, which was entitled "Granny Say". At that time he sang under his original sobriquet of "Sugar Stick". He left his Aunt's home at 22 and come to live and work in Port of Spain. Although he had trained as a draftsman, he had little practical knowledge about the building trade and set about gaining some experience while he lived in the city. Initially life in the city was tough, but he worked hard and learnt quickly and developed the essential survival skills, necessary to make it in the capital.

Lord Kitchener and the Mighty Sparrow were the early icons after whom he modelled himself. During my interview with him he recalled how he marvelled at their versatility and their ability to produce numerous records, on the wide variety of topics that they did over the number of successive years.

In responding to the question: who were his inspirations? He recounted as follows:

For diction, I admired Superior, whose name is very seldom called. He was a master of Calypso. I loved his diction also Christo. The Mighty Sparrow was always the king of them all. I learnt a lot from him, as I also did from Kitchener. 
It was only after getting involved in Calypso that's when I really appreciated Kitchener. His genius is shown by his ability to keep the audiences' attention. He is out of this world! Sparrow is a great performer. He puts life to the music and performs as no one else does. With Kitchener it is the idea, the story, the picture that he is able to paint with words. He has also written all of his own work. Kitchener is a genius! Take for example the song: "The Carnival is Over". The music enables you to sense that sentiment. You get the sense that that is what is being conveyed even before he begins singing.

When he released "Pan in a Minor" I thought he had reached his limit and when he gets to that level the next thing is death. But he later went beyond that and released the "Bees Melody" and then sill after that "The River". He was a unique artist.

When asked about his future in Calypso, he responded

As I grow, I am experiencing more liberation. I am no longer constrained by competition or peoples' comments etc. I am liberated in doing what I feel is necessary to be done not singing for popularity or to win the competition just expressing whatever comes to me. So I do a thing as it comes to me and not stuck to the Carnival fraternity. So, my stuff is different as I am free now. Just letting the music come out.

An example of this is "Jamu Woman" which was done in the Shorty style of music. Shorty is also someone who I admired as well. I visited him in hospital during his illness, he paid tribute to his wife and he recognised that he did a lot of things that could be described as unkind, and asked her to forgive him. That touched me.

Before he died she was on a TV interview and one of the questions that the reporter asked was: how is she able to cope with the illness at the middle of his life. Her response was that she learnt to let go and she held on by letting go.

I pondered on that for the rest of the day and she did it with her children, and that is how she held on to them. I started focusing on her then and realised that indeed this woman is a strong woman. When he died she stood up and really demonstrated strength. Garfield was really a nice man and I know him from the love man as Lord Shorty and then as Ras Shorty I

When he died I felt compelled to pay tribute to his life so I felt I had to do that song to him and his wife and found a way to do so after battling with the idea for a while. "Jumu Woman" is the name of the song that is the tribute to him. Garfield Blackman. Love-man. The sex symbol of Calypso. On the other hand, Duke was a dresser-man.

Today Luta lives in Port of Spain and has a full time job as a secondary school teacher. 


\section{Michael Anthony Osuna - Sobriquet: Sugar Aloes}

Michael Anthony Osuna, comes from Santa Cruz in Trinidad. He was first christened a

Roman Catholic by his mother and father with whom

he lived. He subsequently changed to the African

centred Orisha movement.

His interest in Calypso, as well as the influences in the art-form, both started at a very early age. He first went to school at Nelson Street Boys R. C. and from there went on to Mucurapo High School. While at Nelson Street Boys', he joined the school choir with Chalkdust as the choirmaster.

During my time with him, he mentioned that his formula for inspirations was: From Sparrow I adapted diction; melody from Shorty; from Duke dress code;

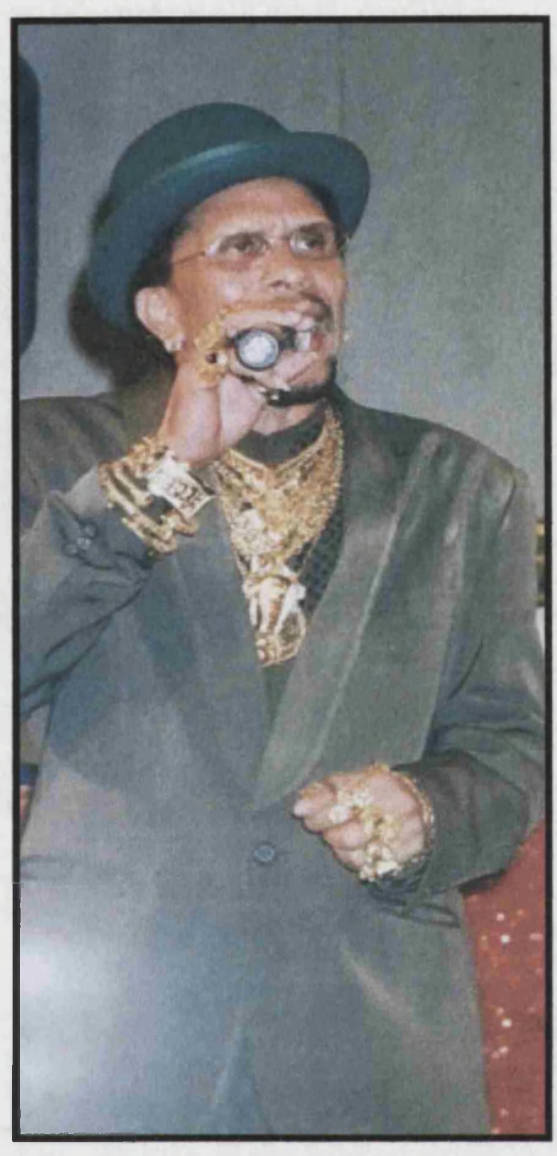

Figure 3.2 - Sugar Aloes and from Kitchener attitude and lyrics.

He recalled that Lord Pretender once said to him if you are dressed well you will capture the audience. When on stage, Aloes is adorned with gold jewellery that he wears around his neck, wrists and on his fingers. His smile also reveals gold caps on his teeth. (See the picture below which was taken with Aloes, and showing his gold jewellery, adorning his chest as well as his golden smile). He stated that the gold has no part in his presentation, it is simply an investment for a rainy day. Seeing how he dresses for his 
performances, it is clear that he has made Lord Pretender's idea, a hallmark of his presentations.

Michael first worked as a butcher for 27 years, before beginning his professional career as a Calypsonian in 1979 at the Young Brigade Tent. However, two years before that he started singing.

When asked about the origins of his name, Aloes recalls that its selection was not really premeditated. He told me that when he was being introduced to an audience in 1977 , while on stage the emcee asked him for his name and Sugar Aloes was the first thing that

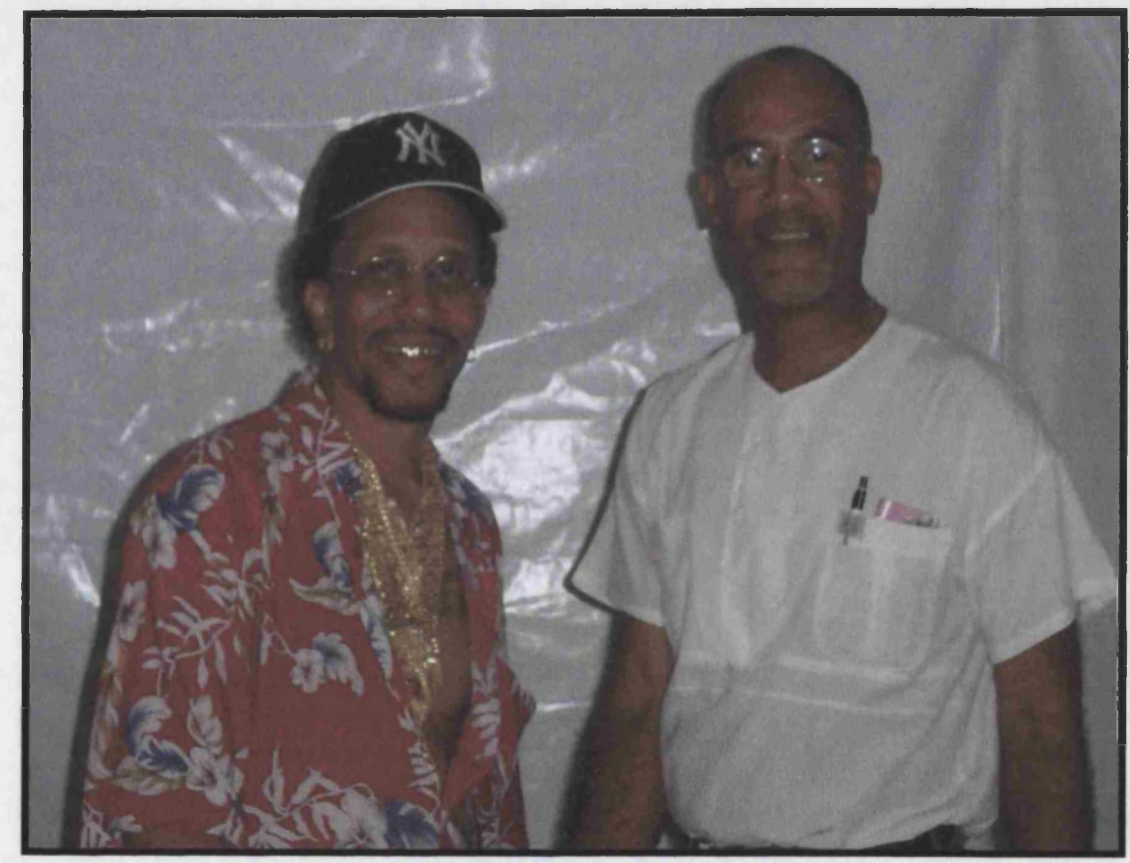
Figure 3.3 - Aloes and Phillips came to [his] mind. He confirmed that today he is very comfortable with the name, and states that it is appropriate in as much as it represents his sweet voice, bitter lyrics.

Michael described himself as a family man and invited me to visit him at his home in Bon Air where he lives with his wife and children. Although prompted, he declined to reveal the number of children he has. 
Chapter 3 - Calypsonians and Their Lives: Fieldwork in Action

Quite apart from his biting political commentary, Aloes also has a finger on the social ills of the country. In speaking of attitudes to children, he expressed strong views on the trend of Caribbean parents who, in seeking a better life for themselves and their families, "leave their children in Trinidad while they work abroad". These parents then send barrels of clothes, shoes and toys back to their children at home. He questioned this tendency asking: How can parents take care of their children with a barrel? Can you pack morals and values in a barrel and send them home?" he asked. He went on to state: "No matter where I am, or what I'm doing, I make time for my children.

He observed that there is an ever-increasing flow of people leaving home (i.e. Trinbago) for this illusion of a better life overseas. He then went on to reiterate what I recognised as the sentiment of his Calypso "Why ah Stay" when he questioned: If you can't make it here in the country where you were born then how can you expect to make it anywhere else?

Clearly, the breakdown in family life and the degradation of family values in Trinidad and Tobago is a source of deep concern and distress to Aloes. He acknowledged that the lyrics of some of his Calypsos demonstrate his commitment to addressing current issues while drawing the nation's attention to them. This greater urgency to sing on current issues predominated over hï need to address historical matters in his Calypsos

He recognised that there was a price for being outspoken and controversial. He asserted that he had been victimised both as a Calypsonian, as well as in his private life. One way in which this showed up in his private life was in the difficulties he experienced, and the blocks that were put in his way, while trying to get the property in which he now 
Chapter 3 - Calypsonians and Their Lives: Fieldwork in Action

lives with his family. He recalled the victimisation and feelings of being punished because of the biting political commentary in the lyrics of his Calypsos. In "This Stage is Mine" he alludes to this when he sings:

Even though they chastise me, they can't take away this voice

In the same Calypso, he later goes on to state his claim that:

It is very plain to see that I am the people's choice He said that: In 1998 I saw people cry when I was denied the crown when I sang "Ish" and "Ah Ready to go".

He showed a sign of acceptance and resignation when he expressed his view on his treatment when he exclaimed: "well despite my feelings of unfairness, if that is the price I have to pay, I cannot be deterred by a panel of six people". He continued: My moment of happiness was after the competition when I was engulfed by the masses and could not go forward, sideways or backwards. Even swamped in this way, I told the people to leave them.

He did not claim any level of impartiality stating quite categorically "I consider myself the property of the PNM".

In querying his source of inspiration, he responded that this "came from the everyday man in the street, from conversations". This notion he clearly expressed in the lyrics of the Calypso 2001 when he stated:

It's from the public I get my lyrics, You does give me inspiration You does give me the strength and courage, To slaughter them politicians, 
Chapter 3 - Calypsonians and Their Lives: Fieldwork in Action

He did however recognise that this inspiration was only one part of the whole and that he still needed to complete his research as well as present his lyrics in such a way that ensured that no libellous action could be taken against him for any of his Calypsos'.

He went on to identify some of his perceptual views as expressed in the lyrics of his Calypsos. He identified that he focuses on a body of basic questions such as: "what about the poor? Claiming that it is "basic common knowledge that the rich man does not bank. It is the poor people who put money into a bank for the rich man to borrow $i t$ ". In being pragmatic about developments about the different racial groups within The Republic of Trinidad and Tobago he stated that: "Chaguanas [an area in central Trinidad that is largely Indian] was once a cane-field" now it is a very developed and highly sophisticated community. In-looking at the changes from the perspective of race he showed his recognition of the disparity between the Indian community and that of African origin saying that unfortunately "the poor people John-John and Lavantille have not changed". He asserted his view that "the poor man has no power behind him". In discussing what he saw as his specific role, Aloes asserted that he did not just see himself as a Calypsonian, but rather as an international entertainer a singing of Rhythm and Blues as well as Gospel.

In responding to his function as a Calypsonian, he stated: "I am a vicious commentator and a representative of the poor man". He continued that in his view: "The people are continuously mislead and I'm not going to stay quiet about it". 
Chapter 3 - Calypsonians and Their Lives: Fieldwork in Action

He then went on to explain that from his observations "the poor man only had a voice once in every five years and he has taken it upon himself to speak out on his behalf of the injustices and unfair practices of those in authority".

As a Calypsonian, he saw himself very much as the people's spokesman. He echoed these sentiments in his Calypso entitled "Why Ah Stay":

On the numerous occasions on which I spoke with Aloes, I somatically detected that there was more, much more to this man than is accessible at first sight. There was a latent quality that was very abiding, a hunger. A hunger, a fervour that existed in him that I could only identify as one for social justice. I recognised that this hunger was clearly expressed in the lyrics of "Why Ah Stay" where he expresses his need to, in my words: 'break his fast', which is what the word "breakfast" really means, as he sings:

And if ah leave now, what jazzy go say

Then its only Cro Cro remain to take up the task

Boy ah start to write fast, do care if ah come last

Ah want to eat Danrhaj for breakfast

Since there is no literal expectation that Aloes will actually 'eat' Danrhaj Singh, I can only interpret this as a metaphor, embodying Aloes' need and hunger for social justice.

Aloes stated that he planned to keep his Calypsos in the same vein. Clearly, he is tough and unwavering in his passion for improvement in the socio-political and economic situation in Trinidad and Tobago. As a staunch PNM supporter, Aloes promised me that no matter what the cost, his lyrics will always be controversial. He stated that he saw this function as being the result of his unquestioning loyalty and sense of responsibility to the people of Trinidad and Tobago. 


\section{Winston Peters - Sobriquet: Gypsy}

Winston 'Gypsy' Peters was born in rural Mayaro, on $20^{\text {th }}$ October, 1952. He was one of thirteen children, having three sisters and nine brothers. He recalled that as a child growing up, the family experienced financial difficulties.

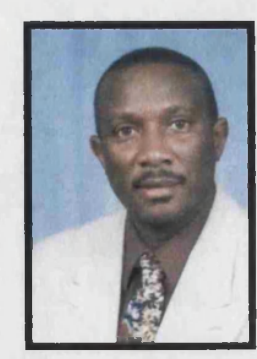

Figure 3.4-Gypsy

He attended Mayaro R.C. School and later progressed to Mayaro Government School. As is not uncommon in large families in rural areas in Trinidad, Gypsy interrupted his schooling at the age of 13 to start working so that he could help support the rest of the family. He left Trinidad at the age of 15 for St Croix. From there he migrated to the USA, where he completed his high school education at the Central High School, New York. Gypsy's name and nature seemed to be in harmony and he explained that it was this nature that drove his acquisition of the name Gypsy. He stated that he was a hyperactive child and this caused him to earn the name Gypsy, long before he became a Calypsonian. This tendency to be constantly on the move shows up in the principal places that he has lived. These he explained have been Boston, the Virgin Islands and Canada, as well as New York and now Trinidad and Tobago.

Gypsy started singing when he was 4 years old; however, he won his first Calypso competition in the Mayaro Village Hall at 5, singing his own composition.

He acknowledged the inspiration he received as a singer and Calypsonian. More generally as a Calypsonian he was inspired by the Mighty Sparrow, Black Stalin and Kitchener. He said to me that when he was a new-comer to the field of Calypso singing he sought ideas from these idols as part of his own development as a composer and singer. Although during these early days he was resident in the USA, he "returned to 
Trinidad for carnival, every year to sing in the Tents. After the season I would leave to fulfil other engagements in other parts of the Caribbean and the USA."

Gypsy who is married and has ten children of his own, (most of whom are teenagers and young adults), told me that singing is and has always been one of his favourite recreational interests. He also said that as a recreation he likes all types of sport.

Gypsy's eyes lit up as he explained how elated he was to have been the first

Calypsonian to have performed before a US

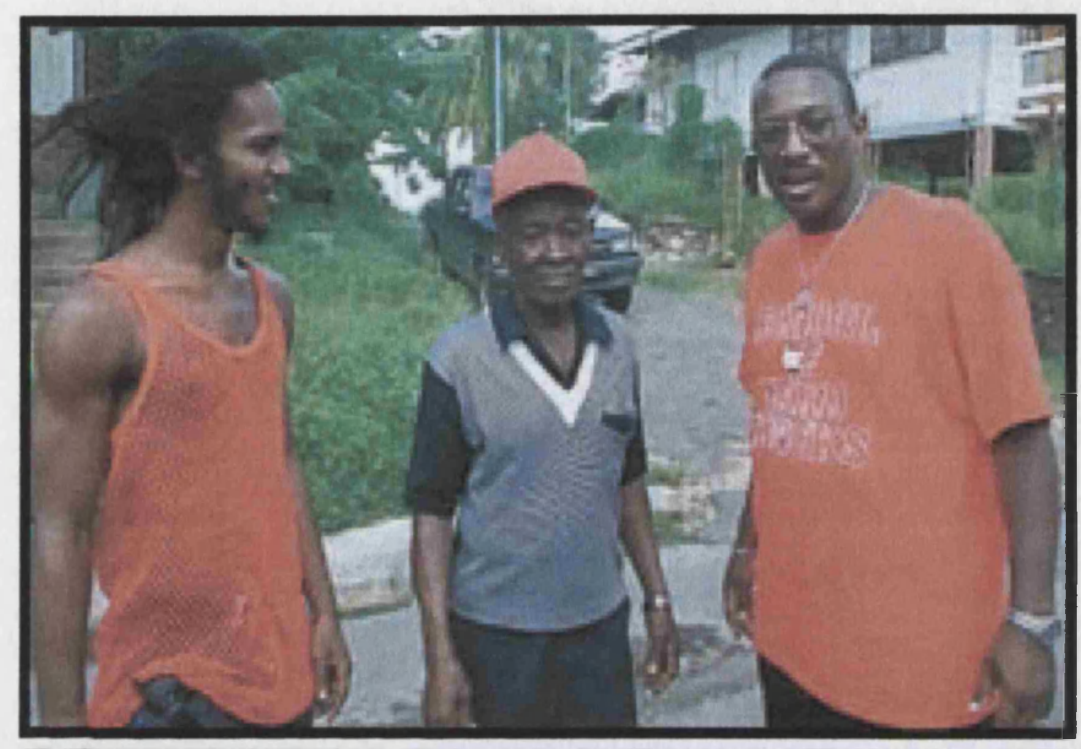

President. On this

occasion, on the

Figure 3.5 - Gypsy (right) his father (Centre) and son (left)

recommendation of the Smithsonian Institute in Washington, Gypsy performed before President Carter. I carefully observed the gleeful expression on his face, as he recalled that for him this event was one of the most memorable occasions in his long singing career. He went on to acknowledge that in 1988 he had the distinction of winning the only Calypso King of the World competition that has ever taken place in Barbados.

Although more recently challenged by Black Sage, for many years Gypsy has been well known in Trinidad as the king of "Extempo". Gypsy has gained a reputation as the man who, since the 1980's has won the most "Extempo" crowns. 
Chapter 3 - Calypsonians and Their Lives: Fieldwork in Action

What in Trinidad is labelled "Emtempo," is a specific branch of Calypso singing where the Calypsonian randomly selects a topic from within a hat containing a variety of topics. S/he is then required to compose a song on that topic on the stage in the presence of the highly critical audience, then sing the extemporaneous composition to the rhythm of a backing band playing "San Humanitae". The art of "Extempo" singing requires considerable spontaneity, a freedom in, and a knowledge of words. The Calypsonians also need to be quick thinking and witty, if they are to create a Calypso, while sustaining the momentum of the evening, and simultaneously pleasing the audience. Seemingly ideal qualities for the hyperactive Gypsy. Extempo Calypsonians need to construct, verses consisting of rhyming sentences extemporaneously, in response to an opponent. The tenor of the exchange is usually good-natured, offering jovial criticism to each other.

In 1996 Gypsy had the unique distinction of being the first Calypsonian to win both the Calypso Monarch title as well as the title of Extempo King within the same year.

Speaking of his successes Gypsy expressed the view I am proud of my achievements, considering the conditions from which I came. He has undertaken a commitment to pay something back to his community. One way of doing so was through schools visit, to try to instil community values, in the children. Another way in which he saw himself paying back was by helping to keep the standards high in Calypso. He stated that one way of doing this was by not singing songs that denigrate women.

On the topic of 'what makes a good Calypso', Gypsy expressed the view that "a good Calypso should be melodious, contain meaningful or sensible lyrics and well 
Chapter 3 - Calypsonians and Their Lives: Fieldwork in Action

structured". Although he stated that.he avoided political bashing, that does not mean that he would not comment on the burning issues of the day. However, his intentions are always to do so respectfully. It came over to me that he was very serious about his work as a Calypsonian when he said "I put a lot of thought in everything that I sing."

Gypsy told me that he sees himself not just as a Calypsonian, but also as a businessman and a politician. As a parliamentarian, he is the representative for the Constituency of Ortoire/Mayaro. On January 3, 2001, he became a Junior Minister in the Ministry of Human Development, Youth and Culture.

As a businessman he has a variety of business interests, one of the most profitable being his petrol station. When I visited his home in Chaguanas, I found that on a plot of land at the back of his home, he had a number of kennels with guard dogs which he bred, the pups of which, from time to time he would breed and sell commercially.

His entrepreneurial spirit also extends to his music. He explained that in the year that he won the Monarch he invested $\$ 70000$ locally to produce the album "Bad" which also contained his "Little Black Boy" hit of that year.

Gypsy recalled that over the years of my Calypso career I have released many Calypsos. Some of the most popular ones were: "Black Man Where Is Your Cry," "Where Do We Go From Here", "Sinking Ship" and " Suzanne". He recalled that while "Little Black Boy" was a commentary on the lives of male youth, in 'Suzanne" addressed the little black girl. Nobody really remembers that song. It was not given the attention that it deserved; neither did I feel that people really listened to many of the other songs that I 
Chapter 3 - Calypsonians and Their Lives: Fieldwork in Action

have released over the years. I could hear the remorse in his voice as he pointed out that for the past ten years; he has composed at least one song each year to inspire AfroTrinidadians towards self-esteem, embracing knowledge and living meaningful lives. He continued: over my years as a Calypsonian I have always urged young Afro Trinidadians to rise up and take charge of their lives."

In saying this he acknowledged that all the other racial groups in Trinidad and Tobago have support systems to take care of their people in times of crisis, we the Afro Trinidadians are the only exception. We have not invested any of our wealth for the benefit of the members of our own community. I have been called racist because of the lyrics of some of my songs, and I have been accused of compounding the feelings of hopelessness in young Afro Trinidadians.

I find that when I talk with the people who say these things I find that they do not understand the lyrics of the song, and they have neither listened to the words, nor have they carefully read the words. He stated I am prepared, willing and able to debate these views and my position with anyone. My Calypsos are inspired by my observations, of Trinidad society. There are real and serious problems that we need to pay attention to.

Gypsy told me that while he believes in God, he avoids organised religion. He did however acknowledge that he considers his talent to be a God given gift saying that he would continue to compose and sing Calypsos that he feels could impact positively on the lives of our young black youths. 


\section{Weston Rawlins - Sobriquet: Cro Cro}

Cro Cro was born in 1953, in the small town of Rio Clario in South Trinidad where he was also educated to secondary level. He has lived there all his life and continues to make this the focal point of his life and the base from which he operates. He is the middle of five children.

In the Calypso fraternity he is frequently referred to as "the mighty midget", this is because although he is $5 \mathrm{ft} 1$ "

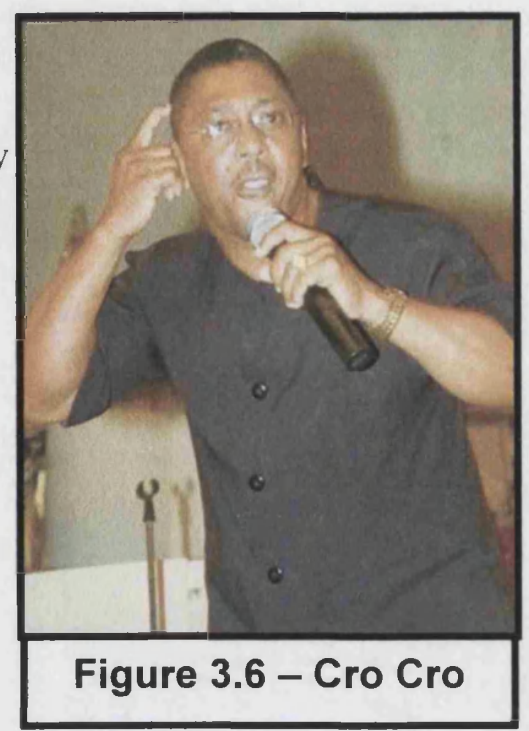
tall, his lyrics are regarded as gigantic.

Cro Cro started singing Calypsos at 5 years entering the professional Calypso arena in 1974 with a Calypso called 'Panty'. Initially, he focused on being accepted by the audience and did not sing on issues of political and social commentary. Cro Cro explained that when he started singing he was without funds. He expressed the view that at that time he felt that singing Calypso was going to be a fun thing. He abandoned recording Calypsos when he realised that they were not being played on the radio, recognising that lyrics have to keep me alive, he decided to write big lyrics songs. Hence the power had to keep me alive so I had to turn to political and social commentary.

He explained that he made it to the finals on 11 occasions. I won three times and had five questionable seconds. I call them questionable. He said that he saw these seconds as him being victimised because of his social and political commentary. 
Chapter 3 - Calypsonians and Their Lives: Fieldwork in Action

In rationalising this view he explained: "When Panday and dem came into power they used to pick 24 Calypsonians they picked 32 that year and they left me out. I want to know how I could drop from number one to thirty-three? You see how they do me a wickedness. The people won't forget how the judges came up with 30 semi-finalists and left me out.

When asked if he wrote all of his songs, he responded:

Co Cro: Yea yea yea man I always write them God and I....... Yea, yea, yea! This year ah fella give me a song to sing, ah wouldn't say give me enh! Ah went to see a show in a little place and ah heard him sing and he had a good song but he could not make it. He had no name! This year he say Cro Cro sing the song nuh man sing the song! But it could not replace any of the two good songs I already had to sing in the Tent. So I did not sing it.

In responding to a question to determine what influences his writing, he responded with the very profound statement: the influence and intuition that helps me to put it together is the happiness I feel to see justice done. During the times I spent talking with Cro Cro he recalled his 24 years' of conflict and the battles he has had with the judges of the Calypso Monarch Competition, frequently indicating how these difficulties were driven by the political party in power.

He recalled his very memorable first trip to the Calypso finals where he sang "Woman, Woman" and "Ling Tang". He lamented: They put me last. He said that for him that day opened my eyes, from that day the innocent, trusting side of Cro Cro vanished, and he vowed not to have mercy, becoming a hard-hitting social-political commentator. 
Chapter 3 - Calypsonians and Their Lives: Fieldwork in Action

He went on to say that in his opinion, From 1974 to 1987 those judges were real stupid, but I never blamed them entirely. It was really the system behind them that was corrupt. It is the people who controlled the judges that make me vexed. The system was always trying to pull me out. In a way I kind of understand that and when I look back at my early days as a Calypsonian I see that in those times I was rough and libellous. I'm kinder now."

Cro Cro said that he recognised that for him the tables turned in 1987 when he entered the Independence Day Calypso Monarch competition sponsored by Stag with "Botha". In that Calypso he launched a stinging commentary about racism in Trinidad. The Calypso featured an imaginary phone-call to Cro Cro from South Africa's P. K. Botha. His second Calypso was "Happy Anniversary", this was a song ideally fitted to the contest's requirement of a nationalistic Calypso.

His desire now is to win the National Monarch title. However in view of the change in government and political influences exerted on the judges, he stated that he expressed scepticism about his chances of winning. In short he stated: I thought there might be some victimisation.

He asserted that "Three Bo Rats" was a doomsday prophecy about the shaky political alliance forming the NAR. His second Calypso there was "Corruption in Common Entrance". He claimed that this Calypso led to one of the biggest investigations in the educational system that this country has ever known. Cro Cro achieved his first national crown when he was crowned "Young King". For him this heralded in a new 
era, for he then made it to the Calypso monarch competition for each of the next ten years.

In 1989 he placed second when defending his national crown, singing: "Fire" and "Where Pan Reach". "Fire" was a criticism of the organisers of the Independence Calypso competition and was sung in direct response to the reduction of that prize money. In this Calypso he borrowed the melody of Stalin's "Bun Dem" (See Chapter 9 discussion of "Call and Response" among Calypsonians), to state why he decided not to defend his crown. He said that 1990 saw the two popular songs: "Party", which was a cleverly crafted political commentary, and "Political Dictionary". It is usual that the Judges would visit each Tent on a specific night to select the Calypsonians that meet the criteria for the competition. However, his father died on the night that the judges visited his Tent so he was not able to sing that night. By singing with the unattached Calypsonians he was late selected and went on to regain his crown. He stated: people used to say you had to have recorded to win anything, but I won that year with no record. I won it for my father. Cro Cro said that he had not cut a record on any of the three years that he had won the Monarchy.

He said that once again he fell victimised, when in 1991 he again fell to a questionable second singing two controversial Calypsos about the 1990 coup. These were "Say A Prayer" which was a plea to understand Abu Bakar's actions. The second was "Still the Best". This was satirical commentary on the condition of Trinbago.

Cro Cro told me that 1992 was a telling year for him, that was the year that he won the Independence crown for the second time. For that contest he sang "Get Something and 
Chapter 3 - Calypsonians and Their Lives: Fieldwork in Action

Wave", and "Rise African Rise". He explained that the former was a humorous criticism of party Calypsos, the type that are frequently referred to as jam and wine Calypsos and have no fundamental message for the people. In this Calypso, he encouraged the people to exercise their criticism of that type of Calypso, by waving a dirty handkerchiefs in the air. For his second Calypso though, "Rise African Rise", he recalled that this was first composed and sung in 1981. He went on to say: do you know that I got nowhere with that song way back then? ... What does that say about judges?

Cro Cro recalled that he returned to the Calypso arena in 1992, placing second with "Wine" and "Sham We Don't Want It". In this later song he accused Sham Mohammed of racism. Sham was an MP with the UNC government and a significant Asian national icon.

Cro Cro recalled that in 1993 he placed fourth with "Hang Them High" and a second Calypso on "Rodney King". The former showed Cro Cro at his controversial best with a graphically gruesome commentary in support of the death penalty. Cro Cro acknowledged that he made a bad decision that year in not singing "Run Blue Boy Run" instead, as was his originally intention, for which he paid a heavy price. He recognised that his decline continued through to 1994 when he came fifth singing a political commentary Calypso called "Respect the Law", criticising politician Hulsie Bhagan. In his second Calypso entitled: "Is only Carib", he questioned the forces behind the Calypso judges.

Cro Cro explained that his commitment to his work of opening the eyes of his countrymen continually drives him. In 1995 he recovered to second place with a demand 
Chapter 3 - Calypsonians and Their Lives: Fieldwork in Action

for a government apology entitled "Apology", In that Calypso he asserted that there was "Corruption in Common Entrance" and the Government was wrong for branding him a racist. His second Calypso for that year was "Jump and Wave". Generally, the controversial Calypsos that Cro Cro. sings are generally considered to be a challenge to the status quo. Judging from the articles that appear in the newspapers as well as the talk shows on radio and TV, these songs by this king of controversy, usually generate much anger from politicians, and other addressed groups. From my conversations with him, Cro Cro recognised that one of his most controversial Calypsos was "All You Look For Dat". In that Calypso Cro Cro blamed Afro-Trinidadians for appointment of $\mathrm{Mr}$ Basdeo Panday's as Prime Minister. A second such Calypso was "Kaiso Gone". This was a melodic lament about the death of traditional Calypso. Cro Cro proudly recalled that in 1996 he again won the Monarch title. This year he ended up being one of the most talked about Calypsonians for that year.

Time and time during my meetings with Cro Cro, he clearly conveyed his view of himself as a defender of the people. He acknowledged that he was very much involved in the work of resolving conflict. He communicated that he felt he had to struggle hard to gain his status and recalled: "I realise now that during the days of the NCC, when I was a starter, I had to get the shaft, pay my dues, so to speak. I got more mature from that and I forced those judges to accept me, I had to force my way through the door." 
Chapter 3 - Calypsonians and Their Lives: Fieldwork in Action

\section{Anthony Francis - Sobriquet: Almanac}

Almanac was born on St Lucia on $20^{\text {th }}$ August 1942, moving to Trinidad as a child and eventually applying for, and becoming a citizen of Trinidad.

In talking about the significance of his name Almanac pointed out that:

An Almanac is a thing with dates and when you want to keep charts of dates and events. An almanac is more or less a historic type of document. I like history and dates and current events and all these sorts of things........ and that's what I try to portray in my Calypsos......... Although my name is Anthony Francis the company is Antalmanac.

Almanac who is blind, frequently invited me to meet with and interview him at his modest home, which was in an apartment block in Nelson Street, Port of Spain.

Almanac, became blind at age 5, after his eyesight deteriorated from glaucoma.

He asserted that he started composing Calypsos at age 16, I made my debut in the world of Calypso and entertainment in 1962 that's 40 years ago, but I have been composing for 44 years. He explained that he had composed for other people, but it had not worked out satisfactorily so I am very ambivalent in giving other people my work because of the experiences I have had.

Phillips: What experiences have you had?

Anthony: Well people have asked me, and I have allowed them to sing my song and I got nothing for it, not even the acknowledgement of being the composer. Well fortunately, I remembered my songs and I have them in my repertoire. I have a lot of songs you know. 
Chapter 3 - Calypsonians and Their Lives: Fieldwork in Action

When asked, he said that he did not have $a$ contract with these people, however when I sign a contract they try to evade you and ignore it. He acknowledged that unfortunately he did not commit to a contractual arrangement using a lawyer. From what he said it seemed as though he worked on a gentlemen's agreement. He acknowledged to me that he did not run his company Antalmanac as a business and stated: "You learn from your mistakes as you go along". He said that these days if he had to do it again he would appoint someone to act on his behalf. But in the main these days I will sing all of my songs. That way I would find myself in less difficulty.

In relation to his own career, he stated that for the past four years he had sung with a Tent, run by the north zone of TUCO called "Classic Ruso" and acknowledged that he only went into competitions if he was fortunate enough to be picked and that was largely at the judges' discretion.

In 1973 he participated in the Buy Local competition, coming $4^{\text {th }}$ with the songs: "The Buy Local Argument" and "False Prophets." Many people were of a different opinion thinking that I should have placed higher up in the order. Again, in 1983, I was in the semi-finals for the Calypso Monarch competition for the first time. For that competition I sang "Will I" and "Best Republic" two songs that offered satirical commentary on the current state of the country at that time. Although these songs were good, unfortunately, they did not take me onto the finals. At this point, although asked, he did not offer a view on why he did not come higher in the ratings. 
Chapter 3 - Calypsonians and Their Lives: Fieldwork in Action

He stated that his most popular Calypsos were "Build a Better World", "False Prophets" and "Sweet Exotic Soca Music". Copies of these Calypsos were available only in Braille.

In talking about his process for writing a Calypso he said that this was different from other Calypsonians in that they wrote in print, whereas he wrote in Braille while also using a tape recorder. Apart from this, his system is the same as for every other Calypsonian. He did attribute his ideas to his life experiences and from all of his observations of what has happened in life around him and the things by which we are affected. He stated that as long as one lives and as long as things happen, there will be topics on which to sing. In saying so he acknowledged that in the past there had been times when a casual conversation with someone resulted in a topic on which to sing and said that, in this way, he saw himself as speaking 'to' and 'for' the people in relation to their issues.

He recognised that he, as with all other composers draws on a source of inspiration. In particular, more often than not, for him this inspiration would come from reading a magazine written in Braille.

I found Anthony to be very deeply philosophical. This showed up in numerous ways during the conversations. This was partly illustrated by the following words from his autobiography:

Life is not as complex as some people believe, nor is it as simplistic as others make it appear. Between these extremes, the true meaning of life can be discovered as long as we are willing to accept the divinity of God and the brotherhood of man. The life of an individual is characterised not by the things he says but by the way he lives. 
Chapter 3 - Calypsonians and Their Lives: Fieldwork in Action

In relation to his religious beliefs, when asked he said: Religion and spirituality are two different things. Well religion is man looking for God, ...... Spirituality is God reconciling Himself to man.

He then went on to illustrate examples of how he saw religion as being very restrictive, arguing that if one really believes in one's God, whomsoever that is, He will inspire and put words and thoughts in your mind, that no man and no religion cannot do for you. He contended that the spirituality of God is higher than anything that man could provide. He identified himself as a steadfast follower of the Roman Catholic faith in that he has never wanted to change his religion, but quickly went on to state that those are my views.

He recalled that at his first appearance at the Independence Tent in 1962 he sang “Almanac's Dream" and "Wabeen Government". In 1963, he returned to the Independence Tent singing "Keep Your Business to Yourself”. His popularity was helped by his appearance on the television show: "Scouting for Talent". Also for several months, he had a regular night club spot at the "Pepper Pot" in St James.

Although he continued to compose Calypsos for other Calypsonians, he did not return to the Tents until 1968 when he began a nine-year run at Kitch's Revue (Lord Kitchener's Revue Calypso Tent). For Carnival 1968, he sang two songs that were well received, these were: "Irresponsible Mothers" and "Carnival '68". In the former, he addressed the issues of parental responsibility, while in the latter he offered guidance on how to make the carnival a safe and happy event. He returned in 1969 with "Carnival Pan" and 
Chapter 3 - Calypsonians and Their Lives: Fieldwork in Action

“Love for Money". In 1970, he released his risqué "Leather Haunting" and

"Grandfather's Advice". For '71, it was "No Ways Different", and in '72 "Facts of Life".

In ' 73 he participated in the Buy Local competition singing "The Buy Local

Argument" and "False Prophets". In '74, he released "Unfair Treatment" and

"Disenchanted Youth". He sang "Carnival Controversy" and "Do You Approve" in '75, and ended his run at the Revue in '76 with "Build a Better World" and "No Man Works Alone". During my conversations with him, he expressed the view that all of these Calypsos offer advice and guidance and support to the community. He frequently returned to talk about "Build a Better World", which he rated as one of his all time best Calypsos.

In 1971 while performing at the Calypso Revue, he met a Calypsonian using the sobriquet "Short Shirt". Short Shirt was so impressed by Anthony's performance that he undertook to bring him to perform in his homeland of Antigua. This undertaking was fulfilled 10 years later when in 1981 he had his first and only overseas performances. In talking about his time in Antigua, Anthony said that it was a nice experience and that he was well received, even though he was not that well established in Antigua as a Calypsonian.

On some of the occasions on which we met, Anthony would reach out for his guitar and begin strumming and singing some of his compositions as a way of illustrating a specific point. But in his so doing, I sensed that there was more going on for him than I was immediately aware of. I felt that for him, my visits became opportunities for him to have some appreciative company, and show his talent. Thus, my visits permitted him the opportunity to draw the curtains in the room of his blindness and the isolation of living 
Chapter 3 - Calypsonians and Their Lives: Fieldwork in Action

alone. On one such occasion we were conversing about the nature of his songs and

their contribution to social and political commentary, as an illustration of his views and contribution to people's consciousness he suggested that I listen to one of his Calypsos.

Reaching out for his guitar he strummed while he sang the following verses:

Ah little boy by the name of Anthony

Was asking me to explain democracy

He say he 'fraid to ask a politician

So that's why he came along

so I could give him an explanation

Ah tell him

$D$ means you must be determined

To develop your country

E means you must endeavour

To ensure its prosperity

$M$ stands for morality

In your private and public life

If you are against that philosophy

Then you are opposed to democracy

In a democracy

Each man has an opinion

And he must express that free

Without fear of any man

You could talk about Health Administration or VAT

And if a man tell you, you can't do that

Partner he is not a democrat

Remember $O$ is for objectivity

In everything that you do

$C$ is for communication

Consent, commitment and caring to

$R$ means you must respect your brother

Although you both disagree

If you en like that philosophy

Then you are a threat to democracy

He acknowledged that his available tool bag that help to make his work effective, contained a number of figures of speech like metaphor, pun and satire. He illustrated his use of metaphor by singing a Calypso on the problematic matter of the construction 
Chapter 3 - Calypsonians and Their Lives: Fieldwork in Action

of Trinidad's new International Airport saying that all the names that he mentioned in the Calypso could also be assumed to be those of "Jack Public".

He spoke very openly about his blindness stating that one of the songs on his album was composed about sight and the things he doesn't want to see. He expressed the view that he would not object to his sight returning, but if that meant I would have to see all these ugly things going on, then I would prefer not to have sight. He challenged the view that he lived in a world of darkness just because he did not have sight. In objecting to that notion, he commented that I could still find time to be happy in my world of darkness. He remarked that comparing his blindness to living in darkness was garbage.

In speaking about his drive and motivation to be in the Calypso fraternity, he recalled a conversation he had with Calypsonian "Black Stalin". In conversation, both he and Stalin recognised that they:

.........did not enter the Calypso arena for financial gain but for the pleasure and sincere opportunity to enjoy ourselves and to make other people happy. Well of course we discovered that it have a dollar in it as some people would say. And naturally, we want to get the dollar because we have to eat we have expenses to meet. But the focal point was never to make money like these young people telling you now. They want to make money.

He acknowledged that there was a range of pay scales in the Calypso Tent and that was determined by a person's popularity. and demand so that people got paid from $\$ 800$ upwards per week.

He recalled that he joined Stalin's Calypso Court in 1977 singing "Save the Children", returning in 1978 to the new Kingdom of the Wizard Tent where he sang four songs, 
Chapter 3 - Calypsonians and Their Lives: Fieldwork in Action

"Reprising", "Save the Children", "Bow Wow Wow" and his "Tribute to Maestro". The late "Maestro" was a Calypsonian of whom on many occasions he spoke very fondly, saying that he influenced him and his style greatly. He was again at the Kingdom of the Wizards in 1979 with Sweet Exotic Soca Music, which was later recorded in 1980 and released as a single in 1981.

Though he continued to compose Calypsos, he did not perform in the Tents again until 1983. That year started a six-year run for him at Sparrow's Young Brigade Calypso Tent and also resulted in him making it to the monarchy semi-finals with "Will I" and "Best Republic". He retold that in 1984, he released "What is Macho" and "Find a Way" and in 1985 he sang "West Indian Girls" and "Mr Society". In 1986, he did "PCC Affairs" which was commentary on the current scandal in the City Council.

Almanac lamented that he wrote two songs that were sung by Ailene Ligar, as a result of which she won the award for most promising female. The songs were "In the Name of Democracy" and "Tableau of Lottery Ticket". He believed that they had an understanding that he would be rewarded, had she placed in the finals, he expressed the view that: regrettably, she never lived up to that promise.

He sang "Until" in 1987 and "Smart Cashier" in 1988. He did not perform in '89 or '90 but returned in 1991 to the Vintage Calypso Tent to sing "Question Is". He did not perform in ' 92 or ' 93 . His last year to date in the Tents was 1994 when he performed at Kaiso House singing "Save the Family," and "If It was Me." The latter being about Kitch's refusal to accept the Nations award of the Cachonia Gold Medal. That year he also sang: "Why You Sit." 
Chapter 3 - Calypsonians and Their Lives: Fieldwork in Action

He had planned to put out his first album entitled Simply Classy, in 1994 but due to financial constraints was prevented its completion, allowing him to release only an audio-cassette instead.

It was clear that he was proud of his achievements. The walls of the room in his home that we used for the various interviews were decorated with framed awards that he had received over the years. Almanac recalled that he celebrated his $23 \mathrm{rd}$ annual concert at the Mas Camp Pub on July 17, 1998. Over the years, he had received a number of awards from different bodies: in 2001 he was honoured for his 39 years in Calypso. In 1997, the National Carnival Commission (NCC) honoured him for his contribution to the music and the copyright organisation also honoured him on $14^{\text {th }}$ August 1998 for his contribution to the field of Calypso music. He also recalled that he was honoured in 1998 at the show staged by the local businessman, John Williams. That show was designed to honour all Calypsonians who between the years of 1962 to 1998 achieved the status of Monarch. He has also received an award been victorious at the Young Kings Calypso Monarch Competition.

Anthony is not the only blind Calypsonian in Trinidad and Tobago. He recalled that there was "King Irie" who became blind then changed his sobriquet to "Blind Sensation," Irie died in 1988. He identified two others, one by the name of "Psycho" who currently is not an active Calypsonian and Joseph La Placillea, a young man who entered the field within the last year. 


\section{Eric Taylor - Sobriquet: Pink Panther}

Eric is the first of the six children born to his parents in the town of Sangre Grande Trinidad. His stage name of Pink Panther was a nickname given to him from his schooldays, having its origins in class at a time when I was a tall, slender and very quiet guy. He explained that this quietness was more linked to planning that submissiveness. He likened his personality to the characteristics exuberated by the cartoon character of similar name who did not say much but was always into mischief. Initially the name was given to him as a joke, but it stuck and followed as a natural Sobriquet when he entered the Calypso world. He stated that at first, he did not like it, but subsequently grew used to the name and now embraces it.

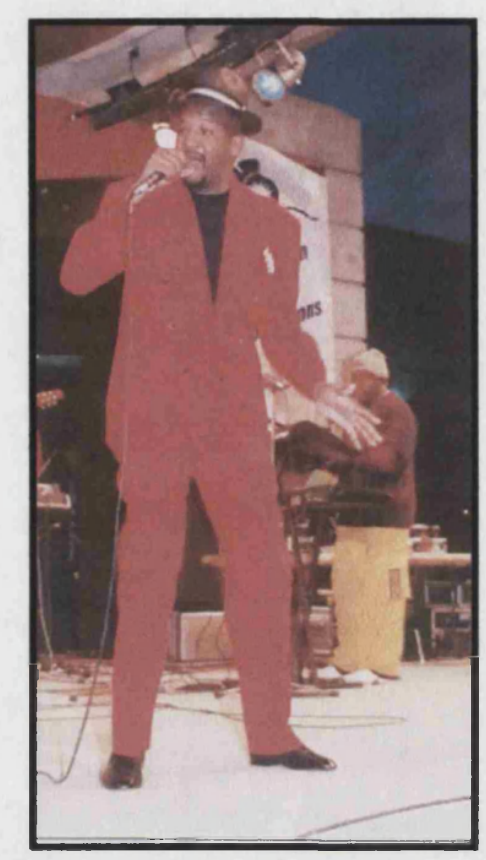

Figure 3.7: Pink Pantha

He has been a Calypsonian for 22 years having started as a shy poet, writing verses to fellow female students in school, who had caught his admiration. He expressed the view that he was good at this and produced some nice lines and ting yuh know.

He revealed that for him, his art form developed through the medium of the schools Calypso competition that accompanied their annual Carnival celebration. At 13 he entered the school's Calypso competition and during these performances, the other members of the class would function as his back-up singers. He explained that he really got to like......this Calypso thing and after leaving school, the next obvious step was to participate in the Sangre Grande Calypso competition which was being held as part of 
Chapter 3 - Calypsonians and Their Lives: Fieldwork in Action

his local community Carnival celebrations. It was there that he met some of the more established local Calypsonians such as Commander, Poser, Scrunter, a fella called Mataphal, Valliant, Calypso Height, All those guys. I was kinda ..... well the baby in that whole Sangre Grande Carnival setting.

Eric: I took part in the Calypso competition and in little fairs and so, and I really loved it. In 1979 we had a competition here with Scrunter being the defending .... the incumbent monarch. They say I gave him a good licking. I was first and he was second. At 19 it was a great achievement for me to beat Scrunter, as he was already well established as a Calypsonian in Kitchener's Tent. He recalled that for this accomplishment the prize was $\$ 500.00$. He stated though that the achievement and recognition were worth much more than the monetary prize value. It also meant that he had started to become famous locally.

For that competition the two songs that I sang, which I will always remember were: "We Still in Slavery" and "Jesus is Coming Soon." Eric explained that the first of these songs revolved around the notion that although we do not any longer have chains on our feet we still have them on our minds.

Eric went on to recall that as a result of this victory, Calypsonians such as Scrunter and Poser took him to sing in Lord Kitchener's Tent which was one of the main Tents in Port of Spain. After an audition for Kitchener and acknowledging that he wrote his own songs, Kitchener accepted him into his Tent. It was with Kitchener's Tent that he matured being shown many aspects of the art of performing as a Calypsonian. 
Chapter 3 - Calypsonians and Their Lives: Fieldwork in Action

Eric's first trip to the National Semi-Finals in 1984 marked another mile-stone in his Calypso career. On that occasion he sang Something to Sing About. It was also the year in which he made his début on the opening night of Kitchener's Tent as it opened in Arima. Eric explained that although he prepared himself by having a new stage suit made, he did not really expect to sing at the event. However being proud of his suit and being keen to wear the new garments he put them on while still in the dressing room and began parading himself. As it turned out, very much to his good fortune, the Calypsonian Brigo who was due to perform next was not yet ready to appear on stage, so Eric was called in his place. Eric explained that the public's response was overwhelming and he was called back to the stage five times. This level of acceptance and popularity heightened his awareness that he would go far with his song that year.

Eric said he did not belong to any formalised religion, but was a great lover of justice. When asked, he went on to say that although he won the crown as the 1992 Young King, he had never won the crown for the Senior Monarch Competition. He stated that his spiritual awakening helped him to accept the circumstances around his level of achievements as a Calypsonian. In áccepting his level of achievement, he asserted that many factors, some political and outside his control, come together in the crowning of a Calypso Monarch. This was also a view that was expressed by many other Calypsonians to whom I had spoken. He illustrated his point by recalling that in 1998 his potent combination of songs was rejected as an entrance to the semi-finals. It was only Kitchener's intervention that secured him a place in the semi finals, from which he then went on to place fifth in the finals. In our conversation, he expressed dismay at the fact that, from at first being denied a place as one of the 32 semi-finals, he eventually ended up placing in the first five in the championships. He questioned whether that 
Chapter 3 - Calypsonians and Their Lives: Fieldwork in Action

drastic change did not suggest that it was corruption that originally prevented him from being selected for the championships.

Recognising the power of resistance through Calypso, he argued for the legitimacy of the process of using our local art to deal with our situation in the Republic of Trinidad and Tobago. He stated that in his view, Aloes had won the crown on many occasions, but because of political pressures, was not granted it. In a much later interview he expressed the view that: if the UNC was in power this year, Aloes would not be permitted to win when he did.

Phillips: What do you see as the role of the Calypso in society?

Eric: Well the role of Calypso has to be ....... just like the role of music, you see when we talk about the role of Calypso we are being very specific in relation to a particular type of music.

Phillips: My research is specifically about Calypso

Eric: Well the role of Calypso! Dealing in a specific way let us forget the overall role of music: to entertain, to this, to that, and the other, Calypso in particular apart from entertaining, informs particularly in this setting. It makes you aware of things that maybe you won't be aware of otherwise, e.g. if you talk about my interaction with the community, it does help as it influences my composition as I may say things that people wont see in the Express. So it informs across the board. It also has a historic role to play, in the sense that it documents events and eras in our history in a way that volumes of books might not be able to .... You know in a short space of time. You listen to Jean and Dina. You get a clear, clear thing about the war days, the behavioural patterns that existed at the time with the woman and so. So, it has a role to play to document things. 
Chapter 3 - Calypsonians and Their Lives: Fieldwork in Action

It has a role to play to inform people, it has a crucial role to play especially with the problems we experience with AIDS and domestic violence. It enhances or ease learning in getting people to try to behave a certain way. In terms of society it plays a significant role here in terms of gearing them we have the extremes in individuals but there are also the bridges.

Philips: So you don't see yourself as being either one side or the other?

Eric: No, I cannot be.

Phillips: What do you mean "you cannot be"?

Eric: Because my God does not belong to me, you know my God is for everybody and we are his children.

Phillips: Well we are all his children but some of us listen to him more than others.

Eric: Well, well yes that's true.

We then went on to briefly discuss the human/God relationship. What was important though was that Eric expressed the view that Calypsos mirror society and in so doing give society the chance to look at itself. He stated that he felt that this was necessary as: things happened so quickly that many significant things might pass by and we would not really grasp at it. But for the Calypsonian now, something may happen in February and you find that all year he will go on to a lot of other things. But a Calypsonian may have taken the event in February so next Carnival, you have a whole new perspective, you have a stance on it, you know! He agreed that it allowed for reflection.

He explained that he purchased and read the local newspapers of any country he visits in order to acquaint himself with the local issues. He also researched the internet for 
Chapter 3 - Calypsonians and Their Lives: Fieldwork in Action

information on local situations well before he arrived in a country. Arguing that this process always makes his lyrics current, he said that it gave him a cut above the rest making his lyrics relevant to the local situation.

Eric: Referring to the original point of Calypso assisting with conflict resolution that is good you know, cause it has that component as well

Phillips: I see the mediator as being impartial and neutral, and that is what I see the Calypsonian doing as well. And it is also drawing the attention of the people to the issues. I mean the people who are in dispute.

Eric: Well it could mediate between different points of view, it could mediate between different personalities, for example deceased Lord Pretender had a song dealing with two views, whether to stay married or to stay a bachelor and he started his song by saying:

Big argument round the savannah

Between a married man and a bachelor

The married man say you don't know what you missing

repeat

Eric: He put all the point of the married man then he come back and say the other view, you know. So he deal with conflicting views in a Calypso

Phillips: Yes, yes both sides in the.....

Eric: A mediator's strategy as well

Phillips: Exactly

Eric: Then you come with your last verse and you conclude.

Phillips: Exactly, Exactly, Exactly. Remember the song with Steel Beam? Sparrow sang that .........

Eric: yes, yes "We like it so" 
Chapter 3 - Calypsonians and Their Lives: Fieldwork in Action

Phillips: Different points of view.

Eric: Sparrow sung that, a classic man!

He agreed that Calypso and carnival are opportunities for the people to express

themselves, to vent their feelings and their frustrations. He also acknowledged that he used humour in his delivery as a way of getting people out of their positions, to bring them to a point of commonality, getting them to laugh or to smile. He agreed that Calypso really had that feature. He contended that his Calypso, Ocha Dance was a classic example of the use of humour to get a serious message across. 


\section{Denyse Plummer - Sobriquet: Denyse Plummer}

Denyse was the first female Calypsonian to ever win the Young King competition. She made her debut in the Calypso world in 1986, making it to the Calypso Monarch finals in 1988, 1989,1991 , but it was not until 2001 that she took home the coveted title for the first time. On stage, she is always a burst of energy putting her all into her performances.

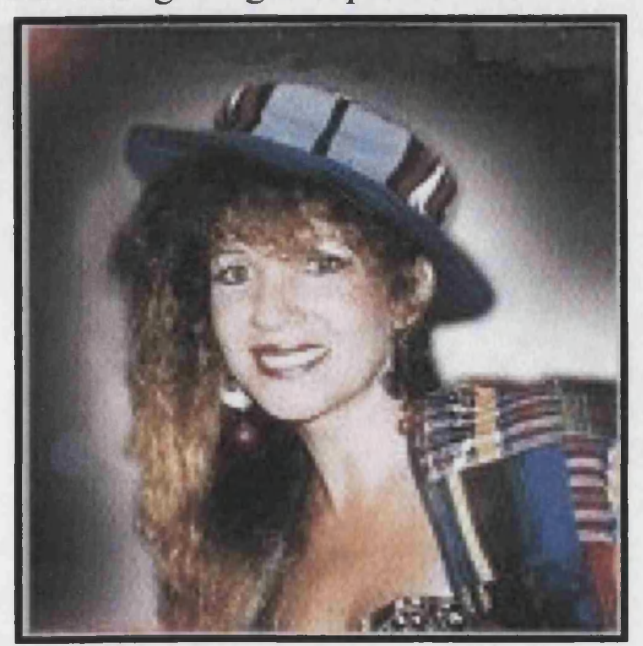

Figure 3.8 - Denyse Plummer

Denyse is the only female Calypsonian of

European descent in Trinidad, however she is not the only Calypsonian of European decent as she is also accompanied in that sphere by Calypsonians: "Soca Elvis" and "The Mighty Trini". She was born in 1954 in Trinidad and has had all of her education on the island, with her secondary education obtained in the prestigious Holy Name Convent. She is married, and a mother of two children, a boy who is 16 yrs and a daughter of 7 yrs old.

Denyse started as a classical singer in school, performing in all the music festivals and the junior school competitions. After leaving school, recognising that classical singing was not popular in Trinidad, so that neither was it going to be a money earner, nor was it leading to popularity or fame, she branched off into pop music, some reggae, disco and ballads. She later started working as a resident singer at the "Chaconia Inn Hotel" in Trinidad, becoming their resident singer for 16 years. At this time she sang country and western music, ballads, pop music and a little reggae. She recalled that at one point she 
Chapter 3 - Calypsonians and Their Lives: Fieldwork in Action

invited the pianist and leader of Phase II steelband, Len Boogsie Sharp, to be a guest performer. Boogsie was very popular with the audience. He later asked her to vocalise the Calypso he had written for his steelband at the forthcoming 1986 Carnival celebrations. This was a change from the traditional male singers. After some reluctance, she agreed. The songs were "Pan Progress" and "One Love". As a result, of her rendition the band which traditionally had placed around $8^{\text {th }}$, sky- rocketed to $2^{\text {nd }}$ and with that ascent, also went Denyse's popularity as that year (her first year of entering the competition) she placed among the top 25 semi-finalists out of the 250 Calypsonians to enter the Calypso Monarch Competition. She said that, on this occasion, she found herself singing to an unappreciative Skinner Park audience, who were not quite ready to accept the first white female Calypsonian in the history of the island. Some members of the audience demonstrated their opinions of and attitudes towards her by hurling oranges, cans, umbrellas and rolls of unused toilet paper at her, while she sang on stage.

Phillips: What did you sing then?

Denyse: "One Love", which was a song about the whole nation and its various cultures living in harmony with each other. There I was singing this and I was being stoned. Phillips: How did you feel then?

Denyse: It was horrible. It was an awful feeling, and I had to do two songs and when I was finished the Pan song, I had to go into that one, so I had to brace myself. You know every year people go to that competition and if the audience doesn't like them they will pelt them, and they would leave the stage before their song is over. They would just get off the stage and never come back. I was so mad and angry that the reason that they 
Chapter 3 - Calypsonians and Their Lives: Fieldwork in Action

were pelting me had nothing to do with the fact that the song was crap, or that I was sounding bad but just to do with my heritage. I was so angry that I stayed on that stage deliberately, and I smiled right through both songs and I picked up every missile they sent to me and I turned it into choreography, playing with it, as I finished my two songs. They couldn't believe it.

Phillips: So you won their hearts?

Denyse: I refuse to give them that satisfaction!

Phillips: Was that a turning point for you?

Denyse: After that year the following year they made me their queen, their Calypso Queen. But it was horrible; I would not wish it on a dog. But the respect that I gained after that and the support. They wrote hundreds of letters in the newspapers after that incident, supporting me, saying how much guts I had, how strong I was to deal with that. Ifelt that God gave me the inspiration to deal with the situation

She went on to say that she very much saw God as her inspiration for the work she does as a Calypsonian.

Denyse: I have 11 Calypso queen titles, the Young King title and the Monarch title. Nothing that I did, did I do on my own. There was Someone-else looking out for me and in control and in charge.

Denyse asserted that before any performance she would say a prayer She also informed me that she got guidance and inspiration when writing her material. She acknowledged 
Chapter 3 - Calypsonians and Their Lives: Fieldwork in Action

that she has bought songs from very good song-writers and at times writes her own. She proudly stated that she wrote the words for six of the seven titles that she has held.

In relation to the songs that she has written she stated: I don't know what other song writers write about, but I feel very strongly about a point that I want to make, something that I want to change, something that is not right. You know! Whether it be children and what they are going through, or my island is so beautiful and we take it for granted. I need to feel strongly about a point I make and then it goes from there.

Phillips: If you look at categories you will see that there are lots of different categories that people sing in. One of these is Social and Political Commentary.

Denyse: That's what I am best at, that's what I am best at!

Phillips: What is your most popular social and political commentary Calypso?

Denyse: Well I think that "Heroes" and a song that I wrote "Together Right Here" are two .... The songs that give me the most feeling. Heroes is a commentary on the lives of our Calypsonians that they are the most famous people in our land and as they get older they are down-trodden and not treated with either the respect or the care that they deserve. Why can't they die with dignity, why can't they live out their old, their aged years in comfort and respect and knowing that they are loved and respected for all that they have done for our country. Look at Ras Shorty I; look at Pretender, Look at Kitchener. Where are their honours? Where is their glory?

She went on to assert that: Sparrow had received many awards since my song "Heroes" came out and is still continuing to receive awards. However she lamented: But why 
Chapter 3 - Calypsonians and Their Lives: Fieldwork in Action

only Sparrow and why so late? They do not value us. Look at all the old Calypsonians and how they are not treated. It is that, that inspired me to do the Heroes song:

Always wait till we heroes dead

To put a crown on their head

During the various times I spent talking with Denyse, she alluded to a view that there are a number of aspects to Carnival and that each aspect has its own variety of problems. She said:

The Calypsonians have endless grievances, things that the people haven't a clue about. All they see is the Calypsonian on that stage giving 100\%, giving a grand performance and they have no idea what we go through to enable that to happen.

She said that Calypsonians often feel that they were not treated appropriately by the institution. In support of this assertion, she sited a time during the prize giving ceremony for one Calypso season, at the turn of this century, when the Calypsonians turned up to the prize giving ceremony, to be presented with a trophy and an envelope that has no money in it. She recalled that on that occasion she was meant to have got $\$ 100,000$ TT but left with only $\$ 20,000 T$ T and a promissory note for the rest. She stated that she found this very disrespectful.

She said that most of the artists annually invest between $\$ 20$ or $\$ 30$ thousand dollars for their presentations and identified the conflict in how they felt when they were let down so badly by not being given their prize money on time when they in turn had their financial commitments to meet. She identified that although the first responsibility was with TUCO for not dispensing the cheques ultimately it lay with the Ministry of Culture who are TUCO's paymasters. 
She has won the Calypso Queen show 10 times and the Calypso Monarch once. She describes this latter as a very incredible feeling but recognised that she needed to stabilise herself, and not let it run away with her. She has seen others who having once won the Monarch, allow it to run away with them and not prepare themselves for the following year, by getting good material, consequently they flopped that year.

As part of the recipe for success, she identified the need to release a CD early in the season, so that she could have her song playing on the radio.

When asked if she felt valued in Trinidad as a Calypsonian she said that she did, as this is her base and she considered that if she did not do well in Trinidad, then she would not do well internationally. This was so much the case that in order to get work for the next 12 months she saw the need to be successful at Trinidad Carnival. She identified her need to be treated as a novelty in Trinidad first, before that level of treatment can be propagate outwards to other countries. In support of this, she again identified the Calypso "Heroes" in which she states that, why do people always wait till the heroes dead To put a crown on their head

In terms of the geographic scope for her performances she said that she had performed all over North America, Canada, Europe and the Caribbean islands, She has also performed in London many times as well as in Sweden, Finland and Denmark. On the South America continent she has performed in Guyana and Surinam. She stated that:

When I travel overseas I see myself as an ambassador, and I see myself as selling my culture. When we as Calypsonians are out there it is no longer about you and how fabulous you are, how pretty you are, how wonderful you are. It is about the platform it is about using the platform to make a difference. It is an opportunity to speak publicly and draw attention to the issues. We have been 
given these platforms to talk about battered women, to talk about children who are abused, women who are abused, issues that are problematic that we need to make a difference. Use your voice, now you have a louder voice people are listening, deal with those issues, because the issues we have here, there are Caribbean people all over the world that are going through the same things, whether they are Caribbean people or not they are all going through the same things. What you have to say might make the world of difference. 'Gore! did you hear what Aloes said? Did you hear what Denyse Plummer said?' What comes out of our mouths people take as gospel truth because of who we are. So, use that platform to make a difference

Phillips: So do people come to you afterwards and comment on...............

Denyse: Oh yes! Oh yes! Oh yes! I had a little girl that came to me. Her mother came to me in Washington, she suffers from muscular sclerosis, which is a very painful thing, she was only 18 years old and I was her total inspiration, she said she came to the show in a wheelchair and her mother came to me and said, Denyse Plummer I had to bring my daughter here today' cause you have been her inspiration. When she heard the song "Na Leaving"

Phillips: Yea!

Denyse: she sent her mother out to get that $C D$ because she is a Trinidadian living in Washington, she loves Trinidad, she doesn't want to live out there, she has no other alternative. She dreams about her homeland everyday and she has this terrible disease and she has to go for treatment every week and the treatment is very painful, and when she goes for the treatment she screams to the top of her voice and bawls until the treatment is over because it is so painful. And she went and got the CD "Na leaving" and she put it in her Walkman. Her mother told me from the day she got "Na leaving" she went for her treatment and played "Na leaving" right through the treatment and she never made a sound. She never cried, she never screamed, she never bawled. And now she does not go for her treatments without "Na leaving" 
Chapter 3 - Calypsonians and Their Lives: Fieldwork in Action

Phillips: Very powerful!

Denyse: Do you know what that does to me? Do you know how rewarding that is to me!? That is the most precious prize and gift I could ever receive, knowing what I have done for that child. When she heard we were coming to Washington, she said I am going to be in the front row in that wheelchair.

Phillips: Yes! she had to see you!

Denise: Let me tell you something I cried, my heart broke when I held that little girl in my arms

Phillips: How old was she?

Denyse: 18 years old

Phillips: 18!?

Denyse: She did very well at school and got into a university to study for her BSc. She started university and had to drop out because the illness got too bad. She was so intelligent, you know? And cheerful, if you hear her outlook on what's happening to her. Gives you so much inspiration and we quarrel everyday because we can't get a shoe or we can't get this to eat or we can't go here or .... You know! That's what makes my entire 16 years in this business, in this Calypso business, entirely worthwhile.

Phillips: You have been in Calypso for 16 years!?

Denyse: 16 years this year but I have been in show-business an entertainer ever since I was 18 and I am now 48, you work out the math.... That's what its all about! Phillips: What do you see as the role of Calypso in conflict and bringing that to focus and bring it to their consciousness, to the awareness of people? That's part of what we have been talking about. 
Denyse: That's what it's all about. It's the good that you can do with the gifts that you have received

Phillips: And its giving something back, giving back, isn't it?

Denyse: Yes, giving back!

Phillips: But what do you see as the role of Calypso in conflict and bringing that to focus, bring that to their awareness, to the attention of people? That is part of what we have been talking about, but how central is that? When you sit down to write your songs or when you are given a song to sing are you really, or to what extent are you conscious of $\ldots . .$.

Denyse: You have to believe in what you are singing. It has to be something that you really want to say you know, and a Calypsonian is the voice of the people. Its story telling in the form of music. You are telling a story, that's what Calypso came from. It was called the Chantwell, from the days of slavery when they were not allowed to speak so they had to find a form of communication to say what they wanted to say to each other and to bad-talk the Massa and cures him. So they were allowed to sing. That's all that they were allowed to do. So they conversed in song. So when the Massa thought that they were singing their hymns and their church songs they were really cursing the Massa, mocking them and saying what they wanted to say amongst themselves. So it became like their way of conversing. So that's what Calypso is. It's telling a story in music. The voice of the people, saying what they want to say. Making a point to create changes about an issue

Phillips: I suppose that's where double entendre comes in as well?

Denyse: Yes! That's right

Phillips: Do you subscribe to that in the things that you have to say? 
Chapter 3 - Calypsonians and Their Lives: Fieldwork in Action

Denyse: No! I think the humorous Calypsos tend to do that more and I have not really gotten into humour that much, as yet. I tend to sing party Calypsos and social commentary.

Denyse has shown her commitment to the field of Calypso churning out a combination of party and commentary songs year after year. She continues to excite her audience with her style, charisma and energy. Attending many of her shows as I did, certainly brought me to recognise that when the large numbers of people present at one of her performances dance together, that act in itself is significant, it is meaningful. It is an authentic statement of their commitment of their solidarity and of their pleasure in making those statements.

\section{CONCLUSION}

I have used the richness, the depth, and complexity of these seven Calypsonians as icons that are representative of the work of the wider range of Calypsonians that perform in the Republic of Trinidad and Tobago.

In the light of my interviews with these informants, so far, I consider I am in a position to respond in the affirmative to the research questions: "Does the Calypsonian recognise $\mathrm{him} /$ herself as facilitating the resolution of conflict?" Indeed, as samples of the wider Calypso body, all of the informants have shown intentionality. In these interviews, they have all shown their ability to consciously deal critically and creatively with the reality of the situations that obtain in the Republic of Trinidad and Tobago. In doing so they have acknowledged their reality, while simultaneously helping me to discover how they see themselves participating in the transformation of the country. 
Chapter 3 - Calypsonians and Their Lives: Fieldwork in Action

While this Chapter is the result of interviews which were held primarily with

Calypsonian informants, I am of the view that there are other Calypsonians who, although they were not interviewed, have made a significant contribution to the field of social and political commentary, and therefore needed to be represented, in some way in this work. Thus Appendix 4, looking at the work of Dr Slinger Fransisco and David Rudder, honours that recognition.

It seems sensible now, to try to contextualise the work of the Calypsonian in relation to the wider perspective of the history of conflict occurring in Trinidad and Tobago. 


\section{CHAPTER 4 - CONFLICT IN TRINIDAD: THE WIDER PERSPECTIVE}

Carnival with all its images, indecencies, and curses affirms the people's immortal indestructible character. In the world of Carnival the awareness of the people's immortality is combined with the realization that established authority and truth are relative.

Bakhtin, M., 1968:257 Rabelais and his World

\section{INTRODUCTION}

$\mathrm{G}$ rounded in a view of Calypso as a medium in the resolution of conflict in Trinidad, and aware of the synergistic link between Calypso and Carnival, it is necessary to examine the nature of the conflict that forms the backdrop for this particular work. This Chapter therefore focuses on the institutional expressions of conflict in the following four areas:

1. Stickfighting and Steelbands

2. Canboulay/Carnival

3. Calypso

4. Contemporary expressions of conflict

The nature of this enterprise requires that the approach be cyclic in nature as opposed to linear. This means examining each of these four areas in accordance with the sequence of events occurring within them. This approach inevitably means that at times, in accordance with the chronology for each, times and dates will be discussed then set aside, only to be later revisited in a subsequent section of the work.

In as much as I will be revisiting the circumstances around the development of the conflict under discussion, it is therefore inevitable that I will need to adopt a historical perspective on the events leading up to the various areas of discussion. In view of this, I recognise the need at the outset, to state clearly that, this Chapter is not intended ostensibly to be a historical record of the conflict occurring around any of the events that 
are associated with the development of Trinidad. That information is already eloquently and adequately documented in Cowley (1998), and Liverpool (2001).

The central purpose of this chapter is to shed some light on the range of conflict that historically, has surrounded the various aspects of the Trinidad Carnival. I will be doing this by setting the context for understanding the background conflicts, giving a broader view of the events that have brought Carnival in Trinidad and Tobago to where it is today. In following this course, it is my intention to enable a fuller understanding of their place in the sequence of events, the nature of the development of the society and the conditions therein. Through this approach, it is expected that the reader will be able to get a fuller understanding of the role of the Calypso in helping to resolve conflict in Trinidad and Tobago. I will end this chapter by examining some contemporary issues in conflict as they manifest in the Calypsos today. In this way, this chapter presents a panoramic view of the metamorphosis of conflict in Trinidad.

As stated in the previous Chapter, both Liverpool $(1990,2001)$ and Hill (1997) acknowledged the existence of conflict in Carnival, recognising its existence, while charting its development. I have also previously pointed out that Johnson (1984) observes that in the Caribbean region, Carnival only become important in those countries where there was the dual existence of Roman Catholicism and a significant enslaved African population. The question which needs to be addressed is: why is this so? Stating that Roman Catholicism was the significant religion was synonymous with stating that there was a predominance of Europeans (i.e. the numerical minority) in positions of power.

In those early days in the history of Trinidad, Africans made up the largest proportion of the labouring class. Although the enslaved Africans, as a group, were greater in number, they had no access to the realms of law making, being disenfranchised and disregarded, so that not even their religious beliefs were legitimated. As such, Johnson (1984) delineates that while Brazil has a Carnival, Argentina does not, similarly Haiti 
does but the Dominican Republic does not and Vera Cruz does but not Mexico City. As already stated, this statement of Johnson's is the fulcrum for this work and is central in generating my research questions.

Although I have stated that this is the case in relation to Carnival in Trinidad, resistance of those who feel disempowered and disenfranchised, through a type of Carnival, is not unique to the Caribbean region. This experienced reality of the underprivileged has in various locations around the world, generated expressions of what can be interpreted as 'resistance'. These demonstrations that are particular to the cultural traits of each individual set of people, are frequently regarded locally as a Carnival.

The caption in the shaded box at the head of this chapter epitomises the reality of the disenfranchised and dis-empowered, in that for them In the world of Carnival the awareness of the people's immortality is combined with the realization that established authority and truth are relative, (Bakhtin, 1968:257). This is frequently the view of dispossessed people.

I propose in this chapter to look at this area of conflict in Carnival, tracing the trajectory of direct and implied conflict that is associated with the Trinidad Carnival. In doing so I will look at this conflict from its early days, observing some of the ways in which it has manifested in the Carnival celebrations, as the country transitioned to being the Republic of Trinidad and Tobago that it is today. Although initially I will be looking at the early years, overall, in focusing on the place that conflict has played in Trinidad Carnivals, I am endeavouring to shed light on the evolution of the social and political processes at work in the country.

\section{THE YEARS IN BETWEEN - 1834 TO 1888}

As stated in Chapter 1, although slaves were emancipated in 1834, up until 1838 they then experienced a compulsory period of apprenticeship. This meant that in-effect, it 
was not until 1838 that they had their freedom, (Cowley 1998:33). This event in effect released a new class of over 22,000 free people aligning themselves to the coloureds who were free by racial ancestry.

In the fifty-years between the end of the compulsory period of apprenticeship (i.e. 1838) and the year in which the jubilee of emancipation was celebrated (i.e. 1888), the celebration of Carnival became an arena for much conflict between the land owning class and the working class. Doubtless, this was a major period of transition both on a personal level (i.e. on the part of the ex-slaves and their previous owners) and on an institutional level (i.e. on the part of the governance). During this period, conflict was broadly over labour and social issues and showed up primarily as a dichotomy wherein a plantocracy tried to establish European values and order, on what primarily was a population of African-origin, who had their own intrinsic retained systems that they wished to adhere to. To the African mind-set, now residing in the Diaspora, with no access to the "reins of power", there was a constant struggle to retain much of their traditional customs, against the onslaught of this new enforced European way of life. Moreover, an undercurrent struggle to gain a say in defining and redefining law and justice was being waged in the society. Under such circumstances, festivals such as Carnival have been used to reverse .... the norms of superstructure, (Brereton 1979:166171). In Europe, under a similar set of circumstances, Carnival became a mechanism of “organised" action for those so excluded from the "reins" of privilege and power. However, in relation to Trinidad Carnival, I am suggesting two things, first, that conflict is not necessarily, always violent, but that it can be implicit or subtly expressed in the nature of the masquerade or the Calypso. This can mean that at times, the very nature of the expression, although pleasurable, does not obscure the reality of the protest. Second, it must be said that this does not suggest that every Carnival gives birth to the reality of violent protest, but rather to a degree of "misrule". By using the term misrule I am identifying with Natalie Zemon Davis' concept as depicted in her study of religious and social discontent at Lyon, of poor relief, humanism and heresy of the role of women in religious change of 'youth groups' and Carnivals and festivals of 
Chapter 4-Conflict in Trinidad: The Wider Perspective

ritual violence, printing and popular beliefs as expressed in the use of proverbs. (Davis 1977:80).

Essentially, Davis argues that these types of Carnival festivals serve a function that exceeds that of just being a mere safety valve, deflelcting attention from social reality. She contends, that on the one hand, festivals may support and perpetuate certain community values, while on the other hand, they can serve to criticize political order. This process is both circumscribed and underwritten by conflict, a veiw which in relation to Trinidad, I very much agree.

\section{SOCIAL StRATIFICATION IN PRE-EMANCIPATION TRINIDAD}

Europeans were the first people to migrate to the Caribbean. They in turn brought large numbers of captive Africans to the island as enslaved workers. From the outset of immigration, the groups that came to live on the island were socially stratified into an upper white, land and slave owning class and a lower black slave, working class. Such was the social stratification in Trinidad.

Despite this social stratification there was cross-strata sexual activity as evidenced by the birth of children who were mixed of European and African parentage. This gave rise to a new recognisable social group of "Coloured" people who eventually came to be recognised as a middle-class (Powrie 1956:224). By way of description, this group was frequently referred to as "the Coloured Middle-Class". This combination of words was unique to the situation in Trinidad and a by-product of the stratification of the population on the island at the time..In identifying the complexity of the structure of the population, Powrie tells us that there was not a simple horizontal stratification of the population into upper, middle and lower strata across the whole society. Rather the society consisted of a layers of self-contained social hierarchies simultaneously existing 
in parallel with each other, with each strata having its own sub-strata of upper, middle and lower class.

Broadly speaking, these hierarchies are one of two types: the first, and it is applicable to one large segment only, is based on colour, this is the whitecoloured-black structure; this second is of a purely ethnic type, and contains such segments as the East Indians, Chinese, Portuguese, and Syrians. The coloured group contains a tiny proportion of persons whose ancestry is further complicated by occasional marriages with individuals from the ethnic structures.

(Powrie 1956:225)

In 1797, the population of Trinidad consisted of a tapestry of assorted people. These varied groups were each considered to have their own needs and the maintenance of the status quo required that the administration put into place appropriate laws to sustain the structure of the population. In 1797 this population was made up as follows:

$\begin{array}{lllll} & \text { White } & \text { Coloured } & \text { Slave } & \text { Indian } \\ \text { Spanish } & 150 & 200 & 300 & 1,127 \\ \text { French } & 2,250 & 4,700 & 9,700 & \end{array}$

Such was the intent of the Governors that laws were passed to enforce the stratification within the society. These laws made provisions to sustain the exclusive position of the white elite, excluding the free coloured from the social and political privileges of this group. Hence, some of the steps that were implemented with the intention of sustaining the division within the society and limiting the ability of the coloured middle-class to enter the upper class were: First, they prohibited a coloured person from obtaining a commission in the military. Second, they made provisions that only coloureds were entitled to become police officers, i.e. the office of Alguacil. these officers were revered by slaves and despised by white. Third, a discriminatory regulation known as the "Fandango Licence", was passed making it necessary for any free coloured proprietor wishing to give a dance party in the night to first obtain permission to do so from the Commandant of the Quarter, they were simultaneously forbidden under penalty of a fine of $\$ 25$ to admit any slave to the party, (Pearse 1956:178). 
From the year 1797 to the time of the emancipation of slaves in 1834, Fraser (1881) informs us that the type of Carnival that was developed by the French and adopted by the British was seen as an exclusive social institution for whites and free coloureds. That is to say, black slaves were excluded. The restrictions on the slaves were such that they were only allowed to hold dances at approved places and under no circumstances were they to go later than 8 p.m., (Hill 1997:33).

Quite by contrast, Wood alludes to the fact that while Europeans experienced no restrictions and could hold balls at their discretion, free coloureds had to pay a tax of $\$ 16.00$ in order to get the permission to hold similar, (Wood 1968:41).

Clearly, the authorities showed a different type of regard to the various sectors of the population. It is to be surmised that this difference caused great resentment from the numerically superior Africans, who were not so favourably considered.

\section{Stickfighting, SteELbAND AND CONFLict}

The hardwood stick or staff (the poui, gasparee, balata, anare, called after a tree of these names (Hill 1997:25) was an essential part of the paraphernalia necessarily in use by the African. Initially this stick was carried by the African slaves for use as a protection against snakes and other animals. It was also intended for use as an aid when cutting cane. The stick later became a standard part of the dress code of the Africans and was used on occasions such as holidays.

With time, the function of the stick evolved and it began having a place as a weapon, being used in violent quarrels. In an 1810 Cabildo, the carrying of the stick was banned for both free and enslaved Africans. The provision laid down that transgressors who 
were slaves would be imprisonment for one month, while, free person would receive twenty-five lashes for the violation of this Cabildo.

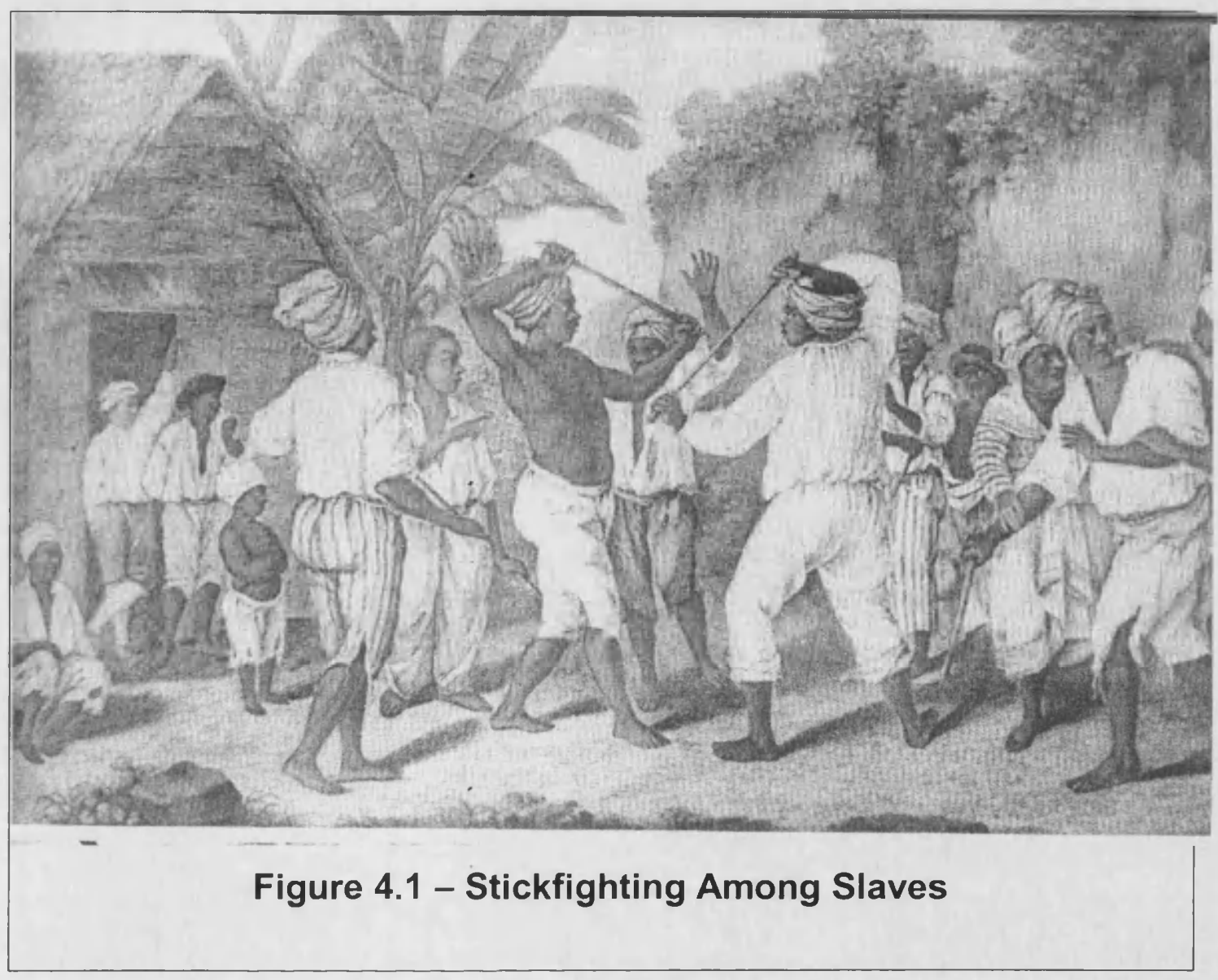

One of the by-products of various communities of slaves coexisting, while simultaneously enduring the difficulties of plantation life was the development of a type of comradeship or brotherhood among slaves who belonged to the same plantation. This gave way to the development of a friendly rivalry among the various estates. In turn, the planters built on this rivalry, encouraging competitions between their various estates, including a challenge to establish an overall Stickfighting champion. This intercommunity competitivness, emerging as it did from inter-plantation sport, sewed the seeds for the active inter-band conflict that followed several years later. 


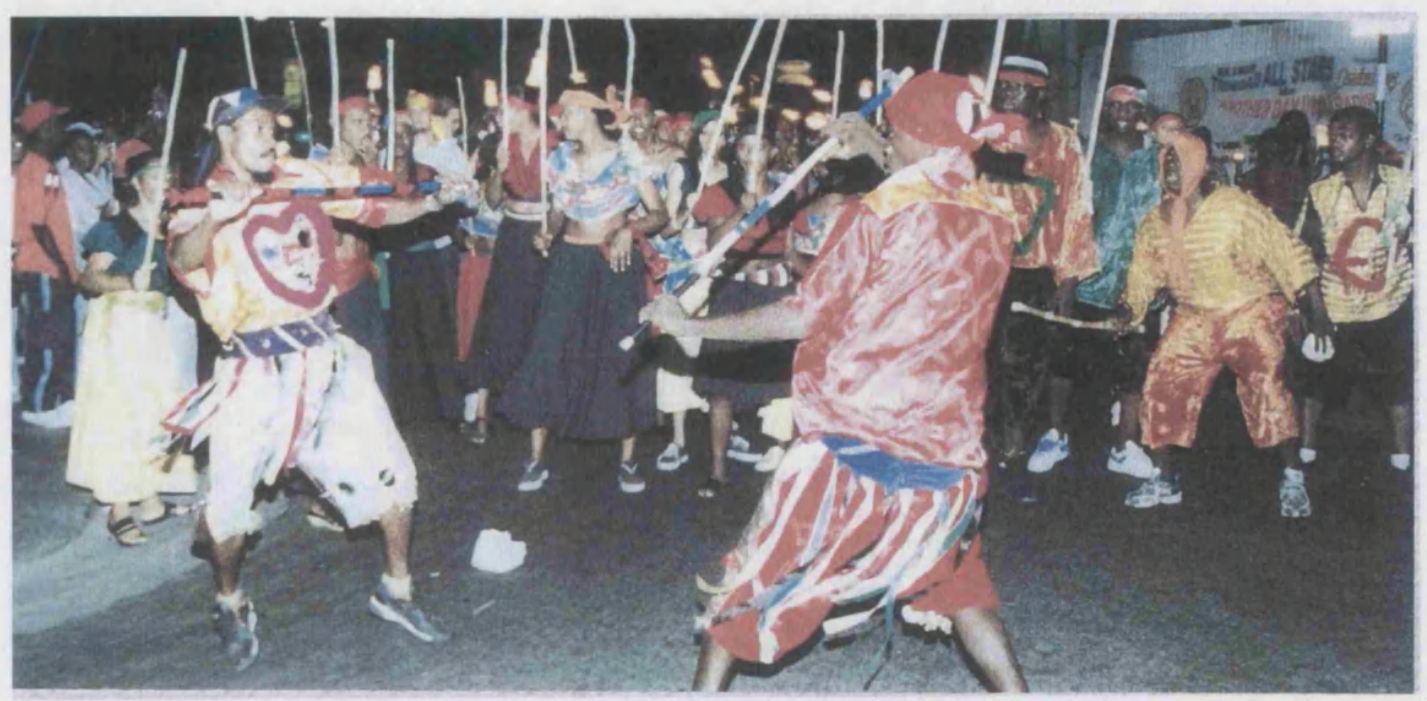

Figure 4.2 - Stickfighting Today, Used as a Tourist Attraction

The advent of the 1834 Emancipation of slaves allowed freed Africans to develop their own settlements. Naturally, those coming from the same plantations were most familiar with each other and chose to settle in the same enclave. In those early days in Trinidad, there was no infrastructure enabling effective communication among the various settled groups. Hence, there was very little social communication between the different groups as they developed independently, with each enclave becoming insular, retaining only some aspects of their former rivalry.

Each settlement had its own music band with the instruments made from pieces of bamboo each cut to a different length. When each piece of bamboo was struck, it resonated with a note from a different part of the musical scale. Hence, when they were all struck in a particular sequence they would produce a musical melody. This gave rise to the Tamboo Bamboo which was, a forerunner to the Steelband. 
Chapter 4-Conflict in Trinidad: The Wider Perspective

Another forerunner and still at times used today was the "Bottle and Spoon" band. Having had personal experience of these, when played appropriately, I can vouch for their melody, rhythm and harmony. In this arrangement, bottles of different sizes are used to produce different notes. When combined they produce the appropriate melody.

During times of conflict, this range of musical instrumentation frequently doubled as weapons. It was not uncommon therefore for what started as a friendly Stickfighting contest to, at times, degenerate into an affray, with these instruments being transposed into lethal weapons. As the musical forms metamorphosed into the steelband, the steel bandsmen also imported their already engrained mental attitude towards violent conflict. It is true to say that this attitude did not exist in isolation. The impact of slavery had undoubtedly left its mental mark, as well as, for some, physical marks. The trauma of the experience inevitably carried with it, its own associated stresses. These latent stresses brought an accompanying level of volatility, which when vented, at times erupted as an expression of anger and aggression. It is clear that Trinidad was in revolutionary transition. Transitions by their very nature are unstable, instability yields uncertainty, giving rise to insecurity, which in turn can manifest as acts of violence. Hence the period of transition of the steelband, from its earliest days saw considerable violence.

In this section I use the terms 'steelpan' and 'pan' interchangeably. Indeed each individual steelpan that comprises a steel orchestra is made from the discarded steel drums that were used to transport oil. The steelpan is a unique revolutionary musical instrument, having the distinction of being the only acoustic musical instrument to have been created in the $20^{\text {th }}$ Century, (Blake 1995). As already stated the development of 
Chapter 4-Conflict in Trinidad: The Wider Perspective

the steelband inevitable brought with it the conflict that was a part of its revolutionary developmental years. Up until the 60's this conflict would degenerate into levels of violence among rival steelbands as they vied for supremacy in the field.

In Chapter 1, I discussed the origins of Trinidad's heavy social stratification. One effect of this was that those having lighter complexions, invariably occupied the higher echelons of work and society, while those with darker complexion were less privileged, occupying the lowest levels. The aspirations of social mobility required that individuals strove to gain a place in the upper echelons. Inevitably, in those early days, steelbands men came from the lower levels and accordingly, were regarded by the society as lowclass. Furthermore, some of the steelbands came from a notorious parts of Port of Spain called Laventille, and an area known as "behind the bridge"10. Today Laventille is still seen as an area that many Trinidadians would not comfortably venture into.

From the forgoing, it can be appreciated that during the early days of the steelband movement, upward aspiring Trinidadian did not associate with steelbands men. During my years as a child growing up in Trinidad, I recall seeing many incidents of steelbands men being victimised by police officers as the men shuffled through the streets on festive occasions with their 'pans'. These occasions inevitably ended in clashes with the Police. Those who were arrested received heavy fines, so much so that in 1968

Calypsonian "Young Creole" sang:

They does call you thief and rab ...

When you come from Laventille

They don't care if you have a $B$. A. or Ph. D.

You see my friend, you in the dregs of society .....

\footnotetext{
${ }^{10}$ I have in other parts of this work referred to the Calypso "For whom the Bells Toll" which is the very powerful Calypso about Laventille that Singing Sandra sang to win the 2003 Calypso Mornarch competition.
} 
Chapter 4-Conflict in Trinidad: The Wider Perspective

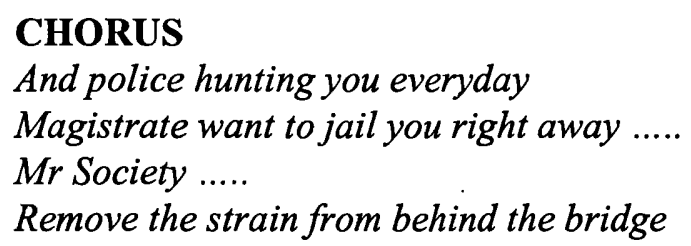

From its inception to the early seventies, the life of the steel bandsman or his supporter was not an easy one and constant pressure was being applied to individuals who were involved in the steelband movement to desist from that activity.

In the main these approaches by the authorities were counter-productive and the authorities who propagated these attitudes failed to realise the specific set of circumstances pertaining to these dispossessed men. They seemed unable to grasp the reality of these men's lives and their struggle to be respected in a culture that despised their art-form. It was among such rejection that steelbands men frequently resorted to fighting both with police officers to retain their culture, and with the men from other bands, to establish and/or maintain their self-respect. In 1950, Canon Farquhar defended the panmen's predicament thus:

Educationally they have been denied everything beyond a smattering of the three $R$ 's. Vocationally they are condemned to conditions in which home life, as understood by their critics, does not exist. In the matter of religion they have been literally abandoned to their own resources. They are normally shunned as the unwanted and undesirable subjected to taunts and reproaches. Thus ostracised and estranged from the circumstances and the people who alone could help them, they are driven out like lepers of old into the wilderness and waste places of the society. Instead of surrendering to sullen despair or violent retribution, they turn to the escapism of music and roam our streets, the gay troubadours of race who traditionally, in the face of adversity have found relief in dancing and song.

Canon Farquhar (1950)

During the late 40 's and early 50's, steelbands really rose to prominence and began coming into their own after the Second World War. The impact of the violence of that war left its legacy on the names that many of the bands chose for themselves. Names like Invaders, Red Army, Renegades, Desperadoes and Tokyo all convey a specific 
image, the latter being the name of a US Battleship. The violence that was an inherent part of this war was frequently crystallised not just by the names the bands adopted, but by their portrayals of aspects of the war, such as soldiers, tanks or even sailors on shore leave.

The 1950 's and the early 60 's saw some of the worst conflicts ever, in the history of the steelband movement. Following a severe clash in the 50's which occurred in central Port of Spain, between Invaders and Tokyo, Lord Blakie sang:

\author{
It was a bacchanal, Tuesday Carnival \\ Fight for so, with Invaders and Tokyo \\ And when the two bands clash - Mamayo \\ If you see cutlass \\ Never me again to jump up in a steelband in Port of Spain \\ Invaders beating sweet \\ Coming down Park street \\ Tokyo coming down beating very slow \\ And friends, when the two bands clash, mamayo \\ If you see cutlass \\ Never me again to jump in a steelband in Port of Spain \\ Bottle start pelting, if you see sledge passing \\ Husband and wife, well they start running for they life \\ An Indian man selling bread shout out \\ Lord, today ah dead! \\ Never me again to jump up in a steelband in Port of Spain
}

Carnival 1959 saw a very severe and violent conflict between "San Juan All Stars" and

"Desperadoes". This was reputed to be one of the worst clashes in steelband history.

This clash took place in Charlotte Street, Port of Spain, in the vicinity of what was then called, the Royal Hospital. In this conflict, "San Juan All Stars" were proceeding up Charlotte Street to one of the band's judging point at the Queen's Park Savannah (QPH). Their carnival portrayed for this year was "Battle Cry". This required of them that they were appropriately dressed in military uniforms. Usually, the bands queued, proceeding in an orderly fashion, one behind the other. From my recollection, there 
Chapter 4-Conflict in Trinidad: The Wider Perspective

were reports that "San Juan All Stars" were queue jumping, running through all the bands they met on the way, rather than waiting their turn. Eventually they got to the place where they were trapped between two bands that had reputations for being among the more aggressive bands around at the time, these being "Desperadoes" who were portraying "Noah's Ark" and "Tokyo". This surge by "All Stars" sparked a sudden eruption of violence. A hail of sticks, stones and bottles were directed to "San Juan All Stars". At times, depending on what is being portrayed, the bands would carry in their hands paraphernalia appropriate to their masquerade. For instance, portrayals of Native Americans would carry in their hands, tomahawks made of wood. On this occasion it was soon realised that the sabres that were being carried by the masqueraders were in fact real cutlasses (i.e. machetes) that had been appropriately painted to support the idea that they were made from wood. The occasion was a carnage. In response to these events, the Calypsonian Lord Kitchener subsequently released "The Road" in an effort to remind all masqueraders of the inappropriateness of their action:

\section{Chorus}

The road make to walk on Carnival day

Constable ah don't want to talk but ah have to say

Any steelband man only venture to stop this band

It's a long funeral from the Royal Hospital

Ah hear how they planning for Carnival coming (repeat)

They say they go beat people and how they don't care about trouble

But tell them, don't worry with me

Is a different thing 1963 .... because

Repeat chorus here

I got information about the situation

They tell me Tokyo is a danger with Desperadoes

They even call Sun Valley.

Trinidad All Stars and Tripoli

They could play they mas'

As long as they don't tackle me when they pass .... Because

\section{Repeat chorus here}


1956 saw the start of the period during which steelbands sought financial sponsorship, with Pan Am North Stars being one of the first bands to be so sponsored.

The advent of this sponsorship required of the band that they integrated their name with that of the sponsor. Since sponsors did not want to be associated with violence, also since the sponsors controlled the financial purse, this enabled them to lay down their criteria by which they wanted the bands to conduct themselves. Consequently in order to maintain, what for them was a lucrative sponsorship, the bands were required to desist from aggressive conflict.

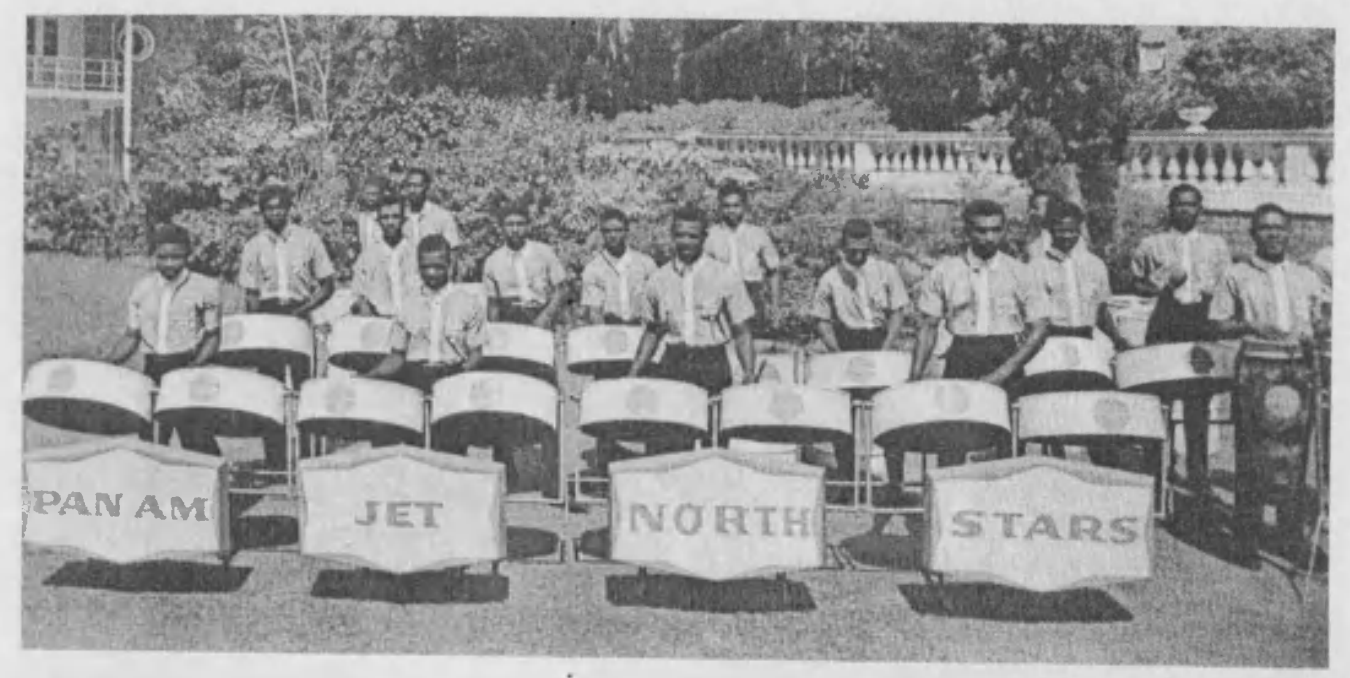

Figure 4.3 Pan Am North Stars Steel Orchestra

Today, bands rarely function without sponsorship and the accordingly, in relation to this type of inter-band rivalry, Carnivals are much more peaceful.

This history underwrites a perspective of the event of the current annual Panorama Competition. This is the competition that determines the band that gives the best 
rendition of a chosen Calypso from any given year's crop of Calypsos. The finals of this competition takes place annually on the stage of the Queens Park Savannah. What has emerged is that this Panorama competition seems to have become a conduit, allowing for marshalling, channelled and refocusing of the energies of the steelbands men, which years ago, manifested as street violence.

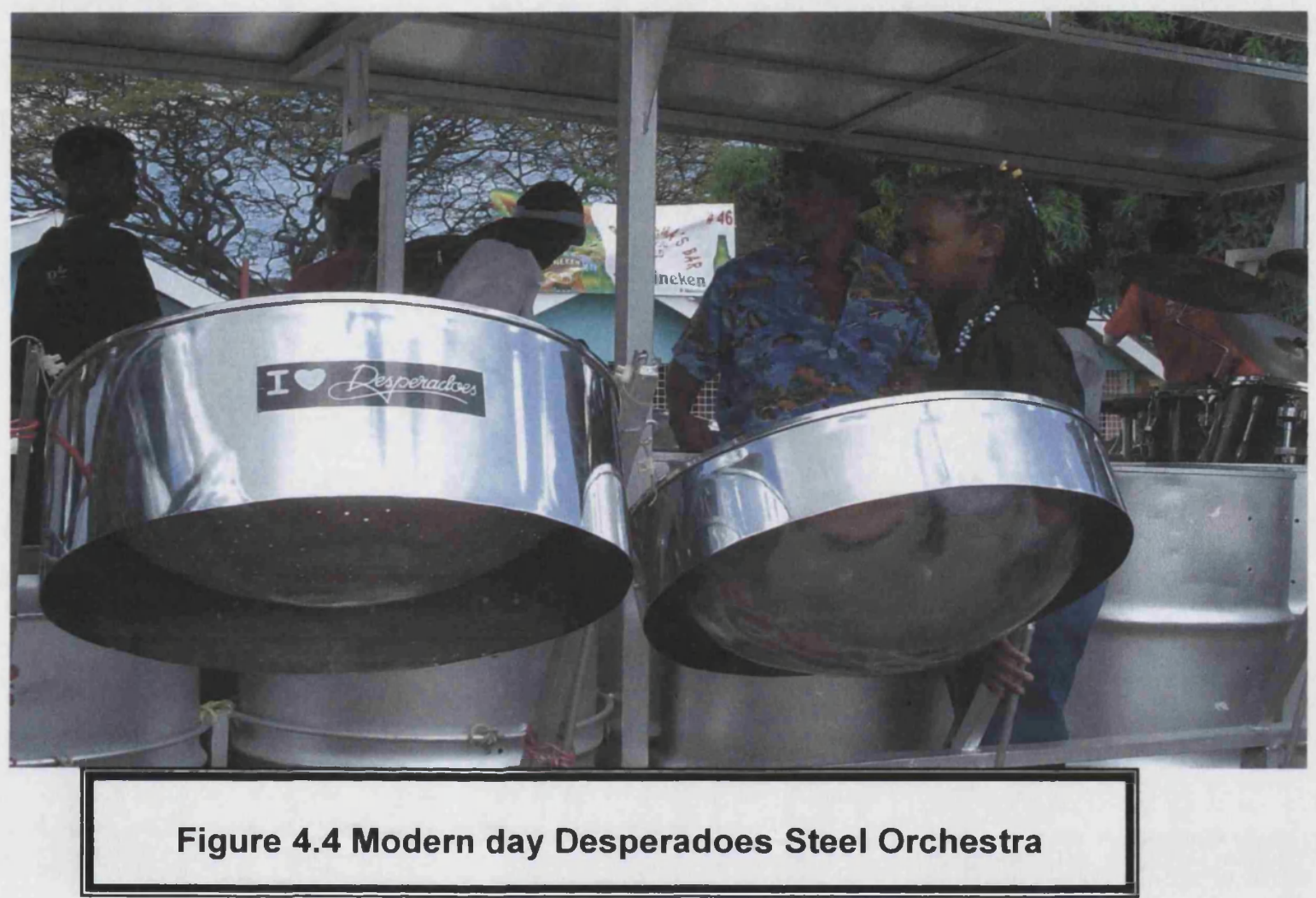

Today, the landscape has totally changed and the experience of Carnival is very different with bands like Desperados becoming household names. In commemoration of this transition Lord Brynner sang:

Not so long ago man, they used to call it "outcast" But we all live, to see it succeed at last Ah talking about the steelband music from Trinidad Started with some oil drum down in a back yard Ah win a bet with one Mr Birch Ah tell him that pan will play one day in church

Who ever taught that the day will come When you would go to church and hear steeldrum? But tell me who ever taught that the day will reach When steelband music will play while the reverend preach? 
Now let us all say Amen .

Amen, Amen to all de panmen

But tell me who ever thought we would see the day

When steelband music would play while the reverend pray?

"Pan in Church" by Kade Simon, Sobriquet: Lord Brynner

\section{Camboulay and Carnival: The Years of Revolt}

The 1834 emancipation of the enslaved Africans saw many changes in the Carnival celebration, not the least of these was the freedom of these free Africans to take to the streets during the Carnival celebrations. This open expression of the African's newfound freedom itself generated changes in the way Carnival was reported.

In the period after emancipation, ex-slaves exercised their right to dance, this was greeted with resentment by the European population on the island who had now ostensibly, withdrew from Carnival, and in many ways, began opposing it, even trying to stop the carnival celebrations, (Frazer C.O. 295 1881). Pearse (1956:183) tells that as far back as 1833, the Assistant Chief of Police, a Mr Peake, being concerned about what he regarded as desecration of the Sabbath day, arrested and charged two persons for wearing masks. Following the 1838 Carnival, the "Port-of-Spain Gazette" reporting on the Canboulay referred to it as a wretched buffoonery [tending] to brutalise the faculty of the lower order of our population. At regular intervals during the remainder of the century, in an effort to bring Carnival to an end, the "Gazette" featured numerous unfavourable reports on the masked Carnival bands. For example; in 1857, Carnival was reported to be an annual abomination and in 1864 it described Carnival as an orgy indulged in by the dissolute of the town.

The Carnival festival in Trinidad offered the labouring population one of their main opportunities for rest and relaxation. Accordingly, they in turn appropriately defended their festival, despite the constant threat of significant police violence. During the 
1800 's there were numerous efforts to attenuate the festival. For instance, in 1846, the practice of street masking was banned by Governor McLeod through an order made by the Colonial Secretary.

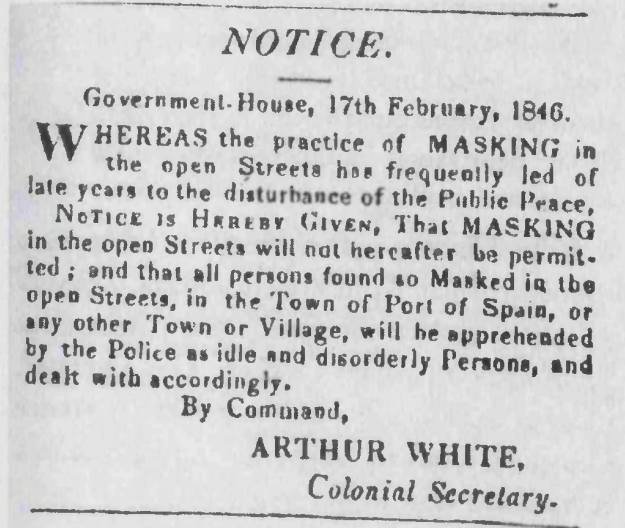

\section{Figure 4.5 - The 1846 notice prohibiting masking}

It was reported that this ban was the consequence of the occurrence of a number of cases of arson, as well as of crimes that were allegedly carried out by persons acting under pretence of masking. However, the African population saw it as the first attempt at retaining masking as a privileged affair for exclusive use by the elite within their ballrooms.

In trying to enforce the ban during the carnival of 1852 , Governor Robert Keate found very few maskers and instead, decided to prey on those in fancy dress, having them arrested.

In the mid nineteenth century, various demands arose from a dominant town group, for the abolition of carnival. Calls for a complete ban on carnival were frequently voiced: None but the vilest of the vile ... now think of appearing in public streets to play mask, why not forbid it altogether? asked $A$ friend to mirth but enemy of folly, in the "Port of Spain Gazette" of January 1856. 
Chapter 4 - Conflict in Trinidad: The Wider Perspective

In 1858 Governor Robert Keate again attempted to stop the practice of masking by trying to enforce this ban. By the Carnival of 1859 , Keates tried to escalate his antiCarnival move, attempting to suppress Carnival itself, having the police confiscate a canoe on wheels and destroyed canopies, (Wood 1968:246). These actions resulted in the would-be Carnivaliers forming themselves into a mob to defend their right to their festivity. As a result of the ferocious response, Keate decided to withdraw his attention from the festivity. His hope was that the festivity would die a natural death, (Wood 1986). It appears that since fewer Europeans were joining the street festivities, this was interpreted by the authorities as a show that Carnival itself was in decline. As a consequence, there followed a period of reduced activity in relation to the suppression of Carnival.

In the January of 1860 , it was rumoured that Governor Keate was planning to place a complete ban on Carnival. The knowledge that Keate himself was well known for indulging in his own enjoyments, was considered evidence of his double standards. In turn this generated increased resentment from the revellers and the authorities decided that they did not want to risk using such a drastic approach. In an article in the “Trinidad Free Press" dated 22 February 1860, it was argued that the better approach would be to let Carnival die naturally. Ultimately the government decided not to stop the 1860 carnival. The authorities were disappointed that their strategy did not work for carnival refused to die as had been hoped. The annual adverse reporting in "Port-ofSpain Gazette" was unrelenting. In 1863, it was described as a licensed exhibition of wild excesses.

In 1874 it was described as a diabolical festival, in 1876, "The Gazette" vehemently expresses its anger about the continuance of the Carnival thus: The thing which the majority of the lower classes here goes under the name of masquerading, acquires new strength and fresh vitality every year that it is tolerated. In 1884 it was reported in the newspapers as a fruitful source of demoralization throughout the whole country. 
In parallel with these goings-on, the 1860 s saw the introduction of an innovative aspect of the African tradition, where caricatures of prominent men enacted contemporary events as a type of mimicry that was sometimes accompanied by song. This tradition though modified, continues through to today in the J'Ouvert ${ }^{11}$ celebration.

In its continued case against the existence of Carnival, two major Ordinances were issued in 1868. Ordnance No 6 provided that Carnival would be limited to three days. It determined that:

every person appearing masked or otherwise disguised, except on such lines as in conformity with such regulations as may, from time to time, be allowed by public notice from the Chief. Officer of the Police, shall forfeit any sum not exceeding five pounds for each offence, or shall be imprisoned with or without hard labour for any term not exceeding one month

(Ordinance No 6 1868)

The second Ordinance of 1868, was in response to the plantocracy's fear that the workers would burn the town down. This Ordinance forbad the Canboulay tradition of carrying lighted torches which were considered a public nuisance. Despite this, Canboulay procession continued to see hundreds of people carry light torches, while parading through the streets of Port-of-Spain.

In 1874 "The Gazette" called for the enactment of a Vagrancy Laws And A Reformatory School. It claimed that the Government has allowed the situation to deteriorate so far that the present order of things does not permit our mothers, wives and sisters to walk the streets and promenades without having their senses shocked by sights and sounds in the fullest sense of the word disgusting.

\footnotetext{
${ }^{11}$ J'Ouvert is celebrated at the break of day on the Monday morning of carnival. Legend has it that the name is derived from a folktale about a vampire woman (a soucouyant) who after shedding her skin before transforming and flying away could not re-enter her skin which had been doused with salt. As day broke she lamented: "jouvay, jou paka ouvay?" i.e. daybreak oh no daybreak?
} 
By 1875 the then Inspector of Police, Mr Fraser, in perceiving a threat to public order from the bands of masqueraders, proposed that the Habitual Criminals Act should apply to persons found guilty of offences and belonging to bands of what he regarded as fruitful sources of immorality and crime (Royal Gazette $15^{\text {th }}$ June 1875).

The above evidences some of the stringent laws enacted that were designed to keep the freed slaves in their place.

The freed slaves saw these laws as mechanisms designed to order their society, consequently they contested them very severely. Trotman's (1986) study of crime in Trinidad showed how the Colonial regimes used the expediently established law as a tool to label some actions of the lower class as "criminal", despite the fact that they were in reality, their legitimate entitlements. McLewin (1987) sees these occurrences in Trinidad as mirroring those of the post slavery days of both Jamaica and Guyana. He recognised that the situation that the working class in Trinidad now found themselves in, was that they were still not equal with the whites and instead of having free and equal access to the judicial system they were now finding that they were victims of it. McLewin found that post emancipation, many overseers were being appointed to posts as local magistrates. This meant that in effect, there was a "transfer of the whip from the field to the courtroom" (McLewin, 1987:87-88).

In 1877 Captain Baker took command of the police force and replaced the more tolerant Lionel Mordaunt Fraser. Baker immediately began displayed toughness towards the revellers.

By 1878 it was clear that instead of dying down, Carnival was showing increased verve. As a consequence, further anti-Carnival attempts were launched and there were severe controls in place for the 1878 and 1879 Carnivals. It was obvious that the elites had lost control of Carnival and resented this change. By 1880 there was an attempt by the 
elite class to regain control over Carnival by trying to suppress the place that the lowerclass' masqueraders had forged for themselves. At midnight on the Carnival Sunday night of 1880, the Inspector-commandant of the police force, a Captain Arthur Baker, demanded from the working class, under threat of force, all of the equipment used by them in their celebration of Canboulay, (this included their torches, their staves and their drums). The celebrants withdrew, with a determination to fight to defend their entitlement to both Canboulay and the rest of their festival.

In 1881, Captain Baker attempted to stop Canboulay, forbidding revellers to appear on the streets. However, defiant, the people came out anyway. This time a major riot ensued as revellers clashed with police. It was the bloodiest confrontation ever. Although there were no fatalities, both sides sustained injuries, with 38 of the 150 police officers being numbered among them, (Pearce, 1956:189). After the riots, the defiant revellers continued their daytime Carnival parades as if nothing had happened.

As a result of the riot, members of the coloured and black middle class protested vehemently in support of the masses and against what they saw as totally unnecessary police interference in the festival. The Governor, Stanford Freeling, being disturbed by the violence and aware that his authority had been usurped by Baker, in an attempt to appease the situation, held a meeting with the Executive Council on the following day. He later addressed the masses in Port of Spain. He commenced his address: My friends, I am come down this afternoon to have a little talk with you. He continued:

I had no idea what your masquerade was like. If I had known you should have no cause for dissatisfaction; there has been entirely a misconception on all sides for the only reason for interference was the fear of fire ... I will give [use of] the town to you for your masquerade if you promise not to make any disturbance or break the law

(Brierley 1912:323-330)

As a result, the police were confined to barracks, as the Governor placed his trust with the revellers and their Creole allies. Although the masses were accepting of this action by the Governor, the white elite were less so. The situation was further exacerbated by 
the revellers who were

parading past the barracks in a

hoax funeral procession, with

many of them dressed in

imitation police uniforms, and

carrying a dummy replica of

Captain Baker. All of this was

augmented by funeral music

also being provided by an

imitation police band. The

revellers who carried torches

along the street, taunted the

confined police. They then

proceeded to burn an effigy of

Captain Baker.

The rioting of 1881 changed

many attitudes. For the

Africans, the way the riot

turned out both generated and

fostered a sense of corporation

among them. On the other

hand, it generated the anger of

the upper class, who resented what

they saw as the attitude of
ADVICE FOR THE COMING GARNIVAE EO FE TIEIE TEIAR

\section{$18 E 2$.}

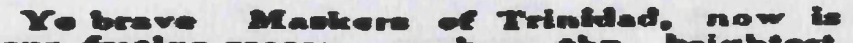

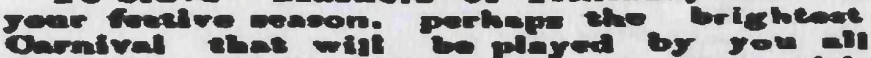

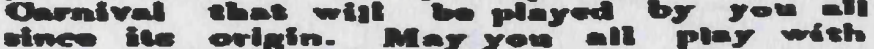
ine Ile orlgin. ney yow all pla with

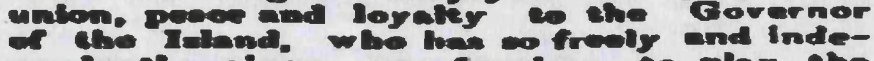

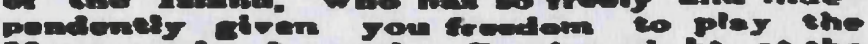

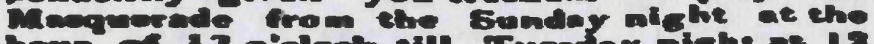

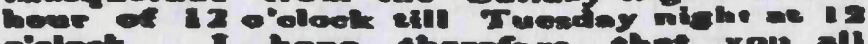
oinent. I pope thernfore chat yoll all

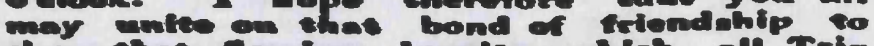

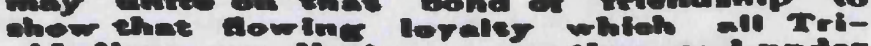

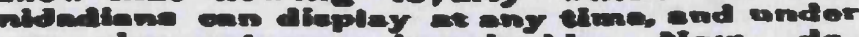

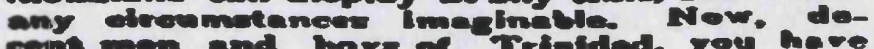

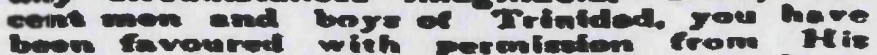
iscostency the Govermor to pler und hero rour ancel amesement a before elme:

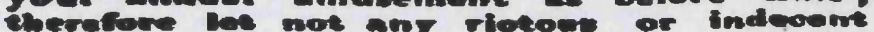

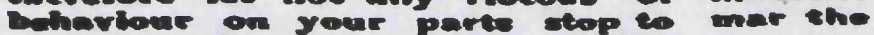

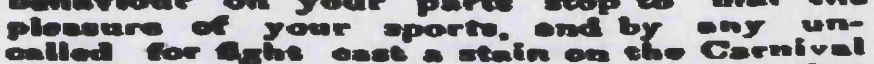

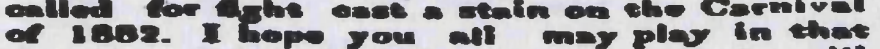

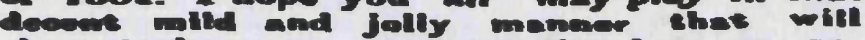

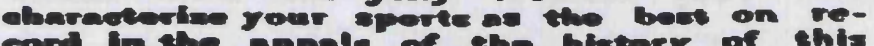

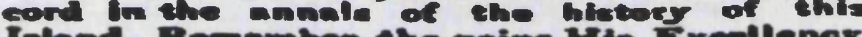

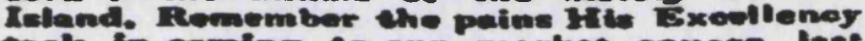
cook in oomiles to over market equare lace year to alk you to play ponowbly and be loyed to the Government, and abo by his

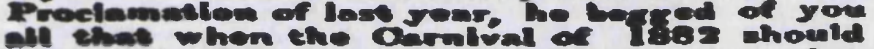

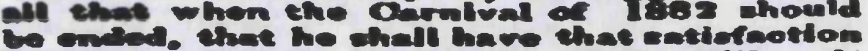

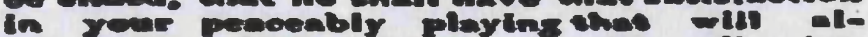

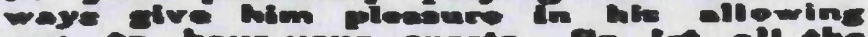

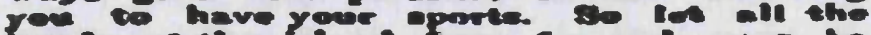

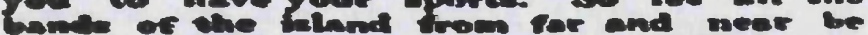

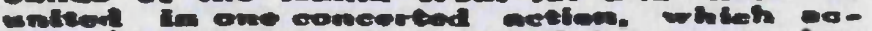

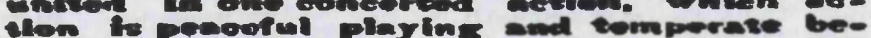

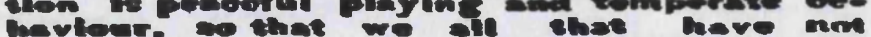

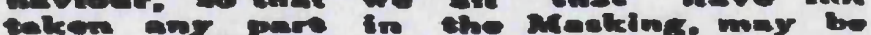

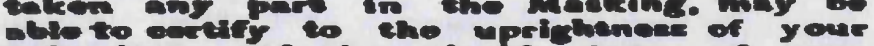
believiour ane the pladi cone of your

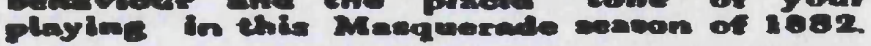

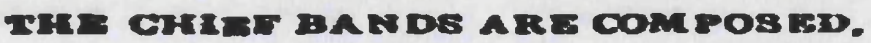

$$
\text { VIE: }
$$

I Cocrel or the Libmenet.

z-linelior of the New Crown.

3-Droo Grammate

4. Cined.

5 - Sindish mork.

Cris Berat.

$\nabla \rightarrow 2-1$ -

D_Plame.

- Davesta.

no-Sedz-8ponistale.

21 Dhernond.

12 - Din Corret.

12 - Daentrand.

Figure 4.6 - Advice for the 1882 Carnival

appeasement of the Governor. The advertisement to the right, appearing in the 1882 
Chapter 4 - Conflict in Trinidad: The Wider Perspective

newspaper as it did just before the Carnival of the following year. It bears out this attitude of appeasement

The 1881 Riots were followed by a one-man enquiry, conducted by Commissioner R. G. Hamilton. The inquiry in an attempt to strengthen the hand of the police against Canboulay, had two main recommendations. These placed a ban on the use of skin drums and the provision of a warship being present off the coast during each festive season. Furthermore, in 1883 the very stringent "Peace Prevention Ordinance", was passed and again amended in 1884 . This ordinance gave the police greater powers over the riotous bands of the colony. (Brierely 1912:327-330). It forbade the playing of drums, tom-toms, cha-chas and even pianos and other musical instruments in places adjoining a public highway after 10 p.m. (Wood 1968:242). In effect, this meant that after 1883 Canboulay was not allowed and it seems that the masses were in the process of allowing it to begin to die down so that Carnival could survive.

Governor Sir Sanford Freeling was recalled to England in 1884 and that same year two separate riots took place in Trinidad. One occurred in the Princess Town area of south Trinidad, where two sizeable bands of about 1000 people in total attacked the police station. These canivaliers used stones and bottles. In this riot, three people died and five police officers were seriously injured. This year also saw the Arouca Riots where, police in attempting to prevent Carnival (Kalinda) from taking place, encountered stiff resistance from the masqueraders. In the ensuing conflict Sergeant Urquhart was struck and fell to the ground, severely wounded. As he lay prostrate on the ground, the crowd resisted attempts made by other officers to rescue him. One eye-witness, an Inspector Brierly, recalling the resilience of the crowd, stated that they could not be dispersed. As 
such, he states that the riot lasted the whole day. The police eventually asserted their control after reinforcements from the St James' Barracks had arrived.

Throughout the rest of the day mounted men paraded the Arena Savannah in their attempt to capture the insurgents but they were fled to the high woods. (Elder 1969:13)

Elder (1969) in discussing this riot notes the underlying similarity between this Arouca Riot and the 1881 Port of Spain riot. He contends that with respect to both events, the underlying issue was:

Whether the Negro Pageant called Cannes Brûlées should be allowed in Trinidad: whether African-type music with its 'primitive' orchestra of conch shells, cow horns and Congo drums should continue within Carnival, and whether the stick-playing and Negres Jardins Flambeaux-lighted dramatics should be allowed to occur within this annual upper class festival.

(Elder 1969:13)

This quote, brings to focus Elder's argument that in reality, the underpinning issue with these conflicts was really one of asymmetric power, driven by the failure of the white dominant class to accept the cultural retention of the black population. This challenge manifested in the actions by those in positions of power (i.e. those who have the entitlement to make the laws). In turn, this gave them the permission to determine for those who were disenfranchised, what actions will be regarded as acceptable. Hence, actions that fell outside of the boundary of those considerations were regarded as resistance, which in turn gave rise to conflict. Hence, this approach did not recognise any entitlement of those dispossessed people to their particular statements of 'being'. The obvious exception to this approach was where those statements were defined and authenticated by those in positions of power. This definition of power alludes to a concept where power is defined as: the ability to define reality and to have everyone else refer to it as if it were their own, (Nobles 1995).

This notion of power can be best understood by taking a holistic view of the lives of the enslaved Africans. Typically, this view embraces the circumstances of their arrival in 
Chapter 4 - Conflict in Trinidad: The Wider Perspective

the Caribbean, the work conditions that they were forced to labour under, the social and family humiliations that formed a part of their everyday life, the marginalisation of the African religious practices by the dominant class. The combination of all of these aspects manifest as a demonstration of power that could only have been derived from an assumption of supremacy by the dominant class.

The combined effect of these three riots (i.e. Arouca, Princess Town and Port of Spain) was the establishment of the Peace Preservation Ordnance, banning the Canboulay Festival. This meant that processions could not take place in which drums were being beaten. It also prohibited the assembly of groups of more than ten people carrying sticks. Under this Ordinance, the maximum penalty for any offence was set to twenty pounds or six months imprisonment.

By the end of the $19^{\text {th }}$ century and the start of the $20^{\text {th }}$ Century, clashes between the police and the revellers had abated, there was a decline in the stick-fighting bands and the start of the individual battonnier masqueraders which replaced the Pierrots. In effect, as this transition occurred for the working class revellers, the festivities mutated from Canboulay to Carnival. It would therefore be true to say then, that the start of the $20^{\text {th }}$ Century saw the launch of a new type of Carnival. The Pierrots can be considered to be the descendants of the battonniers. Hill asserts that the Pierrots which emerged as a type of masquerade, can be traced back to ex-slave rituals. He further contends that the king stickmen, dressed as Pierrots, and lead their band of stickfighters to the fray. He indicated that although the Pierrots operated individually, they were often accompanied by either one or two uncostumed helpers who would carry their long train and their weapons i.e. a whip or stick, (Hill 1997:28). 
The Pierrots who were knowledgeable in history and literature used their verboseness to terrify and threaten. The use of this type of language was combined with the cracking of their three to four meter long whip. Their effectiveness with the whip very much resembles that of a modern day European circus performer.

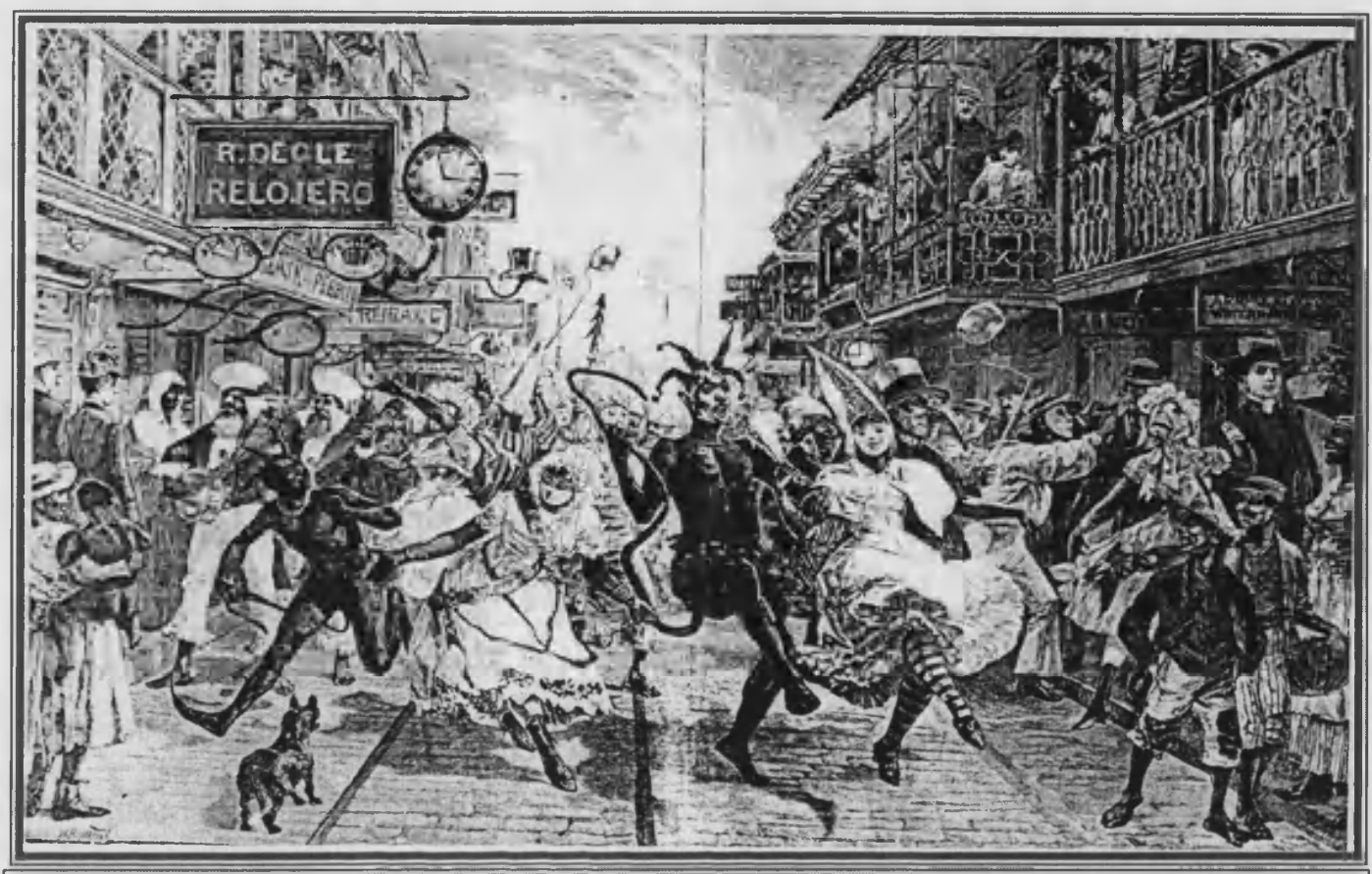

Figure 4.7 - Melton Prior Depicting Carnival on Fredrick Street, Port of Spain in 1888, for the illustrated London News

In these early days of carnival, Pierrots were dressed in gowns of satin, these were padded with sheep or goat skin to protect them from the cut of the whip. Parading through the streets in pairs, they would give displays of their skill with the whip in what seemed to be an artificially constructed fray. On occasions, the spectacle would end up in a free for all, as spectators joined-in. At times, the Pierrots would fight so violently among themselves that in 1892 the Government made it compulsory for all Pierros to carry a license. The period of the Pierrots as a substantial masquerade did not last long as by the first decade of the $20^{\text {th }}$ Century this type of masquerade had virtually died out. 
The cessation of Canboulay and the-multitude of restrictions placed on Carnival, the upper class again began feeling comfortable enough to resume taking part in Carnival. However they sought to make a distinction from the lower class or 'jamettes' by positioning themselves on lorries and bicycles.

\section{CALYPSO}

Historically, the relative freedom of the Carnival period has from time to time allowed Calypsonians brief outbursts and freedom from prosecution. In this context it is worth noting that in 1886 the Attorney General Henry Ludlow, introduced what became known as the 'Musical Ordnance'. This Ordnance clearly illustrates the abundance of class legislation by placing a ban on playing of all percussion instruments (by black Creoles, and people of East-Indian descent), between the hours of 6.00 a.m. to 10.00 p.m., without first getting a licence from the police.

\section{The Seditious Act and Publications Ordinance, 1920}

The Seditious Act and Publications Ordinance Act (SAPOA)1920 followed the Shouters' Prohibition Ordinance (SPA) of 1917. The Shouters, are a religious sect, who, it was my understanding as a child growing up in Trinidad, got their name from the volume with which they proclaimed "the word of the Lord".

While the SPA was used to enable the repression of religions (particularly those followed largely by people of African origin), the 1920 Seditions Ordinance had a different function. Following the 1881 and 1884 Riots as it did, and being mindful of the impact of the nationalist and consciousness raising speeches of Marcus Garvey on the population of Trinidad, this ordnance was used primarily to censor the literature of 
Chapter 4 - Conflict in Trinidad: The Wider Perspective

Black nationalists, socialists and Trade Unionists. Calypsos were seen to also fall within this category.

This Ordnance had an impact that was felt for the next twenty years. During this period, books, pamphlets and newspapers that were considered would prompt hostile feelings between the different classes of coexisting people within the island, were banned, not just from circulating within the island but also from entering it. This prohibition was based on the notion of "Seditious Intention". The provisions of the Ordinance also required that there should be an exercise of control over any literature that was deemed subversive. Such subversion would include criticisms of the King, the Government or those classes in whose interest Crown Colony Government chiefly existed. (Rohlehr 1986:58).

The bill had had the impact of fusing the strategies of control of both the local ruling class with that of the imperialists. By the end of the First World War, life on the island had changed considerably. These times of austerity brought low wages and the resultant labour unrest that in turn, was followed by repression. Despite the existing Ordnances, Calypsonians felt that they had a responsibility to the people to sing out against the existing conditions. Hence, they composed and sang accordingly. This level of Calypso was largely ignored by the local administration and instead, attention was now being paid in this latter half of the 1920's, to Calypsos that were seen to be obscene. During this time the role of the political Calypso had switched to that of supporting and legitimising Cypriani as a political leader, (Regis 1999). By the 1930's, Atilla had already started gaining a name for himself as an intrepid Calypsonians for his fearless attacks on public figures which included magistrates as well as judges. 


\section{The Theatres and Dance Halls Ordinance 1934}

This Ordinance (See Appendix 5 for this document) was created in response to what was regarded as a degree of licentiousness developing within Trinidad. Rohlehr tells us of a powerful committee consisting of a small number of prominent people on the island who were in consensus with the editor of the Port of Spain Gazette regarding the social problems within the island. They argued that the social problems within the island were being enhanced by:

the immoralities of the Carnival, and by the seduction of young girls and the invitation into vice of young boys at drinking saloons and dancing halls on the two days and two nights of the Trinidad Carnival. Rohlehr (1986:60)

Although this Ordinance was intended to exercise a measure of control on the activities of the dance-halls that catered for the lower bracket, in effect, this Ordinance also had jurisdiction over all similar public places and was used in the process of managing and suppressing anything that was regarded as propaganda. Hence, in as much as Calypso Tents also shared the bad reputation of the dance-halls, they also fell within the bracked of the venues governed by this Ordnance.

There were two ways that the measure of control was effected. First, the Ordnance set out that a daily licence was required for the operation of a Calypso Tent. The procedure for getting such a licence required that a system of censorship be used. In practice, in order that the Tent manager could get a licence he needed to submit the lyrics of each Calypso to the police, for vetting, prior to a licence being granted.

The other mechanism of control was through visits to the Calypso Tents. However, the real intent of the visit was frequently called into question. It was 
felt in some quarters that the real reasons for the visits from these officials revolved around the desire of the middle-class men to develop a liaison with women of the lower class. It was also suggested that the censors visited Tents ostensibly to hear the latest gossip on the island.

Whatever the case, the late thirties was a very turbulent time in the history of Trinidad, with considerable conflict in the air. 1937, saw the labour riots lead by Uriah Butler. This period just after the First World War was a period when Trinidadians needed to tighten their belts. The circumstances surrounding life in Trinidad gave rise to much protest, which in turn, was also reflected in the crop of Calypsos being sung. This drove an increased level of censorship of Calypsos. The Calypsonian Atilla the Hun was fervently engaged in the fight against the strict censorship that was being exercised, as a way of controlling the lyrics of political Calypsos (Rohlehr 1972:3).

In 1939 the world was plunged into a second World War, the reverberations of that conflict were felt in every corner of the world and Trinidad was no exception. At a time when there were shortages of essential food items, as well as the money to purchase these goods, the Americans occupied a base in Trinidad and began spreading their culture through the country. The conflict that resulted from the destructive impact of the proliferation of the American 'throw-away' culture, had a serious impact on family life in Trinidad. This was recorded in the words of the well-known Calypso "Rum and Coca Cola", thus:

Rum and Coca Cola Going down Point Cumana Both mother and daughter Working for the Yankee dollar 
Chapter 4 - Conflict in Trinidad: The Wider Perspective

Here the Calypsonian is singing about a level of family conflict, which was a direct consequence of all of the aforementioned external circumstances. In doing so he is really alluding to the destruction of a family life and the erosion of the society's values.

Quevado added his voice to this conflict by the words:

The Yankees launched a real social invasion

They did as they pleased in my native land ......

I must confess they helped us financially

But they played hell with our morality

They took all our girls and had a glorious time

And left us blue-eyed babies to mind

Quevedo (1983:140-41)

When Rum and Coca Cola was pirated by the Andrew Sisters, a multi-million dollar lawsuit against Morey Amsterdam and the Andrew Sisters ensued. Although this was Lord Invader's most popular Calypso, he did release numerous other Calypsos along the same theme.

Post the war, quite apart from the rippling impact of these global events and the localised conflict and destruction that they caused in the country, there remained the quite separate issue of censorship. 1948 saw 'King Pharaoh' sing about the inquisitiveness of the governor. Using double entendre, he gingerly wrapped up the tendencies of the governor to get into the affairs of others. Recognising the Governor to be tall in stature he sang:

The Governor tall, tall, tall,

The Governor peeping over the wall

This Calypso was seen as offensive and as a consequence, the Police demanded a copy of the lyrics from the manager of the Tent with the view of determining the possibility of bringing a prosecution. 
Chapter 4 - Conflict in Trinidad: The Wider Perspective

1950 saw a particular confrontation between the law and 'Atilla' who was the Calypsonian-manager of the Victory Calypso Tent. This conflict was over the words of two of Neville Marcano's ( the Growling Tiger) Calypsos that were sung in the Tent, these were entitled: "Leg'o the Dog Gemma" and "Daniel Must Go".

"Daniel Must Go" was considered tasteless, as it recalled the issues around the charge for drunkeness that the Police had levelled against the Director of Education. "Le'go the Dog Gemma" was considered to be an obscene attack on the sexual attitudes of upper class women, it argued that they exhibited double standards in their conduct.

For these reasons, it was determined that these Calypsos were unacceptable for public airing. On that occasion, the Guardian newspaper received and printed numerous letters from the upper echelons of society describing the words of the Calypso as "cowardly", "scurrilous" and "vile". With such a public outcry from people in high society, the Calypsos were then banned. Atilla, the manager of the Tent was subsequently brought to court to answer charges. The charges were duly dismissed on a technicality that centred around the licence that had been issued to Atilla's Tent.

In his work entitled "From the Horses Mouth", Liverpool (2003:163), in illustrating the disregard that the State held for Calypsonians tells of an occasion in 1955 when a group of four Calypsonians were publicly singing to passers-by on Wrightson Road. The police chased after them and arrested three of them 
with the fourth (The Mighty Sparrow) evading apprehension by the officers. The three apprehended Calypsonians (Lord Superior, Intruder and the Mighty Striker) were charged with "molesting the passers-by" and "obstructing the free passage way". They spent two days in prison and were subsequently fined five dollars or sentenced to seven days in prison.

Another example is that of Lord Shorty (subsequently Ras Shorty I). It is well established among Calypsonians that props can be of enormous help, as an aid to getting their message across. As such, on the night of the Dimanche Gras show, those selected to compete for the Monarchy, in the process of getting their messages across, use drama, engaging various props to assist in the creation of the atmosphere and the delivery of the storyline, drawing on the visual to assist in the process of raising consciousness. During Shorty's presentations at the 1973 Dimanche Gras show, while singing "The Art of Making Love”, he used his middle finger as a prop, to gesticulate the processes about which he was singing. The Dimanche Gras show, being the grand occasion that it is, the audience usually has many dignitaries. On this occasion the then Prime Minister, Dr Eric Williams, was present in the audience and took exception to the antics of Lord Shorty. As a consequence, the PM subsequently requested of the Carnival Development Committee (C.D.C.) that they explain why Shorty was allowed to give this manner of presentation, given the laws of the country. As a direct consequence of that event, the C.D.C. (currently known as the National Carnival Commission, N.C.C.) now stipulates that they see the lyrics of the Calypsos that will be sung at any of the shows that they sponsor. 
Chapter 4 - Conflict in Trinidad: The Wider Perspective

Today, both Calypso and its twin sister, Carnival have moved a long way since those early days. Currently Calypsonians are freer to sing, even though those in government show great sensitivity to the lyrics of Calypsos and threaten to bring into force Acts of Parliament that in effect enable a level of control on the Calypsos that they consider offensive. The situation for the masqueraders is much the same. Although individuals are free to 'play mas' with any band they choose, in reality, certain sectors of the population seem to have a preference for playing with particular bands, where they can enjoy the comradeship of a client group that, in the main, enjoy the same status as they do. However, this is a election of choice and not compulsion.

\section{CONTEMPORARY EXPRESSIONS OF CONFLICT}

I have shown how historically, aspects of the Carnival art-forms have been enshrined in conflict. This engagement with conflict, having been sustained throughout the history of carnival continues to today to be an integral part of it. In this section of my work I will focus on two aspects of contemporary conflict. These being:

- Conflict through the conduit of carnival

- Calypsonians: Conflicts of Acceptance

\section{Conflict Through the Conduit of Carnival}

The face of masquerading and its function is ever evolving. In the early days, Carnival itself was conflict, in more recent times, Carnival has been used as an icon displaying the conflicts Trinidad, and even the world faces, as we race to acquire and acquaint ourselves with technology. Although in the Trinidad carnival, examples of this type of application abound, I will cite Peter Minshall's trilogy as one illustration of the process. 
Chapter 4 - Conflict in Trinidad: The Wider Perspective

On the carnival days of the consecutive year's 1983 to 1985 incl., Minshall's carnival band acted out a myth on the stage of the Queen's Park Savannah in Port of Spain, Trinidad. This trilogy was underpinned by concepts of the differences between good and evil and began by depicting the impact of the growth of technology on an unsophisticated woman, washing her clothes at the side of a pure, un-contaminated river. In this metaphorical display, Minshall used powerful, symbolic representations of occipital images to depict the conflict faced as industrialisation grows, bringing us to recognise the cost, in human terms, of the impact on our pure, unspoilt landscape, as we pursue technological advancement.

In this work Minshall combined spatial, temporal and poetic structures in a commentary that is relevant to Trinidad and the world. The objective of this trilogy was to awaken our consciousness to a point where we begin to show concern for the current global 'contest' between the Western World's surge for technological development and the ecological cost of that development,

The first year Minshall called "The River," this was a story in two acts. On Carnival Monday, Act 1 was presented on the stage, with Act 2 being presented on the Tuesday. On the Monday his band symbolised a river of people. He used ancestral costumes to represent the multi-ethnicity of the island - African, Amerindian, Chinese, East Indian, European. He represented the harmony and unity in the diverse ethnic make-up of the nation's people by means of the soft sculpture of a white canopy that covered them all. This therefore was the clean, un-polluted river, which was symbolic of nature, pure and uncontaminated. Commensurate with and symbolic of this natural state of 'mothernature' was a simple Washerwoman. 
Chapter 4 - Conflict in Trinidad: The Wider Perspective

[The] "Washerwoman," Queen of the "River," likewise was consistent with the tradition of relevance. Although decidedly un-technological in the technological age, that was precisely her relevance, for she raised the question for whether mankind's innocence, purity, and simplicity could survive these times. Beyond that, without any specific precedent, her pure white cotton dress and her lines of pure white linens were decidedly West Indian, evocative of our heritage. And finally, this queen may be more traditional than we realize,

(Minshall 1985:18)

The Washerwoman was set against the technological devil, as personified by the imposing male figure of Mancrab, (Fig 4.8).

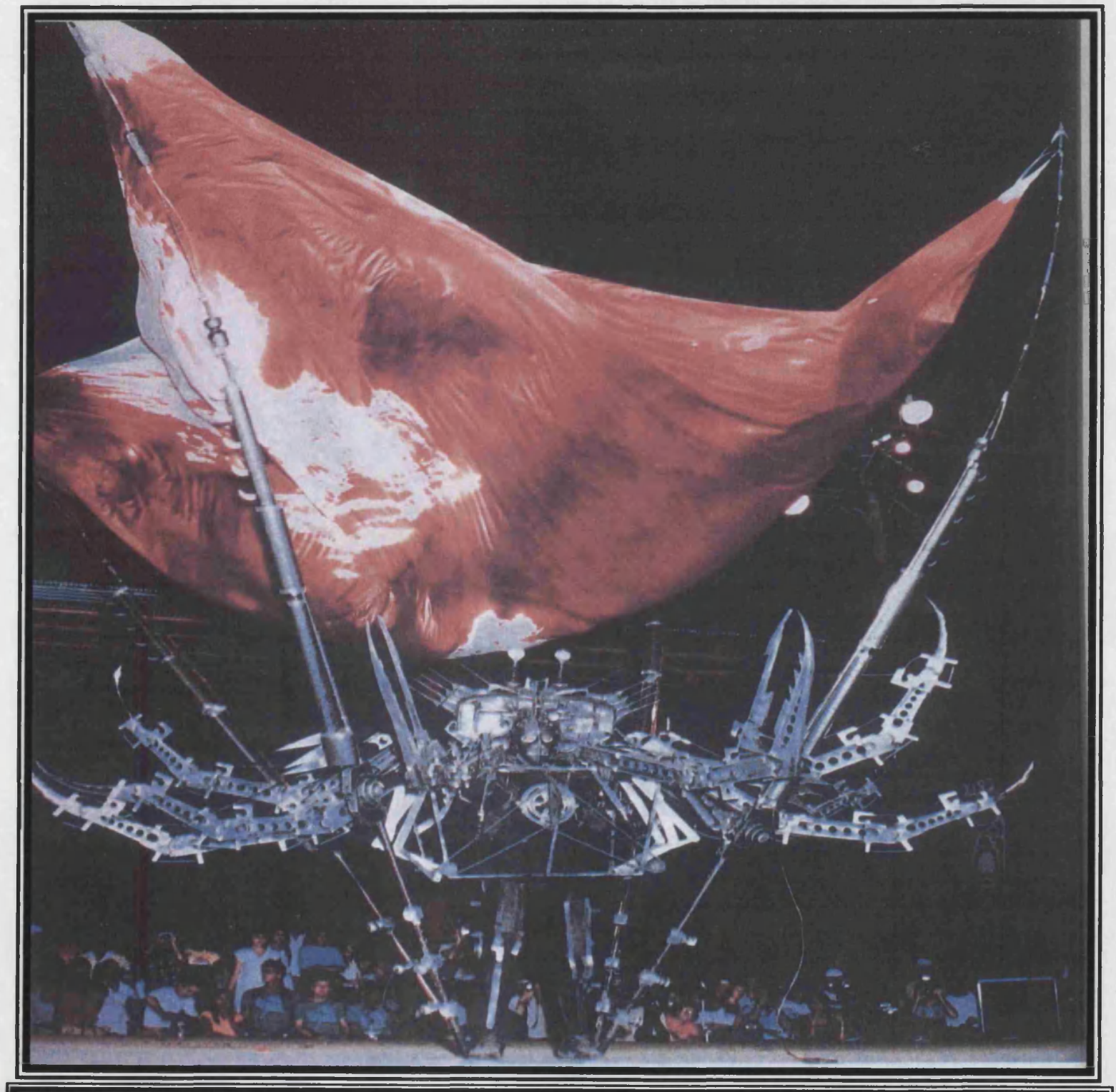

Figure 4.8 - The half-human half machine figure of Mancrab 
Mancrab, a combination of beast and robot, was representative of the metallic monster of technology, who strove to rape the washerwoman of her purity. Mancrab wanted to construct his factory on the banks of the pure river. Marching under a 25 foot square piece of pure white silk, he displayed a threatening "Erector" set of mobile legs that bristled to the deafening beat of tassa drumming.

The construction of Mancrab's bodý was symbolic. It included a cassette recorder and television, with paws made of a gun barrel and a hypodermic needle. During his time on the stage, he released the canisters containing red dye to envelop the white canopy above his head. Thus, symbolising the cost to mankind in blood of advancing technology. This collection of:

Steel hinges, trick collars and poles. With a bicycle chain on a wheel, Mancrab turned his little tank body towards the audience. There was a moment of stillness then in an instant the silk canopy was drenched in bloody paint from a hidden canister on his back. Dripping red, Mancrab did a furious victory dance, and pulling 30 yards of red silk from his belly, dropped the entrails on stage and exited.

(Healy, 1986:43)

The story continued through to Act 2 when, on Carnival Tuesday. Mancrab, through seduction and persuasion, using the spectrum of colour as manifest in a rainbow, - (this idea Minshall conveyed through enabling the masqueraders to paraded through the streets and onto the stage of the Queen's Park Savannah, pouring coloured dyes onto their costumes,) - won over the people to the benefits of technology. Nature, pure and pristine, having been raped, could hold out no longer. The Washerwoman was carried onto the stage of the Queen's Park Savannah. She was dead. 
Chapter 4 - Conflict in Trinidad: The Wider Perspective

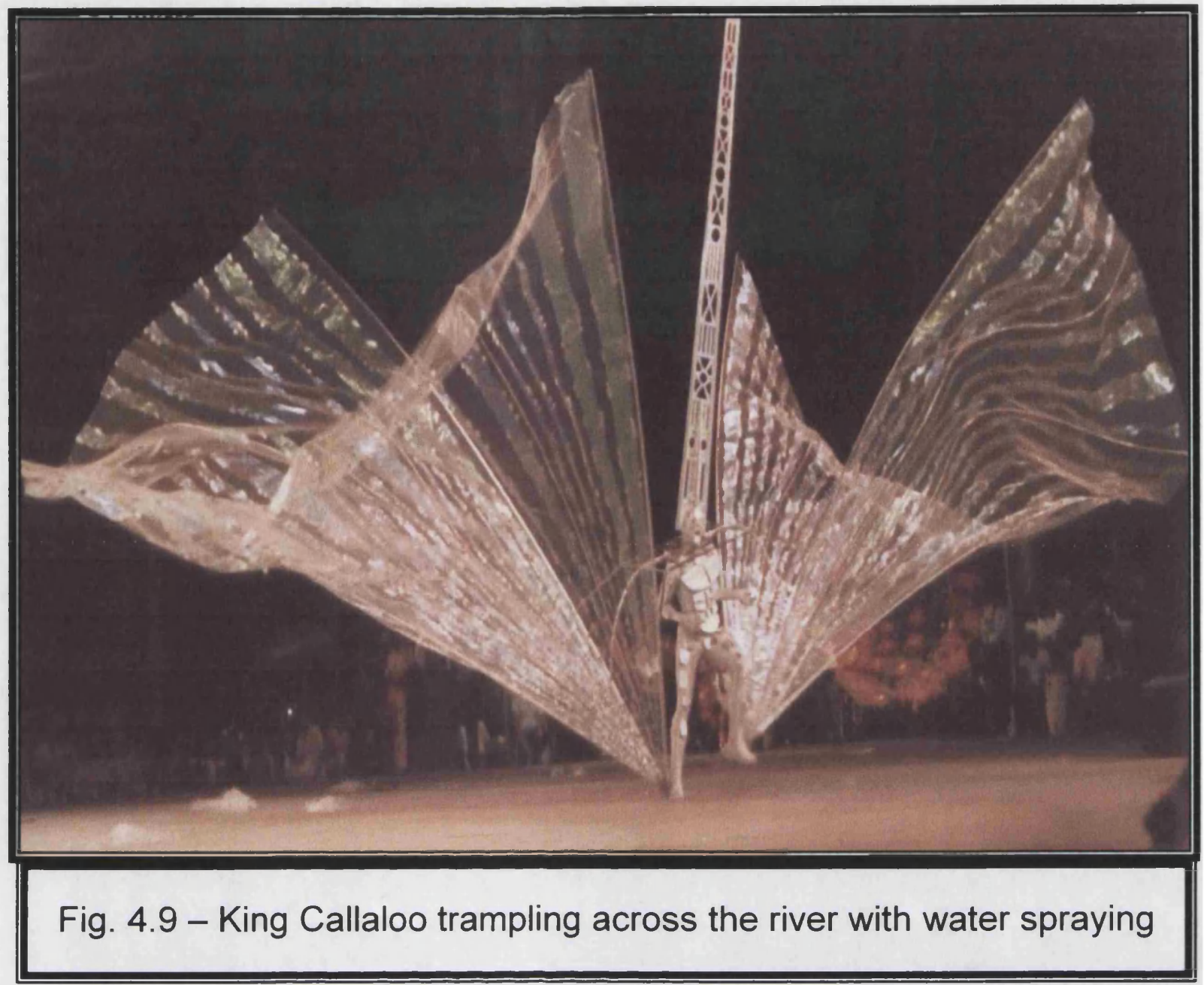

The following year (1984), through 'Callaloo' ${ }^{\prime 2}$, (see Fig 4.9) Minshall continued the story, by seeking to raise consciousness even more by further drawing attention to the continuing and abiding conflict between good and evil. That year, Callaloo, the son of the Washerwoman, who had the supernatural ability of walking on water, showed the potential of mankind by defeating Mancrab in battle.

As a result the "Children of the Moon" (See Fig 4.10) - depicted by wearing halos of light symbolising peace and love), joined their hands and celebrated. They then built an image of Mancrab, which they subsequently burned.

\footnotetext{
${ }^{12}$ Callaloo is the name of a Trinidad and Tobago dish which is a melting-pot of ingredients. The dish can be regarded as a symbol of the mixture of races comprising the nation.
} 


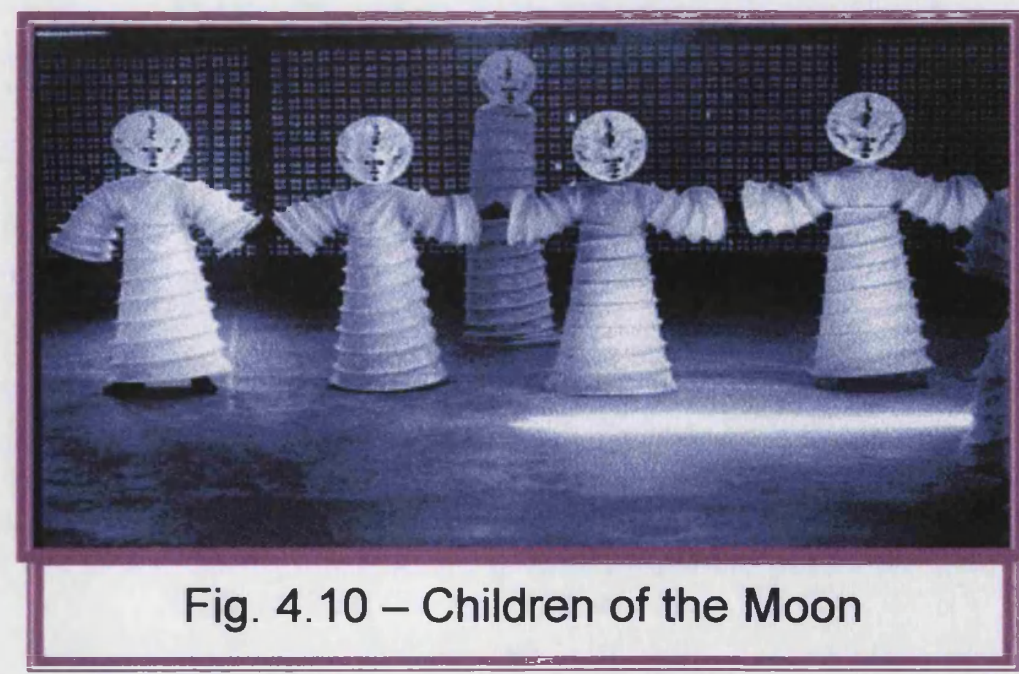

Mancrab's protégé, had been stirred. Madam Hiroshima was depicted as a shocking and gaudily dressed, quite rotund figure, garbed like a crude Las Vegas showgirl. Above her head was a mushroom cloud of fiery hot smoke of varying colours. This figure, a "Whore of Destruction", with its swollen belly and enlarged breasts, presaging the birth of only death and disease, was a personification of the nuclear bomb.

Arriving as she did on Carnival Tuesday and with the help of the "Seven Deadly Sins" she sprayed and dirtied the masqueraders who were dressed in white. On seeing this Callaloo became depressed, dejected and disillusioned, and could only be revived by mankind's love.

In the third year, (1985) Minshall depicted "The Golden Calabash: ${ }^{13}$ "Princes of Darkness" and "Lords of Light". This Calabash, the source of the Washerwoman's strength, her valued cup of life, was lost. Minshall in depicting the search for it, created two opposing and rivalling factions who were to do battle in the process of finding the cup. These factions were the "Lords of Light" and the "Princes of Darkness". The battle for the cup was enacted on the stage of the Queen's Park Savannah on Carnival Tuesday against smoke bombs and the refrain of a Calypso called "ApoCalypso" which included the phrase "I can't see the light". In finality, the Princes of Darkness (Hell's Angels,

\footnotetext{
${ }^{13} \mathrm{~A}$ Calabash is the shell, the produce of a plant. In days gone by it was used pervasively as a utensil.
} 
Global Warming, Passion Fruit, Destruction of the Ozone, Nuclear Fallout, Filthy Rich) overpowered the delicate Garden of Eden of the Lords of Light.

This year (1985), Hiroshima (Fig 4.11) appeared again, having evolved into a distortion of a religious icon, this time being dressed all in gold and white, with a halo of exploding nuclear golden debris in the form of a pure white mushroom cloud overhead. In her left hand she carried a sceptre that was shaped like a golden nuclear warhead. In her right hand she carried a globe. This positioning of these artefacts in different hands, represented the opposition, and conflict that abounds for humanity. The battle terminated with the apocalyptic representations of horror and destruction as symbolised by "The Adoration of Hiroshima".

Through this phenomenon, Minshall titillates the eye with a feast of color, he continues to jolt the mind into contemplation of the harsher realities of life, (Juneja 1988:98) while demonstrating a belief that the powers of love are too frail to withstand the forces of destruction which man has unleashed on mother earth.

Quite separately, Minshall also presented the "The Adoration of Hiroshima" figure during an anti war rally in Washington D.C. in August 1985. Minshall eloquently describes this occasion thus:

[this] was one of the most noble, genuine, worthwhile, eloquent and effective endeavours of which I have ever been a part.

Sixty people. Sixty masked players. Faces fixed in silent screams of pain. Leering grins of death. Tassa drummers. Iron beaters. High priests. Men. Women. Children. All in solemn procession in adoration of Hiroshima. We walked, we danced, we drummed, from Lafayette Square in front of the White House, through the streets of Washington, to the steps of the Lincoln Memorial. We showed them. We communicated. Without a single placard, in our masked silence we screamed out to the world about the threat of nuclear war. It reached the housewives in their kitchens. It reached the children in their schools. ... This was the first and only time in my knowledge that a small country has made in its indigenous art form an international statement against the threat of nuclear war. The mas undoubtedly made a positive impression, and we felt happy, and proud, and honoured.

(The Callaloo Company 2004) 


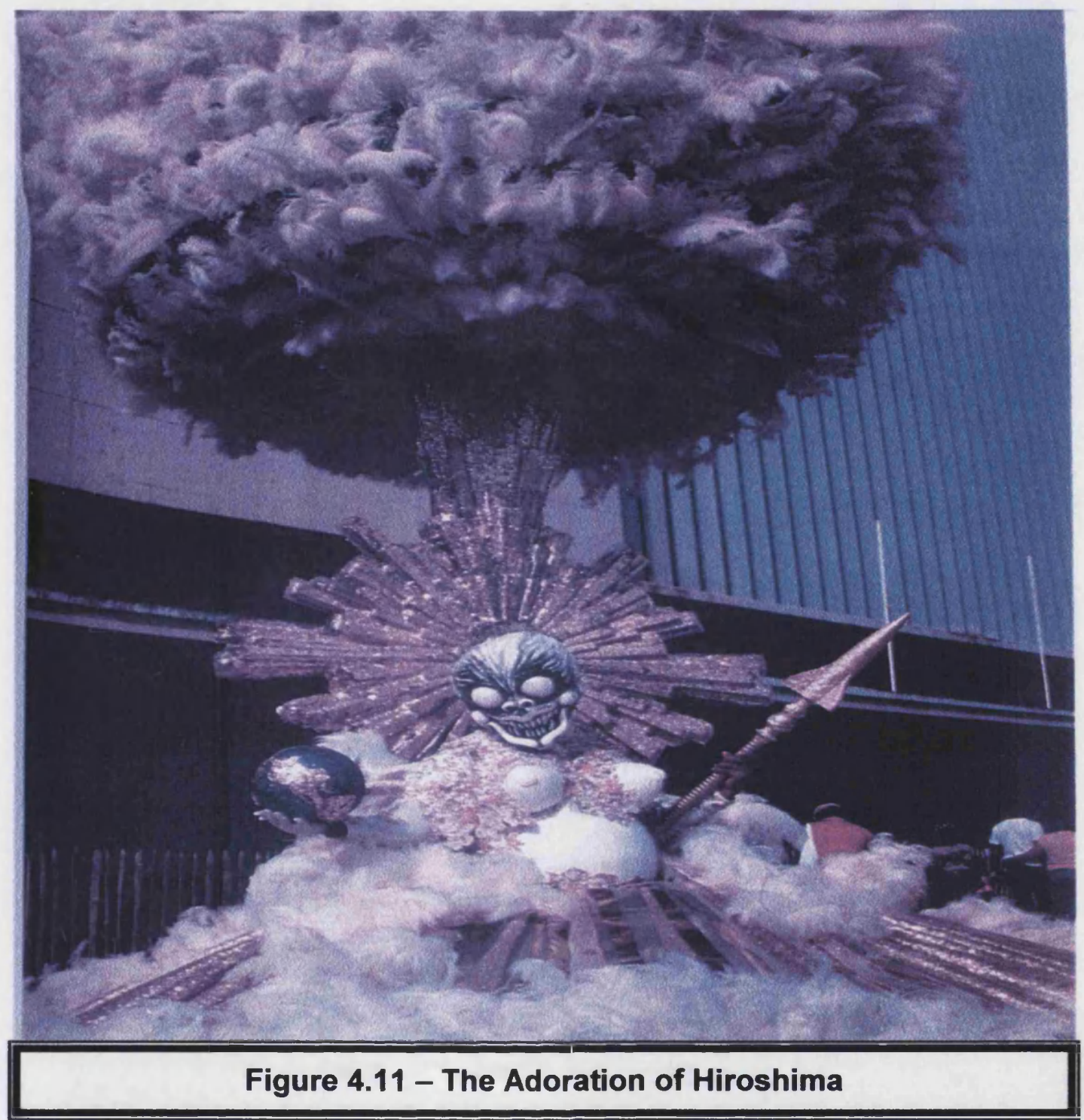

While the quotation above helps our understanding of the other side to Carnival, the whole symbolism of the trilogy is but one of numerous examples that show, not only the conflicts that circumscribe carnival but also, how Carnival has been used to draw attention to conflict.

\section{Calypsonians: Conflicts for Acceptance}

Although today, in the main, Calypsonians are regarded as celebrities in the society, and the Calypso art-form is supported at a variety of levels from school children upwards, 
Chapter 4 - Conflict in Trinidad: The Wider Perspective

this has not always been the case. As is to be expected from a society born out of the reality of enslavement, the social structure of the island has always been very heavily stratified, and with varying degrees, has to a very large extent, remained that way for a number of years.

In the light of my experience growing up in Trinidad, in my current role as an indigenous ethnographer, I easily recall incidents of stratification of the citizens by complexion, I recall that even as late as the 60 's very few people of dark complexion were allowed to work at the front desks of public establishments, particularly the foreign owned banks. Until the consciousness movement of the very late 60's and early 70's, such jobs were almost entirely reserved for people of lighter complexion. This tendency is attributed to the phenomenon that Náim Akbar calls the ghost of the plantation, (Akbar 1984:4). Children of 'well-to-do' families were brought up with the expectation that they would eventually acquire a job in one of the "er" professions. As such there was an expectation that these children would become either a Lawyer, teacher or 'Docter'.

Such was the conflict among the strata of the society that even as late as the 1950 s, the elite and those aspiring to be associated with that 'higher' rung of society, regarded Calypsonians as belonging to the lower class. The Mighty Sparrow sang about this aspect, combining it with the then prevalent views of steelbands men, in the words of the Calypso "Outcast", as follows:

Calypsonians really catch hell for a long time To associate yourself with them was a big crime If you sister talk to a steelbands man Yuh family want to break she hand, put she out Lick out every teeth in she mouth Pass, yuh outcast! 
Chapter 4 - Conflict in Trinidad: The Wider Perspective

In my conversations with Andrew Macarno, a Calypsonian who was prominent from the 1950 to the early 70's (and who goes by the Sobriquet Lord Superior), he recalled that in the early days, Calypsonians were regarded as the lowest of the low, (Marcano 1999). Going further back from this, Liverpool (2003:76), in recalling the comments of Lord Iere remembers that Calypsonians were regarded in much the same vain as dogs were.

It is difficult to determine whether this regard for Calypsonians is a cause or an effect. That is to say, is it a natural part of the societal hierarchal structure, or, is it that the function that Calypsonians serve within the society, being the ones who hold up the mirror of self reflection, showing the foibles, causes such discomfort for those viewing their reflections that they in their rejection of their image scapegoat the messenger?

Be that as it may, over the years the path of Calypsonians has been punctuated by censorship. These attempts at censorship came in many guises as shown below:

- Various Ordinances were passed during the period 1835 to 1837 . These were primarily intended to ban the use of the drum that Africans considered to be key to their method of music.

- The Laws of $1841,1842,1845,1868$ - these limited what was called the singing of obscene or profane songs

- 1920 - Seditious Publications ordinance placed regulations on the nature of the lyrics of a Calypso

- 1934 - Daily licence required for a Calypso Tent. This put a system in place whereby the Tent manager needed to submit the lyrics of each Calypso to the police for vetting prior to the licence being given. 
Chapter 4 - Conflict in Trinidad: The Wider Perspective

- 1936 - Ordinance 23 made provisions that there should not be suggestive dancing, profane songs, or songs that insult members of the upper class.

- During the 1920's and 1930's the Guardian, a conservative local newspaper awarding prizes for the best decorated lorry as well as for the best biblical masquerade. This was seen as a way of eroding much of the Africentricity that was present in Carnival.

\section{Contemporary Conflict in Calypso}

From the forgoing in this Chapter, it is easy to understand that the very existence of Calypso is rooted in an expression of some type of opposition to the prevailing condition. As a consequence, this counter expression can at times be seen as diametrically opposed to the circumstances that initiated it, hence leading to a manifestation of a level of conflict.

On close observation, it can be seen that, hardly a year passes without some spirited, public debate arising as a result of the words of one of that year's or the previous year's crop of Calypsos. As was to be expected, that was the case during the first year of my fieldwork. As a result, in accordance with established pattern, the 1999 Calypso season, saw the release by Sugar Aloes of the Calypso: "This Stage is Mine". The impact of this Calypso was phenomenal, containing as it did lyrics which some considered highly controversial. It consequently spawned the traditional conflict expected from such controversial lyrics. 
In this Calypso Aloes was defending, what he saw as his entitlement to, exercising poetic license, sing freely about the Prime Minister's wife, Mrs Omah Panday.

Although nowhere in the Calypso does Aloes call her by name, by defiantly singing in the first verse:

All dem Hindus they criticise me,

Because ah call a name in meh song, (Available on CD at track 3)

Yet again in verse four:

She would ah know drunk or sober she husband is Prime Minister And once you have elevate yourself, leave them ways in the gutter Checking out she face value she is a really beautiful woman But don't pray to bounce she up when she playing mass in Poison Band All she skin exposed with glass in she hand when she hit that ramp Which reminds me of a song: "the Lady is a Tramp"

Those familiar with Trinidad society saw these lyrics as well as those of his 1998 Calypso as a strident attack on Mrs Panday.

This conflict gave way to a vociferous debate on the rights, entitlements and permissions that as representatives of the people, Calypsonians have. Discussions abounded in all venues regarding what Calypsonians are entitled to express and how they should express these views. As is usual under these circumstances, the newspapers became one avenue through which individuals sought to air their differences of view. I propose to detail the conflict verse by verse and the responses as manifest in the media. In my process of acquainting readers with the various aspects of this polemic, I consider that it is vital that both in relation to this Calypso and the attention which my work pays to Calypso as a process of resolving conflict, that I highlight some distinctions. 
On reading the words of the Calypso and hearing it sung, it is my view that in this

Calypso, Aloes is not trying to be the representative of 'the people'. Rather, he is

defending what he sees as his right to express himself as he sees fit, and for that

entitlement to be respected, hence the first two lines of the Calypso. I recall hearing the gasps from the audience as they heard the lyrics of Aloes' Calypso as he sang the following:

Title of Calypso: This Stage is Mine

Sobriquet: Sugar Aloes

Performer's Name: Michael Osuna

NB: This Calypso is available on track 3 of the CD

Verse one

I don't own a TV station, ah don't get air play on the radio

The only time the nation does hear me, is when ah sing on Dimanche Gras Show All dem Hindus they criticise me, because ah call a name in meh song

Even Edison Isaac was against me, so he give Mystic Prowler the crown

But even though they chastise me, they can't take away this voice

It is very plain to see that I am the People's Choice

And I'm going to jam them hard anytime they cross the line

Commonsense must tell them this stage is mine!

So when Carlos John told me that I couldn't appear on the show

Because of my contribution in song ah ready to go

He told me the Savannah will be filled with dignitaries

And they couldn't hire me to embarrass the lady

He said what they want was people who could fill the night with joy

So they hire Puppet Master to come and sing 'bout he boy

So when he choose Puppet Master in front me, I didn't get vex

Because I don know meh Prime Minister love sex

\section{Verse two}

Carlos John that big dog then told me, Aloes boy try and understand

I want you to work for your money, but ah can't disobey the man

He pretend to be sympathetic, apologise, raise and shake meh hand

Then he call Champs in Concert and told them to take me off the programme

But I told him straight to face, in case alyuh want to know

I doh want to be no part of Panday's Demanche Gras Show

Soon after that Panday made a statement most blatantly

Saying: "Men like me can't spend tax payer's money"

But Sat Maharaja racial like hell, and we know he hate nigger

Yet its tax payer's money does finance the Maha-Sabha

For I to work and earn money from the State they find it unfair

But I am a Trinbagonian and I does pay tax here 
We roads in a mess and most of the time W.A.S.A $A^{14}$ gives us air $B$ ut he put roads water and lights for he family in India Like they want me to apply for political refugee But it go take more than them to run meh from this country

\section{Verse three}

The truth is always offending, the old people they always say so They continue doing the wrong thing and don't want the public know Whenever they address this nation, they do it with a sincere tone But if yuh check them under the surface, they all corrupt to the bone The corruption at $N P^{15}$, up to now they eh do a thing Yet all the big contracts still.going to Gal Barangsingh But their time is drawing near we know that without a doubt The same way they come in, we will get them out

Cause while the cost of living sky high and oil rate causing panic They making big fuss because I call she a "Kitchen Mechanic" When Hulsie did cross the line and end up Marvin's bobolee Not a Hindu voice was heard none ah dem didn't defend she The record shows that Hulsie took blows from every Calypsonian Down to we Prime Minister they call she a "Neemakharam" And when I sang about Pan's bladder, they all laughed till they get a pain So ah was wondering if all woman not the same

\section{Verse four}

I doh like to attack these women, Ah love to treat all them women kind The only time they does get meh venom, is when they jump in the firing line But meh old granny had a saying, son always look before you leap And if they not too dam old to bend down, you're not too young to peep Once yuh playing with fire, you could bet you bound to get burnt These are some lessons in life that all young ladies should learn Not because you do not like the speaker do not be absurd Because young ladies are seen and not heard

But if she was a lady she would not be seen doing them foolish thing Like standing up in public with company booing Jimmy Singh She would ah know drunk or sober she husband is Prime Minister And once you have elevate yourself leave them ways in the gutter Checking out she face value she is a really beautiful woman But don't pray to bounce she up when she playing mass in Poison Band All she skin exposed with glass in she hand when she hit that ramp Which reminds me of a song: "The Lady is a Tramp"

\section{Aloes is recalled to the stage by the emcee ${ }^{16}$}

\section{Verse five}

Sparrow and all criticise me, that old ungrateful Grenadian

He and Prowler is two outsiders, so he join with the Vincentian

\footnotetext{
${ }^{14}$ WASA is an abbreviation for the Water and Sewage Authority

${ }^{15} \mathrm{NP}$ stands for National Petroleum

${ }^{16}$ In Chapter 9 entitled: "The Audience as Co-Mediator", I address the concept of "Call and Response"
} 
He forget he sang Jean and Dinah, May May and Mary Bunta Jean And I am sure most of you can remember, he even sang a song on the Queen ${ }^{17}$ But when they say the Judges cheat, Sparrow he start making strife Saying that I should ah known, that ah can't sing on de man wife But long before Morgan Jobe desecrate women and treat them mean Sparrow called them Jagabats and Whabiens

So when he talk about disrespect right away I was shocked for so Ah keep doubting meh self saying that's not the Sparrow I know The Sparrow I know did sing "Both ah dem", "the More the Merrier" That same Sparrow years ago drop he pants in de Savannah The Grand and the North Stand did have a lot of women with class But Sparrow say all who boo him could kiss his Grenadian ass So when he mention disrespect the man really had me thinking Is it possible that Satan could correct sin?

Aloes is again recalled to the stage by the emcee, while the audience can be heard applauding in the background.

\author{
Verse six \\ Allot of people saying I racial, they say me Watchman and Cro Cro so dread \\ But me eh preaching no racialism, ah just repeating what Sat Maharaja said \\ When Sat Maharaja uses sarcasm, no one tells him button he lip \\ But when we Calypsonians attack him, they calling for censorship \\ The situation with the press right now is a disaster \\ We don't have a Prime Minister, what we have is a gang leader \\ Cause if you could encourage your members to beat up the press \\ Then the end result is social unrest, \\ Its either this man illiterate of rum have him stupidee \\ Maybe he forgetting this is a democratic country \\ He have to be out he mind to declare war on the media \\ $H e$ 's not a Prime Minister he's a damn dictator \\ He have a next bad-john one, beating woman and flashing he gun \\ The whole of Tunapuna knows that there is a new sheriff in town \\ Come next election they both might end up in a mental ward \\ 'Cause I done know the pen is mightier than the sword (Track 3 on CD)
}

\title{
In relation to verse one
}

Clearly, in this verse Aloes laments the fact that except for Dimanche Gras, he has very limited opportunity for his views to be heard. He therefore asserts that while those in

\footnotetext{
${ }^{17}$ As a youth growing up in Trinidad I can recall the days when Sparrow sang not only on the Queen, but also on Princess Margaret. The lyrics of thóse songs are available in Appendix 1.
} 
Chapter 4 - Conflict in Trinidad: The Wider Perspective

power have the media for their views to be heard by the nation, his avenue is the stage of the Queen's Park Savannah.

In an article appearing on page 5 of the Sunday Guardian dated $21^{\text {st }}$ February 1999, Gail Alexander in reporting on her interview with Aloes presents his side of this conflict, thereby, at least on this occasion allowing his views to be represented. In her report, she states that in speaking of his political allegiances, he asserted: $\operatorname{Iam} P N M^{18}$ property. This was also the expression that he used when I interviewed him during my fieldwork.

During my research I spoke to citizens in Trinidad who asserted that, based on their observations, Aloes is so much for the PNM that when they are in power he has nothing to sing. It is only when one of the other parties is in power that he has something to compose and sing. In view of these comments, it is interesting to note the contents of the last column of the first page of this article. It is also helpful to see a photo of the subject of all of this conflict on the second page, particularly since in verse four of his Calypso Aloes refers to her physical features.

The article follows on the next two pages.

\footnotetext{
${ }^{18}$ PNM is the abbreviation for Peoples' National Movement, one of the political parties in the country.
} 
Sunday Guardian February 21, 19995

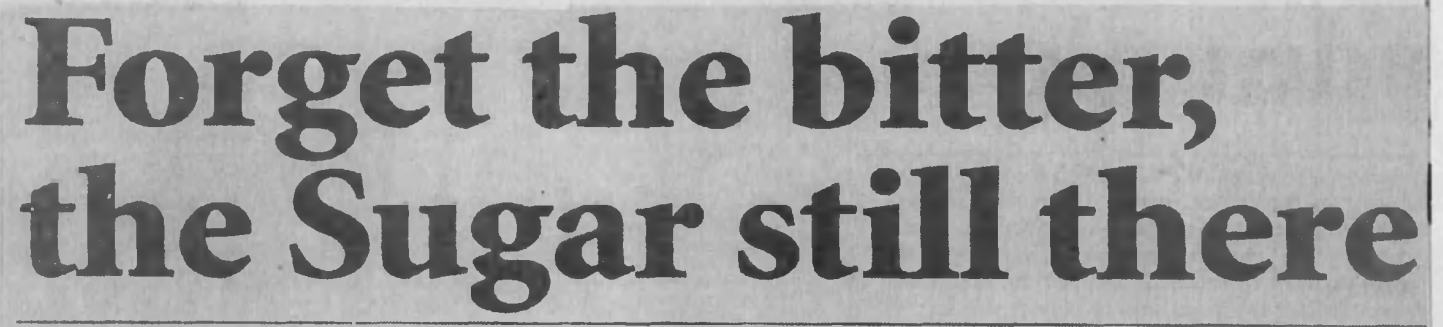

IS Sugar Aloes as bitter as some think? Particularly since he lost the calypso monarch crown? GAIL ALEXANDER discovers that he doesn't appear as displeased with the Prime Minister's wife as he was before Carnival.

THAT he is a member of the Opposition PNM,

Sugar Aloes does not deny.

But the man who last week boasted of being the "property of the " NM" $^{\prime \prime}$ is still at a loss to understand why some believe politicking is what really lies at the root of his contruversial declaration for 1999 "This Stage is Mine".

Now with Carnival a fading memory, the former butcher turned fulltime calvpsonian, says he's satisfied that his cutting commentaty achieved its purpuse. And the Prime Minister's wite has now found some favour in his eyes, he claims.

If the figure of a less acerbic Aloes elicits a double take (and some uneasure of disbeliet) he shouldn't be 100 surprised. The man better knowin by his stage name rather than his real handle - Michael Osuna-drew tire from several quarters for his strident criticism of Oma Panday, the PM's wife, in "Stage" this seasur.

Among the press re leases and other statements, the presentation by [NC chairma1] Kama Maharaj at last Monday's l'Ouvert telegraphed better than mest, exactly what the ruling party felt lay behind the composition. Maharaj, complete with a sprig ot aloes plant dangling from his neck, bore a sign with the word "Sugar" crossed off and the definition, "Bitter" substituted rinstead.

"Aloes as well as orh. er calypsonians like.Cro Cro and Watchman who came into being in 1986 after NAK won are simply bister the PNM "i in power." says Mahardi. "And Says Maharaj. "And we re well aware that's the truc reason for this wence and the sudden awareness' of the role of the calypsonian. These fellas are simply Opposition's voice.

"But people look up to calypsonians as exemplars, if thev're divisive or cohesive, it sive or cohesive, it did notice at this year's Calypso Monarch show hat some went for divithat some went for siveness and some for cohesiveness - so there is a dichotomy. But the thing that disturbs me about calypsonians is when they do things to own agenda - when they instigate, rather than merely reflect (and accurately so what's taking place." and the sudden 'aware divide society for their don't care yes... not even about the results. Yes I am in the PNM, I can't recall how long, I sing at all their functions, in fact I am the property of the PNM, lady, that's how I see myself. But I also see things through the eyes and ears of the people, I speak for those with no voice, so this gues beyond politics.

"Everybody belongs to some group. Sit Maharaj speaks for the Hindus, Nizam Mohammed for the Mohammed for the somebody have to represent the PNM. But nobody can say l'm politically biased because I criticise everybody from George Chambers when I was singing in tents, to Patrick Manning and Rubinson..."

Last year, Aloes caused some intrigue caused some intrigue when he claimed that "lot of big Indian busi nessmen" paid him "bíg money" to criticise Robinson when he was NAR's Prime Minister:

"But I wasn't saying I was for sale, eh, what I meant was, they would hire me for every funchire me for every tunc-
tion they could get me to perform at and they enjoyed it. The Indians used to line up in the centre aisle to hear me; they used to push $\$ 100$ notes in iny hand when I used to sing... like a tip!"

But why break pattern from singing about Prime Ministers - a subject normally tackled by calypsonians - to a PM's wife?

Figure 4-12 Pt 1 of Article from Trinidad Guardian 21 Feb 1999 


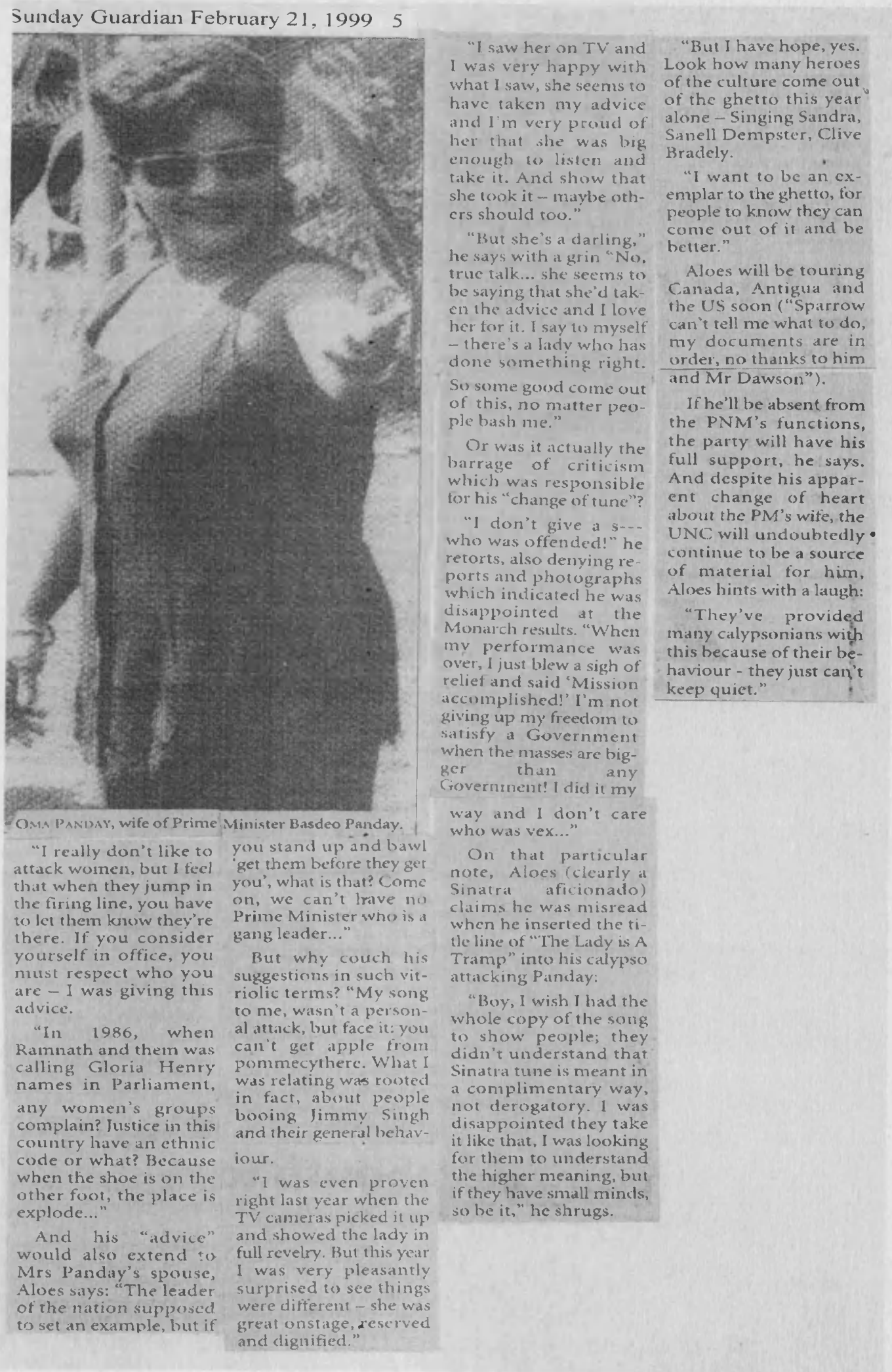

Figure 4-12 Pt 2 of Article from Trinidad Guardian 21 Feb 1999 


\section{In relation to verse two}

The second verse highlights the level of conflict prevalent between Calypsonians and the government and the obstructions that the government officials can place in the way of Calypsonians as they try to fulfil their function within the society. One way that the government can seek to do this is to overtly or covertly impose censorship and in this way effect a level of control on the accessibility by the public to the lyrics of Calypsos that they consider 'offensive'.

By using the words:

I want you to work for your money, but ah can't disobey the man In this Calypso, Aloes is recognising the considerable pressure that the National Carnival Commission faces from the government which in the end is supported by the Ministry of Culture. So Aloes is showing a recognition that the hand that pulls the purse strings is the hand in control. As a result, some of the Calypsonians I interviewed alleged that pressure is placed on the NCC by the government in an attempt to regulate which Calypsonians get to go on to the show. It has also been rumour by some some Calypsonians that the government's influence can be seen to manifest in the outcome of the judging for the Calypso Monarch at the Dimanche Gras Show.

One of the issues behind this Calypso is to do with the fact that Aloes had the previous year, composed a Calypso in which he commented adversely about the then PM's (i.e. Mr Panday's) wife. The article that follows appeared on page 11 of the Sunday Express of $21 \mathrm{Feb} 1999$. In it Ryan asks significant questions that relate to poetic licence. 


\section{How free is Aloes?}

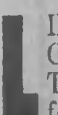

IKE the proverbial "curate's egg", Carnival 1999 was gond in parts.

There were many outstanding per-

formances by individuals and groups which gave much enjoyment to those who participate in the festival even if passively. There was also much that was poor or mediocre in the tents and elsewhere. Among the persons whose artistry I particularly enjoyed were Singing Sandra, "Voices from the Ghetto", Kitchener, "Toco Band", Bradley and Despers, Rudder, "Adrenalin City", Errol Ince who played beautiful trumpet for those of us who played in Poison, Pink Panther, "Apology", Chalkdust, "Tribute to Pretender" and Duke, "Horn Proof".

I wish I could have added Sugar Aloes tn my list of cherished pertormances. I have in the past been a supporter of Alces and defended him when he was under attack from Maha Sabha propagandists during and after the 1997 and 1998 Carnivals. I heard Aloes in the tent again this year, and my immediate reaction was negative. Aloes was a tent favourite, and it was clear that much of what he had to say found resonance among many who vicariously enjoyed the "picong" and the "ponging" that UNC public officials and others received. In the minds of many, Aloes spoke for them. His was the authentic voice of the "peoplen, the "people" in this case being those opposed to the UNC.

There is a line between "picong" that is subtle and economical in its true or "under-use" of language, and vitriolic and direct abuse. My own feeling is that Aloes strayed beyond the crease this year, and I am not referring only to the comments about $0 \mathrm{ma}$ Panday's behaviour about which we had heard a great deal last year. Carlos John, chairman of the National Carnival Commission, was also verbally abused, though, to the best of my knowlenge, no words of protest have been forthcoming on his behalf by those who have rushed to Mrs Pandav's defence.

My intervention, however, has noth. ing to do with whether I liked Aloes song or not, but with whether or not as a calypsonian operating in the historical and cultural milieu of Trinidad and Tobago, he is free to sing whatever he pleases, all in the name of freedom of poetic expression. Alnes claims that he has complete freedom to sing whatever he wishes. The society is, however, divided, mainly but by no means exclusively on ethnic and political grounds, as to whether he does in fact have such freedom. Bristled Alnes: "If dropping the verse means I will win. I have to

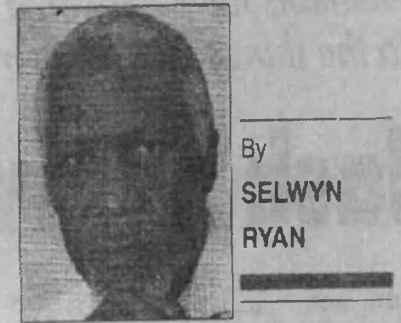

It would appear that Aloes had given thuught to dropping the offending verse, but felt he had no choice but to sing it after the UNC Couva group publicly attacked him. Given this (so the tale goes), he had to stand firm, not only on his own behalf, but on behalf of calypsonians to come and the calypso tradition. He had to defy the politicians. Not to do so was to capitulate to the long arm of the State.

Whether Aloes was aware of it or not this was the same position taken in 1950 by Atilla and the Growing Tiger when the authorities sought to silence the latter whose two songs, "Legro the Dog, Gemma" and "Daniel Must Go", outraged the social elite of the day. Oma Panday was not the first visible Indian woman to be attacked in calypso. "Leggo the Dog" was in fact greeted with more outrage than that which was generated by "This Stage is Mine". The song was called "vile",

"scurrilous" and "cowardly" by its critics who told Tiger, "Don't sing Dat", but instead sing only clean and uplifting songs! Plus ça change!

As tent manager, Atilla told Tiger to sing the two songs despite the ban whioh was imposed on them by the Police acting in accord with the 1934 Theatres and Dance Hall Ordinance. Atilla's position was that the ban involved a gratuitous attempt to censor calypsonians without benefit of trial. In his view, there were laws on the books against defamation which could be invoked by the state if it so wished. Why a special law for entertainers and the renues at which they performed?

Interestingly, the Guardian mounted a crusade against the song which was supported by the Women's League.

Clearly, what we witnessed during the past few days is a reprise of an age-old battle that has been waged over the last six decades or so between the calypsonian and the visible social elite in general and women in particular. Ethnicity has only served to complicate it. $\mathrm{n}$ the past, it was a case of black calypsonians lampooning members of the black political elite and black women of all classes. It was "black on black" verbal warfare, and many took it in stride. It was part of a tradition which deemed it acceptable for blacks to "denigrate" other blacks, particularly those who were upwardly mobile, and or course women. Once the guns were trained on persons of other ethnicities, especially on a group which was less confident of. and determined to establish its place in the Caribbean sun, an attack on one was seen as an attack on al. It is not only the amour propre of the individual that was being singed by Aloes, but that of the group, all of whom were expected to rally, flock-like, to the deplumaged bird.

But where do we go from here? Must we say that because Sparrow Kitchener et al sang sexist songs and were applauded by all and sundry, including some of the latter-day critic of Aloes, that we must continue to condone and applaud such songs? Each era has a spirit, what the Germans cal the zeitgeist, which helps to define that which is culturally acceptable or unacceptable, even if legal. It is no longer acceptable to disrespect women in the manner in which our calypsonians were wont to and we have to encourage our bards to respect women (in effect our mothers, wives, mates and daughters, etc), lo find ways to say things about them in song, if necessary; that are more allusive and less direct. Kitchener has got the message and his creativity as an artist has not suffered. (By the way, when are we going to give our highest honour to Kitchener?)

There is une ather imperative. We have to prevent the politicians from using songs like that which was sung by Aloes and the remarks which were made in the name of Christianity by the Thusians, as pretexts for Section 7 of the Equal Opportunities Bill. Freedom of expression is a dangerous concept. Legislation to curb freedom of expression can have even more dangerous consequences!

Figure 4.13 - Newspaper article discussing Calypsonians' freedoms 
Chapter 4 - Conflict in Trinidad: The Wider Perspective

\section{In relation to verses four and five}

In the article that follows, Professor Theodore Lewis, observing the criticisms levelled at Aloes, tries to bring a sense of balance to the debate. While supporting the notion that women should not be denigrated in Calypso, he does make the salient point that some of those who criticised Aloes, themselves were in times past, the very architects of the denigration of women.

In verse five, Aloes recalls that Sparrow, who in some of his earlier Calypsos, seriously denigrated women, now finds himself seriously criticising the lyrics of Aloes' Calypso.

Without entering the argument regarding whether Aloes is acting appropriately or not by singing about the PM's wife in the way that he did, I have to state my personal experience. In my youth, Sparrow became a national figure and very much a household name. His Calypsos were played profusely on the radio and in other local venues. I can therefore vouch for the fact that as I transitioned from a child to a young man, while growing up in Trinidad, I frequently heard many caustic Calypsos on women that were sung by Sparrow.

On this count, recalling some of Sparrows Calypsos, Aloes reminds us that in "Philip My Dear" he even sung a song about the queen. The lyrics of which are available at Appendix 1. Not only did Sparrow sing about the Queen but also Princess Margaret's wedding to Anthony Armstrong Jones. More recently in a Calypso, released during the leadership of Mrs Thatcher, he asserted that two women were ruling the Town and hence London Bridge was burning down. These Calypsos loaded with pun and innuendo bear testimony to Sparrow's view of women. 
Professor Theodore Lewis' article follows:

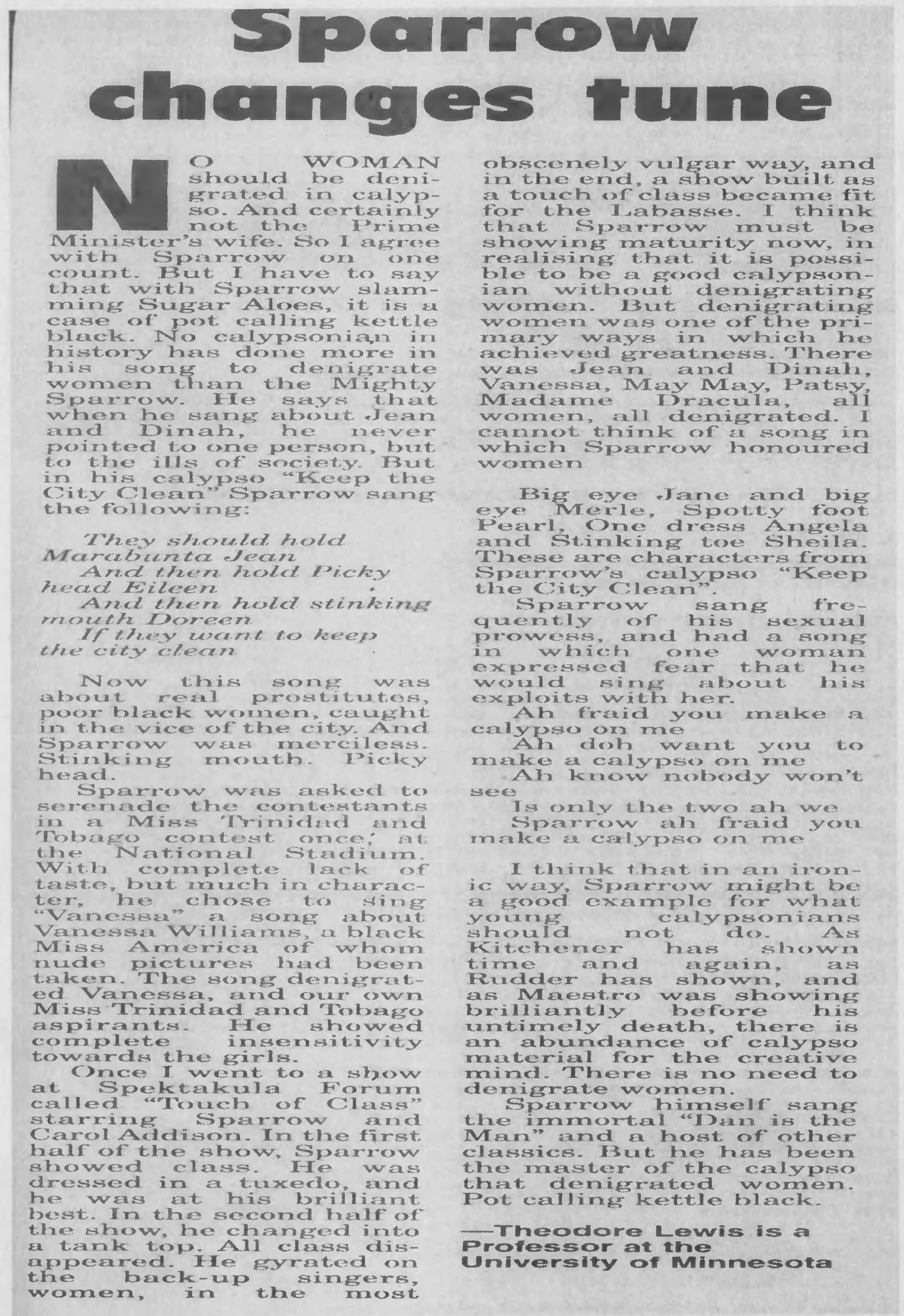

Figure 4.14 - Newspaper discussion by Prof. Lewis 
For his part, the treasurer of the UNC expresses his view on the events below:

\section{Calypsonians are cheap pawns in a deadly political game}

IT seems that every year around this time the nation becones embroiled in a bitter controversy between calypsonians and the victims of their lyrics.

These debates, more often than not, consist of charges of racism. bigotry, slander and character assassination. The victims are invariably politicians or prominent personalities, and the calypsonians claim artistic license, a right to comment on what they perceive to be the ills of the society. For two years running, Oma Panday, wife of the Prime Minister, has been singled out for persunal and vicious attacks by one calypsonian.

It is sempting to engage in a counter-atiack, but I think that would be counter-productive. It is better to look on the positive side and highlight the attributes of Mrs Panday as a sharing and caring personality.

proved.

Local political nasters viewed the ghettos as major vote banks for their own political agendas, and probably perpetuated the sutterings of these residents in orter wo control the votes. In effect, the politician imposed a new type of psychological domination, based on a dependency syndrome.

The role of the calypsonian or social commentator must be one of highlighting the serious socia ills affecting communities rather than settling for scoring cheap political points while the real culprits waik tree.

The calvnsonians are being used as cheap paswns in a deadly polit ical game. The IINC is portrayed in song as perpetrators of ghetto litestyles, as though it was a recent phenomenon.

Christoplie Grant, writing for Singing Sandura, was introspective, relevant and brilliant in his topic

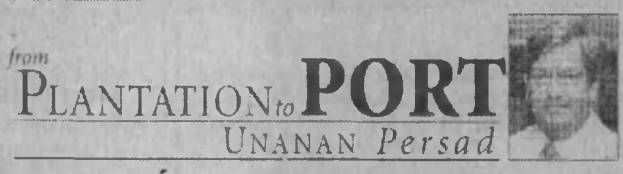

Oma Panday can be considered a pioneer in promoting total participation in Camival. At a time when Indo-Trinidadians were accused of nut participating in Carnival, she was active in street mas as far back as 20 years ago. Today, thousands of Indo Trinidadian women join with women from all other racial origins to outnumber men in parading openly, in the street bands.

Mas is now considered in vogue, and local participants are ioined by thousands of foreigners who enjoy clean, uninhibited fun on the two days of revelry.

Oma Panclay is also the patron and tounder of the Organisation for Social and Economic

of choice for the calypsoes he penned. His serixe of protessionalism is unpraralleled in the history of calypso lyrics. In a victore interview, he said he tried to "place my finger on the inajor issues of the day." Recalling The Mighty Shadow's "Poverty is Hell", Grant said his composition was in:end ed to go further and deal with the psvchological degradation of the people who live under these cunditions from day to day.

His other composition was probably in response to the current asinune debate taking place between some religious groups who are attacking each other's religion and faith. This composition, "Song for Healing", expressed the view that people must know "that no matter what religion they belonged to, they could pray for healing."

It is calvpsues like these that re ally make the art form relevant to the evolution of the society.
Developinent (OSED). Through this non governmental organisation, she is involved in the physical and psychological development of communities. Funds raised by the OSED provide assistance and $\mathrm{seT}$ vices which are not available through public sector progranumes to depressed villages and neglected communities.

Oma Panday gives selflessly of her time and effort to those in need of assistance.

The UNC Governmelt also continues to be the target of many calypsoniaus who highlight the negative aspects of our country. In the three years of LNC governance, much as been done to alleviate the conditions of the depressed communities with the
Instead of adderessing the periph eral issues that are symptomatic of the problems, we need to identify the maladv itself

Singing Sandra's calypsoes are an in-depth and analyrical exploration of the ghetto problem that affects both urban and suburban Trinidad and Tobago. Now that the problem has been identified. solution can found. Unlike Singing Sandra, who has taken a positive approach, other calypso. mans have chosen (o) obfuscate and confuse the issues with narrow and petty agesidas.

They will continue to strut and tret their hour upon the Carniva stage, with tales told by idiots, full of sound and tury, and signifying nothirig

History will be their harsh judge. the UNC Treasure assistance of many NGOs. These communities have not been cre ated uvernight.

The mass migration of the African slaves to the city began with emancipation. In an effort to distance themselves from the plantations where they were forced to work long hours under inhumane conditions ex-slaves migrated to urbars townships, settling in cramped communities. This was the genesis of the modern ghetto.

These communities are characterised by crowded and substandard housing, lack of running water, no electricity and an absence of basic services for health and sunitation. This svas typical of the colonial period. Artainment of self rule and eventually independence from the colonial masters did not see much change in the physical conditions of ehetto lite, and in some instances conditions deteriorated rather than im-

UnALAN Pfrsad is

Figure 4.15 - Newspaper discussion by UNC treasurer 
Chapter 4 - Conflict in Trinidad: The Wider Perspective

\section{In relation to verse six}

As is usually the case in these circumstances, this conflict was not localised only to those who were seen to be either educated or prestigious. The following article shows that a cross section of the community also felt confident and free to comment on the situation. In The Republic of Trinidad and Tobago this type of debate happens frequently and is spontaneously generated in public spaces. It has been my experience while travelling in one of the localised, privately owned buses (commonly known as a Maxi Taxi), that conversations and debates occur between and among total strangers on any of the prevailing issues of the time. Conversations about what is currently happening in the field of Calypso are no exception.

The articles on the following page share some of the views of other citizens. 


\section{Why criticise Sugar Aloes? \\ THE EDITOR: To the Sparrow would join critics of Sugar Aloes. \\ Have any of you ever stopped to consid- er that rather than being bitter as you hypothesise, that this man is suffering from broken heart? \\ He is hurt by the attacks on democracy attacks on democracy mayed by the eorrup tion in the corrup- bleeding for the attacks bleeding for the attacks on African popular cul- ture here in Trinidad and Thaso, and dis- gusted by the analicious mischief aimed agains him by this govern- ment and its puppets. \\ Anyone who was watching that lonely figure on the Dimanch Crras stage, and listen ing to the mournful tone that delivere This stage is Mine should have had an emotional and pusitive reactinn to sugar Aloes. You have would have understood that he is trying to uplift this nation hy hringing what is in the dark to light. \\ with BWLA's chairman Lawrence Duprey and the woman's arm of the UNC to attack Suga Alocs. Does the "calyp so king of the world think that if Suga Aloes had sung about Mrs Man sung about there Manning that there would have been these people? He these people? He that he allowed himed that he allowed himself to be used in this way. The death knell of the black man has been be at the hands of the house Negro. \\ He needs to sit down and listen to Stalin's song. "Suffer- ers". As a former sur- ferer Sparrow should know that Sugar Alpe \\ The only sim of peo ple like the UNC women and Duprey, a women and Duprey, a establishment, is to keep Africans in this keep Africans in this country in a passive state. What better way to do that than to shut, up their preatent The criticy should \\ also note that seven of 12 competitors at something negative to sing about this govern- ment. Two of the 12 had scathing cumments of the social ills plagu- ing certain areas of this country. Do the of that equals is 75 per cent. \\ Rather than trying to fix Sugrar Aloes, why UNC women and this gov- well, I said fix ituelf well, I said fix \\ As Sugar Aloes's ritics you should also realise that he could not exist if the people did exist if the people did not doem him nec- essary. Now you must be running scared because he has proven to be a formidable opponent. He told you phint blank before the competition that he rather lose than kow- tow to yout. Like a true warrior he stuck to his \\ Thank you, God, for Sugar Aloe: \\ BIANCA T JACOB Point Fortir}

\section{Sing on Sugar Aloes}

THE EDITOR: I find it ironical Panday and, of al people, Sparrow took a turn at this very popular bard. Sugar Aloes. Does Panday forget when he was in the opposition the things he said of those in the Government and anyone who opposed his view? Sparrow? used to sing on anyone and his brother and didn't give a damn.

Sugar Aloes sing on and don't give a damn it is you time now tell that to Sparrow and all those who don' like it.

M PESTANA,

vist $e$-mail.

Pt in bevetar Guandien ar/2100

\section{Kaisoman calls for better image}

SINCE the 19th century, Carnival has always been a tension releuse valve for our society. A reflection of what was going on in $T \& T$.

Respect for our culture begins with an appreciation of its history. Competition in Carnival can be productive or counter-productive, depending on the perspective.
To my mind it is not to be an instrument of disharmony but an exercise of joy, creativity, harmony and to. getherness.

Congrats and good luck to my fellow calypsonians who have made it to the $2001 \mathrm{Ca}$ lypso Monarch finals. It is an honour, not a right. Enan honour, not a rish

joy the experience.
Trinidad and Tobago, if we love Carnival, calypso and pan, wo must desist from actions and statements that will bring into disrepute

Let us be constructive and solution-oriented - the time has come to end the Carnival is confusion and bac chanal image.

HOLLIS WRIGHT,

\section{Sugar Aloes}

has become predictable

ON February 17, singing "You Got the Government You Deserve", Michael Osuna, better known as Sugar. Aloes, supports and endors es the overthrow of the Government by calling for "re bellion against the tyrant". In this case, the tyrant he is referring to is the Prime Minister.

I call on all civic-minded, decent Trinidadians to take stock of these tents that prostock of the tent of promote this brand of calypso. While the calypso has it role in the evolution of society, I am of the opinion that Mr Osuna has gone too far Incidentally, Osuna's 2001 offering sounds very much like his 1999 and 2000 offerings. One can now with a high degree of accuracy predict what Mr Osuna will sing about

I was impressed with 1 was impressed with Denyse Plummer and Bomber who both put on high-quality performance which moved the crowd. believe that Plummer and Bomber stand excellent chances of winning the 2001 Calypso Monarch crown.

DIR MOHAN BABOOLAL, Curepe.

Figure 4.16 -Various Newspaper articles expressing views on Calypsos and Claypsonians 
Chapter 4 - Conflict in Trinidad: The Wider Perspective

\section{Taking an overall view}

In addressing this conflict, the Psychological Research Centre of the University of the West Indies conducted a survey asking questions relating to Aloes, trying to determine whether the public considered that he needed to show more respect. The results of this survey were published on page 3 of the Sunday Guardian dated $21^{\text {st }}$ February 1999 and are available on the following page. This article suggests that of those interviewed assuming that they were a cross section of the citizens of the nation - the majority were of the view that Aloes' comments were inappropriate.

I have been in Trinidad for every Calypso season that has occurred during the course of my research and recognise that because of the directness in the way in which he communicates, much debate is generated relating to some of Aloes' presentations. 


\section{Aloes should show more respect}

\author{
IN THE 24 th nationwide \\ survey conducted by the \\ ANSA MCAL Psychological \\ Research centre at the Uni- \\ ( versity of the W'est Indies for \\ the Sunday Guardian, more \\ women than men believed \\ that calypsonian Sugar Aloes \\ should have removed the \\ controversial verses from his \\ calypso "This Stage is Mine". \\ 5. Fifty-six percent of the \\ women surveyed felt Sugar \\ Aloes should have removed \\ the controversial verses, in- \\ 7 cluding references to the \\ 2 Prime Minister's wife, com- \\ pared to 52 percent of the \\ men interviewed. \\ In terms of ethnicity, 73 \\ percent of Afro-Trunidadians \\ and 35 percent of Mixed per- \\ sons responded negatively to \\ the question, as compared to \\ only 12 percent of Indo- \\ Trinidadians who gave neg- \\ ative responses. \\ Some of the comments \\ that accompanied the re- \\ sponses were: \\ - As a senior calypsonian, \\ one would expect him 10 \\ have a lot more respect for \\ the svife of the Prime Minis- \\ ter, 4 in 11 in's \\ - Sugar Aloes ofly sing \\ with pure hate and he nceds \\ to address his problem. \\ - By attacking the Prime \\ Minister's wite he shows how \\ really low he is. \\ Some of those who sup- \\ ported him said: \\ - What he sing is the truth." \\ - They are always putting \\ pressure on hin about the \\ calypso he sing; but that is \\ what calypso is all about \\ - Sugar Aloes shouldn't \\ change any verses in his song \\ because of freedom of \\ speech.
}

(2) Do you agree with the selection of Singing Sandra as the Calypso Monarch for 1999?

An overwhelming 86 percent of the respondents agreed with the choice, while only six percent did not More Indo-Truidadians - 94

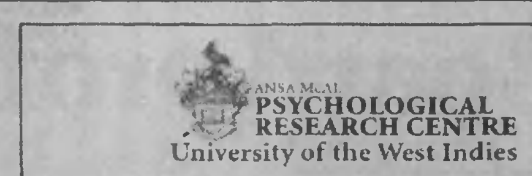

Do you agree with the selection of Singing Sandra as the Calypso Monarch for 1999?
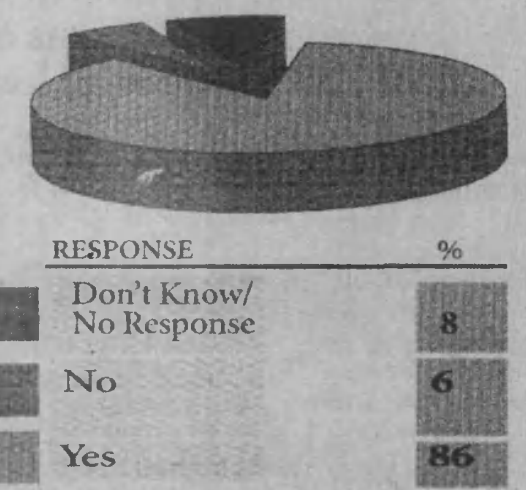

Dos you think that corporal punishment in primary and secondary schools would reduce the level of violence in schools?

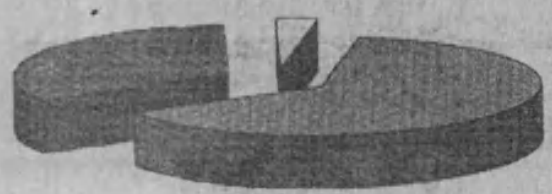

RESPONSE $\%$

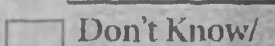

No Response

Gita No

bisen Yes $\%$
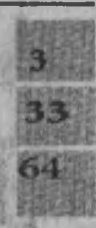

percent - supported the decision, compared to 84 percent of the Mixed population and 83 percent of A1roTrinidadians. A remarkable 100 percent of the unemployed population agreed with the decision, compared to 92 percent students and 89 percent of the lower class

(3) Do you think that corporal punishment in primary and secondary schools would reduce the level of viulence in schools?

Sixty-four percent of the respondents belicved corpo- to have more control of their students.

- If it worked in my diays I don't see why it wouldn't work now.

- Recause 9 percent of the crimes that are committed is done by youths ages 15-25 so it begins at a very young age and if children are punished for what they do from small then they will learn that there is a penalty for breaking rules or laws.

Others felt it was

- a violation of the rights of the child and some teachers punish children unnecessarily and

- if corporal punishment is introduced the violence will increase because the youths will feel threatened.

\section{Figure 4.17 - Finding of research conducted by Uni. of W.I.}


Chapter 4 - Conflict in Trinidad: The Wider Perspective

\section{Positive Aspects of Conflict}

In contemporary Trinidadian society, the concept of conflict is used positively. It is

used as an attraction, "a crowd puller". The advert below demonstrates this well.

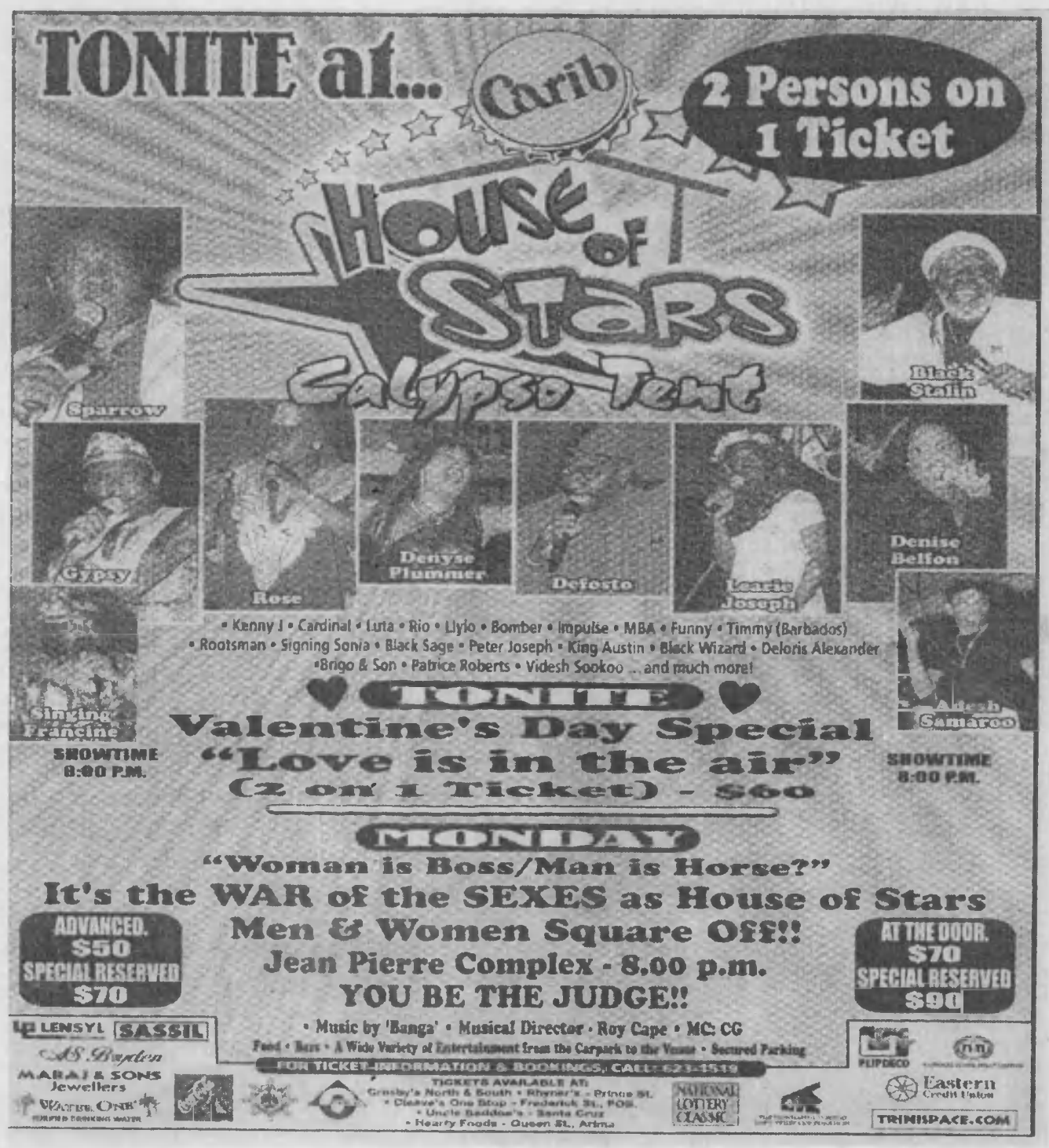

Figure 4.18 - The positive aspects of conflict 
This advert, which appeared in a daily newspaper, celebrates the appearances of male Calypsonians against female Calypsonians in the War of the Sexes at the House of Stars. In this portrayal, it used the concept of the conflict as a lever of attraction to swell the numbers at this Calypso Tent. In this way the process of conflict has been turned back on itself.

\section{CONCLUSION}

I have used this Chapter to set the scene for an understanding of the nature of the conflict that has occurred in the society of Trinidad as the country has changed over time.

The four main areas that I have looked at are the conflict that has existed around canboulay/Carnival, the Calypso, Stickfighting \& steelbands, and contemporary expressions of conflict. I have shown how these have been the result of the pressures applied by the ruling class in a heavily stratified society, I have also shown how they have been a response by the working class to the oppression that they have experienced.

This chapter then forms a back-drop for the remainder of this work, as it sets the scene for and understanding of the work of, the Calypsonian as s/he, using language as symbolic action, raises social consciousness in an approach to resolve inter-strata conflict within the society of the Republic of Trinidad and Tobago. 


\section{CHAPTER 5: LANGUAGE AS SYMBOLIC ACTION}

The method would involve the explicit study of language as the "critical moment" at which human motives take form, since a linguistic factor at every point in human experience complicates and to some extent transcends the purely biological aspects of motivation.

Burke, K. (1945:318)

\section{INTRODUCTION}

$\mathrm{T}$

his Chapter has two key functions. First, it sets the background for understanding the extrinsic context of the art form, that is to say, the Calypsonians' basic act of artistic creation as well as ritual communication. This is set against a context of understanding how these attributes drive the outer act of communication. Equally important though, it also sets the context for understanding the inner act of authorial intention i.e. the intrinsic context, while also paying particular attention to the contents and structure of these Calypsos. These methods and techniques as used in the presentation of Calypsos, are underpinned by Burkes work on "Language as Symbolic Action".

In relation to this work, Burke's theory of "Language as Symbolic Action" offers a view of the verbal acts of Calypsonians as symbols in action, representing the verbal parallel to a pattern of experience (Burke 1968:152).

Burke's work was a development of an already existing paradigm, that in the animal kingdom, humans remain uniquely separated from other species by their ability to use a structured language in a process of symbolic communication. Burke developed the concept by highlighting a distinction between action and motion, recognising that while things may have motion, humans act. In using the word $a c t$, I recognise Burke to mean 
any verb, no matter how specific or-how general, that has connotations of consciousness or purpose (Burke 1969:14). This distinction therefore rests on intent, as he identifies utterance as an act, in that it captures a methodology that recognises and unveils something about the interaction among the imaginative worlds of those present, as each individual witnessing the act, is transformed by the language. Burke considered that language is a fundamental tool used by humans to symbolically transmit ideas of reality to each other. In "Grammar as Motives," he writes:

The method would involve the explicit study of language as the "critical moment" at which human motives take form, since a linguistic factor at every point in human experience complicates and to some extent transcends the purely biological aspects of motivation.

Burke, K. (1945:318)

Adopting this approach, I argue that Calypsos, in commenting on social, political and economic issues within Trinidad, are taking critical action. They rely on the effective use of language to generate for the audience, an altered understanding of the issues, which subsequently, permits individuals to change their actions, hence having an impact on the conflicts in their lives. From my perspective as an analytical practitioner in conflict resolution, I intend showing, not only the use of Calypso language, but also how that language is structured to effect specific outcomes.

Burke's declared intention for his study of the use of language, was "to identify the substance of a particular literary act by a theory of literary action" (Burke 1957:ix). Burke defined literary act as either written or spoken words (Burke 1968:123). In the context of the Calypso, (and with the exception of extemporaneous Calypsos), all Calypsonians firstly write down the words of their Calypsos, they then learn those words, before subsequently performing them to music. It is for these reasons that 
although Burke refers to the spoken word, I make no distinction between words that are spoken, and words that are uttered rhythmically to musical accompaniment (i.e. sung).

\section{THE PuRPOSES OF SYMBolic ACtion}

Using Burkean philosophy, we can derive a relationship between a symbol and our orientation to an experience. In fact, we frequently find that the symbol of an experience is intrinsically embodied in our experience of the event or series of events. Symbol, when used in this way, can make multiple representations to an audience. Given this set of circumstances, we arrive at a junction where interpretations become individual in an array where, for a given symbol, understanding is derived and meaning constructed by that particular individual. This point can best be illustrated by considering the following four ways that Burke offers in which symbols can be used. First, symbols may be used to interpret an event by providing a terminology for the codifying of the experience of the event. That is to say that this presents an opportunity for the experience of the event to be codified i.e. ordered or schematised.

This point is graphically illustrated by the words of "Voices from the Ghetto" sung by Singing Sandra (see Appendix 1 for the full text of this Calypso) where Sandra relives and re-stories the experiences of those who experience the misfortune of living in a ghetto:

The sun rises slowly over the hills Everywhere is golden sunlight but still Most lives with sad tales are crowded Their days a dark cloud is shrouded They don't smile and they never will Only vultures get their fill 
Chapter 5: Language as Symbolic Action

Outside the sirens keep howling

Inside your belly real growling

Police raid very often

Simpson measuring a coffin

One night in bed yuh sleeping

Next night is a wake that you keeping

So yuh praying to win the lotto

Not to hear voices from the ghetto (Avaialble at Track 4 on CD)

But to reinforce the point of her personal experience, towards the end of the Calypso she

states that she is communicating from her own personal experience thus:

I was born and bred in the ghetto

Ah know what ah talking about yuh know

I is from the ghetto

Second, a symbol may be used to support the acceptance or acknowledgement of a

prevailing situation. In doing so, this is also underwritten by an attempt to elicit a

correction of that situation. This combined process is central to resolving conflict, the

process of being the mouthpiece that voices what is considered unacceptable, thereby

releases latent or submerged experience for conscious attention. In considering this

point, we need to pay due regard to the following excerpt from Sparrow's "Rip Off".

Help! Murder!

That's the cry of the average man in the land today

The pressure is terrible, All ah we in trouble

And very few in government helping out the people

Yuh shut your eyes when businessmen start brewing

Surplus profits for them foreign misery

Import freedom is less and less

The local produce goods is a total mess

Substandard, price to excess.

Who go take the blame, for the amount of shame

Rasakality and skulduggery

I believe we have reached where somebody should be impeached

For breach of promise, disloyal practice

Anywhere you turn is some underhanded business 
Where is the lesson in ethics that we should get Where are the good examples that they should set We are not the idiots out about So put them guilty ones out! . The welfare of the people is too much in doubt

Ah can't stand the pain, Ah tired 'holding strain' Its only tears and a heavy set of prayers Teachers, preachers, rastas, police and thieves The man who on food stamp the kitchen assistant Their salary so scant that they can't buy food and pay rent

Where are the politicians in whom we trust? Where are the labour leaders who leading us? Do they ever hear the people cry? Do they see tears in big man eye? Asking why, the cost of living so high?

Fire in the place, Customs gone to waste Because of the abject and sad neglect Now the general expression from all who love this nation Is ruination, humiliation Like if the devil have a hand in running this land

Ah can't forget all the campaign promises Cheap food, good school the total priority The cost of living get so rough

To merely exist is touch And half the leaders in the country is a rip off (Available at track 5 on CD)

Third, A symbol may also be used to liberate certain values at the cost of others. In so doing, the symbol alters the audience's attitude towards a previously held value that is now considered to be untenable. This is done by drawing attention to the relationship between an initial value and certain other ignored but conflicting value. This polarity between these two sets of values is graphically illustrated in the Calypso "The People Will Talk" as it draws attention to the lived reality of many Trinidadians. We find that the words of this Calypso urge individuals to recognise the centre within themselves. It does this by getting them to address what is appropriate for their needs as opposed to 
being caught up by and drawn into the fragility of a destructive vortex that swirls feelings that drive a need to adhere to popular opinion while seeking approval of others.

“The People will Talk" by King Fisher graphically illustrates this point.

Not only here in the West Indies

Ah find people is hard to please

This is really true

No matter what you do

I aint talking nonsense

This is practical experience.

Don't mind how you try

They will criticise and ah don't know why

If you changing steady and looking fancy

they will say how you showing off

an if you keeping yourself like a bad john

They will watch and laugh

But ah forwarding a plan

I aint watching no man

Ah just doing to suit meh self

Because if it is not how you dress

But just the way that you walk

The people will talk!

Take for instance when ah was small, every day was a bacchanal

Well ah always misbehaving with expression and street fighting

Well they talk all over the place how ah so bad and ah out of place

Now ah playing cool and easy

The same people say how ah stupidy

How ah can't even fight

Ah always stepping light with socks and shoes on meh feet

And how ah playing a this and playing a that

And like a girl meh skin smelling sweet

Ah ent watching no man ah just doing to suit me self

Because it is not how yuh dress, it's the way that yuh walk,

The people will talk

(Available at track 6 on CD)

Finally, some symbols offer a direct appeal to the individual's aesthetic senses for balance, order or beauty (Burke 1968:154 - 156). A point made by the Calypso "Good time" by Stalin. 


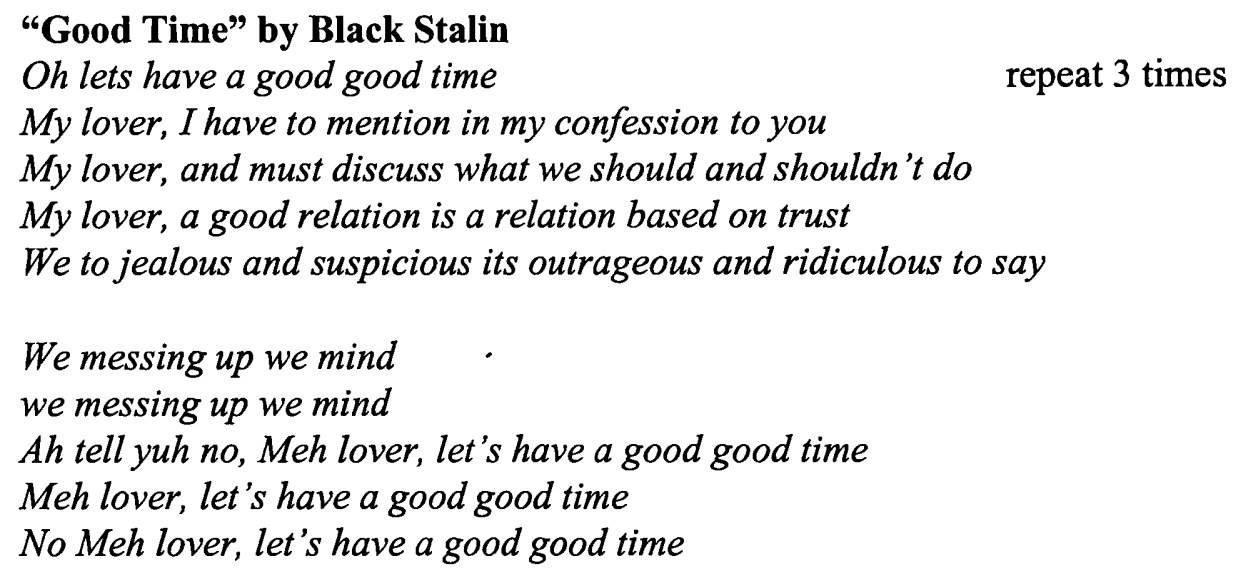

\section{THE LEVELS OF SYMBOLIC ACTION}

Burke identifies three levels of symbolic action, that, for the purpose of this work, I will interpret and translate in view of the subject of this manuscript. The first of these, and what I identify as the most ossified, is the biological level of kinaesthetic imagery. This kinaesthetic imaginary is the driving force in the Calypsonians' world that eventually manifests as a Calypso composition. Given vent in this way, the "Calypso is a mediator" between the oppressed individuals and the structure of society. With some reservations, this scenario can be equated to Lévi-Strauss' presentation of the shamanistic cure. In this scenario, we find a "believer" or client (in this case this can be the individuals who make up the audience), a myth or technique (the Calypso) and finally the shaman (here the Calypsonians).

The second level of symbolic action is the personal or familial and revolves around symbolic behaviour. At this level there is a regard for relationships. In this regard, I needed to identify the relationships existing within the Calypso Tent. In Chapter 9, I identify and develop these relationships in the context of the Audience as Co-Mediator. 
Finally, the third level of symbolic action involves the speaker breaking down the boundaries and joining the specific social group, hence the speaker enrolling himself in a band, through the use of various insignia, (Burke 1957: 31-33). This third strand is intrinsic to the Calypsonian in as much as given the social stratification in the society of Trinidad, it is worth remembering that in the main, Calypsonians have usually originated from the middle to lower orders of social stratification of the population of African origin. This point of origin automatically caters for the concept in Burke's theory of enrolling in a band. In this process the Calypsonian establishes partiality with the parties (i.e. the individual as manifest in the audience juxtaposed with societal) $\mathrm{s} / \mathrm{he}$ makes himself/herself a part of each group, building a role for himself/herself and thus enrolling in each band.

When symbols are used in a Calypso in these ways, they are not necessarily being used for the purpose of experiencing or re-experiencing an event, but rather as a social means of dealing with an occurrence by making a claim in relation to that occurrence. Such claims can transform a previous role of the occurrence, thereby giving it an alternative role. This process creates for the Calypsonians and/or the audience, a new or altered identity. As a result of this process, we find that a self-consciously voiced expression then becomes the process of adopting of various strategies for the encompassing of situations. These strategies size up the situations, name their structure and outstanding ingredients, and name them in a way that contains an attitude towards them (Burke 1957: 54) and (Abrahams 1968:145).

Overall, this process allows for the formulation of the problem from the perspective of the persons or "actors" in Trinidad society. To accomplish this, Calypsonians need to 
begin with an understanding of how Trinidad society constructs its basic form of classification of stratification. I contend that whether consciously or unconsciously, Calypsonians engaging the Calypso; inevitably elaborate recurrent social dramas, inventing regular actors be these the Prime Minister or other individuals of notoriety.

This requires of the Calypsonians an assumed starting point that, like dramatists, they also recognises that society relates its drama through its actors. This involves, not only play and plot, stage and scene, but also roles and actors, as well as an awareness of the conditions under which the piece is to be staged and received. In relation to this manuscript, when I use the collective mode of expression "dramatisation", I am simultaneously examining actors and social roles, because the rules and regularities underlying the drama also tend to underlie the deep motivations of the actors. It is worth recognising that both are subject to the same norms and travel the same pathway, reproducing themselves on various levels in different scales. In turn these interactions yield the unevenness that eventually leads to what we perceive as "social change"

Consequential to this understanding of the concept of Dramatism (or Symbolic Action) is identifying the parallelism between it and the theory of Drama, from which Dramatism derives its name. In drama, the central focus is on the acts that are performed by the players of the scene. In a play, the act is central in so far as it reveals human motives. Thus, drama can be regarded as a means of transformation and as a byproduct of that process. Hence, engaging in drama is also engaging in a transformation of identity. On closer examination, we find that the process of that transformation requires that certain sequential steps be followed, these being to firstly define the current position. At some internal level, this process in turn leads to the recognition of a degree 
Chapter 5: Language as Symbolic Action

of separation. At any level, healing of conflict occurs with incorporation with the later emergence of a renewed sense of identity.

This aforementioned process alludes to a Dramatic that in the Burkean epistemology allows us a technique of analysis of language and thought as basically modes of action rather than just means of conveying information (Burke 1966:54).

In considering this approach to the Dramatic, Burke identifies five terms that shed light on what he sees as the basic order by which we may examine linguistic transformations of experience. This Pentad of terms is Act, Scene, Agent, Agency and Purpose. These are understood as:

Act i.e. "what took place," in thought or in deed,

Scene i.e. "the background of the act," the situation in which it occurred, Agent i.e. "what person or kind of person ... performed the act" Agency: "what means or instruments s/he used" and Purpose: "why" the agent performed the act (Burke 1969:xv).

In relation to the events within a Calypso Tent, I translate these and see them as having a relevance to the process of resolving conflict as:

Act i.e. what took place during the presentation of the Calypso

Scene i.e. what is the background of the act, i.e. in what situation did it occur Agent i.e. what person or kind of person is the Calypsonian Agency: what means or instruments did the Calypsonians use/have at his/her disposal 
Purpose: why did the Calypsonians perform the act.

In relation to the drama, these terms do not exist in isolation, but they have varying degrees of overlap while forming a contrastive yet dynamic flowing relationship with each other, allowing the terms to be transformed into one another. This idea of a 'contrastive dynamic flowing relationship' can best be illustrated by using as an example, the differences in orientation that a painter decorator and an artist may have to a dwelling house. To the artist his/her role as a painter is to focus on the character of the house, expressing this in the final product, the work of art. Under these circumstances, the house may be regarded as the property of Agent. On the other hand, for the painter decorator, the same house may serve as a Scene or venue on which to practice his/her trade.

Similarly, as Calypsonians draw attention to the perceived issues about which they are singing, their orientation in relation to these issues can form a contrastive, dynamic, flowing relationship between themselves and audience, or between themselves and subject matter as they highlight the issues

In the final analysis, we recognise that there exists a type of interaction between these five terms. This type of interaction Burke labels as "ratios". We can therefore see from the earlier artist/painter example, these terms do not stand in rigid isolation but have some degree of overlap and degree of transformation from one to the other depending on the situation. Hence, as is to be expected with terms that are generative in this way, they may be regarded as ambiguous. This generative ambiguous terminology, can be appreciated by recalling my earlier distinction between action and motion and 
recognising that the type of human action we are here considering involves thought that is inextricably linked with language. This in turn requires an internal engaging process that requires the transformation of the "raw" outer world which the Calypsonians sees and represents in his/her Calypso.

Burke contends (and I agree, particularly in the field of conflict resolution) that the best method of debating human action cannot be one that is based on fixed terms. He contends that this can be best done through the contrasting ambiguity inherent in language:

We take it for granted that, insofar as men cannot themselves create the universe, there must remain something essentially enigmatic about the problem of motives, and that this underlying enigma will manifest itself in inevitable ambiguities and inconsistencies among the terms for motives. Accordingly, what we want is not terms that avoid ambiguity, but terms that clearly reveal the strategic spots at which ambiguities necessarily arise.

(Burke, 1945:xii-xiii)

It is essential for the purpose of this work, grounded as it is in understanding this approach to conflict resolution, that we embrace the concept that whenever we express or envelop a situation in words, by the very nature of that accomplishment, we have thereby created a one-sidedness, since only a portion of the reality can be expressed. This means that the expression lacks the totality and/or completeness or unity. Therefore in contemporary forms of expression we engage in the binary thinking of good or bad, illusion or truth, this illusionary way of thinking and presenting, blinds us to the totality of the world in which we live, thus we cannot see that never is expression totally one way or another. To my mind, the expression of this challenge to conflict resolution is best expressed through the following quotation: 
Today on the street I met, separately, two friends of mine who had gotten angry with each other. Each one told me the story of their quarrel. Each one told me the truth. Each one told me his reasons. Both were right. It is not that one saw one thing and the other something else; or that one saw one side of the matter, the other a different side. No: each saw things exactly as they did happen, each saw them exactly according to the same criterion, but each saw something different, hence each was right. I found myself perplexed by this double existence of truth.

(Pessoa n. d.)

The above quotation beautifully illustrates the dilemma of the mediator and allows us to keep our eyes firmly focused on these concepts, thereby bring us to the realisation that the use of "Dramatism" in this way offers a foothold to engage in the debate between subjectivism and objectivism.

With such engagement we find that we are not essentially trying to determine whether reality in and of itself is subjective. Burke contends that the salient issue here is more to do with addressing the question of whether human terms "enveloping" reality are incapable of capturing the crucial objective substance of reality. This brings us to the terminology used by Burke in describing man as the "inventor of the negative". By the very nature of language as it functions in the world in which we live, we recognise that we are confined to 'knowing' by ways of contrast and variation. In this way, it is easier to determine what something is not rather than what it is.

Hence, in relation to actions that have been taken, we can find ourselves in a position wherein we are able to arrive at an understanding of human motives dialectically by merging and dividing terms. It is in this way that we find that each term of the Pentad can be understood in relationship to the other terms, thus dependent on the context, as with the illustration of the artist and painter, each term can be transformed into another in this dynamic process. 
Chapter 5: Language as Symbolic Action

This understanding of Burke's philosophy can be applied in relation to the events in the Calypso Tents by considering the Calypsonians as the agent who acts and in so doing, may organise the opposition to act. Through this continuing process, the agent then attempts to engage his audience to see the situation from a different perspective, thus helping them to arrive dialectically at knowledge, (Burke 1966: 367).

For Burke, rhetoric is rooted in an essential function of language itself. This function is the use of language as a symbolic means of inducing cooperation in beings that by nature respond to symbols (Burke 1966:43).

Like Vigotsky, Burke sees rhetoric as a significant tool of learning and social education.

The individual person, striving to form himself in accordance with the communicative norms that match the cooperative ways of his society is by the same token concerned with the rhetoric or identification. To act upon himself persuasively, he must vigorously resort to images and ideas that are formative. Education ("indoctrination") exerts such pressure upon him from without; he completes the process from within

(Burke 1969:39).

I have come to the conclusion that, Burke's rhetorical approach is principally concerned with a process of influencing and persuasion to change by means of identification: whenever there is persuasion, there is rhetoric. And whenever there is 'meaning' there is 'persuasion'. (Burke 1969:72). Engaging the possibility of linguistic transformation (Burke 1969:402), Burke tries to identify key terms, in an attempt to decide which of these is ancestral and which one is derived. One seeks to characterise the disposition and the transposition of terms (Burke 1969:402). It is in this way that rhetorical analysis begins with an analysis of each symbol or verbal image as a bundle of principles (Burke 1969:86), I then intend to proceed to examine which principles of the 
Chapter 5: Language as Symbolic Action

bundle are included and which are excluded in a given Calypso. Here I regard the Calypsonians as selecting from the range of possibilities of meaning, those aspects that clearly identify with the audience (Burke 1969:38). Hence in the Calypso Tent the singing of the Calypso is the "performance" of a verbal act. This act attempts to shape the response (identification) of the audience through a process of symbolic transformations.

By this approach to the rhetorical work of Calypsonians who sing on social and political commentary, I am therefore paying attention to how verbal acts affect the audience at a socio-cultural level. Thus, referring to Burke's work, "motivation" is synonymous with "structure" rather than just an expression of a level of psychological stimulation (Burke 1957:91). Also, transformation is the movement from one order of motives or structure to another (Burke 1969:11).

At this point, it is helpful to reflect on the work of John Cawelti. In his work in the field of popular art, Cawelti argues that works of popular art are enjoyed by mass audiences because they articulate conventional themes within the bounds of formulaic structures and by so doing, they appeal to the basic social and psychological makeup of a community, (Cawelti, 1969). Cawelti holds the view that "the dialectic of cultural and artistic interests" can, at any specified moment in the history of the development of a community of people, be studied to reveal the major social, political and psychological concerns of an age as they manifest through the people's popular art forms. However, on the other hand, it is also true to say that the way in which art is appreciated can allow us to arrive at an understanding of how the art forms reflect the concerns of the time. 
Thus Cawelti sees the study of the formal qualities of popular art as a way of bringing to the fore the revelations of social history and human psychology of that community.

On the other hand, although the work of Burke is well established in the academic world that looks at issues of communication, it is not generally considered to be significant in the field of popular arts. However, I have determine and intend showing how Burke's work on the nature of Form has applications to works of Calypso-art, when viewed extrinsically. That is to say, that Calypsos relate to the wider social context out of which they emerge. I also will be showing in this manuscript how the Calypso art-form also relates intrinsically, i.e. in terms of the formal structures that are inherently used in the Calypso art-forms. Through my approach, I will show the contribution of the Calypsonian artist and the inter-play between the work and its audience.

Burke's concept of Form is well defined in his 1931 work called Counterstatement (reprinted in 1968 and referred to as Statement in future references within this work). In this work Burke defines Form as:

the creation of an appetite in the mind of the author, and the adequate satisfying of that appetite

(Burke 1968:31)

This view is consistent with that which states that Calypsonians are singing of aspects of life experiences, not just elements that are disjointed and separated from the other components of human existence. Burke holds the view "Art, at least in the great periods when it has flowered, was the conversion of transcendence of emotion into eloquence, and was thus a factor added to life", (Burke 1968:41). What we then find is that formal conventions can occupy a role that is intrinsically intertwined with human experience. So that for Burke, Form is a tool that enables us to structure our inner 
feelings and represent these feelings symbolically through the use of language. In turn, it is this Form which serves to bond both Calypsonians and audience, in the process of getting to a unified understanding in relation to the presenting issues.

Understanding the nature of Form and distinguishing it is important. Burke spends a significant amount of time doing just that in a chapter in "Statement" called "The Psychology of Form". Herein Burke makes the distinction between the psychology of information and the psychology of form.

Truth in art is not the discovery of facts, not an addition to human knowledge in the scientific sense of the word. It is, rather, the exercise of human propriety, the formulation of symbols which rigidify our sense of poise and rhythm. Artistic truth is the externalisation of taste.

(Burke 1968:42)

With information, then there is a requirement for the presentation of facts as they are presented for example, in a court hearing. This stoical way of presenting information usually examines what was done, rather than how it was done. To sustain the interest of the audience it is essential to have an appropriate balance between both form and information. To yield only to information can cause the audience at a Calypso Tent to succumb to what Burke calls "radical appetites". That is to say, the absence of symbolic analogise to human emotion. For the audience, a failure to link with them in this way can create a dearth in any urge for repeatability which would be indicated by a significant lack of interest in a Calypso. In general during my fieldwork audiences have not been nonchalant. Most audiences are attentive and responsive to the Calypsonian, even if that attention is to display a definite rejection of some aspect of the Calypsonian's presented view, (see "The Symbolic Use of Toilet Paper as a Mechanism of Response" in Chapter 9). The interest and involvement of the audience at a Calypso 
Tent can be appreciated from the recording available at Track 23 and 24 of the CD.

These tracks permits us to hear, in the background, the quality and quantity of audience involvement and interaction, helping in our appreciation of both the psychology of information and the psychology of form.

\section{DEFINITION OF TERMS}

In the process of developing my argument about the function of Calypsos that comment on social and political issues, I will be relying heavily on terminology that embraces the concept of Form, Function, Framing and Reframing. It is therefore appropriate to share my understanding of the terminology so that I enable a clear understanding of the trajectory of this work.

Form: I am taking this to mean the formal means and structures from phonology, to grammar, to speech style to larger structures of discourse such as generic packaging principles

Function: Primarily ritual text, that in this case, manifests in the practice of entertainment, for the purpose of focusing on an issue that needs to be addressed Framing: the setting of text in the context of the events driving it Reframing: this term refers to the meta-communicative management of text that has been recontextualised.

\section{UNDERSTANDING FORM}

Burke contends that Form is a set which is analogous to the inner states of our humanness. As such, a prior understanding of 'form' is important and pivotal to our purpose i.e. that of understanding how Form is incorporated into the communication 
process used in certain Calypsos, which are engaged in the function of resolving conflict. Having done so, I then intend in Chapter 6 to show how these dimensions of form are actually and actively used in Calypsos.

Burke identifies five aspects of form as used in art, these are:

1. Syllogistic progression

2. Qualitative progression

3. Repetitive form

4. Conventional form and

5. Minor or incidental form.

At this stage, it will be helpful to bring some clarity to these Form as a precursor to examining their actual use in Calypsos that commentary on social, economic and political issues.

\section{Syllogistic Progression}

Burke writes of syllogistic progression that it is the form of a perfectly conducted argument advancing step by step (Burke 1968:124). By way of example, this type of form can best be illustrated by considering public literary works like Arthur Conan Doyle's fictitious character Sherlock Holmes. In that series of novels Syllogistic Progression can be observed in these ratiocinations stories by the way the detective Holmes ably assisted by Dr Watson, progressively, systematically and methodologically sifts through the clues eliminating possible suspects one by one. Through the use of inductive and deductive processes, readers are able to understand the reasoning behind the characters actions, the process used in detection, with the outcome being that the 
culprit is brought to justice. The readers experience the intrigue and share in the development, as the story grows and they develop a desire for justice as the plot unfolds.

\section{Qualitative Progression}

Unlike syllogistic progression, where there is a sequential development of the events in a progression of the plot, Qualitative Progression relies not on the connectedness of the incidents in the plot, but rather the inter-relationship of the "quality" of chosen scenes. This inter connectedness is frequently demonstrated in many works where scenes of high tension or violence alternate in frequency with those of much calmer less stressful and perhaps even comic scenes. This process of alternating the quality of scenic content allows the audience to briefly relax. In doing so, it enables the creation of a psychological distance for the audiences allowing them to reflect and assimilate the issues, while gaining other perspectives on the events that just occurred.

Burke asserts that this process is unlike the logical progression of Syllogistic Progression wherein we come to expect the next development. In this process firstly the event happens, it is only subsequent to that event that we are able to "recognise the rightness after the incident". In the context of addressing conflict situations through the lyrics of Calypsos, it is vital to recognise that qualitative progression can be expertly crafted if they allow the audience to be put into a state of mind which another state of mind can appropriately follow (Burke 1968:25) thereby allowing the participant to take an alternative perspective on the issues. 
Examples of this process abound on the screen and on stage performances. As an example, let us consider the film "Gladiator". Pietro Scalia, editor on Gladiator Comments as follows:

One of the things I'm really proud of is the first shot. It's an example of how writing is done editorially. The "hand over the wheat" shot was not in the script. Ridley had shot it for part of the heaven sequence. I used it at the beginning of the film for two reasons. One was the poetic beauty and power of the image. For me it represented a cinematic and thematic clue. Ridley had intended to start with a closeup on Maximus. With the "hand over the wheat" shot, the idea was to show Maximus' soul or inner state. You go inside of him. That shot contains the theme for the entire film. Visually and thematically it's a poetic shot. It's up for interpretation, but it will linger with you, and it's used and repeated all the way to the end. It fits well as a thematic link to Homer's "Odysseus." To me it shows how you can anchor a film and how material gets unified in the editing process by consolidating themes and by empowering an image with multiple meanings.

Gladiator History and Times (n.d.)

It does not just rest there, early on in the running of this film we see Russell Crowe who plays the part of Maximus, the General in Germania showing considerable tenderness and gentleness to men under his command and to his horse and dog. This scene is in direct contrast to the ferocious battle that follows immediately afterwards. For the types of Calypsos under consideration, this process is implemented in two distinct ways.

First, the biting commentary of the verses are punctuated by the choruses, secondly the emcee provides contracting connectedness through an interlude that changes the tempo of the atmosphere in the Calypso Tent.

\section{Repetitive Form}

Burke described this as the consistent maintaining of a principle under new guises

(Burke 1968:125). This approach shows up in a variety of ways. An example of this that Burke offers us is that of Swift's Gulliver's Travels. In this story, the details that 
Swift enumerates serve to illustrate the discrepancy in size between Gulliver and the Lilliputians so that each detail reinforces the main theme. Yet another way in which this could be demonstrated is through the association or clustering of images appropriate to a particular theme or topic. This can show up as a series of associated images that may be performed or presented that illustrate a particular lyrical theme or topic. Examples of this can be seen abundantly when Calypsonians, while performing their Calypsos, have aspects of their song enacted on stage by a group of people, as they sing in accompaniment.

Burke contends that Repetitive Form is fundamental to any work of art as it is to any act of human communication. This suggests that it is necessary if we are to be properly oriented to a particular topic. As Burke eloquently puts it: it is our only method of talking on the subject (Burke 1968:125).

\section{Conventional Form}

Burke describes this as the reliance by the audience on categorical expectancy. This relates to the audiences' expectations of some sort of convention for the order and/or flow for a particular genre. In regard to form it identifies certain structures as associated with specific themes, or specific modes, or moods. These structures are widely understood on either side of the artists/audience divide, with both audience and artist giving tacit agreement to the "appropriateness" of that structure to the particular area of artistic work. 
Chapter 5: Language as Symbolic Action

In general, we find that examples of this tradition can be found in the structure of most songs and shows as the regularity of the number of lines of each verse or chorus and the regularity of the rhyming scheme.

\section{Minor or Incidental Form}

Finally, what Burke describes as, Minor or Incidental form is in fact stylistic considerations. Here we begin to take on board and pay regard to metaphor, satire, metonymy, Polysemy, Frames and Masks etc., as they manifest in the artistic work and in this context, the leverage that they give to the process of resolution.

Although in literary critique it is not unusual for minor forms to be taken out and regarded as separate entities in their own right, in this manuscript they will be regarded in the context of their general purpose in terms of the unfolding of the Calypsos that are being considered at any given time.

\section{THE APPEAL OF FORM}

Having paid attention to the major aspects of form, it is helpful to understand the appeal of form, particularly in the context of my established objective for this work. Second, I recognise the importance of determining the standards by which Form is seen to be appropriate for use as an application in the process of negotiating a resolution.

In relation to the first of these two issues, Burke claims that the formal structures that appear in Art are directly related to the cognitive human reasoning structures. In “Statement” Burke writes: 
There are formal patterns which distinguish our experience. They apply in art, since they apply outside of art. ... We establish a direction by co-ordinates, we establish a curve by three points, and thereupon can so place other points that they will be intercepted by this curve. Thus, though forms need not be prior to experience, they are certainly prior to the work of art exemplifying them.

(Burke 1968:141)

On closer examination, we find that even the minor forms are implicit in the processes of abstraction and generalisation by which we think (Burke 1968:142-143). In relation to the issue of the appeal of these Forms, Burke writes: the formal aspects of art appeal in that they exercise formal potentialities of the reader. They enable the mind to follow processes amenable to it, (Burke 1968:142-143). In relation to conflict resolution then, it seems to me that Burke is saying that the principal function Form serves is very much analogous to that of a conflict resolution handrail providing guidance through that process.

It is the second of these questions which, in the context of this work on Calypso art that I consider to be the more significant. Coming to grips with the standards by which Form, as used in Calypso, is to be judged as "correct" for the specific purpose of resolving conflict within the society, requires engaging with the work dialectically.

The aspects of Form that I have looked at in this work so far have engaged with the philosophical concept intrinsically. However to make a judgement on its appropriateness requires that I go beyond this boundary and have a regard for the whole spectrum from artistry to audience response. Burke holds the view that Form, having to do with the creation and gratification of needs, is 'correct' in so far as it gratifies the needs which it creates (Burke 1968:138). In this case, I understand that Burke is writing of the audience's needs. 
In relation to the use of the term dialectic, I understand this term to mean the dynamically sustained, ongoing relationship between a Calypso, on the one hand, showcasing as it does, powerful symbols of human experiences, effectively expressed through the medium of Calypso by a mixture of aspects of Form. On the other hand it can also be regarded as a process of engaging the audience with the prescribed elements that, to the best of the ability of the Calypso art, parallels the "lived experience" that accompany the emotions of Trinbagonians.

As an overview, the only way an application of Form can be judged to be correct is by checking to see that it meets all established "categorical expectancies".

"Correctness" can therefore be equated to appropriateness for the task at hand and acceptability for that task by audience and Calypsonians alike. Implicit in this statement therefore is that this requires that the applied Form works on two levels or "Scenes". As already stated, the first of these is the intrinsic context and appropriateness of the work at that level and the second is the extrinsic appropriateness within the reality of the lived world.

In the final analysis, Form may be regarded as the vehicle used by the Calypsonians artist to transmit patterns of experience to an audience. In turn Burke defines a symbol as a verbal parallel to a pattern of experience (Burke 1968:152). Earlier in this chapter I looked at this process in the context of the Calypso: "Voices From the Ghetto" sung by Singing Sandra. Where at the end of this Calypso Singing Sandra expresses:

I was born and bred in the ghetto, Ah know what a talking about, yuh know 
This level of first-hand lived experience which is the subject of the Calypso, is not necessary and always essential for the artist, however, it may at times be the case. What is more crucial though is the level of homogeneity between the patterns of experience existing between the Calypso artist and the audience. The closer the homogeneity between these two the easier it is for the Calypsonians artist to transmit the symbols. This is not to say that a pattern only has relevance when resonance exists between both audience and Calypso artist. The reality is that patterns that are new or strange can also have considerable appeal.

Under these situations and particularly in relation to resolving conflict, the use of symbols can serve to shed new light on situations that have hitherto been identified as complex and ambiguous. Symbols can also help in the process of exposing latent or submerged patterns. By so doing they can provide vicarious opportunities not just to get away from the boredom of everyday life, but to address the issues within the society in which both Calypsonians and audience live.

\section{Evaluating The INTRINSIC AND EXTRINSIC APPLICATIONS OF FORM}

So far I have examined the epistemological issues around Burke's approach to "Language as Symbolic Action" as this applies to the Calypso art-form. In Chapter 6, I propose to take a more detailed look at the application of "Form," in relation to its use in Calypsos that comment on the social, economic and political issues in the Republic of Trinidad and Tobago. I do so with a view to showing how those Calypsos help in the resolution of indigenous conflict. In itself, such an intrinsic and extrinsic examination 
Chapter 5: Language as Symbolic Action

of the applications of Form requires. a "Breakthrough into Performance" (to quote the title of a ground breaking essay by Hymes (1975)).

To effectively complete my objectives I recognise the need for my work to simultaneously address the dual levels of text as well as that of text in context. That is to say that in order to complete the set objectives of this work, I need on the one hand to unravel the actual words of the Calypsos, while on the other hand, I also need to look at those words in the context of the events that generated them. My analysis of both text and context requires of me that I discuss the events of occurrence within a Calypso Tent with regard to the following five variables:

1. Calypsonians and Their Lives: Fieldwork in Action - Previously offered in Chapter 3

2. Linguistic Form in Calypso: Employing Reframing as a Multidimensional Tool in Resolving Conflict - Chapter 6

3. The Media Used In Calypso Presentations - Chapter 7 (the use of and the inter-relationship between performance, spectacle, theatre and ritual)

4. Conscientização: Calypso as an agent of social cognition - Chapter 8

5. The Audience as Co-mediator - Chapter 9

Since the nature of performers has already been dealt with in the previous Chapter, the remainder of this work addresses the outstanding latter four items mentioned above. 


\section{CHAPTER 6 - LINGUISTIC FORM IN CALYPSO: EMPLOYING REFRAMING AS A MULTIDIMENSIONAL TOOL FOR RESOLVING CONFLICT}

In reconstruction we must deal both with forms and with functions. To reconstruct forms alone, without attention to their functional position, is first and foremost to create a hopelessly unrealistic linguistic situation

(Watkins, 1990)

\section{INTRODUCTION}

$\mathrm{T}$ his chapter, looks at the rhetoric of performance communication through the medium of the Calypso as facilitated by Calypsonians as they engage in reframing. In doing so, I will be responding to the 4 th research question, as I offer insights into the tools, skills and processes used by those Calypsonians who sing on topics of social and political commentary.

In the process of influencing and persuading, the Calypsonian exercises his ability as an artificer, adeptness in the art of code switching, navigating along a spectrum of meanings that range within a Standard English or colloquial dialectic. Using pun and wordplay the Calypsonian successfully manoeuvres within this spectrum, demonstrating a degree of sensitivity to each of the attributes of an active triadic, co-existing relationship that engages the audience, the encompassing social world and the performer. Focusing on this intersection, allows me to establish a dramatic structure for the process of addressing the prevailing conflict. 
My approach acknowledges the difference between the lived-in world of the audience, the encompassing social universe and the liminal world of the performing Calypsonians, as s/he mediates the tensions between the social world and the lived-in-world.

In Chapter 5, I referred to Burke's work in relation to the analysis of 'language' and 'reality'. In this Chapter, I look at both the context and content of Calypsos that comment on Social and Political issues within the country, as these Calypsos mediate the struggle in the competing class structure. In so doing, I look at both their function and Form. This Chapter therefore explores political and sociological issues, as these are addressed through the language of Calypso art.

This approach requires that I explore the mechanisms that underpin the concept of "dramatism" as it manifests in the Calypso art form. In this cause, I show how Calypsonians use reframing in the process of raising consciousness, when they engage in their approach to resolving conflict. For my purpose, it is helpful to draw on Hall's definition of reframing as:

Taking a frame-of-reference so that it looks new or different, presenting an event or idea from a different point of view so it has a different meaning; content or context, reframing a change pattern.

(Hall, 1998:230)

The lyrics of the Trinidad Calypso are a mirror reflecting the country's pertinent issues. They frequently show how the inter-relations of the social phenomena of the island bear on each other. Hence, the Calypso is uniquely poised to prize open the window to the understanding of motives as we try to grasp of the lyrics therein, thus bringing an awareness of the relationship between: language of motives, motives in language and 
language as motive, in relation to the conflicts which inevitably result within the social world of the people of the islands.

The use of reframing is central to the Calypsonians' role in the process of resolution, as it gets their audiences to see alternative perspectives. When reframing, Calypsonians change the conceptual and/or emotional setting of a set of experiences, placing the experiences in another frame that equally well fits the 'facts' of the same concrete situation. Through this process, the Calypsonians change the entire meaning of the circumstances, thereby enabling a new and different vision of the situation.

\section{FRAMES AND MASKS}

I have already stated that Calypsonians, singing on the social and political issues occurring in Trinbago, enable their audiences to take an alternative perspective, thereby helping their development of a social construction of reality. This chapter looks at the processes that Calypsonians employ in achieving this outcome.

The experience of my fieldwork showed the extensive use of frames and masks by Calypsonians, as they endeavoured to effectively deliver their messages to their audiences. Used as a tool in this way, reframing permitted one idea or object to be thought of as fitting into a different category. Hence Calypsonians abundantly used metaphor, metonym, and Polysemy. The work of Bateson (1972) and Goffman (1974) form a backdrop for this work. Hale (1998:147:162), has further grounded this area of work and as an academic and practitioner in the field of conflict resolution, has taken a perspective on frames which uses the Burkean epistemology as a touchstone. 
Embracing the concept of "Dramatism," she shows how a practitioner in the field of conflict resolution can reframe a conflict. In doing so, she argues that in conflict, individuals can find themselves in one of the "tragic fames". She contends there are a number of different types of frames that can be placed into two fundamental categories. These she identifies as the problematic frame and the hopeful frame. While the former does not necessarily help resolution the latter can and more frequently does.

Using frames, Calypsonians plausibly juxtapose principles and pragmatics, exposing the inconsistencies of Caribbean experiences. Rohlehr (1985:2) refers to this process as oscillation between geographical and situational opposites as a way of shaping, not only the Caribbean aesthetic, but the social and psychic experiences of its people as well. The Calypsonians artistic use of Linguistic Form deploys a nebulous haze that invites multiple meanings and interpretations to the lyrics of a Calypso, Benjamin (1995) calls this process cognitive dissonance.

I refer to Calypsos that engage this process as having 'lamina lyrics'. Much like an onion, these Calypsos have a number of different levels of meaning, concealed one underneath the other. Achieving this phenomenon, Calypsonians use frames and masks that manifest in Calypsos as metaphor, metonym, Polysemy, irony and satire. Ras Shorty I admirably demonstrates the use of these reframing devices in the chorus of “Watch Out My Children":

Watch out my children

Watch out my children, yeh

It have a fella called Lucifer with a bag a white powder

And he doh want to powder yuh face

But to bring shame and disgrace to the human race 
Nowhere in this Calypso does Shorty reveal the names of any of the drug lords, but through the use of the imagery of frames, we are able to see that Lucifer represents the drug lords while white power represents illegal drugs.

I have met numerous people in Trinidad, as well as here in the UK, and in various other parts of the world that I have visited, who, unfamiliar with the culture and ethos of Calypso, on initial introduction, are oblivious to the messages that are masked by the seemingly light-hearted, frivolous and carefree frame of the music. In recognising this misconception, Brown contends: lightheartedness really masks a serious purpose .... the Calypsonian's notorious practice of converting private as well as public lives into objects of ridicule (Brown 1978:102) and in so doing subscribes to what Hale calls, the problematic frame (Hale 1998:149). Recognising the tendency to stereotypically categorise Calypso Music because of its easy-going sound, Warner writes:

...this easy-going nature should not be mistaken for complacency or stupidity. The most serious of issues can receive what looks to the outsider like frivolous treatment, but is actually cleverly disguised criticism and analysis. In other words, beware the mask!

(Warner 1987:56)

This duality in the meaning of the lyrics of Calypsos is supported by the type of wordplay that is abundant in the dialectical culture of the country's hetroglot linguistic environment.

There is yet another level at which frames and masks apply to the Calypso. In discussing these applications to the work of resolving conflict, Hale (1998:149) advocates that there are fundamentally two types of frames: the problematic and the 
Chapter 6 - Linguistic Form in Calypso: Employing Reframing as a Multidimensional Tool

hopeful frame. I will take each of these frames, examining them for their application to the area of the Calypso.

The first of the problematic frames is the "tragic frame". In this way of working, one party views itself as a hero in a battle against hostile forces (Hale 1998:149). In the following excerpts from "This Stage is Mine", Aloes brings these ideas together:

I don't own a TV station

Ah don't get air play on the radio

The only time the nation does hear me

Is when ah sing on Dimanche Gras show

All dem Hindus they criticise me

Because ah call a name in meh song

Even Edison Isaac was against me

So he give Mystic Prowler the crown

But even though they chastise me

They can't take away this voice

It is very plain to see that

I am the People's Choice

And I'm going to jam them hard

Anytime they cross the line

Commonsense must tell them

This stage is mine!

The other aspect of the tragic frame engages a view of the other side of the dispute as

evil and omnipotent, as the excerpt below, again from "This Stage Is Mine", shows. In

this verse Aloes is referring to the Dimanche Gras show and the lady to whom he refers

is the PM's wife, about whom it is reported he had previously made derogatory remarks.

So when Carlos John told me that I couldn't appear on the show

Because of my contribution in song "Ah Ready To Go"

He told me the Savannah will be filled with dignitaries

And they couldn't hire me to embarrass the lady

He said what they want was people who could fill the night with joy

So they hire Puppet Master to come and sing 'bout he boy

So when he choose Puppet Master before me, I didn't get vex

Because I don know meh Prime Minister love sex 


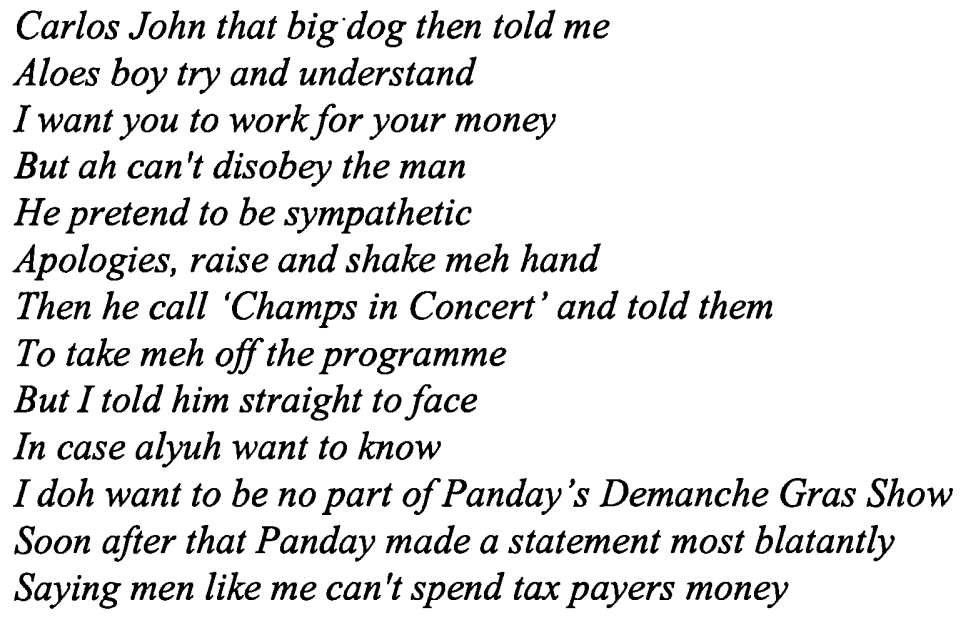

The contention here is that from the perspective of the hero, the other side has no legitimate concerns, no valid but different point of view, (Hale 1998:149). It is clear that holding perception such as this can limit the options for bridging differences. This frame is tragic since the dispute becomes protracted and seemingly irresolvable, as the parties caught in it can show little willingness to resolve the dispute.

Hale also identifies the "euphemistic frame" as another problematic one. In this frame, at least one of the parties believes that its view of the conflict is justified by a higher order such as God or justice (Hale 1998:151) and as a result leads that party to hold on to the status quo. The following verse shows that process:

Last year after the competition ah sit down and draft out a plan Ah say ah going and spend some time in the snow ah finish with Calypso Ah tell myself this is not for me, no one man could be so damn bad lucky And with my fans and them telling me ah loose, you get rob, Ah going in Brooklyn and look for a decent job

$B$ ut then ah remember Panday still in power And if ah leave here meh fans go suffer, Vital information the public won't know Then something open meh eyes and made me realise Ah was born to sing Calypso 
The challenge with such a disposition is that as the party becomes entrenched in this type of one-sided thinking, the possibility of any resolution fades remotely into the distance.

Yet a third problematic frame that Hale identifies is the "debunking frame", (Hale, 1998:153). In this mode of operation, one party sees the other as being wholly guided by "self-serving motives" (Hale, 1998:153) rather than having a principle centred approach that is guided by mutual concern. Frequently in this frame the "debunker uses language aggressively and restrictively" (Hale, 1998:153). As with the other frames in this category this approach hinders the successful resolution of the conflict.

Unfortunately, in her article Hale does not explicitly state that 'masks' are a special case of framing. This type of framing relates to the creation of identity. I have already indicated that Calypsonians separate themselves from their everyday role by creating such an identity through a sobriquet that is their stage name.

In reality, by having regard for the social or political context of the conflict about which a Calypsonians sings, we can see the developments as those of a drama, thus allowing us to identify the existence of the supporting "cast". In its broadest sense, this cast may include any or all of the following: the enemy, the setting, the themes, the plot lines.

In general, during conflict, this process of masking can operate in three unique ways, First, the use of a Sobriquet, enables the Calypsonians to adopt another identity and thus function in the ascribed role. Thus $\mathrm{s} / \mathrm{he}$ is able to hold in place, quite a separate identity, as a Calypsonian. (Appendix 3 list Calypsonians and their sobriquets). Second, 
it is a way of forcing the other entity in the conflict to accept the identity that the Calypsonian has created for him/herself. Sugar Aloes does this through the title of one of his Calypsos, wherein he addresses what he sees as the failings of the current government, and argues for his entitlement as a Calypsonians, to challenge them on their poor performance. In that Calypso entitled: "This Stage is Mine" he contends that the Prime Minister has the entitlement to the Red House (i.e. the seat of government) while his domain is the stage. Finally, through masking, the Calypsonians can hold in place the identity that has been constructed for the other person. Again this process is shown in another Calypso by Sugar Aloes entitled "The Judge", an excerpt from which is given below where Aloes reminds the Prime Minister of his jurisdiction as PM:

But this man show me plain that he have a grudge Forsake he job as PM and turn Calypso judge This man say how 'Tamboo' is the best Calypsonian

For' 89 he had the best composition and For Tamboo he have a special place in he heart It was a real pleasure to hear the 'Journey Now Start' (Track 7 on CD)

In Hale's model, the key role of the practitioner in facilitating resolution is to reframe the story into a "comic or hopeful" frame (Hale, 1998:154). The significant difference with this new frame is that it assumes that change is possible. Working from this hopeful premise, the assumption is that "people can change, situations can change, systems can change (Hale, 1998:155). Working within this frame then the role of the practitioner in resolving this conflict is to "reframe to focus on the larger system, or the bigger picture" (Hale, 1998:155). It is this process, which, if skillfully executed by the practitioner that promotes the belief in change by the disputing parties and generate the process of self-examination. In this regard Hale states that a comic frame monitors the symbols by which others define situations and bring about identification (Hale, 
1998:161). It is through the judicious use of Form, such as metaphor, stories, symbols and guided discussions, that Calypsonians, working as practitioners in the trenches of Alternative Dispute Resolution (ADR), are able to guide the parties to resolution. This process of constructing the hopeful frame is ably demonstrated in the following extracted words from the Calypso "Watch out My Children" by G. Blackman, Sobriquet: Ras Shorty I.

\section{Verse 2}

I give you my council because I want to see

All you young people live righteously

What you fill your mind with form your characteristics

And shape the path that you must walk tomorrow

Darkness or low, joy or sorrow

That's why I'm concern so.

\section{Chorus}

Watch out my children

Watch out my children, yeh

It have a fella called Lucifer with a bag a white powder

And he doh want to powder yuh face

But to bring shame and disgrace to the human race

In this Calypso, using concealment, Shorty offers many hints, but never directly states what he is singing about; hence, interpretation is left to the listener.

\section{REFRAMING}

In a real sense Calypsonians have no power to direct a resolution let alone to be directive in defining for the parties the nature or boundaries of the perceived problem. What Calypsonians do is represent their perspective on an issue that they have identified. Having so identified, their only course is then to influence the parties' views persuading them on a course of action. In doing so, the Calypsonian reframes the issues by restating them in different words and phrases. There are numerous approaches to 
reframing, some that Zoub (1998) identifies and are also used in Calypsos are: rephrasing, focusing, proposing an option, creating metaphors. I recognise these terms as restatements of Burkean terminology. I will therefore be using the rest of this Chapter to focus on how Calypsonians use Symbols, Dramatic Themes, Ironic Ilumination, Syllogistic Progression, Qualitative Progression, Repetitive Form, Conventional Form and Minor or Incidental Form, (Metaphor, Metonymy and Polysemy) to reframe either implied or actual disputes, while drawing attention to the prevailing issues, with a view to influencing their audiences to take action in resolving a presenting challenge.

Fisher recognised the use of symbols in reframing a conflict. In her work in this area, she identified that a symbol can be either a: ritual, visual art, metaphor and story (Fisher 2000:88). In effect, these symbols can be expressions of the duality of a conflict, they work by deliberately permitting the creation of a space where there can be communication of a contradictory perspective (as in "We Like It So", which can be heard on Track No 8 of the CD, the lyrics are also available below), or through ironic illumination, (as illustrated by "Still the Best" Track 9 of the CD, see Appendix 1 for the lyrics of these Calypsos).

In relation to the following excerpt from "We Like It So", it is worth noting that the words of these verses and choruses do not follow the tradition already established in this text that italics represent quotations. In this excerpt, I have used italics to distinguish one side of the polemic from the other. So that the italics here are the other person's responses to Sparrow's views as he seeks to engage them and get him/her to take an 
alternative perspective. So, the italicised words are those of the PNM supporter while those non-italicised words are those of the O.N.R. supporter as sung by Sparrow.

"We Like It So" by Dr. Slinger Fransisco, Sobriquet: The Mighty Sparrow Available on CD at track 8

Anything that's wrong he go put it right George Porgy tell we the other night So instead ah displaying impatience Cool yourself and give the fella a chance.

How the hell you could say ONR go do better.

We can't get house so we squat Living with cockroach and rat Take your steel beam and go Your cesspit flowing over You could catch Yellow Fever Take your steel beam and go Soldier in bulldozer break down your shack in Movant Take your steel beam and go It's plenty sexual favours to be a ten days worker We know we like it so

It eh have a single thing you could say Could make me abandon me balisier No steel beam could fall down on top me head Sparrow ah is a PNM till ah dead.... (Available at Track 8 of CD)

Taken separately, Cro Cro's "Still the Best" coming after the coup as it does, is a classic example of ironic illumination:

I say we are still the best In spite of all the unrest, But somebody loco or boozed When I watch CNN news They say that the whole country burn down And Port of Spain is no more a town I want to tell the world they lie For Trinbago's flag is still.flying high

\section{Chorus}

Cause, where else in the world government overthrown

And so much people get kill?

Where else in the world government overthrown 
Big football match playing still?

Where else in the world government overthrown

Your main police station-burn down?

Where else in the world so'much fire in town and

In St James, man drinking beer and rum?

So if Trinidad eh nice,

Trinidad is great

This country of my birth

Trinidad and Tobago, is the greatest island on earth

(Track 9 of CD)

When read, in the critical light of the aftermath of the coup that took place in 1990 it will be seen that Cro Cro is using thick irony to make the point that Trinidad and Tobago is "Still the Best". In this Calypso, Cro Cro takes ideas that ordinarily, we would consider to be abhorrent or at least unacceptable in society, juxtaposing them with those that are acceptable. By this "perspective incongruity" he is bringing some focus to bear on the ridiculousness of the situation that many people faced during and as a result of the upheaval. This perspective by incongruity allows for the creation of a vocabulary for the expressions of this dramatic. The Calypsonian who engage in this process need first to identify the issues, express these issues in an appropriate vocabulary and finally externalise their perspective.

\section{The Use of Metaphor, Metonymy and Polysemy}

It is appropriate to commence this discussion by setting out a definition of the terms being used. Generally the Collins Dictionary of English Language (Hanks, 1979) defines metaphor as a figure of speech in which a word or phrase is applied to an object or action that it does not literally denote in order to imply a resemblance.

In the field of Alternative Dispute Resolution (ADR), Benjamin (1995:8) asserts that a metaphor is a compressed story that highlights the critical pieces of the experiences in a 
Chapter 6 - Linguistic Form in Calypso: Employing Reframing as a Multidimensional Tool

different and more graspable way. On the other hand, the linguists Lakoff and Johnson (1980) argue that: the essence of metaphor is understanding and experiencing one kind of thing in terms of another.

Finally, yet another practitioner in the field, working in the trenches of $\mathrm{ADR}$, writing on this type of form, defines that:

Metaphors function as instruments of knowing by juxtaposing two terms usually perceived as belonging to different classes of experience. One thing is understood and experienced in terms of another ......By organising reality in particular ways, selected metaphors cause acts because each contains assumptions, evaluations and points of views and so structure attitudes regarding whatever they describe and provide reasons for behaving in certain ways

(Troester and Kelley, 1991:29)

In general, all of these authors are in broad agreement that metaphors map from one field of experience on to another. By contrast, in metonym the mapping is within the same domain. It is worthwhile noting though that although metaphor and metonym are distinctly different, Louis Goossens, has recognised the occasions when a figure doubles as metaphor and metonym coining the phrase "metaphtonymy" to describe this phenomenon.

Some examples will illustrate these differences. Consider the implications of the phrase "argument is war"; Lakoff and Johnson contend that when we speak of defending, destroying and defeating arguments, what we are doing is partially structuring arguments in relation to the terms we usually use to describe warfare. From this premise, we can begin to get a view of arguments that is shrouded in hostility, contention, destructiveness, strategizing and so on. When used in that way one can see that the expression "argument is war" is metaphoric. However, it is also true that 
Chapter 6 - Linguistic Form in Calypso: Employing Reframing as a Multidimensional Tool

"argument is war" also involves metonym for in reality there is frequently a thread of continuation between argument and war, so much so that most wars usually start with some form of verbal disagreement. Hence, we can see the proximity between recognisable causal sequences. Through this logical process, it is easily recognisable that an argument is a stifled war. The other side of that coin is equally true, that is to say, that a war is in reality an argument that has been escalated, and so this argument has come to blows.

The example of this metonymy is so striking that we can easily be lured to a position where we fail to recognise the metaphoric aspect of the phrase "argument is war". In the context of the above, I suggest that the reader reviews the words of the polemic "We like it so".

On the other hand Polysemy, as with other types of form in this category such as lexical semantic change and pragmatic ambiguity, involves one form being used for more than one function. Sweetser (1990:1) defines Polysemy as the synchronic linking of multiple related senses to a single form. More generally, in Trinidad, observers of the field of Calypso refer to this type of meaning change as double entendre.

When these types of form are used in situations that involve conflict, they can either reveal the true issues, or through masking, hide them. More importantly though, used appropriately, they can facilitate a discovery of the hidden meanings contained in the symbols, thereby increasing the awareness of those involved, and hence the potential for resolution. 


\section{APPLICATIONS OF FoRm to THE CALYPSO}

Although examples of the use of Metaphor and Metonym and Polysemy abound in Calypsos, for the purpose of this work, I will utilise three Calypsos that I consider expertly illustrate the application of form. These are: "The Banana Death Song""19, by David Rudder, "Sinking Ship" by Gypsy and "Chauffeur Wanted" by Chalkdust. An exposition of each of these Calypsos shows each of them as arising from a vastly different background. In turn, this requires that I put each of the Calypsos in its context, highlighting the background. I will therefore commence with an illumination of the vicissitudes of the Banana industry.

\section{THE VICISSITUDES OF THE BANANA INDUSTRY}

The main parties involved in what came to be called the "Banana War" have been Europe, the Caribbean, Latin America and the United States. In understanding the significance of the Calypso "Banana Death Song", it is important to understand its lyrics in the context of the development of the banana trade. To enable this understanding requires that I put the positions of each of the countries in context.

\section{Background to the banana war}

What can be regarded as the Banana War is the evidence of a six-year trade quarrel with the principal countries being the United States and the European Union. This aspect of the "war" commenced in 1997 when the US lodged a complaint with the World Trade Organisation (WTO) that the EU was breaking the free trade rules by allowing special access for banana producers from former colonies in the Caribbean. The US having won its claim, the EU was instructed to alter its rules relating to imports of bananas.

\footnotetext{
${ }^{19}$ These three Calypsos are available on CD 1 tracks $9,10 \& 11$
} 
It is important to understand that the European banana marked grew out of a series of national measures. These measures were an attempt to protect the incomes of favoured companies and sources of supply for Europe. Since 1975, the Caribbean banana producing islands together with the other African and Pacific banana producing countries, had been given special treatment by Europe, with each country having its own quota for the supply of bananas. This meant that these countries could sell to Europe as many bananas as they wanted to export. This arrangement for trade offered these developing ex-colonies of England and France, a way to build up their economies with trade, rather than having them rely on aid.

On the other hand, the ex-colonial rulers, now members of the European Union, sought to protect banana farmers in the Caribbean from competition from the cheaper Latin America bananas.

In relation to the European banana market, it is important to understand that there were three sources of supply. These were: First, EU bananas, grown and marketed within the EU itself, for whom the major producers were the Canary Islands and the islands of Martinique and Guadeloupe (the French Departments d'Outre-Mer or DOM). In 1990 the DOM was recognised as being responsible for $10 \%$ of market share. Second, growers in African and the Caribbean (part of the Africa-Caribbean-Pacific group of countries, or (ACP)) of which the Caribbean accounted for $11.2 \%$ while Africa accounted for $6.7 \%$ of the marked. Third, there was Latin America with $57.9 \%$ of the market. 
Chapter 6 - Linguistic Form in Calypso: Employing Reframing as a Multidimensional Tool

It is also important to note that the EU's market increased rapidly during the latter part of the 1980's from 2.99 million tons in 1988, the EU market rose to 3.47 million in 1990 and then to 3.89 million tons in 1992 . The main beneficiaries of this growth had been the Latin American producers, whose share of the market went from just 53.6\% of the total in 1988 up to $61.8 \%$ in 1992.

In 1988, the DOM supplied $12.3 \%$, and the ACP $17.2 \%$ of the European market, two thirds of which came from the producers in the Caribbean region. By 1992, the figures were $9.6 \%$ and $17.7 \%$ respectively, with the ACP Caribbean producers still furnishing around two thirds of that amount. However, in 1999, only 7\% of Europe's banana came from the Caribbean, with the US multinationals that control the Latin American banana crop, holding three-quarters of the EU market. In this trade flow, it is important to realise that the US itself did not export bananas to Europe (CEC, 1995: Annex 1).

This situation gave rise to particular trading groups on either side of the Atlantic with each having its own particular interests at stake. For instance in the case of France, Spain and the UK, they sought to preserve their market position. This point can best be illustrated by considering the UK which, in 1991, was dominated by Geest who had $60 \%$ of the available UK market and Fyffe having $25 \%$. These Caribbean companies sustained a close relationship with the UK. They were active in shipping, ripening and wholesale distribution of bananas. Alternatively though, the Latin American banana producing companies selling to Europe favoured an open market system. Since they were cheaper producers such a system would provide them with a price advantage. Here the US trans-national corporations (TNC's) were dominant: in this case, Standard Fruit (Chiquita) with $43 \%$ of the EU market and United Fruit (Dole) with 13\%, (Pedler 
1995). From the perspective of the US trans-nationals, they felt disadvantaged in that they did not enjoy the same level or quality of access to European Union government. This meant that the interests of the US trans-nationals in the processes of importing, ripening, wholesaling and retailing of Latin American bananas in the European market, was represented by their European "clients".

\section{The Caribbean situation}

As explained earlier, for the DOM, the banana trade was governed by French national regulations. For the UK, there were other regulations that governed the banana industry, relating to the Caribbean, these specifically applied to banana productions originating from the Windward Islands (these islands included Dominica, Grenada, St Lucia and St Vincent) as well as Belize, Jamaica and Surinam. It needs to be understood that the production and sale of banana is one of the principal agricultural exports from the DOM, accounting for $60 \%$ of Guadeloupe's export revenue and $49 \%$ of that of Martinique (Nurse and Sandiford, 1995: Table 1.3). Along with this production, costs are also seen to be high. As such, export sales are maintained only because France has had a policy of reserving up to two-thirds of its market for DOM bananas and one-third for bananas from African i.e. the ACP (Pedler, 1995: Figure 8). So for instance in 1992 France obtained $37 \%$ of its bananas from Martinique and $22 \%$ from Guadeloupe. Latin American Bananas were only sought to plug any shortfall. For the Latin American producers and their American owners, the issue here was that from 1963 these bananas were subject to a $20 \%$ common external tariff (CET).

It stands to reason then that for the Caribbean the banana is an important export to the EU. This level of importance is non-homogeneous but in reality varies from island to 
island throughout the archipelago. We can see from the data already presented that the Windward Islands have the greatest level of dependence on this product as a form of revenue. It is therefore clear to see that the collapse of banana prices and hence exports from these islands would in the words of a recent report by Gill and Gonzáles, be disastrous, with severe economic consequences contributing to a socially unmanageable fallout and an explosive political situation, particularly since there is no real alternative to banana production in those islands (Gill and Gonzáles, 1995). This is the background against which David Rudder wrote and sang his Calypso: "The Banana Death Song", the words of which are given below.

In the opening verse of this Calypso Rudder asserts that the United States initially bought bananas from the Caribbean islands. The exhaustive research that I have done on the topic has not uncovered the existence of a direct banana trade between the USA and the Caribbean. There was however trade between the American owned, Canadian Banana Company and the banana associations of Dominica, Grenada and St Lucia as early as 1934 and with St Vincent in 1935 . Between these parties, there existed a five year contract for the shipment of Gros Michel bananas to Canada. Given that the Canadian Banana Company was owned by the American United Fruit Company, (Clegg 2000:2), it needs to be stated therefore that technically Rudder is incorrect by asserting in Verse 1 of his Calypso:

Well, Uncle Sammy used to visit the Church of Banana He used to go to church with a girl, named Grenada And then he went to church with a girl named Jamaica He used to bow down to one Dominica Then he used to go and pray to one called St Lucia He say he loved the way they preached in the Caribbean chapter

Extracted from David Rudder's "Banana Death Song" (Available at Track 10 of CD) 
We must not allow the realisation of this inaccuracy to obliterate our appreciation of this timely and appropriate use of metaphor, as Rudder maps the church, which is traditionally recognised as an icon of hope and growth onto the hope for financial independence and expectations of economic growth, of these banana producing islands, through the medium of the banana.

In the above verse, Rudder is mapping a sense of reverence and importance of what we all understand for a church to the significance and importance of the banana to both parties in this dispute. What is implicit here is the significance that has been given to the Banana. For Rudder calls it the Church of Banana. He explores the whole concept of the trade and very much links it with the feminine form, he says: He used to go to church with a girl, named Grenada. There are a number of important issues here. Firstly, traditionally in the Caribbean, a girl is seen as an expression of potential, of opportunity for growth, growth into womanhood and all that the responsibility that parenting carries with it.

In effect, Rudder is here mapping from the domain of the expression and experience of a female to the expression and experience of the Caribbean islands as they struggle to maintain their trading position and sustain themselves and family against the South American banana threat. By combining the two large South American banana producing companies: Chiquita and Dole, Rudder implicitly gives them more power, thus upsetting the whole equilibrium and creating the level of antagonism existing as the whole thing turn sour. The lament and crying which follows is associated with the disappointment and disheartenment caused by the loss of their position as preferred suppliers, and a recognition of the knock on impact of this death on both the economy 
and standards of life for all of those who are dependent on the banana as a source of their livelihood.

In the second verse of the Calypso, Rudder articulates beautifully, the bullying attitudes

of the Americans when he sings:

Well the church had a European benefactor

So he decide to come to the aid of the chapter

But Uncle Sammy say, NO, I want them to suffer,

They never do me wrong, but I love my Chiquita.

And by the way, don't deal with mama Africa.

My Chiquita's cheap, and you know I'm a miser

Extracted from David Rudder's "Banana Death Song"

In reading the above excerpt from the Calypso, it is worth recalling the report by Patrick

Barkham entitled: "The Banana Wars Explained." This report was published in the

Guardian on 5 March 1999. In particular, one of the questions to which it responded

was: If the US doesn't export bananas direct to Europe why are they so angry? In

response to this question Barkham writes:

Whether Democrat or Republican, American administrations have long championed an ideological commitment to free trade. But the "banana wars" are murkier than that clear principle.

The US government is concerned about its economics. The US trade deficit is at a nine-year high. Its current account deficit could reach $\$ 300$ billion in 1999, surpassing previous record levels in 1986/7. The government feels it can't afford to allow any European protectionism, no matter how petty, to disadvantage its troubled trading balance.

The US government is also pressurised by powerful US-based muiltinationals which dominate the Latin American Banana industry. The Clinton administration took the "banana wars" to the WTO within 24 hours of Chiquita Brands, a powerful, previously Republican-supporting banana multinational, making a \$500,000 donation to the Democratic Party.

(Barkham 1999) 
This understanding of the scenario lends a new dimension to the sequence of events and a better understanding of the words of David Rudder who, acting as a liminal servant, exposes the position of the US in pushing as they did for an outcome that unilaterally favours them.

Having presented such a clear historical perspective of the events, I believe the literary

Form in the lyrics of the Calypso as set out below, speaks for itself.

\author{
Lyrics of "The Banana Death Song" by David Rudder \\ Well, Uncle Sammy used to visit the Church of Banana \\ He used to go to church with a girl, named Grenada \\ And then he went to church with a girl named Jamaica \\ He used to bow down to one Dominica \\ Then he used to go and pray to one called St Lucia \\ He say he loved the way they preached in the Caribbean chapter \\ But one day Uncle Sammy, he went South America \\ And he bounced up a girl, she name was Chiquita \\ Chiquita Dole is she name and she got plenty power \\ Then West Indian girl get vexed and the whole thing turn sour
}

The West Indian girl start to cry West Indian woman start to cry:

Banana dead, banana dead, banana

The future dread, the future dread for banana

Well the church had a European benefactor

So he decide to come to the aid of the chapter But Uncle Sammy say, NO, I want them to suffer, They never do me wrong, but I love my Chiquita. And by the way, don't deal with mama Africa. My Chiquita's cheap, and you know I'm a miser. They gonna cry for a while, but it will blow over. LET THEM EAT CAKE, or plant mama Coca Them West Indian girls I know are born survivors Don't worry about the and the "Church of Banana".

West Indian woman start to bawl West Indian woman start to bawl Banana dead, banana dead, banana The future dread, the future dread for banana. 
Chapter 6 - Linguistic Form in Calypso: Employing Reframing as a Multidimensional Tool

Don't hurt me, don't hurt me so Uncle Sam, don't let me go

Banana dead, banana Dead banana.

(Available at track 10 of CD)

\section{THE USE OF FORM IN: THE SINKING SHIP}

The Sinking Ship is yet another example of the use of Form in the process of resolving conflict. In order to understand the importance of this Calypso, sung as it was for the Calypso season of 1986, I recognise the need to define the circumstances that drove this Calypso.

Dr. Eric Williams formed the People's National Movement (PNM) a political party early in 1956, becoming its leader. Later that year, they won the national election against the Democratic Labour Party (DLP) lead by Mr Albert Gombs. Williams then became the Chief Minister of Trinidad and Tobago from 1956 to 1959, then Premier from 1959 to 1962 and Prime Minister from 1962 to $29^{\text {th }}$ March 1981 when he died in office. The post of Prime Minister and leader of the PNM was then taken over by George Chambers. I am describing the pedigree of Eric Williams as this is important in gaining an understanding of how this pedigree affected the tenure of office of his successor George Chambers.

Williams who is frequently and affectionately referred to as the "Father of the Nation" remained as one of the most significant leaders in the history of modern Trinidad and Tobago. Dr Eric Williams who as a young man won the coveted Island Scholarship to study at Oxford University placed first among those gaining a First Class honours degrees in the School of History. He also received his Doctorate of Philosophy degree at Oxford. He subsequently took up a post at Howard University as an assistant professor of social and political science at Howard University before returning to Trinidad and Tobago to launch the PNM. It is reported that Williams considered himself to be a teacher, historian and philosopher.

(Office of the Prime Minister, Jan 2004) 
It can therefore be appreciated that the loss of Eric Williams, was regarded with great sadness. Having brought the nation to independence, he was seen as significant in holding the twin islands together. When on the death of Dr Williams, George Chambers, became the second Prime Minister he was generally considered to be following in the footsteps of Williams, Chambers

had the unenviable and, perhaps, impossible task of attempting to fill the shoes of Dr Eric Eustace Williams.

(Alexander, 1997:3)

Consequently, remarks were frequently made about Chambers that were mostly attributed to a comparison in expectation between the two leaders. In general, these remarks expressed some measure of discontent about Chambers with some individuals even labelling him "a dunce. In writing about Chambers, who had a high school education and was not a graduate, Taitt states that:

The former law clerk, a graduate of Burke College and Osmond High School, maintained a quiet dignity while many tried to pull him down because he didn't have Williams's QRC/Oxford-type education.

(Taitt, 1997:2)

Being left to fill the shoes of the distinguished Dr Williams as he was, many people felt that Chambers could only stand in the shadow of Dr Williams. As a consequence, unfavourable subjective judgements were made of Chambers. Writing in the Trinidad Guardian Alexander states that:

Trinidad and Tobago's second Prime Minister, George Michael Chambers, had the unenviable and, perhaps, impossible task of attempting to fill the shoes of Dr Eric Eustace Williams, "Father of the Nation", who died suddenly in office on March 29, 1981.

(Office of the Prime Minister, Jan 2004)

Furthermore, it was reported in the Express Newspaper that Chambers: 
was a victim of unfavourable circumstances, which were beyond his control. Oil prices, which rose during Williams's tenure and which led to the growth of the economy, went into a free fall during Chambers' time. Chambers had a difficult 'row to hoe' as he tried to steer the economy, at US $\$ 9$ a barrel, from a state of collapse.

The general consensus is that he managed this process well, but the ordinary man did not think so because the adjustment measures put to stem the collapse hit people where it hurt most - in their pockets.

The Demas Report and the Bobb Committee warned that the level of spending was unsustainable and recommended adjustment measures.

These measures were not palatable to the population which by then was being exposed to all kinds of revelations of corruption involving former ministers, Johnny O'Halloran and Francis Prevatt. The tide of unpopularity that developed punished the Chambers' administration severely at the polls in 1986.

(Taitt, 1997:2)

Despite this, the PNM, sustained its position as the political party in government and was led by Prime Minister George Chambers from 1981 up until the party was voted out during the national election of $1986^{\circ}$, being replaced by the National Alliance for Reconstruction (NAR) led by Mr A. N. R. Robinson.

I have given a thumbnail sketch of the political and economic background just prior to "Sinking Ship" being released. This is necessary to fully understand the national and global context against which the Calypso was released for the 1986 carnival. This helps in our understanding of the situations faced by the citizens, reducing their spending power. The consequence was that the Prime Minister became the scapegoat. Hence the line Captain the ship is sinking,

The global picture towards the end of the period in office of the PNM showed significant economic instability. 
As an overview, we see that in the 1970's the world experienced an energy crisis during which the price of oil rose very sharply and quickly on the international market. Since Trinidad was (and still is) an oil producing country, it experienced considerable benefit from this rise. By global standards, and most certainly, by all Caribbean standards, the country was considered to be wealthy. As a result, this influx of wealth brought considerable stability and buoyancy of the economy to the nation that was being led by Eric Williams. Being in such a strong and stable position, the country, offered assistance to other Caribbean nations. This act earned the nation the nickname "The Caribbean Godfather" (Sugar Aloes, 1990).

With the global recession of the mid ' 80 s and the end of the oil-boom the fortunes of the country had changed. There began a period of austerity under the leadership of George Chambers, with the consequential need for a tightening of belts. This led to feelings by sectors of the population that the PNM, who had been in government for 30 years, and particularly this new leadership, was to blame for the hard times during this period of recession. Hence, in the 1986 general election, NAR led by Mr A.N.R. Robinson, replaced the PNM. (See Appendix 2 for a Chronology of key events in Trinidad).

This is the background against which Gypsy released "The Sinking Ship". In this Calypso, he uses linguistic form abundant. The title of this Calypso is itself a metaphor telling its own story. It brings to mind the concept of a floating ship, as a positive measure, while a sinking ship suggests despondency, vacating rats and a dying captain. Hence, the image generated by the title is one of distress with associated SOS messages. 
By way of symbolism, a ship is identified with the containment and contentment of its passengers, moving them forward. Used in this way, the term 'ship' becomes a metaphor with the passengers symbolised by the citizens and the cargo the resources of the nation. This relatively narrow piece of metal, floating as it does on the surface of the sea, augers for balance and stability. Of course the level of safety and security that the voyagers may have can be determined by the level of turbulence of the water. The use of this metaphor is not unique to Gypsy as Sparrow in his attempt to mediate prevailing ills also refers to the country as a ship in the Calypso "Prophet of Doom" thus:

Don't upset the ship of state.... Accept the status quo and don't play hero

Other Calypsonians who have also used this metaphor include: The Mighty Trini who sung a response to Gypsy's Calypso that included the catch line "if Trinidad is a boat, Ah go sail on it sink or float". "Soca Boat" is yet another example of the use of metaphor. However, were I to extend the theme to incorporate that of transport, we recognise Chalkdust's "Chauffeur Wanted" in which he refers to what he considers to be the inability of the PM to manage both the country and the economy, asserting that the driver can't drive. Yet another example is Tambu's: “The Journey Now Start".

Remembering that the Republic of Trinidad and Tobago also produces oil (gas), and this is the source that the Trinidad and Tobago Electricity Commission (T\&TEC) uses to generate electricity for domestic and commercial enterprises, we can now embrace a new understanding of the expression in the first sentence quoted below wherein Gypsy states that: We gas tank almost empty,

We gas tank almost empty

We have no electricity

We oil pressure reading low (Available at Track 11 of CD) 
In the "Sinking Ship", Gypsy likens the role of the Prime Minister to that of the Captain of a ship. In times of distress the Captain takes charge and tells us what to do, and so, on behalf of the people, this Calypsonian makes this plea to be aware of the ship, which in his opinion, is sinking. Indeed, as this first verse of the Calypso states, it was produced at the time when the helm of the country had been newly taken over by PM, George Chambers. By stating: For thirty years she had the same crew, it becomes obvious that this Calypso in not just a commentary on Chambers tenure in office as PM. Rather, it is a commentary on the accumulated 30 year PNM's term of office. This is some of the background to the Calypso "Sinking Ship".

A glance through the entire lyrics of the Calypso "Sinking Ship" which are available in Appendix 1, shows the abundant use of Metaphor, Metonym and to a lesser extent Polysemy. An example of metonym, drafted within the same domain, is the expressions The Trinidad a luxury liner Sailing the Caribbean Sea

In retrospect, it can be seen that, not only is "Sinking Ship" predicated on metaphor with Gypsy identifying the nation as a ship of state, he goes further to identify the initial state of the nation and suggesting getting help from the World Bank. As we read the verses, we see that each of them builds on the previous and in so doing, there is an extension on the theme of the ship sinking. This approach takes the audience from the recollection of a 'then' with the abundance of the luxury liner to the reality of a 'now' sinking ship, needing significant and substantial help. It is in this way that this Calypso, as with the Banana Boat Song, use the various aspects of Linguistic Form to influence and persuade. 
As stated earlier, if in Metaphor one domain is mapped onto another, in Metonym the mapping is within the same domain while, Polysemy there is the application of multiple layers of meaning.

Having previously thoroughly examined the application of Metaphor I will now use Chalkdust's "Chauffeur Wanted" to exemplify the abundant use of Metonym and Polysemy. This Calypso is frequently referred to, and at times mistakenly titled The driver can't drive, i.e. one of the key lines of its chorus. In it the domain is movement or travel and there is a relationship between the travel of the N.A.R. political party, who were the government of the day, with a brand new mandate of the next car when the country installed a new driver after the NAR had a landslide victory winning 33 seats in the 1986 election.

You asking me what is wrong with Trinidad You can't understand why things going so bad You find we so rich in human resources And yet the country going to pieces Well let me tell you my friend where we went wrong After Eric Williams old car break down We call the NAR, we ordered a next car And installed a new driver (Available at Track 12 of CD)

Chalkdust communicates a perception of the inability of the new PM using a localised form of privately owned public transport known as a maxi taxi, referring to the 33 new MPs as passengers.

With 33 passengers from the Party

We gave him a maxi taxi

Fitted with mag wheels, tape-deck, computer

Air conditioned eight cylinder

With posh new fittings this maxi car arrived

Then start to swerve and nose-dive

It took a year for passengers to realise

They say ... "The new driver cannot drive" 
In Chapter 1, I referred to the unpopular and stringent changes that the NAR brought into legislation to address the economic downturn of the country. Using Linguistic Form the following verse points to these. The new legislation reduced the availability to children of parents in the lower income brackets, of free school lunches and books. It also removed the Cost Of Living Allowance (COLA) for 57,000 public servants, hence slam de brakes, while offering them the compensation of Government Bonds after freezing pay rises.

Well some school children by the road run like hell

They loose their lunch and books as well

He driving on the fast Neil and Massy Lane

And pelt Mr COLA straight in the drain

He slam de brakes on dem public servants

Some get injured no ịnsurance

Den he tied them up in bonds that he connived

They say ..... "The new driver cannot drive"

Finally, each of the three Calypsos chosen in this Chapter illustrate the use of Linguistic Form poignantly demonstrating:

- $\quad$ Syllogistic Progression, i.e. the progressive development of the argument.

- Qualitative Progression, the connectedness of the verses and choruses with the choruses offering some respite from the biting commentary.

- $\quad$ Repetitive Form, by consistently maintaining and being locked on to the identity and/or issues about which they are showing concern.

- $\quad$ Conventional Form, i.e. the categorical expectation of the audience, (I develop this point further in Chapter 9)

- Minor (or Incidental Form) i.e. the manifestations of metaphor, metonym and Polysemy as delineáted earlier in this Chapter. 
Chapter 6 - Linguistic Form in Calypso: Employing Reframing as a Multidimensional Tool

\section{CONCLUSION}

In this Chapter, I have shown how Calypsonians, using various methods of Linguistic Form, Reframe experiences, presenting them to their audiences, in a way that gets them to see them from a different light.

For our purpose, what is significant about reframing is that it utilises for the individual's benefit, his/her innate ability and tendency to rank events into categories of good, bad etc. Under normal circumstances, these categories remain static. However, through the skilled use of reframing, conflict resolution practitioners get parties to shift their categorical understanding of an experience, thereby reordering these experiences. This outcome raises awareness and invites the individual to take action leading to resolution. This is the effect that I contend that the Calypsonians manages. 


\section{CHAPTER 7 - THE MEDIA USED IN CALYPSO PRESENTATIONS}

To grasp how people actually experience their lives, we need to attend ... not [to] their terms for gods, institutions, calendars and rituals so much as [to] the concepts with which they feel and think about, and handle, the tasks and tribulations of their individual existences

Wikan 1990

\section{INTRODUCTION}

$\mathrm{T}$

his Chapter focuses on the ritual communication within the Calypso Tent,

looking at it as a medium used in Calypso presentations. In doing so, it

addresses the research question that asked whether Calypsonians who comment on the social, political or economic issues within the country, do so as a deliberate and conscious attempt to facilitate the resolution of conflict within the society.

One objective of this chapter is to bring to the fore and contextualise the mechanisms of ritual communication that Calypsonians use to deliver their messages. In doing so, I recognise that to the audience, the Calypsonian is a performer and in this relationship, the means of communication is partially a locally based language that is frequently steeped in colloquialism, folklore and Polysemy, and sometimes wrapped in a thin veil of humour. Calypsonians use this language-set as a means of effecting engagement through a lyrical type of narration. From my intimate knowledge of the Trinbagonian lifestyle and the society, I recognise that humour is used as a rhetorical strategy, permitting a level of coexistence with the conflict that is inherent in the prevailing structure of the society. What's important here though, is that humour becomes an integral part of a ritual method, enabling discourse between factions of a cosmopolitan 
whole. The principal impact of this ritual use of humour in resolving conflict, is the destabilisation of the audience through the creation of cognitive dissonance as both the Calypsonians and emcee alternate (are juxtaposed) in a form of Qualitative Progression. Hence, by amiably problematizing the issues of concern, the Calypsonian's use of humour begins to have a social function that is tied into the resolution of conflict within the society of Trinbago.

This Chapter then recognises how the cultural ritual of Calypso, the symbolic action of its language and the individual Calypsonian all fuse, allowing the humour of the Calypso Tent to work as ritual. In consideration of this process, my work is based on the premise that the Calypsonians' use of oral narrative in dramatic performance is the means by which they - to use Fishers definition of dramatic - state[s] some sort of conflict which is eventually resolved (Fischer 1963).

Engaging in this approach requires that I take a view of the Calypso from the studies on "performance theory" (including theatre) as applied by Turner (1974, 1982, 1986a, 1986b, 1990), Kapferer (1976) and Frisbie (1980) and, the area of "verbal art", as developed by folkloric narrative genres. In the process of taking this perspective, this work adds a particular set of intellectual tools to the study of Calypsos that are sung on the social, political and economic issues occurring in Trinbago as these Calypso becomes a medium for the resolution of conflict in the country.

\section{Cross-Fertilization Among Festival GenRe}

In Chapter 2, I showed that considerable work has already been done by various researchers on a number of different aspects of the Trinidad Carnival art-form, including 
the Calypso. However, I am not aware of any research having been devoted to the performance of Calypso per se, specifically in relation to the relationship between performance, spectacle, theatre and ritual, when used as mechanisms for resolving conflict. This is surprising, particularly so, since the Calypso art-form plays such a central role in the society of Trinidad.

The dearth of previous research in this area of Trinbago life and society leads me to recognise that it would be helpful to identify what similarities exist in other parallel or similar forms of cultural performance. This approach allows a level of synthesis, enabling some cross-fertilisation from other areas of study in cultural performance, theatre and narrative. In this respect, I found the work of DaMatta (1990 and 1991), appropriate. In his work, DaMatta made a study of Brazilian social rituals, focusing on the trajectories of three types of public ritual, these being: Carnival, Independence Day and other military parades, and local-level religious processions. He uses these as a principal axes in defining the values and attitudes that shape urban Brazil. More specifically though, in relation to his study of the Brazilian Carnival, he identified it as an example of a people differentiating themselves, then engaging in the process of reconstituting through the spectacle of what is the Carnival.

By examining the styles, forms and actors of these three sets of rituals, Da Matta's work made a significant contribution to the theory of dramatisation and ideology. In his work, Da Matta places an emphasis upon three particular ways that ritual manipulates and transforms elements and relationships, these being through reinforcement, inversion and neutralisation. 
Bauman (1992) has researched the symbolic dynamics present in the spectacle of folklife festival in Washington while Gregor (1977) invites us to see daily life in a Brazilian village as spectacle. Harrison-Pepper (1990) presents an astute study of the street performances that take place in Washington Square Park in New York City as representative of the entire neighbouring community and its culture, while Kisliuk (1988) examines the musical activity taking place at a Bluegrass Festival, and Nunley \& Bettelheim (1988) engage in an analysis of Caribbean festivals. All of these studies are significant in their own way, being touchstones that serve as handrails for further understanding and interpretation of the activities taking place during the Trinidad Carnival.

\title{
INTENTIONS OF CALYPSONIANS
}

As has been argued by Liverpool (1996) and Nehusi (2000) the current Calypso art-form is a modified version of an African custom. In his account of the development of the Calypso Quevedo tells us that:
Kaiso is a particular form of folksong undeniably African in origin which was brought by the African slaves to the West Indies. Conditioned historically by its new environment and by French acculturation the kaiso developed most distinctively in Trinidad into a form of mass art in song and dance uniquely or typically West Indian.
(Quevedo 1983:2)

\begin{abstract}
Although having gone through a significant metamorphosis, the art-form has evolved, has transcended time and continues to survive today. I showed in Chapter 1 that initially, the Trinidad Calypsos was a response to a Matrix of Domination. In view of the transition that the social structure of the society has experienced over the period, from pre-emancipation to today, one question for consideration is: although the
\end{abstract}


structural makeup of the society has gone through a significant metamorphosis, what is it that still drives the need for the current annually recurring crop of Calypsos?

In response to this question, my research in Trinidad showed that although the cultural, social and financial pre-emancipation stratification are now confined to the corridors of history, there is still a level of social stratification and a significant chasm between the 'haves and the have nots'. This social structure is such that the financially better-off, the people who consider themselves to have "class", invariably feel special. From my interaction with them, I have found that in turn, they can be indifferent to the lived experiences of those less fortunate than themselves.

In crafting their lyrics, Calypsonians are raising awareness of the societal issues that come to their attention. It is to this extent that Calypsos engage in denouncing a set of social practices that ordinarily are not given overt attention in the society. It is in view of the foregoing that attention needs to be paid to the intentions of the 'real' Calypsonians. This question was answered by the work of Sugar Aloes, Chalkdust, Gypsy and Cro Cro

In the Calypso entitled "The Judge"; Aloes asserts:

\section{My intention is to sing out for the poor man}

The lyrics of "Why ah Stay" are a further indictment to his drive, purpose and intentions, for here Aloes gives a number of reasons why singing Calypso is important to him. 
However, in relation to this Calypso (Why Ah Stay), it needs to be remembered that it was released for the 2000 Calypso season. Aloes had the support of many members of the public, who like him, held the view that he was denied the Monarchy in retaliation for his outspokenness during the 1999 Calypso season. In the following verses from "Why Ah Stay," (Track 13 on accompanying CD) Aloes' clearly articulates his reasons and deliberate intentions for functioning as a Calypsonian.

\section{The following verses are extracts from "Why Ah Stay" (Track 13 on CD)}

\section{From verse 1}

For when ah read the clip on the newspaper Saying how Carlos John pave the savannah And Daphne saying that it was unusual, No one give him the approval And up to now the whole country confused 'Cause he can't tell we yet, who money he use Ah tell myself New York ah cayh go, Is why ah stay back to pound them in Calypso.

\section{From verse 2}

For when ah hear 'bout the corruption in URP And Sumah Sing wrote a letter saying they threatening he Danrhaj admit he saw the letter as man and started investigation But Danrhaj Sing reminds me of Spoiler, Himself suspect himself guilty of murder They tell me check Ramish because he might know Is why ah stay back to blaze him in Calypso

\section{From verse 3}

And the claim that pan is the latest invention is still yet to be proven But like Sat Maharaj, Rhajnee must be loco,

That's why the Flags Man call she a queen cobeaux

The facts of we culture that woman do know, Is why ah stay back to tell she in Calypso

\section{From verse 4}

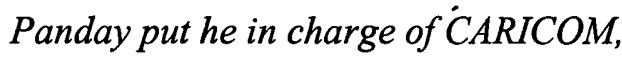
They believe Trinbagonians dumb But it was Shar that same Kamar brother, Who said it was time for an Indian Prime Minister Prove how these people racial for so Is why ah stay back to remind you in Calypso 


\section{From verse 5}

Ah tell meh self look how these people lose their life

I was sorry for Penco wife

But when ah see Omar ball and hold she head,

I almost believe it was Panday who dead

You see how this woman lonely for so,

Is why ah stay back to romance she in Calypso.

\section{From verse 6}

And when ah remember some time in last year 13 million in coke, they just so and disappear

The Venezuelian drug lord, ah sure he laughing at we

Because of the police greed, Lewis Gomez was freed, on a technicality

And when ah see that there was no enquiry by the Prime Minister neither the AG

Who ensured us in their manifesto: "To jail all drug lord must go"

But instead they appoint a committee,

To investigate we judiciary

Next election UNC must go,

Is why ah stay back to ensure that in Calypso

\section{From verse 7}

For when a read right there in Tobago

Ah couple of millions disappear just so

Where it went Hochoy Charles cannot say

While poor people can't get pay

But instead they take 40 million or so

And give Eddy Grant for the Ring Bang show

When they do wrong things the public must know,

And that is why commentary must always stay in Calypso

From verse 8 and in the manner of Call and Response he states:

Next election UNC must go,

Ah want your promise and I'll always sing Calypso

From Aloes' perspective then, he sees seven distinct reasons for singing Calypsos.

These, in the order he has given them, are:

1. to pound the wrong doers,

2. to blaze those involved in corruption,

3. to keep the public informed,

4. to remind the public of the wrongs committed,

5. to romance those women experiencing emotional neglect,

6. to ensure a change in government, and

7. to make strident political commentary. 
Equally significant are the lines of the first verse of the same Calypso where Aloes, in asserting his dedication to Calypso, recognises that being a Calypsonian is his life's work, thus:

And if a leave here, meh fans go suffer,

Vital information the public won't know

Then something open meh eyes, and made me realise,

Ah was born to sing Calypso

For his part, Chalkdust puts forward his view of his role as a Calypsonian in the Calypso entitled "The People's Parliament," which is available at Track 14 on CD. Through the lyrics of that Calypso, he responds to the question regarding why he has not sought to be elected as an MP. Part of his response is given by the following very powerful words, extracted from the Calypso. Chalkdust asserts:

With kaiso the Nation becomes my constituency

Ah know Dan Rhaj Singh can't come here and wine on me

So the $P P P^{20}$ already chose me

Honourably to serve this country

In my Chamber, Tommy Joseph is the speaker

And the opposition is all them harbingers of corruption

So don't confuse me with Gypsy or Jimmy

Jack eh pay me a cent

And the Kaiso Tent is meh parliament

Kaiso and the kaiso Tent

Goes back to the days of enslavement

Where under a spreading tamarind tree

Blacks sung against Whites fearlessly

Through kaiso they made their laws

Through kaiso they fought their wars

Kaiso and its sweet minor cords

Was the poor blackman's House of Lords

So Kaiso is our big, big insurance policy

Against dictators and the parasitic oligarchy

Kaiso is the atomic bomb in our possession

For all who want to degrade our Constitution

So real kaisonians are important men

${ }^{20}$ PPP stands for Poor People's Party 
They bigger than Red House Rats my friend

They sing sociology

And spew out Philosophy

So to join the Red House set

Is to climb down from a king to a jammet ${ }^{21}$

So North Stand and Grand Stand

You are an important institution

You more important that government

So all-yuh welcome to Parliament

(Available at Track 14 on CD)

In "Respect the Calypsonian" (Track 15 on CD), Gypsy expresses his view on his role in declaring:

I who write the songs to make you sit and think

I who write the songs that does tickle you pink

-

I could write a song to make governments strong

I could write a song to bring governments down

I could do it with real humour

Or venom like a cobra

(Available at Track 15 on CD)

In the Calypso "Fire" (Track 22 on CD), Cro Cro, in identifying himself as a

Calypsonian clearly states:

I am proud to be a Calypsonian

And my ambition is to sing out for the poor man,

(Available at track 22 of $\mathrm{CD}$ )

In identifying with the plight of the poorer citizens, Cro Cro acknowledges that he aspires to represent the poorer class of Trinidadians, representing them and their drive to be recognised, as they strive for greater equality within the country.

\footnotetext{
${ }^{21}$ Here Chalkdust asserts a hegemonic relationship between MPs (Red House Rats). He goes on to assert that those in the Stands of the Queens Park Savannah constitute the real Parliament with him being their representative.
} 
These 'real' Calypsonians clearly acknowledge their awareness of the work that they do, its place in raising consciousness, and are aware of the impact that this has in resolving indigenous community conflict.

\section{The Calypso Tent}

In this work, I have repeatedly referred to the location of the main venue for the performance of a Calypso as a "Calypso Tent". This terminology is based on linguistic retention, for today the "Tent", as it is often called by Trinbagonians, is much less of a Tent than a properly constructed building, consisting of bricks and mortar. Quevedo's (1983) description of the construction of a Tent during the days when syndicated Tents were linked to Carnival bands, helps with our understanding of the construction of an original Tent and shows the extent to which the structure of the modern day Calypso Tent has evolved:

The construction of the carnival Tent in those days, in the tradition of the gayap, was a communal effort. Bamboos were cut from the St. Ann's hills back of the 'government House, Port of Spain, and refreshment in the form of local rum was served at the cutting and building operations. The completion of the Syndicate's Tent was the occasion for hilarious enjoyment and a general free for all.........

(Quevedo 1983:35)

In relating the events within the Tent he describes:

During the day the Tent was the rendezvous of kaisonians, their apprentices, and members of the band who came to learn the choruses for the night's display. The Chantwell had no need to worry about the preparations of his meals, that was his least concern. In fact, he was lavishly provided for by the female members of the band. At nights the Tent was open to visitors who walked in and out at their own sweet will, while the Chantwell and band practised in preparation for the two days of carnival. Basic musical accompaniment was usually provided by the quarto and the guitar, though in some cases there were cello, violin and even flutes so long as members of the band played these instruments. Borrowed chairs were placed in the Tent to accommodate gentlemen of the upperclass who might come down town to listen to the kaiso. Women armed with waiters and holding the bouquets matching the colours of the band would collect donations from strangers at the end of the performance.

(Quevedo 1983:35-36) 
The picture below is of the "Kaiso House" Calypso Tent. The building usually functions as a cinema or "theatre," as it is called locally. It is hired from the proprietors for the six-week period just prior to the event of carnival. The bamboo façade that is visible in the front of the building is a temporary cladding designed to create the appearance of the original Tent. This cladding is removed once the season is over. Under this façade lies a structure of brick and mortar.

Cardboard cut-outs of the faces of the more popular Calypsonians make up the top awning of the building. This one shows from left to right: Singing Sandra, Shadow and Iwer George. This sort of advert of the stars of the Tent is done to attract patrons to the Tent.

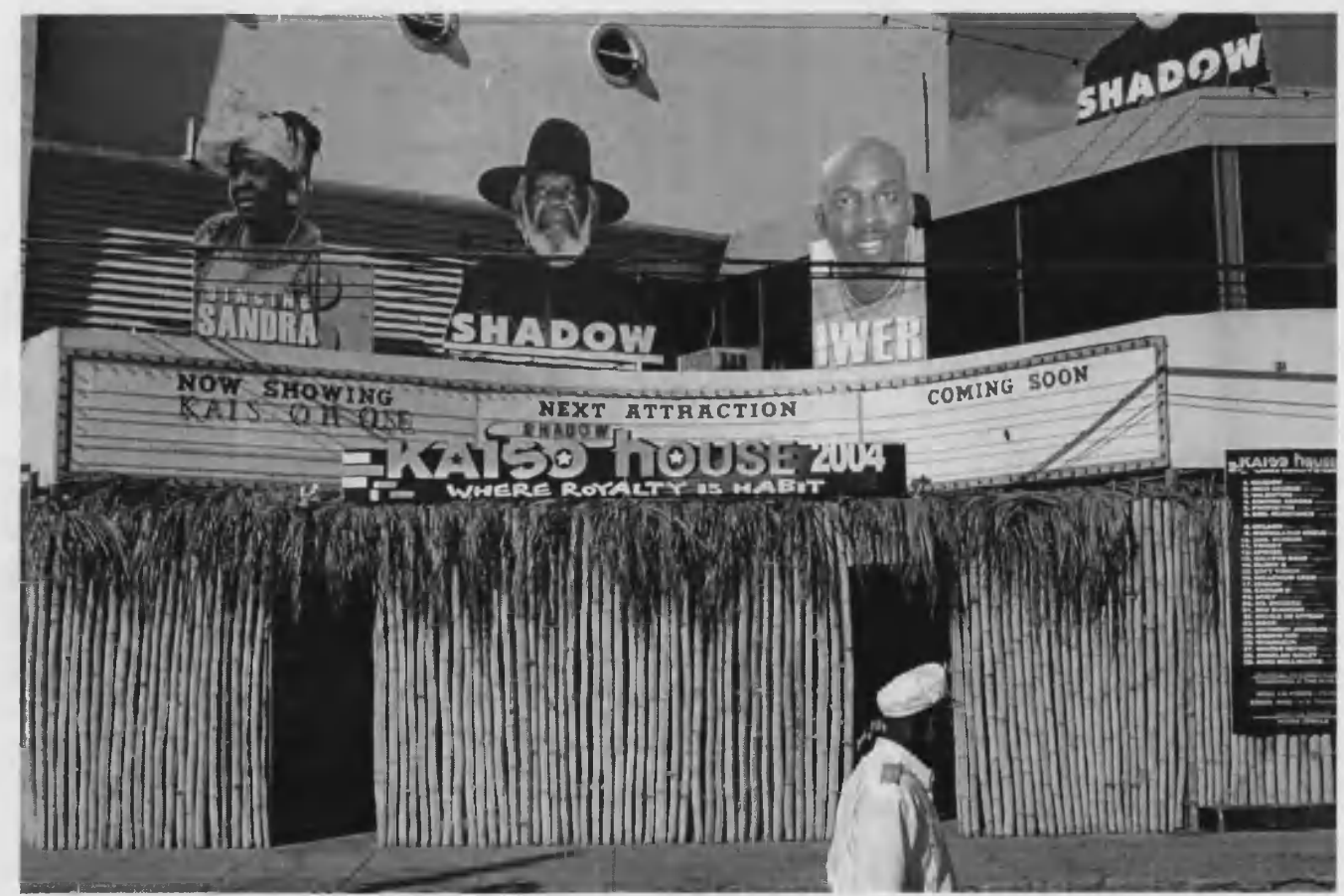

Figure 7.1 - Kaiso House Calypso Tent 
Tents can also advertise a list of the Calypsonians appearing at that Tent as is the case with the black board appearing on the right of the picture above. The photo below magnifies this board.

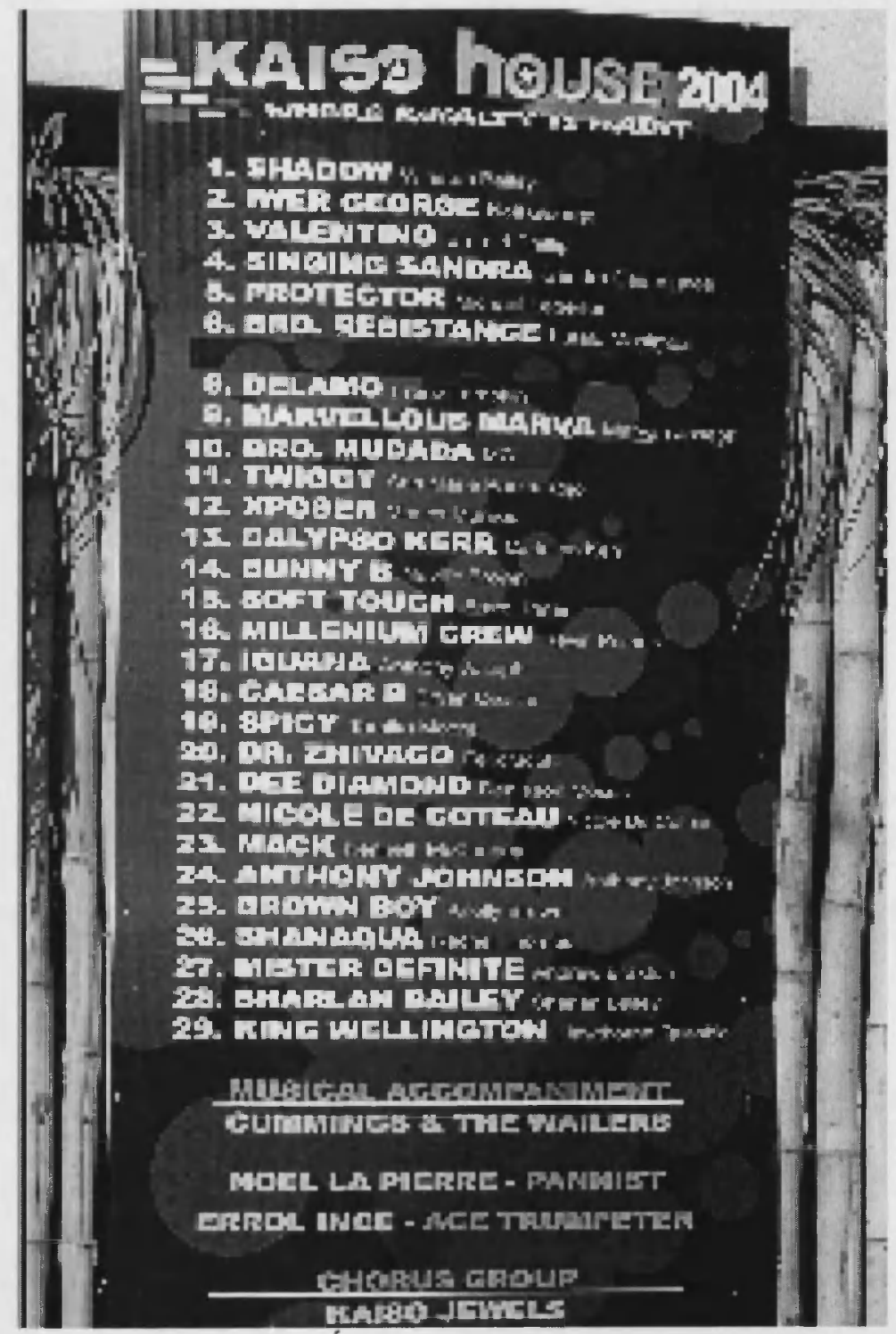

Figure 7.2 - Calypsonians Advertised as Appearing at Kaiso House Calypso Tent 


\section{Ritual AND Theatre of a Calypso Performance}

Practitioners in the field of conflict resolution are aware that the successful resolution of conflict usually follows a specific process. One way that this process can flow is: introductions, the hearing of individual parties' points of view during uninterrupted time, acknowledgement and dialogue, summary of issues and needs, suggested offers and requests, with the ultimate choices being made with agreement on these. Similarly, this approach to Non-formal resolution also follows its own process. It follows laws of rite that constitute ritual. The Calypso Tent, the Calypso Fiesta semi-finals in Skinner Park, the Dimanche Gras show, each of these major Calypso events has its own, very individual flow, order and their laws, i.e. their ritual. These are brought to performance on the stage of a venue that is a type of theatre that we call a Calypso Tent, or the stage in Skinner Park, or the stage of the Queens Park Savannah, respectively. Tent and the stage are the places where theatre and ritual are interwoven. These performances, are ritual. They are discrete behaviour patterns that are linked to a larger, generally unstated ideology. This aspect of the ritual is born out by the unique language of the Calypso, and in my view, is parallel to the strange language of status, voiced in a Balinese cockfight, or as the language may indicate the tensions of an evolving society, as we derive from Geertz's other famous example of the breakdown of a Javanese funeral. For the Calypsonian, the symbol as manifest in the language of the Calypso, encapsulates both the energies and the doubts of a transitional culture, into an effective ritual vision. The issue for the Trinbagonian Calypsonian, is that of fusing the needs of the multi-faceted heterogeneous culture of the country, while explaining and facilitating an interaction of the separate strands of the society, in a way that is appropriate to an integrationist vision. 
My fieldwork helped me recognise and understand the different roles and uses of both satire and humour as they punctuate the evening. Not always, but frequently enough, I came to see a dynamic equilibrium between the presentations of the Calypsonians, as this was balanced by that of the emcee of the show.

I recognised the work of the Calypsonian is enshrined in satire while that of the emcee is enshrined in humour. This humour is abundantly demonstrated by the following soliloquy from Sprangalang (real name Dennis Hall) in which he talks about a male being denied his 'manhood'. The actual vocal delivery of this text can be heard at Track 16 of the CD. Sprangalang says:

Fellas we get it at last.... seven years de 'oman who zisttt! Seven years! As dey playing they pipsing and dey out with the kitchen knife and swisssst...... seven years, seven years and ah hear they getting a year ah inch.

Dey cyah play dotish with we. Ah know some ah alyuh wife go get time off for good behaviour, because there is nothing to cut, but ah know it have some woman that will make 15 years if they going a year ah inch, you understand what I am saying?

But they cannot play stupid and just wake up a morning and just swisssst. Seven years.... Ah like how they moving.

The thing is ah do like the goal the woman get, because she get hard labour, and the hard labour is to cut wood. They should ah send she to mix cement, she know how to cut wood already.

And the ........ ya know last week I reading in de papers how de 'oman appeal, and say that she cut something and didn't know what she cut. It has never been any place else. Once yuh gone down stairs and you swisssst, is dat yuh cut.

And then the next thing she claim was that they was cuffing up one another and it was in self defence...........I never know that to fight back yet! Is a mad 'oman Seven years. down she pweffen!

We spoke to the Mount Hope Medical Sciences Complex and they say from 1997 they making boy children with two! So when they get big and these woman Swisssst they have two... huh, huh, huh. 
They have to do something, is a madness going on, they cannot do we dat!

Now the most surprising thing is where Medical Science reach. For $\$ 19,000 U S$ plus VAT yuh could get a new one! Dat worry me why they didn't tell me dat all de time, I would ah abuse the old one and trade it in, and start afresh at this age. The problem at 19,000US plus VAT

And plus VAT worrying me eh.... Because yuh know when we had the normal one we used to plus VAT and the ladies didn't use to like when we plus VAT, but now is extra cost and it manual, so in the middle of nothing, dey give we a pump by we waist. So why we operating my dear we hah to pfut, pfut.

What the hell ....... They want to kill we or what? At 19,000 plus VAT I want an automatic with a foot pump. While ah talking to she ah say .... "Darling you go get the hardest hard." What the hell they think it is at all? Let we ent waist no time talking this thing because this could get slack.

The woman swisssst! ......... They ent find it yet! And that worrying me because it have no name salami sausage in de grocery.

Anyway look le'we ent talk that talk before we get in trouble.

In this soliloquy, clearly Sprangalang is making fun of a serious issue. In the Tent, this siloloque was preceded by Stinger's "The People's Advice" (Track 23 on CD) at the end of which, the emcee acknowledged the seriousness of the Calypsonians message by saying: Put your hands together for a serious song. Sprangalang then follows Stinger's Calypso with this soliloquy. It is a traditional part of the culture of the Calypso Tent to have the serious and the playful side by side, that is, for them to alternate. This approach is neither new nor unique to the Calypso Tent. The instances of its occurrence are widespread among various cultures. Another famed example of the creation of confusion through this type of symbolic inversion occurs in many of Shakespeare's plays where he used the clown as a way of jolting us, bringing us to our senses. For the frame surrounding his stupidity is impregnated with the camouflaged wisdom of an 
alternative perspective that challenges our thinking. It is this challenge that dislocates us, and through this alternation, this inversion, forces us to question our sense of order. In this regard, the anthropologist Julian Stewart, who extensively studied the phenomenon of tomfoolery, penned

The clown is the person par excellence who is privileged to ridicule burlesque and defile the most sacred of and important ceremonies and customs ........ He is licensed to behave as no ordinary mortal would dream of behaving. He is held accountable for nothing. In his transgression of custom lies much of his comedy

(Stewart, 1930:189-190)

This application of humour, interrupting the seriousness of the show as it does, presents a contrast that accommodates the Qualitative Progression of which I wrote earlier in Chapters 5 and 6. In this approach to resolution, the satire of the Calypsonian is a form of ritual attack, while the humour of the emcee is ritual accommodation, and both are forms of communalising play, (Huizinga 1949:5)

My fieldwork shows the events of the Calypso Tent to simultaneously subscribe to both Ritual and Theatre and the diagram below juxtaposes the attributes of both, relating them in the context of efficacy as opposed to entertainment. This allows for an appreciation of how the ritual communication of the Calypso Tent is brought to performance in the venue of a theatre, allowing an appreciation of the relevance of the process as I see it applied to the work of resolving conflict.

Before proceeding to look at the table, it is worth mentioning that the expression relating to the performer possessed, in trance refers to the performer assuming the identity of his/her sobriquet, while on stage 


\begin{tabular}{|c|c|}
\hline EFFICACY & ENTERTAINMENT \\
\hline RITUAL & THEATRE \\
\hline Results & Fun \\
Linked to an absent Other & Only for those here \\
Symbolic time & Emphasis now \\
Performer possessed, in trance & Performer knows what s/he's doing \\
Audience participates & Audience watches \\
Audience believes & Audience appreciates \\
Criticism discouraged & Criticism flourishes \\
Collective creativity & Individual creativity \\
\hline Figure 7.3 - A Comparison of the Attributes of Ritual and Theatre \\
\hline
\end{tabular}

In this comparison between the attributes of the spectacles of both theatre and ritual, it is recognisable that in relation to the intention of the Calypsonian to Non-formally resolve conflict, there is an essential need for him/her to strike a balance between being effective in the delivery of the message while simultaneously being entertaining. The accompanying $\mathrm{CD}$ to this work is living evidence of the Calypsonian's ability to effectively straddle both of these criteria.

It will be recalled that, in relation to the general phenomenon of Carnivals, earlier in this work I identified a link between Carnival and the geographic seasons and showed how this related to existing religious belief systems. Indeed, Gaster, (1950) has identified that it is usual for elaborate theatrical activity, of the type to which the Calypso Tent subscribes, to have been generated and concentrated in agricultural societies. In reflecting on the development of the Calypso as a communication process for enslaved Africans, forced to work the agricultural plantations, it is therefore natural to find that the Calypso became one of the key mechanisms through which they were able to voice their true thoughts, feelings and observations of the society in which they were forced to live. 
Furthermore, this seems to be corroborated by Turner's work linking theatrical activity and ritual behaviour. He claims that theatrical activity originates from ritual. He argued that sacred ritual serves as a model for social ritual and in turn social dramas (Turner $1974 \& 1982)$. This developmental process helps focus thematic material, used in drama for presentation to the public. In the diagram below Turner and Schecner share a perception of the degree to which staged dramas are interrelated with social dramas, a concept familiar to performance theorists.

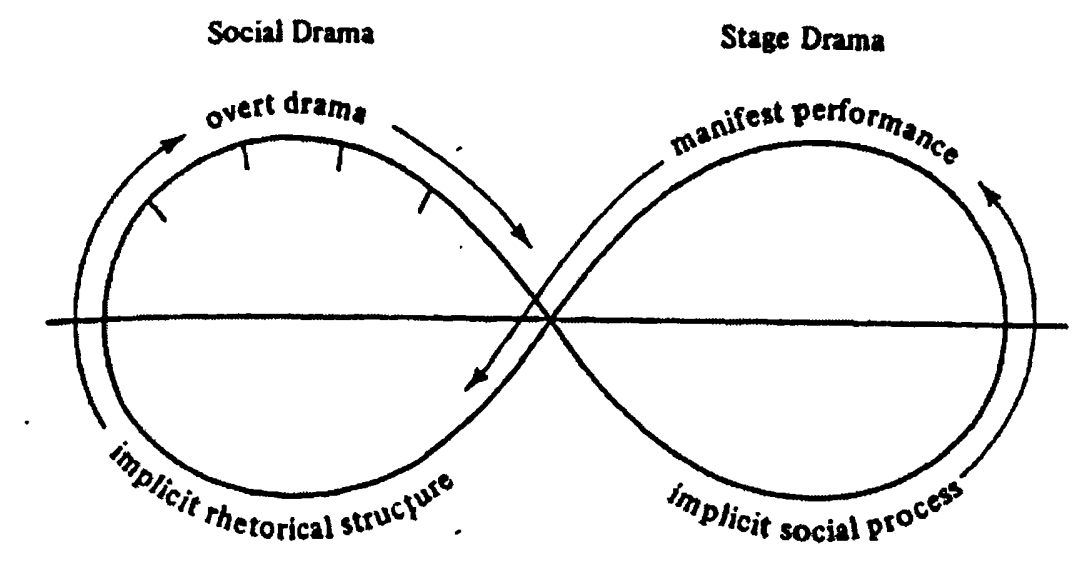

Figure 7.4 -diagram showing the inter-relationship between Social drama and Stage Drama (Turner 1990:8-18)

Through the totality of this engaging exercise, Calypsonians are thereby developing a psychological bridge between themselves, the event about which they are singing and the members of the audience (i.e. the spectators). This they maintain throughout the entire performance. The institution of the Calypso Tent then, lends support to this process through the aspects of the ritual of the event as made manifest in the lighting, the dress the language, the music and motion thus fulfilling a phatic function, (Jakobson 1960). It is this phatic function which Jakobson argues is the cornerstone of a 
communication process that keeps all parties engaged with each other during the duration of the communication. For in the Calypso Tent, this type of engagement works for the Calypsonian and audience alike, serving to evoke and ossify a regenerative network of social and cognitive relationships that triangulates between performer, spectator and the world at large.

This phenomenon of constant rebirth, as it occurs within the Tent, inevitably means that no single experience in a Calypso Tent, is ever exactly the same as a previous one. In turn, this generative approach to the resolution of conflict, brings its own degree of intrigue, and since the outcome is completely dependent on the interactions on the night, the outcomes are not necessarily repeatable.

\section{Discussing the Ritual of the Calypso Tent}

In this manuscript, I contend that Calypsos offering commentary on the socio-political and economic issues in Trinidad, function as facilitators in a dialectic that attempts to raise awareness of the prevailing pathologies within the society. By so doing, they empower Trinidadians to take action to resolve the contradictions and in-authenticities in their community. In the extreme, I see the lyrics of these Calypsos as protest action, with any consequential decisions by the audiences to act, as mechanisms of 'rebellion'. Under these circumstances, I recognise the entire process of the performance in the Calypso Tent, to action by the audiences, as a "Ritual of Rebellion".

One of the most influential theories regarding the function of institutionalised rebellion is Max Gluckman's work, based as it is on fieldwork conducted among African tribal people. Gluckman (1963) uses the term "Ritual of Rebellion" in recognition of the 
cathartic release permitted by the temporary ritual inversion, of the normally asymmetric power imbalance within the researched communities.

In seeking to establish correspondence between the Trinidad situation and that researched by Gluckman, it is worth noting that in the main, Calypsonians do not originate from the strata of people in Trinidad society who are born into positions of power. Secondly, it is questionable whether Calypsos that are sung in public, do provide an occasion for the Calypsonians to temporarily invert the power status quo, temporarily seizing power.

In the most pure sense, the authenticated ritual reversal is demonstrated by the events of the religious feast, celebrated annually in the Ancient Orient Babylon. During this feast a slave would be exalted to the position of the king, having all the power and authority of the king to issue orders and indulge in his luxury and the accompanying debauchery of the king's concubines. At the culmination of the feast, this fake-king was either hanged or crucified. The earnestness of this enactment of reversal is borne out by the occasion in 2054 B.C., when the impromptu and untimely death of the real king during the period of the reversal left the mock-king continuing to usurp the throne, in favour of the real-king's son, for twenty-four years after the king's death, (Weidekuhn 1976). Even during the days of slavery, this level of inversion has never been available in Trinidad.

This seizure of power by the Calypsonians over the Carnival period is only tantamount to an inversion if we consider that by listening to the Calypsos, those who are normally in the positions of power, are now by so listening, placed in a position of submission. In 
reality, this inversion is localised and time bound (both within the Calypso Tent and only for the short periods of the night's show during the Carnival season). The fact remains that those in the ruling strata, have lost neither their substantive political nor economic power. Hence, the claim of inversion is based on an illusion, particularly since Calypsonians can sing and be heard only within a limited range of venues. With this in mind, I do not subscribe to the popularly held view that there is any true inversion of power. Alternatively, I submit that by taking the microphone there is a temporary equalising of power. It is from this position of equality that the drive for the resolution of inter and intra-strata conflict in Trinidad, is launched. Aloes shows his recognition of this when, in "This Stage Is Mine", he sings:

\section{I don't own a TV station Ah don't get airplay on the radio The only time that the nation does hear me Is when ah sing on Dimanche Gras show}

It must also be noted that those in substantive positions of power, who temporarily occupy these 'simulated reversals', listen to Calypsos through an act of choice. In this respect, certain observations with regard to the fundamental notion of reversal have wholly been ignored by other academics studying 'reversal' in the Trinidad Carnival. In general, Calypsonians, in representing the poorer strata of society, articulate their demands for equality, their demands for a better way of life. Gluckman suggests that such expressions are a process of the cathartic release of psychological tension that once so discharged, completes the cycle, for a subsequent cyclical recommencement. This cycle is neither unique nor new. Indeed, I recognise it as a very similar process to the stages of the Gestalt Cycle ${ }^{22}$

\footnotetext{
${ }^{22}$ See Appendix 6 for further explaination of this cycle.
} 
Gluckman contends that, as a consequence of this cathartic release, the various strata can then comfortably revert to their original power asymmetry. This ritual process only has the long-term effect of allowing individuals to accept their previously existing positions in life. Hence such "Rituals of Rebellion" have the ultimate effect of reinforcing the existing social hierarchy.

While the various Calypso King, Queen and Monarch competitions that occur throughout the island offer some examples of a quasi-ritual process of reversal, Gluckman's theory does not hold to be universally true in respect of the Trinidad Calypso. This failure of Gluckmnan's theory in relation to the Calypso, and the idea of reinforcing the status quo, can be observed to be the case particularly since Calypsos have been known to shift Trinbagonians' consciousness (see Chapter 8). In this respect, they have claimed responsibility for influencing the electoral changes in political parties, as well as influenced the trends of consumer purchases (See Chapter 8 for a further development). Furthermore, both crops of Calypsos preceding the two major rebellions of 1970 and 1990, are also recognised to have had a significant impact in driving a lasting reversal of the status quo within the power divide of the country. The 1970 Black Power Rebellion is one event that clearly bears testimony to this shift. Prior to that revolt, frequent comments were made, in relation to observations that in Trinidad, the scale with which privilege was granted, depended on the shade of colour of one's skin. One outstanding way that that manifested in private enterprise was through the retail-banking sector in the country where it was frequently observed that few of the clerks who served the public were of dark complexions. It was on this type of segregation within the country that Chalkdust commented when in 1970 he sang: 
don't you call yourself no Whiteman, or no Syrian

You're not a Chinese, Englishman, or Lebanon

Every citizen must know he is a damn Trinidadian

'Massa day' must done

Following the rebellion, in recognition of the shift in consciousness, Aloes, in acknowledgement of the efforts of Makandal Daaga, one of the key activists driving for release from the legacy of the Colonial past, sang:

Remove Cypriani [statue] and put Makandal Daaga there I say! Is he who have black people working in banks today

On the other hand, the 1990 rebellion was inspired by a discontentment with the policies being implemented by the NAR Government. The Calypsos of the time, being driven by this discontentment, reflected it, and are seen to have effected a change in the government. In recognition of this power to shift the minds of the populace, in the Calypso "Respect the Calypsonian," Gypsy penned the following lines:

I could write a sóng to make governments strong I could write a song to bring governments down I could do it with real humour Or venom like a cobra... Gypsy 1988

This impact of Calypsos, as the drivers for discontentment among the citizens, ultimately leading to change, further serves to make the application of Gluckman's theory of a "Ritual of Rebellion" that reinforces the status quo, very questionable, in respect of the Trinidad situation.

Under these circumstances, it seems more appropriate to turn to the work of Peter Weidkuhn (1976) for a more apt interpretation of the dynamics of political protest of 
various groups within the forum of Carnival. Functioning as a social scientist examining the documentation of the Basle Carnival of Europe, which went back over hundreds of years, Weidkuhn studied Carnival as an arena for political protest by various groups being denied political access, and their resultant demand for change. In his work, Weidkuhn establishes that the ritual mood of rebellion is central to and a necessary part of the efficiency of the political protests that take place during Carnival celebrations. Furthermore, they form part of a wider, longer- term, ongoing rebellion in the given society, and need to be regarded in the context of the overall drive for social change within that society.

When viewed against the backdrop of the ongoing socio-political orientations obtained in Trinidad during both the 1970 and 1990 revolutions, it is easy to see that Weidkuhn's theory has particular relevance to the Trinidad situation.

\section{Communicative Action of Calypso}

Chapter 8 shows that any given year's crop of Calypsos serve as a springboard for raising consciousness. However, it is also true that these Calypsos reflect the ongoing issues within the community. This recycling of ideas opens a window that allows a view of the annual occurrences that take place in a Calypso venue as, a complex array of ritual communicative actions, which inherently contain substantial and continuous cultural elasticity, a point that is abundantly illustrated in Chapter 9.

It is in relation to the process of communication occurring within the Tent, that it is helpful to regard Victor Turner's analysis of the functional structures of ritual activities. Turner's main interest in the processes of ritual is the way that they relate to the social 
hierarchy and organisation of society. Stressing as he does, the communicative richness that is intrinsic to ritual events, it may initially seem, that his approach has a particular relevance to the activities within the Calypso Tent, particularly when paying attention to the Language of Calypso as "Symbolic Action".

Despite the reality of the socio-economic divide within Trinidad, localised expressions such as: all ah we is one, would on a first approximation, seem to embrace the concept of 'human equality', of the brotherhood that is the manifestation of Turner's universalistic philosophical ideal of "communitas". Turner purports that when time bound ritual occurs within a highly stratified social system, they create equalizing. This notion can be loosely applied to the ritual of Carnival, occurring as they do within a recognised timeframe. It is only within this limited timeframe that communitas between the various strata becomes relevant, bringing about, not an inversion as suggested by Turner, but what I consider as a temporary communication melting-pot since these new opportunities for communication do not remain fixed and static but are dynamic and flowing within a temporarily homogenised societal strata. This concept is quite different from Turner's suggestion of a "Ritual of Reversal", which inverts all the traditional societal structural rules.

In developing his notion of a universalistic ideal manifesting as a ritual process Turner states:

.......structure tends to be pragmatic and thus-worldly; while communitas is often speculative and generates imagery and philosophical ideas

(Turner 1977:133) 
This speculative concept that brings in imagery and ideas through Linguistic Form is less tangible than the pragmatic worldly paradigm, hence, there is no suggestion that any changes that are brought about, are likely to be permanent, and far reaching. So, any societal change, influenced by the process of the ritual is not lasting, as:

......they reaffirm their order of structure; they also restore relations between the actual historical individuals who occupy positions up that structure.

(Turner 1977:177)

Turner uses as the basis of his idea, the extensive fieldwork completed in Africa. From this he suggest that the temporary reversal does not produce any long lasting feelings of brotherhood, but rather the ritual over, individuals re-assimilate into their original respective strata, continuing a lifestyle as appropriate to that strata, oblivious to the daily realities of those in other strata. Applying Turner's concept to the various Trinidad Carnival art-forms, the temporality of the lived experience brings about a whole question about the extent of the psychological 'penetration' of the real lived experiences of those in the temporarily assumed strata of the reversal. He expresses these views thus:

......the ultimate desideratum, however, is to act in terms of communitas values even while playing structural roles, where what one culturally does is conceived of as merely instrumental to the aim of attaining and maintaining communitas......the seasonal cycle can be regarded as a measure of the degree of drift of structure from communitas ...... Rituals of status reversal ... ... placed at strategic points in the annual circle ... ... are thought of as bringing social structure and communitas into right mutual relation again.

(Turner 1977:177-179)

In relation to the range of ritual activities that make up the Trinidad Carnival, but more so the events of the various Calypso venues, some of the challenges identified earlier in relation to the application of Gluckman's philosophy also apply in relation to Turner's. This rigid, limited, structural presentation of the function of ritual does not necessarily 
apply to the rituals that are intrinsically part of the Trinidad Carnival, for, as stated earlier, there is significant and substantial evidence that shifts in the socio-economic structure of the country occur as a consequence of the Calypsos released. Furthermore, as enshrined in the country's National Anthem, and supported by the Inequality Porblematic, the nation embraces, and has moved towards implementation of the ongoing concept that:

\section{Every creed and race find an equal place}

For their part, in the context of the Inequality Problematic ${ }^{23}$, Calypsonians have recorded their observations on the process of progress within the society thus:

Because my people they are daily making progress

Without any form of stupedness

And in this way we must gain success

And when we moving, we all move as one body

No bickering between you and me

Our policy stands for racial equality

\section{The Mighty Sniper}

And again, looking further afield at the mobility needed for inter-strata unity that was needed in relation to the movement towards a federal union of the Caribbean islands, Sparrow recorded:

Whether you're a damn Trinidadian

We all is one

And, if they say you're a smart Barbadian

We all is one

Get away from me you greedy Grenadian

We all is one

I don't care if you're a bad Jamaican

We all is one

So let us join together and love one another

We all is one

If you born in New York and you parents West Indian

We all is one

Singer: Sparrow, Title: "We all is One"

\footnotetext{
${ }^{23}$ See Footnote in Chapter 1 for an explaination of this term
} 
This opportunity for inter-strata mobility has been the stated goal of the Trinidad Government since the country's attainment of Independence in 1962. All of this is in direct opposition to Turner's concept of the practicalities of ritual, where he sees the various strata drifting back to their traditional mode of operation thus:

In the process of social life, behaviour in accordance with one model tends to "drift away" from behaviour in the other

(Turner 1977:177-178)

The social and political dilemmas that Trinidad has transcended, (as delineated earlier in chapter 1), show that these models do not subscribe to the paradigms suggested by Turner and Gluckman. Indeed, for Trinidad, the 43 years since its acquisition of independence has seen considerable transition and mobility in the composition of the various strata constituting the structure of the society. This progressive movement questions the appropriateness of the application of the Gluckman and Turner models to the Trinidad situation, suggesting that at least in relation to Trinidad, they are oversimplified views of an ongoing human processes. Under our specific set of circumstances, they contain structural-functional oversights that make them inappropriate and therefore inapplicable to the Trinidad Carnival Art-Forms. This being the case, I have found the work of the folklorist-ethnographer Roger D. Abrahams (1974) to be more appropriate and significant in relation to the Trinidad situation.

Abrahams has completed a substantial amount of research addressing various African Diaspora ritual processes in the West Indies and the USA, classifying these rituals into categories of feasts and festivals. Abrahams contends that the fundamental nature of ritual, is underpinned by the subjectivity of human experience, and that this inevitable 
involves contradiction. Using numerous examples of ritual to illustrate this point, Abrahams shows how, for the population of African Diaspora, the ritual process juxtaposes social norms with values, yielding contradictions. Furthermore, the presentation of the performance engages a symbolic repertoire customarily used in the society. This is precisely the case in point with respect to the events within the Calypso Tent, where Calypsonians, utilising a local dialect that is readily recognisable by the audience, further load these expressions with a degree of double entendre. They often do so, by engaging sexual and/or political connotations, which usually transcend the class, social, political, economic or ethnic divides.

Abrahams alludes to the way in which, as a part of their Carnival presentations, performers regularly juxtapose opposites. I have observed this tendency in relation to the Trinidad Carnival where for instance the Carnival band-leader Peter Minsahall has presented in Masquerade "The Sacred and the Profane", or the fact that the once outcast, steel bandsmen now play their music in churches. On the other hand, the various contradictory statements made by the very costumes of the J'Ouvert morning celebrations also bear testimony to this juxtaposition. This juxtaposition can also all too frequently be recognised in Calypsos, as the picture illustrates.

The Calypsonian in the picture below, helps to convey the message in his Calypso by dawning the garb of a baby, expressing his wish to return to babyhood. Dressed in a Nappy, holding a feeding bottle and a teddy bear, with a comforter dangling from the pink ribbon around his neck, he conveys the visual imagery that accompanies the story that he is sharing with the aduience. But the dress and the paraphernalia that he carries 
in his hand are principal examples of the juxtaposed contradictions that this adult male inevitably brings to the forefront.

Customarily the colour pink is reserved for baby girls.

Furthermore, he carries a feeding bottle containing the milk that is essential for a baby's nutrition and growth, he is backed by an advert for Coca Cola, which many nutritionists believe is harmful to a young baby.

This photograph clearly

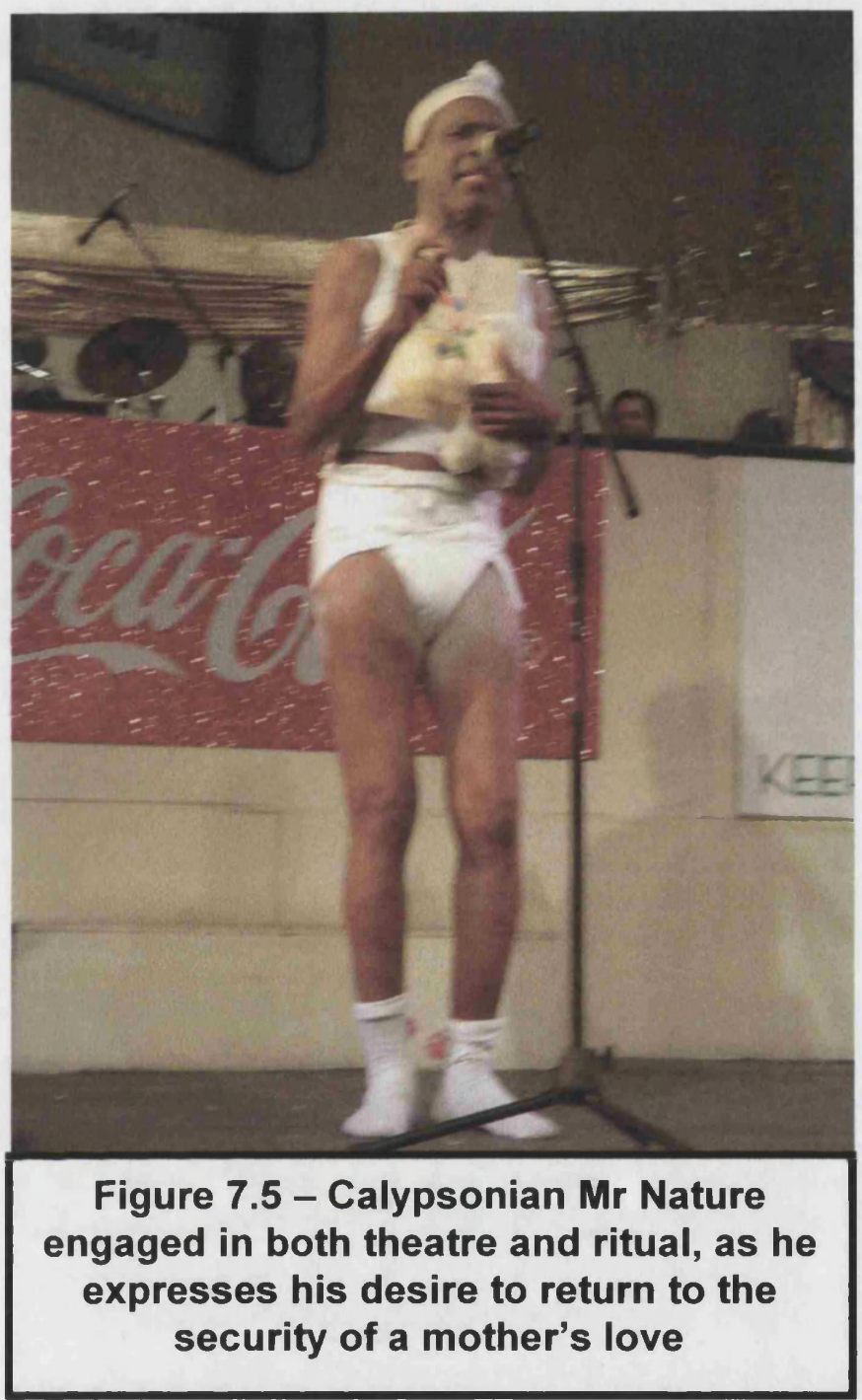
demonstrates the reversal that is a characteristic occurrence in the Calypso Tent. The only characteristic of this ritual reversal that could not be photographed, was the psychic disposition of the Calypsonian.

In Chapter 1, I described Calypso as the wind beneath the wings of Carnival. Indeed, my fieldwork unveiled Calypso as a metaphorical communication system, enabling one of the main performance aspects of Carnival. 
It is through the mechanism of Calypsos that comment on the social and political issues in Trinidad, that members of the establishment are made objects of mockery and ridicule, as these Calypsos offer caustic, satirical condemnation and criticism. It has been known that even the names of Calypsonians (e.g. Sugar Aloes) become a metaphor that supports the juxtaposed contradiction inherent in this process of communication. In general, this juxtaposition of social norms and values, utilising the society's symbolic system, presents contradictions within the context of a most compressed symbolic, aesthetic art-form. (Abrahams 1974:18)

Each of the performance aspects of the Trinidad Carnival (Calypso being a significant one) showcase ways in which the local society perceives the circumscribing world to be structured. Generally, Carnival, (but more specifically for my purpose, Calypso) constitutes a series of predictable performances, occurring over a specific time ${ }^{24}$, in which the various artistic forms that constitute Carnival offer a non-developmental, ritual way of celebrating an inherent belief system. Indeed not only are the performances within the Calypso Tent a ritual, but rituals in themselves are performance, (Abrahams 1974:19). In relation to the Trinidad Carnival such reflective turns permits a piquant vision of the inter-relation between the many different types of artistic ritual performances ${ }^{25}$ that make up Carnival.

The very nature of performance requires that the performer exercises a conscious choice in the way that the material is presented. Set in such a context, Abrahams (1974) argues

\footnotetext{
${ }^{24}$ Like the Calypso season which commences six weeks before Carnival. This season constitutes: the nightly Calypso Tents, also the festive occasion of the Calypso Fiesta Semi-finals taking place at Skinner Park, as well as the finals that take place during the Dimanche Gras show in the Queen's Park Savannah on the night preceding the formal start of the Carnival.

${ }^{25}$ Diagram 1.5, Chapter 1 delineates these
} 
that performances are framed in a highly stylized way, with the whole process of the presentation isolated from the audience by the use of a performance area or stage. $\mathrm{He}$ develops the notion of the frame, suggesting further isolation in time, with the performance having strict observation of the limitation of the performance. My fieldwork, bringing into focus the reality of the Calypso Tent as it did, permitted me to reacquaint myself with the reality of the institution of "Trinidad Time." "Trinidad Time" subscribes to a unique and arbitrary, culturally created set of rules. This time system can dictate that the start time of a performance, billed to commence at 8.00 p.m. could begin at anytime up to a half hour later. Also, because of the numerous encores that Calypsonians receive, at the end of their performances, the length of their allocated time on stage becomes protracted. Hence, the concatenated effect of this time slippage on the evening's performance could easily result in it extending into the early hours of the morning of the following day. But this very unique adherence to 'time' is expected by the locals, forming an ongoing part of the stylized frame.

The stylized behaviour within the Tent can take various forms, including observations on the daily behaviour of the society's upper strata, satirizing this behaviour, while bringing it under focus, to be revealed as corruption, discrimination or acts of aggression. Alternatively, this stylized frame may be utilized to congratulate the achievements of Trinidadians at home or abroad. Indeed the achievements of national heroes like Dwight York, Brian Lara, Wendy Fitz-Willaims, Atto Bolton, Hasley Crawford and Penny Commissiong, have all been commemorated in Calypso. 
A third application of this stylized frame is dramatizing the plight of those who occupy the lower echelons within society, demanding for them better conditions of employment, more affordable cost of living, or even better political representation.

Calypso drama presentations of this sort, create for their audiences, a relationship between the reality of audience's social domain and stage drama, much as Turner has shown in the diagram above. This interwoven reciprocal relationship leaves audiences free to reflect on the contents of the Calypso, eventually coming to their individual conclusions. Abrahams contends that the audiences' familiarity with the genre and the items being performed increases their familiarity with the possibilities of the performance. It results in what he calls a progressive opening ' $u p$ ' of the sensibilities. It is this reflection and the subsequent action taken by members of the audience that I contend drives the progression to resolution of conflict.

Abrahams contends that performance as art, places everyday behaviour in a recognisable, interchangeable dramatic form, (Abrahams 1974:1-2). A position not dissimilar to Turner's, (see Figure 7.4 above). In this dramatic form, man [the Calypsonian] is conceived of as an actor (with lines and routines, in scenes with a scenario or script, and playing a role or having a role-repertoire) a game player (with rules or codes, perhaps even a game plan), (Abrahams 1974:1-2).

Although, this approach does not necessarily make the unpleasant situation more acceptable, it does focus attention on the inconsistencies between the juxtaposed values and social norms. Through the dramatisation of everyday situations that typify many of the daily experiences of the population, it focuses the attention of the audience causing 
them to take specific corrective action. Abrahams argues that such events have a collective benefit for performers and their audiences in as much as the performances help the participants to come to terms with their daily situations. That is quite unlike the Gluckman and Turner paradigm of reinforcing the status quo, it raises their audiences' consciousness about the issues at hand, getting them to a point where they are willing and able to take action in order to rectify their problematic situations.

Such artistic performances of the type that take place in the Calypso Tent are not just an attempt by an artist to interpret normal or deviant behaviour patterns in the social system. This type of performance is an end in itself. It is its own experience having its own energy. It does not exist simply to mirror The Matrix Of Domination ${ }^{26}$ occurring in societal norms, but more importantly in articulating an Inequality Problematic it projects philosophical views of transitional changes, be these social, economic, racial, political or educational. This process yields a progressive departure from everyday experiences of Trinidadians showing them a vision of hope for their future, projecting a philosophical basis for change, (Abrahams 1974:19-21).

This process, engaged in through the mechanism of the Calypso, honours the spirit of Communitas. It facilitates an understanding that, regardless of the individual circumstances of our birth, at an organic level, all of mankind, is one. This communiatave spirit of Communitas, as available in the Calypso Tent was viewed by Turner as important, central and an integral part of the process of a ritual. I pay further attention to this phenomenon when, in Chapter 9, I address the issue of Call and Response.

${ }^{26}$ See the footnotes in Chapter 1 for a definition of this term 
When applied to the ritual processes engaged in, in a Calypso Tent, Gluckman and Turner's theories ignore the weight and significance of the artistic and creative aspects of this type of performance. Indeed these Tent performances are more multifarious and intricate than those studied during Gluckman and Turner's fieldwork. Consequently, the folkloric approach of Abrahams to this Diasphoric, ritual, cultural showcase, is more appropriate with regard to the process of increasing the people's awareness of the prevailing issues within the community. In turn the increased awareness from this ritual process can be a source that instigates a change, which subsequently has a rippling effect propagating that change throughout the community.

\section{CONCLUSION}

You have to be creative, talented and sensitive To jump up on the Calypso stage To put lyrics together, filled with wit and satire Was an art in which the great men engaged Of course it called for men who could marry Meaningful lyrics with melody

Now men who don't have that skill Jumpin' on the boat at will And calling themselves Calypsonians still

Too much quacks and invalids...

Long ago before you start

You have to practice the art of presentation and rendition

Your sentences have to rhyme

Syllables in perfect time in the right key of orchestration And you have to learn to extempo

In case you forget a line or so And if your topic made no sense You'd be booed by the audience for insulting their intelligence

"Too Much Quacks" by the Mighty Chalkdust 


\section{CHAPTER 8 - CONSCIENTIZAÇÃO: CALYPSO AS AN AGENT OF SOCIAL COGNITION}

Born in struggle, born out of protest, today the Calypso is the medium whereby many groups, ethnic and otherwise, are being united. Today the Calypso has become a powerful educational resource used in schools by many teachers from primary to university level, not only to make the lesson more interesting, but to motivate children to learn, and to make them better understand our social, economic and political development,

(Liverpool 1986: 53).

\section{INTRODUCTION}

$\mathrm{I}^{\mathrm{n}}$ $\mathrm{n}$ this Chapter, I attend to the process used by Calypsonians as they comment, mainly on localised situations, thereby raising the awareness of the population to the social, political or economic issues within the twin islands. First, though, I will consider the traditional approach to cognition before I look at the more recent development of social cognition, drawing on some views of cognitive semantics, as this applies to the institution of Calypso.

In this thesis, I have used the term "culture" to encompass the symbolic systems of the people of the Republic of Trinidad and Tobago. This system incorporates the process by which values, attitudes, definitions, feelings, meanings, symbols and behaviours are transmitted within the society. My research has therefore been an investigation designed to achieve an understanding of the process of resolving conflict as these are reflected in the social and cognitive behaviour.style of the people of the Republic of Trinidad and Tobago. 
In my particular set of circumstances, I hold a regard for Trinbagonian culture in general, but more specifically, the culture within a Calypso Tent, as a system from which I inferred or abstracted the distinctive cognitive and/or social mode of life of Trinbagonians.

Hence, in this manuscript, by using the term social behaviours, I am referring to individual or collective activities such as individuals' gestures, their demeanour, their facial displays and their simple or coordinated actions. More particularly, I am also considering the social aspect of language and speech and I am doing so from an interpersonal, situational standpoint, paying particular attention to the activities that take place in a Calypso Tent, that are intrinsically part of the events of the evening. In doing so it is my contention that an understanding of the appropriate performance of social roles is central to an understanding of this category of behaviour. This is also the case with regard to the subjects' "natural" participation in activities which are imbued with shared meaning and which reflect the norms in the group.

On the other hand, I regard cognitive as the individualistic correlates of the observable social behaviour. The term suggests that learning has taken place and that this learning is a consequence of the internalisation of the common, shared symbols of Trinbagonians. In this way, we can see that there is a symbiotic relationship between both categories of behaviour (i.e. social and cognitive) with each inevitably implying the other. For my purpose, I consider cognitive behaviours to embrace phenomena such as thinking processes, the rules within the Tent for the expression of emotion (as they show up for example in "call and response" - see the developed paradigm in Chapter 9), the 
perceptions of the audience resulting from attending a Tent and the audiences' approaches to resolving the identified problems.

In order to understand the function of the Calypso as an agent of social cognition, it is first necessary to understand the relevant theories on the development of cognitive skills, as these bear relevance to the role that Calypsonians play through the Calypso art-form.

\section{Calypsos, Image Schema and Restructured Cognition}

Language is the key medium for communication that's available to Calypsonians.

However, since language is systematically grounded in human cognition, (Sweetser 1990:1), central to my understanding of and belief in the resolution of conflict through the development of cognition, is my contention that the process of learning, growth and change (O'Connor, McDermott 1996:IX) is intricately and inextricably woven into the growth of Cognition. Furthermore, that practitioners (be they mediators, negotiators or Calypsonians) facilitate this development through the appropriate, effective and skilful use of language.

In this manuscript, I contend that the main tool that any practitioner in the field of conflict resolution (be that formal, informal or non-formal conflict resolution) has at his/her disposal is language. In the light of my experience as a mediator and trainer, I have found that when language is used effectively and appropriately, engaging cultural narrative through the use of sedimented meaning ${ }^{27}$, semantic frames and prototypes,

\footnotetext{
${ }^{27}$ To understand this concept consider the following segment of a conversation: Tom: Mary, would you like a piece of cake? Mary: I'm on a diet! In reality, on the face of it, Mary's statement of refusal does not follow as a logical response to Tom's offer. Our understanding of her statement however is predicated on links in a chain of reasoning.
} 
Chapter 8 - Conscientização: Calypso As An Agent Of Social Cognition

disputants are better enabled to manage their conflict, composing situations and

relationships that enhance the possibility for meaningful and constructive interaction, (Nussbaum 1986).

Calypsonians engage in cognitive linguistics (what in local parlance is called "conscious lyrics") through the use of metaphorical elaboration and manipulation of image schema, to connect different domains within the experience of Trinbagonians to enable them to have an altered experience of prevailing challenging situations, thereby helping them to restructure their understanding.

When Calypsonians engage cognitive linguistics, they draw on aspects of Trinbagonian's conceptual system, indulging in the meaning given to things, and localised understanding of situations, the knowledge which we have of events, our sense of values, and hence, our morality.

This concept of cognition is central to the development of any argument which links the Calypso to the domains of conflict resolution and by implication, enabling the parties involved in the conflict to move forward through a process that involves both education and learning. In this sense, it seems judicious to consider the views of some of the main contributors to the field of cognition.

Piaget (1977) is one of the main contributors to the field of cognitive theory. His contribution was greatly influenced by his early work as a biologist. He saw the way organisms adapt to the environment as similar to the way cognitive structures adapt to incoming information. To Piaget's way of thinking, activity is fundamental to organisms. He recognised that growth, or what can colloquially be called 'change', is essential. 
Organisms perform this change in one of two ways. They either incorporate the environment into their existing structure, i.e. taking on the other's point of view (assimilation), or they change their existing structure to fit the environment i.e. they may change their mental frame in relation to the situation (accommodation). Piaget therefore argued that cognitive structures also adapt to incoming stimuli by either assimilation or accommodation.

In reality, assimilation and accommodation are inseparable and inevitable. They occur simultaneously in all organisms. Piaget argued that when these two tendencies are in equilibrium, balanced adaptation has been accomplished, yielding cognitive development.

Piaget has traditionally held the view that there is a link between social and cognitive development (Piaget 1928, 1932), expressing the view that social interaction was central to the development of operational thinking. He argued that it is only through the polemic, when one attempts to justify one's view that one opens to other points of view. In these earlier writings, Piaget expressed the view that peer interaction has a causal role in cognitive development. However, he later abandoned the idea of the importance of peer interaction in playing a causal role in cognitive development, in favour of the concept of the two domains (i.e.: the social and the cognitive) being governed by identical operations, and that the development of these operations has a simultaneous effect in both domains. In- keeping with this change, and his view that the social and cognitive worlds are seen as a single reality and causal effects from one domain on the other cannot be separated, he subsequently suggested that social interaction had an effect on cognitive development, (Piaget 1.976). It is in response to this that Barker and Newson (1979) pointed out that Piaget is not addressing psychological questions regarding the effects of certain types of experiences on the development of cognitive structures but rather he is addressing the epistemological issue of how the structure of thought develops. 
Over the last 20 years or so, Cognitive Linguistics has emerged as a field of study in its own right, with considerable attention being paid to it. This work has helped bring about a better understanding of the link between the social domain and cognition. This relatively new field of study offers the most powerful arguments for the role of the Calypso as an agent of cognitive development. The results of this work also have applications with regard to semantics, and are appropriate when considering the process of resolving inter and intra-strata societal conflict in Trinidad and Tobago.

I mentioned earlier that language is the key tool that practitioners in the field of conflict resolution have, with which to help disputants in their process of resolving their issues. In Chapter 6 I showed that Calypsonians utilise Linguistic Form to help in this process. In reality, music is a fundamental feature of Calypso and its impact is central to the process of resolution.

In her work in the field of peace studies Skyllstad (2002) states:

Music, dance and theatre are important arenas for training in democratic participation and conflict transformation.

(Skyllstad 2002)

In writing about classical music, she goes on to state that:

Musical interaction creates social values. Two or more people create something that is greater than the sum of what they create each on their own. And sympathies are formed-strong feelings of belonging. Music making in a group brings out the social dynamics of the group. Harmonic as well as strained relationships are brought to the front. This is the very essence of chamber music. Through musical dialogues the interrelationship within the group is explored. (Skyllstad 2002)

These remarks, although about classical music are in essence similar to those expressed by the Rt. Hon. Albert Gomes ${ }^{28}$ when in speaking of Calypso he says:

The Calypso is the most effective political weapon in Trinidad. The singers - all of them-are men reared in poverty and oppression, sing of the life they know. Thus it is that even when cleverly camouflaged with wit and banter, the sharp

${ }^{28}$ The Rt. Hon. Albert Gomes is a former PM of the country 
tang of social criticism is evident in their songs. Moreover, people go to the Calypso Tents to be entertained. What politician, who must harangue from the rostrum, can boast of a better opportunity for influencing people's minds. The fact that the Tents are so sedulously supervised by the police reveals the extent to which the Calypso singer influences political thought.

Brown (1947:251-252)

Any approach to understand the link between the use of Calypsos in conflict resolution and the development of cognition, has to revolve around the following five key attributes:

- Embodiment

- Temporality

- Imagination

- Social Interaction

- Morality: Heteroglossia and Nascent Counter-Hegemony

\section{Embodiment}

We function in this world as individuals who are confined to our physical bodies. As a consequence, our consciousness arises from the quality of our experiences while we are consciously in this state. This condition yields the product of "form oriented consciousness". That is to say, it is often our experiences in this world, through a constantly renewing and reciprocal arrangement that inform our awareness of our situation. The media through which we obtain all of our information are our visual, auditory, kinaesthetic, olfactory and gustatory senses. As individuals, meaning takes on form for us as our current interactions are interpreted and then constructed and reconstructed through our five senses and as interpreted through our mental processes, when events are fed back to the reference points of the reservoir of previously held knowledge in our consciousness. 
Through this interactive, regenerative process, we can recognise that as we grow (and this growth may take place at any level i.e. biological, social, political, cultural, moral, and economic), so also does the environment of which we are part also grow. Through this whole process, we ossify and embody meaning which in turn is expressed through linguistics, in speech, (Sweeter 1990). In recognition of this, cognitive linguistics establishes an association between semantics, syntax and pragmatics, identifying a link between them, as all having a dependency on our bodily experiences. Churchland (1979) establishes this link for young pre-linguistic children recognising that language then becomes but one form of a skilful coping strategy which serves to enable survival and flourishing of societies. In turn, since we belong to a society which has its own culture, the payback is that our bodies become "culturally inscribed" through the lived experiences of our senses, as brought about by our sensorimotor experiences. Patricia Churchland lends some weight to this concept when she writes:

Cognition is not neatly detachable from the organism's ecological niche, way of life and bodily structure. ........... Looked at from an evolutionary point of view, the principal function of nervous system is to enable the organism to move appropriately. Boiled down to essentials, a nervous system enables the organism to succeed in the four F's: feeding, fleeing, fighting, and reproducing.

(Churchland 1987: 548)

Any casual observation of the Carnival art-forms shows these $4 \mathrm{~F}$ 's to be very central to the festivity.

In tying these concepts together, I will use an illustration that is grounded in basic ontological ways of experiencing the world that are transparent of cultural orientation, nevertheless demonstrate the way knowledge is encompassed and how that recursively informs the sensorimotor system. 
Consider the middle baby in a family of three children, as it grows to childhood. There comes a point when this child grows into the recognition that there is an association of age to ability, in relation to what $\mathrm{s} /$ he can do relative to the two other children who flank him/her. So for instance for the 'normal' growth patterns of a child, there is the expectation that as it grows older, the size numbering of its clothes becomes numerological higher, and so also does the actual/physical size of the clothes worn. This type of vertical association in space, of patterns of our mundane bodily experiences of growth, is one example of what, in the development of the cognitive theory of metaphor, has become labelled as image schemata, (Johnson 1987 and Schmidt 2002).

\section{Temporality}

From her research in the fields of Science and Metaphysics, Helen Rhodes Wallace (1983) has exquisitely shown how the scientists' understanding of this world is very much the same as that of the metaphysist's. Another recognition that emerges from her work that is very highly significant is that although both camps may be using different words to describe the phenomenon of our existence in this world of form, fundamentally, they are both saying the same thing. Using a somewhat different approach, Wilde also sheds some light to this school of thought, (Wilde 1996). Both of these authors are among many others who share similar views that both the scientific and the metaphysical camps are saying that as individuals, we are more than just what we can see showing up in our physical appearances. Furthermore, this philosophy holds that what we experience is a world within a world, and that this second world is functioning at a frequency that is different from ours, yet supports the functioning of this physical experience. Emerging from this double world theory is the concept of "imminence" and "transcendence." 
Furthermore, although we are individuals as defined by the physical boundary of our outer perimeter, nevertheless, metaphysists contend that we are all linked to each other through a universal energy field. Within the defined imminence of the physical boundary, we engage the experiences of time and its counterpart, space. With time, our understanding can change, and so can the meaning which we give to events/things in our lives. What this shows is that there is a temporal dimension to the triad of meaning, knowledge and understanding. This is a crucial ontological fact, and its significance here is that this triad evolves over the extended period of our lifetime, and therefore this formation of 'self' and therefore of consciousness, is always 'in process.' Furthermore, everything in which we engage, adds to our awareness, with Calypsos being but one element of our 'ever-becoming'. This process of ever-becoming, is driven by the way meaning emerges unconsciously in our bodily experience, becoming available for conscious reflection, enabling transformation, as we constantly engage in the act of constructing our lives.

\section{Imagination}

From the writings of Rhodes Wallace (1983) and Wilde (1996), we come to realise that imagination is the link between the two worlds of imminence and transcendence. The world of transcendence acts on our perceptions and using our archetypal images, induce concepts into our other than conscious mind ${ }^{29}$ which are arrested by our conscious. Imagination then enables us to crystallise the perceptions that come to us, converting these into novel orderings within our experience, manifesting as Form.

We bring the crystallised process of imagination to manifest in our worlds by the use of our symbolic image-schematic patterns, which are driven by our experiences and the way we have traditionally ordered relationships. For example, when we look at Star Trek, it

\footnotetext{
${ }^{29}$ This term is borrowed from the field of Neuro Linguistic Programming (NLP)
} 
becomes clear that, in the main, the design of an alien is informed by our knowledge of how we are designed. So there is usually some sort of head which contains the ability to see, hear, eat etc. There is also some sort of body that contains a form of sustaining motion. The point here is that the basic shape of a designed alien, usually mimics the human structure. This limitation in the designer's ability to be significantly unique in the design function is a result of many things, one of these being the absence of actually having met an alien. Similarly, as individuals, our own experience of ourselves drives and informs our imagination and thus causes us to create an expectation that is born out of our own experience.

In the world of the Calypsonian, the key ways in which this functioning of the imagination show up in the process of developing cognition is through the use of 'linguistic form,' as discussed in Chapter 6. This aspect of communication makes it possible for the Calypsonian to be using a particular syntactical structure that allows him/her to be saying one thing, while meaning something totally different. As an example, to Trinbagonians, the lyrics:

\section{To much biting insects}

In reality, are also heard as 'To much biting in sex'. Alternatively, consider David Rudder's ${ }^{30}$ response to the Abner Louima scenario. Abner was a Haitian immigrant, who was arrested by the NYPD and taken to the $70^{\text {th }}$ precinct in Brooklyn. He was later taken to a New York hospital to recover from injuries which included a damaged rectum, torn intestines, and spleen and broken teeth. It was alleged that the weapon used was a toilet PLUNGER. In noting the incident Rudder sings:

The immigrants are here to stay to help build America The immigrants aint going nowhere they're here for America Fighting for a better life, fighting through the grunge America, remember Ellis Island We call came here to TAKE THE PLUNGE I hope you understand me. David Rudder "The Immigrants" Track 17 on CD

\footnotetext{
${ }^{30}$ David Rudder is one of a minority of Calypsonians who uses his real name as opposed to using a sobriquet
} 


\section{Social Interaction}

Bakhtin (1984), Piaget (1976) and Vygotsky (1978) have all, though from different standpoints and for a different age group, proposed that peer interaction through dialogue, within community, has a crucial role in cognitive development. It is through dialogue with, rather than against others, that we raise awareness through achieving mutual understandings while realising new possibilities.

In so doing we become fully human through a practice of communication that promote empathy, openness, affirmation and trust. This process can permit us to recognise that an existential, moral, and even spiritual relation exists between community and ourselves, and that our community is incomplete without our involvement and participation (Arnett, 1986; Buber, 1970 \& 1994; Cissna \& Anderson, 1994; Freire 1972; Gordon, 2000; Murray, 2000; Shotter, 2000). It is therefore through dialogic communication that we contribute to the creation and completion of our community. Our 'becoming' is entwined with that of the community of which we are part. Hence, we find that practices that harm our 'becoming' also harm the 'becoming' of the our community. As such, a dialogic sensibility encourages us to be open, sensitive, and tolerant of new ways of understanding and experiencing the world (Czubaroff \& Friedman, 2000; Pearce \& Littlejohn, 1997; Rodriguez, 2002) and through a developed process of cognition find ourselves reflecting, as it were bending consciousness back on itself. In this respect, in relation to the Calypso, Aho (1984:142) states it, serves both to reflect and to shape public concern, opinion, and conscience about serious social economic and political problems.

It is unquestionable that the yearly crop of Calypsos instigate spirited discussion among the population, about the related issues in the media. Freire calls this act the development of 'Conscientização' through dialogue. He considers that the process of 'Conscientização' goes beyond the lèvel of mere subjective perception of a situation, but 
Chapter 8 - Conscientização: Calypso As An Agent Of Social Cognition

through action prepares men for the struggle against the obstacles of their humanization, (Freire 1972:92).

Freire contends that consciousness increases through raising educational awareness. This is similar to the process in which Calypsonians are engaged.

In putting forward his case for the process of "consciousness raising", through which individuals are empowered to change the society in which they live, Freire argues that any community action needs to encompass

critical reflection which increasingly organizes their thinking and thus leads them to move from a purely naïve knowledge of reality to a higher level, one which enables them to perceive the causes of reality. (Freire, 1972: 101)

The key aim of this work is to show that the Calypso ably serves this function.

Paramount in the attempts to define'cognitive processes is Vygotsky who holds that thinking, voluntary attention, logical memory and human consciousness are all higher mental processes and as such, all have their origin in social life. Vygotsky in proposing a law of cultural development holds that mental functioning occurs firstly between people in social interaction (Vygotsky 1978) and that individual psychological functioning derives from and reflects the structure of social functioning. I understand Vygotsky is saying that in effect, the composition, structure and means of action are internalised by the individual from the social interaction.

All of this suggests that as humans, we cannot disassociate the formation of 'self' from the social circumstances in which we live, and that it is both through and in that social process that we engage the ongoing development of 'self'. In reality, the development of 
'self' is closely linked to the construction of meaning. In turn, meaning is contextualised and sedimented in the reality and experiences of the societies which has engaged in the experience. This therefore leads us to conclude that human subjectivity is closely linked to a social process. That is to say, the very act of cognitive development is linked through and through with social processes.

\section{Morality: Heteroglossia and Nascent Counter-Hegemony}

In approaching this trans-national research work I recognised a strong need to be mindful of the tendency of researchers, limited by 'form oriented consciousness', to regard intricate, historical community activities as homogeneous, rule-governed and ahistorical. Johnson (1984) challenges the view that Carnival is a single unified identity, passed down from generation to generation. The misnomer of homogeneity on the part of researchers, particularly when applied in a trans-national context, as Carnival undoubtedly, can very often lead to a failure to recognise the inevitable effects of cultural pluralism. The effect of this scenario, is to obscure the potential for growth of both individuals and communities, which is a function of the dynamics and conflicting nature of co-existing cultures. In the final analysis this failure to recognise the value of and within other marginalised cultures can support the idea that, for Carnival to be educational, it needs to be reproductive rather than transformative. Unfortunately, 'reproductive' usually implies negating what is of value in the cultures of dispossessed or marginalised peoples with the expectation by the dominant culture that their values are wholeheartedly embraced, foibles and all.

One of the problems of this 'dominant culture' approach is that it fails to facilitate effective communication between the various social strata and therefore inhibits crossfertilisation of ideas between these strata. Bakhtin calls this unmerged dialogue by a variety of names multivoiced, heteroglossia, polyglot and polyphony (Bakhtin 1981). This failure to recognise the uniqueness of the potential contributions that 'forces of 
struggle' can make to the social structure can negate the emancipatory impulse of these strata. Bakhtin felt that Carnival provided a valve that enabled communication of the classes.

Underpinning this work is a commitment to recognise and engage the emancipatory impulses found in marginalised culture as manifest in institutions such as Calypso (and Carnival). It is intended to shed light on the capacity of the various individual aspects of Calypso music to both effect and affect mechanisms of ideological and political transformation in both one's public and private domain.

It needs to be stated that this work does not just focus on the inter-relationship between the various aspects of Carnival culture (Calypso being but one of these) and its role in cognitive development through educational resistance theory (Giroux 1983), but takes a wider view of the domain of Calypso and its twin, Carnival. There is an element of cross-over in that understanding the concept and place of culture, has to be central to understanding its location in cognitive development through expressions of resistance as manifest in Calypso, (Hoy 1992).

Turning more specifically to the issue of 'morality', it is also overwhelmingly obvious that there is the propensity of participants in the Carnival extravaganza to, gyrate over the Carnival period, in such manner as to demonstrate behaviour that may be interpreted as lewd. In the face of this, the question may reasonably be asked: how then does this link to the process of the development of cognition? In order to answer this question I seek to engage the views of Mikahil Bakhtin who argues that fundamentally, through Carnival, the oppressed, disenfranchised, marginalised people have the opportunity to mock the other classes. Implicit in this view is the realisation that these activities can be viewed much in the same light as that of the Shakespearean fool who seeks to ridicule the world of conventional pathos. 
Calypso (and Carnival) are considered mechanism whereby the dispossessed can come to gain some modicum of control. Invariably they are expressions of freedom, of liberation, of escape from the hopelessness of an oppressive world. Calypso and Carnival invariably provide a second world where universal freedom permits the disadvantaged a window of expression in the only ways that they have available to them. It is through these spectacles that there is a need to view the ribaldry of the Carnival occasion as expressions of opposition to and repulsion of the established order. The apparent debauchery, the excessive consumption of food and drink, the suggestive dancing, the processes of excretion and copulation, and parturition that can at times be seen, are all processes of building, flushing and renewal of the physical self. For having no real or significant clinch on the reigns of power, the dispossessed and marginalised use the only medium available to them in order to express themselves and their plight, (Churchland 1987, refers to this as the four F's).

It is precisely because of the symbols and actions of Carnival at this level that individuals are forced into a sense of unity which genders for different social groups their individual social perception of democratic freedom. Among other things, this nascent counterhegemony, can ultimately support the creation of a primordial social ocean wherein nonlegitimated thoughts and feelings may join together to challenge and ultimately give new expressions of social opinion (Quents 1988). Bakhtin calls this multivocality "dialogue". This realignment of the legitimated tensions of official social relations requires a transformative promise.

Before leaving this area of cognitive development, it is worthwhile taking a another perspective on the whole issue of the development of cognition. In doing so, it is worthwhile remembering that in the Christian tradition that Trinidadians and Tobagonians primarily follow, the concept of what is moral is embedded in the culture of the country. It manifests through a metaphorical systems which in turn, define the conception of self as a moral agent, identifying one's moral rights, duties and one's 
understanding of the moral evaluation of our actions. If we briefly consider dancing to Calypso music, we recognise that gýrating in public or "wining" as it is called in Trinidad, is considered by some to be an activity that lies below the diameter of normal acceptability. Alternatively, this type of dancing can also be regarded as the exploratory and creative side of moral deliberation, in which individuals imaginatively try out various possible ways of framing and responding to problematic situations. Dancing in this way then depends on one's experiences, sensitivity and imagination. This requires the dancer to make fine discriminations and the imaginative leaps necessary to compose situations and relationships that enhance the possibilities for the interpretation of meaning.

\section{Calypso: An agent of Negotiation}

At all levels and in all settings the Calypso is known to sponsor social interaction. The structure of Trinidad and Tobago's society and its norms therefore permits interweaving of the various social strata. Calypsos bring an awareness and social interaction which is unique. It is precisely this type of interaction that Liverpool describes when he states:

Into UWI [University of the West Indies] one morning, Bill Riviere walked, bowed his usual salutation to the history class, and played two Calypso records on slavery by Mighty Composer. Having done that, he calmly bowed again and walked out. That was the day's lesson. Students afterwards could be seen chatting. Those who never spoke - shouted. Self appointed tutors held tutorials and learning spread. Students confided to me that they never knew Calypsos contained so much information

(Liverpool: 1990: 68).

Although Liverpool is referring to university students this process of engaging in debate and philosophising on issues is common to most levels of society in Trinidad and Tobago. However, this process is also the cornerstone of problem definition and any subsequent resolution. It is through this form of social interaction that knowledge is constructed, meaning is derived and the cognitive processes that enable understanding and problem resolution are developed. For the Calypsonian in mirroring society provides the population with a platform to interpret and interpolate both local and international 
affairs, ranging from King Edward's abdication to Princess Margaret's wedding, from the launching of the first satellite to skylab, from Mussolini's invasion to the downfall of Idi Amin, from Kennedy's Cuban blockade of Soviet ships to the Watergate Affair, from the demise of the USSR to examining Bin Laden's fate. The point is that the Calypsonian in brokering an understanding of events and stimulating debate in the society, not only presents a chronicle of both local and global events but provides the space for individuals to engage in a

.... process by which men and women (alone, in groups, or in institutional settings) seek to improve themselves or their society by increasing their skill, knowledge or sensitiveness

(Houle 1972: 32)

for the Calypsonian is therefore supporting a

process by which individuals, groups, or institutions try to help men and women improve in these ways

(Houle 1972: 32).

It is in this context that Errol Hill in writing about "Calypso and War" states:

the Calypsonian too has sung of war and its warriors. It does not matter that the struggle may be waged far away on foreign shores, that the event is experienced at second hand. His sense of duty and loyalty, seasoned with a strong dose of self-interest, will dictate who is hero and who villain in any given war, though at times he may question the purpose of the struggle and why his small country has been drawn into it. Where race becomes an issue, we might expect him to identify immediately with his racial group, viewing any attack by European and American industrial powers on a black or Third World country as further evidence of a grasping imperialism that must be resisted at all costs. In this regard it should be emphasised that the Calypsonian seeks to give utterance to the hidden wellspring of thoughts and feelings of the populace, though often he will affirm rhetorically that he is merely expressing his own opinions.

(Hill 1989:62)

\section{The Role of Calypso In the Community}

Calypsonians, through the medium of the Calypso, reach out and touch the lives of individuals from politician to pauper. Calypsos provide a platform that permits the cross- fertilisation of a spectrum of ideas and opinions and often are the drivers that 
encourage individuals to address reality. V. S. Naipaul acknowledged this process when he wrote: it is only in the Calypso that the Trinidadian touches reality, (Naipaul 1969:

75). In "Respect The Calypsonian" Gypsy, in acknowledging the power of the Calypso sang:

I who write the songs to make you sit and think I who write the songs that does tickle you pink I who sing 'bout love and hate And fictitious themes create.

I write the songs that champion performers cause I who write the songs that circumvent the laws from slavery to emancipation

I've made my contribution..

Gypsy "Respect the Calypsonian" Track 15 on CD

"Prophet of Doom" is yet another illustration of the use of a Calypso to focus on community issues. In this Calypso, Sparrow speaks both to and for the people. It is worth remembering that in the face of spiralling inflation and as a result of staggering price rises, the government of Trinidad and Tobago brought in a Cost Of Living Allowance (COLA). The recognition by the government that the allowance itself further fuelled the spiralling inflation, the very ailment that it was meant to alleviate, resulted in a reduction of the allowance with a subsequent attempt to remove it altogether. Sparrow draws attention to the situation thus:

People complaining every day the cost of living too high Still they take all the subsidies away

So man could suffer and die

The situation is much too rough

For anyone to ignore

And ah know that the people can't take it anymore

Sparrow "Prophet of Doom" Track 18 on CD

He stresses the plight of the people by acknowledging what's happening in the field of employment, to the currency and the effects of these on the morale of the people, as manifested in low productivity. He then urges that the people should not be fooled by short-term measures that are a panacea and could be interpreted as 'electioneering'. 
$B u t$, retrenchment and redundancy

Beginning to strangle we

Inflation and low productivity

Done take over already

The 'Integrity Commission' plan

Is a next project also ran

Every move they make now is to insure re-election

In the face of all these occurrences, he later goes on to recognise the need for the workers to exercise the only power that they have i.e. to strike. He says: Unhappy workers on the rampage ${ }^{31}$.

This Calypso, as well as the other works of Dr, Francisco Slinger, (The Mighty Sparrow) all cited herein, engage a process of creating cognitive dissonance so well known to us mediators. These Calypsos are not just enjoyable in themselves, they also feed the imagination, seeking to enhance an understanding of the quality of life of the individuals. They also serve as a link with the local culture, while deepening the individuals' understanding of the conditions in which they live. They speak of the difficulties which people experience, and attempt to foster their awareness. These works help us to understand some of the reasons why the performer was subsequently granted an honorary doctorate by the University of the West Indies.

In order to heighten the people's awareness of their plight under the existing political regime, Sparrow, uses appropriate language to focus on the problem, interpreting the situations in a way that allows them to develop inter-subjective understanding, thereby empowering them to take action. It is this practical application of the combination of positivism, hermeneutics and critical reflection that I identify as an approach to the sustained resolution of the existing socio-political conflict within the country. 
In Sparrow's application of Positivism he uses fact and observable phenomenon as in Prophet of Doom, where he states: With facts and figures prepared to show. He proceeds to comment on the demise of the country, and with the knowledge of currency devaluation states that the economy is no longer in full bloom. On the other hand, he shows a hermeneutic understanding of the issues, offering an interpretation of the human conditions experienced by the citizens. This process is clearly illustrated by his interpretation of the common act of 'liming' round the savannah thus: On every chair round the savannah discuss vicarious politics. Language so used brings about a level of inter-subjective understanding, while focusing on the inherent social processes, as the Calypsonian in grasping power, becomes the liminal servant of the audience, bringing about a type of socio-cognitive development.

Finally, Sparrow goes further than just attempting to explain the origins of the daily practices and the problems associated with them. He teases out the responses to those awkward questions that ask: what should now be done? In this type of interaction, Sparrow is engaging the 'disputants' in critical reflection. When used in this way critical reflection is committed to enabling change towards better relationships, towards a more just and rational society. It does this by identifying the biases and distortions which prevent healthy personal and social growth. It helps in the process of liberating the disputants, freeing them from those malforming constraints, asserting that individuals and groups should assume greater control of their own lives. It has as its goal the notion that people should be able to determine their own destinies.

In both "Prophet of Doom" and "We Like it So", Sparrow demonstrates his recognition of these purposes, actually putting forward reasoned arguments. This approach is an expression of the recognition of the right to self-determination and rational action that leads from self-reflection.

\footnotetext{
${ }^{31}$ See Appendix 1 for the lyrics of these Calypsos
} 
It can of course be argued that the knowledge about society that these songs convey informs the citizens about the condition under which they currently live. Since this awareness is generated by critical reflection, the product is superior to other models because through this form of education individuals are aided in the process of freeing themselves from a type of bondage. In brief, Sparrow seeks to point the way to this freedom and liberation by simultaneously raising the awareness of the current position while trying to show a way to achieve technical control of one's political, social and economic position, thus facilitating the individual's struggle for freedom which in effect becomes a collective struggle for liberation, for freedom, for education.

Consider the following lines from "We Like It So":

Is years you in a union and can't get recognition

The unemployment levy murdering every body.

We grieving with frustration through mal-administration.

In the above extract from the polemic "We Like It So," Sparrow attempts to raise the consciousness level of the person with whom he is debating. In this imagined debate, this 'other person' is representative of 'the general public.' It is clear that $\mathrm{s} / \mathrm{he}$ focus on the short term gains that are inconsequential to their long term quality of life, quite unlike Sparrow's vision.

It is worth noting that this Calypso was released at the start of the run-up to a general election which brought a change of government. It encapsulated many of the pertinent national issues and it is seen to be an attack on the political party in power at the time, the People's National Movement (PNM).

In this style of communication, Sparrow is doing more than just orchestrating both sides of a debate. The actual manner of the presentation of each side's position is an attempt to 
educate the listener on how to present a structured argument from the basis of an understanding of the underlying issues and an attempt to draw attention to the need to move away from a narrow bigoted approach. In the stanza below Sparrow makes salient points that the other person is evidently incapable of refuting or addressing:

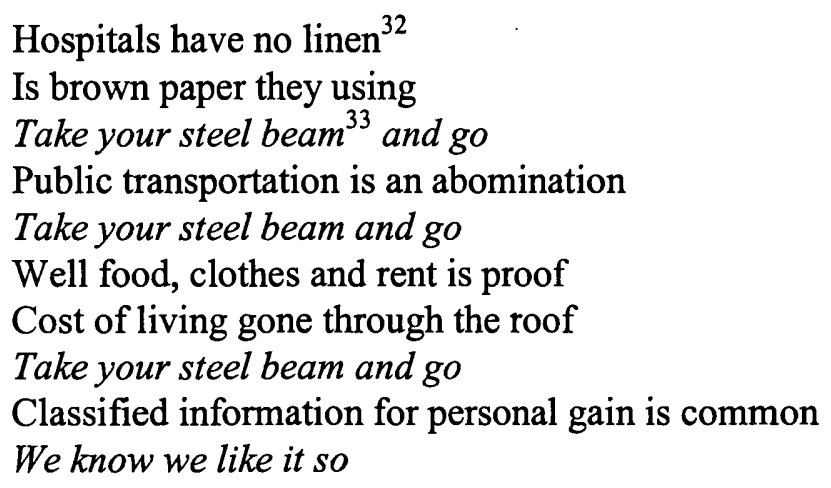

In effect, Sparrow is balancing a pre-independence attitude that is epitomised by the expression:

We have freeness and freedom

Plenty roti plenty rum

fundamentally saying that we need to be moving our awareness, our consciousness, forward.

That the Calypso art-form is a forum for consciousness raising and educating a people is again demonstrated in the economic critique "Capitalism Gone Mad". Here again, in the face of a global recession and spiralling inflation, Sparrow eloquently pleads to the merchants who are going out they brain on behalf of the 'person in the street'. Sparrow's arguments are again pertinent, concise and very relevant to the current situation.

Where you ever hear, A television, for seven thousand, Quarter million for a little piece ah land. A pair of sneakers, two hundred dollars Eighty, ninety thousand for a motorcar, At last here in Trinidad, we see,

\footnotetext{
${ }^{32}$ The italics in this stanza represent the replies in the debate.

${ }^{33}$ The Steel Beam is the symbol of the Organisation of National reconstruction (ONR) and the party which Sparrow evidently supported and the Balisier the symbol of the PNM, the party in power at that time.
} 
Capitalism gone mad, ......

It's sad and getting more bad,

Capitalism gone mad ............. (Available at Track 19 of CD)

\section{Calypsos, Carnival and Cultural Politics}

This section presents an overview of the role of Calypso as a subset of Carnival and what I see as the inter-relationship between, on the one hand, critical thinking (or methodological doubt (Elbow 1981)) which acts to give voice to a struggle, while on the other hand, contextualising an emancipatory pedagogy. I propose to do this in relation to the works of Freire, Vygotsky and Bakhtin, recognising the role of the Calypso as an agent of consciousness, serving as an embodiment of oral literature, raising awareness of self and other while facilitating cognition.

Central to the task at hand is the recognition that at the heart of this Carnival art-form, is a level of communication, of 'multilogue ${ }^{34}$, of high social interaction, which manifests through the process of "call and response" where, in the Calypso Tent, the Calypsonian enters into a dialogue with the audience (see Chapter 9). In this, one of many ways, the Calypsonian is an agent of consciousness.

As stated earlier, I hold the view that in being an agent of consciousness, one of the key functions that the Calypsonian is fulfilling is that of working towards the resolution of existing conflict by educating the parties about respective views and flagging up ways forward. I am using the term "educating" to mean shedding light on a subject and the example in the following paragraph helps to illustrate the process.

The sudden increase in oil prices in the 1970s signalled the start of a global recession. This resulted in a rise in unemployment and inflation in many western counties, Trinidad and Tobago being one of them. Calypsonians drew attention to this plight and translated

\footnotetext{
${ }^{34} \mathrm{~A}$ Bakhtin term for group communication
} 
the events into the terms, forms, values and relations which constitute the reality of the local environment. This process is refereed to by Freire as sociological reduction. In his introduction to Freire's thoughts, Joao da Veiga Coutinho describes the way that local action grows, when urged out of reflection on a specific Third World setting, as situated thought.

Some Calypsos have shown the capacity to present an ideological perspective on local experiences, thereby serving to educate the masses about the reality of their situation. This type of non-formal enlightenment (education) is very in-keeping with what Freire calls "Cultural Action for Freedom" (Freire 1972). These Calypsos fulfil a role that is constructed in accordance with local needs in a way which could not be satisfied if the musical sources originated outside the islands.

In the process of awakening the awareness of the people, the Calypsonian supports what Freire calls 'Conscientization' i.e. the development of a consciousness that has the power to transform reality. Freire claimed that since 'education for liberation' can lead to radical social transformation, this type of education is in itself a revolutionary process. Freire stated that:

Education rather reproduces the dynamism which characterizes the historicalsocial process. It is an act of knowing and a means of action for transforming the reality which is to be known

(Freire 1972b:180-1)

Bakhtin's has also made a significant contribution which suggests a view of language as an eminently social and political act. This is coupled with the ways individuals define meaning and to how they author their relations to the world through an ongoing dialogue, either with themselves, internalised or externalised, with others. Bakhtin draws attention to the andragogical/pedagogical importance of critical dialogue as a form of authorship, giving meaning to the range of voices that make up the texts of everyday life. Indeed 
examples of this are abundantly available in Calypso. One version of external dialogue has already been identified in the 'call and response' conducted between Calypsonians and audience in 'live' performances in the Calypso Tents, and is developed in Chapter 9.

In the context of resolving presenting conflict, I see Bakhtin's concept of multivoice, Freire's concept of dialogue and Vygotsky's concept of peer interaction as the same thing. When used in Calypsos they all support cognitive development and the process of helping each party to engage in a conversation that raises awareness of each other's view, out of which is born the opportunity for resolution. However, while Vygotsky's concept of inner speech connects the individual and society, Bakhtin's idea of non-legitimated voice further locates consciousness in the social dialogue of the historical moment. For Freire however the notion of empowerment is defined as central to the collective struggle for life without oppression and exploitation.

\section{Towards A Pragmatic View Of The Calypso}

The question may indeed be asked what actual claims can be made in support of the theoretical 'good' of the Calypso? What evidence is there that the participants of the conflict take note of the issues being sung about?

It is difficult to determine the exact effect or impact of any given Calypso except by looking at trends. This can be recognised by being aware of the effects of the following Calypso, which is a plea to the government to make appropriate educational provisions within the country:

\section{Education Education}

This is the foundation

Our rising population needs sound education. 
Children go to school and learn well

Otherwise later on in life you will catch real hell

Without an education in your head

Your whole life will be pure misery

You're better off dead

For there is no room in this whole wide world

For an uneducated little boy or girl

Don't allow idle companions to lead you astray

To earn tomorrow you got to learn today

(Available at Track 20 of CD)

The release of this Calypso resulted in a subsequent surge in the demand for places in the nation's schools. As a result, the government, recognising the shortfall in available teachers, thereby established a new teacher training college in Mausica.

Liverpool (1986:16-23) in describing the effect of the Calypso, acknowledges its contribution to the process of effectively changing people's attitudes. Liverpool states:

In terms of class unity the Calypso has over the years become a central stabilizing beam, holding many poles and walls of our myriad societal building together,

Liverpool(1986: 17)

In referring to the Calypso as an agent of unity of the people of the nation and recognising the various competitive, pre-independence fractions within the nation Liverpool adds:

Today, Calypsonians have helped to bring about greater unity in the society by singing praise to the Chinese, the Assyrians and the upper class whites...........countless Calypsos, too numerous to mention, have commented on the beauty and unity of every creed and race that inhabit this land of ours...........Truly the Calypso is the grand promoter of racial unity

(Liverpool 1986:18)

It needs to be emphasised that before the general availability of radios after World War II, and newspapers much later on, and still later yet, televisions, Calypsonians in Calypso Tents performed the function of harbingers of the news. The effectiveness of the Calypsonian in influencing public opinion is well documented by 'Atilla', who in 1947, 
wrote a paper entitled "The Growth and Improvement of Calypso". This paper demonstrated how public opinion was influenced by a Calypso which was released at the time of the 1903 'Water Riots'. In the paper Atilla recalls that one song was:

a decided and potent factor in shaping public opinion, one song actually causing a public outburst at the alleged brutality of a member of the constabulary which, eventually in its repercussion, caused investigations to be instituted and the alleged murderer brought to trial. He was subsequently found not guilty and was discharged. The song went like this:-

Lawyers of the Bar, we must form a deputation Jurors of the land, not to acquit Holder, We must try him for murder. If he escapes the rope, he must die in Carrera Perry waiting with the rope To break his manima.

What Atilla clearly demonstrates here, is the potency of the Calypso in bringing an alleged murderer to justice.

Similarly the Calypsonian has contributed many new words to the colloquial language of Trinidad and Tobago and throughout the Caribbean, some of these are: 'jagabat', 'wahbeen', 'mamapool' as well as adages of the time which have filtered to Caribbean communities world-wide, phrases such as: "Feeling de feeling," "Soca Jam," "Soca Fever" and many more.

Although during my research various individuals had commented on the influence of the Calypso on affecting political choice, there is no bona fide evidence to support this trend. However, the influences of the Calypso on other fields can be extrapolated from work that shows the commercial influence of the Calypso. For example, Quevedo wrote:

A city merchant secured the services of Atilla to advertise the chocolate milk product known as Toddy. Now this Toddy was practically unknown. But after advertising propaganda was launched through the medium of Atilla, lo and behold, the agents were able to announce to the consternation of not a few, the appreciable sale of 80,000 lbs., in three months. (Quevedo 1947: 19) 
In 1975, the Government of Trinidad and Tobago decided to 'go metric.' Chester Morong, the editor to Scope, a newspaper published in Trinidad and Tobago, published an article entitled "Example of the Power of Calypso". In referring to a Calypso which was sung by 'Composer' in the Regal Tent. Morong wrote:

So good is his Calypso that surely in the last few weeks it has done more for the Government metric changeover campaign than the expensive advertising campaign itself........... a shining example of the power of Calypso.

(Morong 1975:3)

In order to publicise the 1965 to 1977 'Buy Local' campaign sponsored by the People's National Movement (PNM), the PNM set up a Local Carnival at the Grand Stand, of the Queen's Park Savannah in Port of Spain, Trinidad. One highlight of this Carnival were the floats depicting products, with Calypsos urging the population to buy the local products (Liverpool 1986: 33). Liverpool goes on to state that locally made products such as Tisane de Dourbon, Berec batteries; Ovaltine, Phosphorine, Stag Beer, Lee Trousers, Carib Beer, and Canning's soft drinks have all been effectively marketed using the Calypsos.

The Calypso has also been used in support of advertising campaigns for a range of shops, organisations and businesses, these have included: film advertising agencies, the Government Census, the Family Planning Organisation, the Forestry Department of the Ministry of Agriculture, Guinness Limited, the National Lottery, Nagib Elias and Son, 610 Radio, the Income Tax Department of the Ministry of Finance and Kirpalani Stores (Liverpool 1986:34).

The impact of the Calypso as a marketing agent is beyond doubt. In this role, it raises peoples awareness and directs them to courses of action. I am suggesting that this function is paralleled by its application to the triangulated processes of learning, growth and change as this applies to the resolution of inter and intra-strata conflict in the Republic of Trinidad and Tobago. 


\section{CONCLUSION}

So far, I have shown that Calypsos are an oral literary art-form. I have also shown how Calypsonians, acting as go-betweens, use a range of techniques to trigger cognitive dissonance for their audiences, asking 'think questions' of values and morality and by so doing, raising the audience's awareness on the presenting issues.

This cognitive approach principally invites an understanding of social, political or economic issues, conveying an interpretation of meaning to the average person, in such a way that it helps them to better understand the pertinent issues.

Calypsonians are well known to have stimulated discussion and debate under the aegis of truth, stimulating modes of thought, the acquisition of which have enabled Trinbagonians to evaluate different courses of action within their society. This approach has created a space which enables the community to 'move forward' in a type of educative process, empowering them to take action to resolving their community issues.

Through the very skilled application of a language, that frequently revolves around linguistics and manifesting in wit and humour, Calypsonians utilise Form to elaborate on image schema that connects different domains within the audience's experience. By so doing, they help their audiences' cognitive process, restructuring their understanding of localised events.

In the final analysis, we see that this education is a function of the language used, as expressed in the Calypso and that the presentations are not just or simply enjoyable. They actually feed the imagination, while enhancing the quality of people's lives by linking them to their culture, deepening their understanding while simultaneously refining their feelings, adding empathy in the process or working towards a resolution of interpersonal and/or community conflict in the Republic of Trinidad and Tobago. 
Chapter 8 - Conscientização: Calypso As An Agent Of Social Cognition

Used in this way, Calypsos become a personal resource for the healthy development of mind and spirit, supporting individuals as they learn to cope with conflict, while being able to see and express their feelings more authentically. In the final analysis, yielding a 'better', a more informed people. 


\section{CHAPTER 9 - THE AUDIENCE AS CO-MEDIATOR}

It is only in the Calypso that the Trinidadian touches reality. The Calypso is a purely local form. No song composed outside Trinidad is a Calypso. The Calypso deals with local incidents, local attitudes, and it does so in a local language. The pure Calypso, the best Calypso is incomprehensible to the outsider. Wit and verbal conceits are fundamental; without them, no song, however good the music, however well-sung, can be judged a Calypso.

Naipaul, (1993:70)

\section{INTRODUCTION}

So far, this work has looked at the media used in Calypso presentations that feature commentary on social, political and economic issues within Trinidad and Tobago. In so doing, I have examined the interrelationship between performance, spectacle, theatre and ritual. Having done so, I then progressed to examine linguistic form in Calypsos that employ reframing as a multidimensional tool used for the purpose of resolving conflict. I undertook to look at the nature of the performers themselves in Chapter 3. It is therefore left for me to present in this Chapter, my perspective on the audience's role as social actors, engaging in a process of co-constructing the socio-cultural order that is a necessary part of the ritual process of resolving conflict. In doing so, this Chapter shows how the ritual communication of 'call and response' is a significant part of this indigenous community conflict management mechanism (Indigenous Conflict Management Mechanisms, n. d.) and that engaging in this process, the Calypsonian utilises some aspects of non-official facilitation (NOF n. d.).

\section{AUDIENCE CO-AUTHORSHIP}

In the previous section I used the word "relationship." This word itself suggests duality, that is to say, that by the very use of the word there is an implicit suggestion that there is an 
aspect of bi-polarity. The relationship that I examine in this Chapter is that occurring between the Calypsonians and the audiences. I am suggesting that, as occurs in formal mediation, this non-formal process of conflict resolution, also requires the audience to function as co-authors. In this context, they embody the concept of intertextuality.

Fairclough (1992) gives an interesting analysis of the difficult distinction between both discursive and social practice. As part of the process of helping us to untangle our understanding of these terms, while creating operational boundaries for them, he embarks on a practical discussion of the importance of the Kristeva's concept of intertextuality. In this concept, texts, or in this case, the sung words of a Calypso, which we have previously identified as symbolic action, are identified as an array of a complex and often contradictory systems that feed off each other. This concept is not new, it can be traced back to the work of diverse scholars such as Mikhail Bakhtin, Ludwig Wittgenstein, L. L. Austin and Bronislaw Milinowski. In my previous chapter, I referenced the work of Vygotsky (1978) in showing how an individual's higher psychological processes can commence through his/her process of social interaction. The 'private language argument' was developed by Wittgenstein (1953 and 1958) and Kripke (1982). This idea which is important to the field of conflict resolution states that a code of a language cannot be contained in someone's mind. In other words as Holquist (1983) contended no one owns it. That is to say, any system of interactional behaviour that includes a protocol (i.e. is rule governed) can only belong to the community that uses it and not to an individual. Implicit in this notion is an idea that runs contrary to Chomsky's (1986) suggestion that a linguistic system can be attained by investigating individual competences. The implication by this is that linguistic systems are best studied and interpreted by documenting particular acts of speaking. This 
approach recognises the power of both parties to meaningfully contribute to this process of communication. It is in this way that the process of co-constitution is made real, possible and meaningful. For the purpose of this work, it is in the Calypso Tents that this process becomes animated by 'Calypso actors', (i.e. at particular times and in particular places, as discussed in Chapter 7).

By the very nature of this mode of communication, if it is to be effective, it essentially needs to be two sided. This bipolar-approach to resolving conflict, needs to be realised simultaneously, as concrete acts of verbal communication through a system that is frequently used in African centred communities and known as "call and response." The recognition of this helps us to understand Wittgenstein's concept of how 'private language argument' manifests in the mundane, daily activities of life, as opposed to being wellexpressed in philosophical debates. That is to say that for us, struggling in the throws of our daily social, economic and political vicissitudes, I recognise, as Wittgenstein suggests in the 'private language argument' that the actions of daily communication can more effectively occur in someone's back yard, in a church service, during a picnic, and for us Trinbagonians, by the very nature of the interaction in a Calypso Tent.

In this indigenous, bi-polar process of resolving community conflict, effective communication is not the prerogative of the speaker, but more the child of the interpretation by, in this case, the audience. It lies with their ability and power to respond, invoking certain conventions, their ability to establish links between different acts and different social personae and by so doing, assigning interpretation. Bakhtin contends:

In the actual life of speech, every concrete act of understanding is active: it assimilates the word to be understood into its own conceptual system filled with specific objects and emotional expressions, and is indissolubly merged with the 
response, with a motivated agreement or disagreement. To some extent, primacy belongs to the response, as the activating principle: it creates the ground for understanding, it prepares the ground for an active and engaging understanding. Understanding comes to fruition only in the response.

Understanding and response are dialectically merged and mutually condition each other; one is impossible without the other

(Bakhtin, 1981:282)

This perspective on the impact of words on the communicative process does not stand uncorroborated, in isolation and without the support of empirical research. Indeed, Schegloff and Sacks, (1973), Schenkein (1978) and Streek (1980) have all conducted research into the domain of 'talk,' recognising the impact and significance of its sequential organisation. Bourdieu (1977) and Kochman's (1983) research into verbal and non-verbal ritual exchanges is also significant in relation to my purpose. Gadamer (1962 and 1976) succinctly encapsulates the concept of these researchers' views in the following paragraph:

understanding can go beyond the author's subjective act of meaning, and perhaps even necessarily and always goes beyond it .... as soon as we consider the appropriate model-for example, the understanding of historical actions, of historical events - we find ourselves in agreement. No one will assume that the subjective consciousness of the agent, or of the participant in the events, is commensurate with the historical significance of his actions. It is obvious to us that understanding the historical significance of an action presupposes that we do not restrict ourselves to the subjective plans, intentions, and dispositions of the agents. At least since Hegel's time it has been clear that history by its very nature does not have its primary focus in the selfknowledge of the individual, and it holds just as well for the experience of the art. I believe that this same insight must be applied even to the interpretation of texts whose informational sense is not open to an indeterminate explanation like the art work. Here too, as Husserl's critique of psychologism had demonstrated, 'what is meant' is not a component of subjective inwardness

(Gadamer, 1962 and 1976:122)

We can therefore come to the realisation that meaningful communication is effected by the nature of the speaker/hearer relationship and becomes meaningful through the interpretation and responses of the hearer. 
In the remainder of this chapter, I will present my observations of the practical tools used in a Calypso Tent for resolving conflict through the inter-activity of durable cultural systems of meanings used in the Tent. In doing so I propose to use Fairclough idea of intertextuality to reveal the complex and enigmatic quality of discourse in a Calypso Tent, showing the significance of the process of 'call and response', and its use as a phenomenon that facilitates engagement of the parties, in such a way that it leaves no room for escape, even in the most private realms of subjectivity.

Earlier in this work, I examined both text and text in context. However in reality, as with any mediation situation, the language of resolution occurring in a Calypso Tent does not just occur purely in context of the events that drive it, I contend that it creates its own context. What I need to do here then is shed light on my analysis of the ways in which context is created, changed and sustained within the Calypso Tent. In the light of my etic and emic (outsider/insider) experience as discussed in Chapter 2, I propose to bring some light to bear on the shared social worlds of the Calypsonians as well as the audience, that allow effective call and response (or intertextual) conversations to take place. Engaging in this exposure requires of me, that I trace back the sources of shared knowledge, (I have in Chapter 8 referred to this phenomenon of shared basic knowledge as 'sedimented meaning'). This sedimented meaning is that which brings commonality and baseline understanding to the issues under consideration. Consider for example, two engineers discussing the details of a project that they are working on together. The context of their conversation can consist in part, of a common language, gained from their fundamental training in the profession. This training would have given these professionals the joint, shared knowledge that is necessary for them to understand the technical terms used by each other when describing aspects of the project. This understanding of communication is also 
familiar in the field of formalised conflict resolution. Philip's (1992) studied judges during legal procedures such as plea-bargaining. She found that the speech patterns of some judges consisted of behaviours that in similar circumstances, other researchers deem to occur when the informant speakers in these other groups, were engaged in a process of repairing the errors in their speech. These idiosyncrasies showed up primarily as: word repetition and hesitation. In offering an understanding of these observations, she contended that these judges may be using these speech behaviour patterns in a deliberate attempt to create a feeling of spontaneity in their speech, as opposed to these incidents being genuine efforts to try to repair their inappropriate use of words. As a consequence, she concluded that these judges are attempting to define the interactional context as an informal, personal, spontaneous speech event, rather than as an instance of routine formal speech.

Similarly, the events of the Calypso Tent have a number of structures that can allow the experience to be regarded as an informal, personal, spontaneous speech event, as opposed to instances of formal, ritualised speech. These structures can be grouped under the term "call and response". Call and response allows the audience to co-author the proceedings of the evening, while they are engaged in the process of co-constructing meaning. Before I delineate details of these processes, it seems appropriate to further develop the concept of audience co-authorship.

\section{The Concept of CALl AND Response}

Call and response is a coactive, reciprocal process that involves inter-communication, taken in turn, between the Calypsonian and the audience as the story is told through the medium of the Calypso. The process enables the performer and the audience to engage 
in a form of rhetoric union whereby they are together able to create, interpret and respond to rhetoric act.

Historically, this tradition has been frequently found in African centred language, music and dance in addition to other communication genres (Asante 1987) and has been appropriately documented as having been extensively used in Calypso, Bilby (1985); Cowley ( 1998:228-231); Elder (1996); Rohlehr, (1990); Liverpool (1993). However, these latter authors have all neglected to demonstrate a clear and total understanding of the process of call and response, its elements and their significance, let alone applying its principle to the field of resolving conflict. Given this omission, this work is therefore my approach to consciously articulate a congruent, coherent paradigm for resolving indigenous conflict, through the medium of the Calypso art-form. The profound difference with my work is that in doing so, I propose to go beyond the work of Bilby, Cowley, Elder, Rohlehr, and Liverpool, and develop a codified system for 'call and response' in Calypso oratory, that is relevant to the resolution of conflict in the Republic of Trinidad and Tobago.

After having identified the individual elements of the 'system, I then intend communicating the dynamics which, inherent in this system, bridge Diaspora and continental African cosmology, ontology and philosophy.

\section{PhILOSOPHIC IMPLICATIONS OF AfRICAN RETENTION}

In order to get a firm grip on this localised approach to resolving conflict, it becomes central to the locust of this argument that I commence with an overview of the social epistemology of the African world-view and its normative assumptions. This approach 
will give a handle to the frame of reference that enables readers to have an empathetic understanding of life from an African-centred perspective.

Tempels (1959) contends that a core ontological belief, shared by most African cultural orientations is that everything in the universe is either "Force" or "Spirit". Accordingly this fundamental African philosophy rests on the firm understanding that everything in the universe is endowed with and sustained by a Supreme Force (Temples (1959) and (Forde (1954). As a consequence this aspect of traditional African culture holds that there is no distinction between the spiritual and the secular.

..........for traditional African people, the spiritual and the material, Church and State, theory and practice form an integrative whole. Any separation of these therefore, is part of buying into the illusion of the experience in which we live, for theory indeed manifest as practice. Similarly, Spirit and matter have a synchronous integrated relationship as Spirit is made manifest as matter.

(Phillips, 1999)

The system extends to a belief that the very nature of existence is the Supreme Force, (Thomas 1961). The extension of this thought system supports the view that the nature of the universe is 'vitalistic' and that all things are 'interdependent' and 'interconnected' (Thomas 1960, 1961).

These particular beliefs characterize, standardise and control the inter and intra-social psychological relations within and between communities (Mbiti 1970). For example it is this belief in interconnectedness that supports the notion that if all things are imbued with the same Supreme Force, then this implies that in essence, all things are one. Because of the separation into individual identities this ontological perspective invites a recognition of "being in the universe" as being characterised by a cosmological 
"participation in the Supreme Force." This approach is very similar to that of God Imminent and God Transcendent.

It therefore follows from this psychological perspective, that for Africans, the community is seen as a reference point wherein everything in existence is perceived as being interconnected to everything else in existence. For us as practitioners in conflict resolution this means that to argue or be displeased with my fellow man, is to argue and be displeased with myself. So, my process of healing is also your process of healing and vice versa.

This interconnectedness extends beyond the physical plane. In this regard, Mbiti (1970) states that for Africans, the individual owes his/her very existence to all members of the community, be they living, dead or yet-to-be- born. This community can consist of either a family, or a tribe or clan.

This notion of "oneness of being" and that of "interdependence" in turn has further implications. They drive the belief which Africans hold that, humans are all at one with, and intimately connected with nature. Thomas (1960) calls this the "vitalistic pneumaticism". This leads to the inevitable conclusion that experience is an intense complementary rhythmic connection between a person and reality. Since all African philosophical notions indicate that our universe is dynamic, interconnected, mobile and vitalistic, in turn these suggest that "vibration" or "rhythm" is a core attribute within the culture (Akbar 1975). Hence, it is the retention of this phenomenon within the Caribbean in general, but more specifically, in the Calypsos of Trinidad and Tobago, that constitute the roots of black culture within the Diaspora. 
It follows therefore that Africans recognise that the tenants of their culture support the preposition that any unifying process of resolution needs to take place on a spiritual and/or a metaphysical level. In this epistemology, the basics of Spirit and vibration are so primary, so fundamental to the concept of 'the Word' (or the call) as manifest in the Calypso, that it is impossible to understand the power of the word to heal and restore without first appropriating knowledge of its constituent parts and its dynamism, viewed within the African belief system.

Practitioners of traditional African culture both recognise and realise that the creative, the healing power of the Word resides in its vibrations. It is the knowledge of this fact that initiates the healing process through the throbbing vocal techniques of the sung Calypso, combined with the use of appropriate questions, padding refrain, halts and pauses, auditory variety and mimicry, that take place during the singing of a Calypso.

In summary then we can say:

At the heart of any attempt at designing a model of African-centred mediation therefore, is a recognition of the key themes of African culture. These being:

1. The assumption/belief that the universe is Cosmos

2. The ultimate nature of reality is Spirit

3. The human being is organically related to everything in the Universe

4. Knowledge comes from participation in and experience of the Universe

5. Human relatedness is the practice of our humanity

6. Participation in the Universe through a balance between the rational (the cognitive left brain) and the intuitive (imaginative right brain).

Phillips (1999)

\section{Developing the Paradigm of Call and Response}

In identifying call and response as one of the methods in 'Afrocentric discourse,' (Asante 1987), I will be applying this process to the proceedings in a Calypso Tent. 


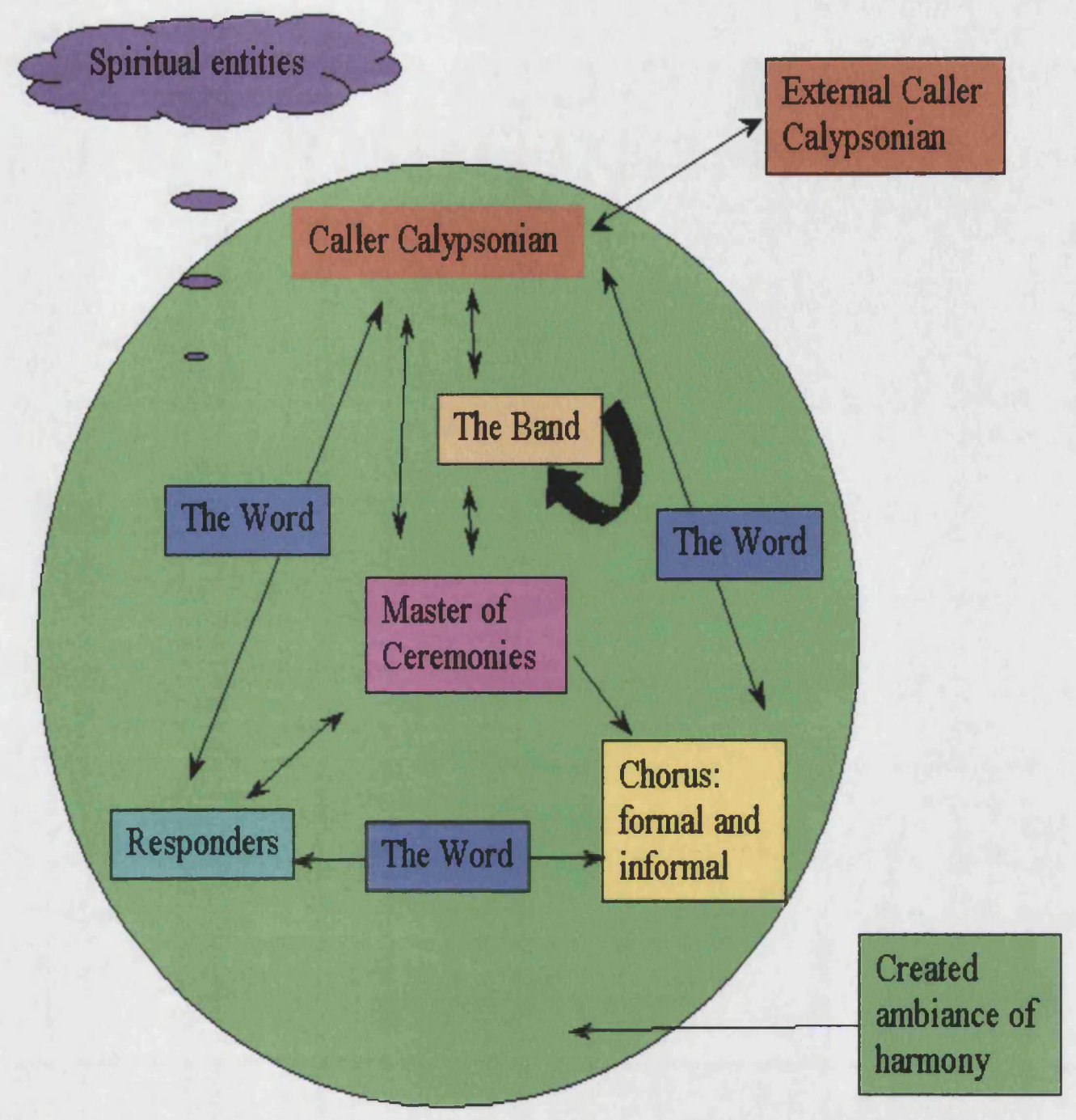

\section{Figure 9.1- A Paradigm of Call and Response: Audience Co-Authorship}

The Trinbago paradigm of call and response as used in the Calypso Tent, features six entities: the word, the master of ceremonies, the caller, the chorus, the responders, the Spiritual entities and the external Caller Calypsonian. In this paradigm, the chorus sets up a pattern and possibility for the respondents in the audience at large.

In relation to this process, I have come to understand the various elements/constituents of this process of achieving Spiritual harmony (or the resolution of conflict) to include a number of constituents. These elements are: Caller, Chorus, the Master of Ceremonies (or Emcee), the message (i.e. the word as manifests in the Calypso), Responders and Spiritual entities. I shall now be looking at each of these in turn. 


\section{The Caller-Calypsonian}

In traditional African culture, (from which I have previously shown that the rhetoric of the Calypso springs), it is the Caller who carries the responsibility of presenting to the people the perceived solutions to the identified social and political problems. Hence, in as much as the Caller initiates the speech ritual, $\mathrm{s} / \mathrm{he}$ is a conduit for the people, initiating the primary creative element in the process of healing. In this philosophical construct, the caller is highly regarded by the people, who have a deep respect for him/her. Accordingly, there is an unwritten, nevertheless specific code of morality with its associated conduct that it is expected of the orator-Caller in classical African culture. In a discussion of the traditional African beliefs in relation to their works of art, Thompson (1974) recognises the deeply held belief that for Africans an improved character improves the art form. In practice, with regard to this area of oral art that is my concern, this wholesome character of the caller enhances the quality of their word as well as its potency. So the moral character of the Caller has a direct effect on his/her power and efficacy. The caller's effectiveness is also affected by his/her strength of commitment and vision as well as his/her skill as an orator. Thompson (1974) regards this as a "double admonition of art [skill] and goodness" [character].

Since Africans traditionally view humanity as a spiritual force (Jahn, 1979:100), in turn, the requirements of the poet-performer (Caller) demand that he/she must direct his/her creative powers towards the higher level of consciousness. By so doing, s/he creates a vibratory resonance that allows her/his energy to merge with the Cosmic energy, activating the rhythmic vibrations of the universal Cosmic energy that are a necessary part of, in this case, the process of successful resolution of conflict. 
A significant similarity that Calypsonians in the Diaspora share with continental practitioners is a fundamental humanistic approach that governs the practical applications of their created processes in relation to resolving conflicts that involve social injustice and issues of national morality. This view affords the comfort of believing that goodness and morality, uplift, advance and benefit the people. In parallel with the idea of modern deep democracy, there is an acceptance that it is the people who determine for themselves, what is right, proper and moral for them as a group. As a general approximation, this philosophical and cosmological African views on morality is grounded in the belief that is guided by a practical, humanistic approach. This assumes that either God can be in error, or when expedient humans can deliberately misinterpret the holy scriptures, to suit their own selfish interests, (Wiredu 1980).

It therefore follows that the community and the caller-Calypsonians, in keeping with a subliminally retained traditional African belief system, inadvertently recognise that it is not that something is good because God approves of it. Rather it is the converse, God approves of a thing because men and women find it good for their society in the first place.

What this approach necessitates is the recognition by the caller that he/she needs to be preoccupied with human welfare. It is this understanding that drives the Caller's deeprooted humanistic approach. So that for the Calypsonians, the word expressed in the Calypso lays claim to and reflects the Calypsonian's fundamental belief that what is morally good is what benefits us as humans. It is a belief that what is decent, is that which supports and reinforces our dignity, our self-respect, our contentment, our prosperity, our joy as a people. Conversely, the Calypsonian also understands that what 
Chapter 9 - The Audience As Co-Mediator

is morally bad is that which brings misery, misfortune and disgrace, (Wiredu 1980).

When Calypsonians forget or flaunt this understanding they are dealt with as appropriate by the community. For a classic illustration of this point please see the section entitled:

"The Symbolic Use of Toilet Paper as a Mechanism of Response."

\section{Mechanisms of the Call}

The application of the Call, in order to gain a response, is used in a variety of ways in Calypsos that are sung on topics that comment on the social, political or economic climate of the Republic of Trinidad and Tobago. Although I will now delineate these, it needs to be remembered that in documenting them, I am subject to the limitations of the medium in use. The effect of this is that despite my very best endeavours, there are limitation in my reporting the style, content and function of these artistic creations. This point I have addressed in more detail in my chapter "Establishing Resonance".

The Call is achieved through a variety of mechanisms, these include: Questioning, Pauses, Mimicry, Padding refrain and Auditory variety.

\section{Questioning}

When in October 1999 I visited the Hofstra University, in the USA to complete my Advanced Transformative Mediation Training, one of the trainers, commented on the use of questions in mediation. I recalled that statement to be "when as mediators we don't know where to go, we cut in with a question." At the time I consider this to be an ad hoc use of a technique that has a phenomenal potential to shape, guide and steer someone's perception of events. 
I identified the fact that as a general approximation, numerous ways that Calypsonians put questions to their audiences during the call, can be distilled to fit into two fundamental approaches. Principally, these are the interstitial question and the substitutional question.

As its name suggests, the interstitial call is randomly situated between verses of a Calypso. The objective in using this technique is to try to establish the level of audience engagement and participation. In some cases, the Caller-Calypsonian asks the question: “Are you ready to go home?” To which the audience usually answers No! This is seen as an indication of their commitment to and evidence of their engaging in the proceedings of the evening. Another question can come as a request to "Wave your flag?" The flag referred to here, is any piece of cloth that the individual may freely have at their disposal, this can for example be a handkerchief, a bandana, or just available bunting.

Another form of this questioning occurs when the Calypsonians stops singing in the middle of a Calypso to ask the audience to repeat a specific set of lines. In doing so, the Calypsonians frequently holds the microphone out towards the crowd, for their voices to be caught by it. In this way, $\mathrm{s} /$ he engages in a process of recycling through the speakers, thereby enabling them to hear themselves as they respond to the question. This process is not dissimilar to that in formalised mediation where the mediator repeats the paraphrased words of the disputants thereby enabling the disputing parties to hear an acknowledgement of the issues that are being brought to the table. 
I have also observed incidents where the performer asks rhetorical questions such as:

“Ah lie?" When translated, this is a request for agreement on what has been said, i.e. am I telling the truth, or am I saying it as it is? Or am I telling it as you also understand it? All of these are possible interpretations, depending of course on the situation to which they are being applied. On one occasion, the Calypsonians, Ronny Mackintosh, in sharing in song, his observations on a number of local situations, repeatedly asks the question "Ent?" during the Calypso. This was a deliberate, rather than an interstitial use of the questioning technique. It was a call to the audience to rally round and declare "if it isn't really like that"

In the substutional question the Calypso incorporates the question as part of the verse. Examples of the use of this approach abound in the art form, but for our purpose, I will draw on just the few examples given below, in order to cement the point.

In the Calypso about the musical art form entitled "Calypso Music" Rudder directs the consciousness of the audience by asking:

Can you hear the distant drum, bouncing on the laughter of a melody? And as the rhythm tells you come, come, Does your spirit do a dance to this symphony?

Does it tell you that your heart is afire?

And does it tell you that your pain is a liar?

Does it wash away all the unlovely?

And are you ready for a brand new discovery?

David Rudder

I consider these are very powerful words in a consciousness raising process, leading to resolution. For his part, Gypsy litters "The Sinking Ship" with questions. It is these 
questions that helped it to be the effective Calypso that it was. The chorus of the

Calypso is given below.

\section{CHORUS}

Captain, the ship is sinking

Captain, the seas are rough

We gas tank almost empty

We have no electricity

We oil pressure reading low

Shall we abandon ship?

Or shall we stay on it, and perish slow?

We doh know, we doh know,

Captain you tall we what to do?

Again later in this Calypso Gypsy asks questions of responsibility:

Who is to be blamed for doing her wrong?

Later, in requesting guidance, asks the most pertinent question:

We don't know, We don't know, Captain you tell we what to do?

In a very direct critique of the newly elected PM, Mr Basdeo Panday, Cro Cro asks some very searching questions, relating to incidents that occurred before he was elected, and for which he had been duly charged by the police:

Ah man on a charge for interfering

Black man all yuh still go and vote for him

Blackman how on earth you could condone this?

Your daughter might have to work in this man's office

Then imagine this sex silver-headed pest

Quail fingers under your daughter's dress?

Me eh saying that Patrick should have win

But even Jim Baker would have been better

In another verse he raises still further questions in relation to the incident when he

challenges the women's liberation movement to be conscious

All dem women who went Beijing the other day

About this fella what all yuh have to say? 
Above are some examples of the powerful and effective use of questions by Caller-

Calypsonians.

\section{Mimicry}

We shall see in a while, mimicry is frequently used on its own. However there are incidents where it is used in conjunction with other Call-techniques. Consider the Calypso "Still the Best" sung by Cro Cro, the chorus of which is given below. Here Cro Cro in mimicking is showing the ridiculousness of the situation juxtaposing the state of unrest with people's everyday living such as beggars, party-goers and potential murderers.

Cause where else in the world government overthrown And for your life you could still beg?

Where else in the world yuh -want to kill a man, and shoot him in he leg? Where else in the world government overthrown And man fêting in curfew? Where else in the world yuh fêting in curfew, Yuh drunk and police escorting you?

There are many examples of the use of mimicry. During these times, the callerCalypsonian deliberately tries to use the identical speech and mannerisms of the person being mimicked. A classic example of the use of this type of mimicry occurs with Sugar Aloes sings the words, How Panday cry like a little baby, in a whimpering manner, in an effort to mock Mr Panday. It is assumed that Aloes is referring to the incident when Mr Panday addressed the nation on television after his party lost most of their seats in a by-election. For his part, in singing the line "Well I'll drink to that", the Calypsonians Watchman is considered to be mimicking the intoxicated Mr Rambachan. When such mimicry occurs, it is usual to find that the audience responds by cheering loudly. 
Sparrow's "Get to Hell Out" is yet another powerful example of the Calypsonian's use of mimicry. In this Calypso, Sparrow mimics overwhelming arrogance of the PM of the day: Dr Eric Williams and his decision to reinstate the Patrick Solomon, the Minister responsible for the Trinidad and Tobago Police Service, after in his capacity as the Minister responsible for this service, he entered the custody cell of the police station where his stepson was being held and released him. Solomon resigned following a Commonwealth Commission of Inquiry into the running of the police service. A few days later, Williams decided to reinstate Solomon in his previous post, an event reported on in the newspapers who on $21^{\text {st }}$ Sep 1964 ran an article written by George Harvey which had the title: "A Job for Solomon: I have the Power, PM tells Arima Crowd". On the $21^{\text {st }}$ September 1964, Vincent-Brown wrote another article in the Sunday Guardian, entitled: "Solomon Back Again”. This article quotes Williams as saying “.... and those who don't like it could go and live abroad". Although on their own, the lyrics of this Calypso mimic the arrogance which was Williams' hallmark, the combination of lyrics and attitude focused the use of mimicry to bring the point to the audience.

I am going to bring back Solomon

Who doh like it complain to the Commission

None of them going to tell me how to run my Country

I defy any one of you to dictate to me

I am no dictator

But when I pass an order

Mr. Speaker, this matter must go no further

I have nothing more to say

And it must be done my way

Come on, come on, meeting done for the day

This land is mine

I am the boss

What I say goes

And who vex los'

And if I say that Solomon will be Minister of External Affairs

And you ent like it

Get to hell outa here 
Who the hell is you to jump and quarrel

PNM is mine lock, stock and barrel

Who give you the privilege to object

Pay yuh taxes, shut up and have respect

I am a tower of strength, yes

I am powerful but modest-unless

I'm forced to be blunt and ruthless

So shut up and don't squawk

This ent no skylark

When I talk no damn dog bark

My word is law

So watch yuh case

If you slip yuh slide

This is my place

And if I say that Solomon will be minister of External Affairs

And you ent like it

Get to hell outa here

Mimicry is part of the "debunking" process that was discussed earlier in Chapter 6.

Although in formal mediation, debunking of this sort is not seen to be fruitful, in this

type of non-formal setting, where power is asymmetric, it serves to remind the audience

that these MPs and people who share these exalted positions of power, are only but

human, having feet of clay.

\section{Padding refrains}

A padding refrain is a bit of lullaby that acts as an authentic vocal signature for a

particular Calypsonian. As is to be expected, each Calypsonians can have his/her own

padding refrain. On the occasions when, prior to a Calypsonian coming on stage, an

emcee hums this, it automatically alerts the audience, to the next performer.

Calypsonians frequently sing this padding refrains between the verses of their Calypso, before or after the chorus is sung. These elements of oral delivery serve a number of functions; they may call the audience to respond to the Calypsonians personally or to the 
topic that he is specifically singing about. They may also help the musicians to keep a steady rhythm, or the audience to remain pregnant with expectation. Most importantly, they are a way of building rapport with the audience in this crucial process of resolution. The use of a padding refrain can instigate cheers from the audience. They can also get audiences to shout the Calypsonian's name, or simply to applaud. Padding refrains used by some of the more popular Calypsonians are: "le le lie lay" as sung by Aloes; or "due bye due bye" as sung by Chalkdust. Many Calypsonians offer a range of padding refrains that they use at random.

\section{Auditory Variety}

Caller-Calypsonians effect their art by varying aspects of their delivery. These variations can take a number of forms. For example, by altering their pitch they can affect the meanings given to what they are singing about. Typically, the high and low pitch could be alternated, to create specific effects. Other variations of the use of this technique can be the changes in inflection at the end of a sentence. This rise or fall can convey specific contextual meanings during the delivery of a Calypso. On the other hand, variations in tone can have a significant impact on the audience's perception of the Caller-Calypsonian's sincerity and believability. Rudder puts these techniques to good use in his Calypso: "High Mas" where at the end of the first 2 minutes of the Calypso the whole band audibly changes key upwards, to revert a few moments later.

In this work, I have spent a considerable amount of time explaining not just the text of the Calypso but the context as well. My principal reason for explaining the text in this way is to create an understanding of the jargon used. This variety, together with appropriate enunciation helps to carry the message in a way that the indigenous 
population understand. Calypsonians usually integrate much of the Trinbagonian parlance in their renditions. These idiosyncrasies in pronunciations usually follow the following patterns:

a. "th" sounds as "d", in such cases as "dis", "de", "dat", "dem"

b. "ing" sound as "in"

c. the final "t" and "d" sound can be omitted at the end of words

d. the "a" sound can be omitted at the beginning of words like "round" and "bout"

e. "til" is an abbreviation of "until," as "cause" is for "because".

There are also other differences in speech that are worth noting; these include colloquial translations such as:

$$
\begin{aligned}
& \text { "ah" for "I" } \\
& \text { "cah" and "cyant" for "cannot" } \\
& \text { "doh" for "do not" } \\
& \text { "eh" and "ent" for "not" } \\
& \text { "goh" for "going to" } \\
& \text { "hah" for "have" } \\
& \text { "meh" and "mey" for "me" } \\
& \text { "tun" for "turn" or "turned" } \\
& \text { "yah" for "you" or "your" }
\end{aligned}
$$

Finally, the rate of speech is also significant as this can convey emphasis and excitement. Calypsonians usually sing slowly when they want to make a specific point, or place emphasis on a certain part of what they are saying, while singing words quickly charges the venue with charismatic excitement. 
There is one other style of discourse that needs to he mentioned here. In this form of internal dialogue the Calypsonian is seen to be communicating with self. An example of this is where The Mighty Sparrow, on singing of the marriage of Princes Margaret to Anthony Armstrong Jones sings:

If I wasn't there in England and see with meh eye And somebody else did tell me, ah would a say they lie Although ah was dere and see, ah still think dey fooling me, Look, Ah cah understand, how a princess could love a camera man

In view of the overwhelming difficulty experienced in bringing these concepts to life for the reader, I have enclosed a CD in the front cover of this work, the tracks of which are a living testimony of the processes described in this work.

\section{Pauses}

The use of this technique requires of the caller-Calypsonian that $\mathrm{s} / \mathrm{he}$ arrests his/her flow and offers an opportunity to the audience to intersperse with the words of the Calypso. It is one way for the Calypsonian to determine if the audience is in phase with him/her. In one such example of the use of this technique Aloes sings the words: They went to drink a straight by a club call. He then offers the microphone to the audience for them to respond with the answer " 88 ".

In yet another example of the use of this technique we again find Aloes singing in the Calypso "Public Advice" the words:

Jamaica had Gilbert for one day

They shedding tears

But what about we who had Robbie for.......

At this point he halts his singing, and offers the microphone to the audience for them to complete the line already started with the words five years. 


\section{The Chorus,}

The chorus is another type of response to the "call," the other is the audience with which I will deal later.

At the outset, I need to say that I hold a view that recognises two aspects of the chorus. I will call these the formal and informal chorus. The formal chorus is the group of about three to five people who are on the stage with the caller-Calypsonian and who follow a systematic structure of support for the progression of the Calypsonians and their Calypso. They chant lines of accompaniment in response to specific parts of the lyrical structure. Specifically they serve as a bridge between the caller and the audience. In the first instance, I see them as 'the audience in miniature', having a first instance response to the caller. In this way, they are significant to and for the larger audience, as it is their actions that signpost the opportunities for the informal chorus.

So, this formal chorus is different in quantity from the informal chorus, and for them the nature of the response is very different. On the other hand, the informal chorus are members of the audience at large, who, so fired by the caller's message and inspired by the support of the formal chorus, are driven to make their own individual responses to the caller. These responses manifest as the shouting aloud, words such as "yes man", “aha”, “yes”, “Oh yeh”, “tell them", "hit them”, “kaiso”, or even wolf whistling. On occasions, individuals have held aloft their ignited cigarette lighters as a mark of their agreement. This is their symbolic way of communicating directly to the callerCalypsonian, that they feel so inspired by what he is singing that he, illuminated their world, or metaphorically, has set their world on fire. Such overt demonstrations of acknowledgement are not unique to this setting, as recent news footage on the $\mathrm{BBC}$ and 
ITV show guerrillas, who regarding themselves as freedom fighters, at times fire their guns into the air, usually after a conflict has been resolved successfully.

The informal chorus primarily consists of members of the audience who in various ways show their approval or disapproval of the message (i.e. the word) coming from the caller who at that time, has taken on the identity of his/her sobriquet, while giving the message in a variety of culturally codified ways. In general, this process of agreement can be considered to be similar to that of bearing testimony to "the Word", as enshrined in the lyrics of the Calypso. In his article on African Liberation Oratory, Abu Abarry (1990) does not differentiate between formal and informal chorus, generally labelling both these groups as the "choric Group".

In this approach to understanding classical African culture as manifest in the attempt to resolve conflict through the reciprocal call and response methods, this collective voice represents the "royal" that is synonymous with the royal 'we.' This approach to resolving conflict is in keeping with classical African culture, where the concept of the community predominates, so that decisions are made by consensus and not by an individual. Appropriate actions that contribute to resolution may then be taken individually.

\section{Master of Ceremonies}

The master of ceremonies (emcee) can be either male or female and may him/herself also have a sobriquet. Some of the more popular masters of ceremonies have been Sprangalang (real name Dennis Hali), Rachael Price or Tommy Joseph. He or she, acting as a skilled conduit between the audience and the caller, contextualises the 
message of the Calypsonians who is about to come on stage. The emcee does this through the use of anecdotes, stories and observations on life, while offering philosophies, using both humour and innuendo as key elements of their delivery. It is $\mathrm{s} /$ he who, by the very nature of his/her approach to introducing the caller, and the very method of so doing, orchestrates the 'spirit' existing within the Calypso Tent, initiating the spirit of resolution. S/he keeps the audience alive and perched on the edges of their seats by providing appropriate and relevant commentary, to guide the audiences' expectations of the Caller-Calypsonian, who is about to come on stage. After the callerCalypsonian has made his delivery and is exiting the stage, it is the emcee who, responding to the stimulus of the audience applause, calls the caller-Calypsonian to return to the stage to satisfy the audience's hunger for more, or for further verses of the Calypso, that they have just been singing. In and of itself, this negotiated recall procedure is central to the process of raising consciousness.

A skilled emcee is able to use a humorous approach that embodies a variety of culturally codified methods. This approach enables the audience to embrace the multidimensionally rhetoric that leads to resolution, by enabling them to shift both their levels of cognition and their capacity to engage in their own cathartic experience. The emcee does this through a literary narrative that is constituted of substantial audio-visual cues permitting the audience to engage their moral and aesthetic judgement, through the rhetorical instrument of the Calypso.

Clearly, the emcee has a central role in the process of 'call and response.' However, to date, this role has been ignored by researchers in the field, (Bilby (1985); Cowley (1998); Elder (1996); Rohlehr, (1990); Liverpool (1993)). So crucial is the role of the 
emcee and so untouched is this area of research that I consider it vital that I spend some time addressing this deficiency.

In identifying the emcee as the locust of Tent activity, it becomes important to spend some time examining the tools used by the emcee. In the context of my fieldwork, I have come to recognise that the skilful use of humour is the most prolific and profound tool available to the emcee of the Calypso Tent. In keeping with this observation, and being aware of the dearth of available research into the operational effectiveness of this pivotal figure, I am aware that the function of the emcee warrants further research attention. In doing so, it needs to be recalled, as discussed earlier in Chapter 1, that in the specific case of Trinidad and Tobago, the Calypso was born out of a struggle against oppression and domination, within a heavily stratified, hierarchical society that gave power to a white European ruling class, with the slaves in the bottom rung of that ladder.

The Calypso Tent of today is a mutation of those earlier days and as such, retains some of its fundamental founding characteristics. These characteristics include the abundant use of humour by both the emcee and within the Calypsos themselves. Having identified this as the backdrop, I need to hasten to add that such use of humour must not be mistaken with the humour used in European settings, as espoused by Plato, Aristotle and Cicero and which has a foundation in ancient Greco-Roman societies (Grant, 1970). In this latter view, not only should humour not be used in excess, but neither should it be used in serious matters nor on serious occasions. In accordance with that conceptual view, the expectations surrounding the use of humour were that when it is used it should be innocent in its purpose and free from anger (Grant, 1970:22). In this framework, 
there was the expectation that any type of humour that is aimed at another and resulting in laughter, was regarded as ignoble,

This European framework for the use of humour is quite counter to that which has, and still occurs in the Calypso Tent, and used not just by the emcee, but also can be found to be effectively embedded in Calypsos themselves. However, this phenomenon has been given little serious treatment in the folkloric literature relating to the field of the Calypso. For my part, in the context of the discourses of the emcee that I experienced during my fieldwork in Trinidad, I have come to recognise the significance of Orwell's perspective that 'every joke is a tiny revolution'. When considered in this way, I recognise that the humour used by the emcee (and others) in the Calypso Tent, has a dual function in that it places those who are the subject of this sort of humour, in the uniquely created, marginalized category, where for them, the clown's custard pies, are experienced as bricks. However, for the audience, the use of humour in this way creates a level of social interaction that results in their consciousness being raised, which in turn, subsequently allows them to engage in the process of negotiating their social reality.

In the long term, humour used in this way has a basis in generating resistance, while instigating the audience to take levels of control of their own lives. In the short term, the role of the emcee can also be seen as a mechanism for Qualitative Progression, serving to distance the audience from the stressful and intolerable social conditions about which the Calypsonians are singing, a point I developed in Chapter 7. 
It is in this deliberate use of humour that the emcee's verbal art manifests as joking behaviour, in a process of negotiating both the sociological and linguistically incompatible frames of reference concerning social reality as understood by the audience. By so doing, the emcee performs the important function of managing the dynamic tension that exists between individual, collective morally and the problematic societal situations.

Principally, during my fieldwork I recognised that the emcees used a number of joking frames to engage the audience. The potency of these frames were effected by the application of linguistic form through the mechanism of the joking language being used and the symbolic meaning and cultural codes associated with the joking behaviour of the comedian emcee and cognised, comprehended and interpreted by the audience. These jokes from the emcee are in reality humorous verbal gestures of symbolic action that subscribe to Goffman's notion of 'sign vehicles' Goffman (1969:11).

For their part, Granfield and Giles (1975:18) invite us to see the application of jokes, through the appropriate use of language, as a form of the transmission of ideas about social reality and morality. They express the view that humour, like language itself, possesses both referential and expressive functions. Hence, while on the one hand the humorous expression can serve to relate a funny incident, on the other hand, it also implicitly provides information about the audience's feelings regarding the individual about whom the humour is the subject. Through a subconscious awareness of this bipolar functional relationship, the emcee in the Calypso Tents uses jokes to linguistically mediate the developmental processes of the members of the audience, 
while enhancing their cognition in his/her attempt to share some knowledge of the relevance and meanings of the observed events within Trinidad.

\section{Responders}

In relation to North American black music, Maultsby (1990) asserts, and I agree, that in relation to the activities occurring within the Calypso Tent, that black audiences, respond immediately where performers are able to interpret and deliver a song within the aesthetic boundaries framed by their audiences. Under such circumstances, their audiences' verbal comments, as well as their physical gestures are an expression of their regard for the singer, as well as the lyrics of the song (or Calypso) being sung.

Although traditionally researchers group responders into one bracket, I contend that a closer examination reveals a lack of homogeneity, recognising three separate categories of responders, these being:

- Other Calypsonians (labelled in Fig 9.1 "External Caller Calypsonian)

- Politicians

- The Audience

\section{Other Calypsonians}

In their attempts to make their Calypsos current, Calypsonians have a live, dynamic interactive relationship with their world and with other Calypsonians. They are ever aware of the situations in which they find themselves and how they represent these situations. Under these circumstances they have been known to respond to each others Calypsos, offering each other advice through the medium of the Calypsos that they are singing. Black Stalin's Calypso: "Burn Dem" and Cro Cro's response: "Fire" are classic 
examples of this type of call and response between Calypsonians. In his Calypso Black

Stalin in addressing the historical problems in the world suggests that St Peter should burn a range of world leaders. Some of those that I have extracted from the Calypso (available at Track 21 of the $\mathrm{CD}$ ) are:

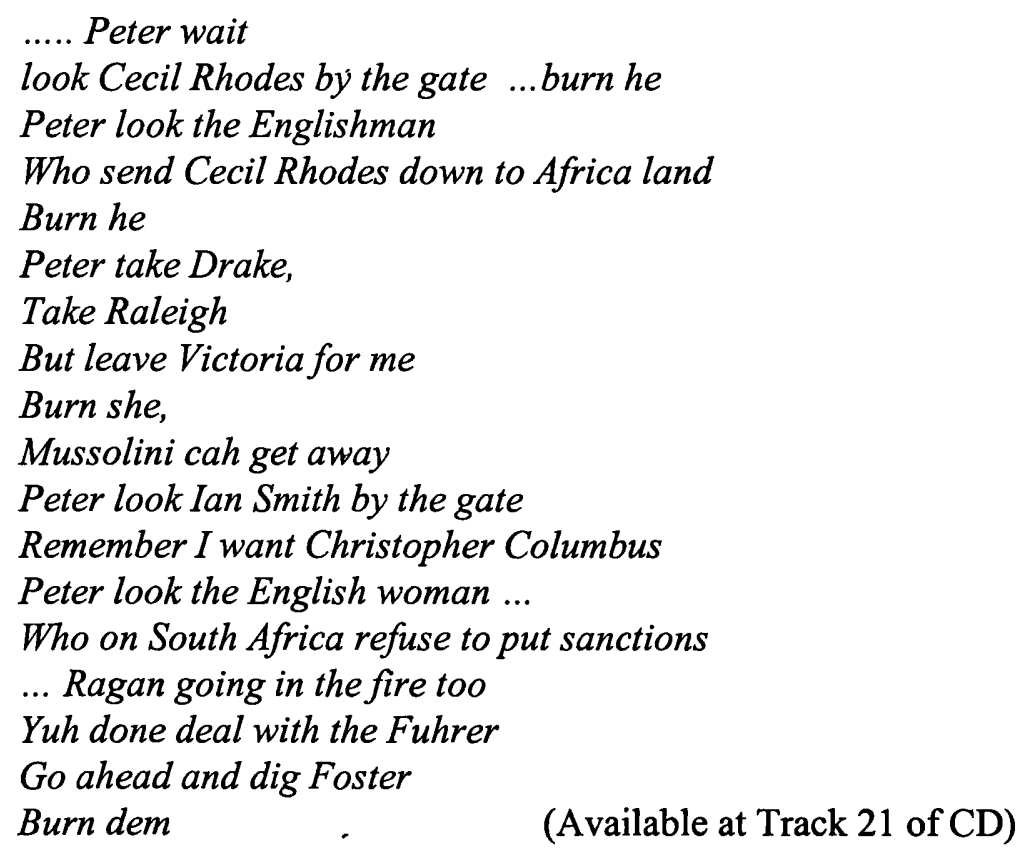

In his response, Cro Cro suggests that Stalin identified the wrong group of people to be burnt, but instead Stalin should have focused on Trinidad. Cro Cro sings:

Ah want you help me burn dem big boys in Trinidad He say I hear a big boy right here in this land And he publicly say he doh like Kaiso and Pan He tell me fire, doh care how he groan Light the matches and let him burn And if a woman could be so absurde and slack To say how Indians doh consider themselves black He tell me fire, Cro Cro I smell trouble And ah feel Stalin burn the wrong people Prepare yourself partner for being so wicked Yuh go burn in hells fire For being so wicked racial and slack Stalin permit me to light up the fire back (Available at Track 21 of CD) 
In responding to Stalin's Calypso, Cro Cro also admonishes him for singing “Burn Them" as a humorous Calypso.

It is recorded that following Aloes public admonishment of Mrs Panday's conduct as the wife of the PM, Sparrow entered the polemic responding to Aloes' comments in "Ah Ready to Go". Discontented with his remarks the following year Aloes engaged Sparrow reminding him and the public of some of Sparrow's antics where it was seen that he disrespected women. In questioning whether it was possible for Satan to correct sin, "In this Stage Is Mine," (Track 3 of $\mathrm{CD}$ ), Aloes, castigates Sparrow, recalling his hypocrisy thus:

\author{
Sparrow and all criticise me \\ That old ungrateful Grenadian \\ He and prowler is two outsiders \\ So he join with the Vincentian \\ He forget he sang "Jean and Dinah" \\ "May May" and "Mary Bunta Breeze" \\ And I am sure most of you can remember, \\ He even sang a song on the Queen \\ But when they say the Judges cheat, Sparrow he start making strife \\ Saying that I should have known, that ah can't sing on de man wife \\ But long before Morgan Jobe desecrate women and treat them mean \\ Sparrow called them Jagabats and Whabien \\ So when he talk about disrespect right away I was shocked for so \\ Ah keep doubting meh self saying that's not the Sparrow I know \\ The Sparrow I know did sing "Both ah dem" "the more the merrier" \\ That sparrow years ago drop he pants in de Savannah \\ The Grand and the North Stand did have a lot of women with class \\ But Sparrow say all who boo him could kiss his Grenadian ass \\ So when he mention disrespect the man really had me thinking \\ Is it possible that Satan could correct sin?
}

(Available at Track 3 of CD)

Needless to say the scenario becomes more complicated, for as Aloes sang these words, he drew a tremendous response from the audience who were mainly acknowledging the accuracy of Aloes words. 


\section{Politicians}

In the sensitive area in the limelight of political live, picong dispensed by the Calypsonian is recognised as stinging the recipient. Calypsonians have well recorded that Dr Williams and his successor George Chambers, more often than not, refrained from opportunities to publicly respond to Calypsonians. Aloes commemorates this by singing:

Years ago when Chalkie used to call Williams "deafy", He never stoop so low to answer anybody. When coming to picong he proved he was not afraid And when he get fed-up he'll take off his shearing aid.

(Available at Track 7 of CD)

On the other hand Prime Ministers such as Mr Panday and Mr Robinson seem to have been so beleaguered by the onslaught of the Calypsonians, that more often than not they were driven to make public responses to Calypsos.

In Chapter 6, I looked at Gypsy's: “The Sinking Ship.” With the forthcoming general election, this Calypso referring to the failures during the Peoples National Movement's (PNM) term in office, generated considerable response, becoming a focus for political rhetoric. Leading into the election, the National Alliance for Reconstruction (NAR), being the main opposition party, began advertising its meetings with the statement: "The Ship is Sinking." On the other hand, "The Ship is not Sinking” was boldly flaunted by the PNM as its campaign retort. For its part an article appeared in the Trinidad Guardian, reporting that the Prime Minister, Mr George Chambers responded to the request in the Calypso: Captain you tell we what to do". The Guardian report stated that the PM said "When I'm ready I will tell him [Gypsy] and all Trinidad what to do, (Political Report 1986:1). 
These brief examples are designed to illustrate the quality of "call and response" existing between Calypsonians and politicians.

\section{The Audience}

With few exceptions, the audience of a Calypso Tent is made up of paying members of the public. As has been explained earlier, their participation in the events of the Calypso creates for them a position as co-authors of the process of resolution. For while the Calypsonians may have his idea of how he will present the material, it is the audience who, as it is with the in-formal processes of mediation, decide the credence they give to the Calypsonian. In this way, it is they who have the last say. Hence they can be regarded as the secondary-creators in the event, sharing a crucial part of the message. The audience exercise this ability by either sanctioning or rejecting the message enshrined in "the word." The mechanisms of the audiences response varies considerably and can depend on a number of local factors. These mechanisms include: cheering, dancing, nodding their heads, swaying, applauding, waving objects (sometimes in direct response to a request from the caller-Calypsonian), whistling, and stomping their feet.

“The People's Advice," (available at Track 23 of the CD), as well as "De Facts," (available at track 24) are faithful recordings of the live proceedings of a Calypso Tent, illustrating some of these mechanisms. Since the sole purpose for mentioning these Calypsos in this text is to illustrate Calypsonian/audience interaction and levels of audience participation in the events that take place in the average Calypso Tent, I have not include their lyrics in Appendix 1. 
The picture below testifies to the level of caller/audience interaction. It shows the audience waving their flags in response to a call from the Calypsonian who, in the picture, is standing on the stage to the left of the picture.

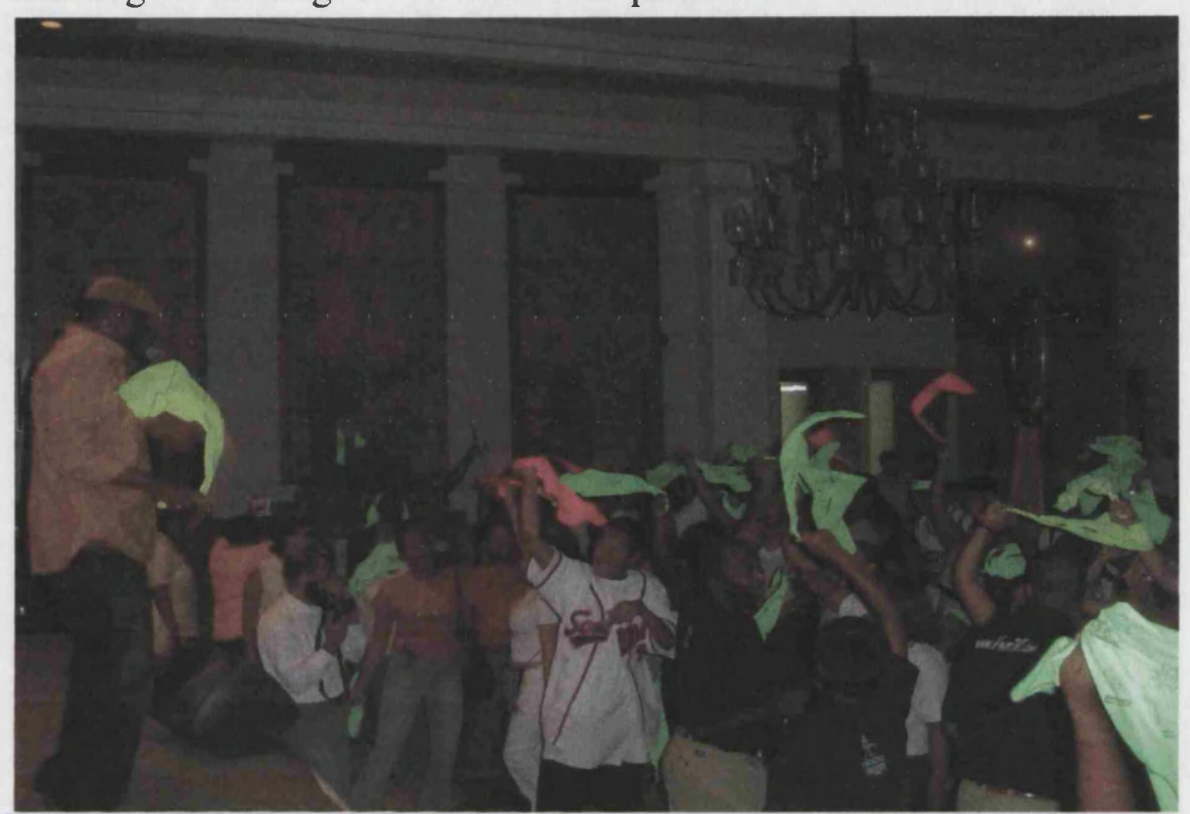

Figure 9.2-Interaction between caller and responders

With respect to the informal chorus, not only are their verbal utterances responses, but also their gesticulations. The window through which the response is orchestrated is the audience's perception of the caller's credibility, and the relevance to them, of the message being delivered, in the context of the current circumstances. In this regard, Thompson (1974) helps us to understand the traditional importance of morality by stating that the audience:

....is therefore, a direct expression of public sanction and opinion. Call and response goes to the very heart of the notion of good government of popular response to the action of the ideal leader Thompson (1974:27)

The caller, although regarded by many as primus interpares, cannot impose a view that is not in concert with the wishes of the Responders, particularly when the Responders 
have begun to question aspects of the moral fibre of the caller. The following section shows this.

\section{The Symbolic Use of Toilet Paper as a Mechanism of Response}

In the previous section, I discussed the matter of high moral standards for the Caller. Also, earlier in this work, I explored the use of metaphor in Calypso. In doing so, I showed how "The Sinking Ship" showcased the use of this form. I propose to show here, how subsequent events to the release and singing of this Calypso had an impact on Gypsy's Calypso career.

In in-formal mediation we recognise the need for the Mediator to remain neutral and impartial and we are aware of the severe consequences to the process of mediation if the mediator flouts these requirements. In this non-formal process of mediation in which the Calypsonians is engaging, and functioning as a liminal servant s/he has the opportunity to function in at least one of two roles. Either $\mathrm{s} / \mathrm{he}$ is presenting the case as the mouthpiece of the people, or is functioning as a presenter of his/her own personal perspective as a Calypsonian talking to the people/audience. This presentation of the views is usually done in such a way that it enables the audience to "open their eyes" and see the adjustments that they should be demanding of their government. In either case, it is generally understood and recognised that the Calypsonians serve the people and is not representative of the government. "The Sinking Ship" was seen to be a critique of the PNM. The assumption from a government that was experiencing such protestation from the people in such turbulent times must have been that "The Sinking Ship" was in support of the governance of the NAR and that Gypsy was a loyal supporter of theirs. 
Accordingly, Gypsy was honoured by Mr Robinson with the award of the Chaconia Medal for the Calypso: "The Sinking Ship".

Prior to this event, the public, regarding Gypsy as having high morals and considered him to be "the people's Calypsonians". His acceptance of the medal was seen as a sellout and he went "from hero to zero" with the people considering that Gypsy no longer represented them. In singing about his acceptance of the medal Sugar Aloes commented:

But if NJAC get into power and Chalkie still alive He'll get an award for singing "The Driver Can't Drive"

Correspondingly, in response to the Call from Gypsy, the audience voiced their discontentment with him and their disapproval of his accepting the medal by refusing to allow him to sing at the semi-finals of the subsequent Calypso Monarch Competition. They did so, in keeping with the traditional ways of communicating their displeasure, these being booing the Calypsonians, also throwing rolls of (unused) toilet paper at him while he tried to sing on the stage. In this way the audience were communicating their view in response, stating to him that in their opinion, as a result of his action of acceptance of the award, he had disassociated himself from them resulting in his Calypso now falling into the bracket of human excretion.

\section{Spiritual entities}

African belief system sustains the belief that in addition to the Great Spirit God, there is the Holy Spirit and other lesser deities, angels, ancestors, the (living) dead, and the (living) unborn (Mbiti, 1989:75). These Spiritual Entities are invoked through the ritual process of the word. It needs to be said here that when the phrase 'ritual processes' is 
used in this text there is no suggestion of any negative aspect or intent. It is used only as an expression of the conditions in which we already live.

Frequently as Trinbagonians in the hustle and bustle of daily living, we move along the fast lane of daily life, and can fail to recognise, let alone honour the very fundamental esoteric function of our daily life. Ritual is seen as one to the ways that allows us as African people, to slow down and develop a communication with our inner selves.

The process of ritual enables us to connect with our ancestral force. This connection with our Ancestral Energy then allows us to begin to do the work at hand. As we call upon our individually named ancestors, we invite in the compilation of that named energy to join us in a process of co-creation, while doing the work at hand, of resolving conflict.

In considering rudimentary ritual process we can commence with most people's process of getting up in the morning, having a shower, dressing, having breakfast, then leaving for work. That process can be considered a ritual. Similarly, on an institutional scale, as a nation we too collectively have many rituals.

During the annual ceremonial opening of Parliament, in the UK, the display of Black Rod, as he bangs on the doors of the House of Parliament requiring that they be opened, can be seen to be a ritual dance of negotiation.

Further afield, those of us who reflect on the inauguration ceremony of President Clinton can recall the clear demonstration of ritual. 
In "The Spirit of a Man" Iyanla Vanzant shares the significance of the ritual process with us in identifying the significance of the place of ritual as demonstrated before the inauguration of Bill Clinton as President of the U.S.A. In doing so she points to the following:

President Clinton retraced the path Thomas Jefferson took from his home to the White House. Along the way he walked across the Potomac River, the sweet water, an energy of purification. He stopped at the gravesides of several other Presidents, where he lit a candle and knelt down to pray. This exercise was not solely a political or patriotic gesture. It was a spiritual ritual. He was calling on the forces of nature (fire, water, and the transmission of the spoken word) and the energy, the memory of those men who paved the way for him, his communal ancestors. When the president-elect did it, it was considered "nice." appropriately patriotic. When black people light candles and call the names of their ancestors, it is called evil or voodoo worship,

(Vanzant 1996: 65).

It is interesting to compare Bill Clinton's actions in the light of considerations of ritual displays.

The whole of Carnival is charged with its own energy. The energy associated with Calypso is only but one aspect of the whole spectrum that is evidently available and consciously felt. In her article entitled "Carnival: Identity, Ethnicity and Spirituality", Pearl Springer eloquently describes aspects of the phenomenal energy that is available through carnival.

The ritual in the Calypso Tent begins with all standing as the band plays the National Anthem. The emcee then introduces himself and the context of the evening. S/he entertains the audience and then presents the Calypsonians with the most experienced 
one usually being left to come on stage last. The emcee speaks at the beginning and the end of each presentation.

In following such a specific pattern, the emcee is invoking the energies of the process of resolution. In formalised conflict resolution situations such as court proceedings there is a specific pattern and order of the 'performance'.

Similarly in the field of ADR mediators have a specific pattern that they also adhere to during the whole process of seeking to attain a solution. All of these processes are, knowingly on unknowingly, a way of engaging in a process of 'tuning-in' with and creating a specific energy. In the case of the Calypso Tent, it is the energy of harmony and resolution.

\section{The Word - The Message as Expressed in the Calypso}

I have used the term: "the Call" and "the Word" interchangeably in this work to communicate the idea of the message as expressed in the Calypso. Traditionally this 'Word' can take many forms. These can range from the prayer, the invocation, the mantra, the chant, the decree, the fiat, the affirmation or latterly, the call.

Resolution or the creation of peace has an abstract aspect to it. It is to this abstract aspect that I have frequently referred as Spiritual. It is with this definition in mind that we need to look at conventional Spiritual philosophies to determine parallel paths. When viewed with this awareness in mind we find that the call is not unique to African Cosmology, Christianity abounds with the concept of "the Call". For instance, in the book of Genesis we hear "And the Lord God called unto Adam and said unto him, 
Where art though?" (Genesis 3: verse 9). Again in Matthew we read: "Out of Egypt have I called my son!" (Matt. 2:15). Again, in other parts of the Bible we recognise the call "Lazarus, come forth!" Even in the Psalms we read: "He shall call upon me and I will answer him" (Pss 91:15) and again in Psalm 99:6, "They called upon the Lord, and he answered them".

Earlier in this work, I discussed the concept of "Language as Symbolic Action". For Africans, the Call is the embodiment of "Symbols". In reality, the Call is the word that is fully charged with anticipation and expectation, which when sent forth, brings into existence the phenomenal potential of binding and unifying a people in an aura of peace, harmony, well-being and power.

The enormous potency of the Call is the result of its mental conception, emotional charge, spiritual guidance, physical utterance with a subsequent manifestation on this plane of existence.

There has been a great schism in the field of Calypso singing with many off-shoots and permutations of the art form all competing for prominence. However, I see Calypsos that offer commentary on social and political issues as ascribing to what Asante (1984:64) refers to as the social, political and religious moments in the history of our society. The potency of the word to create the environment for harmony, peace and reconciliation rests on an understanding of its composite parts, these being the vibration and the energy set up by the caller, as already described earlier, in this work. The caller who has maintained the respect of the people, is very powerful, and regarded as being very significant by the government in power. 
Calypsonians are generally considered as being able to address the wrongs, the injustices that are created by those who are considered "spiritually" lost, or materially misguided. In this cultural paradigm, the ability to re-create peace, unity and order from chaos and confusion is one of the greatest powers that anyone can have in this physical domain. Hence, there is a special regard within the community for the Caller. This power of the Calypsonians comes to fruition through the Call.

\section{CONCLUSION}

In the final analysis, through his/her ability to use non official facilitation (NOF), the caller-Calypsonian is regarded as the human channel who draws upon the cosmic Energy, in the process of creating a discursive act that enables the change process, through the faculties and power of the "call".

Calypsonians, adhering to the values of traditional African culture, are conscious, if only subliminally, of the creative power of the Call and its overwhelming relationship with vibratory energy. This explains the mystery of the impact of the throbbing vocal chords, accompanied by the pauses, mimicry, padding refrains and auditory variety that makes up the refrains that the Calypsonian-Callers use, as they pierce the conflict, bringing about learning, choice and change for the audience as they grow in the direction of peace. It is of this vibratory energy that Rudder sings in: "Calypso Music"

It is a living vibration

Rooted deep within my Caribbean belly

Lyrics to make a politician cringe

Or turn a woman's body into jelly .......

“Calypso Music" by David Rudder (1987) 


\section{CHAPTER 10 - SUMMARY AND CONCLUSION}

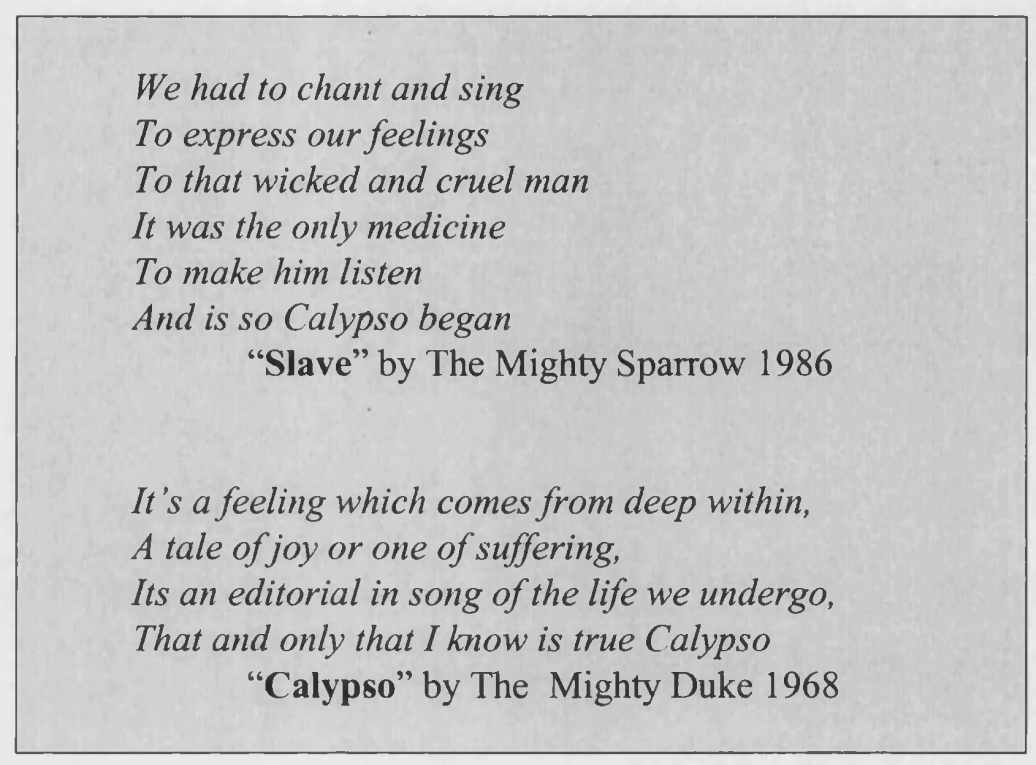

$\mathrm{T}$

This monograph is the result of an ethnographic study of the language of Calypsos

that comment on the socio-political and/or economic issues occurring in the

Republic of Trinidad and Tobago. In setting this type of Calypsos against the background of Kenneth Burke's paradigm of "Language as Symbolic Action",

I approached this work from my position as an "indigenous ethnographer," using written text to express my interpretation of the meaning of my interactions with the

Calypsonians and the other informants I met during my fieldwork.

Underpinning my fieldwork was my endeavour to identify and understand the social and historical context within Trinidad that gave rise to the development of the Calypso.

Being so informed, I engaged in the fieldwork, which consisted largely of a series of interviews with a selection of seven Calypsonians and other informants, combined with research conducted in the National Archives. These strands were supported by a process 


\section{Chapter 10 - Summary and Conclusion}

of participant observation. This combination allowed me to gain a level of intersubjective understanding of the lives of the selection of Calypsonian informants, as well as their approach and attitude to their work.

Through my interviews and interactions with the various informants whom I met during my fieldwork, I came to recognise how, by listening to this category of Calypsos, they engage in a consciousness raising process that got them to think critically about the issues in their lives. In turn, using piquant examples, I have shown in this text how the consciousness raising process supports a non-formal, indigenous conflict management mechanism that is particular to the situation in Trinidad.

In as much as Calypso and carnival are cultural birth twins of the parents of the social and political conflict in Trinidad, it was essential that I honoured the trajectory of the development of these twins, as they crisscrossed the history of the development of Carnival Festival, through the attributes of: Stickfighting, carnival, steelband and Calypso. In going beyond these historical events, I added a further dimension by looking at the use of carnival to portray the contemporary conflict between technological advancement and the cost to our planet of this advancement.

Using Kenneth Burke's paradigm of "Language as Symbolic Action" as a backdrop, I brought into focus the Calypsonians' process of effecting their craft, as they, using “reframing" as a multidimensional tool, manipulate linguistic form to enable their audiences to think critically about the pathologies within Trinidad. 


\section{Chapter 10 - Summary and Conclusion}

Recognising the anthropological relationship between theatre, spectacle and ritual communication, I used a folklorist paradigm, to demonstrate how Calypsonians integrate stage drama with social drama, illustrating their use of image schema to restructure cognition.

In concluding this study, I considered the place that the retained West African tradition of social organisation, rhythm, music and cosmology has in the whole process of resolving conflict. In doing so, I illustrated the role of the audiences, as they engage in the process of co-authorship, in a combined effort to bring about resolution.

In the final analysis, this work examined the social properties and political functions of the defined types of Calypsos and the role of these in resolving conflict. Using a hermeneutic approach to the phenomenology of this cultural art-form, my interpretations afforded me an opportunity to reflect on my initial understanding, re-interpreting the meaning of the lyrics of Calypsos. The implication of this process was that in this work, while Phenomenology permitted me to describe how I orientated myself to the meanings in the lived experience of the "social actors", the application of hermeneutics enabled me to interpret the "texts" of their lives. On the other hand, semiotics allowed me to develop a linguistic approach to the utilised method of phenomenology and hermeneutics.

The conducted research suggests that the type of Calypsos that are the subject of this study, have in the past, and today continue to have, a very profound social impact, raising a corpus of questions that initially get individual Trinidadians to think about 


\section{Chapter 10 - Summary and Conclusion}

their situations. Ultimately, this process of reflection, generates the impetus driving Trinbagonians to effect changes in their lives.

The research shows that, through the medium of the Calypsonian, these Calypsos function as non official facilitators, in an attempt to resolve contradictions or oppositions. I established that the Calypsonians themselves identify with the role of liminal-servant, having both intention and immediacy of purpose. Through the process of the Calypso, while responding to the prevailing pathology, the Calypsonian offers the audience verbal symbols that are incorporated within the context of an artistic rite.

This monograph has as its locus, the dynamic interplay of the diverse fields of ritual communication and conflict resolution, with the history and culture of Trinidad \& Tobago, establishing a symmetrical balance between all of these elements, adding a set of intellectual tools that fuse the ideological paradigms of these diverse academic disciplines, as expressed in Calypso.

This work, addresses the lyrics of the identified subset of Calypsos, offering as they do, commentary on the social-political and economic issues in Trinbago, recognises them as an approach to resolving conflict. It neither addresses the musical structure, nor their musical content. This being the case, there remains a substantial body of work yet to be done, to determine the impact that the musical aspect of these Calypsos offer to the process of creating peace and understanding within the community of Trinidad. Furthermore, considering the importance of the emcee to the Calypso Tent, and the dearth of research on this role, there also remains a substantial amount of work left to be done on the operational effectiveness of the emcee. 
In keeping with the views expressed above, I could think of no, more fitting way to conclude this work, than quoting the very apt words of David Rudder's rendition of

"Calypso Music", encapsulating as it does, the many ideas expressed in this work.

Can you hear the distant drum

Bouncing on the laughter, of a melody?

And as the rhythm tells you come, come

Does your spirit do a dance to this symphony?

Does it tell you that your heart is afire?

And does it tell you that your pain is a liar?

Does it wash away all the unlovely?

And are you ready for a brand new discovery?

Calypso, Calypso, oh Calypso music! Yeah! Yeah!

Singing oh yeah, oh yeah, oh yeah, yeah Calypso

I am the seed of the Growling Tiger

Oh yeah, oh yeah, oh yeah

It is a living vibration

Rooted deep within my Caribbean belly

Lyrics to make a politician cringe

Or turn a woman's body into jelly

It is the sweet soca music, Calypso

You coulda never refuse it, Calypso

It make you shake like a shango now, Calypso

Why it is you shaking, you don't know, Calypso

Calypso, Calypso, oh Calypso music, yeah, yeah

I am the seed, the seed of Atilla

Like a hum, I gotta sing, oh yeah, oh yeah, Calypso

“Calypso Music" by David Rudder (1987) 
Bibliography

\section{BIBLIOGRAPHY}

Abarry, A., (1990), Mapi: African Liberation Oratory, in The African aesthetics: Keeper of the Traditions, Westport, CT: Greenwood

Abrahams, R. D., (1974), Rituals in Culture, Folklore Publications Group, Folklore Students Association, Indiana University

Abrahams, R., (1968), Introductory Remarks to a Rhetorical Theory of Folklore, Journal of American Folklore 81(320) p143-158

Abu-Lughod, L., (1990), The Romance of Resistance: Tracing Transformations of Power Through Bedouin Wómen, American Ethnologist, 17, p14-56

Aho, W. R., (1984), The Treatment of Women in Trinidad's Calypso 1969-1979," Sex Roles, v10, 1-2, pp141-148

Akbar, N., (1975), "Rhythmic Patterns in African Personality." In L. King, V. Dixon and W Nobles (Eds.), Assumptions and Paradigms for Research on Black People. Proceedings from First Annual J. Cannon Research Series Conference, April. p175-189,

Akbar, N., (1984:4), Chains and Images of Psychological Slavery, Mind Production and Associates, USA

Alcazar, A., (1998), "Coming from the Cold," BWIA Caribbean Beat. No.32, July/Aug., p.62-69.

Alexander, G., (1997b), Trinidad Guardian, [Trinidad Guardian on line], November 5, p 3, http://www.nalis.gov.tt/Biography/bio_GeorgeChambers.html, 24 Oct 2002, 13 December 2003

Ali, K., (1989), "Robbie for Monarch," Sunday Punch, Feb. $5^{\text {th }}$, p 3.

Alleyne-Dettmers, P. T., (1995), "Political Dramas in the J'Ouvert Parade in Trinidad Carnival” Caribbean Studies, Vol.28, No.2, July/Dec. p.326-338.

Arnett, R. C. (1986), Communication and Community: Implications of Martin's Buber dialogue, Carbondale, IL: Sóuthern Illinois University Press.

Asante, M. K., (1987), The Afrocentric Idea. Philadelphia: Temple University Press

Augier, F., Gordon S.C., Hall, D.G., Reckord, M., (1960), The Making of the West Indies, London: Longman.

Austin, R. L. (1976), "Understanding Calypso Content: A critique and alternative explanation," Caribbean Quarterly, 22, p 74-83.

Bakhtin, M., (1965) Rabelias and His World, USA: First Midland Books 
Bibliography

Bakhtin, M., (1981:282), The Dialogic Imagination: Four Essays. Edited by M. Holquist. Translated by C. Emerson and M. Holquist, Austin: Texas University Press.

Baptiste, R., (1997), "Vintage Mas: Five Traditional Characters in Trinidad and Tobago Carnival", Caribbean Affairs, Vol. 7, No.6, p.137-15

Barkham, P., (1999, 5 March), "The Banana Wars Explained," [Guardian Unlimited Home], http://www.guardian.co.uk/banana/Story/0,208549,00.html, The Guardian, London, England, Jan 2004

Barrett, W., (1978), The Illusion of Technique, New York: Anchor Press

Bateson, G., (1972) Steps to an Ecology of Mind, New York: Ballantine Books

Bauman, R., (1992), Reflections of the Folk-life Festival: An Ethnography of Participant Experience, Bloomington: Indiana University Press

Benda-Beckmann, F. von, Benda-Beckmann, K. von, Casino, E., Hirtz, F., Woodman, G. R., Zacher, H. F., eds. (1988); Between Kinship and the State: Social Security and the Law in Developing Countries, Dordrecht, Netherlands: Foris

Benjamin, R. D., (1995), The Constructive Uses of Deception: Skills, Strategies and Techniques of the Folkloric Trickster Figure an their Application by Mediators, Mediation Quarterly, 13(1), p 3-17

Bilby, K. M., (1985), The Caribbean as a Musical Region, In S. W. Mintz \& S. Price (Eds.) Caribbean Contours, Baltimore, MD: Johns Hopkins University Press, p181-218

Blake, F. (1995), The Trinidad and Tobago Steel Pan: History and Evolution, Blake: Trinidad and Tobago

Bloch, M., (1974), "Symbols, Song; Dance and Features of Articulation," European Journal of Sociology, No. 15, p55-81

Bloch, M., (1977), "The Past and the Present in the Present," Man. (New Series), Vol. 12 , p. $55-81$

Bloch, M., (1989), Ritual History and Power: Selected Papers in Anthropology, London: Athlone

Bohannan, P., (1957), Justice and Judgement Among the Tiv, Oxford University Press for the International African Institute

Bottomore, T.B., and Rubel, M., (1956), Karl Marx, Selected Writings in Sociology and Social Philosophy, New York

Bourdieu, P., (1977), Outline of a Theory of Practise, Cambridge: Cambridge University Press 
Bibliography

Brereton, B., (1972), A Social History of Trinidad 1870 - 1900, Thesis (Ph.D.), Department of History, The University of the West Indies, St. Augustine, Trinidad and Tobago.

Brereton, B., (1979), Race Relations in Colonial Trinidad 1870-1900, Cambridge: Cambridge University Press

Brereton, B., (1981), A History of Modern Trinidad, 1783-1962, London: Heinemann

Brierly, J. N. (1912), Trinidad: Then and Now 1874-1912, Port of Spain: Franklin's Electric Printery

Brown, W, (1947), Angry Men, Laughing Men, New York: Greenberg

Buber, M. (1994), Genuine Dialogue and the Possibilities of Peace. In R. Anderson, K. Cissna, \& R. Arnett (Eds.) The Reach of Dialogue: Confirmation, Voice, and Community (p 306-312). Cresskill, NJ: Hampton.

Buber, M., (1970), I and Thou. New York: Scribner.

Burke, K. (1957), The Philosophy of Literary Form, New York: Vintage

Burke, K., (1945), A Grammar as Motives, New York, Prentice-Hall

Burke, K., (1966), Language as Symbolic Action: Essays on Life, Literature and Method, Berkeley: University of California Press

Burke, K., (1968), Counterstatement, Berkeley: Univesity of California Press

Burke, K., (1968b:445-452) "Dramatism," in International Encyclopaedia Of The Social Sciences, NewYork

Burke, K., (1969), A Rhetoric of Motives, 1950. reprinted Berkeley: University of California Press

Carib Planet Virtual Citings, (n.d.), Calypso, [CCC Online], URL: http://caribplanet.homestead.com/101 ns4.html, last updated: July 7, 2001, accessed on: 28 Nov. 2002.

Carr A., (1975), Carnival, In David Frost Introduces Trinidad and Tobago, edited by Andrew Carr and Michael Anthony, London: Andre Deutsch

Carter, S., (1986), “Carnival Masquerade in Earl Lovelace's 'The Dragon Can't Dance,"” and Sergio Galindo's "La Comparsa". Ninth Conference of Hispanists, p 82 - 98, The University of the West Indies, Trinidad and Tobago, 7 - 9 April.

Cawelti, J. G., (1969), The Concept Of Formula In The Study Of Popular Culture, Journal of Popular Culture, 3, p381-390

Chanock, M., (1985), Law Custom and Social Order: The Colonial Experience in Malawi and Zambia, Cambridge: Cam. Uni. Press 
Bibliography

Chomsky, N., (1986), Language and Mind, New York: Harcourt, Brace \& World Inc.

Clegg, P., (2000), “The Development of the Windward Islands Banana Export Trade: Commercial Opportunity \& Colonial Necessity," in The Society for Caribbean Studies Annual Conference Papers, Edited by Sandra Courtman, vol. 1, ISSN 1471-2024

Clifford, J., (1986), Writing Culture, Berkeley: University of California Press

Clifford, J., (1988), The Predicament of Culture, Cambridge Massachusetts: Harvard University Press

Cohen, A., (1993), Masquerade Politics, Berkeley/Los Angeles: University of California Press

Collins, P.H., (1990), Black Feminist Thought: Knowledge, Consciousness and Politics Of Empowerment, New York: Allen \& Unwin

Comaroff, J. L., \& Roberts, S., (1981), Rules and Processes: The Cultural Logic of Dispute in an African Context. Chicago: University Chicago Press

Comaroff, J., (1985), Body of Power: Spirit of Resistance: Culture and History of a South African People. Chicago: University Chicago Press

Commission of the European Communities (CEC) (1995) "Report on the Operation of the Banana Regime" [SEC (95) 1565 final; 11/10/95], Brussels, Belgium: Commission of European Communities.

Cowley, J., (1998), Carnival, Canboulay and Calypso, UK: Cambridge University Press

Czubaroff, J., \& Friedman, M. (2000). “A Conversation with Maurice Friedman”. Southern Communication Journal, No. 65, p243-254.

DaMatta, R., (1990), For an Anthropology of the Brazilian Tradition. Work Pap No. 182 of the Latin American Program Of the Woodrow Wilson Center., Washington, DC: The Wilson Center

D'Aquili, E.G., Laughlin, C.D., McMannus, J., (1979), The Spectrum of Ritual: A Biogenetic Structural Analysis, New York: Columbia University Press

Davis, N. Z., (1977), "Society and Culture in Early Modern_France", Renaissance Quarterly, Vol. 30, No. 1. (Spring, 1977), p. 79-81.

Deosaran, R., (1978), “Carnival - The Nations Therapy", Working Papers on Caribbean Society. August, Series C No 3, p 35-40.

Deosaran, R., (1978), "Carnival Mentality is Hatched", Working Papers on Caribbean Society. August, Series C No 3, p 41-45

Deosaran, R., (1978), “Carnival Mocks Modern Society”, Working papers on Caribbean Society. August, Series C No 3, p 46-50 
Bibliography

Dikobe, M., (2003), "Doing She Own Thing: Gender, Performance and Subversion in Trinidad Calypso", PhD Thesis, University of California Berkeley

Dilthey, W., (1976), Dilthey: Selected Writings, edited by: Rickman, H.P., Cambridge: Cambridge University Press:

Dilthey, W., (1987), Introduction to Human Sciences, Toronto: Scholarly Book Services.

Durkheim, E., (1965), The Elemental Forms of Religious Life, New York: Free Press

Elder, J. D., (1968), “The Male Female Conflict in Calypso”, Caribbean Quarterly, 14, p 23-41.

Elder, J. D., (1969), From Congo Drum to Steelband, St Augustine: U.W.I.

Elder, J. D., (1966), “An analysis of the Traditional Calypso of Trinidad and Tobago: A socio-historical Analysis of Song-change". Unpublished doctoral dissertation, University of Pennsylvania.

Espinet, E., and Pitts, H., (1944), Land of the Calypso: The Origin and Development of Trinidad's Folk Song, Port of Spain, Guardian Commercial Printery

Evans-Pritchard, E.E., (1937), Witchcraft Oracles and Magic among the Azande, Oxford: Clarendon

Fairclough, N., (1992), Discourse and Social Change, Cambridge MA: Blackwell.

Farquhar, A., (1950), "Understanding The Plight of Steelbandsmen" Trinidad Guardian $28^{\text {th }}$ January p. 6

Firth, R., 1964, Essays On Social Organisation and Values, London: Athlone Press

Fischer, J, L, (1963), The Socio-psychological Analysis of Folktales. Current Anthropology 4: 235-295

Fisher, J., (2000), Symbols in Mediation, Mediation Qaurterly, 18(1), 87-107

Forde, D., (1954), African Worlds, London: Oxford University Press.

Fraser, L.M., (1881), "History of Carnival," Colonial Office Original Correspondence, Trinidad (C. O. 295), Vol. 289, No 6460, Trinidad Colonial Office

Freire, P. (1993). Pedagogy of the Oppressed. New York: Continuum.

Frisbie, C. J., (1980), South Western Indian Ritual Drama, Prospect Heights, Illinois: Waveland

Gadamer, H. G., (1975), Truth and Method, New York: Seabury 
Bibliography

Gadamer, H. G., (1976), Philosophical Hermeneutics. Translated and edited by D. E. Linge, Berkeley, Ca: University of California Press

Gaster, T., (1950), Thespis: Ritual, Myth and Drama in the Ancient Near East. New York: Schuman

Geertz, C., (1974). "Deep Play: Notes On The Balinese Cockfight,” In C. Geetz: The Interpretation Of Culture, 3-30, New York Basic Books

Geertz, C., (1983), Local Knowledge: Fact and Law in a Comparative Perspective, New York: Basic Books

Gibbs, R., (1999), "Speaking and Thinking with Metonymy," in Metonymy in Language and Thought, Ed. Klaus-Uwe Panther and Günter Radden. Amsterdam: Benjamins p. 61-76

Gill and Gonzáles, (1995), "Economic Consequences of a Banana Collapse in the Caribbean" May, St Lucia: Caribbean Banana Exporters Association

Ginzburg, C., (1980), "The Cheese and the Worms: The Cosmos of the Sixteenth Century Miller," trans. J. and A Tedeschi, London: Routledge and Kegan Paul, xvii

Gladiator History and Times (n.d.), [This Maximus's Colosseum Webring] at URL: $\mathrm{http}: / / \mathrm{www}$. murphsplace.com/gladiator/main.html, updated 12th Sept. 2003, accessed on 2 September 2003

Gluckman, M., (1954), Rituals Of Rebellion In South-East Africa. Manchester: Manchester University Press

Gluckman, M., (1955), The Judicial Process Among the Barcote of Northern Rhodesia, Manchester: Manchester University Press

Godelier, M., (1972), Rationality and Irrationality In Economics, (trans.) B. Pearce. London: NLB

Goffman, E., (1974), Frame Analysìs, New York: Harper \& Row.

Goffman's (1969), The Presentation of Self in Everyday life, Harmondsworth: Penguin

Gordon, R. D. (2000). Karl Jaspers: Existential Philosopher Of Dialogical Communication. Southern Communication Journal, No. 65, p105-117

Granfield, A., \& Giles, H., (1975), “Towards an Analysis of Humour Through Symbolism," International Journal of Symbology, Vol. 6, p 18

Grant, M. A., (1970), The Ancient Rhetorical Theories of the Laughable: The Greek Rhetoricians and Cicero. Madison: University of Wisconsin Studies in Language and Literature (Originally published 1924)

Gregor, T., (1977), Mehinaku: The Drama of Daily Life in a Brazilian Indian Village, Chicago: University Chicago Press 
Bibliography

Gulliver, P.H., (1978), Cross-Examinations: Essays in Memory of Max Gluckman, Leiden: Brill

Hale, K., (1998), “The language of Cooperation: Negotiation Frames,” Mediation Quarterly 16(2), p. 147-162

Hall, M., (1998), The Secrets of Magic, Carmarthen: Crown House Publication

Hanks, P., (1979), Collins Dictionary of the English Language, London: Collins

Harris, M., (1968), The Rise of Anthropological Theory, New York: Crowell

Harrison-Pepper, S., (1990), Drawing a Circle in the Square: Street Performing in New York's Washington Square Park, Jackson: University Mississippi Press

Harvey, G., (1964), “A job for Solomon: I have the power, PM tells Arima Crowd” Trinidad Guardian 21 Sep., p. 13

Healy, C., (1986), “Playing Mas With Minshall”, Americas, May/June, Vol. 38, No.3, p. 43

Herskovits, M. J., and Herskovits, F. S., (1947), Trinidad Village, New York: Knofp

Hill, E. G., (1989), “Calypso and War,” Black American Literature Forum, Vol 23, No 1 pp 61-88

Hill, E. (1997) The Trinidad Carnival: Mandate for a National Theatre, Austin: University of Texas Press

Huizinga, J., (1949), Home Ludens: A Study of the Play-Element in Culture, trans. RFC Hull, London: Routledge and Kegan Paul

Hymes, D. H., (1975), "Breakthrough Into Performance," In: Folklore, Performance and Communication ed. D. Ben-Amos, Goldstein, K., The Hague: Mouton

Indigenous Conflict Management Mechanisms, (n.d.), Community-

Based/Traditional/Indigenous Mediation; Community-Based Conflict

Mitigation; Grassroots Approaches to Peace, [Toolbox], URL:

http://www.caii.com/CAIIStaff/Dashboard_GIROAdminCAIIStaff/Dashboard

CAIIAdminDatabase/resources/ghai/toolbox4.htm, last updated: (n. d.), accessed on: $20^{\text {th }}$ Nov 2004 ,

Jacob, D., (1998), “Carnival Sounds,” BWIA Caribbean Beat. No.31, May/June. p.2022.

Jahn, J., (1979:100), Muntu:The New African Culture. New York: Grove.

Jakobson, R., (1960:350-377), Closing Statement: Linguists and Poetics. In Style in Languageed. T Sebeok, Cambridge Massachusetts: MIT Press 
John, E. (1986) 'Mama Look a Mas' in Masquerading: The Art of the Notting Hill Carnival, Great Britain: The Arts Council, pp7-19.

Johnson, K., (1984), "The Social Impact Of Carnival," In the Seminar Papers: The Social and Economic Impact of the Carnival, St. Augstine, Trinidad, by The Institute of Social and Economic Research, Trinidad: Univ. of the West Indies, p. 171-207

Johnson, M., (1987), The Body in the Mind, Chicago: University of Chicago Press

Juneja R., (1988) “The Trinidad Carnival: Ritual, Performance, Spectacle and Symbol," Journal of Popular Culture, Spring, Vol. 21, pp 87-99

Kapferer, B., (1976), Entertaining Demons: Comedy, Interaction and Meaning in a

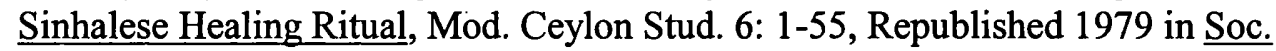
Anal. 1: pp.108-52

Keesing, R., (1974), "Theories of Culture" in Annual Review of Anthropology, eds., Bernard Siegel, Alan Beale, Stephen Tyler, Palo Alto: Annual Review, Inc.

Kisliuk, M., (1988:), “A Special Kind of Courtesy: Action at a Bluegrass Festival Jam Session,” Drama Review 32(3), p. 141-155

Kochman, T., (1983), The Boundary Between Play And Non Play In Black Verbal Duelling, Language in Society No. 12, p. 329-337

Ladurie, E. R., (1979), Camival in Romans, USA: George Blsziller

Lakoff, G. and Johnson, M., (1980), Metaphors We Live By, University of Chicago

Leach, E., (1970), Political Systems of Highland Burma, London: Athlone Press.

Liverpool, H. U. L., (1986), "Resistance and Protest in the Carnival art forms of Trinidad and Tobago, 1783 - 1981", Thesis (M.A.), The University of the West Indies, St. Augustine, Trinidad and Tobago, Department of History.

Liverpool, H. U. L., (1990) Education and Culture, Trinidad: Juba Publications

Liverpool, H. U. L., (1996) Calypsós With Dignity, Lecture given at George Brooker Building at the University of East London, $12^{\text {th }}$ January.

Liverpool, H. U. L., (2001), Rituals of Power and Rebellion, Chicago IL.: Research Associates School Time Publications

Liverpool, H. U. L., (2003), From the Horses Mouth, Juba Publications, Port of Spain Trinidad 2003

Lockledge, A., (1991), "The Geography of Caribbean Holidays", Paper presented at the International Social Studies Conference on the Caribbean, Miami, FL, June 22. 
Bibliography

Lockledge, A., (1992), 'Street Festivals in the Caribbean: Geography Lessons for Elementary Teachers', The Social-Studies; v83, n1, p17-20, Jan-Feb

Lowenthal, D., (1972), West Indian Societies, New York: Institute of Race Relations

Mahabir, G., (1983), A Harbinger of Literary Force: a Critique of Earl Lovelace's "The Dragon Can't Dance (1979), The New Voices, Vol. 11, No.21, Mar.. p.32-41.

Malinowski, B., (1948), (original 1925), Magic Science and Religion, Garden City, NY: Doubleday

Malinowski, B., (1961), (original 1922), Argonauts of the Western Pacific, New York: Dutton

Marcano A., (1999), Sobriquet Lord Superior, Conversation with Lord Superior, March

Maultsby, P., (1990), "Afrcanisms in African-American Music" in Africanisms in American Culture, ed Joseph Holloway, Bloomington: Indiana Univ. Press, $p$ $185-210$.

Maultsby, P., (1995), “A Map of Music,” African American Review, Vol. 29, No 2, Special issues on The Music, Summer, p 183-184.

Mbiti, J. S., (1970), African Religious and Philosophy, New York: Anchor Handbooks

McLewin, P. J., (1987), Power and Economic Change: the Response to Emancipation in Jamaica and British Guiana 1840-1865, New York: N. Y. Press

McNamara, H., (1957), "Will Calypso Oust Rock 'N Roll?” The Toronto Telegram, $25^{\text {th }}$ January, p 9

Meredith, M., (1998), “Calypso Combat,” BWIA Caribbean Beat. No.29, Jan./Feb. p.10-11.

Meredith, M., (1998), "High Mas,” BWIA Caribbean Beat. No.29, Jan./Feb. p. 8-9.

Minshall, P., (1985), “The Use of Traditional Figures in Carnival Art," Paper Presented at the 1st National Conference on The Performing Arts, Port of Spin, Trinidad p. $18,25^{\text {th }}$ June

Minshall, P., (1999), “To Play Mas,” Caribbean Quarterly, Vol. 45, No. 2/3, Jun - Sept. p 30-35

Moore, E., P., (1985), Conflict and Compromise: Justice in an Indian Village, Lanham, MD: Univ. Press America

Nader, L., and Todd, H. F., (1978), The Disputing Process - Law in Ten Societies, New York: Columbia University Press

Naipaul, V. S., (1982), The Middle Passage, Harmondsworth: Penguin 
Bibliography

Nassbaum, M., (1986), The Fragility of Goodness: Luck and Ethics in Greek Tragedy and Philosophy, Cambridge: Cambridge University Press

Nehusi, K. S., (2000), "The Origins of Carnival: Notes from a Preliminary Investigation," In: Ah come Back Home, Edited by: Smart, I. A., and Nehusi, S., K., Trinidad and Tobago: Original World Press.

Nobles, N., (1995), "The Education-of the Black Child," Lecture delivered at The Rites of Passage Conference, Loughborough University, 10 July

N.O.F. (Non-Official Facilitation), (n. d.), Tool Category B: Non-Official Conflict Management Methods, [Toolbox], URL:

http://www.caii.com/CAIIStaff/Dashboard_GIROAdminCAIIStaff/Dashboard CAIIAdminDatabase/resources/ghai/toolbox2.htm, last updated: n. d., accessed on: $20^{\text {th }}$ November 2004

Norton, N., (1990), Noel Norton's 20 years of Trinidad Carnival, Port of Spain, Trinidad: Paria Publishing

Nunley, J., \& Bettelheim, J., (1988), Caribbean Festival Art, St. Louis/Seattle: The St Louis Art Museum/University, Washington Press

Office of the Prime Minister of the Republic of Trinidad and Tobago, (n.d.), Virtual Citing: [opm.gov.tt/index.html], URL:

http://opm.gov.tt/awards/ericwilliams.asp, last Updated: n. d., accessed on: 4 January 2004)

Ortner, S. B., (1987), Sherpas Through Their Rituals, Cambridge: Cambridge University Press

Ostor, A., (1980), The Play Of The Gods Locality, Ideology, Structure And Time In The Festivals Of A Bengali Town, Chicago: University Chicago Press

Ottley, R., (1992), Women In Calypsó, Arima, Trinidad and Tobago: Rudolph Ottley

Ottley, R., (1995), Calypsonians from Then To Now Pt 1, Arima, Trinidad and Tobago: Rudolph Ottley

Ottley, R., (1998) Calypsonians from Then To Now Pt 2, Arima, Trinidad and Tobago: Rudolph Ottley

Parry, J. H. \& Shirlock, P. M., (1956), A Short History of The West Indies, London: Andre Deutsch

Payson, D., (1995), "Electrifying Carnival: Commercialisation and Cultural Ritual." Bulletin of Eastern Caribbean Affairs. Vol. 20, No.2, June. p.12-17, Vermont, USA: St. Michaels's College, Department of Journalism and Mass Communication

Pearce, W. B., \& Littlejohn, S. W., (1997), Moral Conflict: When Social Worlds

Collide, Thousands Oak, CA: Sage. 
Bibliography

Pedler, R. (1995), "The Fruit Companies and the Banana Trade Regime," in R. H. Pedler and M. P. C. M. Van Schendelen (eds) Lobbying the European Union: Companies, p 67-91 Trade Associations and Issues Groups. Aldershot, England: Dartmouth

Pessoa, F., (n.d.), Introductory remarks quoted in DaMatta's, R., (1991): Carnivals, Rogues and Heroes: An Interpretation of the Brazilian Dilemma, Trans. by J. Drury, Notre Dame: Univ. Notre Dame Press.

Philip, S. U., (1985), Strategies of Clarification in Judges' use of Language: From the Written to the Spoken," Discourse Process, Vol. 8, p421-36

Philip, S. U., (1992), Rethinking Context: Language as an Interactive Phenomenon, edited by Duranti A., \& Goodwin, C., Cambridge: Cambridge University Press 1992

Phillips, E. M., (1999), A Traditional Model of Africentric Family Mediation for Use in Urban Communities, Unpublished manuscript, September.

Political Report, (1986), "PM Promises to Deal with 'Sinking Ship”, $\underline{\text { Trinidad }}$ Guardian, $27^{\text {th }}$ Jan, $p 1$.

Powrie, B., (1956), The Changing Attitudes of the Coloured Middle Class Towards Carnival, Caribbean Quarterly Vol. 4 Nos. 3 \& 4, March and June

Quevedo, R., (1983), Atilla's Kaiso: A Short History of Trinidad Calypso, St. Augustine Trinidad: University of the West Indies

Reddock, R., "Contestations Over National Culture in Trinidad and Tobago: Considerations of Ethnicity, Class and Gender." Barrow, Christine. Caribbean Portraits: Essays on Gender Ideologies and Identities. Ian Randle Publishers, Kingston, Jamaica, 1998. p.414- 435.

Regis, L., (1999a), "Williams and the Management of Cultural Change: The Experience of Calypso, the Steelband and the Carnival." Caribbean Issues: A Journal of Caribbean Affairs. St Augustine, Trinidad and Tobago, University of the West Indies Vol. VIII, No. 2, March. p. 31-60

Regis, L., (1999), The Political Calypso, Florida: The University Press Florida

Roberts, S., (1979), Order and Dispute : An Introduction To Legal Anthropology, New York: St. Martin's Press.

Rodriguez, A., (2002), Diversity as Liberation (III): Introducing a New Understanding of Diversity, Cresskill, NJ: Hampton.

Rohlehr, G., (1972), Political Calypsos, St Augustine: Uni. of W. I.

Rohlehr, G., (1985), "The Problem of the Problem of Form: the Idea of an Aesthetic Continuum and Aesthetic Code-switching in West Indian Literature," Caribbean Quarterly, 31/1 March p. 1-52 
Bibliography

Rohlehr, G., (1986), Calypso Censorship: an Historical Overview, Seminar on Calypso. Uni. W.I., St Augustine, Trinidad, 6-10 Jan., Vol. 1 Paper 2

Rohlehr, G., (1990), Calypso and Society in Pre-independence Trinidad, Port of Spain, Trinidad: Gordon Rohlehr.

Rohlher, G., (1972), The Development of Calypso 1900-1940, Unpublished Manuscript Univ. W. I.

Rorty, R. (1979), Philosophy and the Mirror of Nature, Princeton, N. J.: Princeton University Press.

Rorty, R., (1989), Contingency, Irony, and Solidarity. Cambridge: Cambridge University Press.

Schapera ${ }_{2}$ I., (1955), A Handbook of Tswana Law and Custom, London: Cass.

Schegloff, A. E., \& Sacks, H., (1973), “Opening up Closings” Semiotics 8, p 289-327

Schenkein, J., (1978), Studies In The Organisation Of Conventional Interaction. New York: Academic Press.

Schmidt, C. M., (2002), Metaphor And Cognition: A Cross-Cultural Study Of Indigenous And Universal Constructs In Stock Exchange Reports, Language Center at the Åbo Akademi University, Finland

Shotter, J., (2000), "Inside Dialogical Realities: From An Abstract-Systematic To A Participatory-Wholistic Understanding Of Communication." Southern Communication Journal, No. 5, Vol. 65, p.119-132.

Skyllstad, K., (2002), Creating a Culture of Peace The Performing Arts in Interethnic Negotiations, University of Oslo, Norway, Department of Music and Theatre

Snyder, F. G., (1981), “Anthropology, Dispute Processes, and Law: a Critical Introduction. “ Br. J. Law \& Soc. 8:141-80

Sookdeo, A., (1990), "Festivals and Plantations: the 'Misrule' of Carnival and Hosay." Twenty-Second Annual Conference of Caribbean Historians, 1-6 April, The University of the West Indies, St. Augustine, Trinidad and Tobago

Springer, P., (2000), "Carnival: Identity, Ethnicity and Spirituality", in Ah Come Back Home, ed. By Ian Smart and Kimani Nehusi, Port of Spain: Original World Press

Starr, J., \& Collier, J. F., eds. (1989), History and Power in the Study of Law: New Directions in Legal Anthropology. Ithaca, N.Y.: Cornel Univ. Press

Stewart, J., (1930), "The Ceremonial Buffoon of the American Indian," Paper presented at the Michigan Academy of Science, Arts and Letters, Conference papers 14: p. $187-207$ 
Bibliography

Streek, J. (1980), Speech Acts In Interaction: A Critique Of Searle. In Discourse Processes Vol. 3, p. 133-154

Sweetser, E., (1990), From Etymology To Pragmatics, Metaphorical and Cultural Aspects Of Semantic Structure, Cambridge/Mass.: University Press

The Callaloo Company (2004), [the Mas Bands], URL:

http://www.callaloo.co.tt/callaloo/index.html, last updated: n.d., Accessed:April

Taitt, R., (1997), “Least Of The Apostles' George Chambers, 1928 - 1997”, Trinidad Express Newspapers, November 5, p. 2, http://www.nalis.gov.tt/Biography/bio_GeorgeChambers.html, 13 December 2003

Tambiah, S. J., (1985), Culture, Thought And Social Action: Anathropological Perspective, Cambridge, MA: Harvard University Press

Taussig, M. T., (1980), The Devil and Commodity Fetishism in South America, Chapel Hill, N C: University of North Carolina Press

Tempels, P., (1959), Bantu Philosophy, Paris: Presence' Africaine,

The Roaring Lion, (1987), Calypso From France To Trinidad - 800 Years Of History; San Juan: General Printers

Thomas, L.V., (1960), “A Senegalese Philosophical System: The Cosmology of the Jolah People" Presence' Africaine 4-5 (32-33): p 192-203

Thomas, L.V., (1961), "Time myth and History in West Africa". Presence' Africaine 11 (39): p 50-92.

Thompson, R. F., (1974), African Airt In Motion, Los Angeles: University of California Los Angeles Press.

Troester, R. \& Kelley, C., (1991), Peacemaking through Communication, Annandale, Va.: Speech communication Association

Trotman, D. V., (1986), Crime in Trinidad, Conflict and Control in a Plantation Society 1838-1900, Knoxville: Univ. of Tennessee Press,

Turbayne, C. M. (1970), The Myth of Metaphor, Columbia, South Carolina: University of South Carolina Press

Turner, V., (1957), Schism and Continuity in an African Society. Manchester: Manchester University Press, for the Rodes-Livingston Institute

Turner, V., (1969), The Ritual Process: Structure And Anti-Structure, London: Routledge \& Kegan Paul 
Bibliography

Turner, V., (1974), Dramas, Fields and Metaphors, Ithaca, N. Y.: Cornell University Press

Turner, V., (1982), Performing Ethnography, Drama Review 26, p 33-50

Turner, V., (1985), On The Edge Of The Bush: Anthropology Of Experience, ed. E.L.B. Turner, Tucson, Az.: University Arizona Press.

Turner, V., (1986), From Ritual to Theatre and Back, New York: Performing Arts Journal Publ.

Turner, V., (1988), The Anthropology of Performance, New York: Performing Arts Journal Publ.

Turner, V., (1990), “Are There Universals of Performance in Myth, Ritual and Drama?" in Schechner, R., \& Appel, W., eds. By means of Performance. Cambridge: Cambridge University Press,

Vincent-Brown, W., (1964), "Solomon Back Again," Sunday Guardian, Port of Spain, Trinidad, 11 Oct., p. 6

Wallace, H. R., (1983), How to Enter the Silence, Romford: Fowler \& Co. Ltd

Walsh, N. D. (1996), Conversations with God, New York: Purnam

Warner, K., (1982), The Trinidad Calypso - A Study of the Calypso as Oral Literature, London: Heinemann

Warner, K., (1994), "Taking a Six for Nine: Sexual Imagery In the Trinidad Calypso" in Erotic Noire, ed. By Decosta-willis, M., Martin, R., Bell, R.P., Great Britain: Corgi

Watkins, C., (1990), "Indo-European Origins of the Celtic Verb", Vol. I, in Sweetser, E. From Etymology to Pragmatics, Metaphorical and Cultural Aspects Of Semantic Structure, Great Britain, University Press Cambridge.

Weidkuhn, P., (1976), “Carnival in Basle: Playing History in Reverse," in Cultures, Vol. III, No 2, March, Paris: UNESCO Publication,

Wikan, U., (1990), Managing Turbulent Hearts: A North Balinese Formula for Living, Chicago: University of Chicago Press

Wilde, S., (1996) Infinite Self: 33 Steps to Reclaiming Your Inner Power, Pub: Hay House

Williams, E., (1962), History of the People of Trinidad and Tobago, Port Of Spain: People's National Movement Publishing Company.

Williams, E., (1970), From Columbus to Castro: The History of the Caribbean 1492 1969, London: Andre Deutsch 
Bibliography

Wiredu, K., (1980), Philosophy and An African Culture. New York: Cambridge University Press

Wood, D., (1968), Trinidad in Transition: the Years After Slavery, London: Oxford University Press

Worsley, P., (1968), The Trumpet Shall Sound: a Study of "Cargo Cults in Melanesia, New York: Schocken Books.

Wuest, R., (1990), “The Robber in the Trinidad Carnival," Caribbean Quarterly. Vol. 36, No. 3/4 Dec. p.42-53.

Zoub, B (1998), "Child Custody Litigation", Ch 5 in Mediation in Custody Dispute, Illinois: Institute for Continuing Legal Education 
Appendices Supporting the Thesis: Recognising the Language of Calypso as "Symbolic Action" in Resolving Conflict in the Republic of Trinidad and Tobago

\section{APPENDICES}

The following pages contain the Appendices mentioned in the text of this manuscript 


\section{APPENDIX 1 - LyRics Of The CALyPSOS Used IN The TeXT}

The following pages list the lyrics of the main Calypsos that are referred to in the text of this Thesis. Every Calypso that I have ever listened to has made a significant contribution to each aspect of this work. However, to cite them all would be an insummountable task. As such, I need to record that those Calypsos mentioned herein are but samples from a cohort of the abundantly available Calypsos.

Title of Calypso: Rum and Coke

Performer's name: Roy Lewis

Sobriquet: Trinidad Rio

Original by: Lord Invader

CD Track 1

Well if you ever come to Trinidad

We make you feel so very glad

Calypso singing and make up rhyme

Guarantee you a happy time

Singing rum and coke cola

Going down Point Cumana

Both mother and daughter

Working for the Yankee dollaar

Since the Yankees come to Trinidad

They have them young girls going mad

They say the Yankees treat them nice

Makes Trinidad a paradise

Drinking Rum and coco cola

Going down Point Cumana

Both mother and daughter

Working for the Yankee dollar

From Cahcahrary to Monus Isles

Native girls all dance in smiles

Foreigners doh want to leave

They say every day like Christmas Éve

Drinking Rum and coco cola

Going down Point Cumana

Both mother and daughter

Working for the Yankee dollar

Money in the land and the Yankee dollar bill 
Appendices 1 - Lyrics Of The Calypsos Used In The Text

Money in the land and the Yankee dollar bill

Well meh woman leave to go to prayer

Ah went to church she wasn't there

Ah went down Chagauramas bay

What I saw I wouldn't say

Drinking Rum and coco cola

Going down Point Cumana

Both mother and daughter

Working for the Yankee dollar

Money in the land and the Yankee dollar bill

Money in the land and the Yankee dollar bill

Yuh got women in a quantity

Licquor in variety

Vat 19 and Punchen Rum

Calypso music and steel drum

Singing Rum and Coco Cola

Going down Point Cumana

Both mother and daughter

Working for the Yankee dollar 
Appendices 1 - Lyrics Of The Calypsos Used In The Text

Title of Calypso: Watch Out My Children

Performer's name: Garfield Blackman,

Sobriquet: Ras Shorty I

CD Track 2

\section{Verse 1}

My sons and my daughters to you I plea

Ah say wait, doh get no horrors, but please take heed

Ah know you doh want no sermon

But my admonition

Is to guard you against all the evils of life

That create strife

And destroy life

Walk cautiously, children be alert

Cause it have ah enemy roaming de earth

I know you are young and restless

But you don't have to be careless

You see sober thinking leads on to righteousness

True happiness

Spiritual bliss

That's why I tell you this

Chorus

Watch out my children

Watch out my children, yeh

It have a fella called Lucifer with a bag a white powder

And he doh want to powder yuh face

But to bring shame and disgrace to the human race

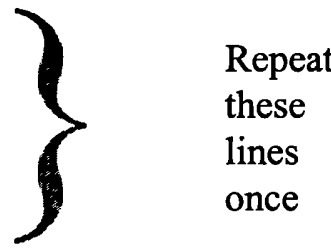

Come on children sing it

Verse 2

I give you my council because I want to see

All you young people live righteously

What you fill your mind with form your characteristics

And shape the path that you must walk tomorrow

Darkness or low, joy or sorrow

That's why I'm concern so

\section{Repeat Chorus}

Verse 3

You are young and your future is ahead of you

Right or wrong, sweet or sour, depends on what you do

Taking the wrong direction, will drain your constitution

And form all mental chaos and confusion, then corruption

To be in your mind

And that is not false pride 
Title of Calypso: This Stage is Mine

Sobriquet: Sugar Aloes

Performer's name: Michael Osuna

CD Track No:3

I don't own a TV station

Ah don't get air play on the radio

The only time the nation does hear me

Is when ah sing on Dimanche Gras Show

All dem Hindus they criticise me

Because ah call a name in meh song

Even Eddison Isaac was against me

So he give Mystic Prowler the crown

But even though they chastise me

They can't take away this voice

It is very plain to see that I am the People's Choice

And I'm going to jam them hard

Anytime they cross the line

Commonsense must tell them

This stage is mine!

So when Carlos John told me that I couldn't appear on the show

Because of my contribution in song ah ready to go

He told me the Savannah will be filled with dignitaries

And they couldn't hire me to embarrass the lady

He said what they want was people who could fill the night with joy

So they hire puppet master to come and sing 'bout he boy

So when the choose Puppet Master before me I didn't get vex

Because I don know meh Prime Minister love sex

Carlos John that big dog then told me

Aloes boy try and understand

I want you to work for your money

But ah can't disobey the man

He pretend to be sympathetic

Apologise, raise and shake meh hand

Then he call Champs in Concert and told them

To take meh off the programme

But I told him straight to face in case alyuh want to know

I doh want to be no part of Panday's Demanche Gras Show

Soon after that Panday made a statement most blatantly

Saying men like me can't spend tax payers money

But Sat Maharaja racial like hell

And we know he hate nigger

Yet its tax payers money does finance the Maha-Sabha

For I to work and earn money from the state they find it unfair 
Appendices 1 - Lyrics Of The Calypsos Used In The Text

But I am a Trinbagonian and I does pay tax here

We roads in a mess and most of the time W.A.S.A. gives us air

But he put roads water and lights for he family in India

Like the want me to apply for political refugee

But it go take more than them to run meh from this country

The truth is always offending, the old people they always say so

They continue doing the wrong thing and don't want the public know

Whenever they address this nation they do it with a sincere tone

But if yuh check them under the surface they all corrupt to the bone

The corruption at NP, up to now they eh do a thing

Yet still all the big contracts still going to Gal Barangsingh

But their time is drawing near we know that without a doubt

The same way they come in we will get them out

Cause while the cost of living sky high and oil rate causing panic

They making big fuss because I call she a "Kitchen Mechanic"

When Hulsie did cross the line and end up Marvins bobolee

Not a Hindu voice was heard none'o dem didn't defend she

The record shows that Hulsie took blows from every Calypsonian

Down to we prime Minister they call she a "Ne Makarham"

And when I sang about Pan's bladder they all laughed till they get a pain

So ah was wondering if all woman not the same

I doh like to attack these women

Ah love to treat all them women kind

The only time they does get meh venom

Is when they jump in the firing line

But meh old granny had a saying

Son always look before you leap

And if they not too dam old to bend down

You're not too young to peep

Once yuh playing with fire

You could bet you bound to get burnt

These are some lessons in life that all young ladies should learn

Not because you do not like the speaker do not be absurd

Because young ladies are seen and not heard

But if she was a lady she would not be seen doing them foolish thing

Like standing up in public with company booing Jimmy Singh

She would ah know drunk or sober she husband is Prime Minister

And once you have elevate leave them ways in the gutter

Checking out she face value she is a really beautiful woman

But don't pray to bounce she up when she playing mass in poison band

All she skin exposed with glass in she hand when she hit that ramp

Which reminds me of a song: "the lady is a tramp"

MC calls: Aloes (call back by MC with audience applause in the back ground)

Sparrow and all criticise me

That old ungrateful Grenadian

$\mathrm{He}$ and prowler is two outsiders 
Appendices 1 - Lyrics Of The Calypsos Used In The Text

So he join with the Vincentian

He forget he sang he sang Jean and Dinah

May May and Mary Bunta Breez

And I am sure most of you can remember

He even sang a song on the Queen

But when they say the Judges cheat, Sparrow he start making strife

Saying that I should have known, That ah can't sing on de man wife

But long before Morgan Jobe desecrate women and treat them mean

Sparrow called them Jagabats and Whabien

So when he talk about disrespect right away I was shocked for so

Ah keep doubting meh self saying that's not the Sparrow I know

The Sparrow I know did sing "Both ah dem" "the more the merrier"

That sparrow years ago drop he pants in de Savannah

The Grand and the North Stand did have a lot of women with class

But Sparrow say all who boo him could kiss his Grenadian ass

So when he mention disrespect the man really had me thinking

Is it possible that Satan could correct sin?

MC calls: Aloes (call back by MC with audience applause in the back ground)

Allot of people saying I racial

They say me Watchman and Cor Cro so dread

But me eh preaching no racialism

Ah just repeating what Sat Maharaja said

When Sat Maharaja uses sarcasm, No one tells him button he lip

But when we Calypsonians attack him, They calling for censorship

The situation with the press right now is a disaster

We don't have a Prime Minister what we have is a gang leader

Cause if you could encourage your members to beat up the press

Then the end result is social unrest

Its either this man illiterate of rum have him stupidee

Maybe he forgetting this is a democratic country

He have to be out he mind to declare war on the media

He's not a Prime Minister he's a damn dictator

He have a next bad-john one beating woman and flashing he gun

The whole of Tunapuna knows that there is a new sheriff in town

Come next election they both might end up in a mental ward

'Cause I know the pen is mightier than the sword 
Appendices 1 - Lyrics Of The Calypsos Used In The Text

Title of Calypso: Voices from the Ghetto

Performer's name: Sandra De Vignes-Millington,

Sobriquet: Singing Sandra

CD Track 4

The sun rises slowly over the hills

Everywhere is golden sunlight but still

Most lives with sad tales are crowded

Their days a dark cloud is shrouded

They don't smile and they never will

Only vultures get their fill

Empty promises is all they hear

No running water from year to year

Hearts that none desire

That if there is a messiah

Some day he will hear their whispered prayer

Cupboard always bare and scanty

Ten people in a one-bedroom shanty

Forced to sell on the pavement

No vagrancy no employment

Crack and fire scatter from gunshot

Blood does flow when things get hot

Afraid to look out meh window

To hear voices from the ghetto

Chorus

Crying, crying, crying, crying

Voices from the ghetto

Mothers does just hold dey head and ball

And dem woman stronger than a wall

Ah pimp push ah ey in she daughter

Son in jail for manslaughter

To bad for the PNM bad boys

No bail, that's the black man's choice

Like Shadow say: "poverty is hell"

She little girl child belly start to swell

Some say life is a cycle

But doh draw she no circle

Where will it all end, only time will tell

Outside the sirens keep howling

Inside your belly real growling

Police raid very often

Simpson measuring a coffin

One night in bed yuh sleeping

Next night is a wake that you keeping 
Appendices 1 - Lyrics Of The Calypsos Used In The Text

So yuh praying to win the lotto

Not to hear voices from the ghetto

\section{Chorus}

Crying, crying, crying, crying

Voices from the ghetto

\section{Spoken words}

Put a hand to us lord

We are not a forgotten people

Hear our prayers

With dented pride they sew their scorn

Revolutions base politicians scorn

And often their tragic story

Brings a journalist glory

No wonder they treat the world with scorn

From since the day they born

Some call them rebels without a cause

These social victims of unjust laws, but

Yet they christen their heroes

Renegades, Desperadoes

Forever knocking on heavens doors

Hear me

Steelband music shatters the silence

Harmony to conquer the violence

Big men run when cops approach

Fighting for scraps with the cockroach

Young turfs their turf protected

Almost every young girl expecting

So tomorrow, beg, steal or borrow

There'll be another voice from the ghetto

Crying, crying, crying, crying

Repeat

Voices from the ghetto

Social amenities, Lord, heaven knows

Opportunities, well dem always close

Can't get work once in white collar

So if yuh can't stretch yuh dollar

Is later for you "crapo smoke yuh pipe"

Yuh sure to dead from gripe

Life does raid dignity and pride

Till there's only bitterness left inside

And everyday is a hustle

Arguments are settled with muscle

Till you're six feet deep by three feet wide 
Appendices 1 - Lyrics Of The Calypsos Used In The Text

Children through life keep on drifting

Is something they smoking or sniffing

Maybe they're trying to forget

This life of misery and regret

No one to come to their rescue

Except Cableton and Buju

So dey boom boxes dey lego

To drum out voices from the ghetto

Crying, crying, crying, crying

Repeat

Voices from the ghetto

I was born and bread in the ghetto

Ah know what ah talking about yuh know

I is from the ghetto 
Appendices 1 - Lyrics Of The Calypsos Used In The Text

Title of Calypso: Rip Off

Performer's name: Dr Slinger Fransisco

Sobriquet: The Mighty Sparrow

\section{Track No 5}

\section{Help! Murder!}

That's the cry of the average man in the land today

The pressure is terrible, All ah we in trouble

And very few in government helping out the people

Yuh shut your eyes when businessmen start brewing

Surplus profits for them foreign misery

Import freedom is less and less

The local produce goods is a total mess

Substandard, price to excess

Who go take the blame, for the amount of shame

Rasakality and skulduggery

I believe we have reached where somebody should be impeached

For breach of promise, disloyal practice

Anywhere you turn is some underhanded business

Where is the lesson in ethics that we should get

Where are the good examples that they should set

We are not the idiots out about

So put them guilty ones out!

The welfare of the people is too much in doubt

Ah can't stand the pain, Ah tired 'holding strain'

Its only tears and a heavy set of prayers

Teachers, preachers, rastas, police and thieves

The man who on food stamp the kitchen assistant

Their salary so scant that they can't buy food and pay rent

Where are the politicians in whom we trust?

Where are the labour leaders who leading us?

Do they ever hear the people cry?

Do they see tears in big man eye?

Asking why, the cost of living so high?

Fire in the place, Customs gone to waste

Because of the abject and sad neglect

Now the general expression from all who love this nation

Is ruination, humiliation

Like if the devil have a hand in running this land

Ah can't forget all the campaign promises

Cheap food, good school the total priority

The cost of living get so rough

To merely exist is touch 
Appendices 1 - Lyrics Of The Calypsos Used In The Text

And half the leaders in the country is a rip off 
Appendices 1 - Lyrics Of The Calypsos Used In The Text

Title of Calypso: People Will Talk

Performer's Name: Roy Lewis

Sobriquet: Mystic Prowler

Original by: King Fisher

CD Track 6

Not only here in the West Indies

Ah find people is hard to please

This is really true

No matter what you do

I aint talking nonsense

This is practical experience

Don't mind how you try

They will criticise and ah don't know why

If you changing steady and looking fancy

they will say how you showing off

an if you keeping yourself like a bad john

They will watch and laugh

But ah forwarding a plan

I aint watching no man

Ah just doing to suit meh self

Because if it is not how you dress

But just the way that you walk

The people will talk!

Take for instance when ah was small, every day was a bacchanal

Well ah always misbehaving with expression and street fighting

Well they talk all over the place how ah so bad and ah out of place

Now ah playing cool and easy

The same people say how ah stupidy

How ah can't even fight

Ah always stepping light with socks and shoes on meh feet

And how ah playing a this and playing a that

And like a girl meh skin smelling sweet

Ah ent watching no man ah just doing to suit me self

Because it is not how yuh dress, it's the way that yuh walk,

The people will talk 
Appendices 1 - Lyrics Of The Calypsos Used In The Text

Title of Calypso: The Judge

Real Name: Michael Anthony Osuna

Sobriquet: Sugar Aloes

CD Track 7

Big big protests in papers, debates on TV

$\mathrm{Ah}$ madman here in this land want to lambaste me

All because Aloes look very simple and small

He find I shouldn't sing about NAR at all

But my ambition is to sing out for the poor man

And this I want all my critics to understand

But this man show me plain he have a grudge

Forsake he job as PM [Prime Minister] and turn Calypso judge

This man say how 'Tamboo' is the best Calyponian

For ' 89 he had the best composition and

For Tamboo he have a special place in his heart

It was a real pleasure to hear the 'Journey Now Start'

Because I say I am PNM he making strife

On television this man said I am corrupt for life

If it's so he and he whole Parliament in the brew

'Cause all of them was members of PNM too.

Years ago when Chalkie used to call Eric 'deafy'

He never stoop so low to answer anybody

When coming to pecong he prove he was not afraid

And if he got fed-up he'd turned off his hearing aid

But this mad man prove to me that he blood near he skin

To let my little simple Calypso upset him

All ah dem dance and sing how Chambers duncee

I'm sure he's happy now and laughing at all ah we.

Because I sing and say he give all the milk away

He find the NCC judges shouldn't bring me up here

On the TV he say I mis-leading the nation

I will never sing about the five hundred million

I must admit we lend the money to Guyana

But at that time we was the Caribbean godfather

But when he give Jamaica the milk we didn't have

Which proves he didn't care if poor people children starve

Dis man got uptight because I sang about de dragon

Told the whole nation it was a PNM plan

Well if its so look how many things needed changing

Why not move Columbus and put back a nice fountain

Move Cypriani and put a statue of Williams

To let the children know that he was such a great man

Move Lord Harris and put Makandal Daaga I say

Its he who have black people working in Banks today

But instead he want to hang meh teacher Chalkie

He say what they gave him wasn't a maxi taxi

And if ah tell you this one you laugh till you flip 
He had a lady minister playing mechanic

She was the one to inspect the vehicle first

Cause on the papers she give Chalkie a brand new verse

Now she too playing judge in case you didn't know

And start talking about censoring we Calypso

When composing is in good faith I write all my songs

But if a thing is wrong I say it damn well wrong

I know that many people here won't agree with me

But scripture declare who have eyes to see let them see

He use he portfolio like molasses to catch flies

And fill up Trinidadians head with a set of lies

The promises that he made were sounding so sweet

But that was to ensure he got in the 'drivers seat'

I know meh pardner Gypsy sang some good Calypsos

He even won the Kaiso King quite in Barbados

But this madman took Gypsy on a St Annes' trip

And give him an award for singing the 'Sinking Ship'

It look like certain Calypsos sure to spoil he plan

So he trying to shut up 'Aloes' and 'Watchman'

But if NJAC get in power and Chalkie still alive

He'll get an award for singing the 'Driver Can't Drive'.

He allowing my Calypso to give him horrors

But he is not studying the other 33 jokers

The other day one pull a hoaxs try to blow we mind

The headline on the papers stated that he resign

He say that TUTOR really make him feel shame as man

And so he decide to tender his resignation

These people really believe that we stupidee

We all know that was one of Williams old strategy

Day of resistance no body eh go to work

The unions say they serious and they eh making joke

On the news ah minister say it was a pleasant day

Everyone turned out for work as usual they say

When $\mathrm{ttt}$ decided to show we what they see

Port of Spain was like a ghost town in the country

But my PM kept the day of resistance also

He went and watch a football game quite in Tobago

The following verses are not included in this $\mathrm{CD}$ but are also sing on public occasions

All the wrong things the past regime do is there to show

But he forgot the PNM did have good also

And he should know that its not important at this time

Cause as we new PM he have he own axe to grind

Forget your neighbour bed and throw water on your own

And show the people of $\mathrm{T} \& \mathrm{~T}$ you are concerned

But he behaving like the greedy dog and the bone

He know he living in a glass house he pelting stone 
Appendices 1 - Lyrics Of The Calypsos Used In The Text

I could point one wrong thing the PNM do And in the eyes of God it was wrong for true Cause if they did put him in jail and pelt 'way the key

He wouldn't be out here now to turn round and pressure we We working hard and we still can't get we kakada To eat not even if it is bread and butter Since this man gain power tut moon baghi shedding tears He do more wrong things than the PNM in three years. 
Appendices 1 - Lyrics Of The Calypsos Used In The Text

Title of Calypso: We Like It So

Performer's name: Dr. Slinger Fransisco

Sobriquet: The Mighty Sparrow

CD Track 8

(NB: The words of this Calypso do not follow the overall convention of this text. The italics are mine. I have used them to distinguish both sides of the polemic, they are the other person's responses to Sparrow's views as expressed in the Calypso.)

It is worth noting that the Steel Beam was the symbol the Organisation for National Reconstruction (ONR) political party and the Balazea the symbol for the People's National Movement (PNM.)

We like it so we free

Neighbour look if I was a selfish man

I wouldn't be involved in this election

I done old already, ah don't want fame

Plus I eh looking for fortune again .

All I asking is that you pay close attention to

The many problems we all face from dawn to dawn

You're intelligent I think and you should face issues

But you behaving like a moron

Cursing me for where ah born.

But your pipe eh have no water

You pay too much for butter

Take your steel beam and go

The terrible school system

Is such a bloody problem

Take your steel beam and go

Agriculture is in a state

Planning is inadequate

Take your steel beam and go

The northern and southern idol

The two king-pins of boball

We know we like it so

We like it so, we free.

Anything that's wrong he go put it right

George Porgy tell we the other night

So instead ah displaying impatience

Cool yourself and give the fella a chance.

How the hell you could say ONR go do better

We go send you back Grenada in a drum

We and George going to put it right together yea

We have freeness and freedom

Plenty roti, plenty rum.

Hospitals have no linen 
Appendices 1 - Lyrics Of The Calypsos Used In The Text

Is brown paper they using

Take your steel beam and go

Public transportation is an abomination

Take your steel beam and go

Well food, clothes and rent is proof

Cost of living gone through the roof

Take your steel beam and go

Classified information for personal gain is common

We know we like it so

We like it so, We free

Sparrow boy you need psychiatry yá

To beat them bourgeois people motorcade

Me eh frade to tell you straight to you face

You backing a jackass in a horse race

George say all you eh getting one damn seat

ONR come out to mamaguy

Bocassa say how all you going to feel the heat

The penalty to oppose is high

That's political suicide.

We can't get house so we squat

Living with cock-roach and rat

Take your steel beam and go

Your cesspit flowing over

You could catch Yellow Fever

Take your steel beam and go

Soldier in bulldozer break down your shack in Movant

take your steel beam and go

It's plenty sexual favours to be a ten days worker

we know we like it so

We like it so, We free

It eh have a single thing you could say

Could make me abandon me balazea

No steel beam could fall down on top me head

Sparrow I is a PNM till ah dead

Birdie you may shock when ah tell you this

Hudson-Phillips is a Yankee CIA

And the whole of ONR is only Communists

They take Carnival away

And make people work each day.

Is years you in a union and can't get recognition

Take your steel beam and go

The unemployment levy murdering every body

Take your steel beam and go

Children come out of College below elementary knowledge 
Appendices 1 - Lyrics Of The Calypsos Used In The Text

Take your steel beam and go

We grieving with frustration through mal-administration.

We know, we like it so,

We like it so we free.

This concern that you showing here for we

Could well cost you your popularity

Francisco how come you doh understand

We eh want no blasted opposition

Just like Georgy porgy I don sharpen my guilt pin

Waiting for the opposition tail

Any time we catch them only back-pedalling

Ah eh even want no bail

Ah eh fraid to make a jail.

Food you could produce here

Is imported from elsewhere

Take your steel beam and go

To fish in you own water is jail in Venezuela

Take your steel beam and go

No one to devise for we a good foreign policy

Take your steel beam and go

Bribery and corruption control every decision

We know we like it so. 
Appendices 1 - Lyrics Of The Calypsos Used In The Text

Title of Calypso: The Banana Death Song

Performer's Name: David Rudder

Sobriquet: David Rudder

CD, Track 10

Well, Uncle Sammy used to visit the Church of Banana

He used to go to church with a girl, named Grenada

And then he went to church with a girl named Jamaica

He used to bow down to one Dominica

Then he used to go and pray to one called St Lucia

He say he loved the way they preached in the Caribbean chapter

But one day Uncle Sammy, he went South America

And he bounced up a girl, she name was Chiquita

Chiquita Dole is she name and she got plenty power

Then West Indian girl get vexed and the whole thing turn sour

The West Indian girl start to cry

West Indian woman start to cry:

Banana dead, banana dead, banana

The future dread, the future dread for banana

Well the church had a European benefactor

So he decide to come to the aid of the chapter

But Uncle Sammy say, NO, I want them to suffer,

They never do me wrong, but I love my Chiquita.

And by the way, don't deal with mama Africa.

My Chiquita's cheap, and you know I'm a miser.

They gonna cry for a while, but it will blow over.

LET THEM EAT CAKE, or plant mama Coca

Them West Indian girls I know are born survivors

Don't worry about the and the "Church of Banana".

West Indian woman start to bawl

West Indian woman start to bawl

Banana dead, banana dead, banana

The future dread, the future dread for banana.

Don't hurt me, don't hurt me so Uncle Sam, don't let me go

Banana dead, banana Dead banana. 
Title of Calypso: Sinking Ship

Performer's Name: Winston Peters,

Sobriquet: Gypsy

CD Track 11

This is an SOS from the Trinidad

Location seven miles off the coast of Venezuela

SOS, SOS, Mayday, Mayday, Mayday

Help!

Help!

This introduction in grey as with all the others greyed sections in this Calypso,

Verse 1

The Trinidad a luxury liner

Sailing the Caribbean Sea

With an old captain named Eric Williams

For years sailed smooth and free

Sadly, Eric Williams passed away

The ship hit rocky water that day

Someone passed the bridge over

To a captain named Chambers

Meh blood crawl

Things start to fall

Hold meh head when a sailor ball

\section{Chorus}

Captain, the ship is sinking

Captain, the seas are rough

We gas tank almost empty

We have no electricity

We oil pressure reading low

Shall we abandon ship?

Or shall we stay on it, and perish slow?

We doh know, we doh know,

Captain you tall we what to do

Verse 2

The Trinidad, oh she was a beauty

With wealth that few surpassed

And in her days she sailed majestically

There were few in her class

Faithfully she fulfilled her sailors' needs

Some were overpowered by greed

And so they pilfered slow

Some took by bulk and go

Now she looks dull

She's at a lull

She could barely sit on her hull

Repeat the Chorus 
Verse 3

The Trinidad in her day of sailing

Was a friend to one and all

She never once ever hesitated

To answer all SOS calls

And yes well she always did her best

To help out those in distress

Now it's so sad to see she's in difficulty

Though she's held dear some of them jeer but sarcastically declare

Repeat the Chorus

If there was only something I could have don't to restore the credibility of this beautiful vessel.

Money is no problem... problem.... Problem

Verse 4

Now there's a lot of fingers pointing

Suspicion running strong

Whose to be blamed for all of her failures

Whose to be blamed for doing her wrong?

Now please remember, I am warning you

For thirty years she had the same crew

Who hold the keys to her vault

So we know who is at fault

Now its up to you its up to me

To make her worthy to go back to sea

Repeat the Chorus with the following adjunct

We don't know, We don't know, Captain you tell we

We don't know, We don't know, you tell we what ....

We don't know, Put up a flag

Oh Gosh! We don't know

To return to the World Bank for help

We don't know, We don't know, We don't know, We don't know

Some body put in an application to the World Bank

Probably we might get some help to do the repairs 
Title of Calypso: Chauffeur Wanted

Performer's Name: Hollis Liverpool

Sobriquet: The Mighty Chalkdust

No 1, Track 12

You asking me what is wrong with Trinidad

You can't understand why things going so bad

You find we so rich in human resources

And yet the country going to pieces

Well let me tell you my friend where we went wrong

After Eric Williams old car break down

We call the NAR, we ordered a next car

And installed a new driver

With 33 passengers from the Party.

We gave him a maxi taxi

Fitted with mag wheels, tape-deck, computer

Air conditioned eight cylinder

With posh new fittings this maxi car arrived

Then it start to swerve and nose-dive

It took a year for passengers to realise

They say ... "The new driver cannot drive"

Well of the 33 chosen passengers

Ramnat, Panday, Humphrey and Sudaman

They wouldn't let the poor driver, drive in peace

They distracting him and wouldn't cease

While he driving they hitting him some big clout

So he stop the maxi and put them out

And to discuss their fate

They went to drink a straight

By a club called 88

The driver call he friend sweet-mouth Fresh Gordon

To give him some driving lessons

Flash appoint himself as the conductor

He pushing round dem passenger

Meanwhile the car running bout helter skelter

Pedestrians started to scatter

Ellis Clarke had to jump and run to stay alive

He say de new driver cannot drive

You questioning me so much 'bout the driver

You want proof to show he can't manoeuvre

Well boy the first month he get dis driving job

You know de man bounce down poor Euric Bobb

He swerving so much John Humphrey get frighten

John ask him where he buy his licence

And while the car swerving

John Humphrey trying to hold on to the steering 
Well some school children by the road run like hell They loose their lunch and books as well He driving on the fast Neil and Massy lane And pelt Mr COLA straight in the drain He slam de brakes on dem old public servants Some get injured no insurance Den he tied them up in bonds that he connived They say .... "The new driver cannot drive"

He lost his way by the IMF station And asking a Yankee for direction And like a vagrant he begging all who pass

To buy back some of his oil and gas

NJAC warned him that his new battery corrode And not to pass on the IMF road

But he eh listening He drop asleep driving And IMF thieves robbed him

Well Lloyd Best sheltering rain under a shop He refused to give Lloyd a drop Preedy and Melody flag down the taxi He pass them straight and pick up Gypsy Some say he going to crash the car before long He can't see 1991

Karl staying far from the driver just to survive Karl know, the new driver cannot drive 
Appendices 1 - Lyrics Of The Calypsos Used In The Text

Title of Calypso: The People's Parliament

Performer's Name: Hollis Liverpool

Sobriquet: The Mighty Chalkdust

Available at CD Track No 14

Anywhere ah walk in town

Ah hearing the same old song

How come you eh go Chalkie?

For elections like Gypsy?

You could be ah minister

You could take charge of culture

You could ah be like Sudaman

Driving million dollar car

Yuh well qualified because you have a big $\mathrm{PhD}$

Why not use your education like Eric and Rowley

Do like the great Attila de Hun in history

Who won his seat elections 1950

Oh yea, yea, yea, yea, yea

Ah tell dem flat

Chalkie not in dat

I'm no doormat

For them Red House rats

Im not siding

With Panday nor manning

I'm not for NJAC

To hell with PNM and UNC

I'm PPP,

The Poor People's Party

Is them I represent

And the Kaiso Tent is meh parliament

I does tell all meh critics

Red House politicians sick

Deceitful to each other

And all of them congosa

But the kaiso Tent my friend

Engages time honoured men

Like the illustrious Kitchener,

Stalin, de super star

Some like the Mighty Shadow does deal in poverty

Pink Panther and Aloes are the true macos of society

Some like the Lion and Cro Cro, sing out fearlessly

Others like Delamo stand for truth and honesty

Car house and look I don't give a hoot

I prefer truth and men of repute

I don't favour: fish, foul or iguana

And for fairness and justice 
Going up for elections can't give me this

I'm for people: black, white, yellow, purple

Race I doh compliment

And the kaiso Tent is my Parliament

If I should do like Gypsy

I would join the family

Of no-loyalty and bacchanal

And turn coats just like Kamahal

For when Gypsy caused the uproar

And walk through UNC door

Town say his actions broke the law

And like Griffith he cross the floor

So I intend to stay in the Kaiso body only

Rather than join a political party

With kaiso the nation becomes my constituency

Ah know Dan Rhaj Singh can't come here and wine on me

So the PPP already chose me

Honourably to serve this country

In my chamber Tommy Joseph is the speaker

And the opposition is all them harbingers of corruption

So don't confuse me with Gypsy or Jimmy

Jack eh pay me a cent

And the Kaiso Tent is meh parliament

\section{Special verse North Stand}

Shading indicates snoken words

Kaiso and the kaiso Tent

Goes back to the days of enslavement

Where under a spreading tamarind tree

Blacks sung against whites fearlessly

Through kaiso they made their laws

Through kaiso they fought their wars

Kaiso and its sweet minor cords

Was the poor blackman's house of Lords

So Kaiso is our big, big insurance policy

Against dictators and the parasitic oligarchy

Kaiso is the atomic bomb in our possession

For all who want to degrade our constitution

Oh yea, yea, yea, yea, yea

So real kaisonians are important men

They bigger than Red House Rats my friend

They sing sociology

And spew out Philosophy

So to join the Red House set

Is to climb down from a king to a jamette

So North Stand and Grand Stand 
Appendices 1 - Lyrics Of The Calypsos Used In The Text

You are an important institution

You more important that government

So all-yuh welcome to Parliament

The greatest of them all:

The great parliamentarians

The nations parliamentarians 
Appendices 1 - Lyrics Of The Calypsos Used In The Text

Title: Why Ah Stay

Sobriquet: Sugar Aloes

Real name: Michael Osuna

CD Track 13

Last year after the competition ah sit down and draft out a plan

Ah say ah going and spend some time in the snow ah finish with Calypso

Ah tell myself this is not for me, no one man could be so damn bad lucky

And with my fans and them telling me ah loose, you get rob,

Ah going in Brooklyn and look for a decent job

But then ah remember Panday still in power

And if a leave here meh fans go suffer,

Vital information the public won't know

Then something open meh eyes and made me realise

Ah was born to sing Calypso

For when ah read the clip on the newspaper

Saying how Carlos John pave the savannah

And Daphne saying that it was unusual,

No one give him the approval

And up to now the whole country confused

'Cause he can't tell we yet, who money he use

Ah tell myself New York ah cah go,

Is why ah stay back to pound them is Calypso.

After considering some job of the sort, ah decide to give it a thought

But what work will I do to make my dreams come through

And keep meh family happy to

First to begin ah have no Green Card

So to find a decent job that will be real hard

Boy ah lay-down on the bed they bussing meh brain

Because ah do want sing no kaiso again

And when ah remember, Watchman gone away

And if ah leave now, what jazzy go say

Then its only Cro Cro remain to take up the task

Boy ah start to write fast, do care if ah come last ah want to eat Danrhaj for breakfast

For when ah hear 'bout the corruption in URP

And Sumah Sing wrote a letter saying they threatening he

Danrhaj admit he saw the letter as man and started investigation

But Danrhaj Sing reminds me of spoiler,

Himself suspect himself guilty of murder

They tell me check Ramish because he might know

Is why ah stay back to blaze him in Calypso

Ah tell meh self ah go try the construction industry

Because that have plenty money

Although I doh have a trade I could still make the grade

Because hard work yuh boy ent 'fraid

I could work hard and save meh money, 
To take care of meh bills and meh family

Meh ent fraid to sing no kaiso what the heck,

Plus things so bad that TUCO giving people bounce check

And when ah remember Rhajnee Ramlakhan,

Say how Calypsonians does only target Indians

She say Indians would be spineless, docile and big fools

If they should all keep their cool

And all government to introduce Calypso in schools

She even say, we national steel band,

Is almost exclusive afro-Trinbagonian

And the claim that pan is the latest invention is still yet to be proven

But like Sat Maharaj, Rhajnee must be loco,

That's why the flags man call she a queen cobeaux

The facts of we culture that woman do know,

Is why ah stay back to tell she in Calypso

Ah sit down inside the house but your boy had two minds,

Ah just feel ah wasting meh time

For even though I stay back and politics I attack,

Me ent sure to win the Monarch

But suddenly it occurred to me,

No one man is greater than this country

And even though meh chances to win may be feeble

Its still meh duty to educate meh own people

For when ah remember, elections so near

And we have some people who don't seems to care

But its your civic duty to come out and vote

Don't behave like a dope and sit down they and hope that PNM go cut they throat

For when ah see Kamahr join the UNC,

I remember something immediately

Panday put he in charge of CARICOM,

They believe Trinbagonians dumb

But it was Shar that same Kamar brother,

Who said it was time for an Indian Prime Minister

Prove how these people racial for so

Is why ah stay back to remind you in Calypso

Aloes is recall by emcee

Well ah make up me mind me ent going no way so its Trinbago I would stay

Ah try to do meh best now and then take a rest, but to live in Brooklyn no way

Me ent shame to admit as man, ah can't do without me Kaiso and pan

And as a citizen of this land ah must declare,

If ah can't make it here ah won't make it anywhere

And when ah remember in the Miss Universe Show

I see Omar make Panday look like a real pappy-show

I see she on the papers, sitting on Hollifield lap that woman is a trap

Why Panday condone that, if it was me she sure get a tap

For when a read about the confusion between Penco Caesar and the young woman 
Appendices 1 - Lyrics Of The Calypsos Used In The Text

Ah tell meh self look how these people lose their life

I was sorry for Penco wife

But when ah see Omar ball and hold she head,

I almost believe it was Panday who dead

You see how this woman lonely for so,

Is why ah stay back to romance she in Calypso.

Aloes recall by emcee

Well ah buy ah ticked and pack some clothes finally ah heading to New York City

Cause to make a living I must leave Port of Spain, ah got to catch the jet plane

But as a reach up in Piarco, ah hear one of meh fans shout out "please don't go"

Well ah get so home sick that ah decide to stay,

Ah call a taxi and head back home right away

And when ah remember some time in last year

13 million in coke, they just so and disappear

The Venezuelian drug lord, ah sure he laughing at we

Because of the police greed, Lewis Gomez was freed, on a technicality

And when ah see that there was no enquiry by the Prime Minister neither the AG

Who ensured us in their manifesto: "To jail all drug lord must go"

But instead they appoint a committee,

To investigate we judiciary

Next election UNC must go,

Is why ah stay back to ensure that in Calypso

\section{Recall by emcee}

\section{By Aloes: Here is the reason why ah does sing this kind a songs}

Calypso is a thing must be edifying not the shit them young boys singing

Lord Pretender told me no matter what it be always try to tell a story

So ah want all them young singers know

Commentary is the roots of true Calypso

Me ent really have nothing against jam and wine

But try your best and give the public a story line

For when ah remember how this government so sad

Yuh got to be conscious to survive in Trinidad

As the bible tells us everything has its season

But like they doing it for spite

They thiefing broad daylight, Without excuse or reason

For when a read right there in Tobago

Ah couple of millions disappear just so

Where it went Hochoy Charles cannot say

While poor people can't get pay

But instead they take 40 million or so

And give Eddy Grant for the Ring Bang show

When they do wrong things the public must know,

And that is why commentary must stay in Calypso 
Appendices 1 - Lyrics Of The Calypsos Used In The Text

Ohy Aloes ohy Aloes all yuh do stop

After considering some job of the sort

Ah decide to give it a thought

But what work will I do to make my dreams come true and keep meh family happy to

First to begin ah have no green card so to find a decent job that will be real hard

Boy ah lay-down on the bed they taxing meh brain,

Cause I doh want to sing no Kaiso ágain

And when ah remember sometime in last year

Thirteen million in coke stay just so and disappear

The Venezuelian drug lord, ah sure he laughing at we

Because of the police greed, Lewis Gomez was freed, on a technicality

And when ah see that there was no enquiry by the Prime Minister neither the AG

Who ensured us in their manifesto: "To jail all drug lord must go"

But instead they appoint a committee, to investigate we judiciary

Next election UNC must go,

Ah want your promise and I'll always sing Calypso 
Title of Calypso: Respect the Calypsonian

Performer's name: Winston Peters

Sobriquet: Gypsy

CD Track 15

You see..... I am an entertainer just like any other entertainer any part of the world. I just need to be treated as such.

I go abroad, I sing aloud, I make my country proud

Exalt your name, with much acclaim

Bring you fortune and fame

But back in my homeland I see

I'm treated with real scant courtesy

And frankly I don't believe that's the way it should be

You should remember me

I who write the songs to make you sit and think

I who write the songs that does tickle you pink

I who sing 'bout love and hate

And fictitious themes create

After all these things I do

I'm not asking much from you

No, all I'm asking in my land

Is more respect for the Calypsonian

Yes man!

I hear you say

I stay away for long and that is true

Its not to say that I don't like to be at home with you

But my songs are not on my radio

My face is not on my TV show

It breaks my heart to see why you treat me so badly

You should remember me,

I who write the songs that champion performers cause

I who write the songs that circumvent the laws

From slavery to emancipation

I've made my contribution

After all these things I do

And I did it all for you

All I am asking in my land

Is more respect for the Calypsonian

Yes man!

Its big parade and motorcade for same who sell my land

And this day I am sad to say the same for the sports man

But do care what the Calypsonian do

No matter how well I represent you

You still make me feel that me and my art-form is crude 
Appendices 1 - Lyrics Of The Calypsos Used In The Text

But may I remind you

I who write the songs to make you sing and dance

I who write the songs to make you jump and prance

From Road March to social commentary

You've always depend on me

After all these things I do

I am not asking much from you

All $I$ am asking in my land

Is more respect for the Calypsonian

Yes man!

No place to sing and do my thing

No I don't have a hall

And I'm afraid promises made are never kept at all

So every back street and ally I roam

I have a culture without a home

Those in authority have little regard for me

May I remind them sincerely

I could write a song to make governments strong

I could write a song to bring governments down

I could do it with real humour

Or venom like a cobra

All these things that I could do

I'm not asking much from you, no!

All I am asking in my land

Is more respect for the Calypsonian

Yes man!

But Calypsonians, in order for anybody to respect you, you first have to respect yourself,

Respect the Calypsonian

This is my humble plee

Respect the Calypsonian

And I am doing it sincerely

Respect the Calypsonian

Ahhhhh..... in my land

Ah want them to understand

Like I said: Calypsonians, respect yourself

Respect the Calypsonian

Calypsonians you must respect yourself

Respect the Calypsonian

Else you would never get respect from anyone else 
Title: Sprangalang's Soliloquy

Performer's name: Dennis Hall

Sobriquet: Sprangalang

CD Track 16

Fellas we get it at last seven years de 'oman who zisttt! Seven years! As dey playing they pipsing and dey out with the kitchen knife and swisssst...... seven years, seven years and ah hear they getting a year ah inch.

Dey cyah play dotish with we. Ah know some ah alyuh wife go get time off for good behaviour, because there is nothing to cut, but ah know it have some woman that will make 15 years if they going a year ah inch, you understand what I am saying?

But they cannot play stupid and just wake up a morning and just swisssst Seven years.... Ah like how they moving.

The thing is ah do like the goal the woman get, because she get hard labour, and the hard labour is to cut wood. They should ah send she to mix cement, she know how to cut wood already.

And the ........ ya know last week I reading in de papers how de 'oman appeal, and say that she cut something and didn't know what she cut. It has never been any place else. Once yuh gone down stairs and you swisssst, is dat ya cut.

And then the next thing she claim was that they was cuffing up one another and it was in self defence...........I never know that to fight back yet! Is a mad 'oman ............ Seven years.......down she pweffen!

We spoke to the Mmount Hope Medical Sciences Complex and they say from 1997 they making boy children with two! So when they get big and these woman Swisssst they have two... huh, huh, huh.

They have to do something is a madness going on, they cannot do we dat!

Now the most surprising thing is where Medical Science reach. For $\$ 19,000$ US plus $V A T$ yuh could get a new one! Dat worry me why they didn't tell me dat all de time, I would ah abuse the old one and trade it in, and start afresh at this age. The problem at 19,000US plus VAT

and plus VAT worrying me eh.... Because yuh know when we had the normal one we used to plus VAT and the ladies didn't use to like when we plus VAT, but now is extra cost and it manual, so in the middle of nothing, dey give we a pump by we waist. So why we operating my dear we hah to pfut, pfut.

What the hell ....... They want to kill we or what? At 19,000 plus VAT I want an automatic with a foot pump. While ah talking to she ah say .... "Darling you go get the hardest hard." What the hell they think it is at all? Let we ent waist no time talking this thing because this could get slack. 
Appendices 1 - Lyrics Of The Calypsos Used In The Text

The woman swisssst! ......... They ent find it yet! And that worrying me because it have no name salami sausage in de grocery.

Anyway look le we ent talk that talk before we get in trouble. 
Appendices 1 - Lyrics Of The Calypsos Used In The Text

Title of Calypso: The Immigrants

Performer's name: David Rudder

Sobriquet: David Rudder

CD Track 17

\section{Verse 1}

So much trouble in the home of the brave

And the land of the NYPD

Am I an immigrant or am I a new slave

Made from old brutality ... I don't think so

Or is it that man has lost his reason

He can't even blame the heat

They're moving like jackals in hunting season

And the refugees soul is the meat

\section{Chorus:}

I'm telling you....

The immigrants are here to stay, to help build America

The immigrants ain't going nowhere they're here for America

Fighting for a better life, fighting through the grunge

America, remember Ellis Island, we call came here to take the plunge

I hope you understand me.

Verse 2

This city is now like a sweet soul Calypso

A compa and a reggae

Like a punta rock and a salsa samba

A highlife, bangra meringue

In other words, this is a different kind of apple now

That is the truth that the haters don't want to face

Its still big, bright and red and juicy, but a little spicy to the taste

\section{Chorus}

The immigrants are here to stay, to help build America

The immigrants ain't going nowhere they're here for America

They know that if they truly want to make it in this apple

They got to turn hate to light

So America don't brutalise your new children now

Just like you they came, to take a bite

\section{Verse 3}

The immigrants are here to stay to help build America

The immigrants ain't going no where they here for America

Fighting for a better life, fighting through the grunge

America, remember Ellis Island now,

We all came here to take the plunge

\section{Chorus}

We hold all these truths to be self evident

That all men are created equal 
Appendices 1 - Lyrics Of The Calypsos Used In The Text

Bring your sick, bring your needy,

bring all your troubled people to our shores

Remember the Founding Fathers

Home of the brave, land of the free

You and me, even the NYPDDE 
Appendices 1 - Lyrics Of The Calypsos Used In The Text

Title of Calypso: Prophet of Doom

Performer's name: Dr. Slinger Fransisco

Sobriquet: The Mighty Sparrow

CD Track 18

If you happen to see and know when politics going wrong

With facts and figures prepared to show

It's better you bite your tongue

To them political boss

Who the people trust and get double-cross

You're an obstacle to be removed at any cost.

$\mathrm{Oh} \mathrm{Oh}$, a social conscience is really very dangerous to your health

The awesome strength of the powers that be

Most certainly will be felt

To tell them that their priorities and performance is under par

It's poetic to hear them describe to you who you are.

First of all you're a megalomaniac

A power seeker

A crazy rocker

Troublemaker

And if you tell them that the economy is no longer in full bloom

Then you become a prophet of doom and gloom.

People complaining every day the cost of living too high

Still they take all the subsidies away

\{refers to COLA- see Glossary\}

So man could suffer and die

The situation is much too rough

For anyone to ignore

And ah know that the people can't take it anymore.

But to show you really and truly care

Is often misunderstood

To express an abiding love for here

Seldom does any good

The system is far from perfect

And most certainly must be improved

But to tell them that is a very dangerous move.

Because, you become

Wicked and infamous

Counter revolutionary

Disciple of Judas

Enemy of the country

You're branded as an impostor

Masquerading in borrowed plume

Well everybody know you're a prophet of doom and gloom.

The fêting is over, back to work 


\section{Appendices 1 - Lyrics Of The Calypsos Used In The Text}

That's what the leader says

But we hearing heckling and plenty jokes

Music blasting upstairs

Every day its power outrage

Unhappy workers on the rampage

And all the food-stuff you have spoiling in your fridge

Tell me, when will we have dependable services from T \& TEC

And will TELCO and WASA be able to fix the roads that they wreck

Don't try to rock the ship of state with them stupid questions so

Accept the status quo and don't play hero.

You're a nation of complainers

Not any tolerance do I see

Just to set up any unrest

Unjustly criticising

BWIA, ISCOT are the envy

Tobago is in great shape we must presume

If you say it isn't so then you're a prophet of doom and gloom.

Questionable deals made in haste

Continue to grow and grow

Blatant refusals have replaced the people's right to know

Predictions are made daily,

To rule for a next century

And all indications are that it may well be.

But, retrenchment and redundancy

Beginning to strangle we

Inflation and low productivity

Done take over already

The 'Integrity Commission' plan

Is a next project also ran

Every move they make now is to insure re-election.

In this land of steady power failures

People houses in darkness

On every chair round the savannah

Discuss vicarious politics

You have to ask yourself which is worst between

A schizophrenic baboon

A megalomaniac and

A prophet of doom and gloom. 
Title of Calypso: Capitalism Gone Mad

Performer's name: Dr. Slinger Fransisco

Sobriquet: The Mighty Sparrow .

CD Track 19

You got to be a millionaire,

Or some kind of petit bourgeois

Anytime you living here, in this country

You got to be in skulduggery,

Making yah money illicitly

To live like somebody, in this country

It's outrageous and inane,

Them crazy prices, they have the people paying

And like the merchants gone clean out dey brain

Lord the working man, is simply toiling in vain

\section{Chorus}

Where you ever hear, a television, is twenty thousand,

Only millions when yuh talking land.

Hundreds ah dollars for a stinking pair of sneakers

Half a million for two motor cars,

It hard here in Trinidad, put a hand Lord,

Capitalism gone mad.

De gladness that once we had

Is gone, because capitalism gone mad

Advantage, sufferage ......... They to greedy

To provide for your family, today on your present salary

Is an impossibility, in this country,

With so many bills to pay, there is no conceivable way,

To save for a rainy day, in this country,

Apolish ask me to be priced

Is why every damn thing, so over priced

Businessman making everybody feel

Government give, them a open licence to steal.

\section{Chorus}

If you think ah lie, one nylon panty is 19.90

Twenty dollars for some baby milk,

Ah round neck jersey is two hundred and sixty

Three hundred and change a yard for silk

It hard, Lord ah feeling sad

Oh Lord, capitalism gone mad

They fleecing the public bad

Put a hand Lord! capitalism gone mad.

Is bribery ..... skulduggery .......conspiracy

To buy a pack of cigarettes, 
Appendices 1 - Lyrics Of The Calypsos Used In The Text

does leave you with a hole in your wallet

And money is so hard to get, in this country

Necessities or luxuries, it doesn't matter what the item is

They charge anything they please, in this country

Primary school books prices lude

Its highway robbery the price of food

All hopes and dreams elude the poor man

Yet politicians expecting good work attitude.

\section{Chorus}

How they chupid so, the cheapest coffin, is twenty thousand

Not even dying today easy,

Thousands ah dollars for them thieving undertakers

So you could bribe you way in to the cemetery

It sad and look so macabre,

Lord have mercy, capitalism gone mad!

We protesting we tired,

But still we see, capitalism gone mad.

You got to have heavy contact

Know how to move up in society.

To make any kinda impact, in this country

You got to know how to chip the field

How to scheme and swindle properly

Perfect the art of wheel and deal, in this country.

Because survival in this land, is not so easy for no man

With unemployment and high inflation

Some ah we go dead, before the end of this recession.

\section{Chorus}

Would you believe me

One mango Julie for eleven fifty,

Forty dollars for water melon

Half you salary to buy fish, get milk and poultry

Time you buy greens all ya money done

It hard here in Trinidad, Oh Lord!

Capitalism gone mad,

It's gladness that once we had

Is gone because, Capitalism gone mad.

They wicked, they crooked, is plain to see,

Is conflict ..... of interest.....is big racket 
Appendices 1 - Lyrics Of The Calypsos Used In The Text

Title of Calypso: Education is Essential

Performer's name: Dr. Slinger Fransisco

Sobriquet: The Mighty Sparrow

CD Track 20

Education, education

This is the foundation

Our rising population needs sound education

To be recognised anywhere you go

You gota have your certificate to show

To enjoy any kind a happiness

Knowledge is the key to success

Children go to school and learn well

Otherwise later on in life you go catch real hell

Without an education in your head

Your whole life will be pure misery

You're better off dead

For there is simply no room in this whole wide world

For an uneducated little boy or girl

Don't allow idle companions to lead you astray

To earn tomorrow you got to learn today

For employment yes employment

You must be intelligent

So its essential, very essential to have your credentials

But if you block headed like a mule

Remember no one will employ a fool

You will be the last one to be hired

And the first one to be fired

Children go to school and learn well

Otherwise later on in life you go catch real hell

Without an education in your head

Your whole life will be pure misery

You're better off dead

For there is simply no room in this whole wide world

For an uneducated little boy or girl

Don't follow idle companions or you will get burn

To earn, to earn, you gota learn

Illiteracy is mans greatest enemy

Its your duty, its your duty, stamp it out completely

Ignorance always make people stress

Education saves much distress

So learn, learn, learn as much as you can

This nation future is in your hands

Children go to school and learn well

Otherwise later on in life you go catch real hell 
Appendices 1 - Lyrics Of The Calypsos Used In The Text

Without an education in your head .

Your whole life will be pure misery

You're better off dead

For there is simply no room in this whole wide world

For an uneducated little boy or girl

Don't allow idle companions to lead you astray

To earn tomorrow you got to learn today

It's a treasure, yes a treasure

Beyond any measure

So secure it just secure it

Do ever ignore it

Ah say to fight life's battles come what may

Education will light up your way

Without it you'll never, never, never get through

Success or failure now is really up to you

Children go to school and learn well

Otherwise later on in life you go catch real hell

Without an education in your head

Your whole life will be pure misery

You're better off dead

For there is simply no room in this whole wide world

For an uneducated little boy or girl

Doh allow idle companions to lead you astray

To earn tomorrow you got to learn today

Its imperative,

As long as you live

Its your prerogative

Give all that you can give 
Appendices 1 - Lyrics Of The Calypsos Used In The Text

\section{Title of Calypso: Burn Dem}

Performer's name: Leroy Calliste

\section{Sobriquet: Black Stalin}

\section{Track 21}

Fire burning fire blazing

Fire burning fire blazing

Judgement morning

Ah by the gate and a waiting

Because ah begging the Master

Gimme a work with Peter

If ah see them sinners comming

Wit dem I go be dealing

Because the things that they do me

Ah want to fix them personally

Peter wait, Peter wait

Peter look Cecil Rhodes by the gate.

Burn he burn he

Peter look the Englishman

Who send Cecil Rhodes down to Africa land

Burn he burn he

Peter take Drake,

Take Raleigh

But leave Victoria for me

Burn she, burn she

Peter ah do care what you say

But Mussolini he cah get away

Burn he burn he

Why!?

This is my time for burning

Ah coming and ah coming and a coming

Peter keep the fire blazing

Blazing, blazing, blazing

Repeat these last four lines

Peter you doh know

The pressure that I undergo

From these madman and woman

Ah feel the full weight'o their hand

They moving slow

They never care about the poor

Peter wait these rich people had their days

Well now its time for Stalin to pay

Peter wait as say peter wait

Peter look Ian Smith by the gate

Burn he, burn he 
Appendices 1 - Lyrics Of The Calypsos Used In The Text

Peter, ah doh want you to make fus

Remember I want Christopher Columbus

Burn he, burn he

Peter look the English woman

Who on South Africa refuse to put sanctions

Burn she burn she

Peter ah just doh care what you do

But Regan going in the fire too

Burn he burn he, Why!?

This is my time for burning

Peter keep the fire blazing

Peter doh grudge me, yuh hand done full already

Yuh done deal with the Fuhrer

Go ahead and dig Foster

But that woman Mary

Remember that's my baby

So much confusion that she make

Yuh gota give Black Stalin ah brake

Peter wait, ah say Peter wait

Look Botha reach by the gate

Burn he burn he

Wid Botha ah doh want you to waste time

Remember we still have Morgan behind

Peter look the Englishwoman

Who send foreign troops in Africa land

Burn she, burn she

Peter ah do care what you say

The Klu Klux Klan man caya get away

Burn he burn he

Why!? This is my time for burning,

Peter keep the fire blazing

Peter, stop pushing

It hah plenty more coming

Take them from overseas

But leave my lokie

During meh lifetime

To me they were so unkind

So much corruption they make

Now it is time they must feel meh weight

Peter, Peter doh hold meh back

Look the one who draft the Public Order Act

Burn he Burn he

Peter look catch dat big belly fella

Who buerry meh money down Panama 
Appendices 1 - Lyrics Of The Calypsos Used In The Text

Burn he, burn he

Peter, Peter look the woman

Who bring foreign troops in the Caribbean

Burn she, burn she

Peter ah just doh care what you do

But ball head going in the fire too

Burn he, burn he

Why?!

This is my time for burning

Peter keep the fire blazing 
Title of Calypso: Fire

Performer's name: Weston Rawlings

Sobriquet: Cro Cro

CD Track 22

Stalin right to side with Saint Peter

But he didn't know that Saint Peter had a brother

Saint Peter working for years, under endless strain

So he ent fighting to get much vengeance again

When Peter brother hear Jahbesah on the TV

Say he doh like kaiso and pan

Its just dan dal and natie

He tell Peter call Cro Cro

Ah was feeling bad

Ah want him help me burn some big boys in Trinidad

He say I'm a good boy right here in this land

And he publicly say he doh like Kaiso and Pan

He tell me fire, doh care how he groan

Light the matches and let him burn

And if a woman could be so absure and slack

To say how Indians say theybdoh consider themselves black

He tell me fire, Cro Cro I smell trouble

And ah feel Stalin burn the wrong people

Prepare yourself pardner,

For being so wicked, yuh go burn in hells fire

For being so wicked racial and slack

Stalin permit me to light up the fire back

I'm proud to be a Calypsonian

And my ambition is to sing out for the poor man

So let my enemies know I sing with no care

Linguistically every year Cro Cro will be there

Jaqueline Kennedy, Bishop and Walter Rodney

Chambers died trying to stop corruption in this country

So all them people who getting a pressure with I

For the truth my fans I am not prepared to die

Those who have racisism should hang they head in shame

The Croke does argue and only four people came

He tell me fire, he to racial and bad

Fire for Indrani Rampersad

Saturday night they put the prize money down to the ground

So I could not go to defend my Independence Crown

He tell me fire, they shouldn't do this

Fire for Dennis Ramdeen and Niki Innis

Prepare yourself quickly

He said that this fire go start from inside of the brewery

For taking out ten thousand dollars was rather slack

So Stalin ask me to light up the fire back

Fire, John Public agree 
Appendices 1 - Lyrics Of The Calypsos Used In The Text

Fire, they try to stop me

Fire, they find ah look small

They cayh muzzle the midget at all

Peter say Cro Cro listen to me

Sing about Eric, Robbie, and sing bout how Chambers dunce

Sing bout Audrey big bumcee, sing netie netie

Sing brown skin girl, why yuh do stay home and mind baby

But big protest from the Guardian

Big debate on TV

If yuh just sing curry, curry or sing 'bout Indrani

When Chalkie sing and ask Gran to run the country

Ah never hear no big protest from anybody

Scandalise ministers and degrade de black woman

But doh sing Om shanty or mention the east Indian

Yuh go get fire, that's what they try on me

They ask the NCC to take way meh prize money

Band'o Juju Warriors and Jab Molassi

But doh miss and put on a chapra or a doti

Yuh go get fire, until yuh wobble.

That's why ah sure Stalin burn the wrong people

Prepare yourself pardner

For being so racial yuh go burn in hell fire

For making that racial serious attack

Stalin permit me to light up the fire back

Peter say fire for Stalin also

For singing Burn Dem as a humorous Calypso

And meh partner Gypsy, fire in he skin

He want to know what is the humour in Ship Sinking

$\mathrm{Me}$ and Chalkie was right there in the category

See Judge Prospect put these two people in front both ah we

So very plainly he tell we to tell Anthony

Review the situation as just robbery with $\mathrm{V}$

NAR feel I see this celebration

They know I was to meet the king Calypsonian

He tell me fire, these people real sick

Fire for Ms Diane Neterrick

I sang the most popular Calypso for last year

All the time me ent see nobody like Cro Cro there

He tell me fire, he vex, he bubble

That's why he say Stalin burn the wrong people

Prepare yourself pardner, for being so wicked

Yuh go burn in hells fire

For leaving little Cro Cro out in the dark

Stalin permit me to light up the fire back

Fire, John Public agree

Fire, They try to stop me

Fire, they find ah look small 
Appendices 1 - Lyrics Of The Calypsos Used In The Text

But they cayah muzzle the midget at all Fire, John Public agree

Fire, They try to stop me

They find ah look small,

but they cayah hush up the Cro Cro at all

Fire, John Public agree

Fire, They try to stop me

Fire, Ah short and ah tall

That's why they cyah stop Cro Cro at all 
Appendices 1 - Lyrics Of The Calypsos Used In The Text

Title: Philip My Dear

Sobriquet: The Mighty Sparrow

Real name: Slinger Francisco

\section{Verse 2}

Philip my dear, last night ah thought was you in here

Where did you go?

Working for good old England, missing out all the action?

My dear do you know,

There was a man in meh bedroom,

Trying on your shoe

Trying on the royal costume

Dipping in the royal perfume

Ah telling you true

There was a man in meh bedroom

And just for a rendezvous

And I thought it was you

\section{Chorus}

He big just like you but younger

He thick just like you but stronger

He lingay like you bet harder

He lalay like you but bader

Ah man in meh bedroom

He came on the bed douix douix

And I took him for you

\section{Verse 2}

The palace guards, were playing hopscotch in the yard

Abandon the throne, me with this perfect stranger

The Jewel was in danger and I was alone

With this man in meh bedroom

Loaded with brute

Yes this maladourous urchin

On top of meh bed was perching, like a cockatoo

Ah man in meh bedroom

Sorry dear I miss construed when I took him for you

He big just like you. .etc

\section{Repeat Chorus here}

In Buckingham, No one respond to the alarm

So this plunderer, displayed inside meh boudoir

A tool made for agriculture

I stood there in awe

With a man inside meh bedroom

Seven feet or more

He told me come hither and foil

And all meh good linen he soil

So nasty and mean 
Appendices 1 - Lyrics Of The Calypsos Used In The Text

Singing to me "God go save de Queen"

He big just like you but harder........ etc Repeat Chorus here

\section{Verse 3}

Evidently, I' ve suffered great indignity

From this commoner instead of being free in London

He should be put in a dungeon under the Tower

There was a man in meh bedroom

Enjoying the view

This vicious immoral scoundrel

Son of a common mongrel

Steered me through and through

There was a man in meh bedroom

Your input was overdue and I thought it was you......

He big just like you but harder..........etc Repeat Chorus here ...

In relation to Princess Margaret's marriage Sparrow also sang:

If I wasn't there in England and see with meh eye

And someone else did tell me

Ah would ah say they lie

Although ah was there and see

Ah still think they fooling me

Look, ah cah understand

How a princess could love a camera man 
Appendices 1 - Lyrics Of The Calypsos Used In The Text

Title of Calypso: Still the Best

Performer's Name: Weston Rawlins

Sobriquet: Cro Cro

I say we are still the best

In spite of all the unrest,

But somebody loco or boozed

When I watch CNN news

They say that the whole country burn down

And Port of Spain is no more a town

I want to tell the world they lie

For Trinbago's flag is still flying high

\section{Chorus}

Cause, where else in the world government overthrown

And so much people get kill?

Where else in the world government overthrown

Big football match playing still?

Where else in the world government overthrown

Your main police station-burn down?

Where else in the world so much fire in town and

In St James, man drinking beer and rum?

So if Trinidad eh nice,

Trinidad is great

This country of my birth

Trinidad and Tobago, is the greatest island on earth

\} repeat

\section{Verse 2}

Tell them watch Iraq, Iran

All dem ha dey confusion

But in we peace loving nation

We solve we own situation

Anywhere else its simple, subtle

Government overthrown da is big trouble

Tell CNN, say the truth bout we

And do mistake Trinidad for Haiti

\section{Chorus}

Cause where else in the world government overthrown

And for your life you could still beg?

Where else in the world yuh want to kill a man, and shoot him in he leg?

Where else in the world government overthrown

And man fêting in curfew?

Where else in the world yuh fêting in curfew, yuh drunk and police escorting you?

So if Trinidad eh nice, my Trinidad is great

This country of my birth

Trinidad and Tobago, is the greatest island on earth

\} repeat once 
Appendices 1 - Lyrics Of The Calypsos Used In The Text

Verse 3

I see hope for Trinidad

Budget wasn't all that bad

Wake up people don't feel sad

Sometimes the journey is hard

We had we troubles but face the fact,

We going to work hard and build it back

And prove to the world, equality is till much alive in we little country.

\section{Chorus}

'Cuase where else in the world government overthrown,

And police right through the land?

Where else in the world government overthrown

And is with fan-belt de beating man?

Where else in the world government overthrown

While King and John house empty?

Where else in the world government overthrown

They loot and end up with four TV?

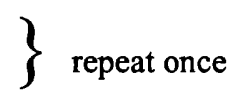

So if Trinidad eh nice, Trinidad is great,

This country of my birth,

Trinidad and Tobago, is the greatest island on earth 
Appendix 2

\section{APPENDIX 2 - A CHRONOLOGY OF KEY EVENTS IN TRINIDAD AND TOBAGO}

This work, featuring the Calypso as it does, and in turn the Calypso being a historical record that reflects the events that take place within the country, it is essential that readers understand and can contextualise the order of occurrence of these events. Aspects of this work rely heavily on the readers' having a knowledge of the major events in the development of the Republic of Trinidad and Tobago. This knowledge could be best facilitated by a time-line of the main events of the country. This time-line enables the reader to be able to place the events in some sort of chronological order, while understanding their significance in relation to each other. This chronology is important as reference is made to these events at various points during the course of the work.

1498 - Christopher Columbus visits the islands, naming Trinidad after the three peaks at its south-eastern tip and Tobago after a local type of tobacco pipe.

1532 - Spain colonises Trinidad, appointing a governor to rule it.

1630s - The Dutch settle on Tobago and plant sugar-cane.

1781 - The French capture Tobago from the Spanish, transforming it into a sugarproducing colony.

\section{British rule}

1797 - A British naval expedition captures Trinidad from Spain.

1802 - Spain cedes Trinidad to Britain under the Treaty of Amiens. 
1814 - France cedes Tobago to Britain.

1834 - Slavery abolished; indentured workers brought in from India to work on sugar plantations.

1889 - Trinidad and Tobago administratively combined as a single British colony.

1945 - Universal suffrage instituted.

1956 - Eric Williams, a moderate nationalist, founds the

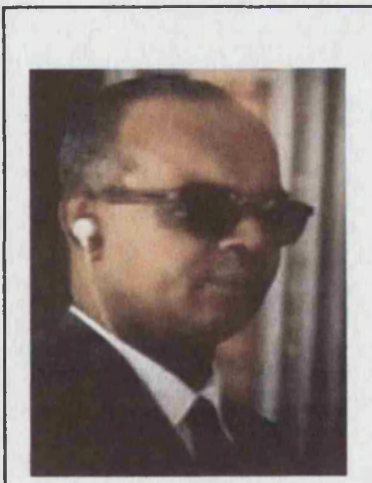

Dr. Eric Williams

People's National Movement (PNM).

1958 - Trinidad and Tobago joins the British-sponsored West Indies Federation.

1959 - Britain gives Trinidad and Tobago internal self-government with Dr Eric Williams as prime minister.

\section{Independence}

1962 - Trinidad and Tobago leaves the West Indies Federation; becomes independent with Williams as prime minister.

1967 - Trinidad and Tobago joins the Organisation of American States.

1968 - Trinidad and Tobago and other English-speaking Caribbean states form the Caribbean Free Trade Area, which was replaced in 1973 by the Caribbean Common Market.

\section{Domestic unrest}

1970 - Government declares a state of emergency after violent protests by "Black Power" supporters who demand a solution to unemployment and an end to foreign influence over the economy. Hundreds of army soldiers mutiny in support, but their rebellion collapses within days.

1972 - State of emergency lifted. 
1975 - Strikes by workers in the oil, sugar, transport and electricity sectors paralyse the economy.

1976 - Trinidad and Tobago becomes a republic with the former governor-general, Ellis Clarke, as president and Eric Williams as prime minister.

1980 - A rash of fire-bombings, arsons and political shootings afflict the country.

1981 - Agriculture Minister George Chambers becomes Prime

Minister following the death of Eric Williams.

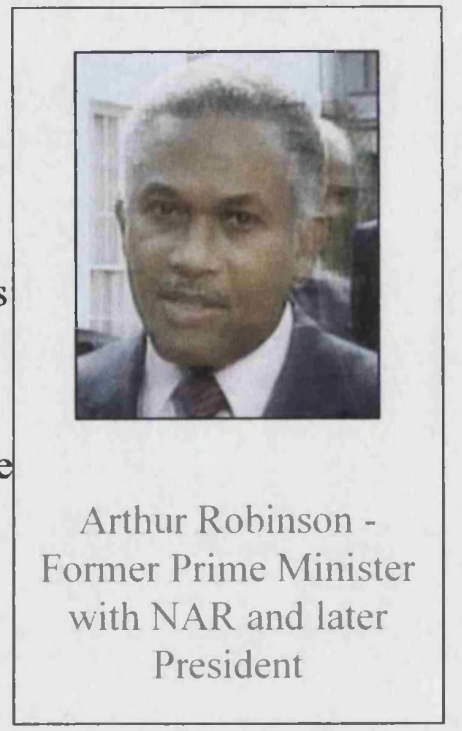

1986 - The Tobago-based National Alliance for

Reconstruction (NAR) headed by Arthur Robinson wins the general election.

1987 - Noor Hassanali becomes president.

1990 - More than 100 Islamist radicals blow up the police headquarters, seize the parliament building and hold Robinson and other officials hostage for several days in an abortive coup attempt.

1991 - Patrick Manning becomes prime minister after his PNM party wins the general election.

1995 - The Indian-based United National Congress (UNC) and NAR form a coalition with Basdeo Panday as prime minister.

1999 - Trinidad and Tobago restores capital punishment.

2000 - Panday wins another term in office after his UNC emerges as the biggest party in the general elections.

2001 December - General election yields an unprecedented tie, with the governing party and main opposition winning 17 seats each. 
2002 April - Prime Minister Patrick Manning requests parliament be suspended because of the continuing deadlock over tied elections.

2002 October - General election - the third in three years - ends months of political deadlock. Prime Minister Patrick Manning's ruling People's National Movement declares victory.

2003 March - President Maxwell Richards is sworn in after being elected by MPs in February.
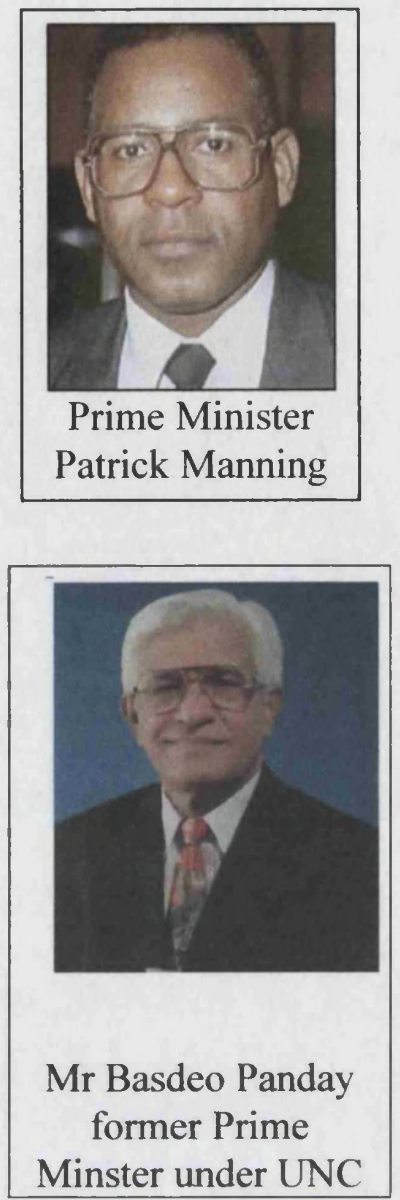
Appendix 3

\section{APPENDIX 3 - SOBRIQUETS AND REAL NAMES OF CALYPSONIANS FROM TRINIDAD AND TOBAGO}

The following list shows the sobriquet follow by the real name of past and present Calypsonians of the Republic of Trinidad \& Tobago.

- Abbi - Abbi Blackman-Thornhill

- Abebe - Neil Baptiste

- Ajala - Keith Sutherland

- Ali - Alyson Ayres

- Allrounder - Anthony Hendrickson

- Almanac - Anthony Francis

- Amuser - Carlton Thompson

- Anasalam - Andre Anasalam

- Andre Tanker - Andre Tanker

- Anslem Douglas - Anslem Douglas

- Artistic - Hugh Lewis

- Atilla the Hun - Raymond Quevedo

- Axeback - Rawle Titus .

- Bally - Errol Ballantyne

- Baron - Timothy Watkins Jr.

- Benji - Benjamin Garlin

- Bertha - Devota Jobe

- Bianca Hall - Bianca Hall-

- Bill Trotman - Paul Emmanuel Trotman (formerly Lord Flying Fish)

- Bindley B - Bindley Benjamin

- Bingo - Errol Rowe

- Bitterbush - Victor Lewis

- Black Pawn - Anthony Blenmant

- Black Prince - Christopher Howell

- Black Sage - Phillip Murray

- Black Stalin - Leroy Calliste

- Blackie - Irvin Blackman

- Blackstone - Allan Thomas

- Blakie - Carlton Joseph

- Blaxx - Dexter Stewart

- Blueboy - Austin Lyons (now Superblue)

- Bokie - Horace Cyrus

- Brigo - Samuel Abraham

- Brother Akil - Akell Ayodele 
- Brother Idi - Rawle Arthur

- Brother J - Selwyn James.

- Brother Marvin - Selwyn Demming

- Brother Mudada - Alan Fortune

- Brother Resistance - Lutalo Masimba

- Brother Superior - Andrew Marcano

- Brother Valentino - Emrold Phillip

- Buddhist - Fitzroy Phillips

- Bumpin - David King

- Bunji Garlin - Ian Alvarez

- Bunny - Bunny Brown

- Burton Toney - Burton Toney

C

- Calypso Height - Solomon Kelly Findley

- Calypso Paul - Paul Noel .

- Calypso Rose - McArthur Lewis

- Candy Hoyte - Candy Hoyte

- CJ - Colin Jackman

- C-Major - Clifford Caesar (Danny King)

- Cardinal - Elon Baggoo

- Chalkdust - Hollis Liverpool

- Charlo - Charles Thorne

- Chickey Chaing - Lennox-Francis

- Chieftain Douglas - Walter Douglas

- Chiller - Cedric Pierre

- Chinese Laundry - Anthony Chow Lin On

- Chris Garcia - Chris Garcia

- Clipper - Joseph Aansalum

- Commander - Alan Daniel

- Commentor - Brian Honore

- Composer - Fred MitchelI

- Contender - Mark John

- Conqueror - Leroy Paul

- Count Robin - Randolph Hilliaire

- Cravat - David Noel

- Crazy - Edwin Ayong

- Creole - Winston Barker

- Cro Cro - Weston Rawlins

- Danny King (C-Major)- Clifford Caesar

- David Rudder - David Rudder

- De Alberto - Winston Albert

- De Lioness - Suzanne John 
- De Original "DeFosto" Himself, Winston Scarborough

- Dee Diamond - Denesian Moses

- Delamo - Franz Lambkin

- Denyse Belfon - Denise Belfon

- Denyse Plummer - Denyse Plummer-Boocock

- Derrick Seales - Derrick Seales

- Designer - Keith Prescott

- Deple - Tyrone Hernandez

- Destra - Destra Garcia

- Devon George - Devon George

- Doctor Kroft - Dr Croft

- Doctor Soca - Dr Kongshíek Achong Low

- Dr PK - Dr Patrick Watson

- Dougla - Claytis Ali

- Drupatee - Drupatee Ramgoonai

- Duke of Iere - G R Plummer

- Duke of Iron - Cecil Anderson

- Duke of Marlborough - George Jamesie Adilla

- Duppi - Patrick Sadlow

- Eagle - Ewart Isaac

- Ebony - Fitzroy Joseph

- Eddie Charles - Eddie Charles

- El Drago - Ainsley Mayers

- Ella Andall - Ella Andall .

- Eric Powder - Eric Powder

- Errol Asche - Errol Asche.

- Ester Dyer - Ester Dyer

- Exotic - Peter Stanisclaus

- Explainer - Winston Henry

- Exposer - Moses Monroe

- Faye-Ann - Faye-Ann Lyons

- Flamingo - Winston Pitts

- Fluke - Cecil Duke Taylor

- Frosty - Andy Brooks

- Funny - Donrick Williamson

- Gailann - Gailann Stephen

- GB - Gregory Ballantyne

- Gabilang - David Bereaux

- Giant - Denzil Parris

- Gibraltar - Sydney Benjamin 
- Grabbler - Ellis Clarke

- Growling Tiger - Neville Marcano

- Gypsy - Winston Peters

- Hamidullah - Hamidullah Waheed

- Happy - Gilbert O'Connor

- Hindu Prince - Kenneth Nathaniel

- Houdini - Wilmoth Hendricks (aka Edgar Leon Sinclair)

- Impulse - Wayne Modeste

\section{I}

- Iron Duke - Brylo Ford

- Iwer George - Neil George

- Jaguar - Alfred Carlton Marryshow

- Jason Lee - Jason Lee

- Jayson - John Perez

- Johnny King - Johnson King

- Johnny Ma Bo - Johnson King

- John L - John L Nichols

- Joker - Winsford Devine

- John Just Come - John Walcott

- Karren Eccles - Karren Eccles

- Kassman - Wayne McDonald

- Kenny J - Kenrick Joseph-

- Kernal Roberts - Kernal Roberts

- King Austin - Austin Lewis

- King Fighter - Shirland Wilson

- King Pharaoh - Andrew Bernard

- King Solomon - Samuel Ryan

- King Radio - Norman Span

- King Soul - Rannie Peters

- King Wellington - Hawthorne Stephen Wellington Quashie

- Kinte - Carey Stephens

- KMC - Ken Marlon Charles

- Kurt Allen - Kurt Allen

- Lady B - Beulah Bobb

- Lady Chaconia - Christiana Balbosa

- Lady Gypsy - Lynette Steele

- Lady Hotspot - Easlyn Orr 
- Lady Iere - Maureen St John

- Lady Paula - Paula Salandy

- Lady Smasher - Genelle Wilson-Moore

- Lady Spencer - Rhoma Spencer

- Lady Tantalizer - Joan St John

- Lady Venus - Marilyn Jimenez

- Lady Wonder - Diane Hendrickson-Jones

- Lennox Picou - Lennox Picou

- Leon Coldero - Leon Coldero

- Lima Calbio - Calbio

- Lord Baker - Alex King

- Lord Beginner - Egbert Moore

- Lord Brynner - Kade Simon

- Lord Caresser - Rufus Callender

- Lord Corbeau - Nap Hepburn

- Lord Cristo - Christopher Laidlow

- Lord Executor, Philip Garcia

- Lord Flying Fish - Paul Emmanuel Trotman (now Bill Trotman)

- Lord Invader - Rupert Grant

- Lord Inveigler - MacDonald Borel

- Lord Inventor - Lloyd Merchant

- Lord Ivanhoe - Clinton George

- Lord Kitchener - Aldwyn Roberts (aka De Grandmaster)

- Lord Melody - Fitzroy Alexander

- Lord Mentor - Mentor Trimm

- Lord Nelson - Robert Nelson

- Lord Orlando - Thomas Ollivierre

- Lord Pretender - Aldric Farrell

- Lord Protector - Oliver Cromwell

- Lord Shorty - Garfield Blackman (once Ras Shorty I)

- Lord Smiley - Gaston Nunes

- Lord Surpriser, Calvin Romero

- Lord Wonder - Victor Atwell

- Luta - Morel Peters (one was Sugar Stick)

- Maestro - Cecil Hume

- Machel Mantano - Machel Mantano

- Manchild - Carlton Collins

- Marcia Miranda - Marcia Miranda

- Marvelous Marva - Marva Joseph

- Marvin Lewis - Marvin Lewis

- Mastertone - Anthony Salloum

- Maximus Dan - Edghill Thomas

- Mba - Gary Thomasos

- Merchant - Dennis Franklyn Williams 
- Messenger - Dennis Cudjoe

- Michael Baker - Michael Baker

- Mighty Bomber - Clifton Ryan

- Mighty Destroyer - Clifford Morris

- Mighty Dictator - Kenny St Bernard

- Mighty Duke - Kelvin Pope

- Mighty Fearless, Mikey Hamit

- Mighty Growler - Errol Duke

- Mighty Indian - Hosein Mohammed

- Mighty Killer - Cephas Alexander

- Mighty Panther- Vernon Roberts

- Mighty Panti - Bernard Pantin

- Mighty Power - Sonny Francois

- Mighty Prowler - Roy Lewis (now Mystic Prowler)

- Migthy Spaker - Alphonso Melville

- Mighty Sparrow - Slinger Francisco

- Mighty Spitfire - Carlton Gumbs

- Mighty Spoiler - Theophilus Phillip

- Mighty Terror - Fitzgerald Henry

- Mighty Trini - Robert Elias

- Mighty Viking - Victor Springer

- Mighty Wrangler - Kenneth Wynne

- Modern Inventor - Henry Forbes

- Mystic Prowler - Roy Lewis (formerly Mighty Prowler)

$\mathrm{N}$

- Nap Hepburn - Nap (Randolph) Hepburn (formerly Lord Corbeau)

- Naya George - Naya George

- Nicole Greaves - Nicole Greaves

- Nigel Lewis - Nigel Lewis

- Nightingale - Bertie Hicks

- Ninja - Kenson Neptune

- Oliver Chapman - Oliver Chapman

- Organiser - Leydon Charles

- Oscar B - Oscar Benjamin

- Pampers - Jazzy Blackman

- Penguin - Seadley Joseph

- Penman - Len Ward (Original Portrait of Trinidad)

- Pink Panther - Eric Taylor

- Plain Clothes - Clinton Moreau

- Playboy 
- Poet - Joseph Cummings

- Poody - Everol Cooper

- Popo - Reginald Blondell Alphonse

- Poser - Sylvester Lockhart

- Potential - 1

- Preacher - Barnett Henry

- Prince - Clifton De Labastide

- Prince Unique - Jeffrey Thomas

- Princess - Teresa De Labastide-Campbell

- Princess Natasha - Natasha Wilson

- Princess Surpriser - Janice Romero

- Pronto - Elvis Escayg

- Prospector - Carl Robinson

- Protector - Michael Leggerton

- Railway Douglas - Walter Douglas

- Rajah - Dhanni-O-Gopal

- Randy Darling - Clarinda Wickham

- Ranking - Richard Sammy

- Ras Iley - Darcy Small

- Ras Kommanda - Stephen Pascal

- Ras Shorty I - Garfield Blackman (formerly Lord Shorty)

- Relator - Willard Harris (Bunny)

- Rendy Darling - Clarinda Wickham

- Rex East - ${ }^{1}$

- Rex West - Richard Chen

- Richard Couer de Leon - Norman Le Blanc

- Rikki Jai - Ricky Samraj Jaimungal

- Ringo - D Pernell

- Roaring Lion - Rafael de Leon (a.k.a Hubert Raphael Charles)

- Roger George - Roger George

- Romance -

- Ronnie McIntosh - Ronnie McIntosh

- Rootsman - Yafei Osei

- Salty - Winston Smith

- Sanell Dempster - Sanell Dempster

- Santa - Dennis Williams

- Scrunter - Irwin Reyes Johnson

- Sean Caruth - Sean Caruth

- Secret Rival - Wayne Brooks

- Serenader - E Brewster 
- Shadow - Winston Bailey

- Shah - Shah Mohammed

- Shakabaka - Andre McEachnie

- Sharlen Boodram - Sharlene Boodram

- Sheldon Nugget - Sheldon Bullen

- Short Pants - Llewellyn McIntosh

- Short Shirt - Emmanuel McClean (now Brother Emmanuel)

- Shurwayne Winchester - Shurwayne Winchester

- Singing B - Bernadette McFarlane

- Singing Francine - Francine Edwards

- Singing Sandra - Sandra De Vignes

- Singing Sonia - Sonia Francis

- Sippy - Chotilal Seecharan

- Skunky - Odian Cyrus

- Sniper - Mervyn Hodge

- Socageneral - Irwin Williams

- Soca Van - Colin Jackman

- Socavan - Hovan Lawrence

- Spongey - Curtis "d Love Sponge" Oliver

- Sprangalang - Dennis Hall

- Squibby - Stanley Cummings

- Stacy Sobers - Stacy Sobers

- Stamone - Victor Cardenas

- Stinger - Dexter Parson

- Striker - Percy Oblington

- Sugar Aloes - Michael Anthony Osouna

- Sugar Stick - Morel Peters (now Luta)

- Super Blue - Austin Lyons (formerly Blue Boy)

- Super Kelly - Kelly Des Vignes

- Super Rod - Wilston Legendre

- Suzanne - Suzanne Wallace-Romero

- Sydney Wellington - Sydney Wellington

- Tallish - Francis Edwards

- Tambu - Christopher Herbert

- Tan Tan - Alyson Brown

- Tempo - Joe Caesar

- The King - David Baptiste

- Tigress - Joanne GA Rowley-Fletcher

- Tobago Crusoe - Orthniel Bacchus

- Tobago Rio - Kenrick Andrews

- Tony Prescott - Tony Prescott

- Trinidad Bill - Paul "Bill" Trotman

- Trinidad Rio - Daniel Brown

- Twiggy - Ann Marie Parks 
Appendix 3 - Sobriquets and Real Names of Calypsonians

- Uprising - Peter Edwards

- Versatile - D Hector

- Viper - Roderick Lewis

- Wanderer - Peter Herbert

- Warrior - Glenroy Preddie

- Watchman - Wayne Hayde

- White Rose - Henry Julien

- Wounded Soldier - Leslie Palmer

- Young Caresser - Rudolph Benoit

- Young Killer - Emmanuel Jardine

- Zandolie - Sylvester Anthony

- Zhivago - Felix Scott

- Zoom - Michael Salloum 


\section{APPENDIX 4 - CALYPSONIANS RESEARCHED BUt NOT INTERVIEWED}

While Chapter 3 is the result of interviews which were held primarily with

Calypsoninan informants, I am of the view that there are other Calypsonians who, although they were not interviewed, have been significant in the field of social and political commentary, and therefore.needed to be represented, in some way in this work. This Appendix therefore honours that recognition.

Let me pre-empt the observations that can be made by those who challenge my choice for this category, questioning the exclusion of a significant Calypsonian like Lord Kitchener. It is beyond question that the Lord Kitchener is a significant Calypsonian who has made an invaluable contribution to the field, having successively won the "Road March" title in numerous and at times successive years.

Many of my informants remarked on the brilliance of Lord Kitchener, and to this I too do attest. However, while I do not wish to enter the Kitchener vs Sparrow debate that has raged regarding the allocation of national awards to these Calypsonians, I need to stand firm in my assertion that while the late Lord Kitchener is unquestionably the "Road March King" his contribution to social and political commentary, is in my view, much more scanty than The Mighty Sparrow's or that of the David Rudder. Hence, I have decided not to include him in this Appendix. 


\section{Dr. Slinger Fransisco - Sobriquet: The Mighty Sparrow}

The Calypsonian who latterly was known as the Mighty Sparrow was born on $9^{\text {th }}$ July 1935 in the town of Gouyave, which is on a smaller island to the north of Trinidad called Grenada. He was the third child of his parents Clarissa and Rupert Francisco who named him Slinger Francisco. At the time of his birth Sparrow's sister Loma was then three years old, and his brother Vivian was 18 months old. Hence at times he is

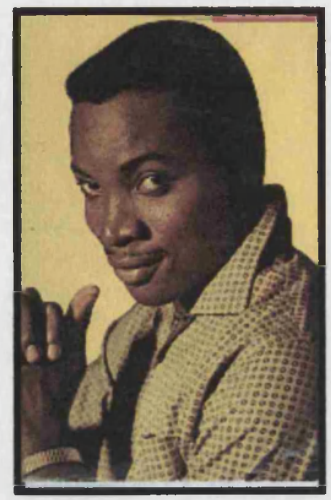
referred to as a "Grenadian" and in particular in the Calypso "this stage is mine, Aloes refers to him as:

Sparrow in his early days

\section{That old ungrateful Grenadian.}

In another part of the same Calypso Aloes asserts that Sparrow stated that:

All who boo him could kiss his Grenadian ass

Sparrow came to Trinidad with his mother who travelled there to meet his father in 1937. At that time he was a year and 9 months old. Initially they set up a family home in Belle Vue, Long Circular, St. James, which is just outside Port of Spain.

When Slinger was 4 years old he attended a private nursery school on the St James, Western Main Road. When he became of age to attend infant school, his parents got him into a school that currently is known as Newtown Boys' Roman Catholic School. This denominational school that was also situated in Port of Spain, was chosen because of his parents affinity to the Roman Catholic faith. While at Newton Boys,' Slinger so excelled in the weekly singing classes and showed such talent that he was encouraged to join choir of the church associated with that school. In keeping with the expectations of 
Appendix 4- Calypsonians Researched but not interviewed

a choir boy, he did not feel free to either sing or even whistle Calypsos around his parents. However, around that time, it was considered more acceptable for him to engage in the pop music of the day in which he was very familiar and at which he excelled, this included stars like Nat King Cole and Frankie Laine, Sarah Vaughn, Billy Eckstein, Frank Sinatra and Ella Fitzgerald. Although those were some of his early influences, much to the amazement of all present, Slinger sang Lord Invader's: "The Yankees Invade Trinidad" at a school concert. This was the first time that he sang a Calypso in public.

From his youth slingers dream was to become a Calypsonian. In the meanwhile, he became a tailor's apprentice, worked in a coffee factory and took typing lessons.

His early influences in the field of Calypsos came from Lord Melody, Lord Kitchener, Lord Christo, Lord Invader (of Rum and Coca Cola fame) and the Mighty Spoiler, to whom he listened carefully, trying to recognise and understood the essential elements the Calypsos of these top artists in the field. He developed a particular affinity to both Lord Melody and Lord Kitchener, the former, for his earthy style, while the latter, for his ability to delight both local and international audiences.

Slinger recognised the need to be able to play a musical instrument and chose to teach himself the guitar through self taught music books. At the age of 19 The Little Sparrow made his first professional Tent appearance at the Old Brigade Tent on South Quay, Port of Spain where he thrilled the audience with his composition "The Parrot and the Monkey." 
Again in 1955, at the age of 20 Sparrow reappeared with four compositions: Race Track; The Missing Baby; High Cost Of Living; and Ode to Princess Margaret.

That year he also began his gramophone recordings by recording three of those tunes. In 1955 Sparrow also made his first overseas tour going to what was then British Guyana and was a major success there.

With the growth in Sparrow's popularity, in 1956 he changed his sobriquet from the Little Sparrow to the Mighty Sparrow, also simultaneously changing Tents to the Young Brigade Tent. 1956 also brought much political change in Trinidad with the election of the

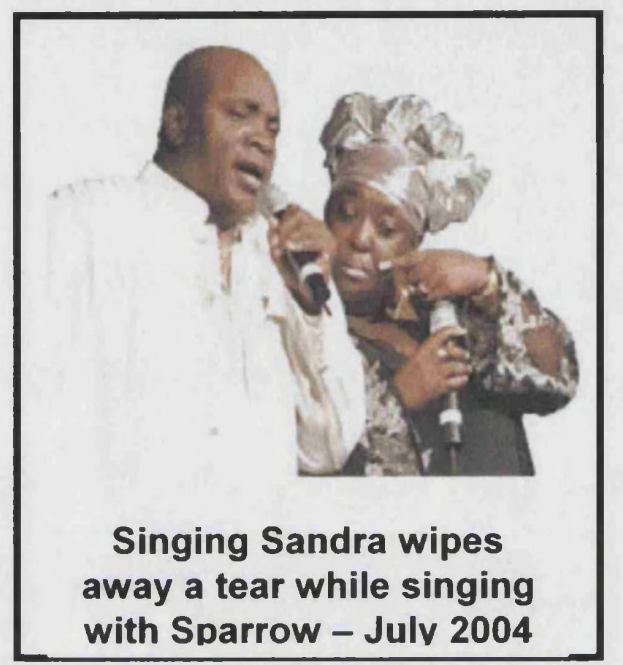

Peoples' National Movement led by Dr Eric Williams. For the carnival of 1956

Sparrow released five Calypsos and won he Calypso King competition in the Queens' Park Savannah with Jean and Dinah, also winning the Road March title with the same tune. The chorus of the Calypso, which for those days was unusually long, is given below. The Calypso is a celebration of the departure of the Americans after the War.

\section{Jean and Dinah, Rosita and Clementina}

Round the corner posing

Bet yuh life its something they selling

But when you catch them broken

You could get it all for nothing

Doh make a row

Cause the Yankees gone and Sparrow take over now

A study of the trend of the Calypsos that Sparrow has released shows that he has led the field, bringing a level of diversity to the art form. In fact Sparrow in setting new trends for the Calypso, has enabled the traditional form to grow and create an exciting artistry in Calypso expression. Sparrow has travelled widely as an ambassador spreading the 
Appendix 4-Calypsonians Researched but not interviewed

popularity of the Calypso art form around the world. Accordingly he has entertained audiences in Jamaica, the Virgin Islands, Puerto Rico, Aruba, Curacao, Panama, Guyana, Antigua, Barbados, Grenada, St. Lucia, the United States, Europe, Africa, and the UK.

Sparrow has shown his ability to make his music relevant to the various locations of his worldwide audience. This fact has been recognised by awarding him a variety of national honours and honorary qualifications. In 1985 he won the King of Kings trophy when he competed against each of the Calypsonians who had in the previous years been crowned Calypso King. In 1987 the University of The West Indies awarded him the honorary degree of "Doctor of Letters". These are but two of the numerous awards made to the man who in bringing his own distinct imprint to the Calypso Art-form, has so dominated Caribbean consciousness that he is considered to be the King of Calypso: The Mighty Sparrow. 


\section{Real Name: David Rudder - Sobriquet: David Rudder}

David Rudder, born in Belmont, Port of Spain, Trinidad on $6^{\text {th }}$ May, 1953, is one of nine children. He spent much of his early childhood with his grandmother who subscribed to African Centred Spiritual belief system, which naturally influenced him. Not only did his early influences come from his spiritual environment but the nearby pan yard also had a significant impact. Listening to Rudders music,

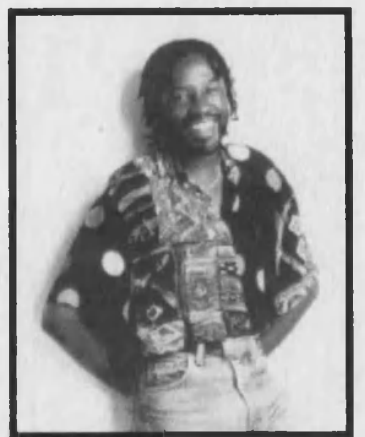
one hears the influence of African Spirituality in the rhythm.

This combination showed up as an unusual one in David's life. One example of this is the fact that he has been baptized into three separate religious belief systems. His grandmother baptised him into as a Spiritual Baptist, while his mother baptised him into the Church of England. He was again baptised as a Roman Catholic when he started school. In his early youth Rudder contracted Polio and today still walks with a limp.

I first met Rudder when he attended Belmont Boys Intermediate RC School, one of the schools that I also attended in my youth. It was there that he first began to express an interest in the arts. David later became an apprentice carnival artistic craftsman to Ken Morris, who was one of the better known metal workers in Trinidad. Still today, Rudder considers himself to be more of an artist than an entertainer. He sees the distinction as one of depth and contends that "An entertainer... deals with the surface and an artist goes below the surface to bring things to the surface."

However, his singing career can be said to have commenced when he was 11 years. At that time he sang with a The Solutions. Rudder first experiences in a Calypso Tent was 
Appendix 4-Calypsonians Researched but not interviewed

as a back-up singer in Lord Kitchener's Tent, at the age of 24, Rudder joined Charlie's Roots as a backup singer. It was in this position that he learnt much of the practical craft of the Calypsonian, while he continued to work as an accountant for the Public Service Transport Corporation (PTSC). Rudder's first introduction to the role of lead singer came during a period when Christopher "Tambu" Herbert the then lead singer of Charlie's Roots, became ill. Rudder's appearance, which initially was meant to be temporary, went down so well with audiences, that he stayed on as co-lead singer of the group, building a reputation for his spirited performances.

In 1986 David first entered the Calypso Monarch finalist competition having already been crowned as the Young Calypso King. On this occasion he sang the Calypsos "The Hammer" and "Bahia Girl". The Hammer, was in remembrance of the deceased steel-bandsman Rudolph Charles, while Bahia Girl told the story told a story of a Brazilian girl who urging the identification of a common musical heritage. With those two Calypsos, that year Rudder won every available award. After unsuccessfully defending his crown the following year, Rudder decided to ride on the international fame he gained from his 1986 victory and turned to developing an international career.

There were a number of things that made Rudder standout in the Calypso world, some of these were the fact that he was talented enough not just to write Calypsos, but to sing them as well. His music had a different beat from the average Calypsonian's, he did not take a sobriquet, he did not consume alcohol and despite the fact that he was a Calypsonian functioning in a Tent, he was quite insular not really mixing with other Calypsonians. The columnist Wayne Brown, in writing about him described him as, "...having acquired the notion of singing as a king of self-sacrifice, involving surrender 
Appendix 4-Calypsonians Researched but not interviewed

of personality and of the singer dissolving to become at once a symbiotic extension of the audience and the anguished medium of the song, a voice of the mercy of a Baptist testifier," (Brown 2004).

Off stage, David is very much a family man and has recently remarried now living in Canada. Rudder enjoys spending time relaxing with his family. He has been known to bring his sons on stage during his performances. He enjoys reading and listening to Jazz music. He has been influenced by the African music of Yossou N'Dour, Salif Keita, Mory Kante and Alpha Bondy.

Through the successive years, Rudder produced a stream of hits retaining a position as an international performer. The Banana Death Song (Track 10 on CD) is but one of these.

In 1997, disillusioned with the breadth of airtime given to his music by the radio stations, Rudder, decided to match his output to their airing. He therefore sought to match his output to what was being played by the radio stations and therefore released a mini-album.

In 2003 he released "Trini to de bone" which became a best seller. However, he has not release a record in 2004. He states that this is as a direct response to his loss in revenue resulting from pirating of his CDs. . 


\section{APPENDIX 5 - TheATRes AND DANCE HALl ORdinANCE 1934}

TRINIDAD AND TOBAGO.

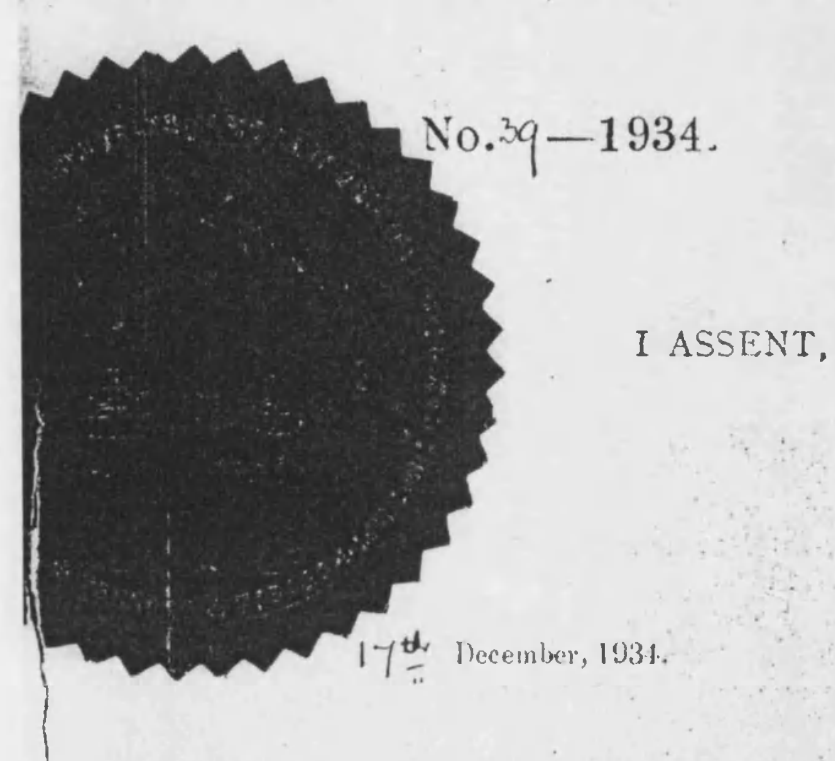

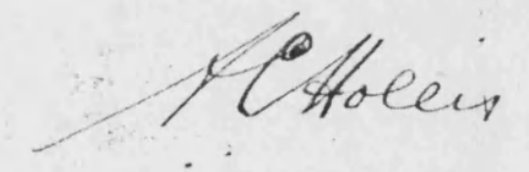

Qacernor.

AN ORDINANCE to regulate the use of Theatres, Dance Halls and other places of entertainment and to provide for the licensing thereof.

$\mathrm{D}^{\mathrm{E}}$ it enacted by the Governor of Trinidad and Tobago $\mathrm{B}^{\mathrm{n}}$ with the advice and consent of the Legislative Council thereof as follows :--

1. This Ordinance may be cited as the Theatres and short title. Dance Halls Orclinance, I934, shall commence on the Ist "ommones. day of January, I935, and shall apply only to such Towns nient.

or other areas as may be specified by the Governor in spplicaton. Executive Council by proclamation in the Royal Gazelte. A Proclamation made under this section may be varied or revoked by Proclamation made in like manner.

2. In this Ordinance-

"Stage Play" includes any tragedy, comedy, farce, opera, burletta, interlude, melodrama, pantomine, prologue, epilogue, concert or other dramatic or musical entertainment or any part thereof.

[Price $\left.2 i^{7}.\right]$ 


\section{Appendix 5 - Theatres and Dance Hall Ordinance}

$\operatorname{No.}^{2} 9$

Thentres and Dance Halls.

I934.

"Theatre." means any building, tent or other erection open to the public, gratuitously or otherwise, where a stage play is performed, presented or held and includes a Dance Hall.

"Dance Hall" means any building, tent or other erection open to the public gratuitously or otherwise, where public dancing or singing takes place.

"Licensing Authority" means any person or body of persons appointed by the Governor by notice in the Royal Gazette to be a Licensing Authority for any Proclaimed area specified in such notice.

"Licence" means a licence granted in the form in the Schedule to this Ordinance and "licensed" shall be construed accordingly.

"Proclaimed Area" means any area to which the provision:s of this Ordinance has been applied in accordance with section I of this Ordinance. place within a Proclaimed area shall not be used its in Theatre or Bance Hall withont a licence.

(2) A Licensing Authority may grant licences for any period not exceeding twelve months to such persons as it thinks fit to use places as Theatres or Dance Halls on such terms and conditions as may be imposed by regulations. made under this Ordinance or as may be endorsed on the licence by the Licensing Authority.

(3) A Licénsing Authority may transter any licence to any person whom it thinks fit.

(4) A Licensing Authority may, in its discretwn refuse to grant a licence or transfer of a licence or may grant it subject to such terms and conditions as it may think desirable.

(5) The following fees shall be payable to the Licensing Authority granting a licence or transfer of a licence in respect of a Theatre or Dance Hall :-

lior a licence for one specific occission $\ldots$

For a licence for a period not exceding It dis:

For a licence for a period not exceeding I momt

For a licence for a period not excceding 10 months

For a licerce for a veriod not exceerling 12 memehs 


\section{Appendix 5 - Theatres and Dance Hall Ordinance}

3

10.39

Theatres and Dance Halls.

I934.

(a) Except where the period for which a licence is in furce does not exceed fourteen days, there shall be affixed and kept affixed in some conspicuous place and so as to be easily legible on or immediately over and on the outer side of the main entrance of every licensed place, the words "Iicensed in pursuance of the Theatres and Dance Halls Ordinamce, 1934".

4. If If any place is used as a Theatre or Dance Hall Ponaities. witim!t a licence the owner or occupier thereof, unless he prosis: it the satisfaction of the Court that the place is so $11+\cdots$ without his consent or comnivance shall be liable on - mumary conviction before a Magistrate to a penalty not excoding five pounds for every day on which the place i. - is isted.

(2) If the holrier of a licence acts in contravention of (1) sits to comply with the provisions of this Orclinance or in: watation made thereunder or with any term, - mulition or restriction on or subject to which the licence i. . inted, he stall be liable on summary conviction before :1 Vhriciate to a penalty not exceeding twenty pounds a: 1 in the case of a continuing offence to a daily penalty In. incecding five pounds for each day on which the withvention continues after conviction therefor and the liw of any person so convicted may be revoked by the I whing Authority.

5. Airy Police Constable detailed for the purpose, may Power of *t . ill reasonable times enter upon any licensed premises WIth il view to seeing whether the provisions of this Grinance or any resulations made thereunder or the cumbtisns of any licence, are being or have been complied wilh, - Hiy person presenting or obstructing such entry Ahiti, wil summary conviction before a Magistrate, be liable 16.1 perialty not exceeding ten pounds.

6. (1) The (jorernor in Executive Council may make Power to make rérulationin.-

(A) prescribing conditions to be observed in reference (1) the erection, alteration and equipment of any theatre or dance hall; 
No. 39

Theatres and Dance Halls.

(b) prescribing conditions to be observed in reference to the safety from fire or otherwise of any theatre or dance hall or for the safety, convenience and control of persons attending any such theatre or dance hall;

(c) generally for the more effective carrying out of the provisions of this Ordinance.

(2) Regulations made under this section shall not have any force or effect until they have been approved by the Legislative Council and when so approved shall be published in the Royal Gazelte and as from the date of such publication or from the date specified therein such regulations shall have the same force or effect as if they were contained in and formed part of this Ordinance.

$\%$. Nothing in this Ordinance shall exempt any person or place from the provisions of any other enactment requiring the licensing for any purposes of that person or place or shall apply to any cinema licensed under the

Cop. 253. provisions of the Cinematograph Ordinance, or to any place in the control of any municipal authority or in any building thereon.

\section{SCHEDULE,}

\section{Form of Licence.}

Colony of Trinidab and Tobago.

The Theatres and Mance Halls Ordinance, 1934

IJCENCE is hereby yranted to the prenises for the period of ....................................... from the........................day
of for the period of ...................................... from the........................day
of for the period of ........................................ from the........................day
Dance Ha for the period of ........................................ from the........................day
Dance Ha of ....................................... subject to the provisions of the Theatres and Dance Halls Ordinance, 1934 and any regulations made thereunder or any

Dated this....................day of .............................. $193 \ldots \ldots \ldots$

Fee paid $\$$

Licensing Authority.

Passed in Council this seventh day of December, in the year of Our Lord one thousand nine hundred and thirty-four. 


\section{APPENDIX 6 - GESTALT PhILOSOPHY}

\section{Appendix 6}

At the beginning of this century a group of German psychologists, including Max Wertheimer, Kurt Koffka and Wolfgang Kohler, founded a branch of psychology that came to be known as the Gestalt School. The word 'gestalt' is a German one that in translation means either 'pattern', 'shape', 'form', or 'configuration'. The subject that most interested Wertheimer and his colleagues was the organisation of mental processes, and in particular the importance of perception in determining each individual's view of reality. Based on their research and experiments, they formulated a number of theories that dealt with the way people organise stimuli into patterns and shapes.

One of the most significant of these theories concerns the idea that the whole pattern of a person's sensory experience is more important than the individual parts of that experience, in deciding meaning. What this really implies is that when we listen to music for example; we do not hear all the individual notes that comprise a harmony. What we perceive is the totality of the music as an undifferentiated whole. Gestalt psychology holds, therefore, that the whole is greater than the sum of the parts, for when we perceive things we are aware of a structure, form, configuration or pattern, which is interpreted as a whole and not as a random group of separate items.

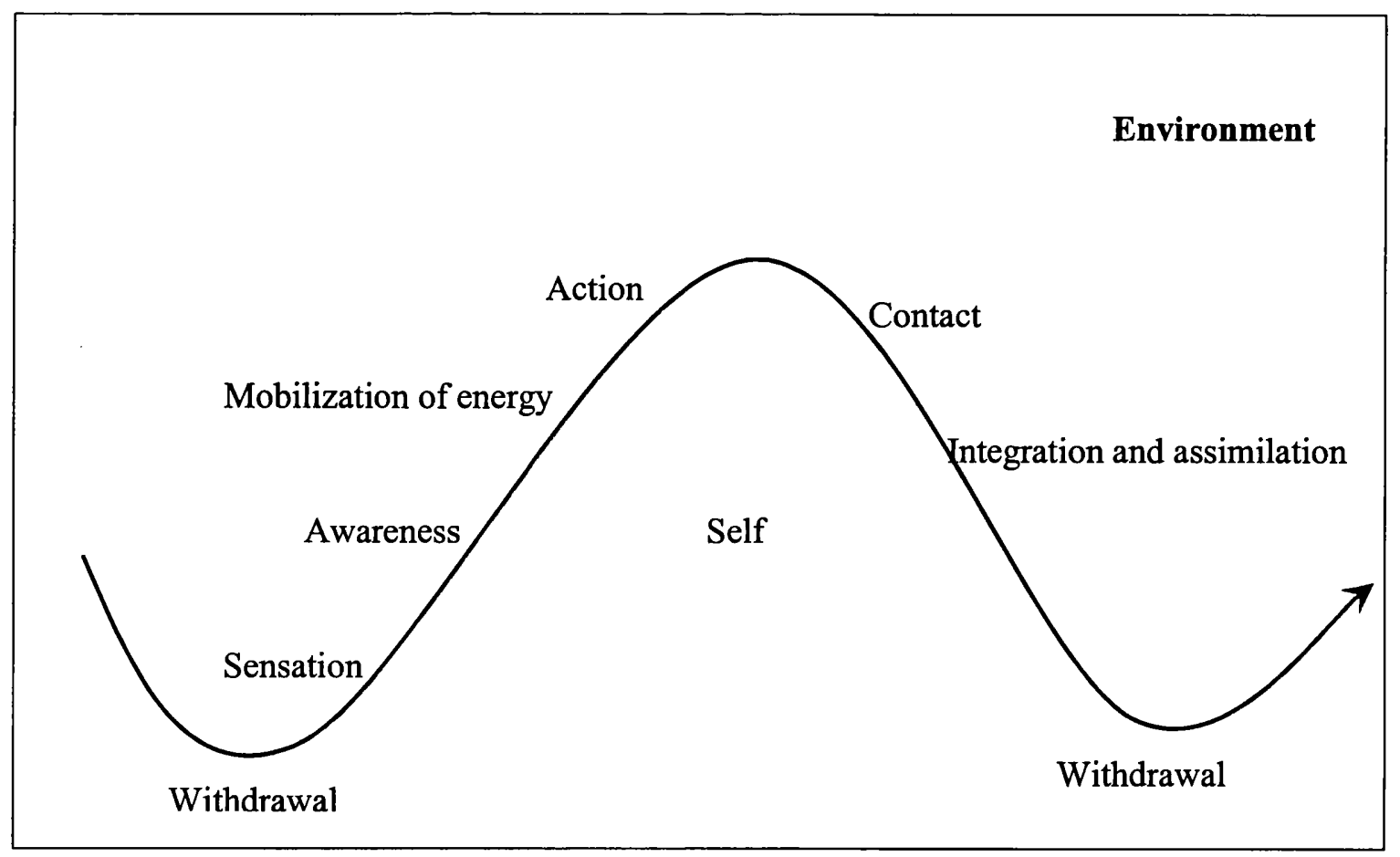

Fig. A6-1 - Interactive cycle of contact - withdrawal of organism and environment (inspired by Zinker 1978) 


\section{Appendix 7 - Calypso Tents and their Performers}

The list below identifies the artists that have performing in each of the Calypso Tents for the 2001 season. Where available I have also included the name of the accompanying orchestra as well as the Chorus accompaniment

Name of Tent: Chutney Tent

- Big B

- Heeralal Rampartap

- Marcia Miranda

- Nermal "Massive" Gosine

- Ras Kommanda

Name of Tent: Eastern Stars Calypso Tent

- Bushy

- Calypso Max

- Candice

- Darlin

- Dragon

- (MC) Eric Powder

- Hannibal

- Harold Steward

- Hunter

- Kenrick Andrews

- Lady IB

- Medicine

- Redman

- Sister Nancy

- Smoke

- Steve Kennedy

- Super Power

- Tobago Rio

- Guest Artist(s)

Name of Tent: Original Youth Brigade (Children's Tent)

- Jamal Calliste (MC)

- Lishoon Carter(MC)

Name of Tent: Kaiso Showkase

Music provided by: Keith McBurnie \& Showkase Orchestra

Backup singers (Chorus): IBO family chorus group

- Breed

- Dangerli>Durango 
Appendix 7 - Calypso Tents and Their Performers

- $\mathrm{CB}$

- D Rhythm

- El Drago

- Joseph Adams

- Kamara

- King Harry

- Kinte

- Lady Adanna

- Lecturer

- Natural (Guest Appearance)

- Nikko

- Nirmal Massive Gosine

- Nobby

- Prospector

- Rainbow (Guest Appearance)

- Ras Kommanda

- Short Pants (Guest Appearance)

- Stamone

- Walker

Name of Tent: Kaiso Karavan

Music provided by Ruiz Brothers

Backup singers: Karavan Girls

- Brother Alpha

- Bingo

- Burton Tony

- Dirty Curty

- Explainer

- Gary Cordner

- (MC) Godfrey Pierre

- Golden

- Jarva

- Johnny King

- Karega Mandela

- Lady Paula

- Lil Jean

- M'ba

- Penguin

- Power

- Prince Unique

- Sheldon Nugget

- Stinger

- Striker

- Willow

- Young Creole 
Name of Tent: Kaiso House

Music provided by: Cummings and the Wailers

Backup singers (Chorus): Kaiso Jewels

- Black Stalin

- Brother Mudada

- Brother Resistance

- Brother Valentinto

- Brown Boy

- Bunny B

- Calypso Kerr

- Dee Diamond

- Delamo

- (MC)GB

- Hollis Wright

- Luta

- Marvellous Marva

- Mighty Terror

- Miranda Joseph

- Mystic Prowler

- Original Natty

- Princess Monique

- Protector

- (MC) Rachel Price

- Rootsman

- Shadow

- Shanaqua

- Sharlan Bailey

- Singing Sandra

- Singing Sonia

- Soft Touch

- Sylvie

- Twiggy

- Uprising

- Xposer

Name of Tent: Klassic Russo

Music provided by Earl Caruth \& the Klassic Ruso Band Background vocals (Chorus) by Klassic Ruso Angels.

- Alicia Gift

- All Rounder, Shirlane \& Diane Hendrickson

- Almanac

- Contender

- Dr Will B.

- Duke

- Ebony

- El Hombre

- Hamidullah 
Appendix 7 - Calypso Tents and Their Performers

- Karen Eccles

- Kassman

- King Soul

- Lady Wonder

- Lasana

- Llylo

- Lynda Byron

- Macomere Fifi

- Manchild

- Marva McKenzie

- Ras Mamba

- Revealer

- Scrunter

- Soul Expression

- Stacy Sobers

- Stanley Adams

- Versatile

Name of Tent: Maljo Humourous

Music provided by: The Brass Institute of Trinidad and Tobago

Backup singers (chorus): Patsy and Jimmy

- Blakie

- Boy Bachannal

- Campanero

- Cyclop

- Deborah Maillard

- El Drago

- Emperor Lee

- MC Errol Fabien

- Hindu Prince

- Jo-L

- Learie Joseph

- Mairoon Ali

- MC Nikki Crosby

- Penelope Spencer

- Power

- Wendell Etienne

Power House (Tobago)

- Bruce T

- Buba

- Bulby

- Calypso Prince

- Combi

- Deony

- Joe Tempo 
- Judy Balfour

- (MC) Mike Baker

- Mystery Man

- Sandra

- Soca Man

- Squeeze

- Wendy Thomas

- Wiggy

- Guest Artist(s)

Name of Tent: Revue

Music provided by: Kenny Stephens \& the Calypso Revue Orchestra

- Baron

- Bomber

- (MC) CG

- Cro Cro

- Dane Gulston

- DeFosto

- Denyse Plummer

- Devon Seales

- Diveno

- Impulse

- Kenny J

- Kernel Roberts

- Pink Panther

- Poser

- Ringo

- Ronnie McIntosh

- Sheldon Reid

- Skatie

- Squibby

- Strongy

- Sugar Aloes(MC) Super Lou

- Young Unknown

\section{Spektakula - Children}

Music provided by: Wayne Bruno and the Rapid Response

- Celtic Invasion

- Chinese Laundry

- Dawg E Slaughter

- Edwin Yearwood

- Iwer George

- Machel Montano

- Maximus Dan

- Militant

- Rex West 
- Rikki Jai

- Rupee

- Soca Elvis

- (MC) Tommy Joseph.

- Treason

Name of Tent: Spektakula

Music Provided by: Wayne Bruno and the Rapid Response

- Bally

- Big G

- Black Sage

- Cardinal

- Cardinal

- Chalkdust

- CJ

- Crazy

- (MC)Donna Hadad

- Funny>

- Gypsy

- Iwer

- Luta

- MacGruffMilitant

- Mortimer

- Rex West

- Rikki Jai

- Roger George

- Rupee

- Scrunter

- Sherwayne Winchester

- Soca Elvis

- Storm

- (MC) Tommy Joseph

- Trinidad Rio

Name of Tent: Yangatang Kaiso

- Bill Trotman

- Choonkie Ting

- Damion Melville

- John Agitation

- Lady Aisha

- Louis Antoine

- Mechanic

- Sexy Susie

- Shirley "Beulah" King

- Sprangalang 
Appendix 8 - Colloquial Words, Phrases \& Expressions in everyday use in Trinidad and Tobago

\section{APPENDIX 8 - COLLOQUIAL WORDS, PHRASES \& EXPRESSIONS IN EVERYDAY USE IN TRINIDAD \& TOBAGO}

A

Ah.....Pronunciation for "l", "a", "of" - e.g. "Ah want ah piece ah pork".

Allyuh.....All of you people. A group.

Aye-ya-yie!.....Expression of anticipation or pain, etc.

B

Bacchanal.....Scandal, quarreling, confusion.

Back chat.....Insolent response, especially from a child to an adult.

Badjohn.....A bully, tough guy.

Bad-drive....Reckless drive.

Bad-lucky....Unlucky.

Bad-mind....Evil thoughts/intentions

Bamboozle....To con or fool someone.

Bamsee/Bumsee.....Butt - the rear end, what you sit on.

Bazodee....Stunned, dazed and confused. Also spelt "bazodi".

Beh-beh....Retarded

Blank....To publicly ignore someone, stand up a date.

Bluenote....Trinidad $\$ 100$ bill.

Bobolee....Someone who is taken advantage of.

Boldface......Pushy, unreasonably demanding.

Boobooloops....Grossly overweight person - usually female.

Broughtupsy.....Decorum, manners.

Buh wait nah.....But wait a minute, now hold on/it.

Buff....To reprimand someone loudly - from "rebuff".

C

Callaloo.....A thick soup made from daśheen leaves, ochroes, coconut milk, usually includes crab.

Calypso.....A musical and lyrical comment on any subject, usually composed for, but not limited to, the Carnival season. (See Soca)

Calypsonian...... One who both writes and sings Calypsoes. (A 'true-true' Calypsonian). 
Appendix 8 - Colloquial Words, Phrases \& Expressions in everyday use in Trinidad and Tobago

Calypso Singer....One who just sings Calypsoes.

Cheups(Steups).....A noise made by sucking your teeth. Expression of disappointment/disgust.

Chinkee.....Very tiny portions of anything.

Chupid.....Stupid.

Chupidee.....A foolish person.

Coki-eye......Cross-eyed.

COLA ....... Cost of Living Allowance

Commess.....Confusion associated with arguments, gossip and slander.

Conk out....Stop working, fall asleep.

Cuff.....Hitting someone or something with a cleched fist.

Cut-eye......A look of anger.

Cyah.....Can't

D

Da....That - e.g "Da is you?" - Is that you?

Dan-dan.....Fancy clothes, any sharp looking outfit.

Dat.....That

Dat good for yuh.....Serves you right.

De....The.

Dey....There - e.g. "Dong dey"....down there.

Doh.....Don't.

Dong....Down.

Dotish (doltish).....Silly, stupid, foolish.

Douen (Dwen)....Spirit of unbaptised child.

Dougla.....Mixture of East Indian and African parentage.

Dress rong(around).....Move over, I want to sit.

Drevait(dree-vay).....Wayward person who likes to "knock about".

Dub....Any type of Reggae music (very confusing for Jamaicans!).

E

Eh.....What did you say?

Eh-eh......No, no way, oh no.

Eh-heh.....Oh really? I understand. Yes: 
Appendix 8 - Colloquial Words, Phrases \& Expressions in everyday use in Trinidad and Tobago

Ent?(ain't).....Is that not so? That's true, isn't it?

$\mathbf{F}$

Faddah.....Father.

Fete......A big party, loud music, lots to eat and drink, dancing to wee hours of the morning.

Flim.....Film, movie.

Fuh....For.

Fuh true/troot?.....Yes that is true. Is that really so?

G

Goin' orf (off).....Going out of one's mind, acting strangely (see Bazodee, Tabanca)

Gun talk.....Fighting words, threatening.

Gyul/Gyal.....Girl

\section{H}

Harden.....Disobedient, stubborn.

Hototo.....A very large amount of anything.

Hoity-toity......Haughty, proud, conceited, stuck-up.

Horn....To cheat on one's spouse/partner. Originally from Shakespeare (!) "To put the horns on the cuckold."

Hornerman....Person your partner is cheating with.

I

In ting.....To be involved in current activity.

Is so?.....Is that so?

J

Jeez-an-ages.....Used for any reason where an outburst is appropriate.

Jook.....To stab at anything.

Jumbie.....Spirit, ghost.

Jumbie (verb)... to harass, to annoy, to irritate. (doh jumbie meh nah man!)

Jus'now...... In a little while.

Jus'so?.....Just like that?

Jus'so...... Out of the blue, totally unexpected. 
Appendix 8 - Colloquial Words, Phrases \& Expressions in everyday use in Trinidad and Tobago

\section{$\mathbf{K}$}

Ketch......Catch.

Klim.....Any brand of powdered milk.

$\mathbf{L}$

Lajablesse (La Diablesse)....Female demon.

Lef' dat.....Leave that.

Leh.....Let, let's - e.g. "Leh go"......Let go, "Leh we".....Let us.

Lick'rish....Greedy.

Lick dong(down).....To hit and knock down someone or something.

Licks.....A beating, physical punishment.

Liming.....(noun) A wildcard word for any social event (cinema lime, pub lime, party lime etc) (verb) the art of enjoying oneself - whether alone or with company.

Long eye.....A person who is envious of the possessions of others.

Look nuh!.....An expression of annoyance.

\section{M}

Maco.....A person who minds other people's business for the purpose of gossip.

Macocious.....A person having the trait of a maco.

Maaga.....Very thin, skinny. From "meagre".

Mamaguy.....To make fun of, to ridicule.

Mama Yo!.....Used for any reason where an outburst is appropriate.

Mash up....Destroyed, broken.

Matter Fix.....Everything is organized/solved.

Mih....Me, my.

Mih hand slip.....An expression used when too much of an ingredient is used.

Mooma......Mother.

\section{$\mathbf{N}$}

Nah......No

Never-see-come-see.....Someone who has recently been exposed to something new and who overreacts to it to ridiculous proportions.

Now-fuh-now.....Instantly. 
Appendix 8 - Colloquial Words, Phrases \& Expressions in everyday use in Trinidad and Tobago

Nowherian.....A person of no fixed abode.

0

Obzokee.....Awkward in appearance, ungainly.

Oh geed!.....An expression used when an offensive smell arises.

Oh gosh!- Oh gorm man!- Oh shimps man!-.....All expressions denoting indignation and exasperation.

Old talk.....Idle chatter, gossip, social chit-chat.

One set ah (of).....A lot of anything.

Own-way.....Stubborn person (see Harden).

$\mathbf{P}$

Pallet.....Frozen lolly.

Papa yo!.....Exclamation of surprise.

Pelau or 'Lau ...... One-pot mixture of rice,meat and pigeon peas.

Pissin' tail.....A person of no class or importance.

Planass.....To hit someone continuously with the flat part of a cutlass.

Playing social.....Someone who pretends to be of a higher social strata than they are.

Pong.....Pound.

Po-po.....Small child, baby.

Presshah!....Pressure, expression of intense circumstances, rough times.

Prim-prim.....Disgustingly proper and formal.

Q

Quenk.....An irritating person.

Quaily/Quail up.....Withered, dried up.

$\mathbf{R}$

Raff.....To grab suddenly.

Ragadang.....Broken down.

Ram-cram.....Packed to capacity.

$\mathbf{S}$

Saddist.....Criminal and/or playboy. From "sadist". 
Appendix 8 - Colloquial Words, Phrases \& Expressions in everyday use in Trinidad and Tobago

Saga boy/girl.....Flashy dresser, dandy.

Skin-teeth.....Grinning.

Skin-up yuh nose.....To turn up one's nose at anything.

Soca.....Fast Calypso - more suited for partying. Originally "Soul and/of Calypso"

Sometimeish.....Moody, unreliable.

Soucouyant....Female vampire that takes the form of a ball of fire.

Steups(Cheups).....To suck one's teeth in annoyance.

Sweetie.....Any confectionery.

Swell up yuh face.....To look angry, to pout.

\section{T}

Tabanca.....The forlorn feeling one gets when a love affair is over (see Bazodee).

Tanty.....Aunt.

Tight...... Intoxicated, drunk, stoned.

T'ing.....Thing. Also girl.

To besides.....In addition.

Totoolbay.....Confused state, in a daze, also head over heels in love. Good form of Bazodi.

\section{U}

Umpteen.....Plenty of anything.

V

Vamping.....An offensive smell.

Vaps(e).....To suddenly behave excitedly or in a strange manner. Have a brainstorm.

Vex.....Vexed, angry.

\section{$\mathbf{W}$}

Wajang.....A rowdy, uncouth woman.

Well yes!.....An expression of disbelief .

Wha'....What

Whappen?.....What's happened. What's the matter with you?

Whey.....Where, what - e.g. "Whey yuh say?".....What did you say.

Wining (Winding).....The gyration of the waist to music. 
Appendix 8 - Colloquial Words, Phrases \& Expressions in everyday use in Trinidad and Tobago

$Y$

Yuh....You, your

Yuh look fuh dat.....It's your own fault.

Yuh makin' joke!......You can't be serious!

$\mathbf{Z}$

Zaboca....Avocado

Zandolie....Type of lizard

Zug-up.....Rough and uneven cutting of anything - usually hair 


\title{
Appendix 9 Appendix 9 - Glossary. OF TeRms Used in the Calypsos
}

\author{
Aloes: \\ A Trinidadian Calypsonian whose stage name is Sugar Aloes \\ balesea: \\ Plant found in Trinidad and Tobago, used as the symbol of the \\ People's National Movement. \\ birdie: \\ boball \\ Refers to The Mighty Sparrow \\ Bocassa: \\ financial corruption \\ BWIA or BWEE: \\ A local politician \\ Calypso Tents \\ The National Airline of Trinidad and Tobago \\ Chalkie: \\ The buildings where Calypsonians perform \\ The Mighty Chalkdust - A Trinidadian Calyposian, named Hollis \\ Liverpool \\ Chambers: \\ George Chambers, a previous Prime Minister of Trinidad and \\ Tobago and leader of the PNM \\ Chutney Soca: $\quad$ A derivitive of Soca and Indian music. It is performed principally \\ COLA: \\ by individuals of East Indian origin. \\ eh: \\ Cost of Living Allowance \\ not, as in: 'eh do noting' meaning 'did not do anything' \\ Dimanche Gras: The grand annual Carnival gala which takes place on the Sunday \\ night immediately before start of the Carnival Monday \\ celebrastions. It is during this gala that the Kings and Queens of \\ the Carnival Bands as well as the Calypso King is selected. \\ driver's seat: \\ the prime minister's post \\ douix douix: \\ a term of endearment \\ Eric: \\ Dr. Eric Williams - the Prime Minister who took the country to \\ independence \\ frade: \\ afraid \\ Fransisco: \\ Georgy: \\ Refers to the Mighty Sparrow whose is Dr Slinger Fransisco \\ George Chambers, The Prime Minister at the time of release of the \\ Calypso \\ George Porgy: George Chambers, The Prime Minister at the time of release of the \\ Calypso \\ Gypsy: \\ Hosay \\ A Trinidadian Calypsonian \\ This is an East Indian procession which forms part of the overall \\ Muslim celebrations of Muharram marking the first ten days of the \\ Kaiso: \\ first month of the Muslim year \\ Calypso \\ Kakada: money \\ mamaguy: \\ to fool someone \\ Mas \\ Masquerade \\ Mas-camps: \\ Mas-man: \\ Me eh frade: \\ the Carnival bands' base. It can be where the mas is made and \\ costume designs are displayed \\ Movant: \\ masquerader \\ I am not afraid \\ An area in Trinidad \\ NCC: \\ National Carnival Committee \\ NJAC: \\ National Joint Action Committee - A political party
}


ONR:

Organisation for National reconstruction - a political party

UNC

United National Congress - a Political Party

Panorama:

The annual steel-band competition, the final of which takes place during the week preceding the two days of the Carnival celebration

Pecong: heckling, jokes

PNM:

People's National Movement, a political party

Soca

A musical rhythm spawned from a combination of Soul and Calypso

St Anne's: the part of Trinidad where the mental assylum is located

Steel Beam:

skull doggery:

tut moon bagh:

T \& TEC:

TELCO:

The symbol of the ONR political party

trickery

everyone

Trinidad and Tobago Electricity Commission

Trinidad and Tobago Telephone Company

The northern and The financial complex in Trinidad and Tobago

southern idol:

WASA:

Water And Sewerage Authority

Watchman:

A Trinidadian Calypsonian

ISCOT:

Iron and Steel Company Trinidad 